\title{
Generalized Extreme Value Statistics, Physical Scaling and Forecasts of Gas Production in the Barnett Shale
}

Tadeusz Patzek, Wardana Saputra, Wissem Kirati, Michael Marder

Submitted date: 26/06/2019 - Posted date: 27/06/2019

Licence: CC BY-NC-ND 4.0

Citation information: Patzek, Tadeusz; Saputra, Wardana; Kirati, Wissem; Marder, Michael (2019):

Generalized Extreme Value Statistics, Physical Scaling and Forecasts of Gas Production in the Barnett Shale. ChemRxiv. Preprint.

We develop a method of predicting field-wide gas (or oil) production from unconventional reservoirs, using the Barnett shale as an illustration. Our method has six steps. First, divide a field of interest (here Barnett) into geographic/depositional regions, where -- upon statistical testing -- gas and/or oil production are statistically uniform. Second, in each region i, fit a generalized extreme value distribution to every cohort of gas/oil wells with $1,2, \ldots, n_{i}$ years on production. Third, obtain accurate estimates of uncertainties in the distribution parameters for each regional well cohort. As a result, obtain $n_{i}$ points for the stable mean $\left(P_{50}\right)$ well prototypes for each region $\mathrm{i}$, and the corresponding high/low $\left(\mathrm{P}_{10} / \mathrm{P}_{90}\right)$ bounds on well production. Fourth, by adjusting the producible gas/oil in place and pressure interference times between the adjacent hydrofractures, fit each statistical $\mathrm{P}_{50}$ well prototype with a physics-based scaling curve that also accounts for late-time external gas inflow. The physics-scaled well prototypes now extend 10-20 years into the future. Fifth, for each region, time-shift the dimensional, scaled well prototype and multiply it by the number of well completions during each year of field production. Add the production from all regions to match the past field production and predict decline of all wells up to current time. These well productivity estimates are more accurate and better quantified than anything a production decline curve analysis might yield. Sixth, by assuming different future drilling programs in each region, predict field production futures. We hope that the US Securities and Exchange Commission will adopt our robust, transparent approach as a new standard for booking gas (and oil) reserves in shale wells.

File list (3)

Generalized Extreme Value Statistics, Physical Scaling an... (3.88 MiB) view on ChemRxiv • download file SOMGeology.pdf (4.32 MiB) view on ChemRxiv - download file 


\title{
Generalized Extreme Value Statistics, Physical Scaling and Forecasts of Gas Production in the Barnett Shale
}

\author{
Tadeusz (Tad) W. Patzek, ${ }^{* \dagger}{ }^{\dagger}$ Wardana Saputra, ${ }^{\dagger}$ Wissem Kirati ${ }^{\dagger}{ }^{\text {and Michael }}$ \\ Marder $^{\ddagger}$
}

\author{
†The Ali I. Al-Naimi Petroleum Engineering Research Center, The King Abdullah \\ University of Science and Technology (KAUST), Thuwal 23955-6900, Saudi Arabia \\ $\ddagger$ Department of Physics, The University of Texas, Austin, TX 78712, USA

\section{E-mail: tadeusz.patzek@kaust.edu.sa} \\ Phone: +966 (0)54 2505321
}

Phone:

\begin{abstract}
We develop a method of predicting field-wide gas (or oil) production from unconventional reservoirs, using the Barnett shale as an illustration. Our method has six steps. First, divide a field of interest (here Barnett) into geographic/depositional regions, where - upon statistical testing - gas and/or oil production are statistically uniform. Second, in each region $i$, fit a generalized extreme value distribution to every cohort of gas/oil wells with $1,2, \ldots, n_{i}$ years on production. Third, obtain accurate estimates of uncertainties in the distribution parameters for each regional well cohort. As a result, obtain $n_{i}$ points for the stable mean $\left(P_{50}\right)$ well prototypes for each region $i$, and the corresponding high/low $\left(P_{10} / P_{90}\right)$ bounds on well production. Fourth, by adjusting the producible gas/oil in place and pressure interference times between the
\end{abstract}


adjacent hydrofractures, fit each statistical $P_{50}$ well prototype with a physics-based scaling curve that also accounts for late-time external gas inflow. The physics-scaled well prototypes now extend 10-20 years into the future. Fifth, for each region, timeshift the dimensional, scaled well prototype and multiply it by the number of well completions during each year of field production. Add the production from all regions to match the past field production and predict decline of all wells up to current time. These well productivity estimates are more accurate and better quantified than anything a production decline curve analysis might yield. Sixth, by assuming different future drilling programs in each region, predict field production futures. We hope that the US Securities and Exchange Commission will adopt our robust, transparent approach as a new standard for booking gas (and oil) reserves in shale wells.

\section{Significance Statement}

Fig. 1(left) provides the history of electricity generation in the US between 1949 and 2018. In 2018, coal- and natural gas-fired power stations provided 62 percent of electricity, nuclear power stations $21 \%$, and water turbines, wind turbines and other renewables supplied the remaining $18 \%$ of electricity. Figure 1(right) charts the number of days per year the US was powered by each major source of electricity. In 2018, for example, natural gas provided 113 days of US electricity.

In $2018,55 \%$ of natural gas consumed in the US was produced from shales, and $31 \%$ of electricity was produced from natural gas. Given the vital importance of natural gas to the US economy, it is of interest to assess how well the past forecasts of production of gas from shale plays have aged.

Early on, Kuuskraa et al. 1998 claimed: “... [T] he Barnett shale might hold 10 tcf of technically recoverable natural gas (depending on eventual size of the productive trend, distribution of well performance, and intensity at which the play is developed.)" Patzek 2019 increased this estimate to 26 Tscf in 2011 in his "high gas rate scenario" (pages 4-5). 


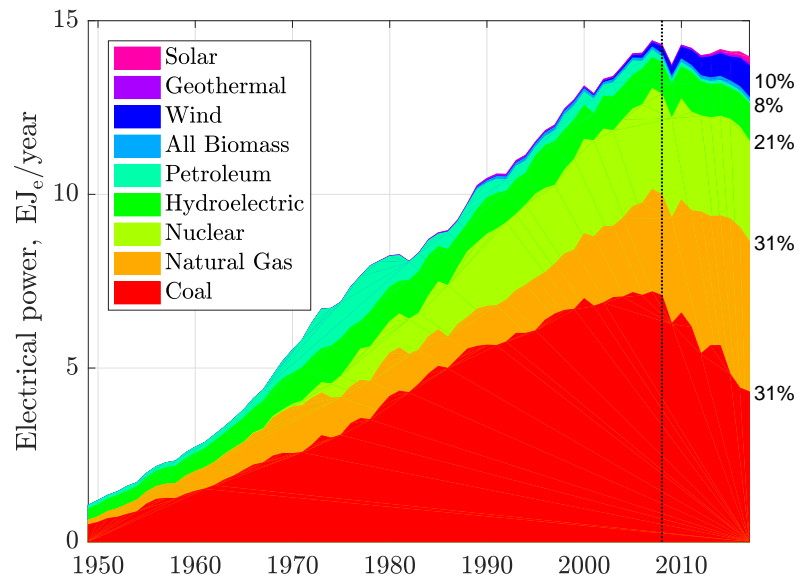

Several detailed 30-year predictions of gas production in the Barnett were made 5-7 years ago, and we know now some of them were too optimistic. A physics-based model by Patzek et al. 2013 was used in the most comprehensive to-date study of shale gas production in the US conducted by the Bureau of Economic Geology at UT Austin, e.g. et al. model restrictions on EURs were subsequently relaxed in $\frac{411}{11}$ and, ${ }^{8}$ resulting in the Barnett and Fayetteville shale gas production outlooks that were overly optimistic.

In this paper, we introduce a rigorous, robust method for statistical and physical modeling of production from thousands of wells, and show how to obtain detailed estimates of future production, that are less subject to bias. Investors and policy-makers should beware of assuming that the shale gas boom will last decades longer.

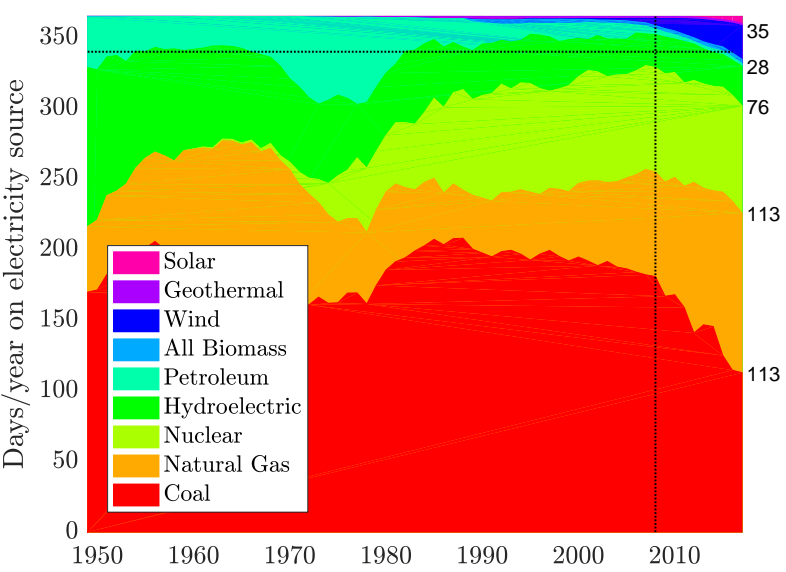

Figure 1: Production of electricity in the US, 1949-2018. Left: In 2018, the mostly baseload power stations produced $90 \%$ of electricity, with $31 \%$ generated from natural gas. Wind and other renewables supplied 10\% of electricity. The vertical line denotes the onset of the 2008 financial crisis. Right: Days per year the US was powered by each source of electricity. In 2018, coal, oil, natural gas and uranium powered US electricity between Jan. 1 and Oct 29, hydropower until Nov 26. All renewables powered US mostly through December. This picture has not changed substantially over the last 70 years, see the dotted horizontal line. Source: US DOE EIA, accessed 1/30/2019. 


\section{Introduction}

The U.S. Energy Information Administration (EIA) estimates that in 2017, about 16.76 trillion standard cubic feet (Tscf) of dry natural gas were produced from shale resources in the United States. This was about $60 \%$ of total U.S. dry natural gas production in 2017.

The net gas withdrawals from the horizontal wells in the 12 plays shown in Fig. 2 were 15.4 Tscf in 2017. The difference of 1.36 Tscf might be caused by us omitting the other, smaller plays that produced $\sim 1$ Tscf in 2017, and excluding vertical wells. Either way, US shales produced over $50 \%$ of all US gas in 2017. Cumulatively, this level of shale gas production was achieved with some 81,000 horizontal wells shown in Fig. 3. Given the high rates of production decline in shale wells, maintaining a constant production level requires continuous drilling. A cautious forecast for the next 20 years might involve some 169,000 new horizontal shale wells to be drilled and completed in the US at an estimated cost of $\$ 1.35$ trillion (Fig. 4).
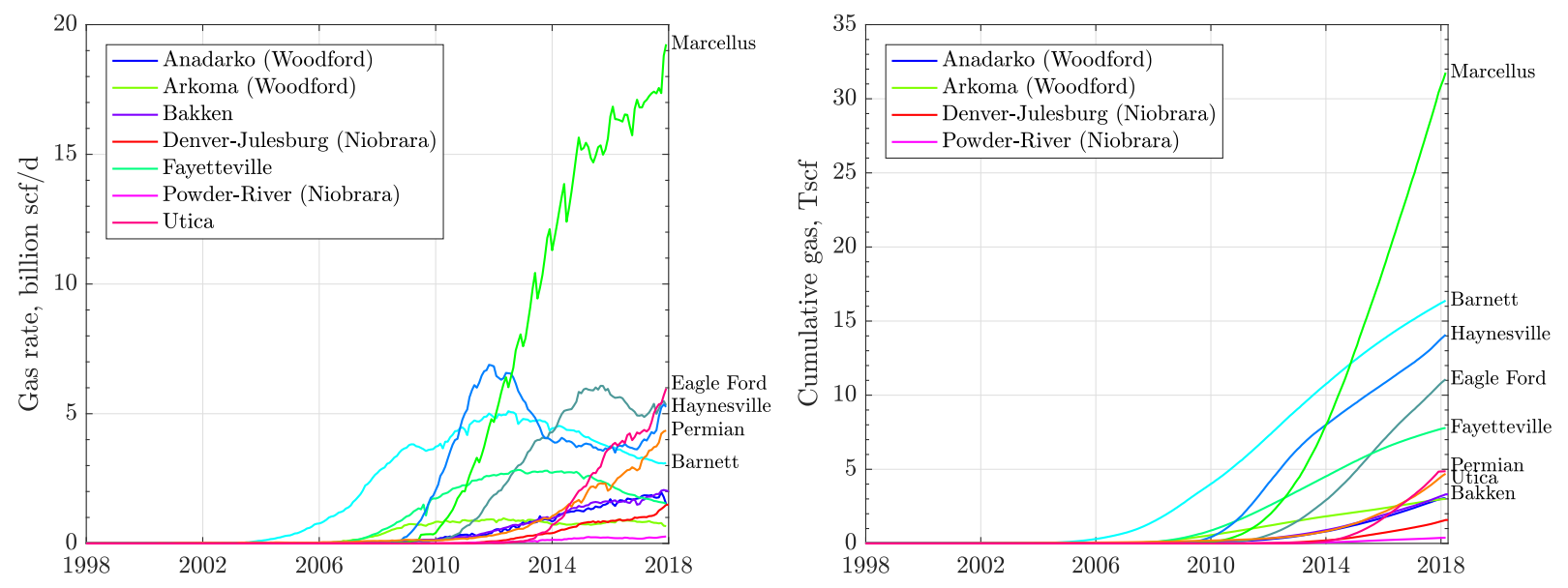

Figure 2: Left: Gas production rates from the horizonal wells in 12 major US shale plays. Right: Cumulative gas production from these plays. Data source: Drillinginfo, July 1, 2018.

Fig. 5 shows mean wells for the four largest gas producing shale plays, the Marcellus, Eagle Ford, Haynesville, and Barnett. The Permian basin wells produce mostly water and oil at the ratio of 3:1 or higher and gas that is being flared there to a significant degree ${ }^{\sqrt{22}}$ at the time of writing of this paper. An estimate of gas flared in the Permian by Rystad 

in the Barnett, which has been in irreversible decline since 2012, see Fig. 2(left).

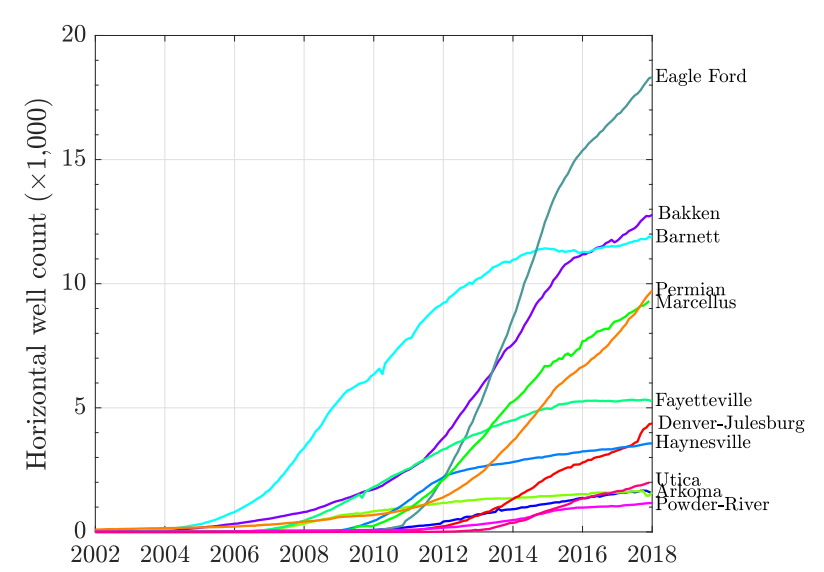

Figure 3: Active horizontal wells in 12 major US shale plays. By the end of 2017, the total number of these wells was over 81,000. Source: Drillinginfo, July 1, 2018.

Energy gives $\sim 0.6 \mathrm{Bscf} / \mathrm{d}$ in 2019. Therefore, all gas produced by a mean Johnson county well is burned continuously every 4 days in the Permian. The Fayetteville wells produce dry gas, but are in deep decline. The mean gas production rates in these four plays are somewhat different, with the Haynesville well being most productive initially, but declining to a level below the more stable Marcellus well. Both the Eagle Ford and Barnett mean wells are similar, less productive, and decline faster than the Marcellus and Haynesville wells. The mean Barnett well declines uniformly and exponentially, while the Marcellus and Eagle Ford wells stabilize by 2018, and the Haynesville well increases its gas production rate. The intensification of drilling in 2017, in the Marcellus, Haynesville and Eagle Ford shales, and the new higher-rate wells stabilized mean well production in these three plays, but not

Until late 2014, the Barnett shale produced more gas than any other shale play in the US, see Fig. 2(right), and had the highest number of wells, see Fig. 3. It is also the oldest gas play, with a few wells that have 18 years of production data. With over 12,000 active horizontal wells, the Barnett shale has been a field laboratory to test drilling and completion technologies and well productivity, and to determine with some accuracy the representative well prototypes and their estimated ultimate recovery (EUR) of gas. 

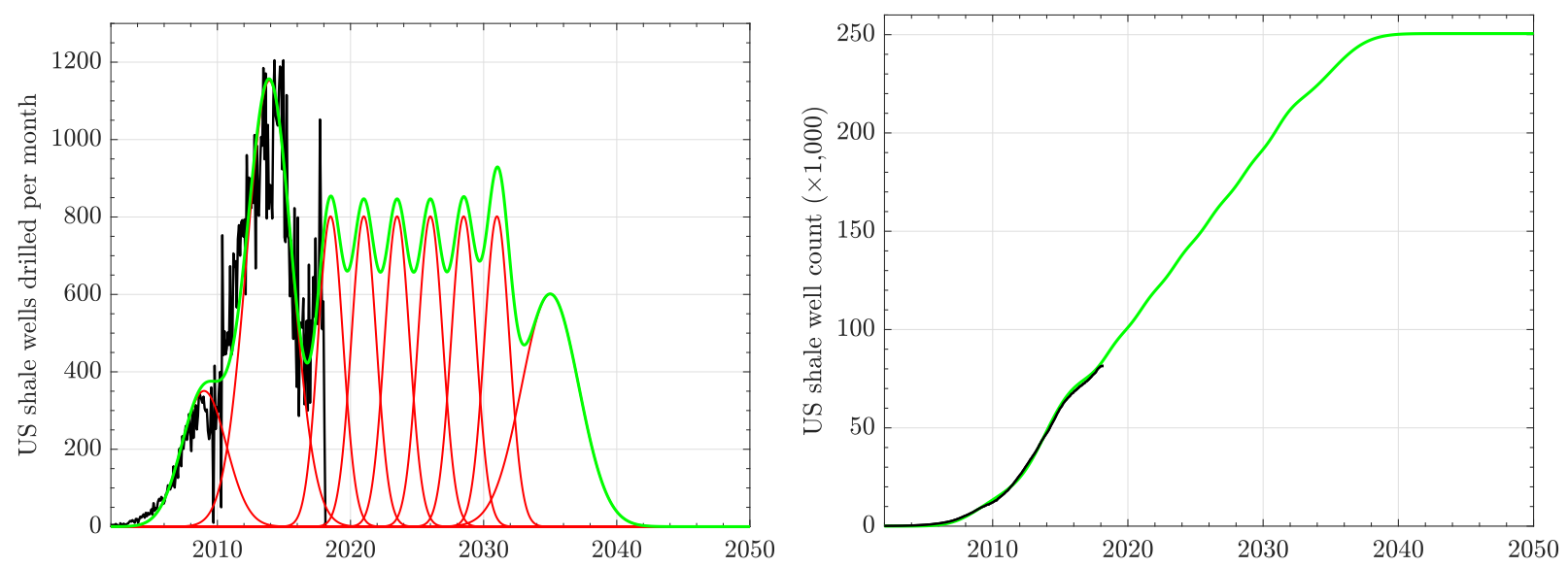

Figure 4: Left: Historic rate of drilling of horizontal shale wells in the US, followed by a plausible drilling forecast at $75 \%$ of current peak rate. Right: Will 169,000 new shale wells be drilled in the next 20 years? Their estimated cost might be $\$ 1.35$ trillion, at $\$ 8 \mathrm{M}$ per well. Possible answers to this question depend on the price of gas and the shape of US economy. At $\$ 10$ per mscf, perhaps all these wells will be drilled and more. Source: Drillinginfo, $7 / 1 / 2018$.

\section{A Brief History of Production Forecasts}

Attempts to obtain reliable predictions of well performance in tight reservoirs have a long history. Patzek 1992, successfully modeled the square root of time, transient linear flow of oil and water in over 1000 hydrofractured vertical producers and injectors in a silicious mudrock field, the South Belridge diatomite. He was able to predict the field production and injection for three years, and capture several extensions of hydrofractures and interwell linkages. Valko and Economides 1996, developed a rigorous semi-analytical procedure for modeling a horizontal oil well with a finite conductivity, longitudinal vertical fracture. Wattenbarger et al. 1998, used classical rate decline analysis to predict the square root of time dependence of production rate in linear flow in an infinite-acting reservoir, followed by an exponential decline in a finite size reservoir. They analyzed a few tight gas wells and showed that their production rates were inversely proportional to the square root to time on production. Valko 2009, used a specialized rate decline analysis to estimate mean EURs for a group of old vertical hydrofractured wells and a comparable group of new horizontal wells in the Barnett, and concluded that the new horizontal wells were several-fold more 

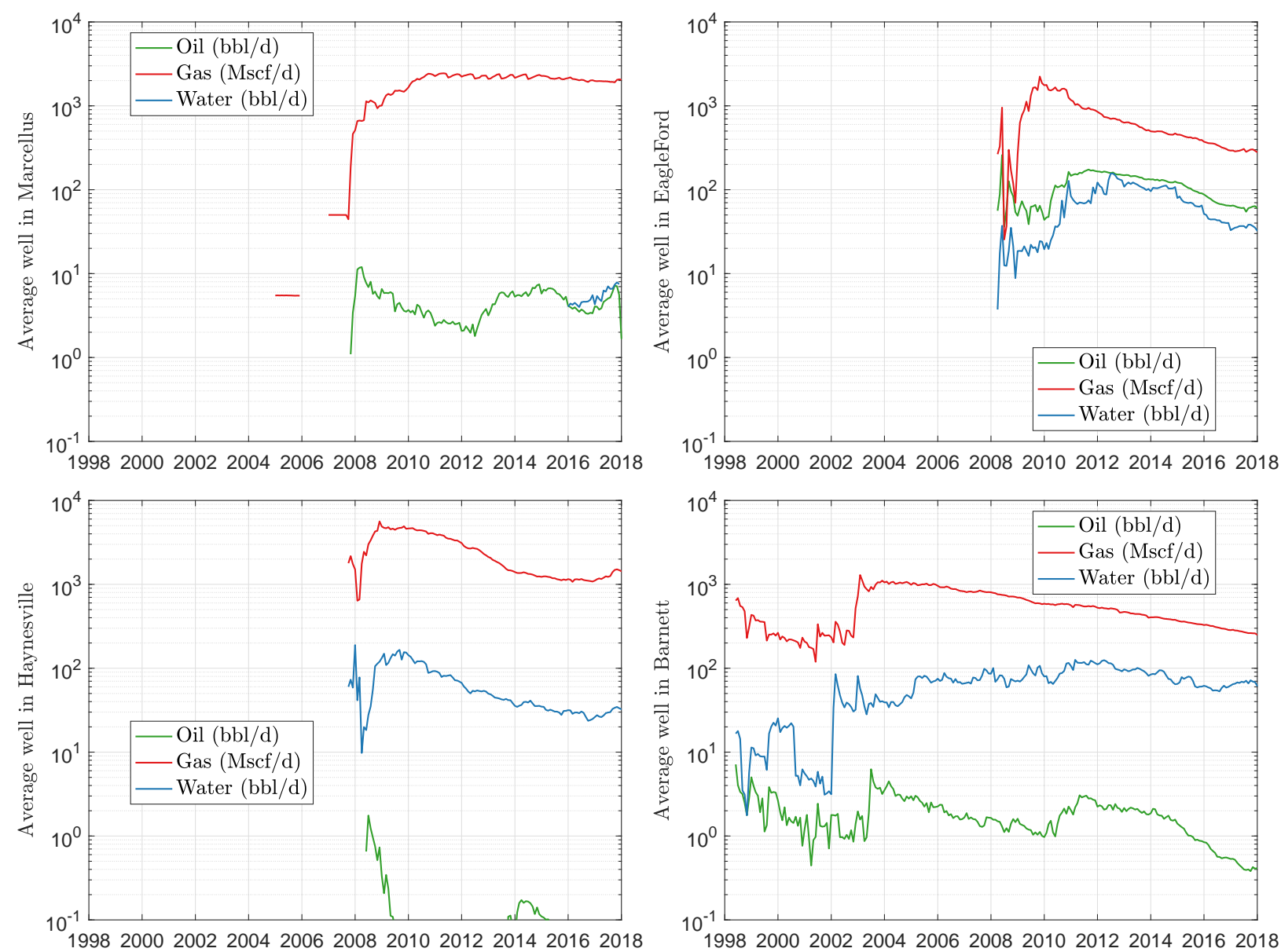

Figure 5: Mean horizontal wells in four major US gas shale plays. These wells were obtained by dividing the total fluid production in given month by the number of wells active in that month. Notice that some oil and significant water have been produced in the Barnett and Haynesville, while Marcellus produced little water and almost no oil. In contrast, the Eagle Ford mean well produces both significant oil and water. Top Left: The Marcellus mean well started in 2008, stabilized by 2011, and slowly declined since then, stabilizing in 2018. The initial improvements in technology and high-grading of drilling locations caused the mean production rate of gas to increase 3-4 fold and stabilize. Top Right: The Eagle Ford mean gas well started in 2009, its production rate then increased 10-fold, but it started declining uniformly until 2017. Bottom Left: The Haynesville mean well started in 2008, and began decline in 2009. In 2016, its production stabilized and increased due to production from the newer better wells offsetting decline of the older wells. Bottom Right: The Barnett mean well. After the initial four years of experimentation, horizontal drilling started in earnest in 2003. Since then the mean well has declined uniformly, indicating that newer wells could not replace the older ones. Water production rate has remained almost constant in the Barnett well; therefore, water cut has increased with time.

productive. He predicted that by 2020, US shales would produce 1.16 Tscf, half of which would come from the Barnett. Valko and Lee 2010, proposed a novel "stretched-exponential" 


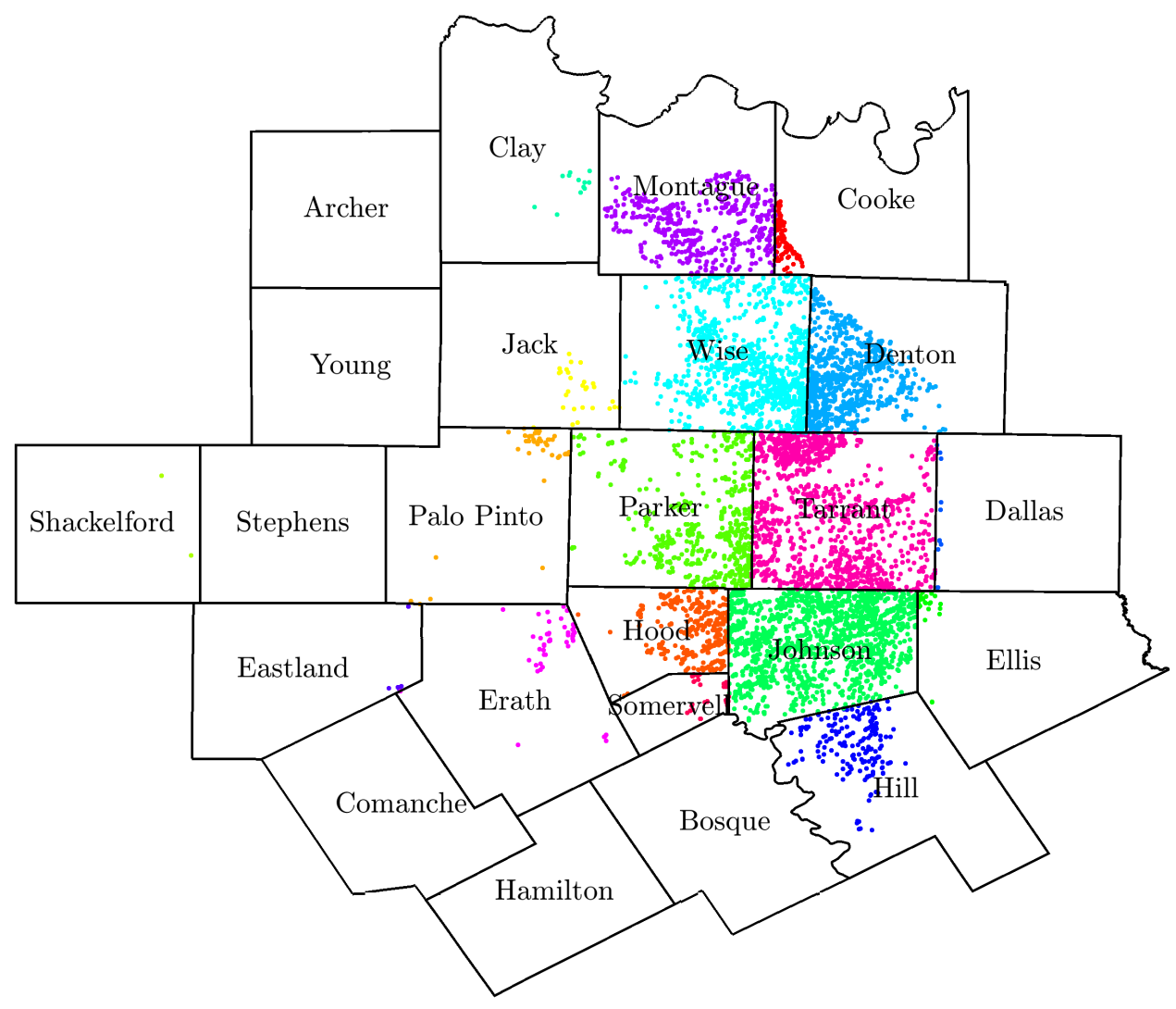

Figure 6: Map of the Barnett showing the major gas-producing counties, Tarrant, Johnson, Denton, Wise, Parker and Hood. Oil and condensate are also produced in Montague county and we have excluded it. All other counties in the Barnett are irrelevant from the point of view of this analysis. For more information on geology of Barnett, please see the Supporting Online Materials, Part I. Data source: DrillingInfo, July 1, 2018.

rate decline method of calculating EUR of unconventional wells and applied it to the Barnett shale. Patzek et al. 2014 showed equivalence of Valko's approach to that of Jones 1942.

Several researchers, $\frac{2[3]}{21}$ noted that the long-time linear flow of gas resulted from drainage of matrix blocks in between parallel hydrofractures and natural fractures of unknown spacing, because the fractures themselves would drain within hours. Using data from several tight gas wells and their semi-analytic model, the authors showed that late-time boundary dominated flow would set in after at least 10 years on production.

The end of the square root of time linear flow regime in horizontal gas wells was connected $^{2427}$ to the depletion of pressure between pairs of consecutive vertical transverse hy- 
drofractures. In order to match well performance, Patzek et al. had to invoke the presence of natural fractures spaced $\mathcal{O}(1-10) \mathrm{m}$ in the stimulated reservoir volume. This assertion

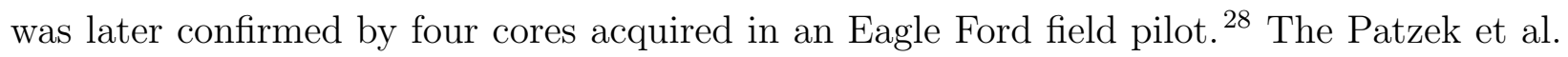
model was based on first-order physics of gas production and had two adjustable parameters, $\tau$, the characteristic time of pressure interference, and $\mathcal{M}$, the mass-in place of gas connected to the fractures. Using these two parameters, Patzek et al. 2013, were able to collapse the dimensionless cumulative gas production histories of 2,057 pressure-interfering wells in the Barnett onto an almost universal type curve. Using reasonable assumptions, they also mapped the dimensionless cumulative gas production histories of 6,237 wells that were still in transient linear flow onto a single straight line, see Fig. 3 in Patzek et al. 2013. Later, Eftekhari et al. 2018, proposed a model of gas inflow from a reservoir region external to the cuboid that contains well lateral and all hydrofractures. This new model allowed them to use data from several old wells in the Barnett to estimate shale matrix permeability and effective spacing of natural fractures. The late time cumulative production response is proportional again to square root of time.

The Patzek et al. 2013 model was used in the most comprehensive to-date study of shale gas production in the US conducted by the Bureau of Economic Geology at UT Austin, with partial funding provided by the Sloan Foundation and Shell. $\frac{516] 18}{18}$ For the reasons

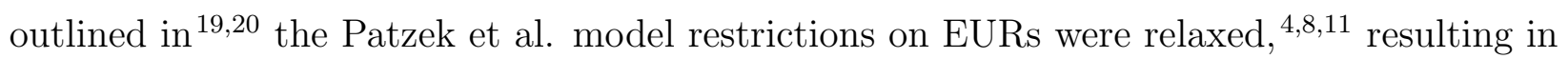
the Barnett and Fayetteville shale gas production outlooks that were overly optimistic. The Haynesville shale production outlook in Gülen et al. 2015 was more realistic.

In this paper, we revisit production data from the Barnett shale several years later, and compare facts on the ground with the analyses performed in 2011-2012. Not all of these analyses aged gracefully. 


\section{Results}

We set out to (i) replace the current industry-standard empirical estimates of ultimate recovery from shale wells with the statistically robust, accurate and precise ones; and (ii) fit the physics-based scaling of well production to the statistical well prototypes. To do so, we must answer the following three questions: (i) Given the long-time production data from thousands of hydrofractured horizontal wells, can one generate the stable, statistically average $\left(P_{50}\right)$ well prototypes for each of the major gas-producing counties in the Barnett shale? (ii) Is it possible to generate stable high and low bounds on gas production (the $P_{10}$ and $P_{90}$ wells) in each county? (iii) Do these statistical well prototypes behave similarly to those obtained by scaling gas production with the first-order physics based models, e.g., $21|24| 27$ ? In general, the answer to these three questions is yes, and we hope that our approach will be adopted by the US Securities and Exchange Commission for booking gas (and oil) reserves in shale wells.

The siliceous mudstones in the Mississippian Barnett Shale of the Fort Worth Basin, Texas, $\frac{15}{15}$ underlie $13,000 \mathrm{~km}^{2}$ in at least 17 counties, see Fig. 6. To limit scope of our statistical analysis we focused on the major Barnett counties that produce gas, Tarrant, Johnson, Denton, Wise, Parker and Hood, with 13,141 qualifying horizontal wells. For more details on how we picked these counties and well samples therein, please see the Supporting Online Materials (SOM), Part I. The entire procedure of arriving at the GEV-conditioned, physics-scaled well prototypes for each well sample is depicted in Fig. 14. The results of our GEV calculations and subsequent physical scaling are summarized in Figs. 15 - 20.

\section{Probability of well survival}

As of the writing of this paper, in our DrillingInfoß database we found 13,141 hydrofractured, horizontal gas wells in the six major gas producing counties in the Barnett shale. For different reasons, $2453+715=3168$ of these wells were shut in or plugged-and-abandoned 
(P\&A) between the years 2000 and 2019, see Table 1. The terminal watercuts and gas production rates in these 3168 wells are displayed in Figs. 7 and 8 . The watercuts are calculated as the ratio of cumulative water production to the cumulative water plus gas production. The produced gas volumes are converted to barrels of equivalent oil. From Fig. 7. it appears that most wells have been shut in between 4 and 8 years on production because of excessive water production or low gas production. The numerous yellow dots depict the high well failure rate in Johnson county. Fig. 8 shows that most wells were P\&A-ed between zero and six years of production for the same reasons.

Table 1: Inactive wells in the key Barnett shale counties

\begin{tabular}{r|ccc}
\hline County & $\begin{array}{c}\text { Shut in } \\
\text { wells }\end{array}$ & $\begin{array}{c}\text { P\&A } \\
\text { wells }\end{array}$ & $\begin{array}{c}\text { Total } \\
\text { inactive wells }\end{array}$ \\
\hline Tarrant & 629 & 183 & 812 \\
\hline Johnson & 996 & 165 & 1161 \\
\hline Wise & 239 & 29 & 268 \\
\hline Denton & 135 & 65 & 200 \\
\hline Parker & 305 & 222 & 527 \\
\hline Hood & 149 & 51 & 200 \\
\hline
\end{tabular}

We now calculate the non-parametric, empirical probability distributions of wells started in a given calendar year, and surviving for $1,2, \ldots$ years on production. For example, one year on production is given by 12 consecutive nonzero monthly production records for a well. If this well were shut in for a month, 13 calendar months would elapse. If we fix attention on the wells started in 2003, these probabilities are calculated as the ratios of the 2003 wells surviving for a given period of time on production to all wells started in 2003. For the oldest wells, it is increasingly more difficult to survive for the longest elapsed times on production. The complicated experimental probability distributions are plotted in Figs. 9 -11. Notice that these probability distributions are entirely field data-driven. Hidden in them are progress in well technology, gradually poorer well locations, excessive water logging of newer wells, well failures, etc. 
And now an important remark. Because the statistics of all well cohorts in the Barnett are sensitive to well failure, the well prototypes we are about to construct will be conditioned by the probabilities of well survival presented in Figs. 9 - 11. This important feature of our statistical/scaling well production model makes our predictions very robust, if the future wells - should they be drilled - continue to obey probabilities of failure similar to those to date.
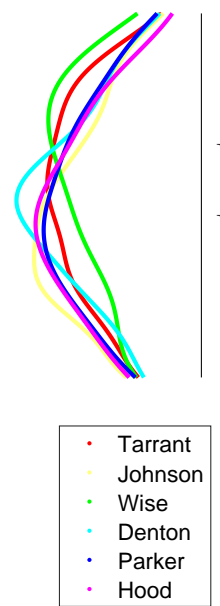

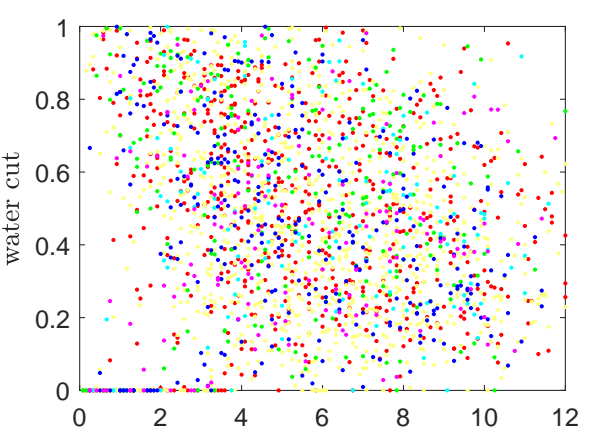

years on production to shut in

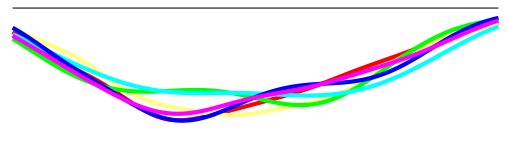

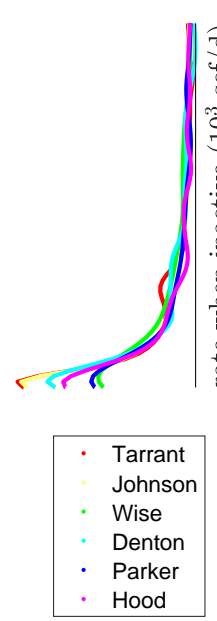

Figure 7: Between 2000 and 2019, there were 2453 wells in the Barnett shale that were shut in and declared inactive for a variety of reasons. In each plot, the left vertical graph is the frequency distribution of the $y$-axis in the main graph dots colored by county, each representing a well at shut in. The horizontal graph is the frequency distribution of the $x$ axis, here years to shut in. Left: The distribution of terminal water cuts by county. Right: The distribution of terminal gas production rates by county.

\section{Average startup years}

With increasing time on production, a well sample is enriched in older wells, as shown in the left panels of Figs. 15 - 20. The shapes of the average well age curves are complicated by the different numbers of wells completed each year. However, for the longer times on production and older wells, these curves have more negative slopes and all well populations are enriched in the oldest wells. 


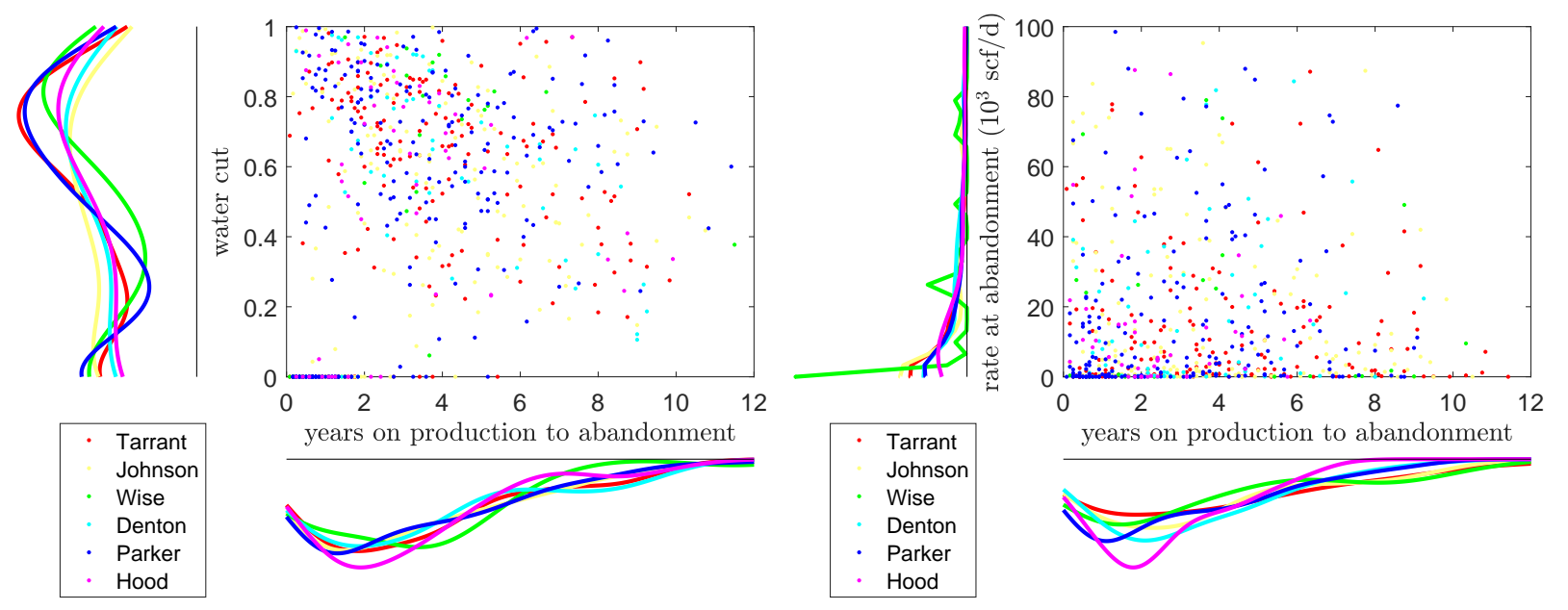

Figure 8: Between 2000 and 2019, there were 715 wells in the Barnett shale that were plugged and abandoned (P\&A). In each plot, the left vertical graph is the frequency distribution of the $y$-axis in the main graph dots colored by county, each representing a well at $\mathrm{P} \& \mathrm{~A}$. The horizontal graph is the frequency distribution of the $x$-axis, here years to P\&A. Left: The distribution of terminal water cuts by county. Right: The distribution of terminal gas production rates by county.

\section{Why Extreme Value Statistics?}

We conjecture that for each fixed time on production $(1,2, \ldots$ years $)$, gas production from each well is the maximum of what this well could produce by (i) draining gas from a myriad of nanopores in the countless matrix blocks in between fractures, $\frac{26}{2}$ and (ii) successfully delivering this gas to the wellbore via a network of the loosely connected fractures into which these blocks drain. We will elucidate this multiscale gas production model in another paper. Therefore, each production record is an extreme event.

The Generalized Extreme Value, GEV, distributions ${ }^{10}$ are used to model extreme events, highest daily or monthly rainfall over a long period of time, floods, earthquakes, appearance of large pores or fractures in a rock mass, or production of hydrocarbons from fractured shales. It turns out that Frèchet and Weibul| $]^{1}$ or Type II/III GEV distributions described below are most applicable. The superiority of GEV distributions in comparison with lognormal distribution is statistically significant, as we will show in another paper. The GEV fits

\footnotetext{
${ }^{1}$ Notice that if $\xi<0$, but $|\xi| \ll 1$, the Weibull distribution has a right tail, but on the left it falls off more gently than the Frèchet distribution.
} 

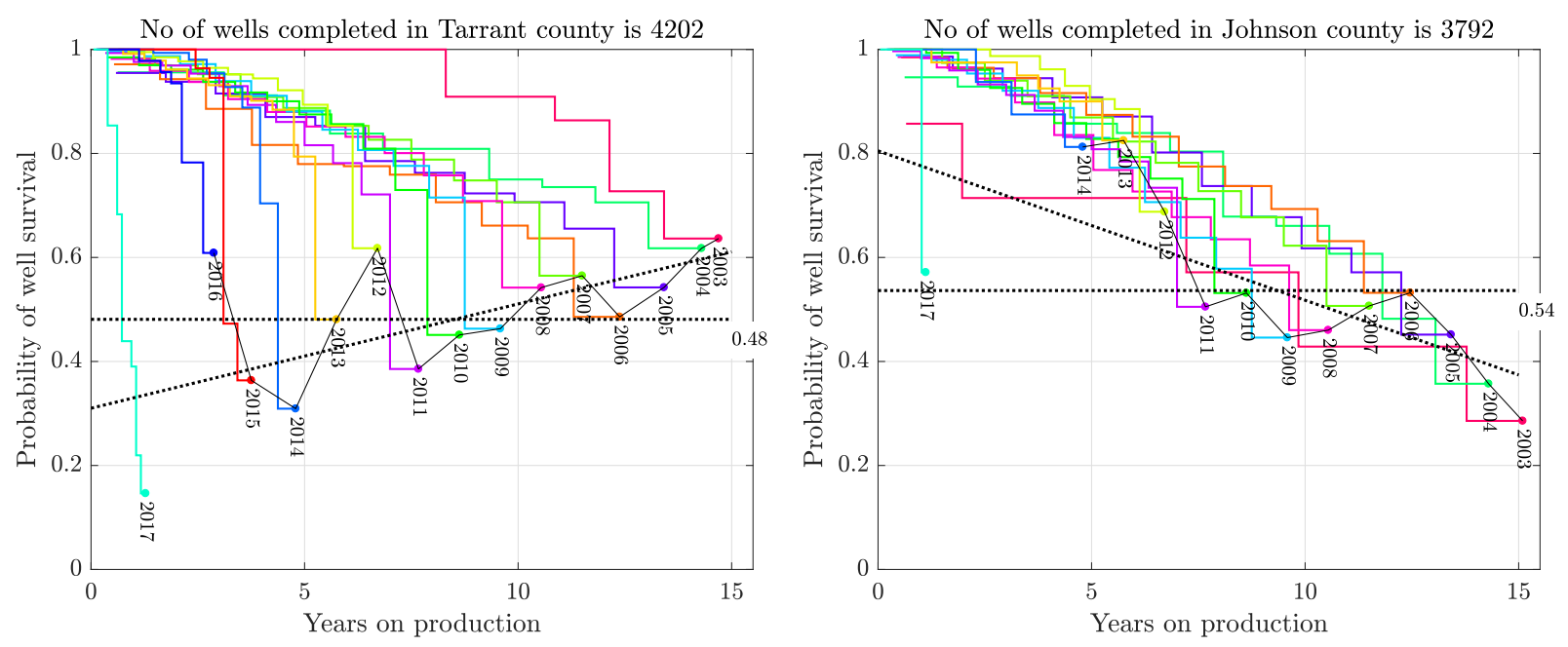

Figure 9: Left: The non-parametric cumulative probability distribution functions (cdfs) of survival of each annual cohort of wells completed in Tarrant county between 2003 and 2017. The earlier and later well cohorts were too small to be meaningful and were rejected. It turns out that the wells drilled in 2003 and 2004 have the highest probability of surviving unscathed, $60 \%$. The younger wells have an almost linearly decreasing probability of survival, down to $30 \%$ in 2014. Of particular interest are the right-hand ends of these cdfs that give the probabilities of wells surviving uninterrupted until present. These ends are highlighted with dots and connected by a black continuous line. The horizontal dotted line is the mean end-point survival probability, here 0.48. The linear fit of these end-points slopes down to the left, meaning that newer wells have lower probabilities of survival. Therefore, the newer well cohorts can never achieve the survival rate of the 2003-2004 cohorts and, as time goes on, the active wells in Tarrant county are gradually enriched in the better older wells. Right: The cdfs of survival of each annual cohort of wells completed in Johnson county between 2004 and 2014. The 2000 - 2003 and 2015 - 2016 well cohorts were too small to display. The 2004 well cohort has a 30\% probability of survival. The linear fit of end-point probabilities slopes to the right meaning that all Johnson county wells are unlikely to survive for longer than 20 years on production.

of all well cohorts in all well samples (here counties) are plotted in Part II of the Supporting Online Materials. 

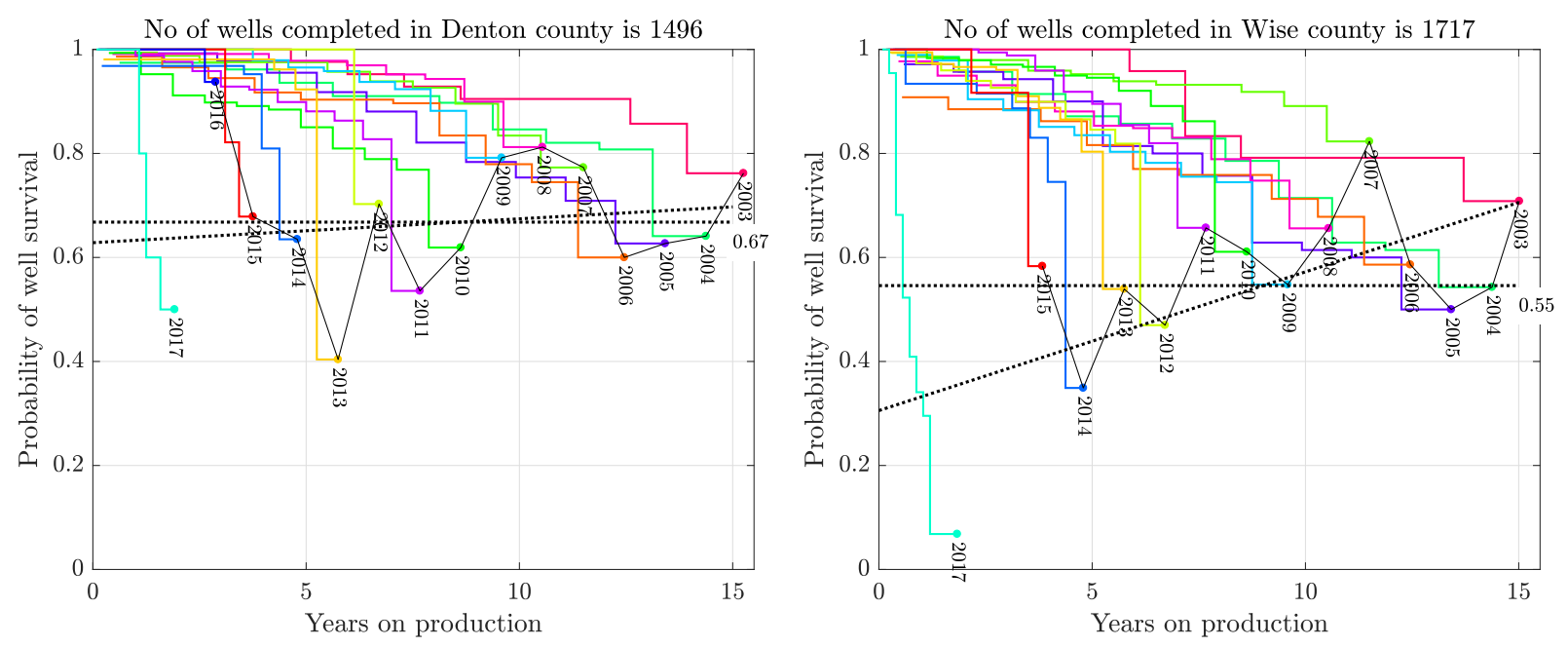

Figure 10: Left: The cdfs of survival of each annual cohort of wells completed in Denton county between 2003 and 2016. The probability of well survival decreases from $78 \%$ in 2003 to $40 \%$ in 2013. Slowly, the well population in Denton county is enriched in the better older wells. Right: The probability distribution functions (cdfs) of well survival in each annual cohort of wells completed in Wise county between 2003 and 2016. Notice that as we move east from the Barnett core, all wells fail more often. The probability of survival declines from $70 \%$ in 2003 to $35 \%$ in 2015 . This means that the newest well cohorts will never reach the survivability of the older ones, and the well population in Wise county is gradually enriched in the better older wells.
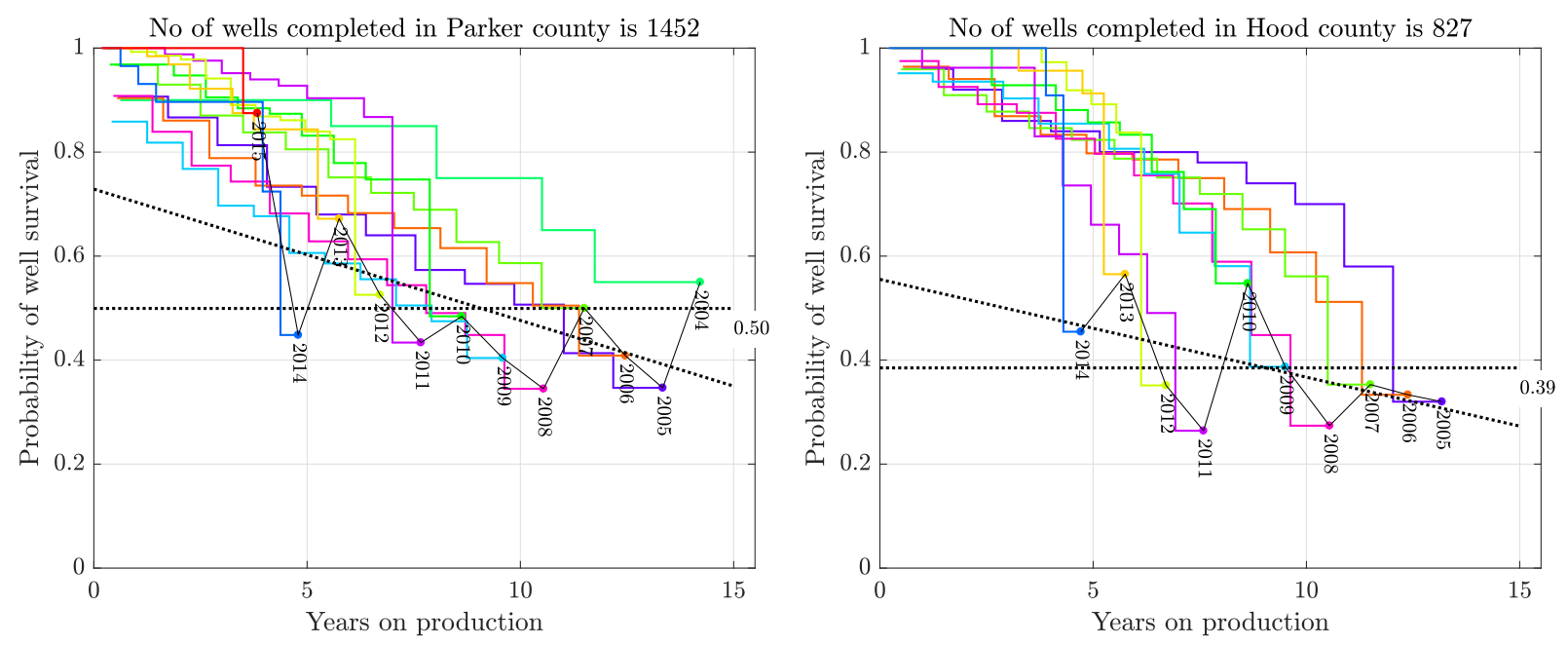

Figure 11: Left: The probability distribution functions (cdfs) of survival of each annual cohort of wells completed in Parker county between 2004 and 2015. Here the 2004-2009 well cohorts survive with about the same probability of $50 \%$, but all wells in Parker county are unlikely to survive beyond 25 years. Right: The cdfs of survival of each annual cohort of wells completed in the marginal Hood county between 2005 and 2014. All well cohorts vary from poor survivability to disastrous, averaging a $40 \%$ probability of survival. 


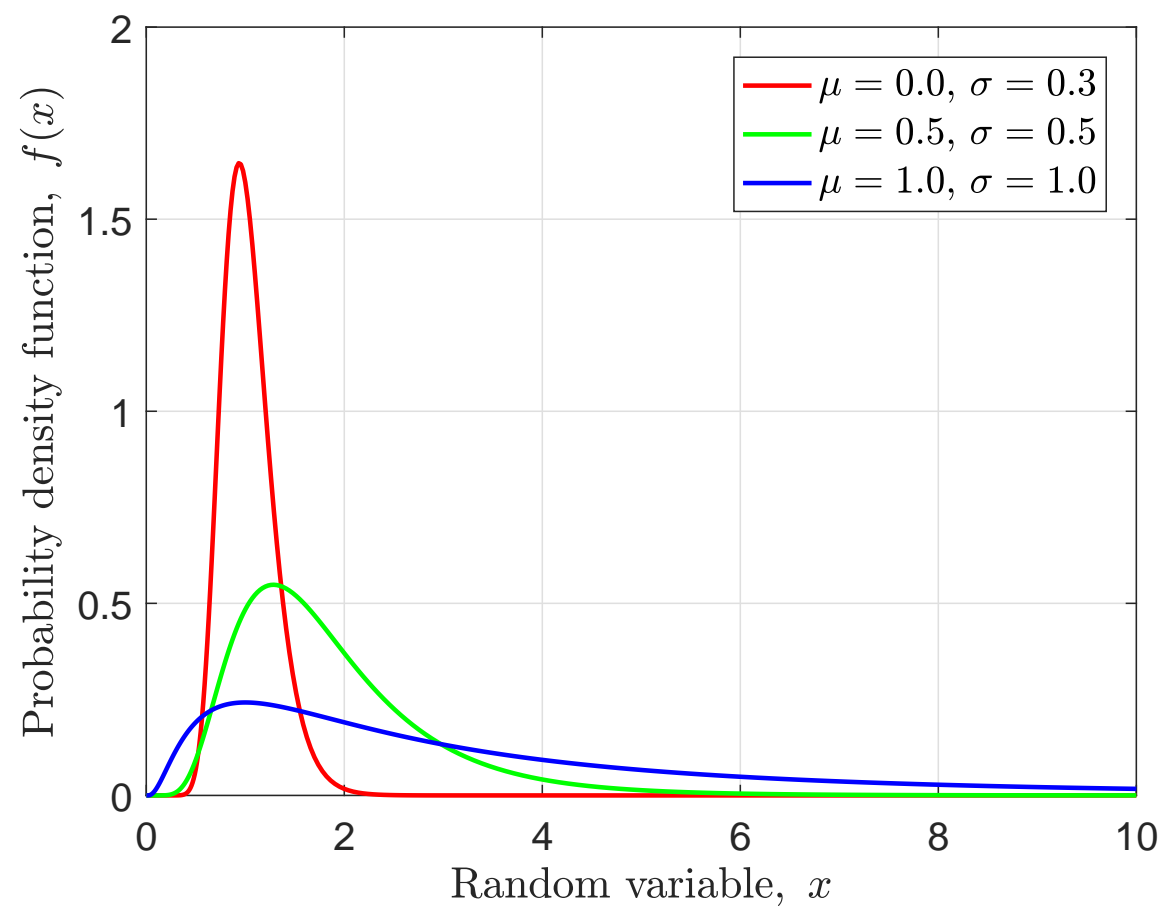

Figure 12: Examples of lognormal distribution with three combinations of location and scale parameters, $\mu$ and $\sigma$.

In probability theory, a log-normal (or lognormal) distribution, 1 is a continuous probability distribution of a random variable whose logarithm is normally distributed. For example, the lognormal distribution describes size distribution of rock fragments, when a parent rock mass is broken into two fragments of random sizes, and each fragment is then repetitively broken in two at random.

In a lognormal distribution of a random variable $\mathrm{X}>0$ that has outcomes $\{x\}>0, \mu$ is mean and $\sigma$ standard deviation, respectively, of $\ln x$ (the variable's logarithm is normally distributed). In cartesian coordinates, $\mu$ and $\sigma$ are called the location and scale parameters, respectively, see Figure $\mathbf{1 2}$.

The lognormal probability density function $p d f=f$ is defined as:

$$
\operatorname{pdf}(x ; \mu, \sigma)=f_{\ln }(x ; \mu, \sigma)=\frac{1}{x} \frac{1}{\sqrt{2 \pi} \sigma} \exp \left[-\frac{1}{\sqrt{2}}\left(\frac{\ln x-\mu}{\sigma}\right)^{2}\right]
$$


The distribution mode (pdf's peak value) occurs at $x$ equal to $\exp \left(\mu-\sigma^{2}\right)$ :

$$
\operatorname{Mode}(\mathrm{X})=\exp \left(\mu-\sigma^{2}\right)
$$

Median is defined as

$$
\operatorname{Median}(\mathrm{X})=\int_{0}^{m^{*}} f(x ; \mu, \sigma) d x=\int_{m^{*}}^{\infty} f(x ; \mu, \sigma) d x=\frac{1}{2} \int_{0}^{\infty} f(x ; \mu, \sigma) d x=\frac{1}{2}
$$

The lognormal distribution's median is equal to

$$
\operatorname{Median}(\mathrm{X})=\exp (\mu)
$$

The most important mean or expected value of lognormal distribution is

$$
\mathrm{E}(\mathrm{X})=m=\int_{0}^{\infty} x f(x ; \mu, \sigma) d x=\exp \left[\mu+\frac{\sigma^{2}}{2}\right]
$$

Variance of lognormal distribution is

$$
\mathrm{V}(\mathrm{X})=\mathrm{E}\left[(\mathrm{X}-\mu)^{2}\right]=\left(\mathrm{e}^{\sigma^{2}}-1\right) \mathrm{E}^{2}(\mathrm{X})
$$

and its standard deviation is

$$
s=\sqrt{\mathrm{V}(\mathrm{X})}
$$

221 Notice that $m$ and $s$ pertain to $x$, while $\mu$ and $\sigma$ to $\ln x$.

\section{The Generalized Extreme Value (GEV) Distributions}

The Generalized Extreme Value (GEV) ${ }^{10}$ probability density function, depicted in Figure 13. models distributions of extrema (minima or maxima) of blocks of data. For example, the WEIBULL distribution with $\xi<0$, can be used to model the distribution of pore throats 
in carbonate macroporosity in the Ghawar with the capillary pressure data from. ${ }^{6}$

In a generalized extreme value distribution, $\mu \in \mathbb{R}$ is the location parameter, $\sigma>0$ the scale parameter, and $\xi \in \mathbb{R}$ (often denoted by $k$ ) is the shape parameter. The GEV distribution is a family of continuous probability distributions developed within extreme value theory to combine the Gumbel $(\xi=0)$, Fréchet $(\xi>0)$ and Weibull $(\xi<0)$ families also known as type I, II and III extreme value distributions.

Always

$$
\frac{y}{y_{0}}:= \begin{cases}1+\xi \frac{(x-\mu)}{\sigma}, & \text { if } \xi>0, c=\frac{1}{\xi} \\ 1-\xi \frac{(x-\mu)}{\sigma}, & \text { if } \xi<0, c=-\frac{1}{\xi}\end{cases}
$$

where a new random variable, $y$, and its scaling parameter, $y_{0}$, are defined by Eq. (8). Here $y=x-(\mu-\sigma /|\xi|)$ and $y_{0}=\sigma /|\xi|$.

The GEV probability density function is defined as:

$$
\begin{aligned}
f(x ; \mu, \sigma, \xi)= & \frac{1}{\sigma}\left[1+\xi\left(\frac{x-\mu}{\sigma}\right)\right]^{(-1 / \xi)-1} \times \\
& \times \exp \left\{-\left[1+\xi\left(\frac{x-\mu}{\sigma}\right)\right]^{-1 / \xi}\right\}
\end{aligned}
$$

For $\xi<0$ and with $c=-1 / \xi$, the Type III GEV distribution can be transformed into the classical WeIBull distribution:

$$
f_{W}\left(y ; c, y_{0}\right)=\frac{1}{\sigma}\left(\frac{y}{y_{0}}\right)^{c-1} \exp \left[-\left(\frac{y}{y_{0}}\right)^{c}\right]
$$

also known as the stretched exponential distribution for $c<1$. With $c=1$, this distribution reduces to exponential distribution with constant failure rate. For $c<1$, the failure rate decreases over time, i.e., the defective items are weeded out from the population early on. Conversely, for $c>1$, the failure rate increases with time. 
The WeIBulL distribution with $c \leq 1$ has been used to model pretty much everything in the Universe, cf., ${ }^{14}$ including the distribution of hydrocarbon volumes in the Gulf of Mexico and die-off of dinosaurs. Its cumulative probability distribution function is particularly simple:

$$
c d f_{W}\left(y ; c, y_{0}\right)=\int_{0}^{y} f_{W}\left(y ; c, y_{0}\right) d y=1-\exp \left[-\left(\frac{y}{y_{0}}\right)^{c}\right]
$$

For $c<1$, the cumulative distribution (11) presents a clear curvature on a log-log plot while exhibiting a relatively extensive apparent linear behavior, all the more so, the smaller $c$ is. It can thus be used to account both for a limited power-law scaling regime and a cross-over to non-scaling.

The GEV distribution's mode (pdf's peak value) is

$$
\operatorname{Mode}(\mathrm{X})=\mu+\frac{\sigma}{\xi}\left[(1+\xi)^{-\xi}-1\right], \quad \xi \neq 0
$$

Median is

$$
\operatorname{Median}(\mathrm{X})=\mu+\sigma \frac{(\ln 2)^{-\xi}-1}{\xi}, \quad \xi \neq 0
$$

Mean or expected value of the GEV distribution is

$$
\mathrm{E}(\mathrm{X})=m=\mu-\frac{\sigma}{\xi}+\frac{\sigma}{\xi} \Gamma(1-\xi), \quad \xi \neq 0
$$

Variance of the GEV distribution is

$$
\mathrm{V}(\mathrm{X})=\frac{\sigma^{2}}{\xi^{2}}\left[\Gamma(1-2 \xi)-\Gamma^{2}(1-\xi)\right], \quad \xi \neq 0, \xi<\frac{1}{2}
$$

if $\xi=0$

$$
\mathrm{V}(\mathrm{X})=\frac{\pi^{2}}{6} \sigma^{2}
$$

and $\mathrm{V}$ does not exist $(=\infty)$ otherwise. 
The standard deviation is

$$
s=\sqrt{\mathrm{V}}
$$

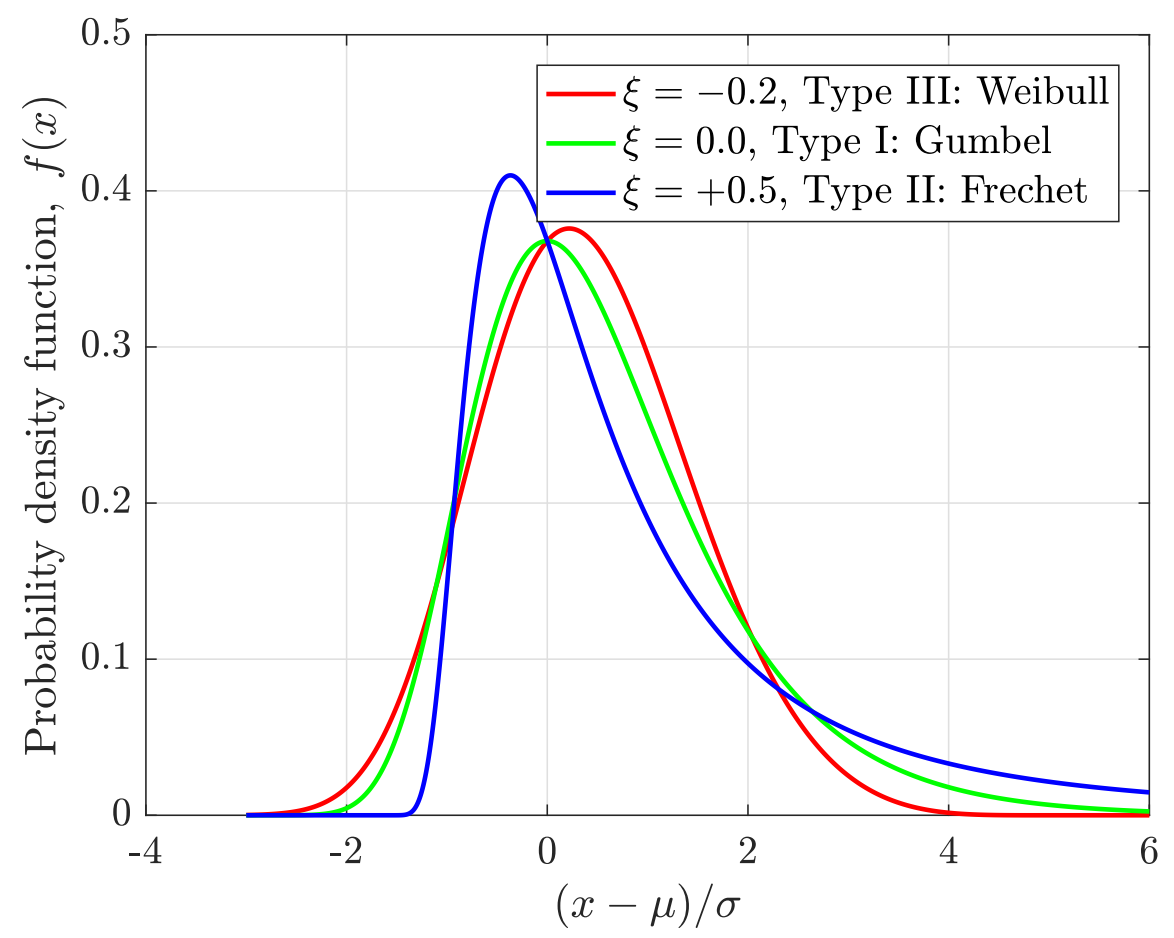

Figure 13: Examples of the three GEV distributions with three vales of the shape parameter, $\xi$, and with a zero location parameter, $\mu=0$, and unit scale parameter, $\sigma=1$. Notice that for $\xi<0$ or $\xi>0$, the density has zero probability above or below, respectively, the upper or lower bound $-(1 / \xi)$. In the limit as $\xi$ approaches 0 , the GEV is unbounded. These cases can be summarized as the constraint that $1+\xi(x-\mu) / \sigma$ must always be positive.

\section{Statistical well prototypes}

We have used the GEV distributions to fit gas production from annual cohorts of wells in each sample of the horizontal, hydrofractured shale wells in Barnett, and acquired their detailed statistics: the location, scale and shape parameters, their confidence intervals, and the confidence intervals on the $P_{x}$ wells, where $x=90,50$, and 10 . The resulting statistical well prototypes in each county are plotted vs. the square root of time on production in the righthand panels of Figs. 15-20. In the initial year on production, time was shifted 
by subtracting the number of months listed in Table 2 for each county. This procedure is consistent with the approaches in.227 It accounts for the initially throttled gas flow during hydrofracture unloading from the frac water and proppant, possibly restrictive wellhead chokes, and often lack of full takeaway capacity. After these time shifts, the mean or expected, $P_{50}$ well production in each county follows the expected linear flow regime with an onset of exponential decline. In the last 2-4 years on production, the admissible well cohorts become skewed towards the oldest best wells, and all $P_{50}$ curves deviate upwards from the expected trends.

The $P_{10}$ and $P_{90}$ well prototypes diverge from the mean with time, indicating that the poorest wells are getting worse and best wells better. This phenomenon might be caused by the usually decreasing probabilities of survival of the younger wells. Conversely, the newer $P_{50}$ wells have tighter bounds on the $P_{10}$ and $P_{90}$ wells. Because of the properties of GEV distributions, the median and most probable (mode) wells always fall beneath the mean or expected well.

\section{Scaled well prototypes and production forecast}

For each county, we map the $P_{50}$ well prototype onto a universal curve through the scaling parameters $\mathcal{M}$, producible original gas in place, and pressure interference time $\tau$. To account for the late time responses of the GEV mean wells, we have added to the scaling curves from Patzek et al. 2013 a correction proportional to the square root of dimensionless time. ${ }^{7}$ This correction incremented the EURs in Table 2 by $0.2-0.3$ Bscf.

We now forecast the future production of the Barnett shale, based upon the existing wells. Later we will explore scenarios that involve drilling additional wells. Since we are matching the statistical $P_{50}$ wells with the scaling curve wells amended with the square root of time late responses, the effects of well attrition are built into the scaled production curves. Therefore, we can add the scaled wells after multiplying their cumulative production by the number of active wells each year in every county, and time-shifting the products in 
one-year increments. Our prediction for the future production of the existing wells in the Barnett is shown in Fig. 21. Our methodology finds the historical part of a prototype well from the GEV statistics generated by field data from existing wells, and then predicts a smooth production decay from these wells into the future using a physical scaling. The best fits to data from the past are obtained by time-shifting the production of prototype wells by 6 months so that the average well begins producing in the middle of the year. The fit parameters appear in Table 2, The predicted recovery from the current Barnett shale wells extrapolates to 24.5 Tscf. Our very simple forecast and field data are in excellent agreement. 

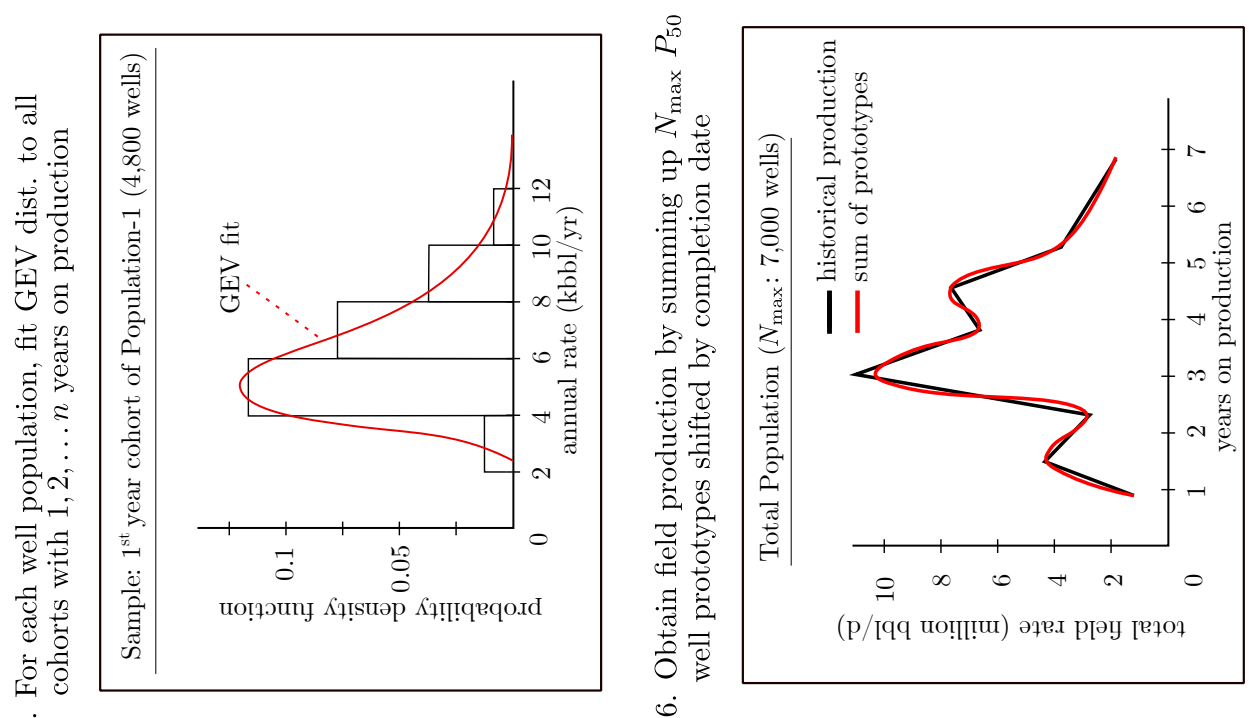

ஸ் 它学我㟔 苂

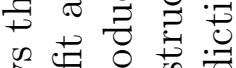
尝药 ज ठ คి

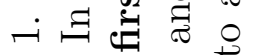

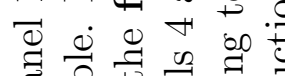
ते $\exists$.

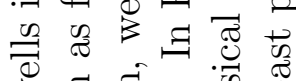
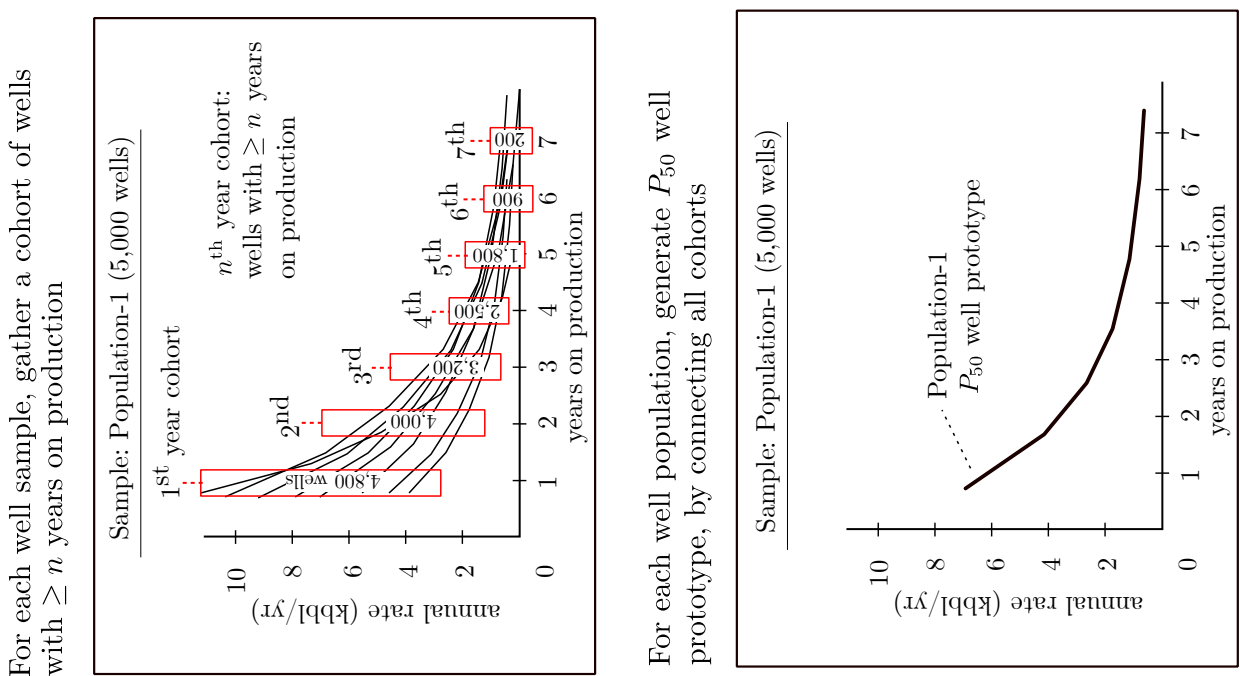

i

เ
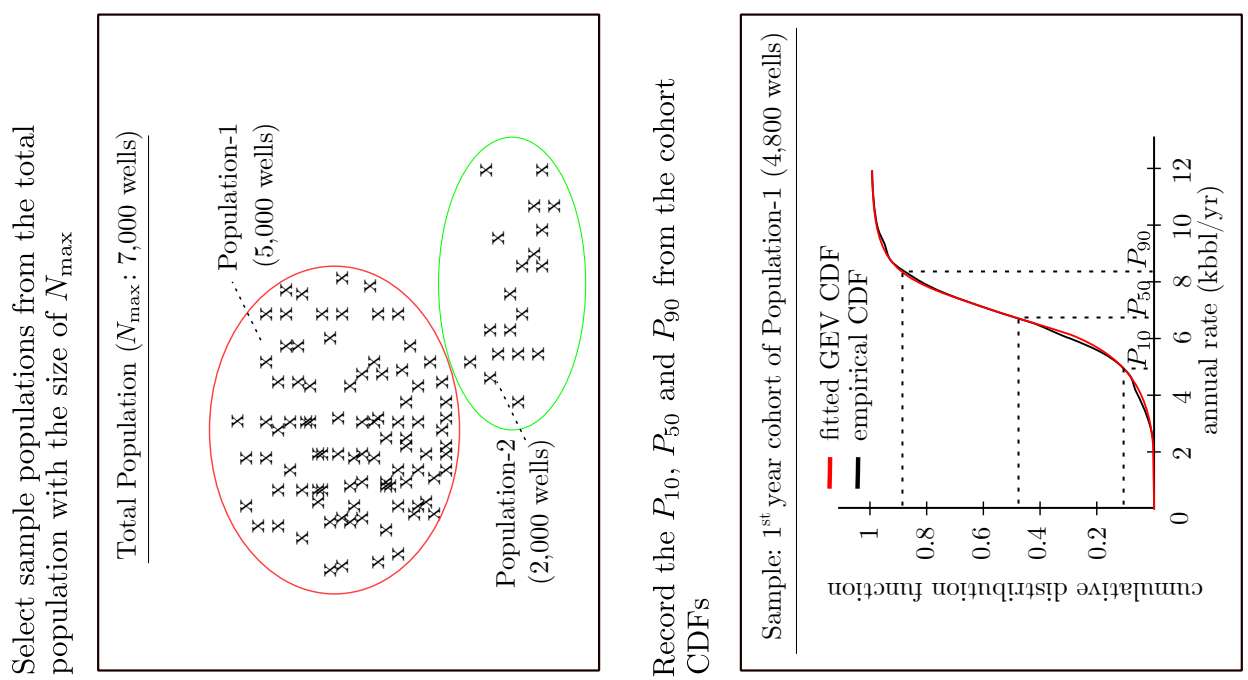

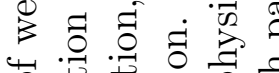
0 艺

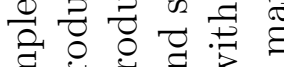
ฮี่

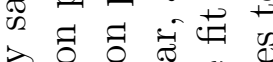

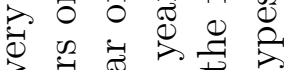

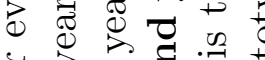
¿̄ $>$ o ô.

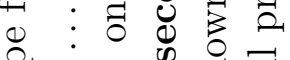

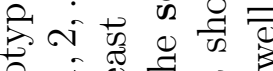

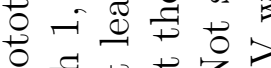

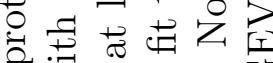

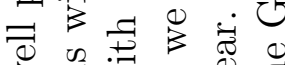

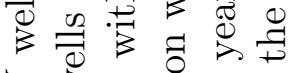

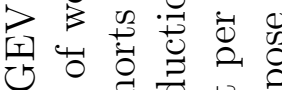

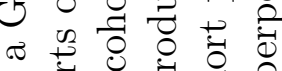
๘

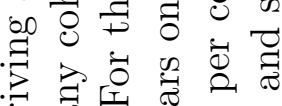

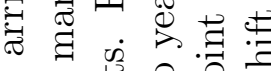

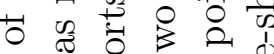
○)

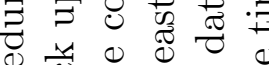
仓ै

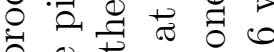

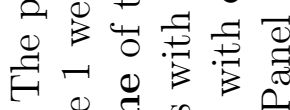

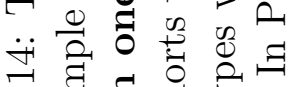

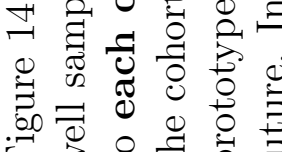



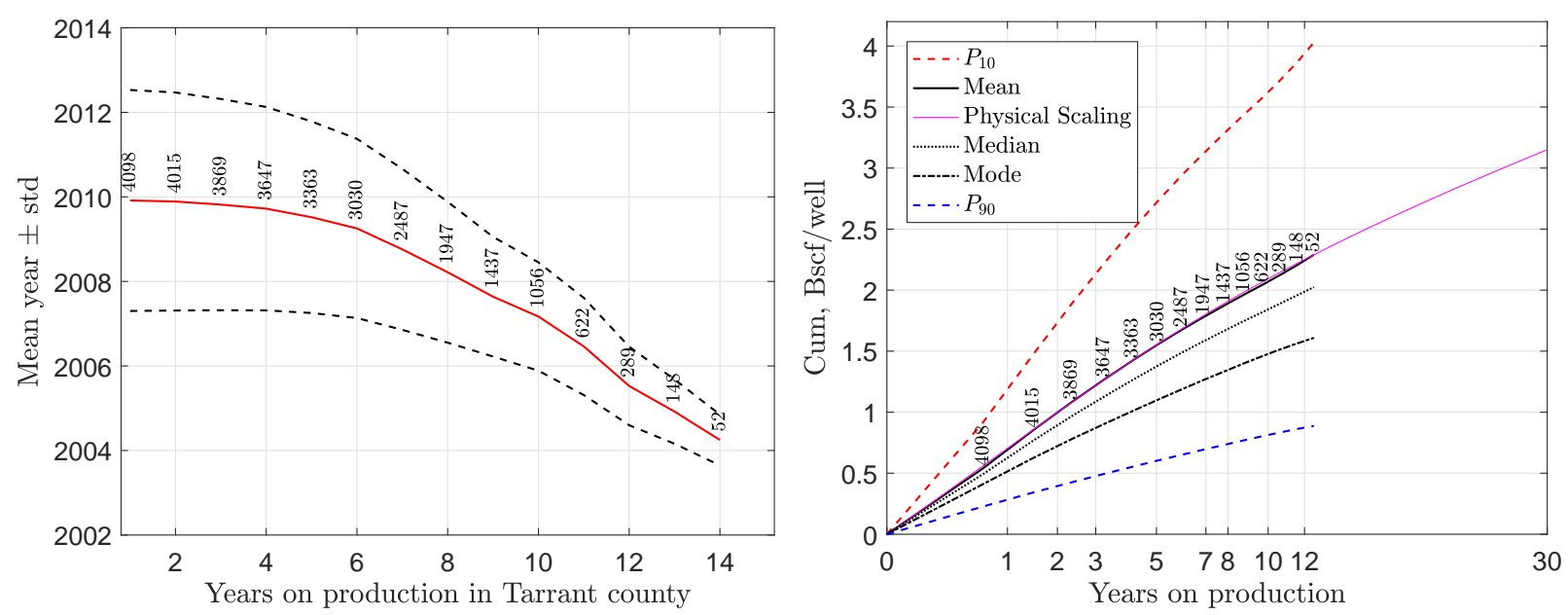

Figure 15: Left: The mean completion dates for the horizontal well cohorts in Tarrant county with at least $1,2, \ldots, 14$ years on production. Notice that during the first six years on production the mean date changes by less than one year, but it changes by four years in the ensuing six years. Essentially, with each year on production the more numerous newer wells are lobbed off from the distribution and gradually the older wells dominate. Right: The average well in Tarrant county. Each year, this well traces the expected values of the Generalized Extreme Value (GEV) distribution fits of all active horizontal wells in the county, which had at least $1,2, \ldots, 12$ years on production. The dashed lines labeled $P_{10}$ and $P_{90}$ denote wells whose cumulative production is exceeded by $10 \%$ and $90 \%$, respectively, of wells in the county. The vertical labels refer to the numbers of wells with at least, $1,2, \ldots, 12$ years on production. The magenta curve is an (almost) universal production scaling curve for the Barnett wells made dimensional to fit the statistically average production of the Tarrant well cohorts of different ages. Sources: ${ }^{7127}$ Drillinginfo, 4/25/2019.
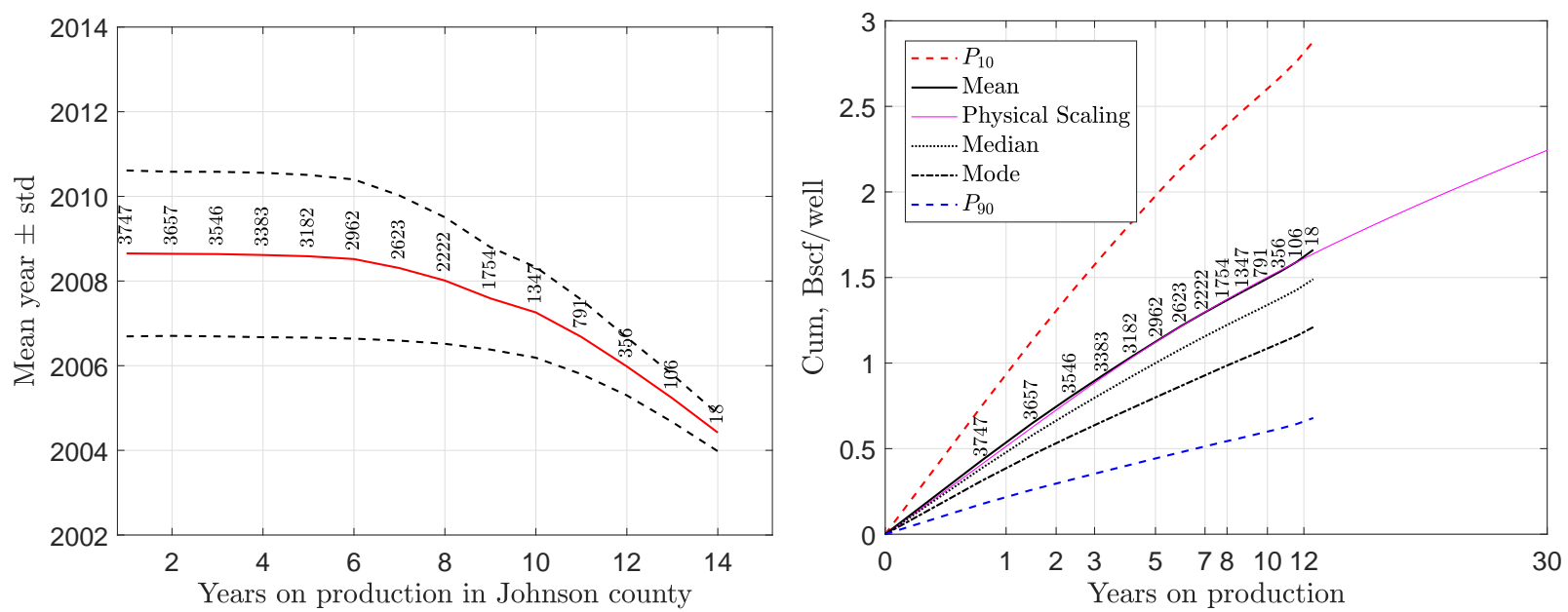

Figure 16: Left: The mean completion dates for the horizontal well cohorts in Johnson county with at least $1,2, \ldots, 14$ years on production. Notice that during the first six years on production the mean date changes by one year, but it changes by 4.5 years in the ensuing eight years. Right: The average GEV well in Johnson county. Sources:, ${ }^{127}$ Drillinginfo, $4 / 25 / 2019$. 

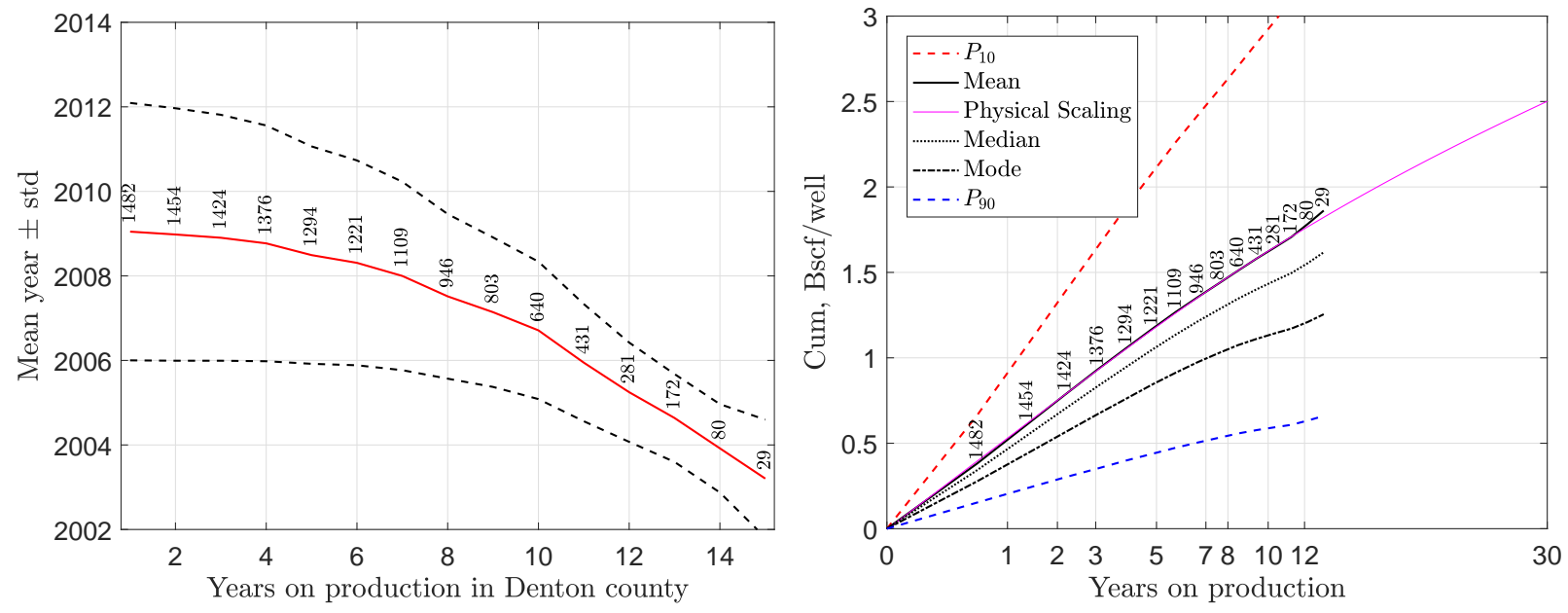

Figure 17: Left: The mean completion dates for the horizontal well cohorts in Denton county with at least $1,2, \ldots, 14$ years on production. Notice that during the first six years on production the mean date changes by one year, but it changes by four years in the ensuing eight years. Right: The average GEV well in Denton county. Sources: ${ }^{727}$ Drillinginfo, $4 / 25 / 2019$.
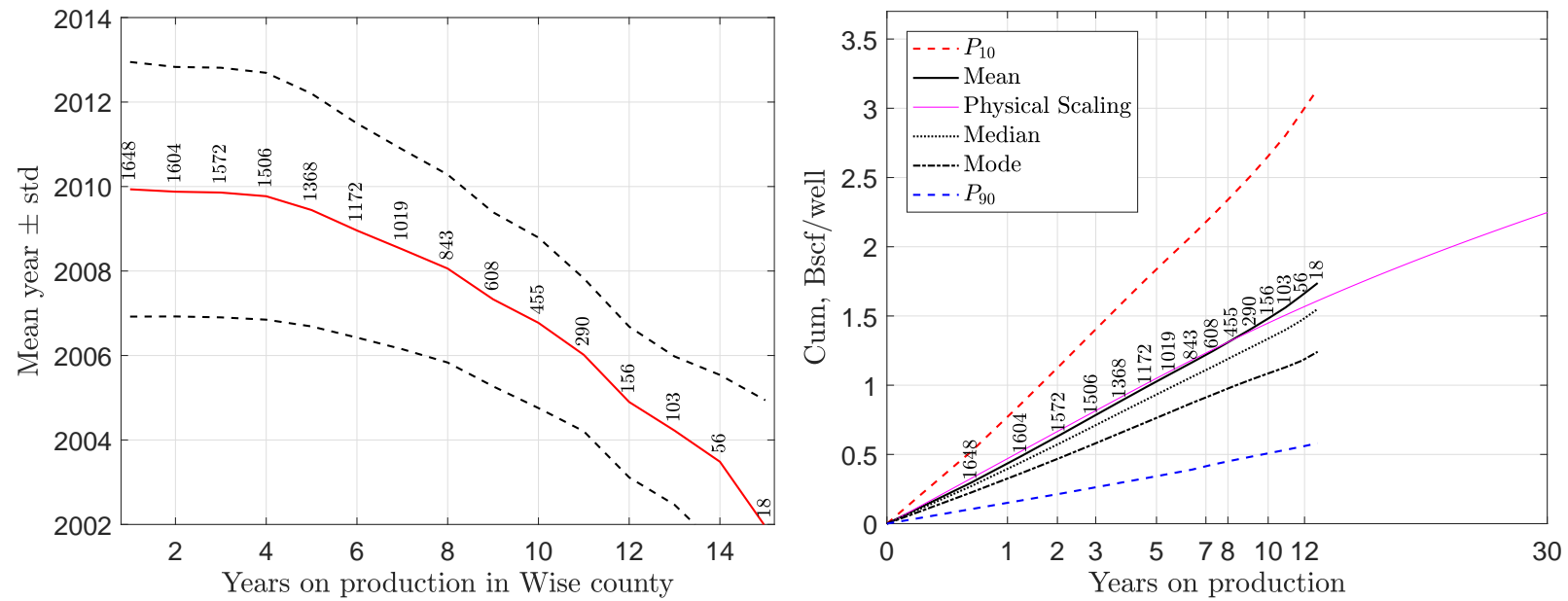

Figure 18: Left: The mean completion dates for the horizontal well cohorts in Wise county with at least $1,2, \ldots, 14$ years on production. Notice that during the first six years on production the mean date changes by one year, but it changes by six years in the ensuing eight years. Right: The average GEV well in Wise county. Sources: ${ }^{\frac{727}{2}}$ Drillinginfo, 4/25/2019. 

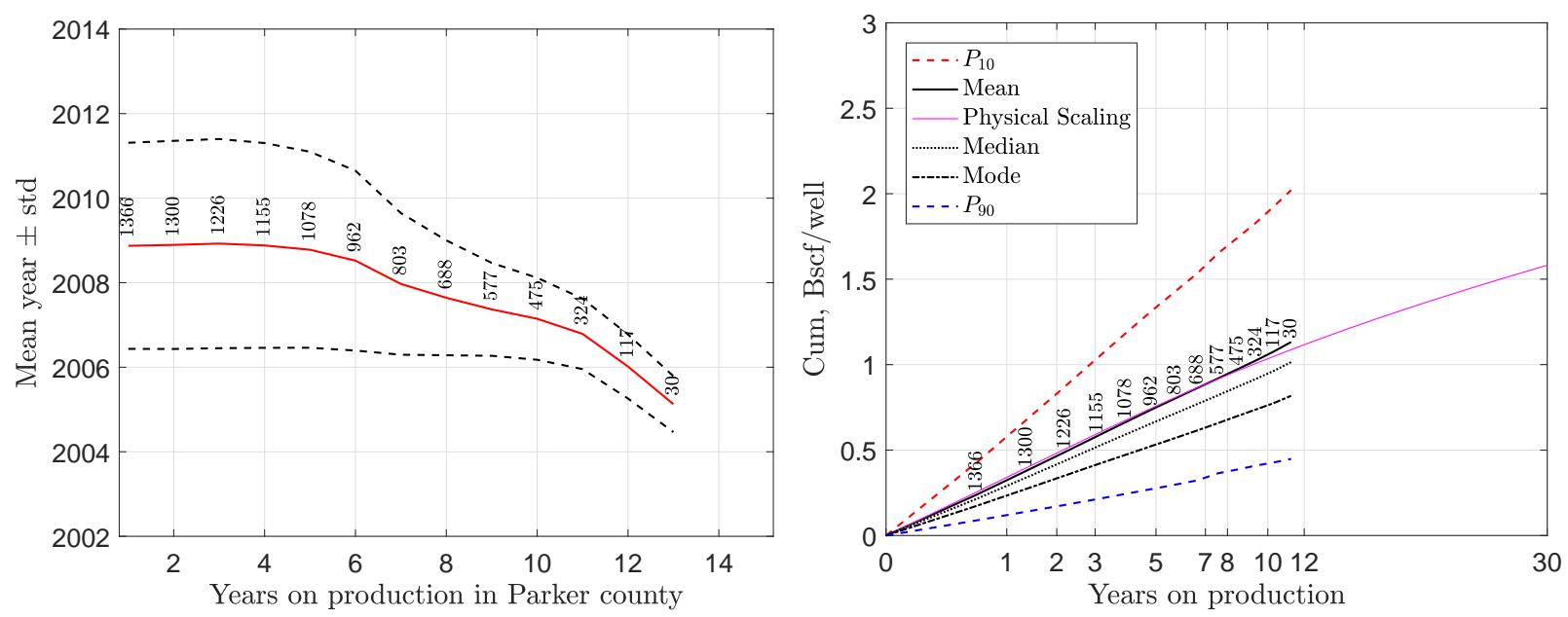

Figure 19: Left: he mean completion dates for the horizontal well cohorts in Parker county with at least $1,2, \ldots, 13$ years on production. Notice that during the first six years on production the mean date changes by one year, but it changes by four years in the ensuing six years. Right: The average GEV well in Parker county. Sources:, ${ }^{[727}$ Drillinginfo, 4/25/2019.
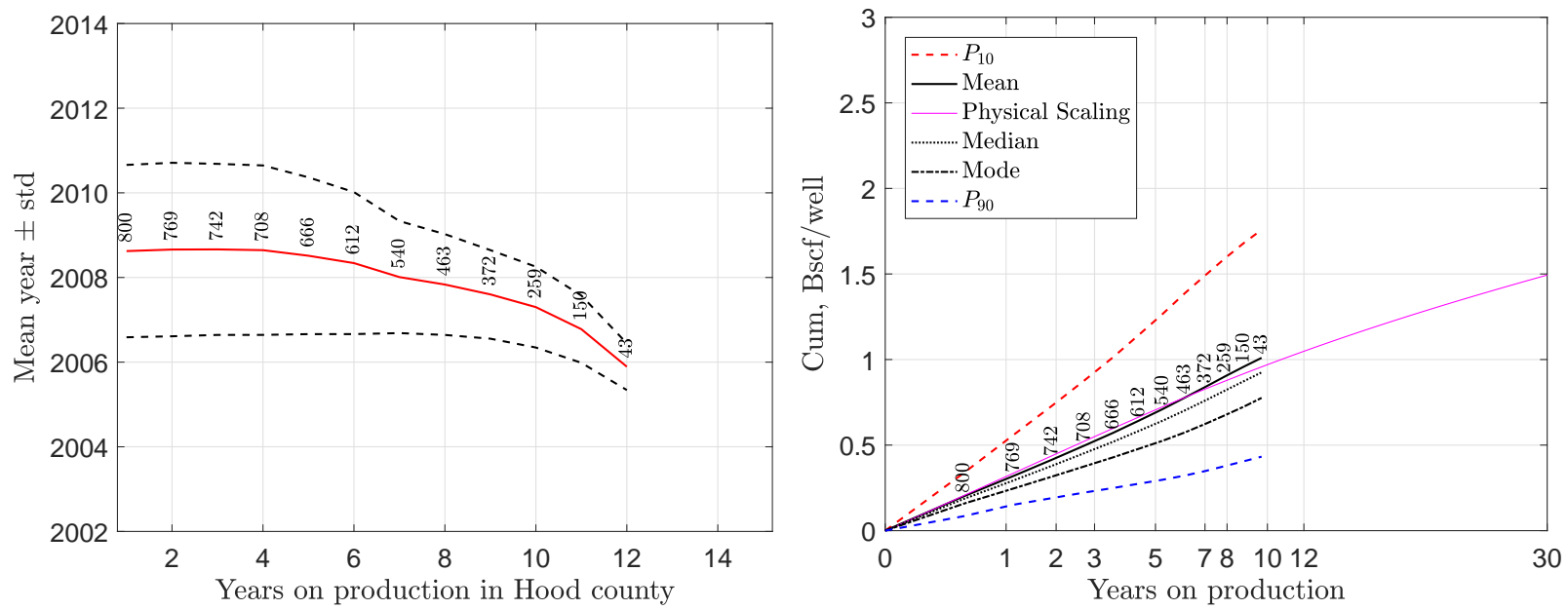

Figure 20: Left: The mean completion dates for the horizontal well cohorts in Hood county with at least $1,2, \ldots, 12$ years on production. Notice that the mean date changes by two years over eleven years. Right: The average GEV well in Hood county. Sources: ${ }^{727}$ Drillinginfo, $4 / 25 / 2019$. 

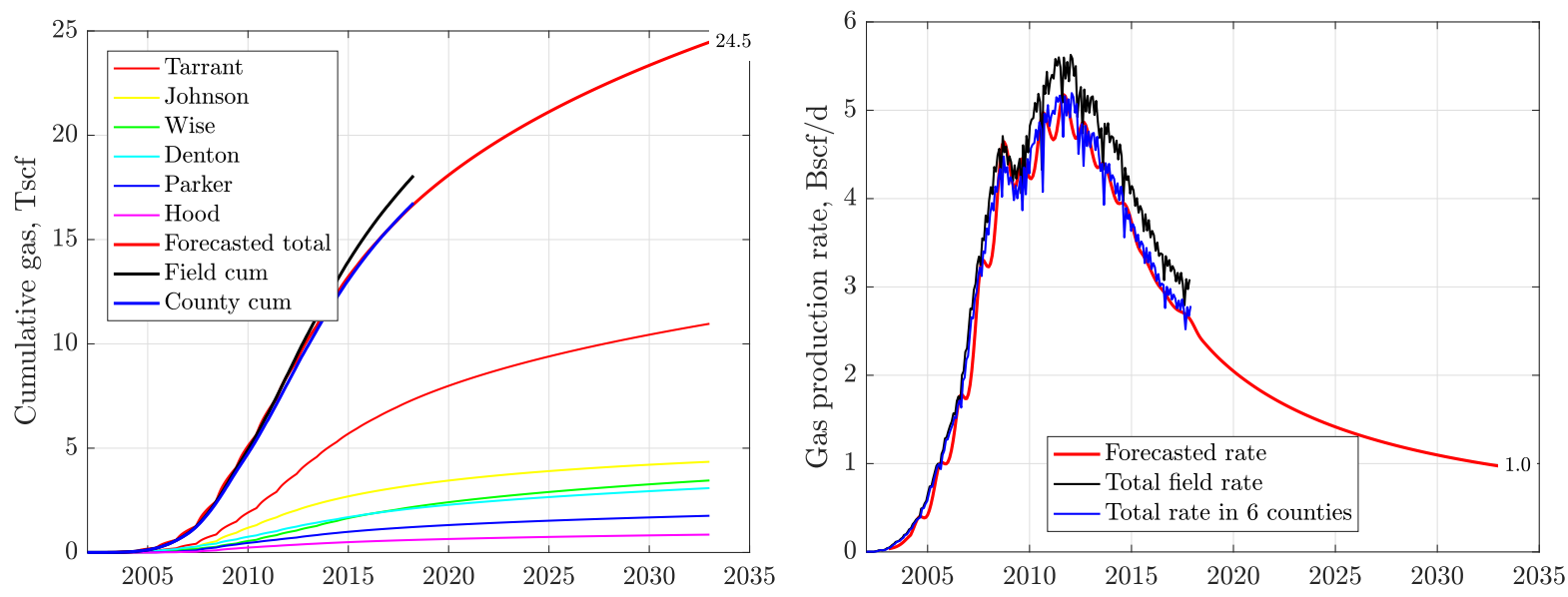

Figure 21: The actual and forecasted cumulative oil (left) and rate (right) of 13,141 gas wells in the Barnett, 2453 of which were shut in over time, and 715 plugged and abandoned. The excellent matches were obtained by time-shifting uniformly all forecasts by 6 months from Jan 1 to Jun 1 of each year. The rates were obtained by differencing the cumulative forecasts and smoothing the sharp kinks at the start of each new well cohort. Well attrition is built into the well prototypes through the influence the failing wells exert on the shapes of the GEV distributions for each annual well cohort. If the current cohorts of active horizontal wells survive in the future as they have in the past, EUR in the six Barnett counties will be 24.5 Tscf. This very important feature differentiates our rigorous statistics/physics based forecast from most other such attempts. 
Table 2: Scaling parameters for an average well in each of the key Barnett shale counties

\begin{tabular}{r|cccc}
\hline County & $\begin{array}{c}\text { Number of } \\
\text { wells }^{a}\end{array}$ & $\begin{array}{c}\text { Time shift } \\
\text { months }\end{array}$ & $\begin{array}{c}\mathrm{EUR}^{b} \\
\text { Bscf/kt }\end{array}$ & $\begin{array}{c}\tau \\
\text { years }\end{array}$ \\
\hline Tarrant & 4098 & -2.4 & $3.2 / 74.97$ & 7 \\
\hline Denton & 3747 & -3.0 & $2.5 / 59.52$ & 10 \\
\hline Wise & 1648 & -3.6 & $2.2 / 53.51$ & 11 \\
\hline Johnson & 1482 & -2.4 & $2.2 / 53.41$ & 6 \\
\hline Parker & 1366 & -3.0 & $1.6 / 37.65$ & 9 \\
\hline Hood & 800 & -4.2 & $1.5 / 35.54$ & 10 \\
\hline
\end{tabular}

${ }^{a}$ With at least one year on production. Calculated $4 / 25 / 2019$

${ }^{b}$ The EIA 2018 Short Term Energy Outlook projects the Barnett core-wide average EUR 2 Bscf/well

\section{Discussion}

Since measurable gas production in a shale well requires volumetric fracturing of reservoir rock, or complex fractures, each production record is an extreme event. Therefore, for each one-year increment, the distributions of gas production from the hydrofractured horizontal wells in the Barnett are superbly fit with the GEV distributions. When plotted vs. square root of time on production, the well cohorts with $1,2, \ldots$ years on production yield a stable GEVmean $\left(P_{50}\right)$ well prototype in each major gas-producing county that for the first 6-10 years is almost identical to the prototype obtained with the universal scaling of gas production with pressure interference, published earlier. After 6-10 years, several of the statistical wells deviate upwards from the physical scaling because of (1) natural high grading of wells; (2) external inflow; (3) decreasing well samples; and (4) refracturing. The interrelated items one and two on this list are most important.

With the very optimistid ${ }^{2}$ assumption that all currently active wells in the six counties will continue to survive similarly to the earliest wells, the current 9973 wells with at least one year on production would ultimately produce $28 \mathrm{Tscf}$ of gas. With well attrition built

\footnotetext{
${ }^{2}$ This assumption is rather unsubstantiated, given the experimental probability distributions of well survival calculated in this paper.
} 
into well prototypes, these wells will produce only 24.5 Tscf, as depicted in Fig. 21.

Table 3: Medium and high 10-year drilling program scenarios

\begin{tabular}{r|c|cc|cc}
\hline County & $\begin{array}{c}\text { Avg probability } \\
\text { of well survival }\end{array}$ & $\begin{array}{c}\text { Medium } \\
\text { wells/yr }\end{array}$ & $\begin{array}{c}\text { Medium } \\
\text { w/ attrition }\end{array}$ & $\begin{array}{c}\text { High } \\
\text { wells/yr }\end{array}$ & $\begin{array}{c}\text { High } \\
\text { w/ attrition }\end{array}$ \\
\hline Tarrant & 0.48 & 102 & 213 & 360 & 750 \\
\hline Johnson & 0.54 & 85 & 158 & 300 & 556 \\
\hline Wise & 0.55 & 68 & 124 & 240 & 437 \\
\hline Denton & 0.67 & 51 & 77 & 180 & 269 \\
\hline Parker & 0.50 & 34 & 68 & 120 & 240 \\
\hline Hood & 0.39 & 17 & 44 & 60 & 154 \\
\hline Total over 10 yrs & $\mu=0.52$ & 3570 & 6820 & 12600 & 24050 \\
\hline
\end{tabular}

We now return to the predictions of Browning et al. (2013), which estimated ultimate production of 44 Tscf from the Barnett shale as the most likely outcome, although at a price of $\$ 4 / \mathrm{mcf}$ that is higher than the actual. We examine the rate of drilling that would be needed to achieve this outcome. In accord with the data in Figs. 9- 11, only 50\% of wells survive for up to 15 years on production, see Table 3. These field data-driven attrition rates are built into the well prototypes through the parameters of the GEV distribution fit to each well cohort. Details are found in Materials and Methods. We conclude that 12,600 wells would have to be completed and survive for the next 15 years in the six counties over 10 years as follows: 360; 300; 240; 180; 120; and 60 wells/year, respectively, in Tarrant, Johnson, Denton, Wise, Parker, and Hood counties. According to the two right-most columns in Table 3. 24,050 wells would have to be completed, given the mean probabilities of well survival in each county. This scenario is depicted in Fig. 22. Our forecast also assumes that the future wells will be as good and durable as the 2003-2017 wells in these counties; this is far from certain, given that the newer wells often have higher attrition rates than the old ones. The rig count in the Barnett shale at the start of 2019 has dropped nearly to zero. This makes it seem unlikely that 24,000 new wells will ever be drilled.

As a third and final scenario, we imagine drilling new wells at a rate that maintains production at the current level. This requires drilling 3570 new surviving wells $(102,85,68,51,34$, 
and 17 wells/year) over the next 10 years, or 6820 wells in total to account for well attrition. Ultimate recovery of 29 Tscf is achieved, see Fig. 23. For comparison, on August 25, 2018, there were two drilling rigs in the Barnett, down from 7 rigs a year earlier, and 19 wells were being drilled in Wise county for Devon. In simple terms, the 6820 additional wells would achieve an incremental recovery of 4.4 Tscf over the base case in Fig. 21. At $\$ 3$ per 1000 scf of gas, the revenue from these wells would be roughly $24 \%$ of the total well cost if each well carried a future price tag of $\$ 8$ millions. Not counting any other costs, the break even price of gas would be $\$ 13$ per 1000 scf. If the future well cost were limited to the current $\$ 4$ $\mathrm{M} /$ well, this break even cost would be only $\$ 6.20 /$ mscf.

This brings us to the issue of water produced from the major US shale plays, Fig. 24 Barnett is the second largest water producer after Permian and gas wells there must be dewatered. Water that accumulates in the wellbore back-pressures the reservoir and inhibits gas flow up to the surface. This water can also imbibe into the reservoir and cause water blockage that will further inhibit gas production. The problem with water blockage becomes more severe with time as the reservoir pressure declines. Gas wells must be put on artificial lift and this further increases production costs and worsens well economics.

\section{Conclusions}

We have provided a robust, transparent non-parametric method to analyze gas (or oil) production in shales. As a result, we have delivered a field-wide forecast of cumulative gas production from 13,141 of active and inactive horizontal wells in the six main counties that produce gas in the Barnett shale: Tarrant, Johnson, Denton, Wise, Parker, and Hood. Barnett was the original field laboratory of shale development. Between 1998 and 2002, the first horizontal shale wells were drilled there and hydrofractured with slick water by Mitchell Energy. By 2018, over 150 Barnett wells had 12 years on gas production (nonzero monthly production records). These wells and many others provide a unique opportunity to revisit 
the past forecasts of gas production from horizontal wells and check if these forecasts have aged gracefully.

In each county, we have analyzed gas production from well cohorts with $1,2, \ldots$ years on production. To fit the distributions of gas production in each of the 83 well cohorts shown in detail in SOM, Part II, we have employed a three-parameter GEV distribution. 10 Using this distribution, we have obtained excellent fits of the field data and accurate estimates of uncertainties in the distribution parameters. As a result, we have constructed the stable expected value, or mean $\left(P_{50}\right)$ well prototypes for each county, and the corresponding high $\left(P_{10}\right)$ and low $\left(P_{90}\right)$ bounds. All statistical well prototypes have precise confidence intervals. For recent wells, the $P_{10}$ and $P_{90}$ bounds are narrow, but for the old wells they diverge considerably, meaning that with time the good wells become relatively better and the poor wells get worse. We also quantify well survival rate, which is the probability that wells will continue producing after up to 15 years on production, and incorporate this survival into our analysis. On average, this probability is $50 \%$ for the six Barnett counties we have analyzed. By adjusting the producible gas in place and pressure interference times, we then fit each statistical $P_{50}$ well prototype with our previously published physics-based scaling curve $\mathrm{f}^{7 / 27}$ that also accounted for late-time external gas inflow. The dimensional, scaled well prototypes, one for each of the six counties, were used to match past production from all 13,141 horizontal wells.

Having obtained an excellent match of the past gas production in the six counties, we predicted that the current wells would ultimately produce 24.5 Tscf by the year 2035. We then used the calibrated well prototypes to predict the numbers of future wells in each county necessary to achieve 41.5 Tscf of cumulative gas production by the year 2035, or maintain current production level until 2028, to ultimately reach 29 Tscf. These surviving well numbers were, respectively, 12,600 or 3570. Twice as many new wells would have to be drilled and completed. Both future drilling scenarios are high, but the first one requires such an enormous investment in new wells, in contrast with the fact that the the rig count in the 
Barnett has dropped nearly to zero, that it is difficult to imagine this will happen. Thus we conclude that some of the older predictions of EUR in the Barnett, e.g., ${ }^{4111}$ were much too optimistic. In fairness to the older forecasts,

- The gas price has been lower than anticipated in the base forecast in Ref. 4, but in accord with a lower forecast at $\$ 2 / \mathrm{mscf}$ that was 26 Tscf, not too far off from our forecast.

- Even if the price were to go up, companies would continue to pour their borrowed money into the Permian basin, because currently it is more attractive. But this does not mean that the remaining gas in the Barnett will never be exploited.

We counter-argue that our negative conclusions about the future viability of Barnett shale are supported by the low cumulative probabilities of survival of the wells started in each of the gas-producing counties every year between 2003 and 2017. The combination of these unfavorable probabilities with pressure depletion in the reservoir around each active well, overdrilling of the best counties, and with the high and increasing water production makes extensive drilling programs in the Barnett rather improbable.

Novel/Additive Information. To our knowledge, this paper is the first successful attempt to (i) generate the complete GEV statistics for different subsets of 13,141 horizontal, hydrofractured gas wells with up to 14 years on production; and (ii) condition the physical well prototypes with the statistical well prototypes to obtain the robust, composite 30-year well prototypes that can represent the entire play. Some of the results are surprising and may lead to a new focus on what makes certain wells be so much better than average.

Our robust non-parametric procedure employs

1. Data-driven scaling of field production records to obtain the mean well prototypes for the geology-based well samples (here the six major gas producing counties), and

2. Matches of the statistical well prototypes with physics-based scaling to allow forecasting 10-15 years into the future. 
Rational investment strategies and planning for future energy supply require realistic estimates of production from oil and gas shales. Both the US Securities and Exchange Commission and the DOE EIA should pay attention to the non-parametric methods we have described, which offer an objective way to avoid estimates that are unrealistically low or high.

This paper will be followed with three other papers that elucidate the physics-based scaling of all Bakken oil wells including refracturing and/or well pumping; the GEV/physical scaling of all oil wells in the Bakken; of gas, gas condensate and oil wells in the Eagle Ford; of all Haynesville gas wells; all Marcellus gas wells; all Utica wells; all Niobrara gas/condensate wells; and all Permian oil wells. Our perfect matches of hydrocarbon production in all of these giant plays and our predictions of the respective declines will be compared with the DOE EIA forecasts and future drilling programs.

\section{Materials and Methods}

From mining public well records, we gathered production, location and completion data for 13,141 horizontal wells in the Barnett with up to 18, but usually 11-14 years of production. The necessary data were acquired from the Drillinginfoß oil \& gas production database and the Texas Railroad Commission website.

The raw data from Drillinginfo were imported into an integrated MATLAB $\mathbb{R}$ software package we designed to perform data cleanup, consolidation, sorting, and analysis and plotting, including automatic generation of the $\mathrm{AT}_{\mathrm{E} X}$ Beamer presentation files that allowed us to inspect over 500 output plots with the results, see SOM, Part II, for 268 such plots.

Our procedure consists of two parts. Part one is as follows:

1. Devise a geology-based procedure of splitting all active horizontal wells in a play into distinct well samples, here counties, see SOM Part I. Ensure that the well samples have enough wells to allow for statistical inferences. 
2. Structure by well sample (here county) horizontal well descriptors and raw monthly production data.

3. For each well sample and for each year, starting from 2003 and ending in 2019, classify that year's wells (well cohorts) with respect to their elapsed time on production. The 2000-2002 well cohorts were too small, and the 2016 well cohorts had wells with up to 1.5 years on production. Estimate the probabilities of well survival by calculating the fractions of all wells completed in a calendar year that survived for $12,24, \ldots$, present months on production.

4. For each well sample and all admissible well cohorts, plot these probabilities as functions of time on production.

5. For each well sample and each calendar year, calculate the mean completion date of wells for that year and the standard deviations from the mean. Plot the results.

In part two, summarized in Fig. 14, we follow up with the following calculations:

1. For a well sample (here a major gas-producing county $c$ ), identify well cohorts with $12,24, \ldots, t_{c, \max }$ months on production, where $t_{c, \max }$ is chosen in such a way that at least five wells remain. For each well, continuous time on production consists of all nonzero monthly production records.

2. For each well cohort in a sample, fit the distributions of annual production rates, i.e., production in the last 12 months, with the lognormal and GEV distributions, and plot the results for visual inspection, as illustrated in Figs. 2526 and in SOM, Part II.

3. For each well sample, use the GEV distribution fits for all well cohorts to plot the resulting well prototypes, the mean $\left(P_{50}\right)$, median, mode, and $P_{10} / P_{90}$ wells, versus time, see Figs. $15-20$.

4. Recall the accessible gas in place, $\mathcal{M}$, and time of pressure interference between two consecutive fractures in a well, $\tau$, both defined in. ${ }^{2427}$ Choose one of the dimensionless 
universal well scaling curves defined in the Supporting Online Materials to ${ }^{27}$ and recast it to the dimensional mean well prototype for well sample by adjusting $\mathcal{M}$ and $\tau$. We chose the 500-3500 psi curve in the spreadsheet published with ${ }^{27}$ and added to it the dimensionless long term production response from. ${ }^{7}$

In Fig. 25, the top left panel shows as gray bars the distribution of gas production rates from all wells in Tarrant county with at least one year on production. In most cases, GEV distributions fit the field data better than lognormal distribution. In addition, for example, for any set of parameter values, $\mu, \sigma$ and $\xi$, we can minimize the misfit, or residual $R_{10}$, that corresponds to $P_{10}$. The smallest value of $R_{10}$ is attained within the critical region of the parameter space where the negative log-likelihood is larger than the critical value. That smallest value is the lower likelihood-based confidence limit for $R_{10}$. This is difficult to visualize in all three parameter dimensions, but we can fix the shape parameter, $\xi$, and vary the two remaining parameters, $\sigma$ and $\mu$. In this case, the blue contours represent the log-likelihood surface, and the bold blue contour is the boundary of the critical region. The red contours represent the surface for $R_{10}$ - larger values are to the top right, lower to the bottom left. The contours are straight lines because for fixed $\xi$, the residual is a linear function of $\sigma$ and $\mu$. For more information, please check manuals and examples for the MATLAB® Statistics Toolbox.

The calculations shown in Fig. 25 were repeated until all admissible well cohorts in all well samples were exhausted. The results were exported to a Beamer file for further visual inspection of the GEV fits. In most cases, quality of the fits was superb. The earliest cohorts of wells with the longest feasible times on production were smallest, and the GEV fits of the experimental cdfs still good but poorest. 

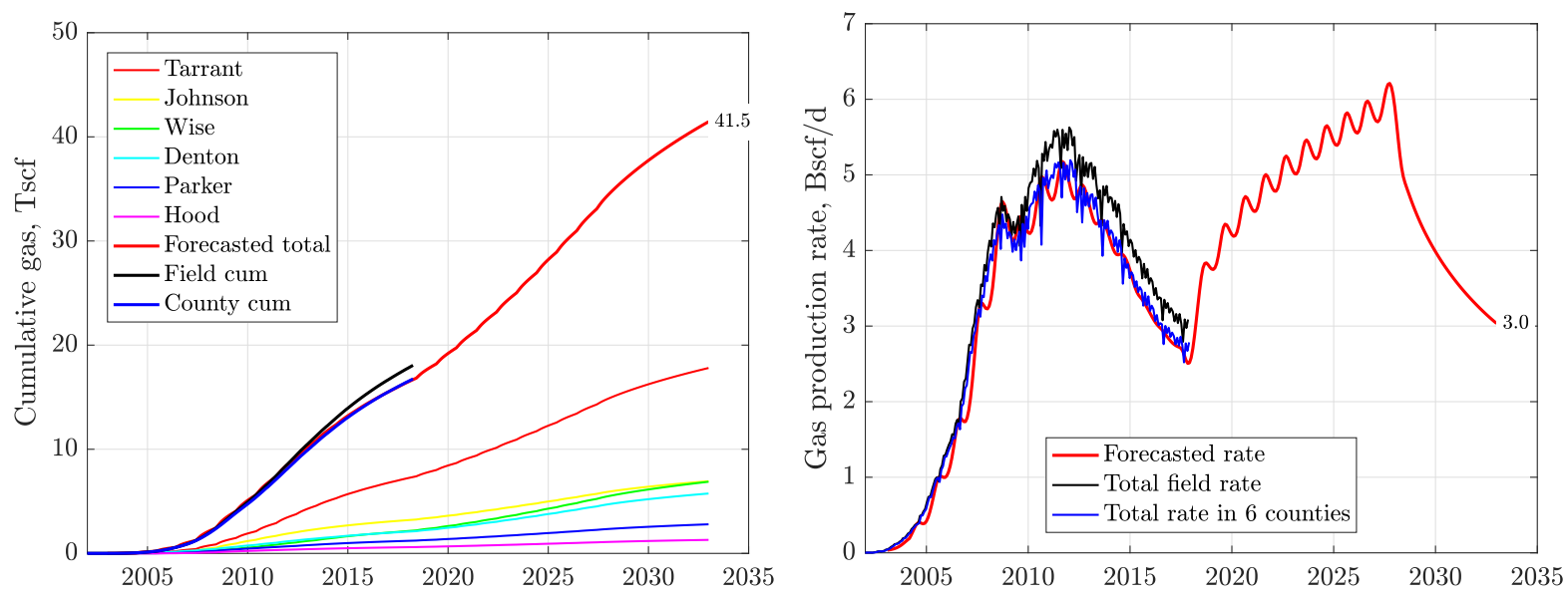

Figure 22: The actual and forecasted cumulative oil (left) and rate (right). This forecast shows that 12,600 new surviving wells (24,000 total new wells) must be completed at a constant rate over the next 10 years in all six counties to achieve EUR of 41.5 Tscf.
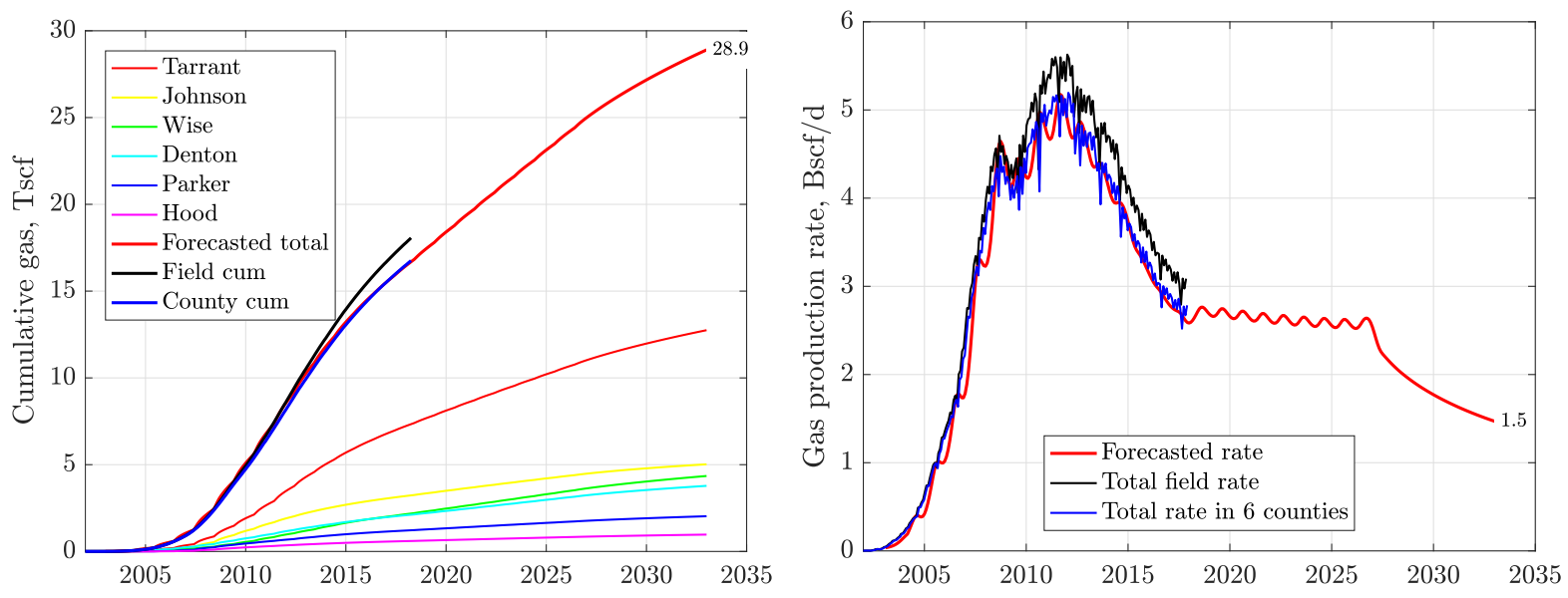

Figure 23: The actual and forecasted cumulative oil (left) and rate (right). This forecast shows that 3570 new surviving wells (6800 total new wells) must be completed at a constant rate over the next 10 years in all six counties to achieve EUR of 29 Tscf.

\section{Acknowledgement}

Wardana Saputra (PhD student) was supported by baseline research funding from KAUST to Tad Patzek. Wissem Kirati (Research Engineer) was supported by the Division of Computer, Electrical and Mathematical Science at KAUST. 

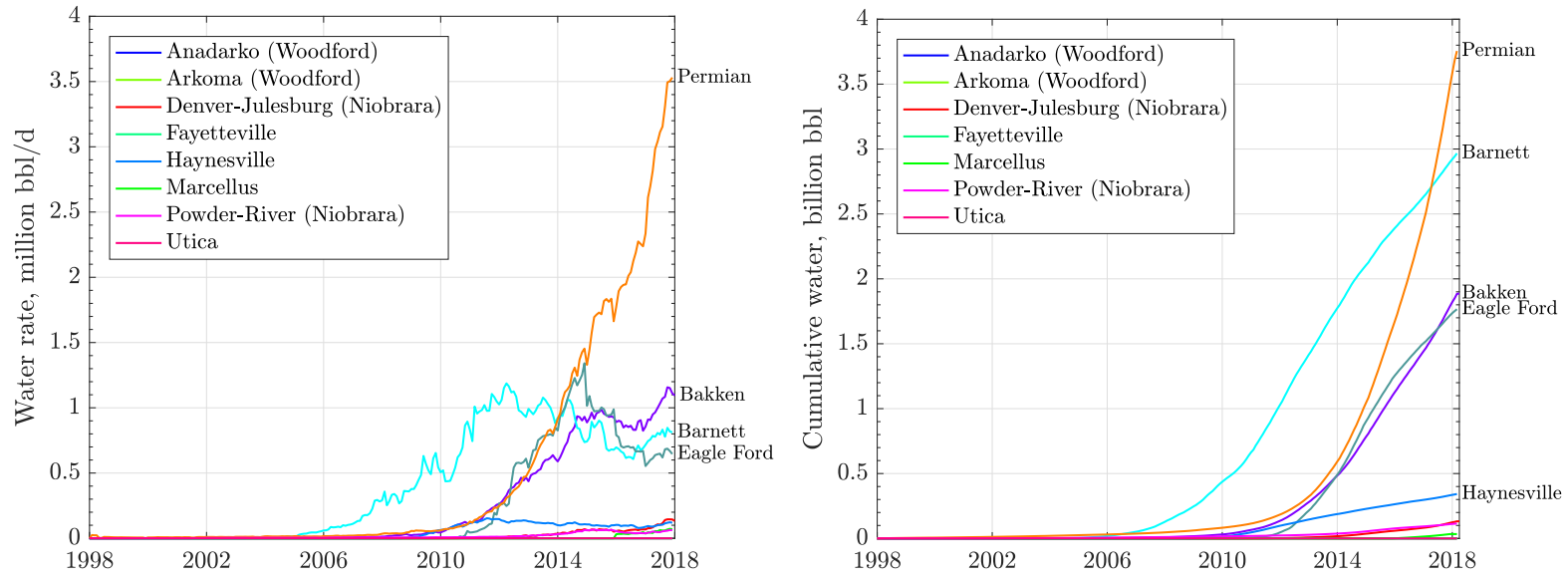

Figure 24: The rates of water production and cumulative water produced from major US shale plays. Source: Drillinginfo, accessed July 1, 2018. 

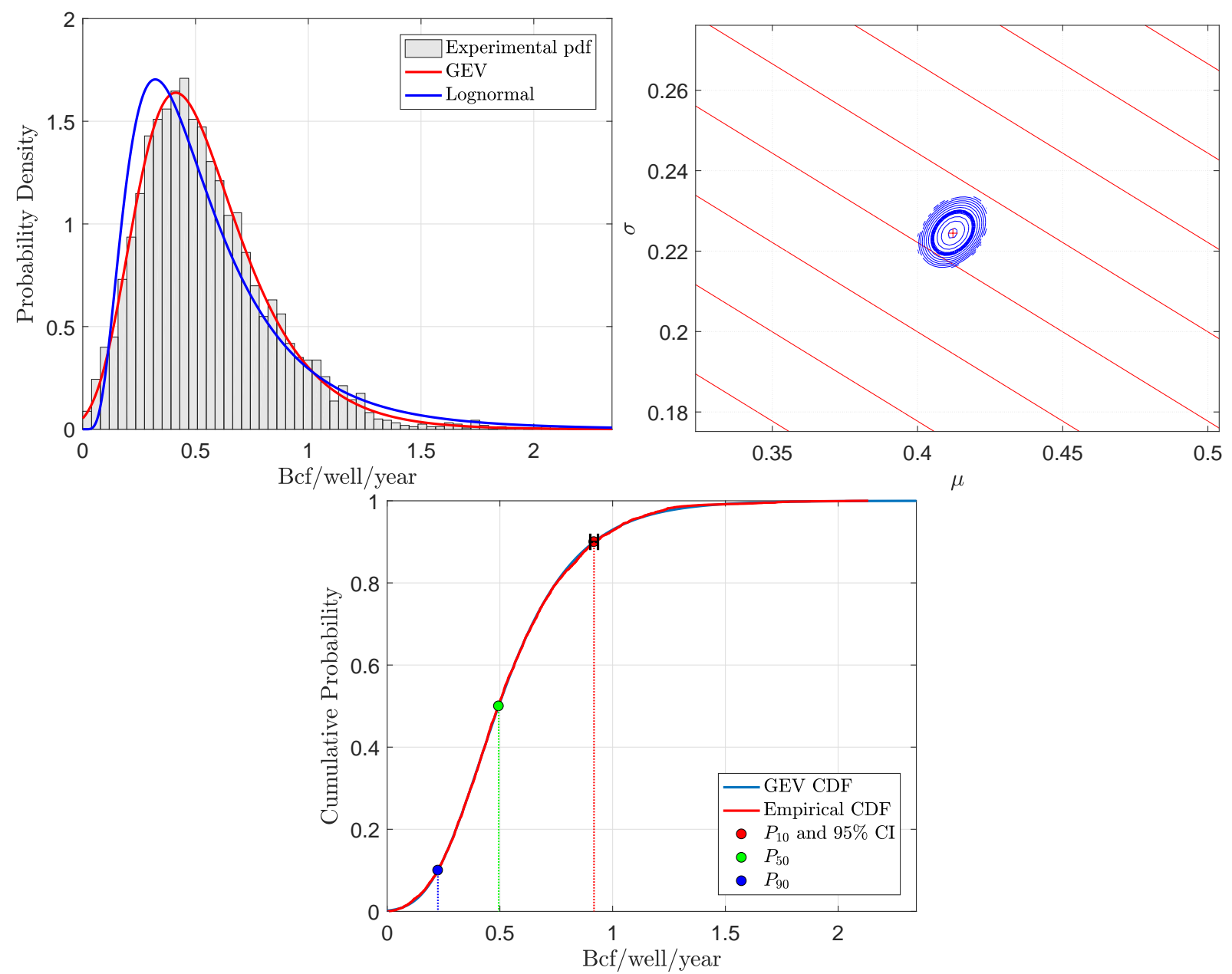

Figure 25: Distribution of gas production rates in the Tarrant county wells with one year on production. Upper Left: GEV pdf: $\xi=0.0002, \mu=0.4122, \sigma=0.2245$. Upper Right: Maximum Likelihood Estimate, 95\% CI for $\mu$ and $\sigma$ after one year on production. Bottom: GEV cdf with the $90 \%$ confidence limits (CIs) on the residual for the $P_{10}$ well. Analogous CIs can be obtained for the $P_{50}$ and $P_{90}$ wells. 

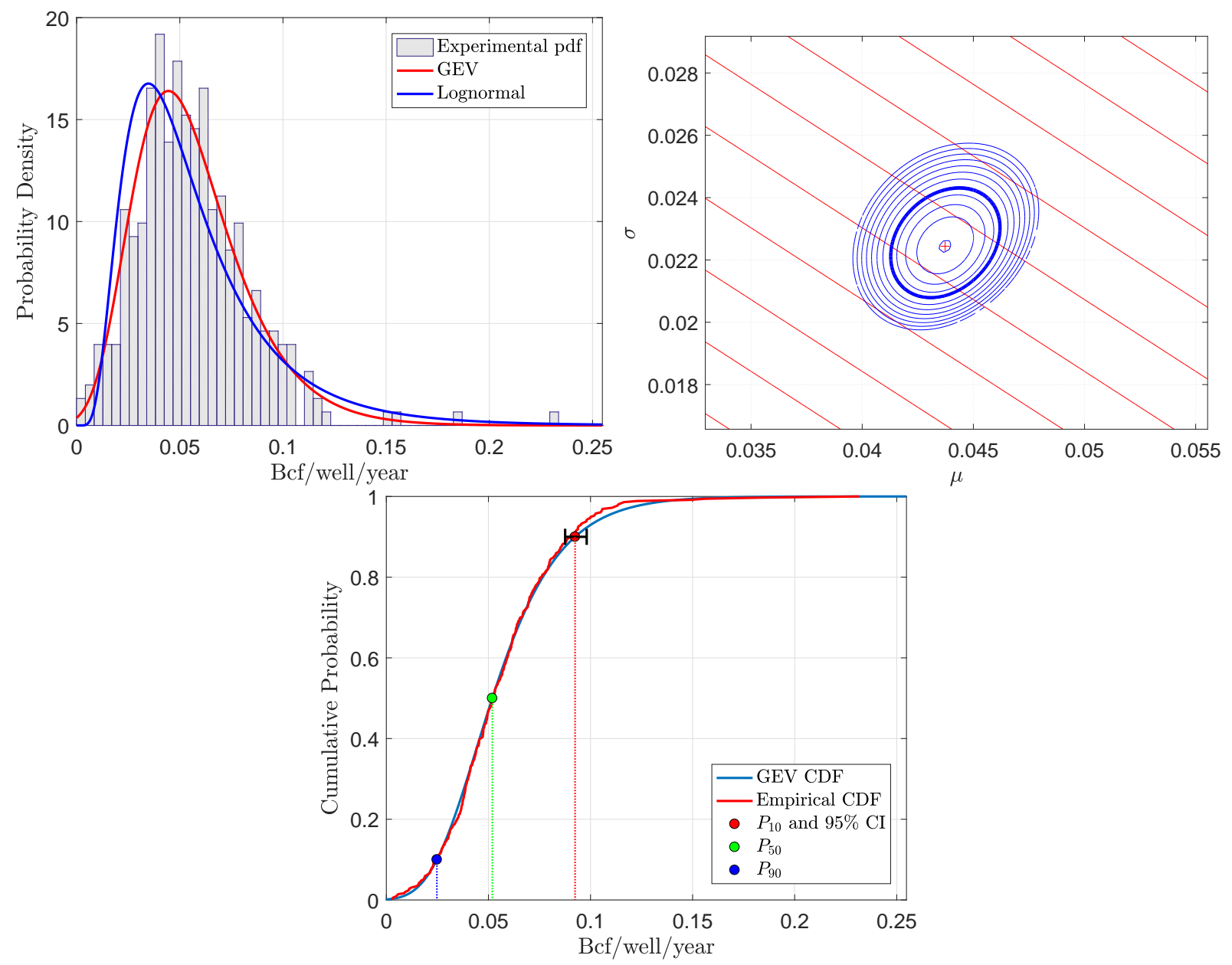

Figure 26: Distribution of gas production rates in the Johnson county wells with twelve years on production. Upper Left: GEV pdf: $\xi=-0.0321, \mu=0.0437, \sigma=0.0224$. Upper Right: Maximum Likelihood Estimate, 95\% CI for $\mu$ and $\sigma$ after twelve years on production. Bottom: GEV cdf with the $90 \%$ confidence limits on the residual for the $P_{10}$ well. 


\section{References}

(1) Aitchison, J., and J. A. C. Brown, The lognormal distribution, with special references to its use in economics, Cambridge University Press, Cambridge, 1957.

(2) Al-Ahmadi, H. A., A. M. Almarzooq, and R. A. Wattenbarger, SPE 130370: Application of Linear Flow Analysis to Shale Gas Wells - Field Cases, pp. 1-10, doi: 10.2118/130370-MS, 2010.

(3) Bello, R. O., and R. A. Wattenbarger, SPE 114591: Rate Transient Analysis in Naturally Fractured Shale Gas Reservoirs, pp. 1-17, doi:110.2118/114591-MS, 2008.

(4) Browning, J., S. Ikonnikova, G. Gülen, and S. Tinker, SPE 165585: Barnett Shale Production Outlook, SPE Economics \& Management, July, 89-1004, doi:10.2118/ 165585-PA, 2013.

(5) Browning, J., et al., Barnett Shale Reserves and Production Forecast: A Bottom-Up Approach, Oil \& Gas J., Part I - August, Part II - September, 2013.

(6) Clerke, E. A., H. W. Mueller III, E. C. Phillips, R. W. Eyvazzadeh, D. H. Jones, R. Ramamoorthy, and A. Srivastava, Application of Thomeer Hyperbolas to decode the pore systems, facies and reservoir properties of the Upper Jurassic Arab D Limestone, Ghawar field, Saudi Arabia: A "Rosetta Stone" approach, GeoArabia, 13(4), 113 - 160, ww.spwla-abudhabi.com/SPWLA2010_Material/GeoArabia\%202008_Clerke_v13_no4_113-160.pdf, 2008.

(7) Eftekhari, B., M. Marder, and T. W. Patzek, Field data provide estimates of effective permeability, fracture spacing, well drainage area and incremental production in gas shales, Journal of Natural Gas Science and Engineering, 56, 141 - 151, doi:10.1016/j. jngse.2018.05.027, 2018. 
(8) Gülen, G., S. Ikonnikova, J. Browning, and S. W. Tinker, SPE 173187: Fayetteville Shale-Production Outlook, SPE Economics 83 Management, April, 47-59, doi:10.2118/ 1173187-PA, 2014.

(9) Gülen, G., S. Ikonnikova, J. Browning, K. J. Smye, and S. W. Tinker, SPE 176022: Production Scenarios for the Haynesville Shale Play, SPE Economics 83 Management, October, 138-147, doi:10.2118/176022-PA, 2015.

(10) Gumbel, E. J., Statistics of Extremes, Columbia University Press, New York, 1958.

(11) Ikonnikova, S., J. Browning, S. Horvath, and S. W. Tinker, SPE 171552: Well Recovery, Drainage Area, and Future Drillwell Inventory: Empirical Study of the Barnett Shale Gas Play, SPE Res Eval \&3 Eng., November, 484-496, 2014.

(12) Jones, P. J., Estimating oil reserves from production and decline rates, Oil \& Gas Journal, 40, 43, 1942.

(13) Kuuskraa, V. A., G. Koperna, J. W. Schmoker, and J. C. Quinn, Barnett shale rising star in Fort Worth basin, Oil \&3 Gas Journal, 96, www.ogj.com/articles/print/volume-96/issue-21/in-this-issue/exploration/barnett-shale-rising-star-in-fort-worthbasin.html, 1998.

(14) Laherrère, J., and D. Sornette, Stretched exponential distributions in nature and economy: "fat tails" with characteristic scales, The European Physical Journal B - Condensed Matter and Complex Systems, 2(4), 525-539, doi:10.1007/s100510050276, 1998.

(15) Loucks, R. G., and S. C. Ruppel, Mississippian Barnett Shale: Lithofacies and depositional setting of a deep-water shale-gas succession in the Fort Worth Basin, Texas, AAPG Bulletin, 91(4), 579-601, doi:10.1306/11020606059, 2007.

(16) Male, F., A. W. Islam, T. W. Patzek, S. Ikonnikova, J. Browning, and M. P. Marder, Analysis of Gas Production From Hydraulically Fractured Wells In The Haynesville 
Shale Using Scaling Methods, in SPE Unconventional Resources Conference, Woodlands, TX, April 1-3, Society of Petroleum Engineers, doi:10.2118/168993-MS, 2014.

(17) Male, F., A. W. Islam, T. W. Patzek, S. Ikonnikova, J. Browning, and M. P. Marder, Analysis of gas production from hydraulically fractured wells in the Haynesville Shale using scaling methods, Journal of Unconventional Oil \& Gas Resources, 10, 11 - 17, doi:https://doi.org/10.1016/j.juogr.2015.03.001, 2015.

(18) Marder, M., C.-H. Chen, and T. Patzek, Simple models of the hydrofracture process, Phys. Rev. E, 92, 062,408, doi:10.1103/PhysRevE.92.062408, 2015.

(19) Marder, M., T. Patzek, and S. W. Tinker, Physics, fracking, fuel, and the future, Physics Today, 69(7), 46-52, doi:10.1063/PT.3.3236, 2016.

(20) Marder, M., T. Patzek, and S. W. Tinker, Fracking and the future of fuels - Reply to reader comments, Physics Today, 70(2), 13-14, doi:10.1063/PT.3.3444, 2017.

(21) Ogunyomi, B. A., T. W. Patzek, L. W. Lake, and C. S. Kabir, History matching and rate forecasting in unconventional oil reservoirs with an approximate analytical solution to the double-porosity model, SPE Reservoir Eval. \& Eng., 19(1), 70-82, doi:https://doi.org/10.2118/171031-PA, 2016.

(22) Palacios, V., and C. Leyden, Vast energy resources wasting away in the Texas Permian Basin, Special report on natural gas flaring, Environmental Defense Fund, 2017.

(23) Patzek, T., Barnett Shale in Texas: Promise and Problems, May 26, 2011, Seminar at the Bureau of Economic Geology, UT Austin, doi:10.18738/T8/3MLRLO, 2019.

(24) Patzek, T., F. Male, and M. Marder, A simple model of gas production from hydrofractured horizontal wells in shales, AAPG Bulletin, 98(12), 2507 - 2529, 2014.

(25) Patzek, T. W., SPE 24040: Surveillance of South Belridge diatomite, in Proceedings of 
the Western Regional SPE Meeting, Bakersfield, CA, posted at gaia.pge.utexas.edu/papers/2-SPE24040.pdf., 1992.

(26) Patzek, T. W., SPE187068-MS: Knudsen-Like Scaling May Be Inappropriate for Gas Shales, SPE, doi:0.2118/187068-MS, 2017.

(27) Patzek, T. W., F. Male, and M. Marder, Gas production in the Barnett Shale obeys a simple scaling theory, Proceedings of the National Academy of Sciences, 110(49), 19,731-19,736, doi:10.1073/pnas.1313380110, 2013.

(28) Raterman, K. T., et al., URTEC-2670034-MS: Modern Completion Optimization in Sampling a Stimulated Rock Volume: An Eagle Ford Example, SPE Unconventional Resources Technology Conference, doi:10.15530/urtec-20172670034, 2107.

(29) Valko, P., and M. J. Economides, Performance of a Longitudinally Fractured Horizontal Well, SPEJ, March, 11-19, doi:10.2118/31050-PA, 1996.

(30) Valko, P. P., SPE-116369: Assigning value to stimulation in the Barnett Shale: a simultaneous analysis of 7000 plus production hystories and well completion records, in Proceedings of the the SPE Hydraulic Fracturing Technology Conference, Jan. 19-21, The Woodlands, Texas, Society of Petroleum Engineers, 2009.

(31) Valko, P. P., and J. W. Lee, SPE-134231: A Better Way to Forecast Production From Unconventional Gas Wells, in Proceedings of the the SPE Annual Technical Conference and Exhibition, Sept. 19-22, Florence, Italy, Society of Petroleum Engineers, 2010.

(32) Wattenbarger, R. A., A. H. El-Banbi, M. E. Villegas, and J. B. Maggard, SPE-39931: Production Analysis of Linear Flow Into Fractured Tight Gas Wells, in Proceedings of the the SPE Regional Low Permeability Reservoir Symposium, Apr. 5-8, Denver, Colorado, Society of Petroleum Engineers, doi:10.2118/39931-MS, 1998. 
Generalized Extreme Value Statistics, Physical Scaling an... (3.88 MiB) view on ChemRxiv • download file 


\section{Supporting Online Materials to "Generalized Extreme Value Statistics, Physical Scaling and Forecasts of Gas Production in the Barnett Shale"}

\section{- Geological Justification of Well Sample Boundaries and

April 27, 2019

\section{Introduction}

The Barnett shale geology and maturity were discussed, among others, by Gonzalez (2005), Bowker (2007), Pollastro et al. (2007), Zhao et al. (2007), and sketched in Figs. 1 - 4. An early assessment of total undiscovered gas in the Barnett petroleum system was presented by Pollastro (2007).

Our paper provides a statistics-based estimates of ultimate gas recovery from all hydrofractured, horizontal gas wells in the Barnett. These estimates are then extended into the future using our previous physics-based approach, Patzek et al. (2013, 2014), Eftekhari et al. (2018). Our statistical estimates are based on six samples of the overall well population, which for the Barnett shale reside within the seven major gas-producing counties in Fig 1 . For each well sample, we then analyze separately up to 15 well cohorts with $1,2, \ldots 15$ years on production.

Three major factors dominate well productivity in the Barnett as we move from the east to west (or northeast to southwest):

1. The formation thickness decreases, see Fig. 4. The thickest shale intervals are in Tarrant, Dallas, and Johnson counties, next to the thrust fault along the Barnett shale eastern limit.

\footnotetext{
${ }^{1}$ The Ali I. Al-Naimi Petroleum Engineering Research Center, The King Abdullah University of Science and Technology (KAUST), Thuwal 23955-6900, Saudi Arabia

${ }^{2}$ Department of Physics, The University of Texas, Austin
} 
2. Shale maturity decreases (the hydrogen index and TOC go down) and so does production, cf. Fig. 5 .

3. The Viola formation underneath the lower Barnett shale disappears. Viola is a limestone formation that isolates the Barnett shale from the water-bearing Ellenberger formation, see Figs. $2-4$.

Pollastro et al. (2003) confirm these observations:

- Production from the Barnett shale is largely dependent on the presence or absence of Marble Falls and Viola limestones. Although these formations are not considered seal rocks in areas where they are tight and not water wet, they serve as barriers to confine hydraulic-induced fracturing (referred to as hydrofracturing barriers) and help retain formation pressures during well stimulation (Bowker, 2007, Shirley, 2002).

- The limestone layer above the lower Barnett shale is called the Forestburg limestone, while the one below the shale is called the Viola limestone.

- In the Fort Worth basin, a water bearing layer exists below the Barnett shale. This layer can either lie directly below the Barnett shale or a limestone barrier separates the shale and the water bearing layer (core area). The water bearing layer is called the Ellenburger formation.

Between 1998 and 2010, well density in the Barnett has increased as follows, Vicario (2011):

- Typical spacing in conventional fields in the USA is one well per 640 acre (1 well per $2.6 \mathrm{~km}^{2}$ ). In the Barnett shale the typical spacing in the beginning was reduced to one well per 160 acres $\left(1.5\right.$ wells per $\left.\mathrm{km}^{2}\right)$. Later-on infill wells were permitted and drilled at 40 acre spacing $\left(\sim 6\right.$ wells per $\left.\mathrm{km}^{2}\right)$. This seems common practice in most shales that are intensively developed.

- By the end of 2010, almost 15,000 wells had been drilled in the Barnett shale. The shale extends over an area of $13,000 \mathrm{~km}^{2}$. This results in an average well density of 1.15 wells per $\mathrm{km}^{2}$.

- Using horizontal wells in the Barnett shale has allowed three or four vertical wells to be replaced with a single horizontal well.

\section{Procedure}

1. For each of the six major gas-producing counties in the Barnett, we calculate the effective producing area by subtracting from the county area all non-productive areas from the DrillingInfo and geology data, and all urban areas from the GIS contour maps.

2. We cover the gas-producing areas of these six counties with the GIS-generated 1 mile ${ }^{2}$ fishnet grids, see Fig. 6 . 
3. For every square in each grid, we count the number of active horizontal well heads, cf. Fig. 6(right).

4. Since we don't know the directions of well laterals, we perform a moving-widow averaging of well density on the $3 \times 3$ stencils of grid squares.

5. We calculate the smoothed average well density per unit effective area of each county, see Figs. $7-12$.

6. We assume that infill wells will be drilled so as increase the effective well density to 4 wells per square mile. This density follows from assuming that a typical well has a mile long lateral, and has perpendicular fractures extending tip to tip $1000 \mathrm{ft}$ plus a buffer zone that adds $150 \mathrm{ft}$ on each side of the lateral. These are conservative values, and indicate that each well occupies a nominal area of a quarter of a square mile, as shown in Fig. 13. Note that if wells are spaced this closely, the operators will forgo a long-time contribution to production described by Eftekhari et al. (2018). Thus, for example, if current well density is 1.9 wells per square mile, we assume that infill drilling will contribute an additional 2.1 wells per square mile, cf. Table $\mathbf{1}$.

7. This approach predicts that infill drilling in the Barnett will be completed by the following program: Zero new horizontal wells in Tarrant, because this county is already overdrilled; 273 wells in Johnson; 1090 wells in Wise; 413 in Denton; 938 Parker; and 286 wells in Hood. Thus, the total number of new horizontal wells to be drilled in the Barnett is 3000. If all of these wells are drilled, the average well density will be 4 wells/square mile in the major gas-producing counties in the Barnett.

8. We assume these 3000 wells will be drilled over 7 years, or roughly 430 wells per year. We assume this rate of drilling because this is the rate that would be required to keep overall production from the Barnett shale from declining further.

9. By combining the horizontal rig count data from Y-Charts with the horizontal well count predicted by JPT, Jacobs (2019), we obtain that in 2019, 20,000 wells will drilled per year by 900 rigs. Thus, one rig will drill 22 wells per year on the average, or one well will be drilled in 17 days. Discounting somewhat this optimistic estimate to one horizontal well per rig per 20 days, translates into 24 rigs drilling continuously in the Barnett for seven years, or $2.4 \%$ of all rotary rigs in the US.

10. The productivity of these future wells is assumed be determined by average productivity of the wells already drilled in each county. We use the $P_{50}$ well prototype for each county, scaled by the physical RF curves.

11. The outcome is stable production at $60 \%$ of the peak rate in the Barnett, see Fig. 14 . and a cumulative recovery of 26 Tscf.

12. With only 2010 Barnett production data in hand, Patzek predicted this outcome independently in 2011, see (Patzek, 2019), page 5, using Gaussians, Patzek and Croft (2010) . 


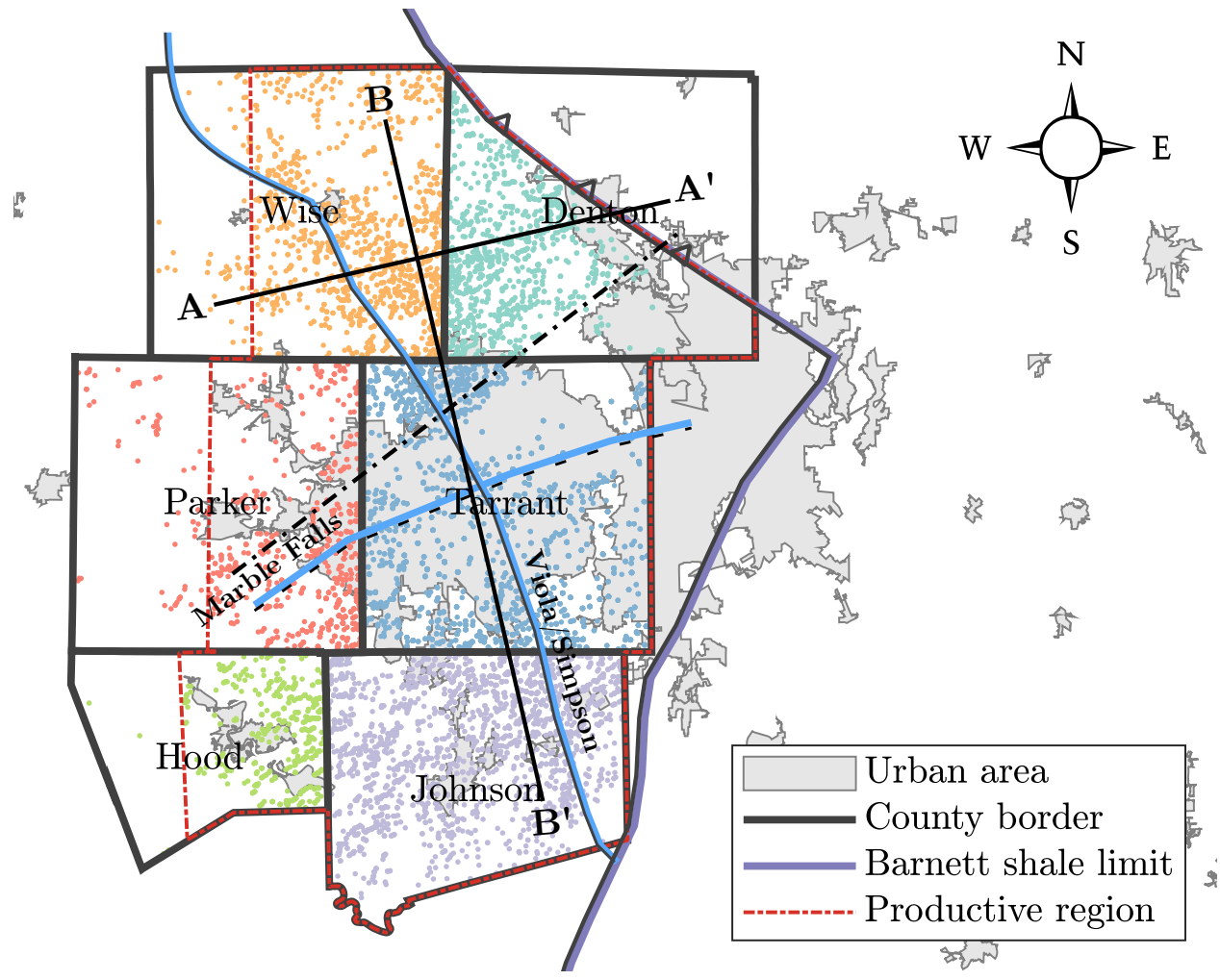

Figure 1: Map of 10,527 horizontal gas wells completed in the Barnett Formation in the top six gas producing counties: Tarrant, Johnson, Denton, Wise, Parker and Hood, respectively. The thick purple line is the boundary of the Barnett shale that cuts Denton county in half. The dashed-red lines delineate the highly productive regions in the six counties. In addition, Wise, Parker and Hood counties are divided into western and eastern parts. The eastern parts are more productive, as demonstrated in Fig. 5. We do not expect significant new drilling in the western parts. The gray-filled islands are the urban areas in and around the Barnett shale. In general, few urban wells have been drilled in Barnett outside of Tarrant county. With $60 \%$ of its area classified as urban, 1,725 of the total of 3,471 horizontal gas wells in Tarrant were drilled in the urban neighborhoods. Tarrant county is the most productive part of the Barnett, better than all other counties. The western boundary (pinchout) of the Viola/Simpson limestone meanders from the SE to NW, see the blue diagonal line. This limestone provides a barrier against hydrofracturing into the water-bearing Ellenburger limestone. Also note the southern pinchout of the Marble Falls limestone, see the blue line that runs from SW to NE across the Parker and Tarrant counties. The EW and NS crosssections that follow are denoted as AA' (Fig. 2), BB' (Fig. 3). There is also the diagonal cross-section shown as the dash-dot line (Fig. 4 ). 


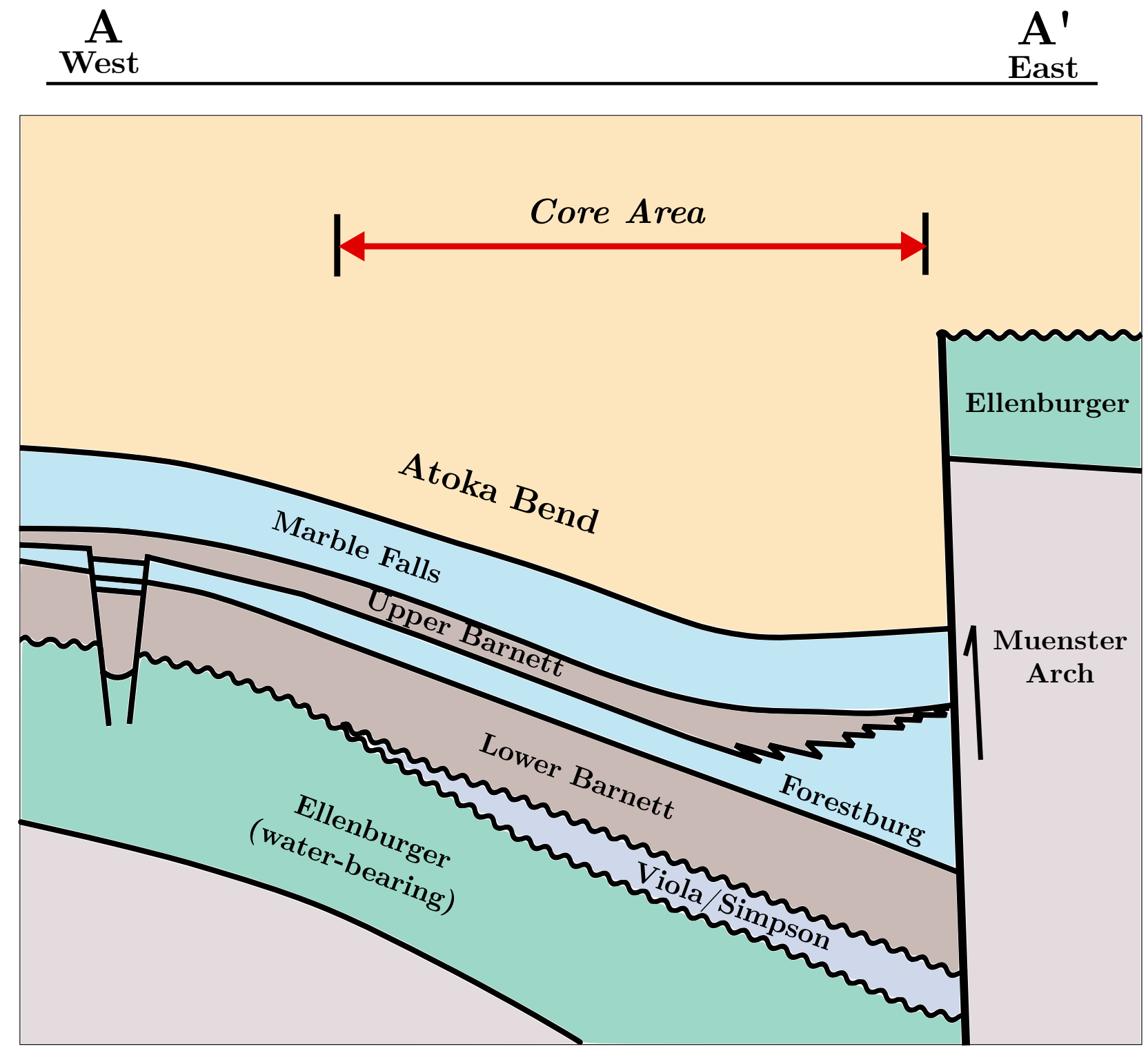

Figure 2: East-west cross-section ( $\mathrm{AA}^{\prime}$ in Fig. 1) To the east ( $\mathrm{A}^{\prime}$ in Denton county), the Barnett shale is terminated by the thrust Muenster Arches fault. Note how the eastern edge of the Upper Barnett is eroded near the Munester. limestones. The underlying porous Viola/Simpson limestone pinches out to the west. Redrawn Figure 7 in Bowker (2007) 
Forth Worth

Metroplex

B

North
Newark East Field

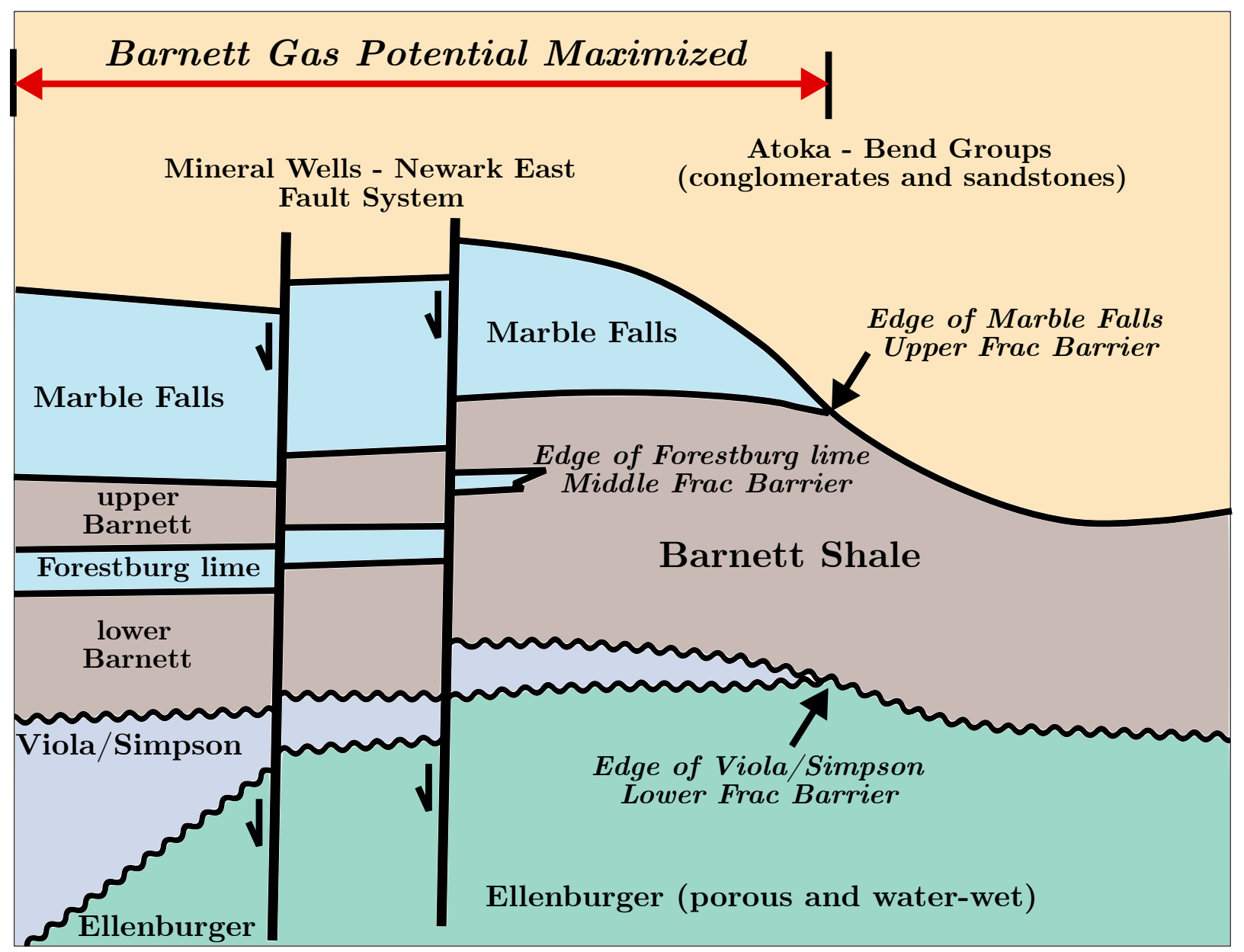

Figure 3: North-south cross-section (BB' in Fig. 1) showing the current economically productive limit of the Newark East field. Note the southern pinchout of the Forestburg and Marble Falls limestones. The northern limit of the field is currently determined by the edge of the gas window and, to a local extent, porous water-wet zones in the underlying Viola/Simpson limestone. The southern limit is the dense population of the Fort Worth portion of the Metroplex. Redrawn Figure 8 in Bowker (2007) 


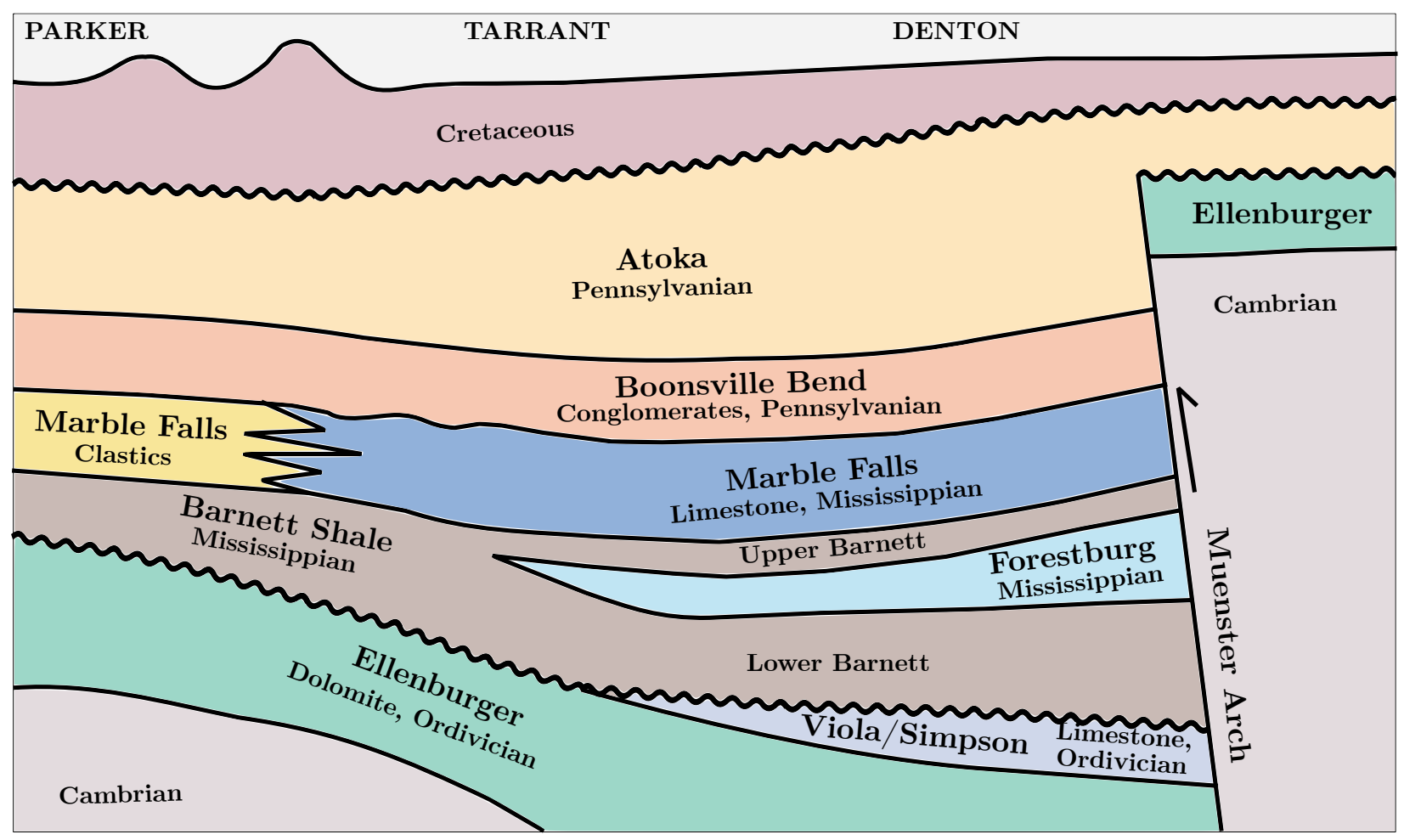

Figure 4: Diagonal cross-section (dot-dash line in Fig. 1) crossing Parker, Tarrant and Denton counties. This cross-section shows best the stratigraphic and structural changes in the Barnett Petroleum System. Notice how the Barnett gets thicker and is underlain by the Viola/Simpson limestone as one moves in the NE direction. Redrawn Figure 2A in Gonzalez (2005) 

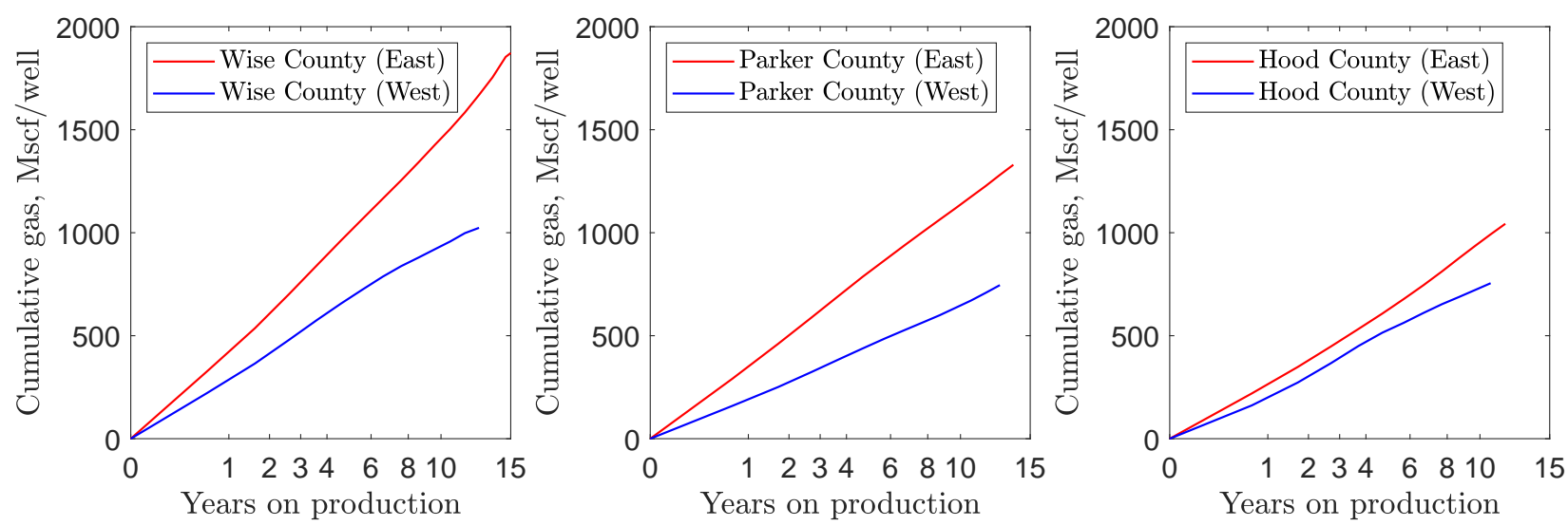

Figure 5: Cumulative gas production per average horizontal well in Wise (left), Parker (center), and Hood county (right). It is clear that the wells located in the eastern part of each county are more productive than those completed in the respective western parts. In Hood county, the differential of cumulative gas production per eastern and western well is smaller than those in Wise and Parker counties. Hood county is least productive among the top six gas producing counties in the Barnett.
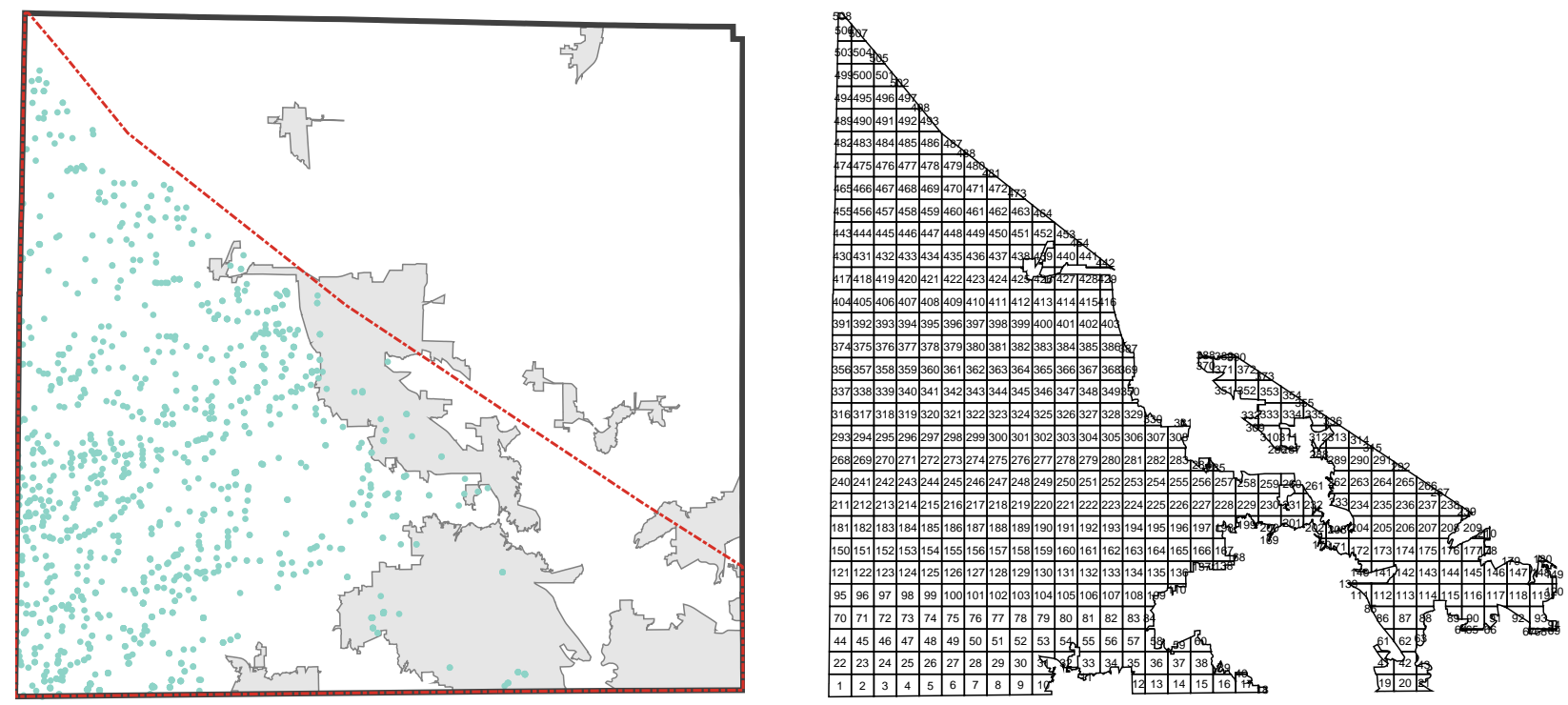

Figure 6: In order to calculate well density in the Barnett shale, we create in GIS the one square-mile fishnets that quantify effective areas for infill drilling. In each county, the effective area is defined as areas of all gas-producing regions minus all urban areas. The figure on the left shows a close up of Denton county from Fig. 1. The effective area for Denton, shown on the right, is covered with a grid of 1 -mile ${ }^{2}$ squares. These squares are numbered from 1 to 508 in this particular example. Subsequently, well density is calculated for each square by counting the number of wells with wellhead locations on it. Because of the rather poor reporting of well trajectories in Texas, we then average these well densities on all contiguous $3 \times 3$ grid stencils. 

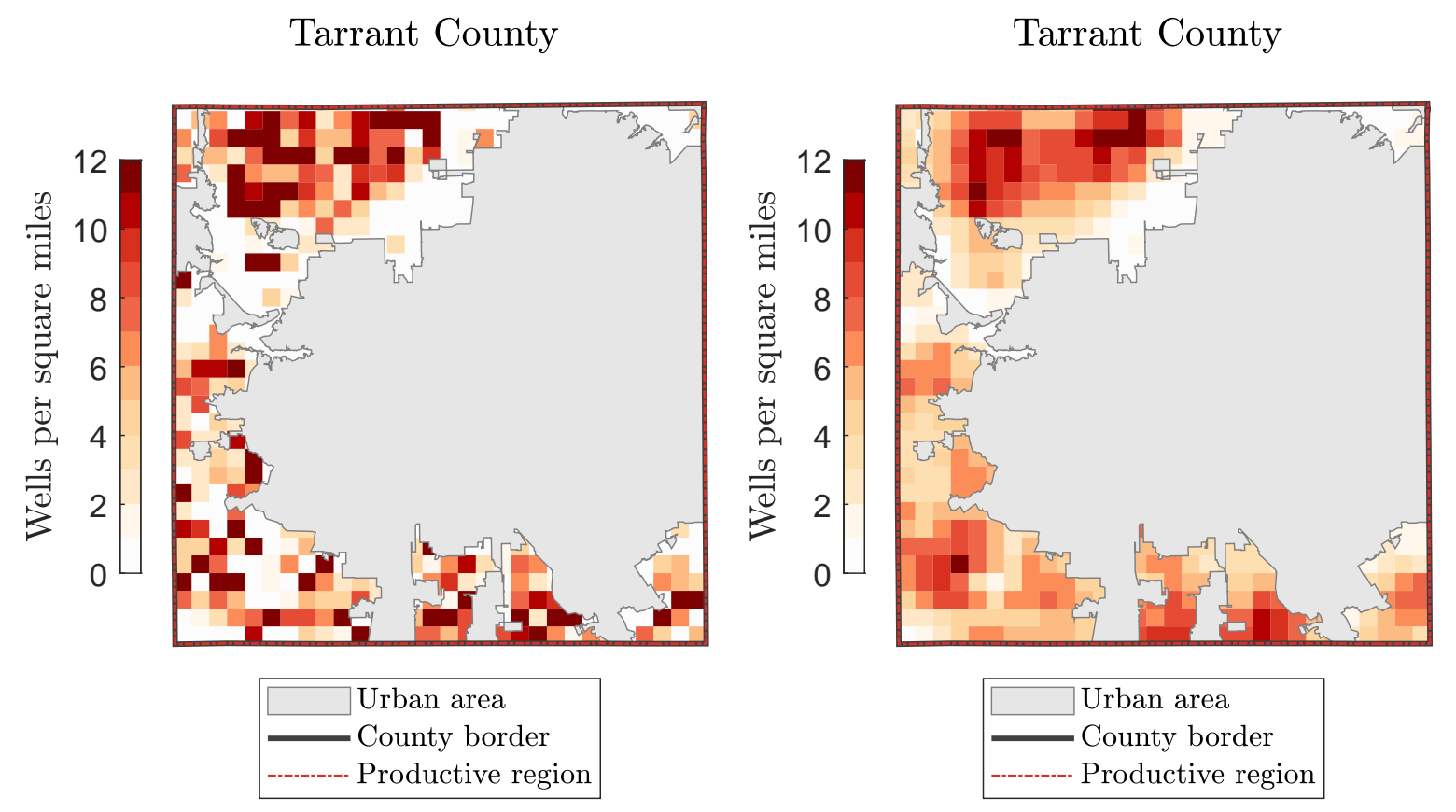

Figure 7: (Left) Well density map for Tarrant county over the effective area squares defined in Fig. 6. The color map is limited to 12 wells per square mile. (Right) The moving window mean of well density in the Tarrant County is calculated as the mean of the density for each square plus up to 8 surrounding squares. Being the most productive county in the Barnett shale, Tarrant is already over-drilled with the average well-density in the effective area of 5.3 wells per square mile. 
Johnson County

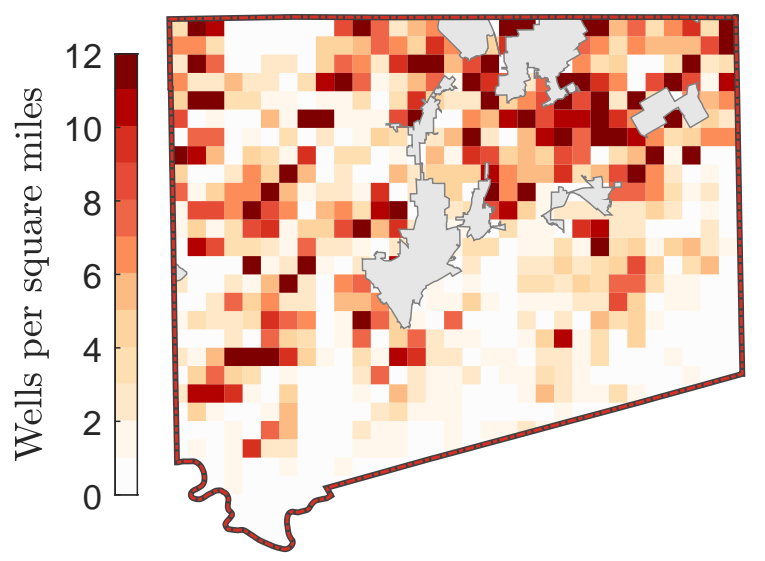

Urban area

County border

Productive region

\section{Johnson County}
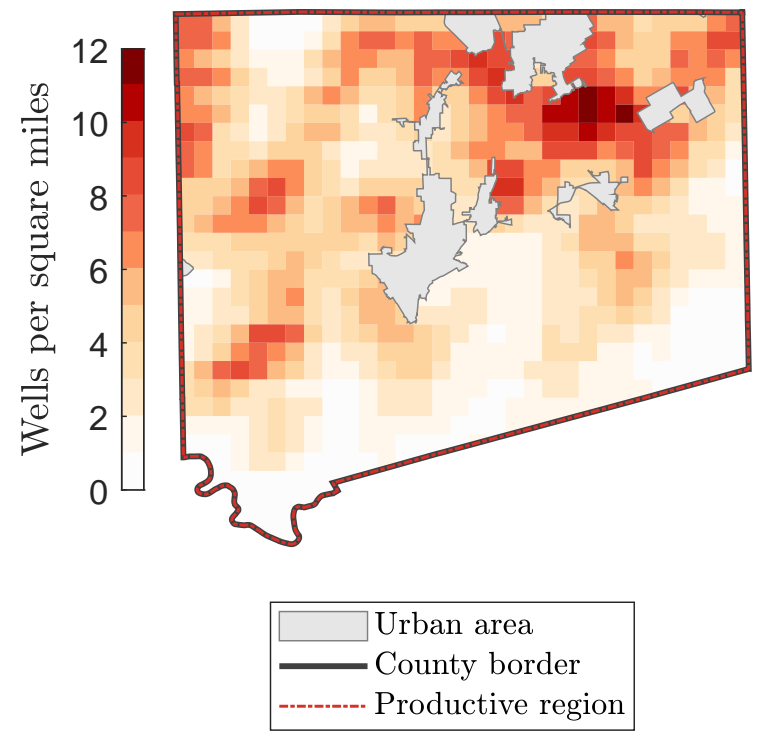

Figure 8: Well density map for Johnson county calculated for each sampling square over the effective area defined in Fig. 6. (Right) The moving window mean of well density in Johnson county. As the second most productive county in the Barnett shale, Johnson has the average well-density of 3.6 wells per square mile of the effective area.

Wise County

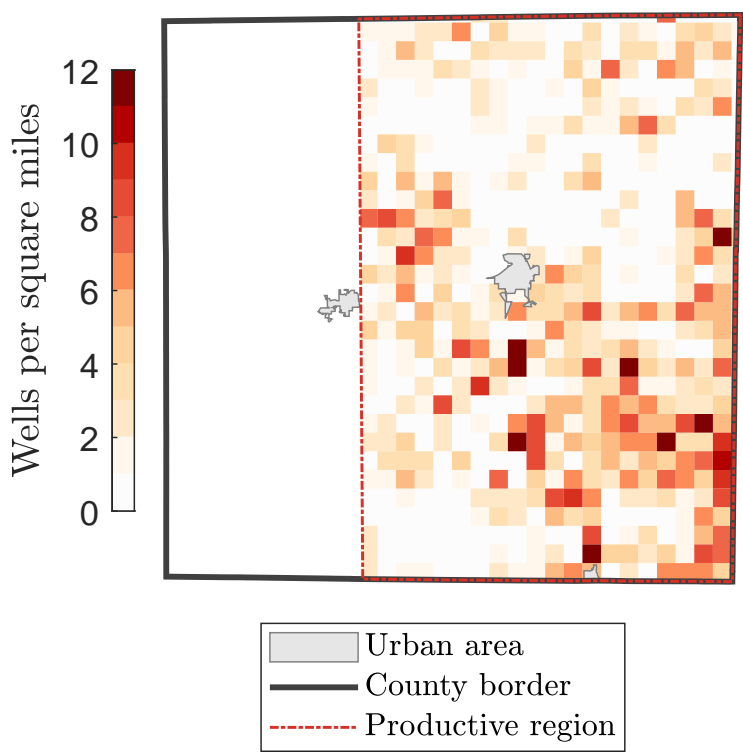

Wise County

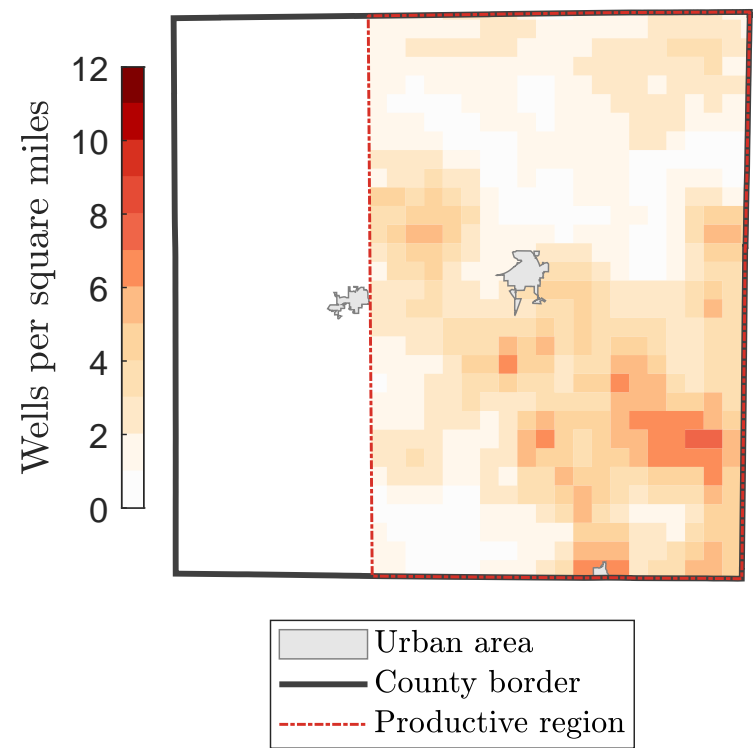

Figure 9: Well density map for Wise county calculated for each sampling square over the effective area. (Right) The moving window mean of well density in Wise county. The average well-density over the effective area of Wise county is 2.2 wells per square mile. 
Denton County

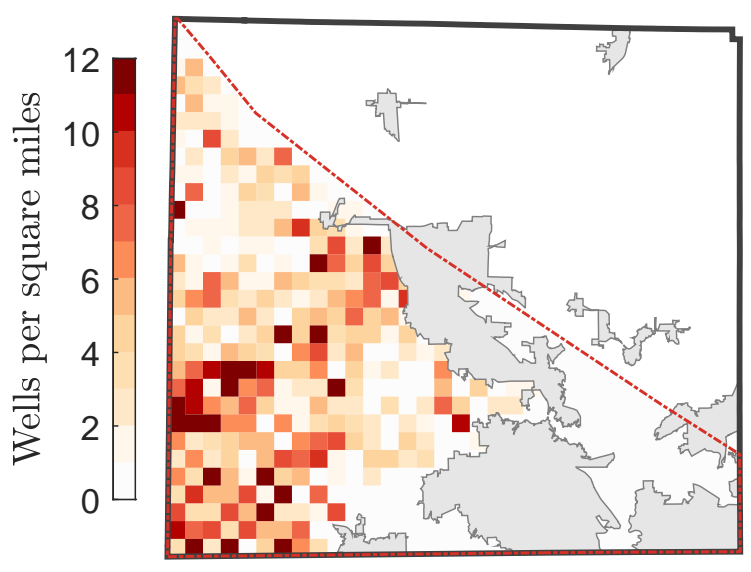

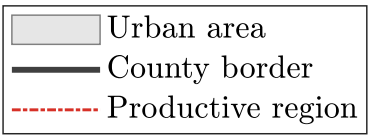

Denton County
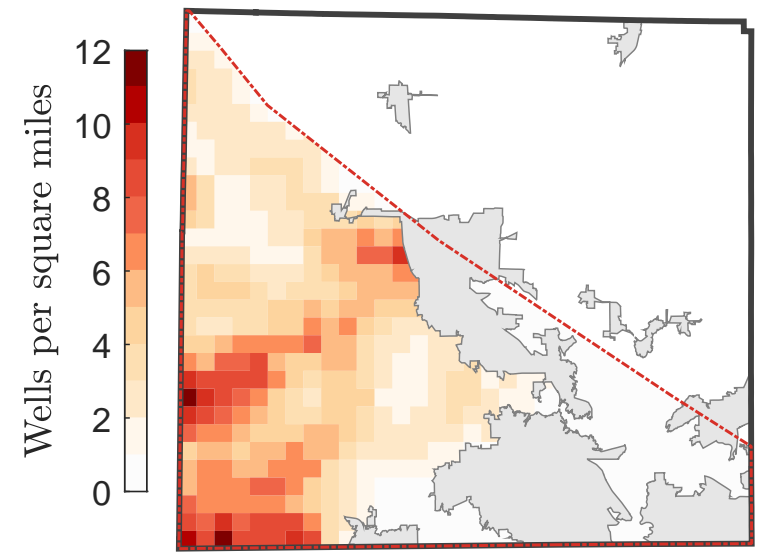

Urban area

County border

Productive region

Figure 10: Well density map for Denton county calculated for each sampling square over the effective area. (Right) The moving window mean of well density in Denton county. The average well-density over the effective area of Denton county is 3 wells per square mile.

Parker County

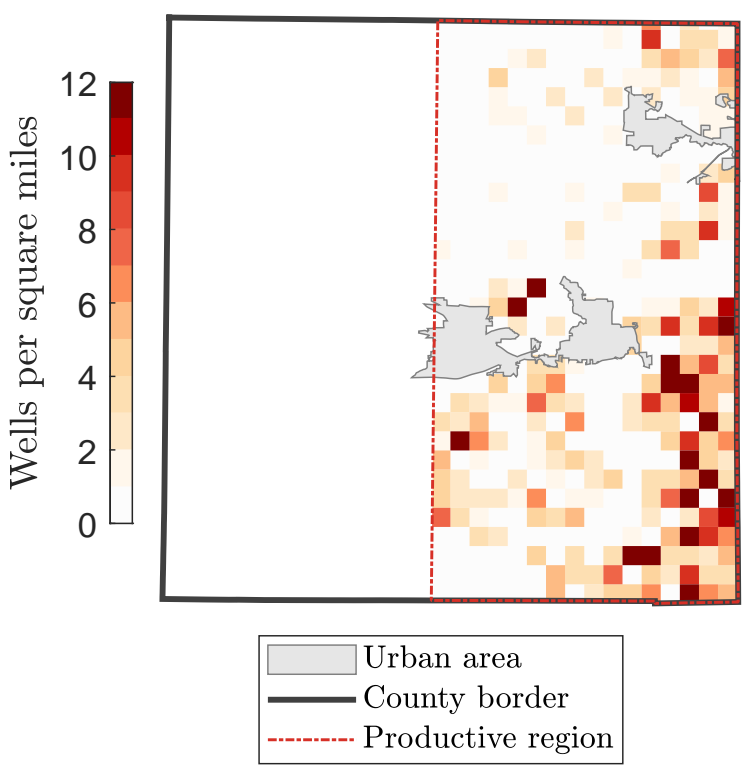

Parker County

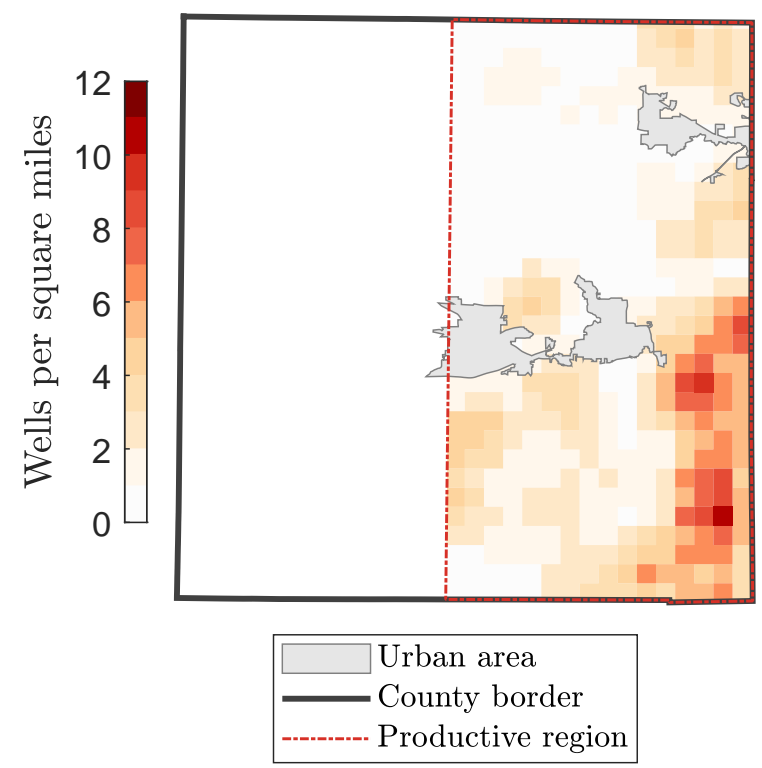

Figure 11: Well density map for Parker county calculated for each sampling square over the effective area. (Right) The moving window mean of well density in Parker county. The average well-density over the effective area of Parker county is 1.9 wells per square mile. 
Hood County
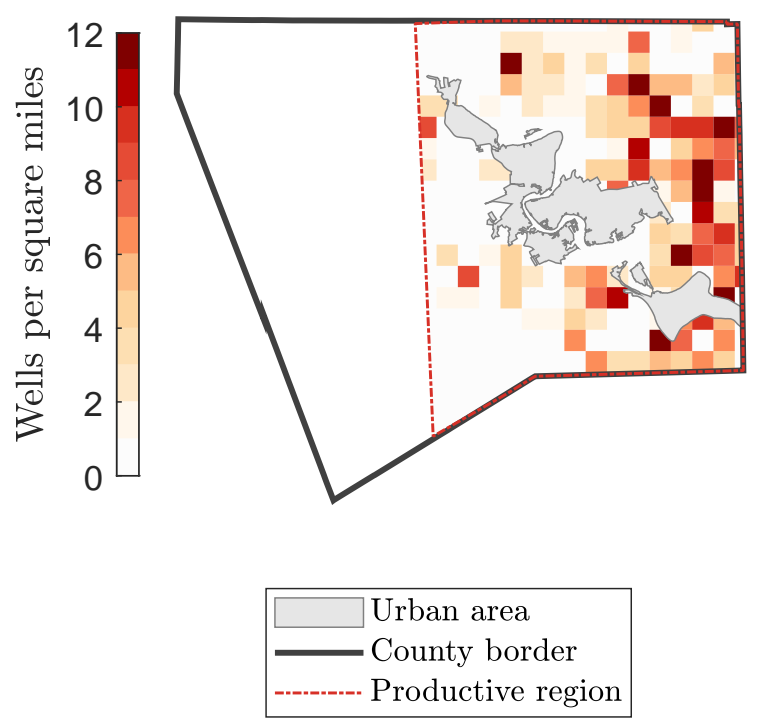

Hood County
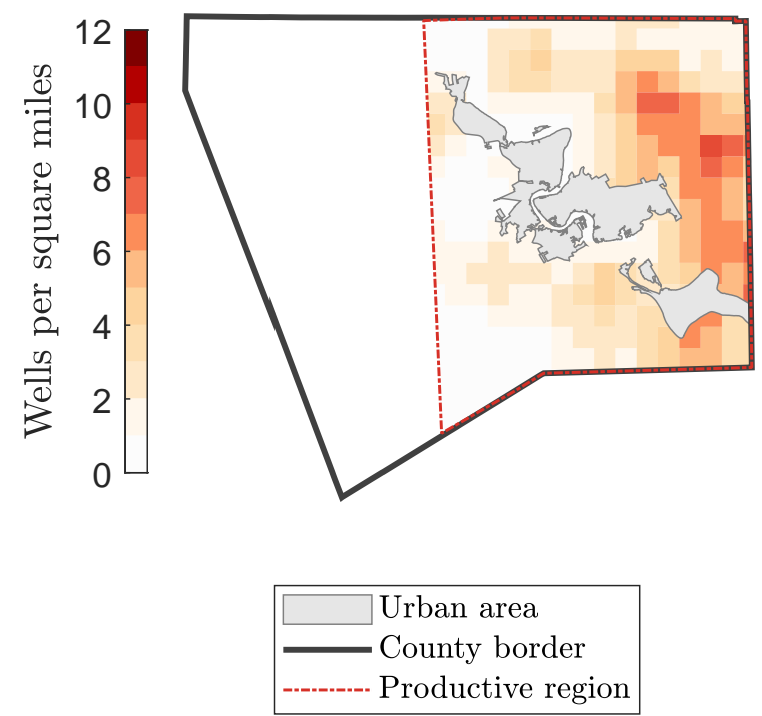

Figure 12: Well density map for Hood County calculated for each sampling square over the effective area. (Right) The moving window mean of well density in Hood county. The average well-density over the effective area of Hood county is 2.7 wells per square miles. 


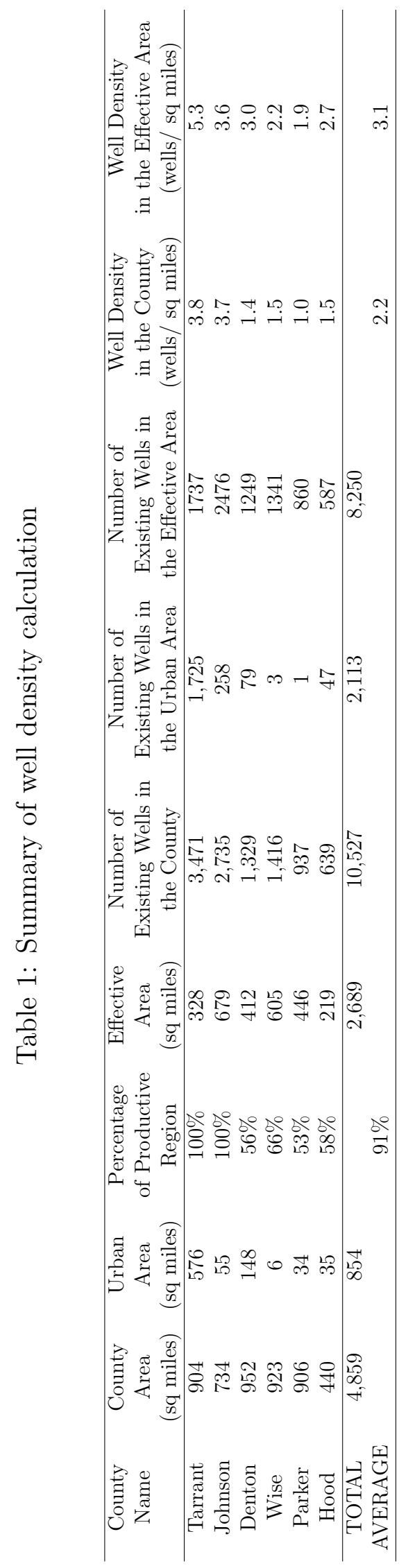




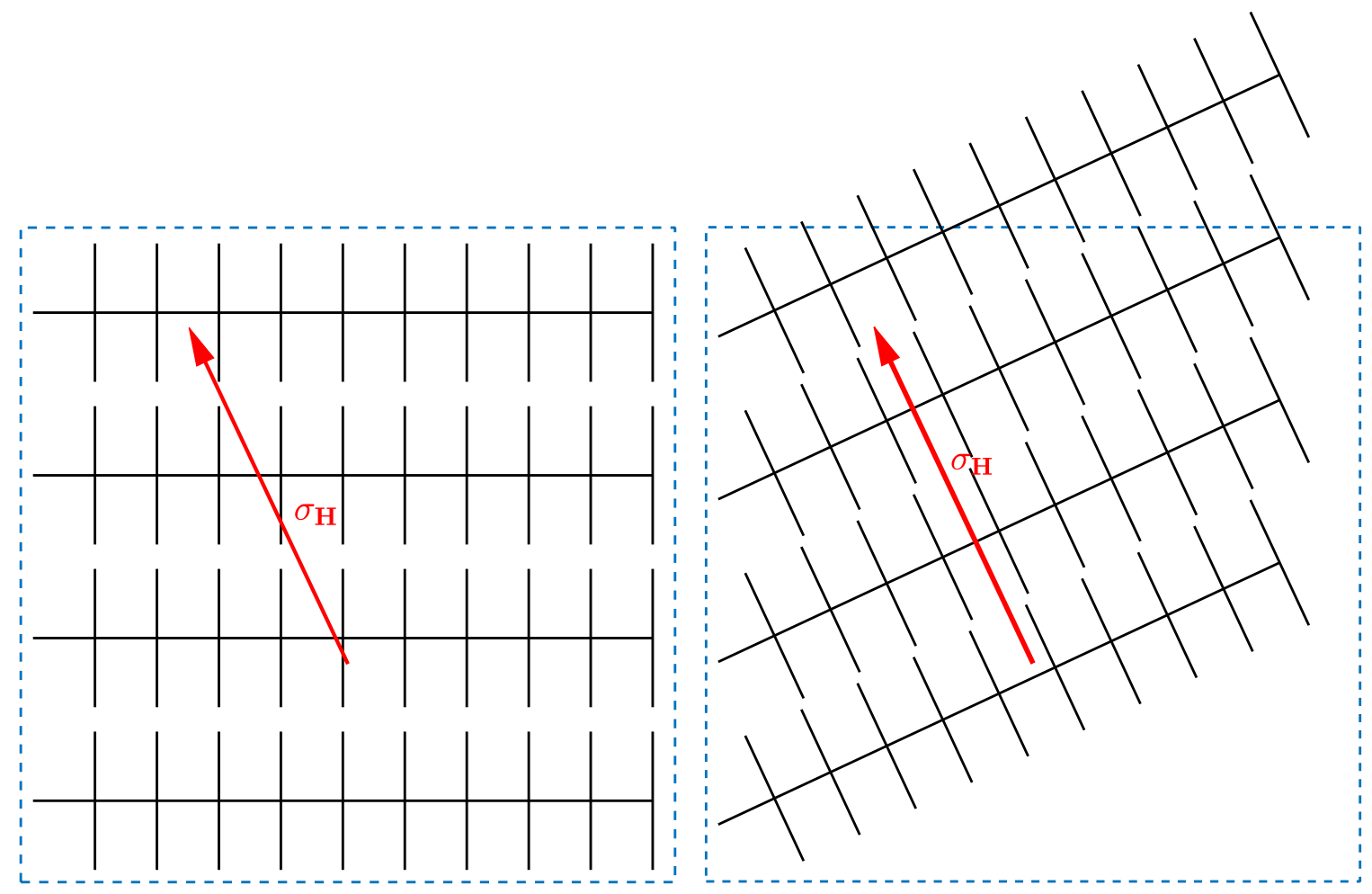

Figure 13: Left: Four 1-mile laterals with the $1000 \mathrm{ft}$ tip-to-tip hydrofractures aligned with the 1 square mile section border. Right: The same wells aligned with the tectonic stress direction. Note that with more than 4 wells per section, the closest hydrofractures associated with adjacent laterals must start interfering with one another before the consecutive hydrofractures in each well do. These lateral-two hydrofractures-lateral interactions accelerate pressure depletion of the stimulated reservoir volumes, may decrease ultimate recovery from all wells, and almost certainly cut into well economics. 

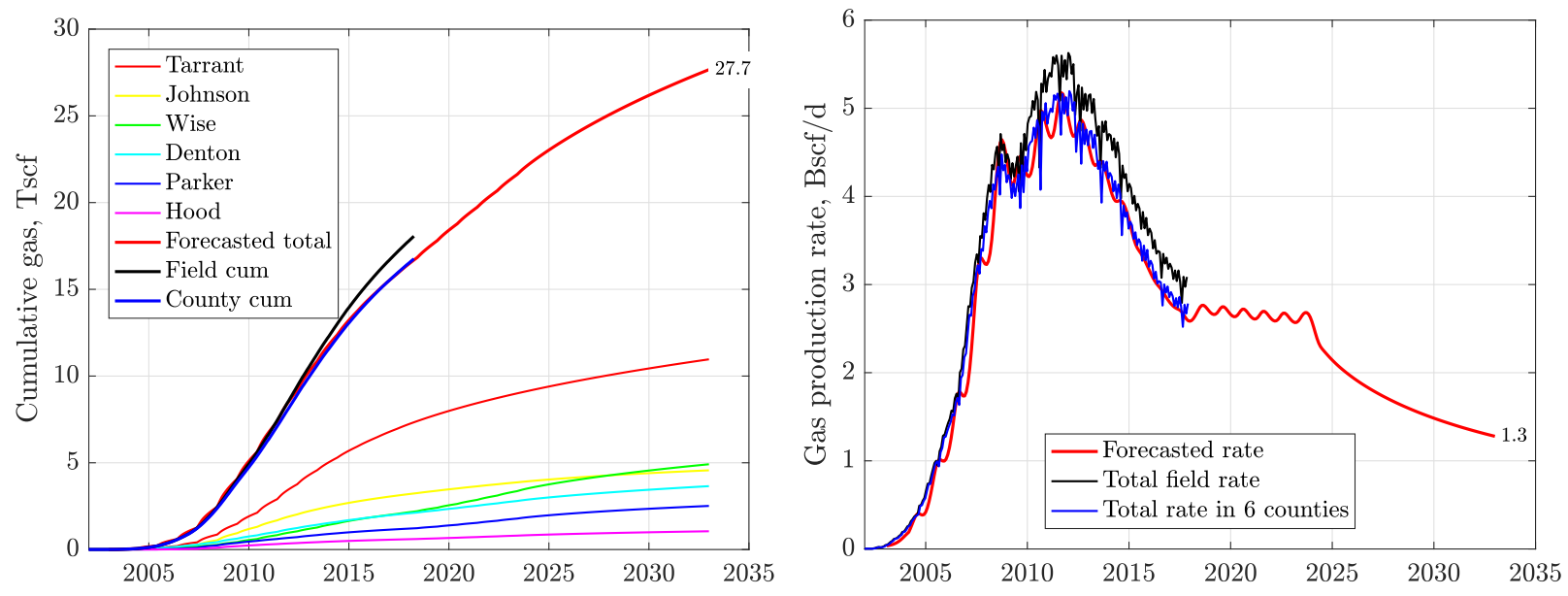

Figure 14: The actual and forecasted cumulative oil (left) and rate (right). The excellent matches were obtained by time-shifting uniformly all forecasts by 6 months. The rates were obtained by differencing the cumulative forecasts and smoothing the sharp kinks at the start of each new well cohort. This baseline forecast shows that 3000 new surviving wells (6000 wells total) must be drilled at a constant rate over the next 7 years in all six counties to achieve EUR of 28 Tscf. The slight waviness of the forecast is caused by the simplified assumption that all new wells come on line mid year. Source: Drillinginfo, July 1, 2018. 


\section{References}

Bowker, K., Development of the Barnett Shale Play, Fort Worth Basin, www.searchanddiscovery.com/documents/2007/07023bowker/, AAPG, Search and Discovery Article \#07023, 2007.

Eftekhari, B., M. Marder, and T. W. Patzek, Field data provide estimates of effective permeability, fracture spacing, well drainage area and incremental production in gas shales, Journal of Natural Gas Science and Engineering, 56, 141 - 151, doi:10.1016/j.jngse.2018.05.027, 2018.

Gonzalez, R., A GIS Approach to the Geology, Production, and Growth of the Barnett Shale Play in Newark East Field, North Texas, www.searchanddiscovery.com/documents/2005/gonzalez/, AAPG, Search and Discovery Article \#40147, 2005.

Jacobs, T., US Shale To Drill And Complete 20,000 Wells This Year, JPT, (2), www.spe.org/en/jpt/jpt-article-detail/?art=5069, 2019.

Patzek, T., Barnett Shale in Texas: Promise and Problems, May 26, 2011, Seminar at the Bureau of Economic Geology, UT Austin, doi:10.18738/T8/3MLRLO, 2019.

Patzek, T., F. Male, and M. Marder, A simple model of gas production from hydrofractured horizontal wells in shales, AAPG Bulletin, 98(12), 2507 - 2529, 2014.

Patzek, T. W., and G. D. Croft, A Global Coal Production Forecast with Multi-Hubbert Cycle Analysis, ENERGY, 35, 3109 - 3122, 2010.

Patzek, T. W., F. Male, and M. Marder, Gas production in the Barnett Shale obeys a simple scaling theory, Proceedings of the National Academy of Sciences, 110(49), 19,731 - 19,736, doi:10.1073/pnas.1313380110, 2013.

Pollastro, R. M., Total petroleum system assessment of undiscovered resources in the giant Barnett Shale continuous (unconventional) gas accumulation, Fort Worth Basin, Texas, AAPG Bulletin, 91(4), 551-578, doi:10.1306/06200606007, 2007.

Pollastro, R. M., R. J. Hill, D. Jarvie, and E. H. Mitchell, Assessing Undiscovered Resources of the Barnett-Paleozoic Total Petroleum System, Bend Arch-Fort Worth Basin Province, Texas, http://www.searchanddiscovery.com/documents/pollastro/index, AAPG, Search and Discovery Article \#10034, 2003.

Pollastro, R. M., D. M. Jarvie, R. J. Hill, and C. W. Adams, Geologic framework of the Mississippian Barnett Shale, Barnett-Paleozoic total petroleum system, Bend archFort Worth Basin, Texas, AAPG Bulletin, 91 (4), 405-436, doi:10.1306/10300606008, 2007.

Shirley, K., Barnett shale living up to potential, AAPG Explorer, 23(7), 18 - 27, 2002.

Vicario, L., Impacts of shale gas and shale oil extraction on the environment and on human health, Report IP/A/ENVI/ST/2011-0\%, European Parliament, Directorate General for Internal Policies, Policy Department A: Economic and Scientific Policy, Brussels, Belgium, 2011. 
${ }_{137}$ Zhao, H., N. B. Givens, and B. Curtis, Thermal maturity of the Barnett Shale determined from well-log analysis, AAPG Bulletin, 91(4), 535-549, doi:10.1306/10270606060, 2007. 
SOM II to Generalized Extreme Value Statistics, Physical Scaling and Forecasts of Gas Production in the Barnett Shale GEV fits of all well cohorts, cohort statistics, well attrition and well prototypes

Tadeusz (Tad) W. Patzek, Wardana Saputra, Wissem Kirati, Michael Marder

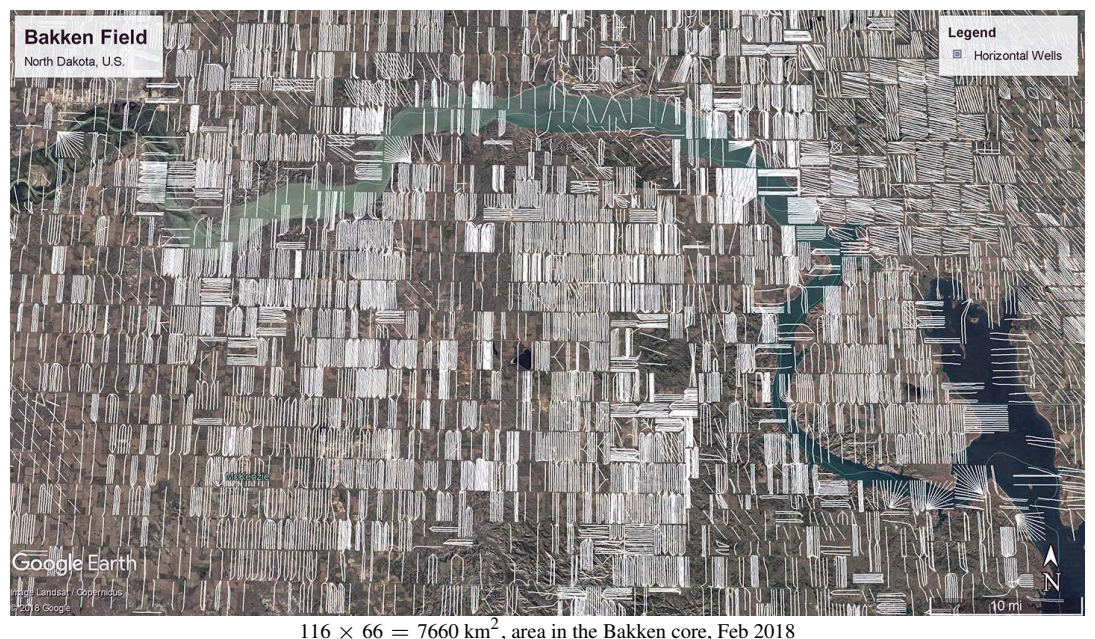




\section{Tarrant county after 1 yrs}

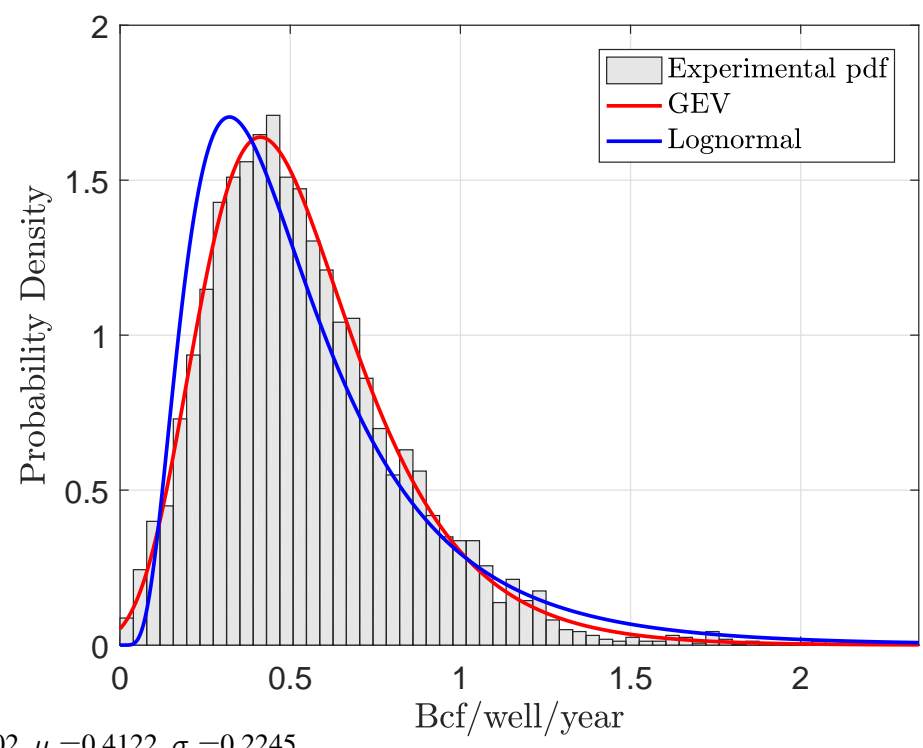

GEV pdf: $\xi=0.0002, \mu=0.4122, \sigma=0.2245$ 


\section{MLE of GEV pdf in Tarrant county}

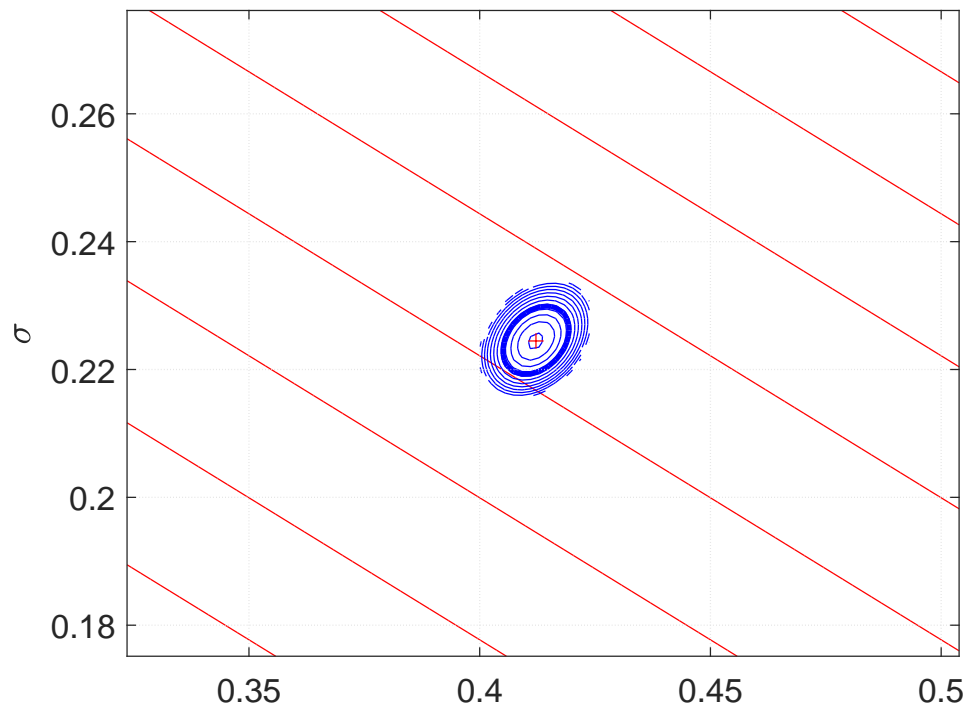

MLE $=$ Maximum Likelihood Estimate, $95 \% \mathrm{CI}$ for $\mu$ and $\sigma$ after $\mu$ 1.00 yrs 


\section{Tarrant county after $1.00 \mathrm{yrs}$}

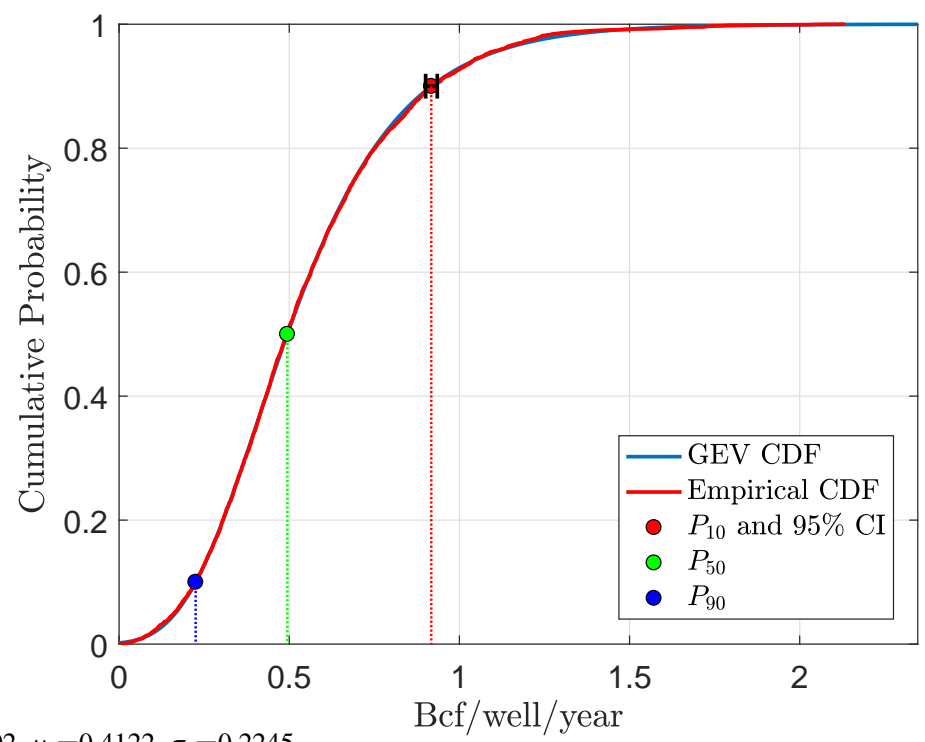

GEV cdf: $\xi=0.0002, \mu=0.4122, \sigma=0.2245$ 


\section{Tarrant county after 2 yrs}

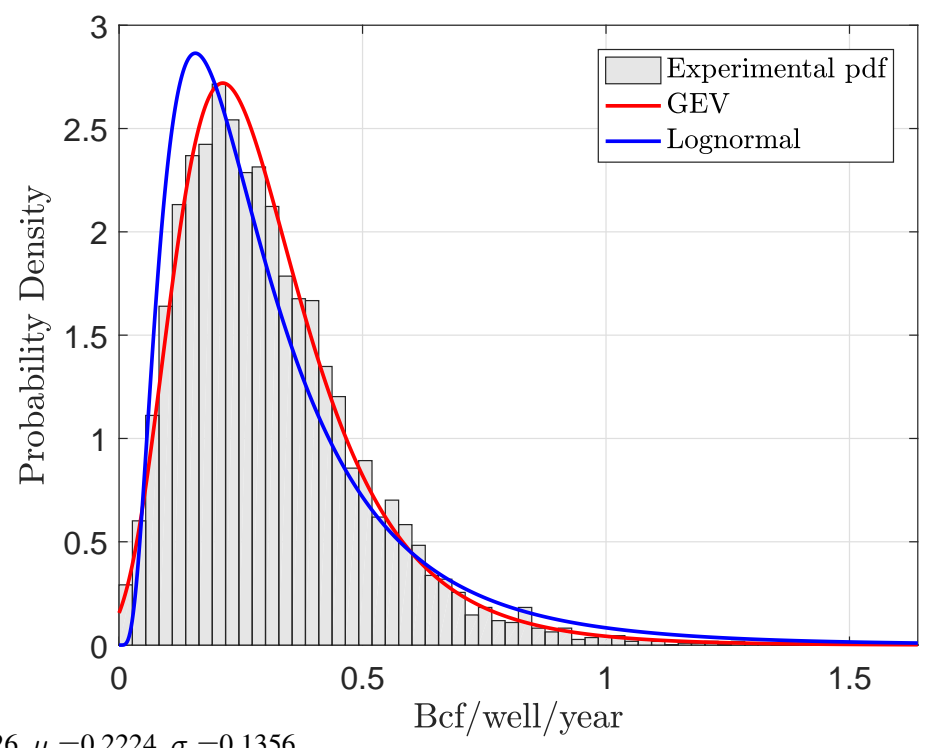

GEV pdf: $\xi=0.0726, \mu=0.2224, \sigma=0.1356$ 


\section{MLE of GEV pdf in Tarrant county}

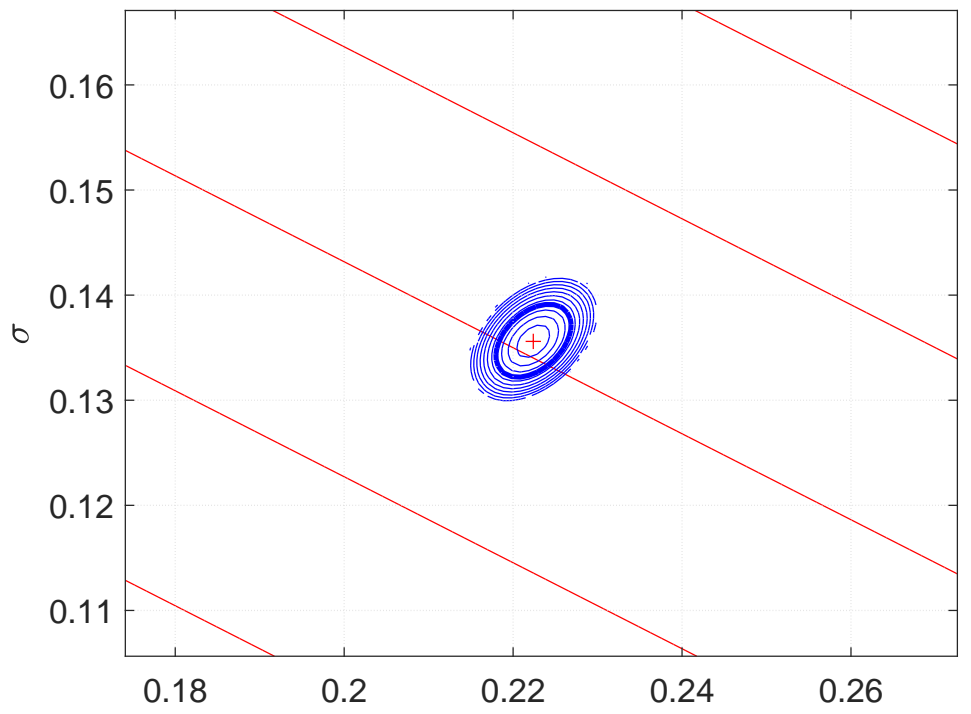

MLE $=$ Maximum Likelihood Estimate, $95 \%$ CI for $\mu$ and $\sigma$ after $2.00 \mathrm{yrs}$ 


\section{Tarrant county after $2.00 \mathrm{yrs}$}

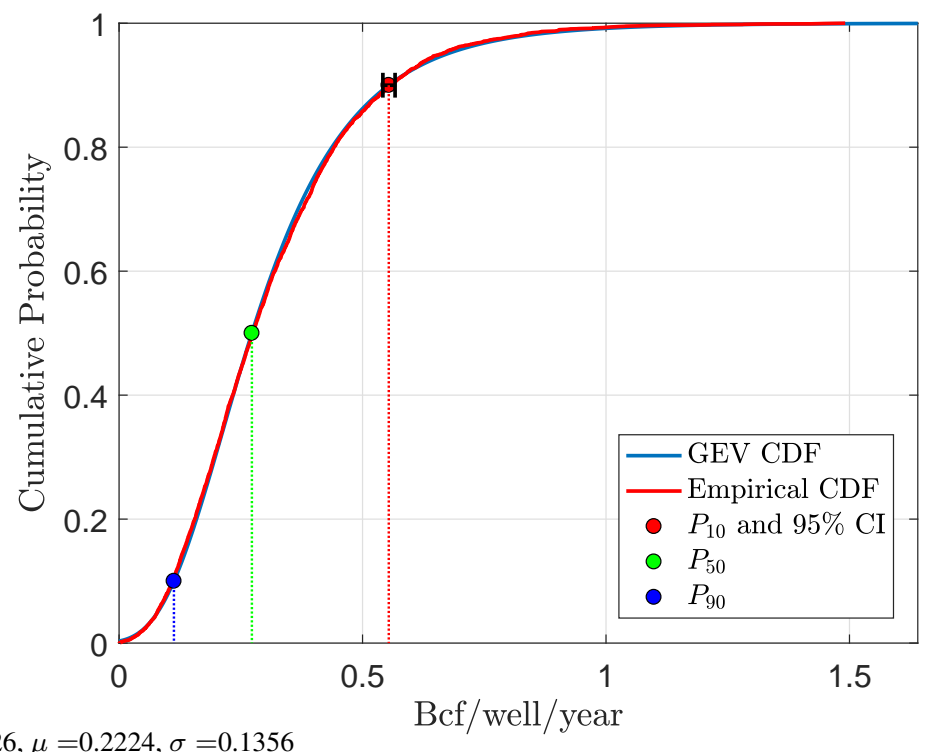

GEV cdf: $\xi=0.0726, \mu=0.2224, \sigma=0.1356$ 


\section{Tarrant county after 3 yrs}

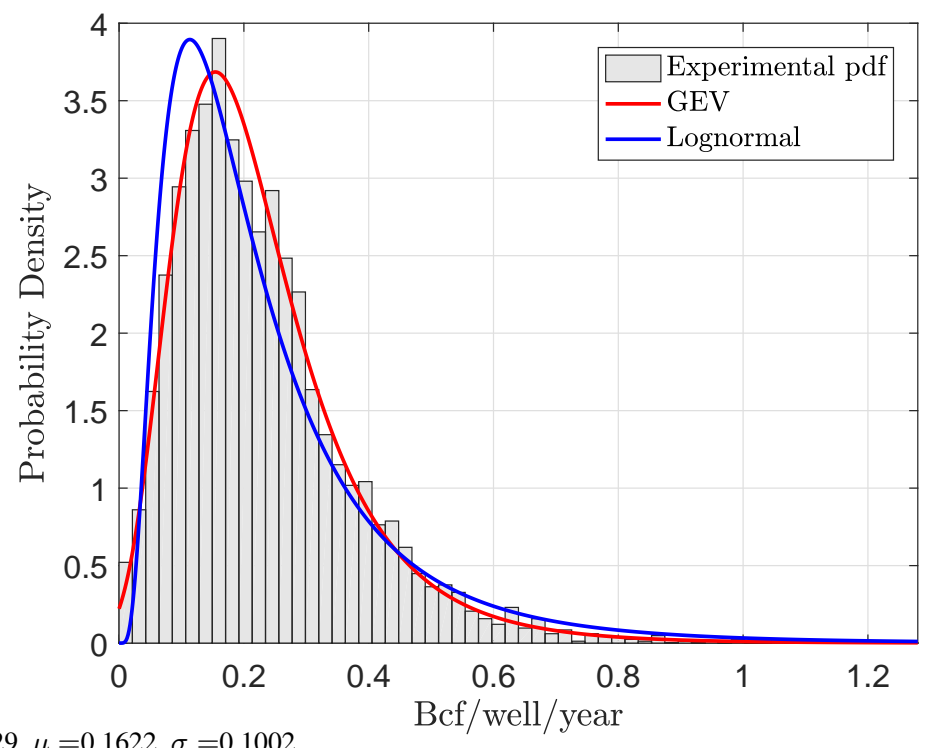

GEV pdf: $\xi=0.0829, \mu=0.1622, \sigma=0.1002$ 


\section{MLE of GEV pdf in Tarrant county}

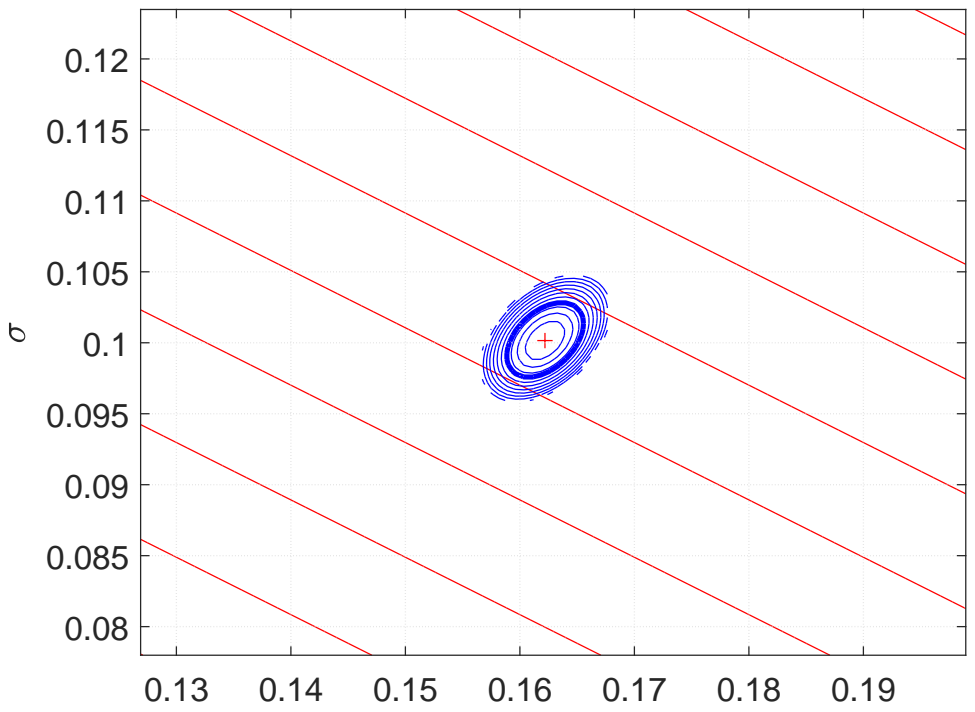

MLE $=$ Maximum Likelihood Estimate, $95 \%$ CI for $\mu$ and $\sigma$ after 3.00 yrs 


\section{Tarrant county after 3.00 yrs}

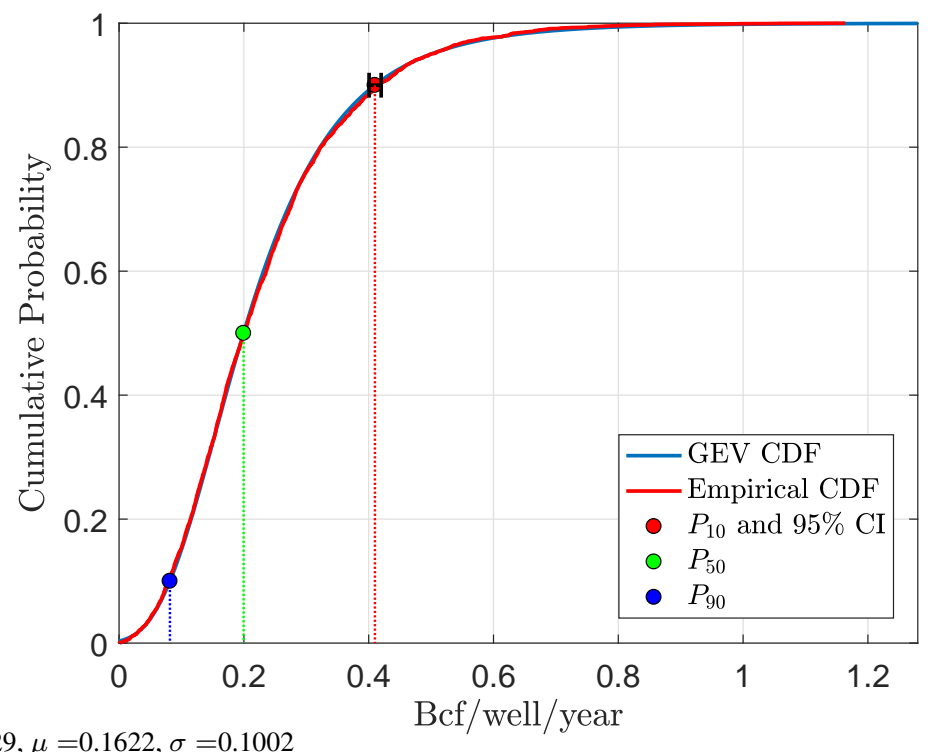

GEV cdf: $\xi=0.0829, \mu=0.1622, \sigma=0.1002$ 


\section{Tarrant county after 4 yrs}

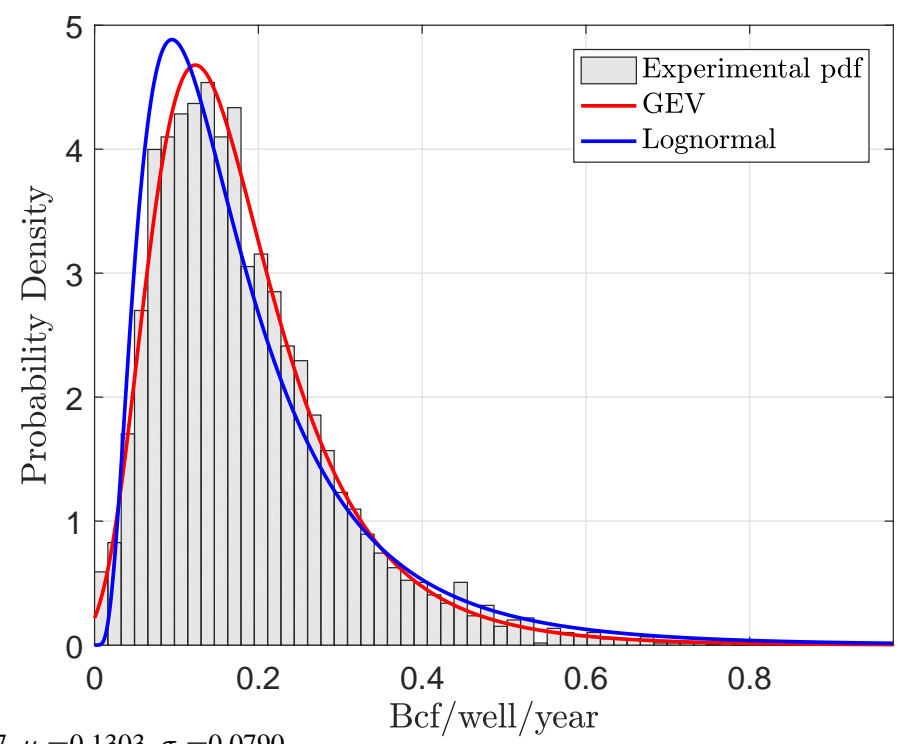

GEV pdf: $\xi=0.0967, \mu=0.1303, \sigma=0.0790$ 


\section{MLE of GEV pdf in Tarrant county}

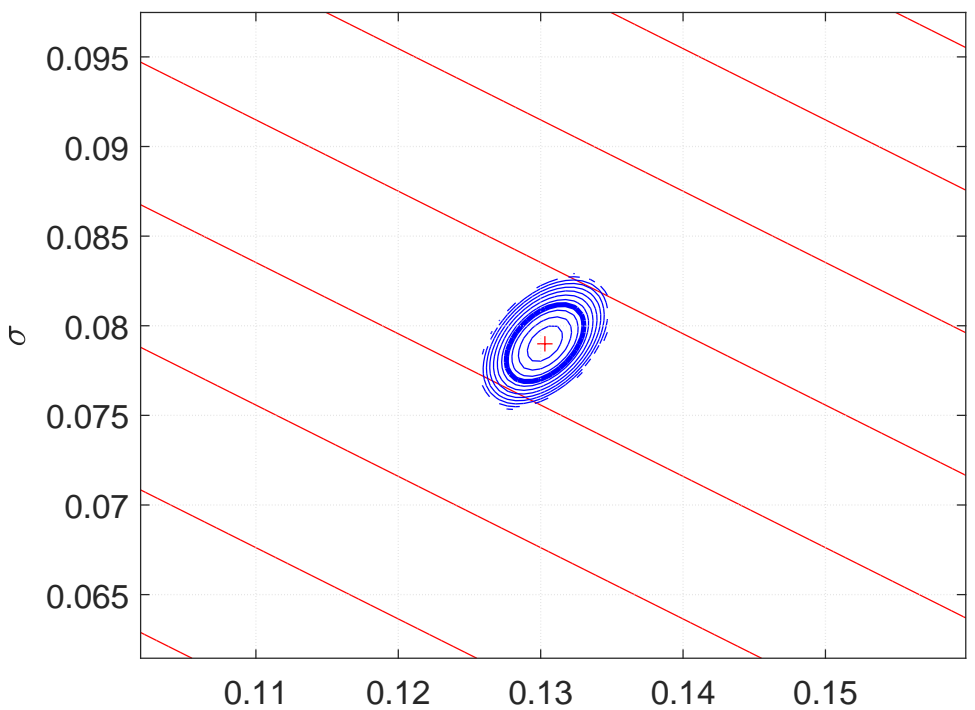

MLE = Maximum Likelihood Estimate, $95 \%$ CI for $\mu$ and $\sigma$ after 4.00 yrs 


\section{Tarrant county after 4.00 yrs}

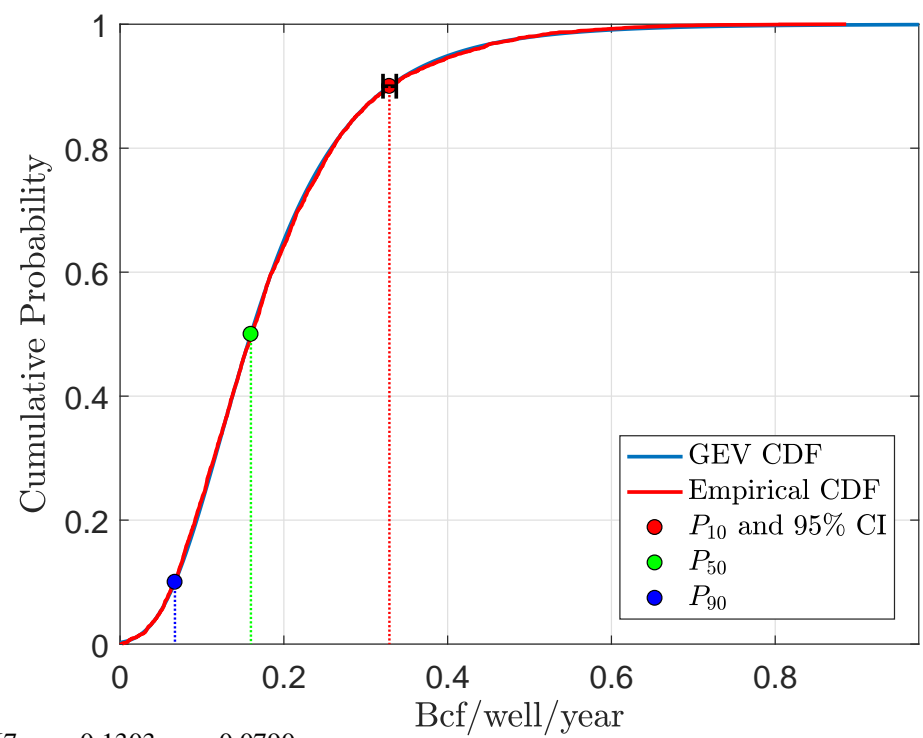

GEV cdf: $\xi=0.0967, \mu=0.1303, \sigma=0.0790$ 


\section{Tarrant county after 5 yrs}

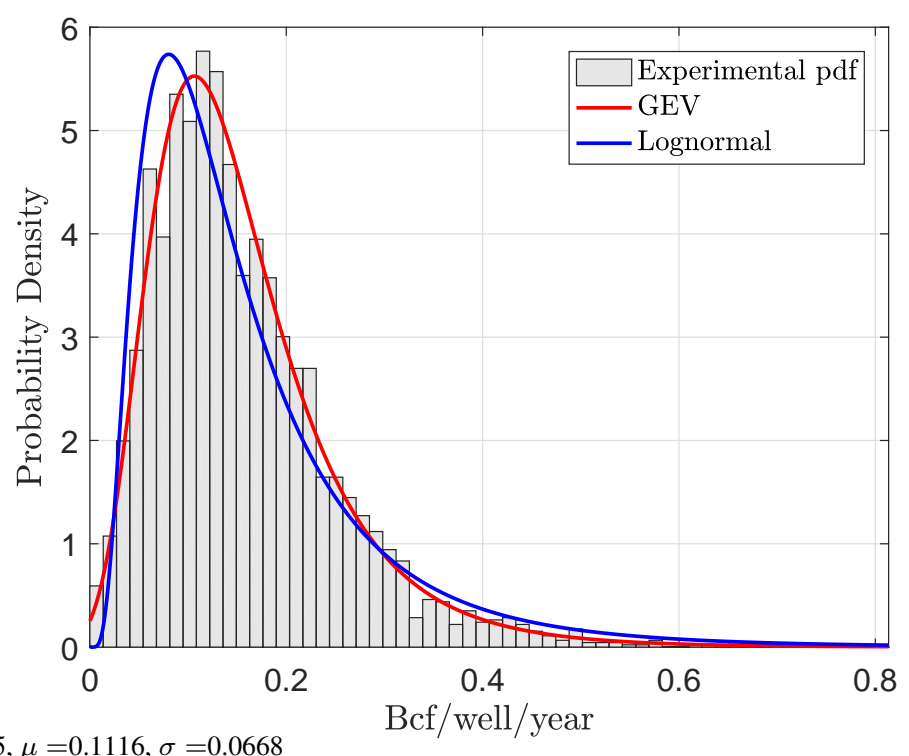

GEV pdf: $\xi=0.0805, \mu=0.1116, \sigma=0.0668$ 


\section{MLE of GEV pdf in Tarrant county}

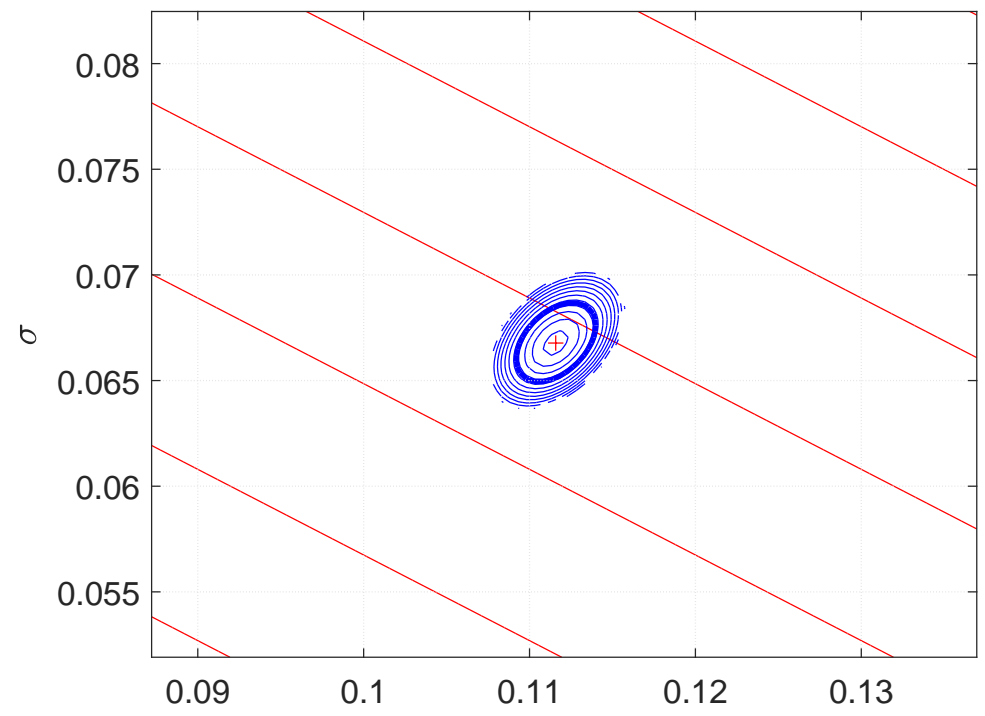

MLE $=$ Maximum Likelihood Estimate, $95 \%$ CI for $\mu$ and $\sigma$ after 5.00 yrs 


\section{Tarrant county after 5.00 yrs}

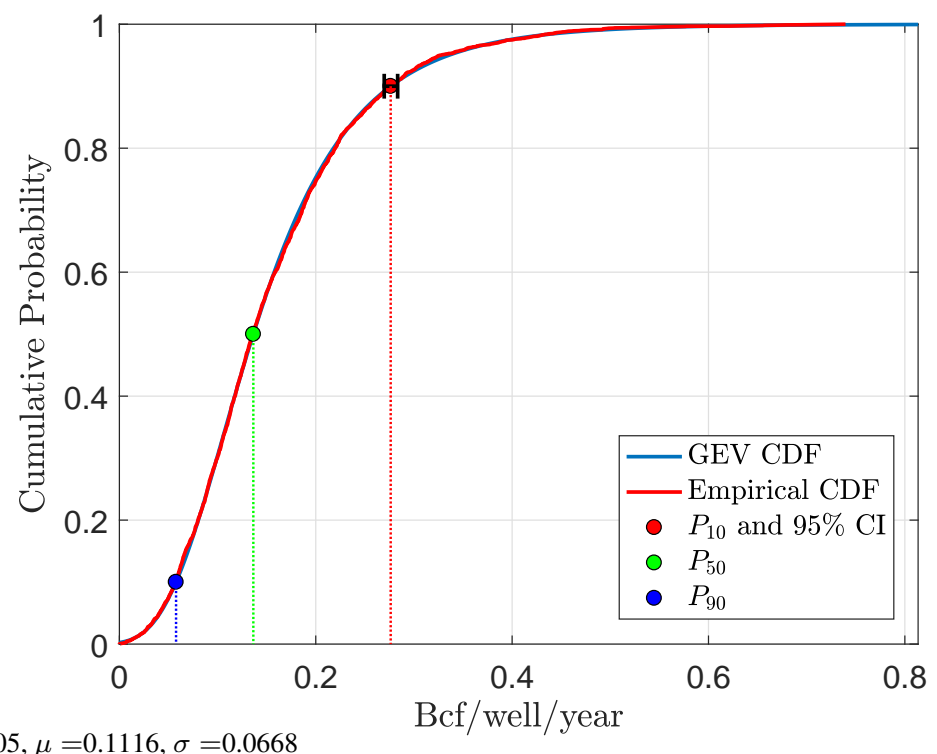

GEV cdf: $\xi=0.0805, \mu=0.1116, \sigma=0.0668$ 


\section{Tarrant county after 6 yrs}

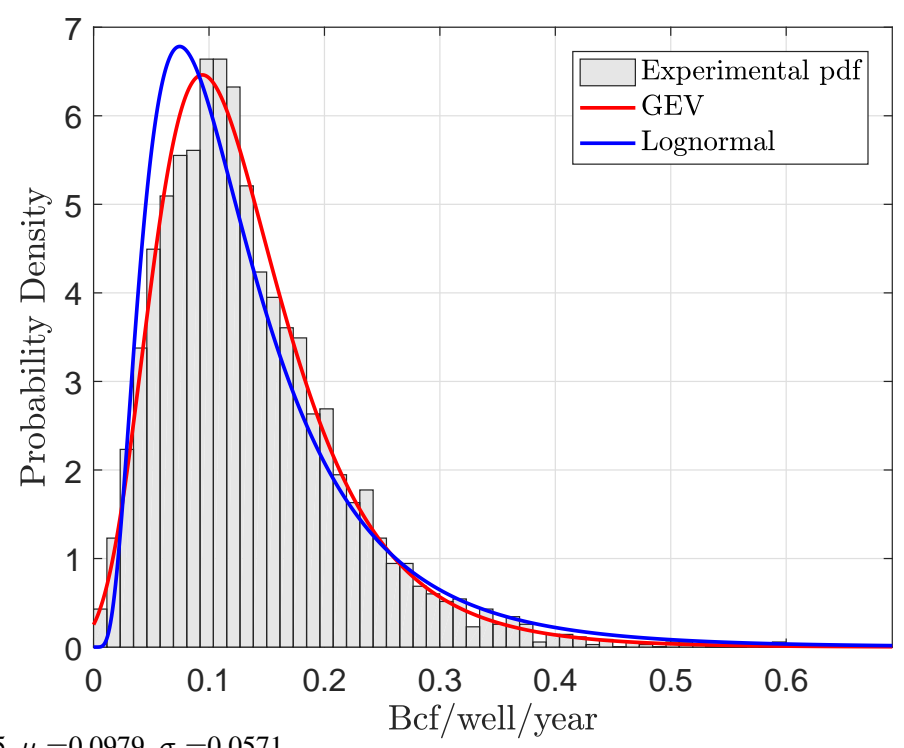

GEV pdf: $\xi=0.0665, \mu=0.0979, \sigma=0.0571$ 


\section{MLE of GEV pdf in Tarrant county}

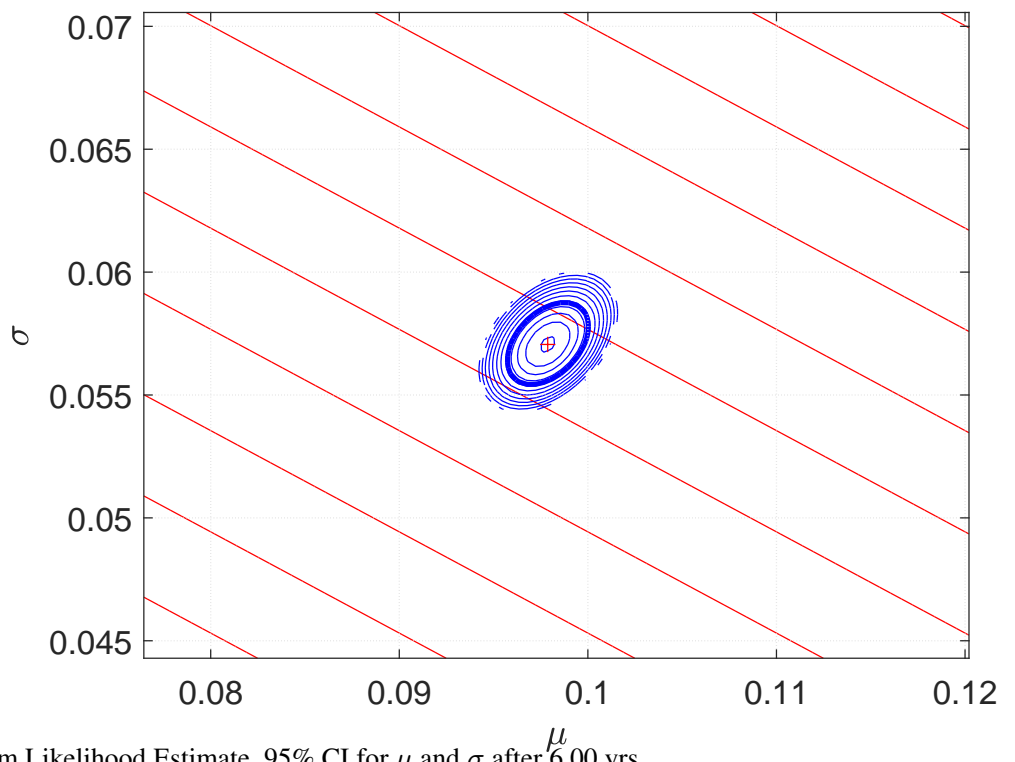

MLE $=$ Maximum Likelihood Estimate, $95 \%$ CI for $\mu$ and $\sigma$ after $6.00 \mathrm{yrs}$ 


\section{Tarrant county after $6.00 \mathrm{yrs}$}

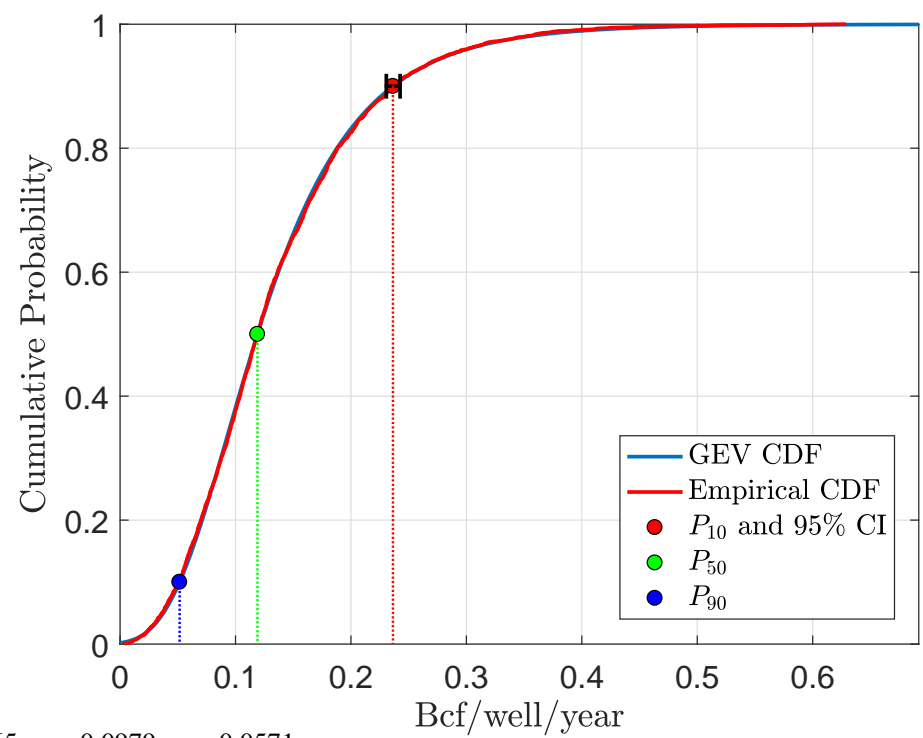

GEV cdf: $\xi=0.0665, \mu=0.0979, \sigma=0.0571$ 


\section{Tarrant county after 7 yrs}

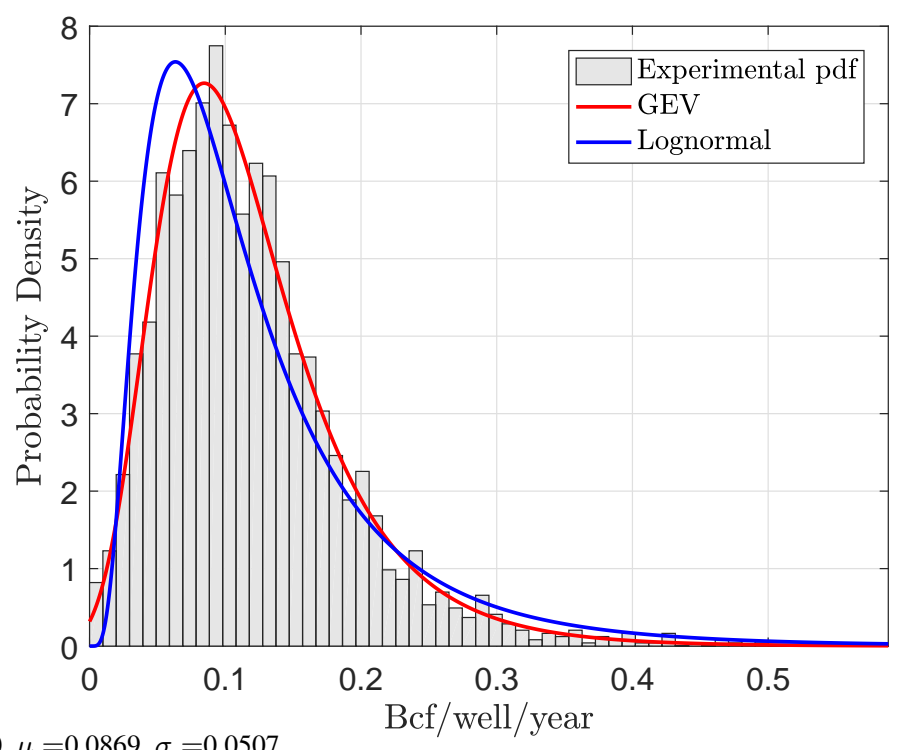

GEV pdf: $\xi=0.0510, \mu=0.0869, \sigma=0.0507$ 


\section{MLE of GEV pdf in Tarrant county}

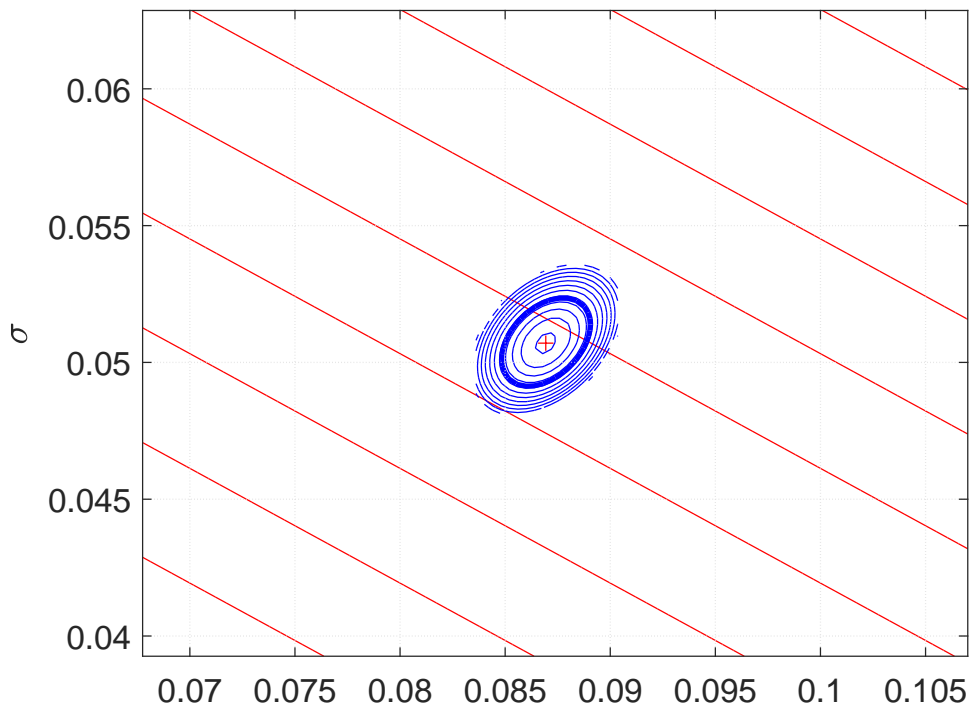

MLE $=$ Maximum Likelihood Estimate, $95 \%$ CI for $\mu$ and $\sigma$ after $\mu_{.00}$ yrs 


\section{Tarrant county after 7.00 yrs}

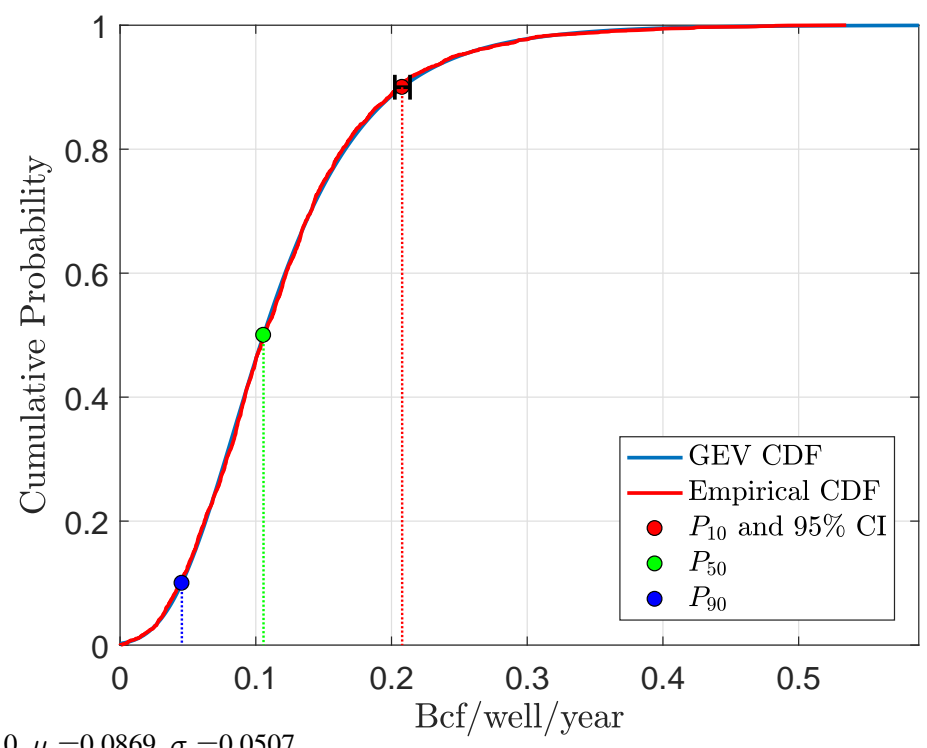

GEV cdf: $\xi=0.0510, \mu=0.0869, \sigma=0.0507$ 


\section{Tarrant county after 8 yrs}

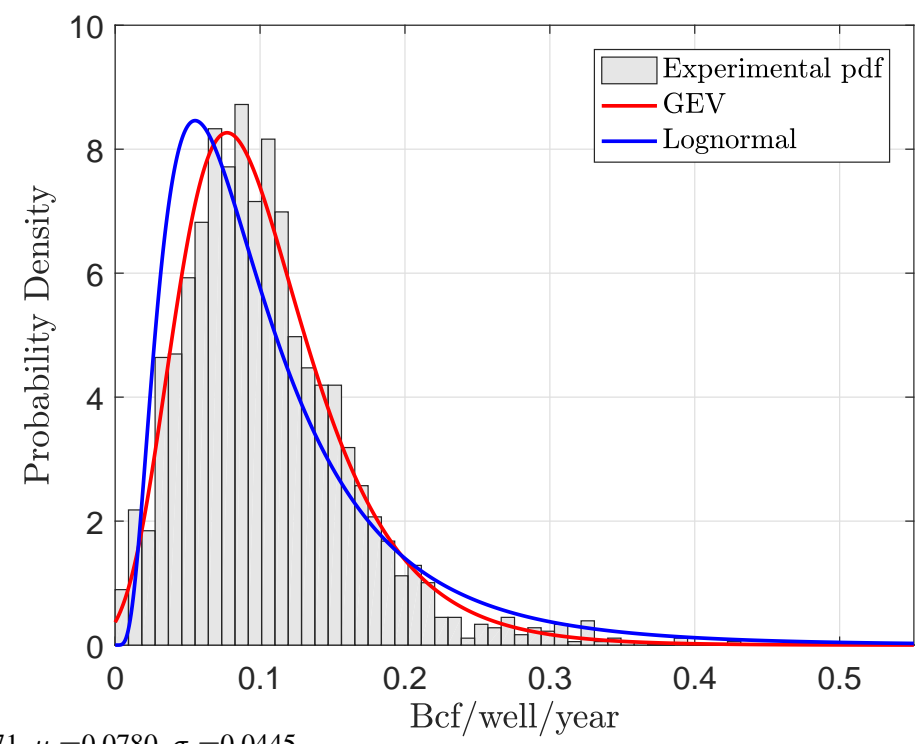

GEV pdf: $\xi=0.0171, \mu=0.0780, \sigma=0.0445$ 


\section{MLE of GEV pdf in Tarrant county}

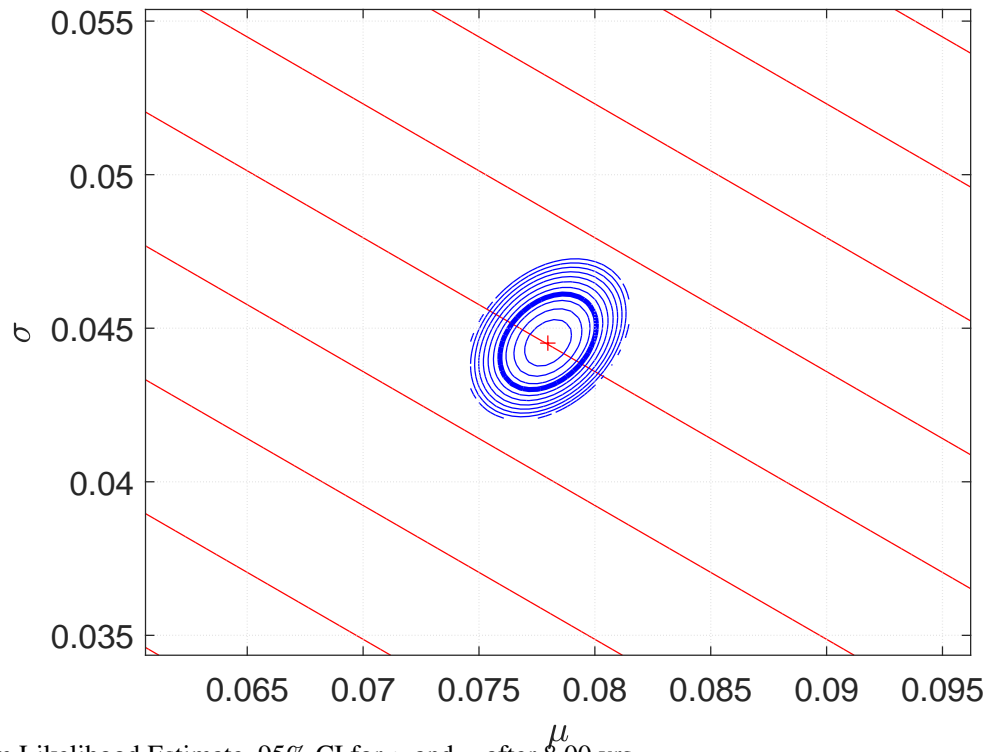

MLE $=$ Maximum Likelihood Estimate, $95 \%$ CI for $\mu$ and $\sigma$ after $8.00 \mathrm{yrs}$ 


\section{Tarrant county after 8.00 yrs}

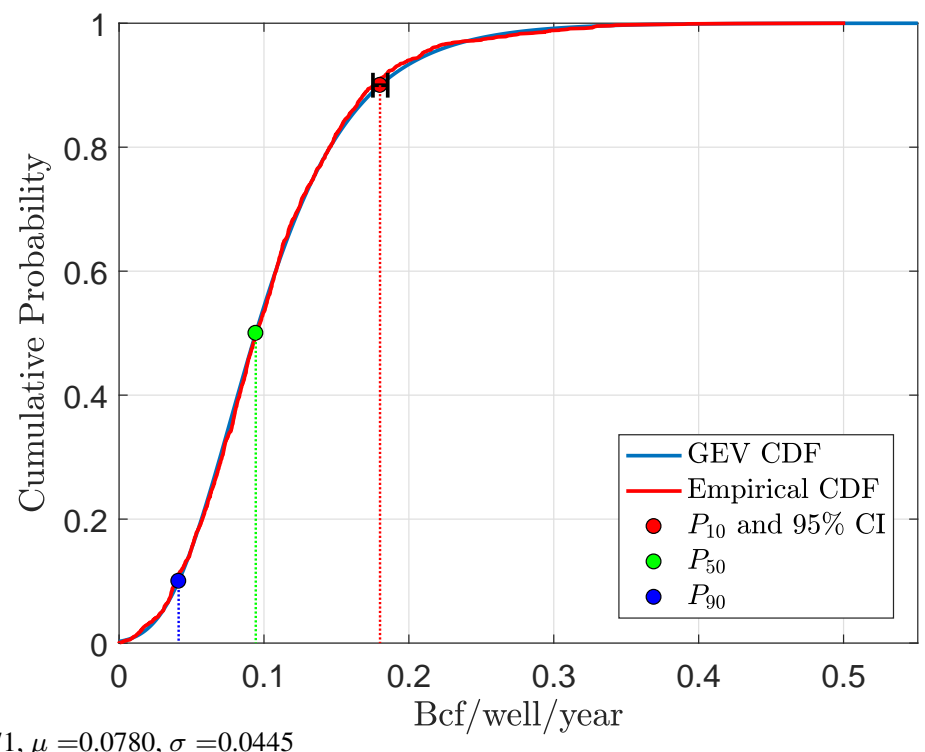

GEV cdf: $\xi=0.0171, \mu=0.0780, \sigma=0.0445$ 


\section{Tarrant county after 9 yrs}

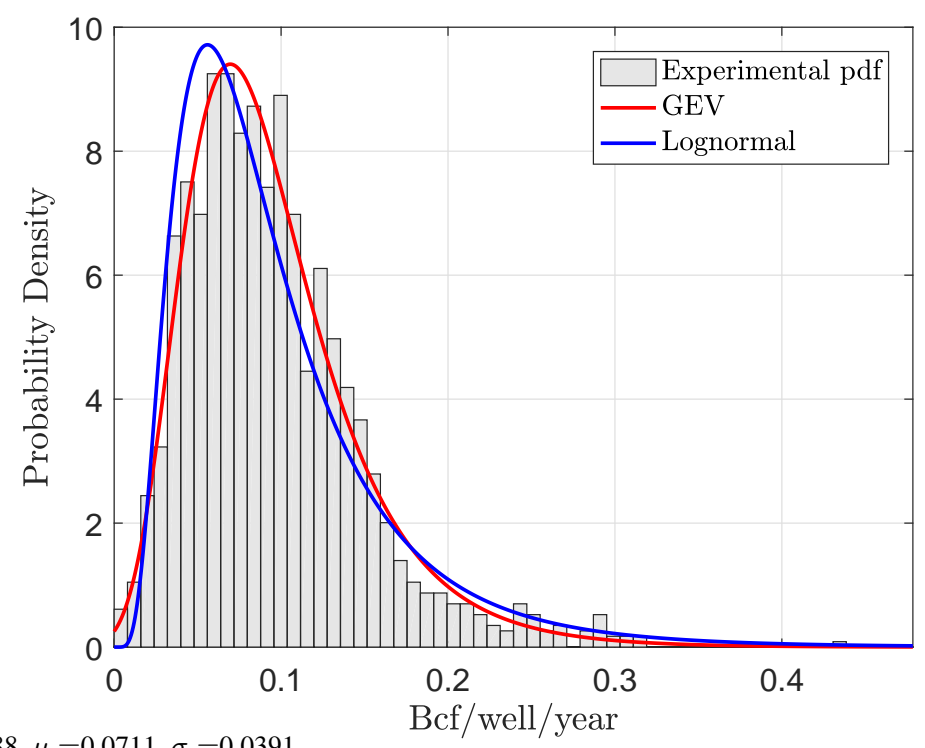

GEV pdf: $\xi=0.0388, \mu=0.0711, \sigma=0.0391$ 


\section{MLE of GEV pdf in Tarrant county}

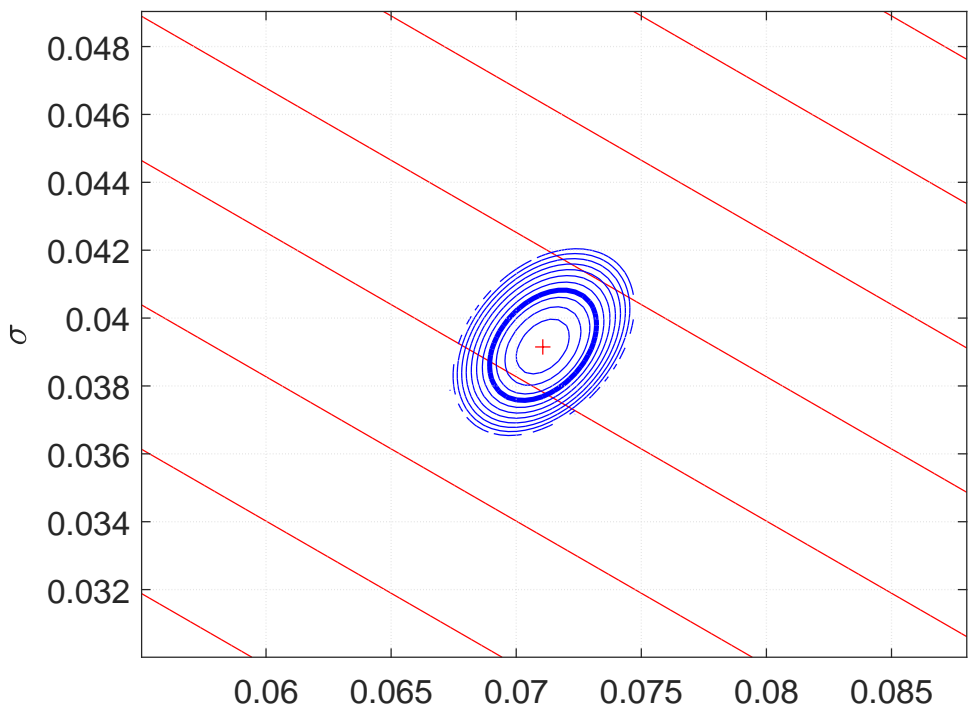

MLE $=$ Maximum Likelihood Estimate, $95 \%$ CI for $\mu$ and $\sigma$ after 9.00 yrs 


\section{Tarrant county after 9.00 yrs}

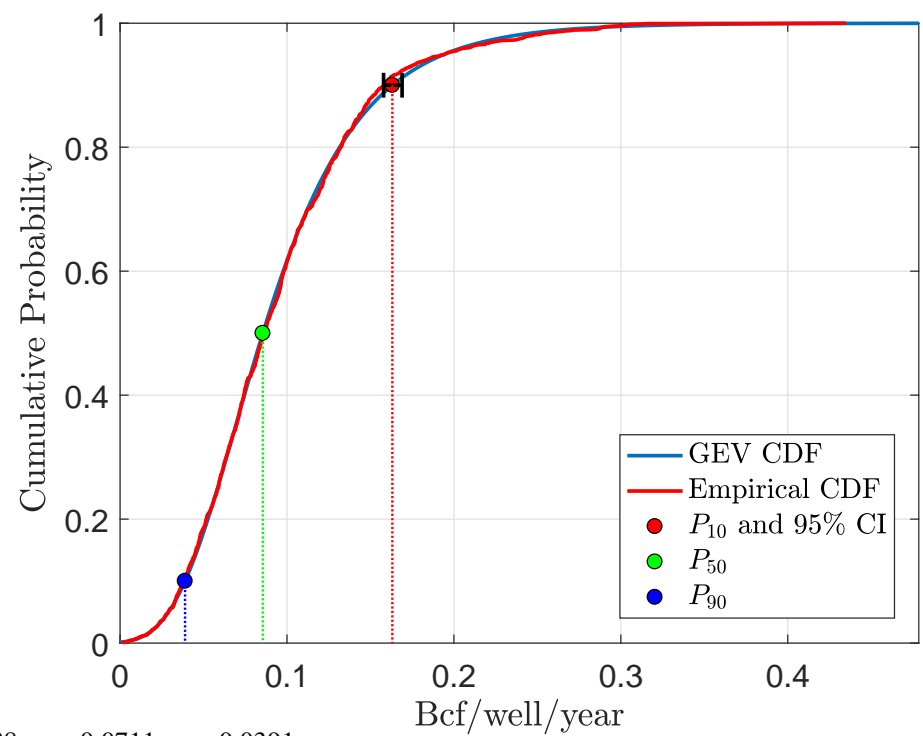

GEV cdf: $\xi=0.0388, \mu=0.0711, \sigma=0.0391$ 


\section{Tarrant county after 10 yrs}

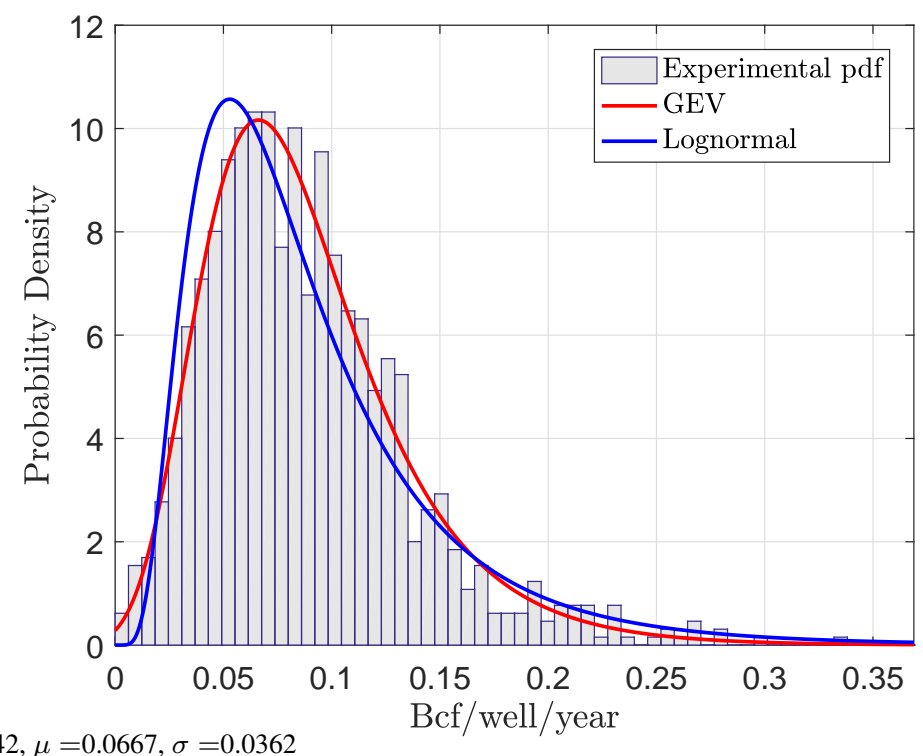

GEV pdf: $\xi=0.0142, \mu=0.0667, \sigma=0.0362$ 


\section{MLE of GEV pdf in Tarrant county}

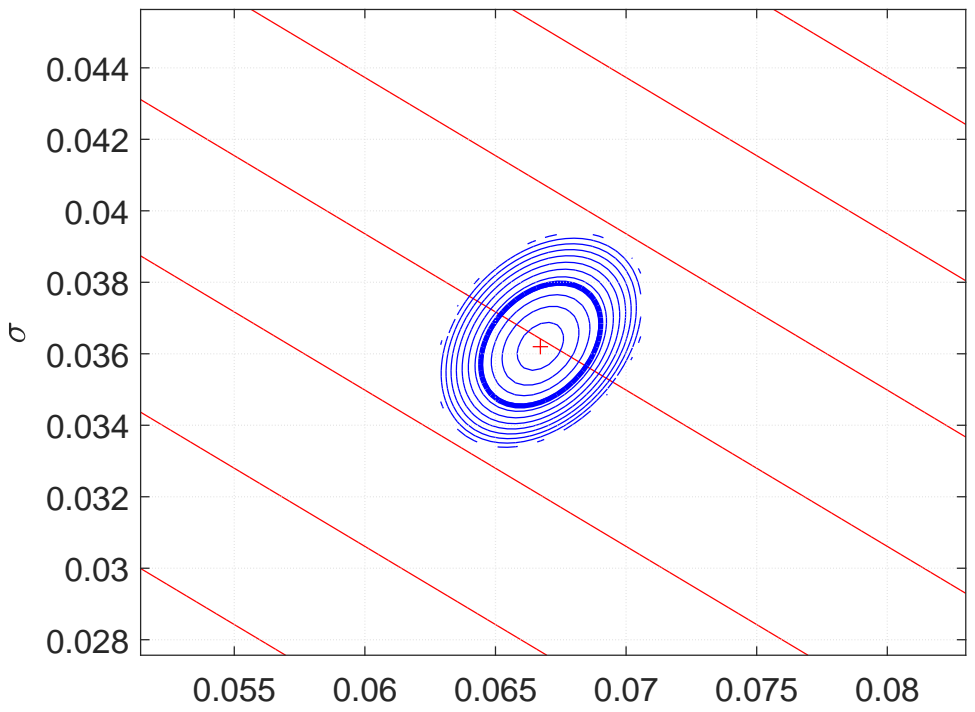

MLE $=$ Maximum Likelihood Estimate, $95 \%$ CI for $\mu$ and $\sigma$ after $1 \stackrel{\mu}{\mu} 0.00$ yrs 


\section{Tarrant county after 10.00 yrs}

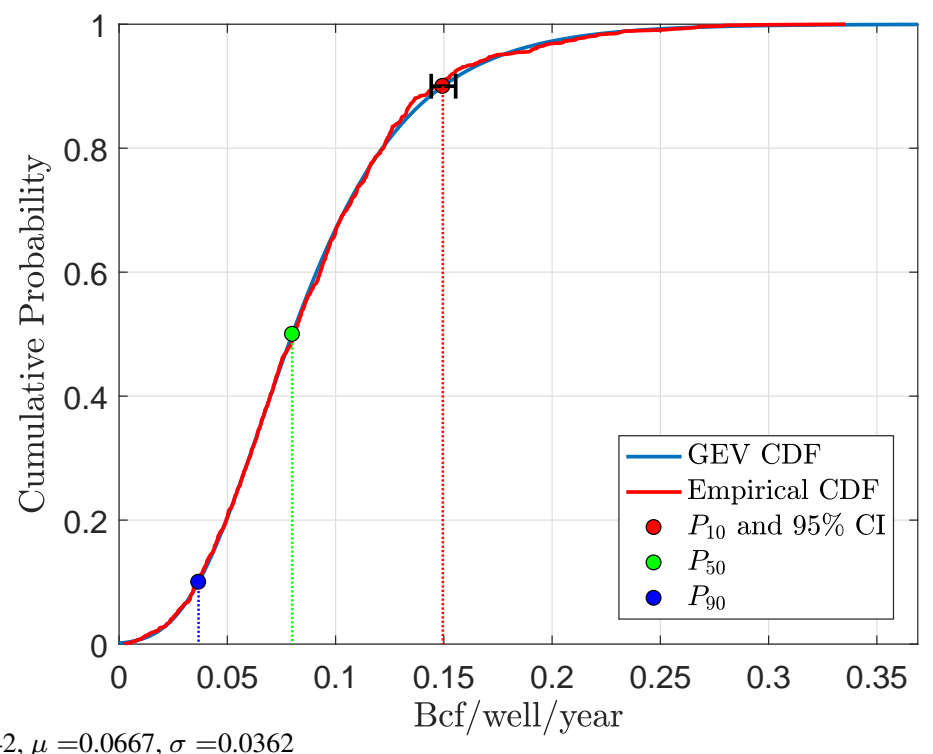

GEV cdf: $\xi=0.0142, \mu=0.0667, \sigma=0.0362$ 


\section{Tarrant county after 11 yrs}

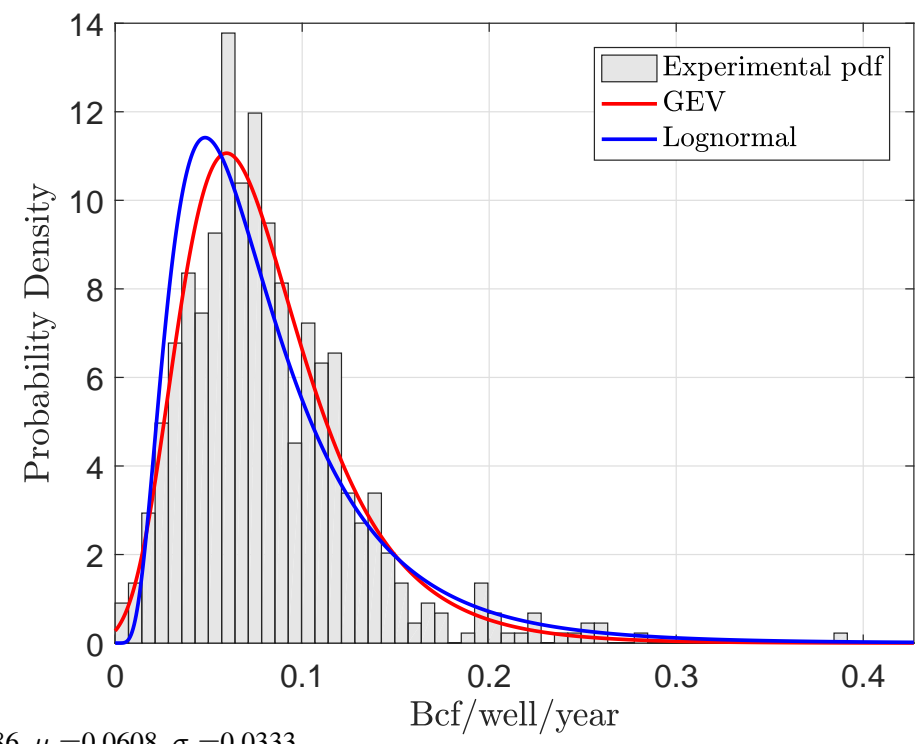

GEV pdf: $\xi=0.0386, \mu=0.0608, \sigma=0.0333$ 


\section{MLE of GEV pdf in Tarrant county}

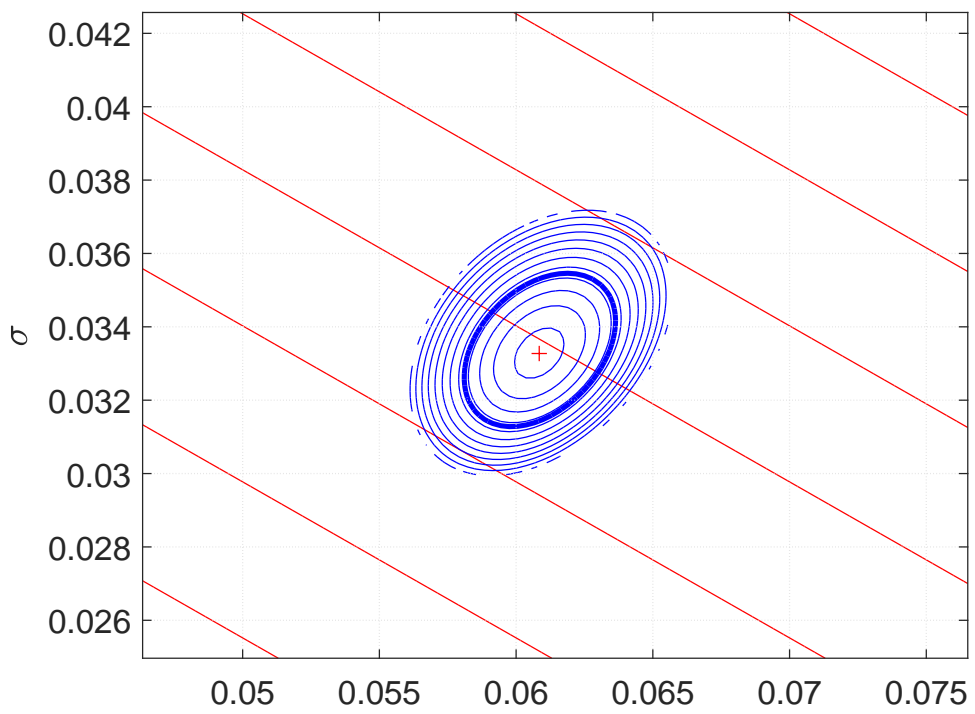

MLE = Maximum Likelihood Estimate, $95 \% \mathrm{CI}$ for $\mu$ and $\sigma$ after $11.00 \mathrm{yrs}$ 


\section{Tarrant county after 11.00 yrs}

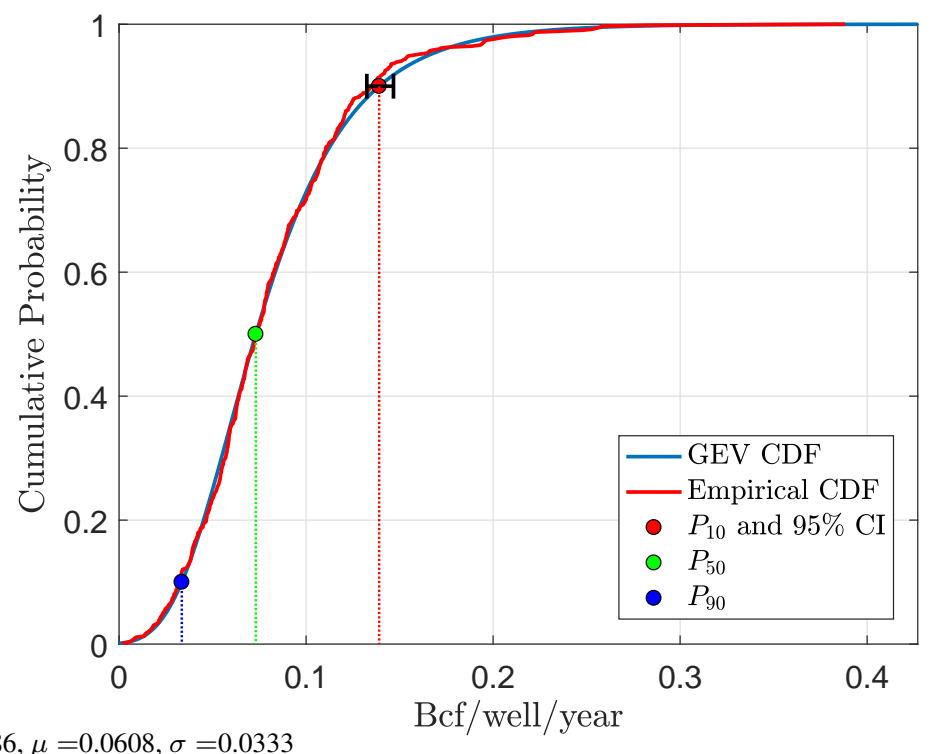

GEV cdf: $\xi=0.0386, \mu=0.0608, \sigma=0.0333$ 


\section{Tarrant county after 12 yrs}

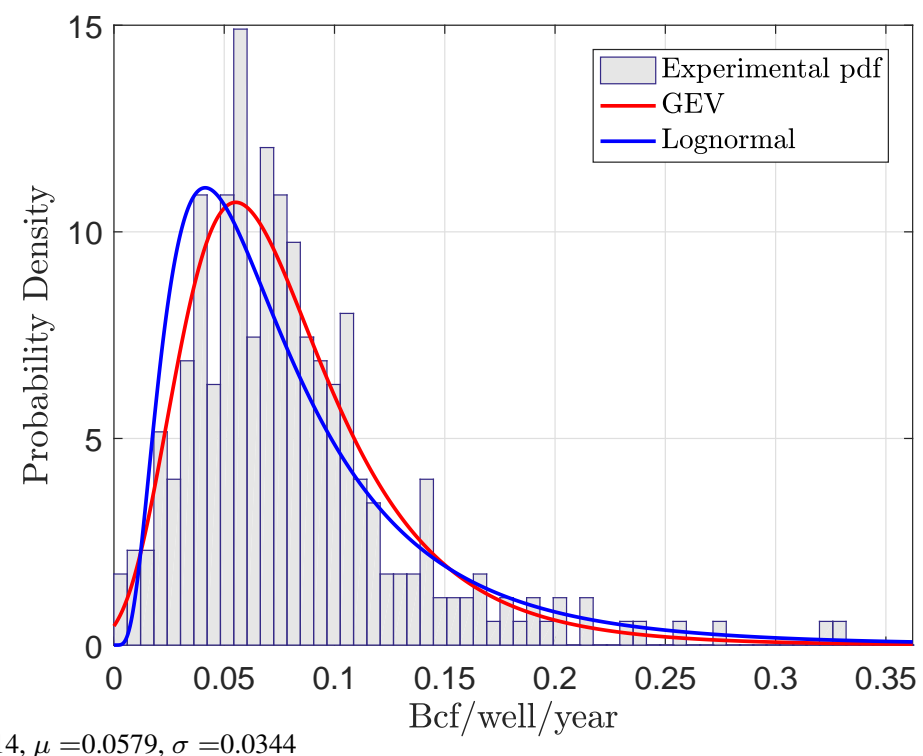

GEV pdf: $\xi=0.0814, \mu=0.0579, \sigma=0.0344$ 


\section{MLE of GEV pdf in Tarrant county}

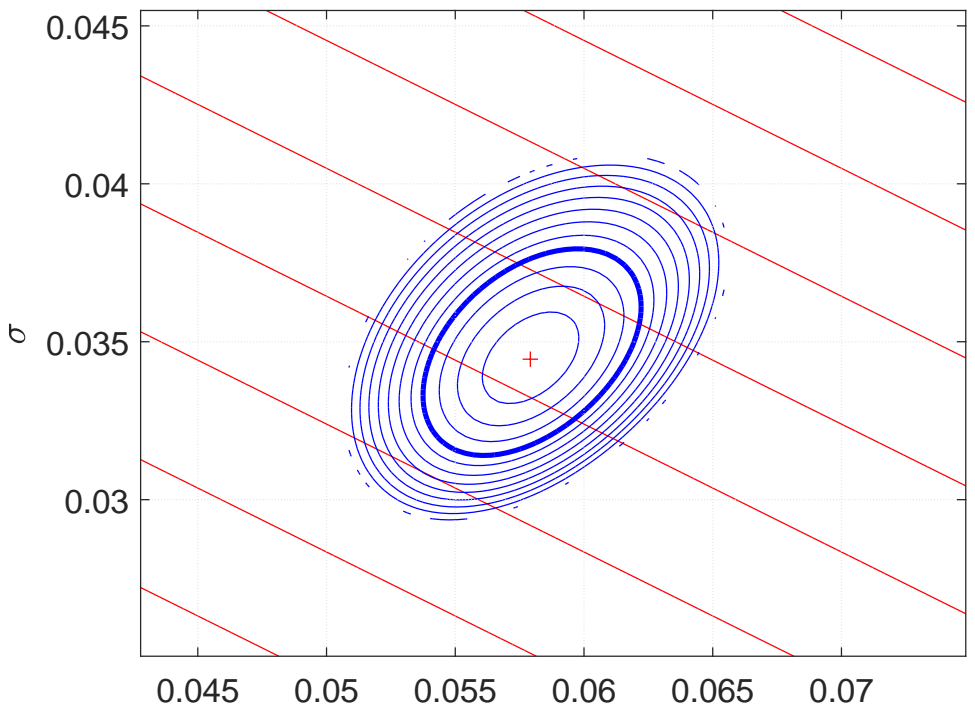

MLE = Maximum Likelihood Estimate, 95\% CI for $\mu$ and $\sigma$ after 12.00 yrs 


\section{Tarrant county after 12.00 yrs}

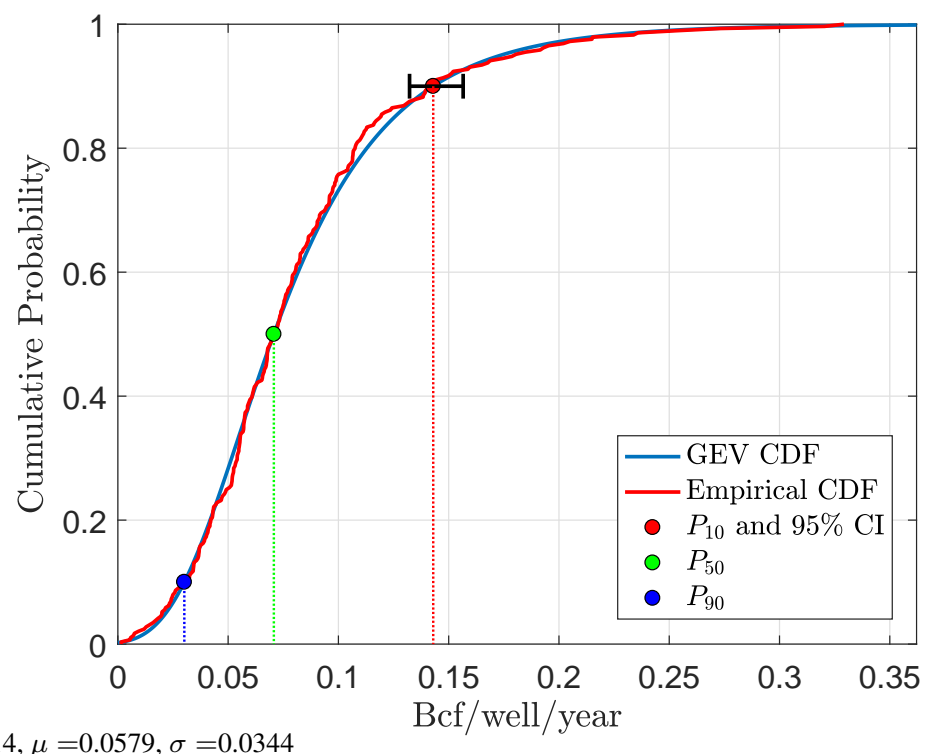

GEV cdf: $\xi=0.0814, \mu=0.0579, \sigma=0.0344$ 


\section{Tarrant county after 13 yrs}

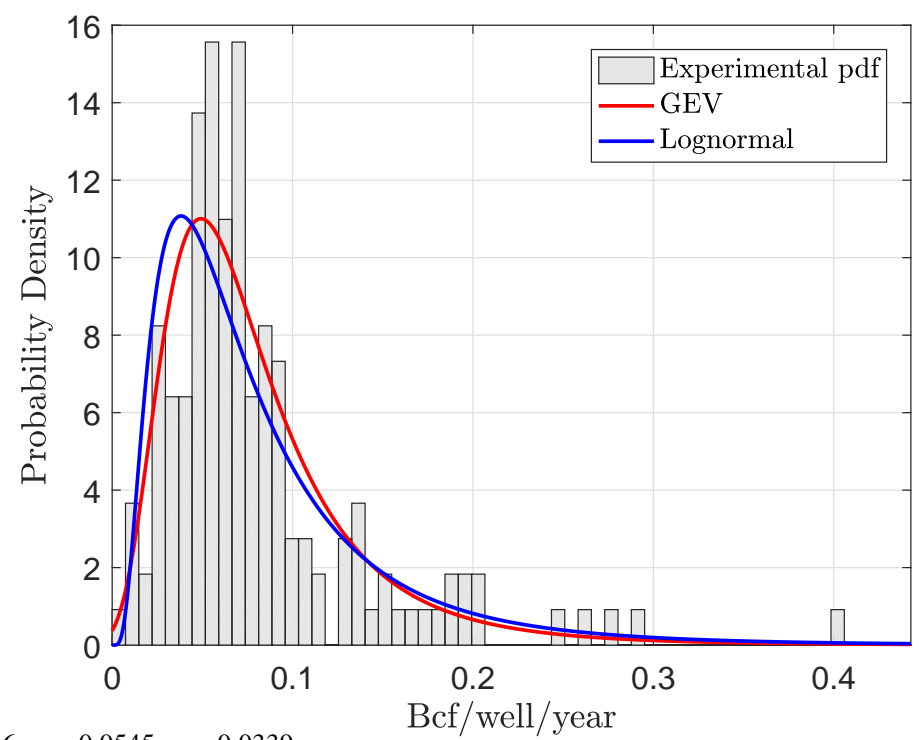

GEV pdf: $\xi=0.1736, \mu=0.0545, \sigma=0.0339$ 


\section{MLE of GEV pdf in Tarrant county}

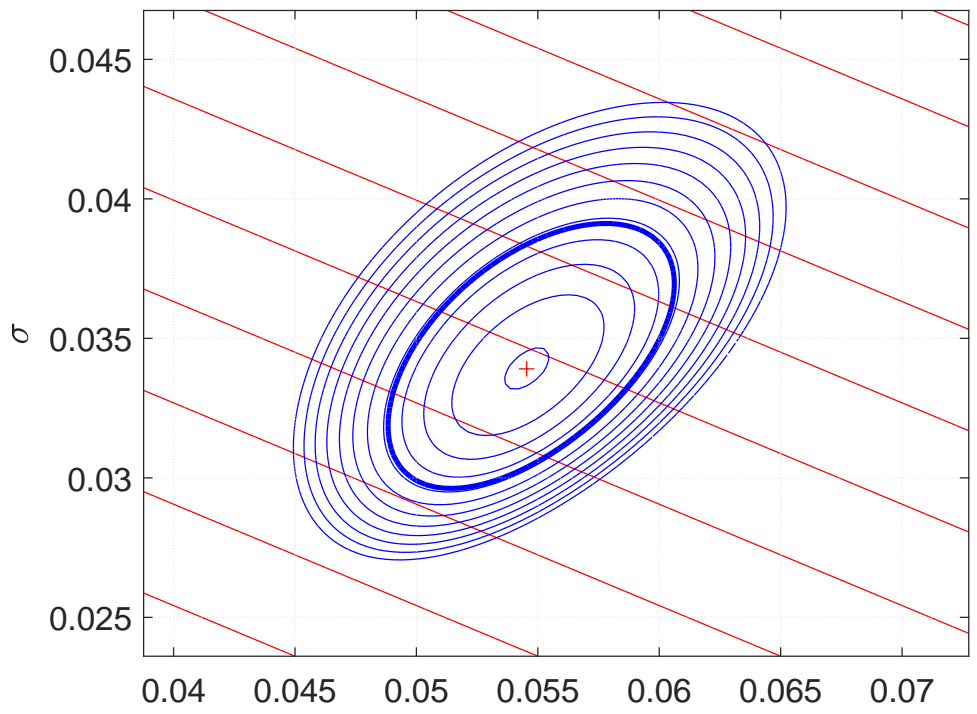

MLE = Maximum Likelihood Estimate, $95 \% \mathrm{CI}$ for $\mu$ and $\sigma$ after $13.00 \mathrm{yrs}$ 


\section{Tarrant county after 13.00 yrs}

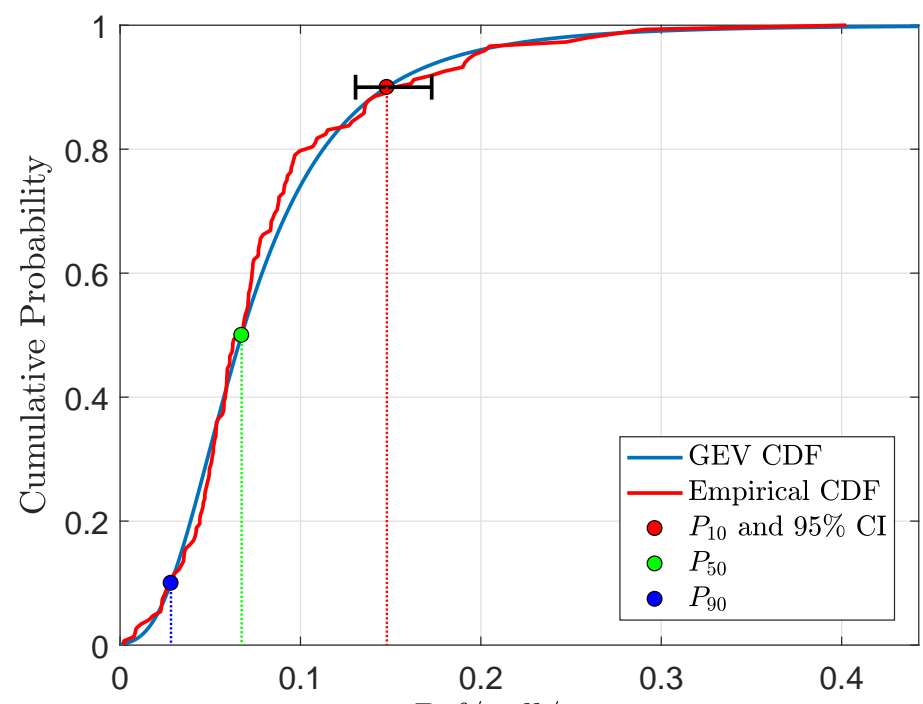

GEV cdf: $\xi=0.1736, \mu=0.0545, \sigma=0.0339$

Bcf/well/year 


\section{Tarrant county after 14 yrs}

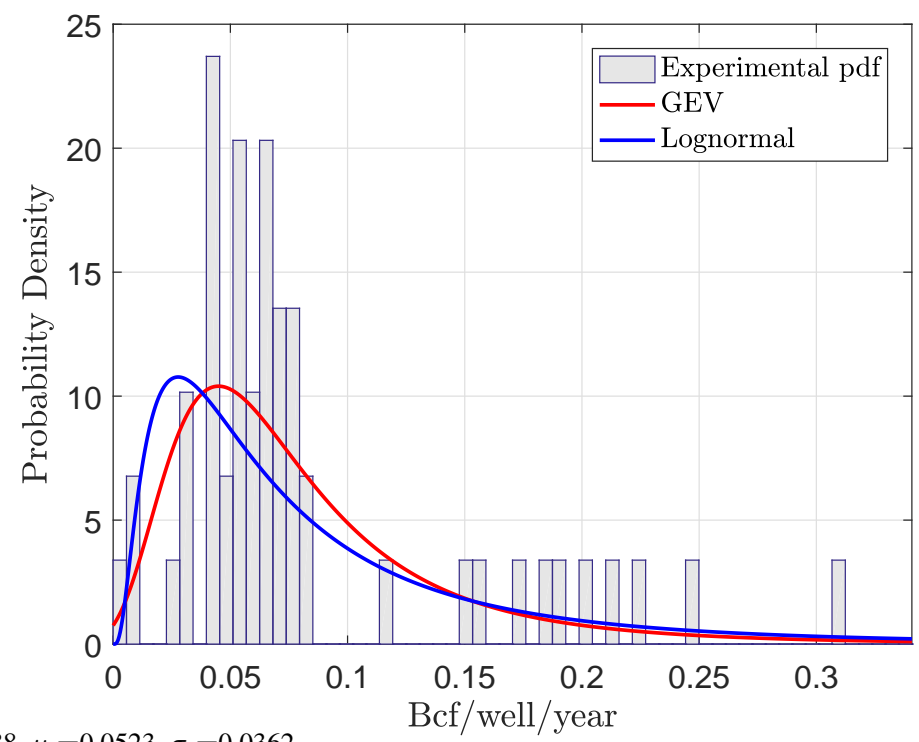

GEV pdf: $\xi=0.2288, \mu=0.0523, \sigma=0.0362$ 


\section{MLE of GEV pdf in Tarrant county}

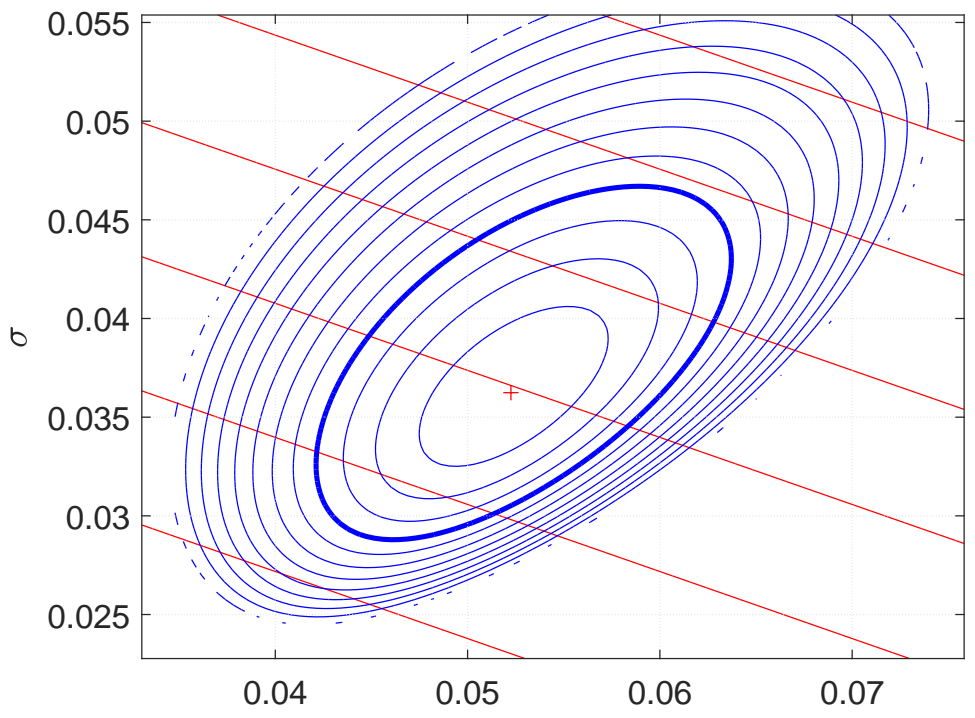

MLE = Maximum Likelihood Estimate, 95\% CI for $\mu$ and $\sigma$ after 14.00 yrs 


\section{Tarrant county after 14.00 yrs}

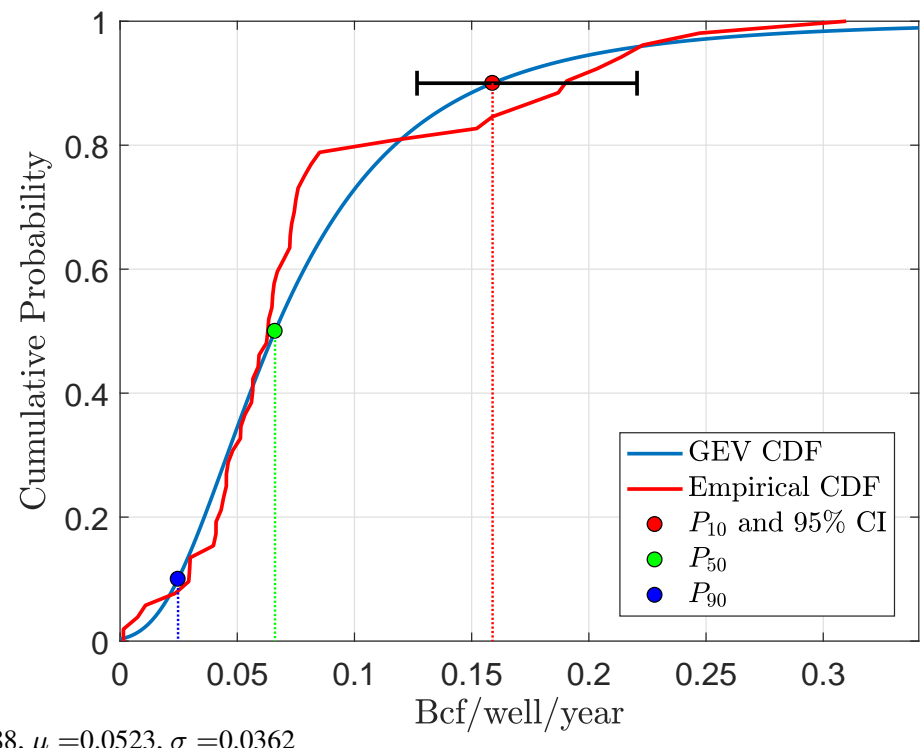

GEV cdf: $\xi=0.2288, \mu=0.0523, \sigma=0.0362$ 


\section{Johnson county after 1 yrs}

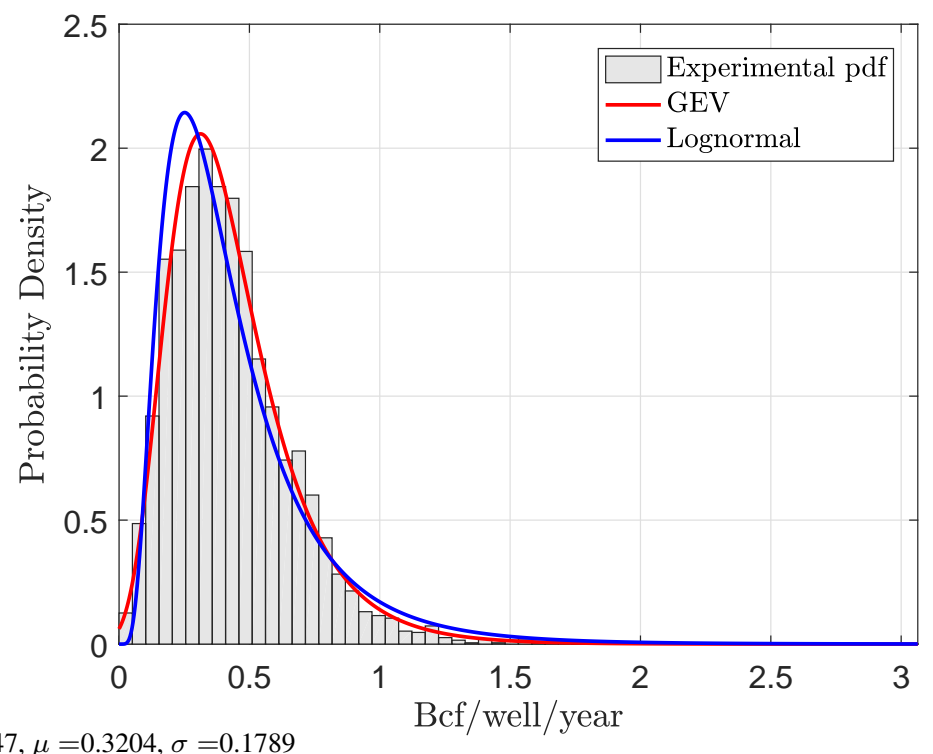

GEV pdf: $\xi=0.0447, \mu=0.3204, \sigma=0.1789$ 


\section{MLE of GEV pdf in Johnson county}

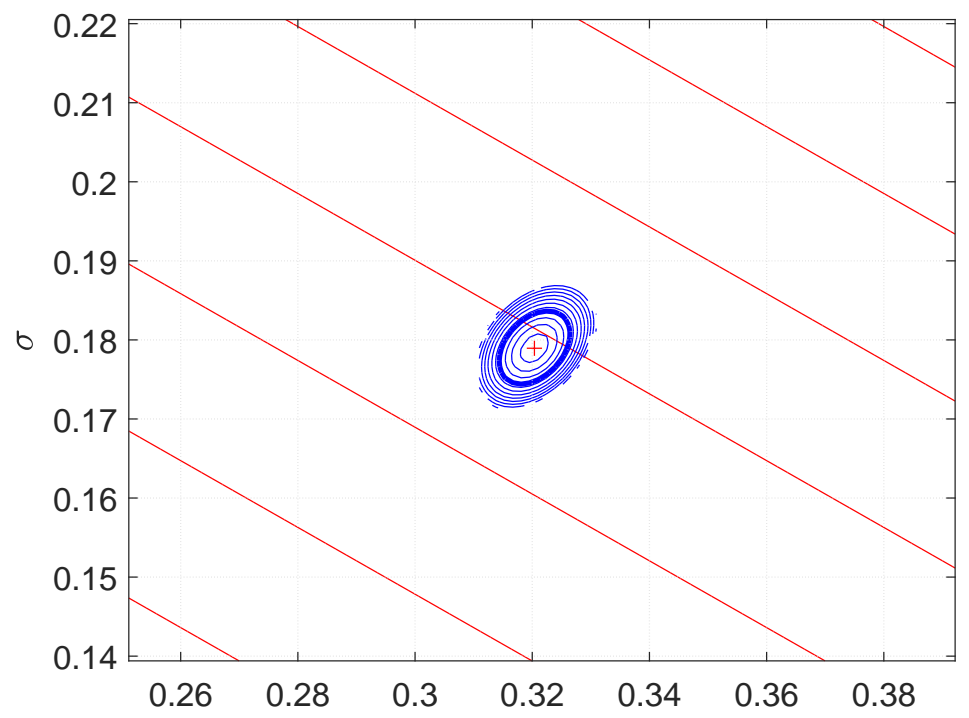

MLE $=$ Maximum Likelihood Estimate, $95 \%$ CI for $\mu$ and $\sigma$ after $1.00 \mathrm{yrs}$ 


\section{Johnson county after 1.00 yrs}

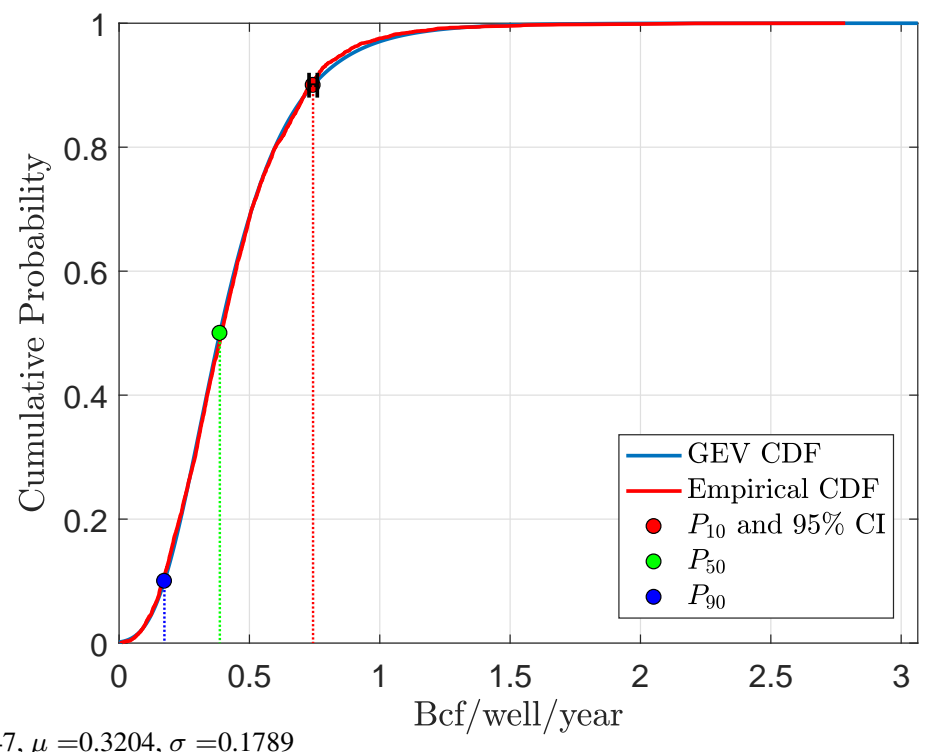

GEV cdf: $\xi=0.0447, \mu=0.3204, \sigma=0.1789$ 


\section{Johnson county after 2 yrs}

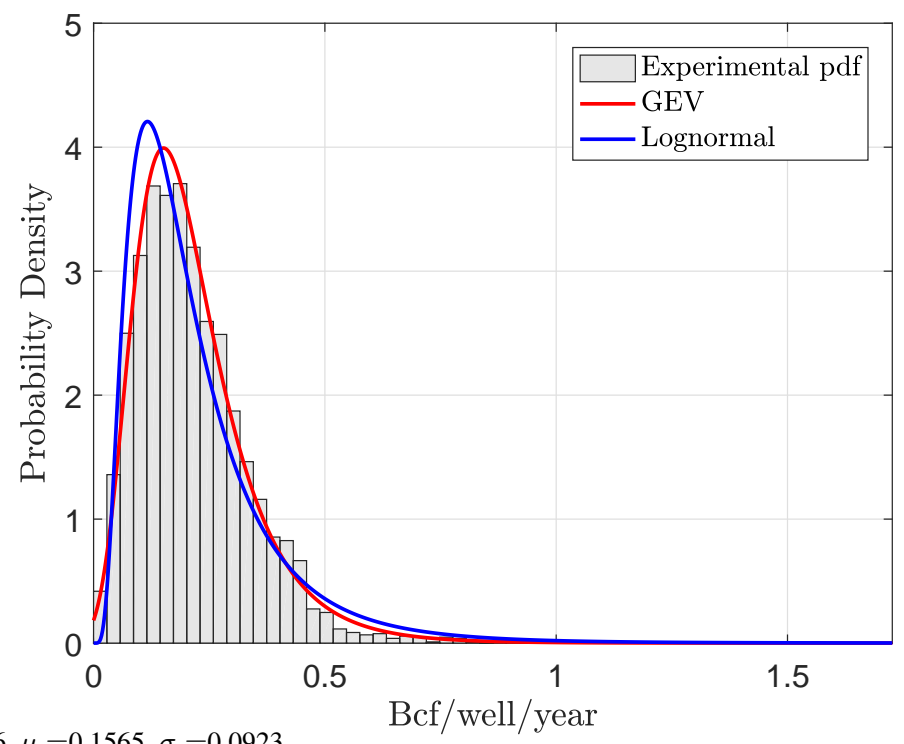

GEV pdf: $\xi=0.0596, \mu=0.1565, \sigma=0.0923$ 


\section{MLE of GEV pdf in Johnson county}

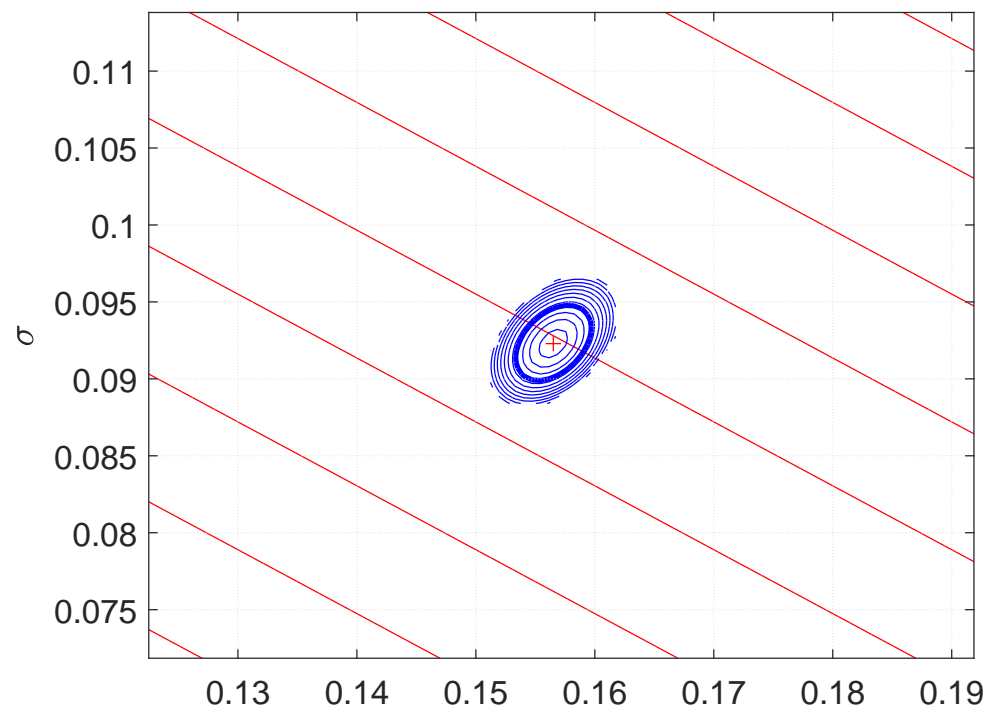

MLE $=$ Maximum Likelihood Estimate, $95 \%$ CI for $\mu$ and $\sigma$ after $\stackrel{\mu}{2.00}$ yrs 


\section{Johnson county after 2.00 yrs}

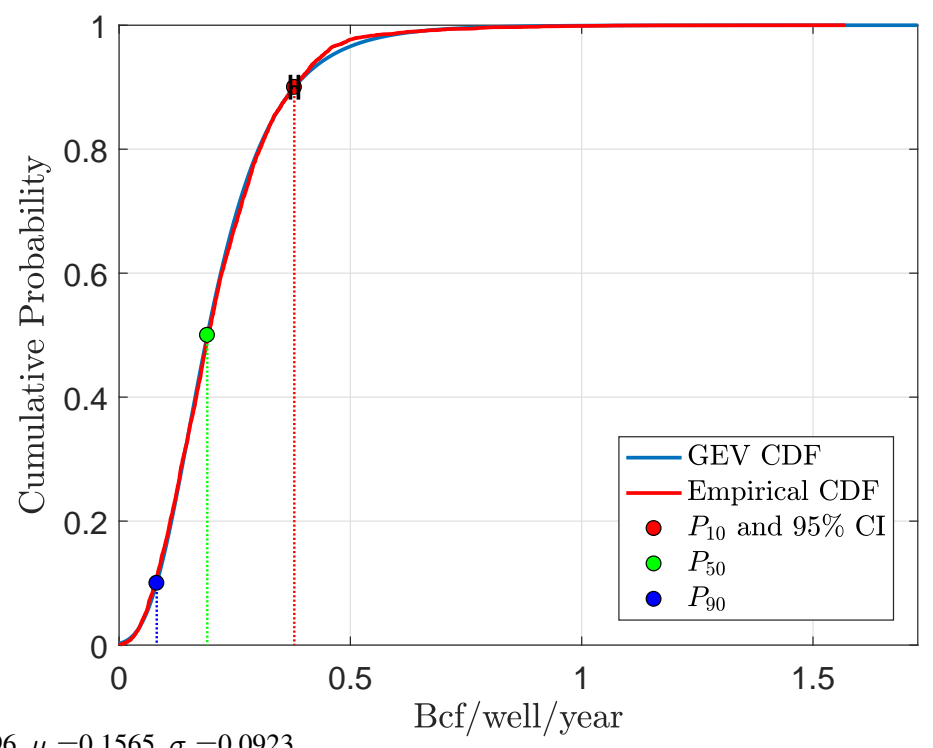

GEV cdf: $\xi=0.0596, \mu=0.1565, \sigma=0.0923$ 


\section{Johnson county after 3 yrs}

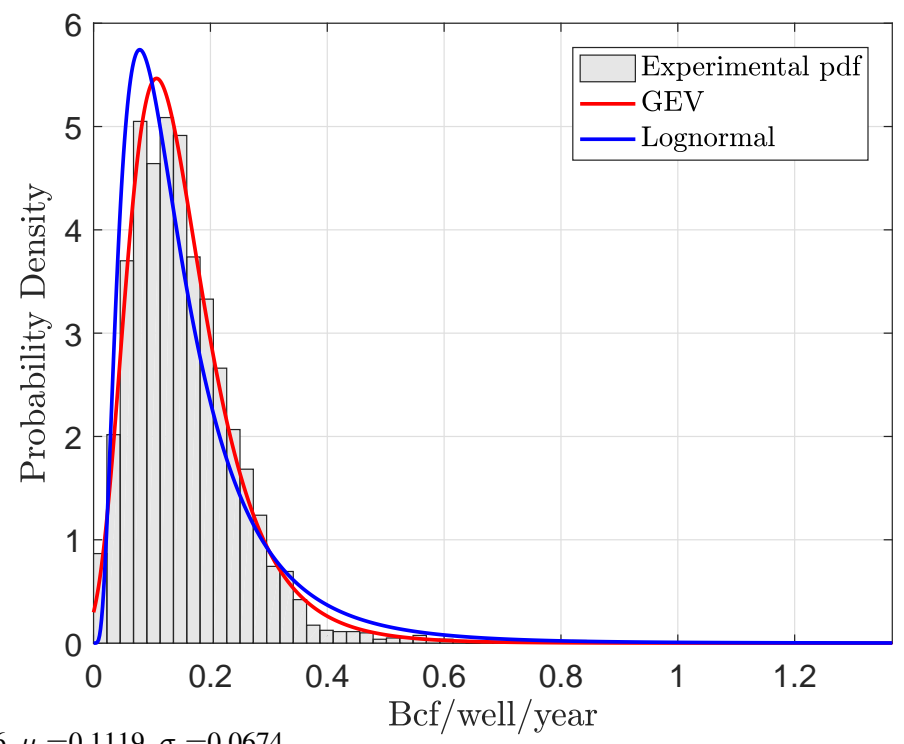

GEV pdf: $\xi=0.0636, \mu=0.1119, \sigma=0.0674$ 


\section{MLE of GEV pdf in Johnson county}

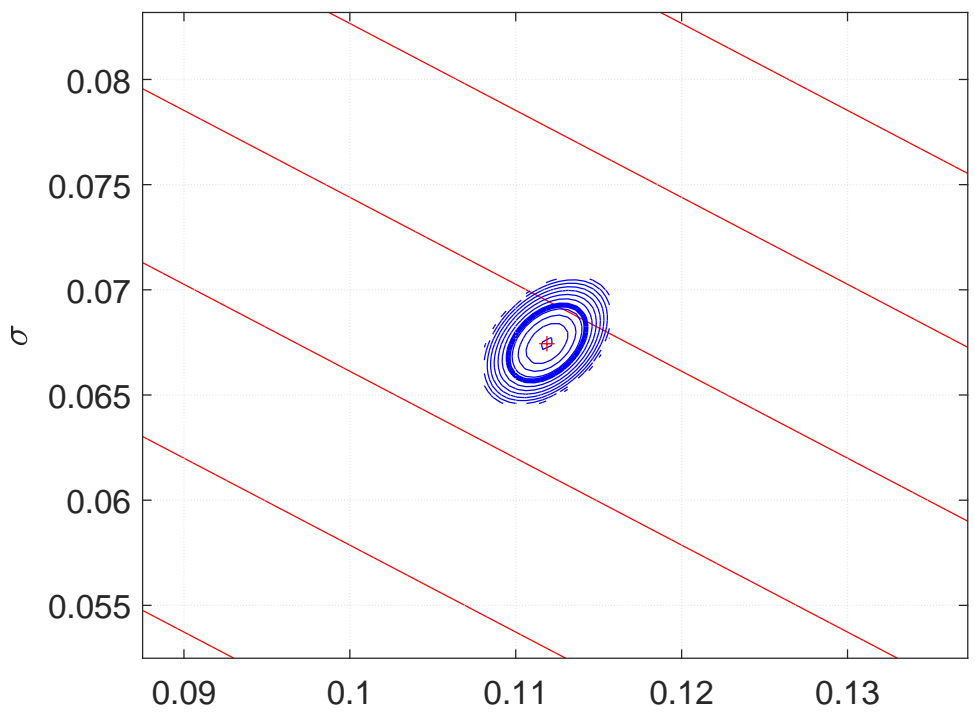

MLE $=$ Maximum Likelihood Estimate, $95 \%$ CI for $\mu$ and $\sigma$ after 3.00 yrs 


\section{Johnson county after 3.00 yrs}

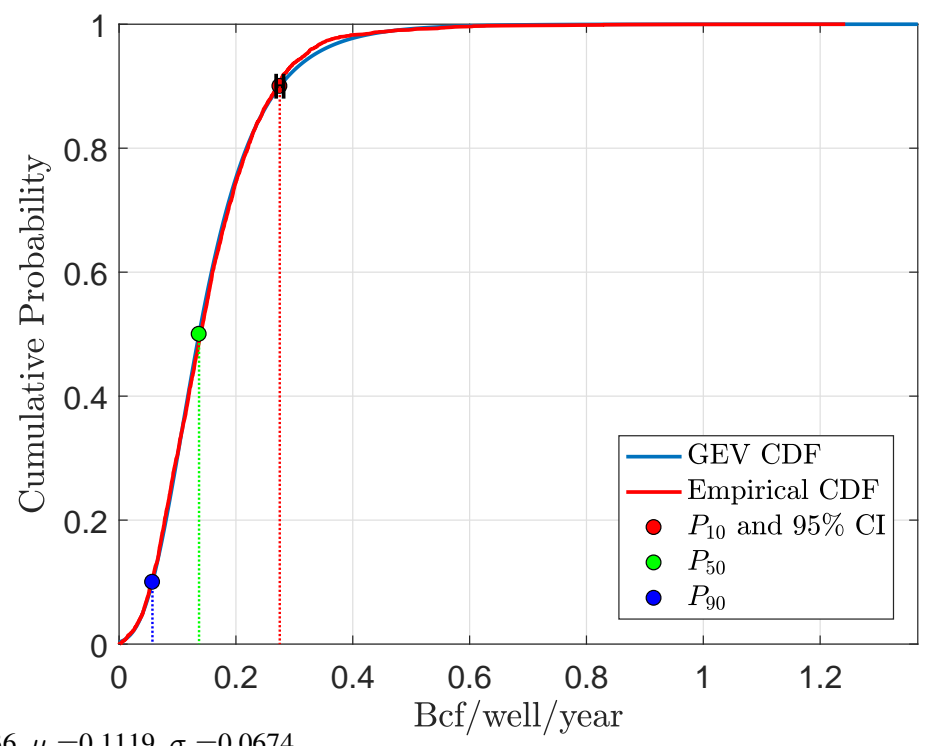

GEV cdf: $\xi=0.0636, \mu=0.1119, \sigma=0.0674$ 


\section{Johnson county after 4 yrs}

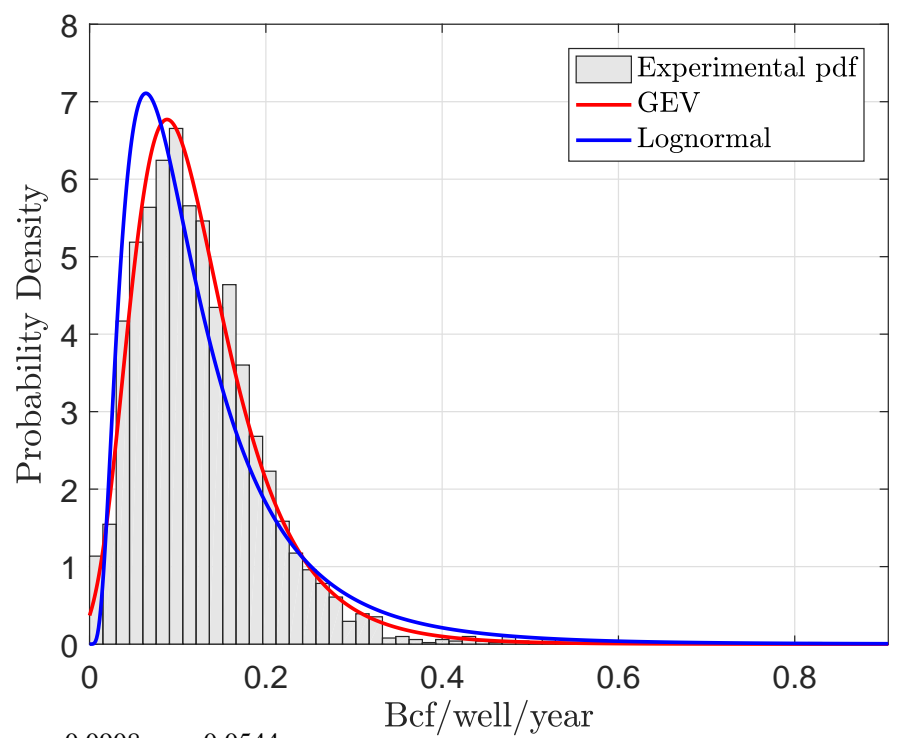

GEV pdf: $\xi=0.0551, \mu=0.0908, \sigma=0.0544$ 


\section{MLE of GEV pdf in Johnson county}

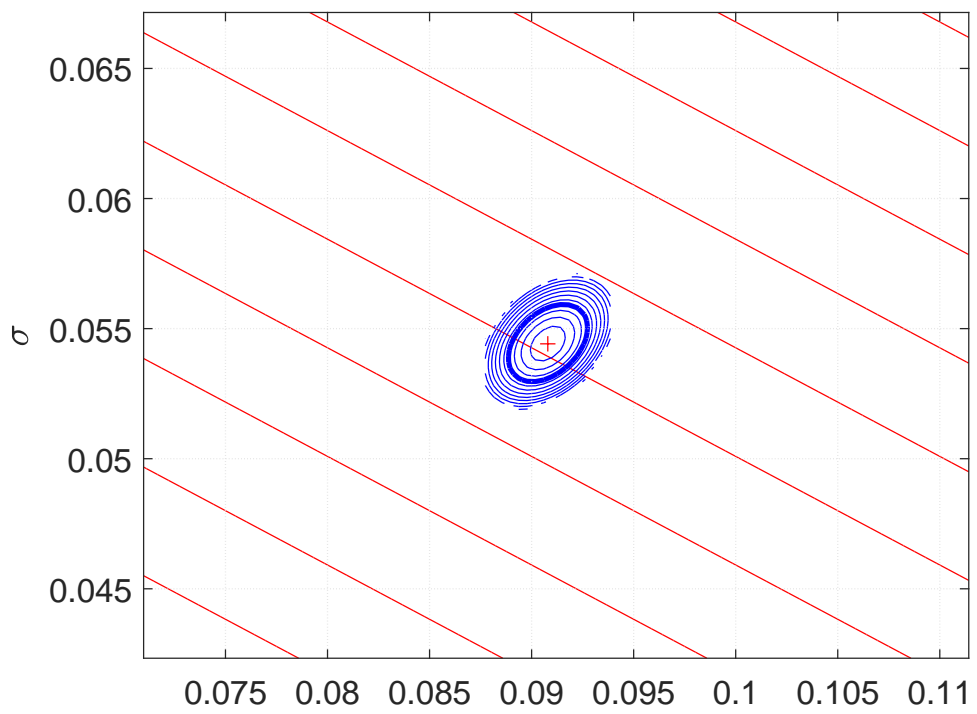

MLE $=$ Maximum Likelihood Estimate, $95 \%$ CI for $\mu$ and $\sigma$ after $4.00 \mathrm{yrs}$ 


\section{Johnson county after 4.00 yrs}

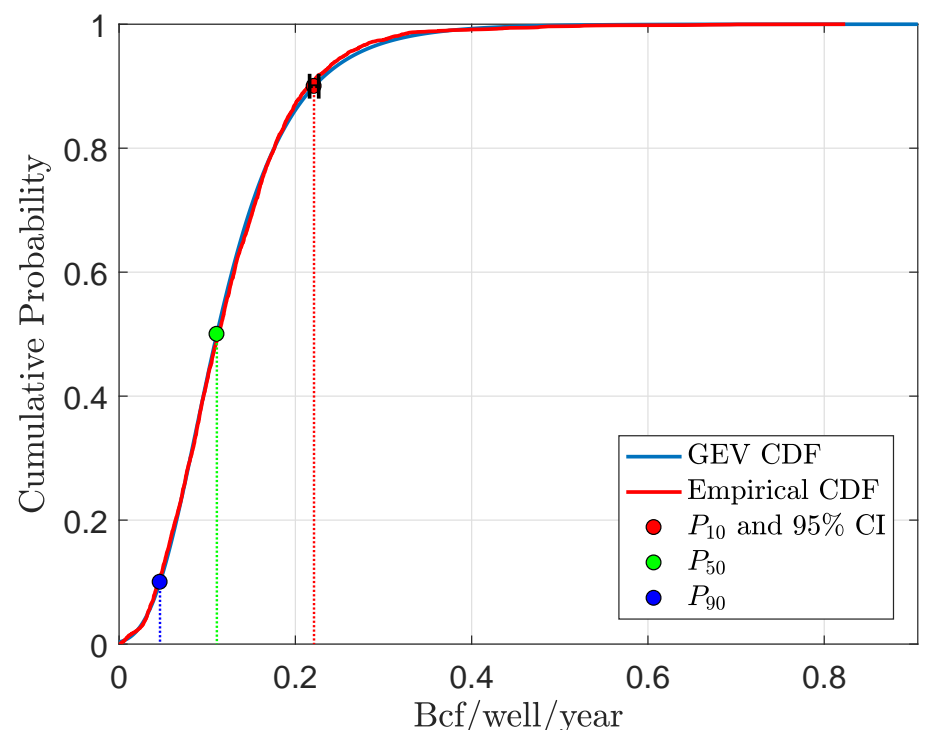

GEV cdf: $\xi=0.0551, \mu=0.0908, \sigma=0.0544$ 


\section{Johnson county after 5 yrs}

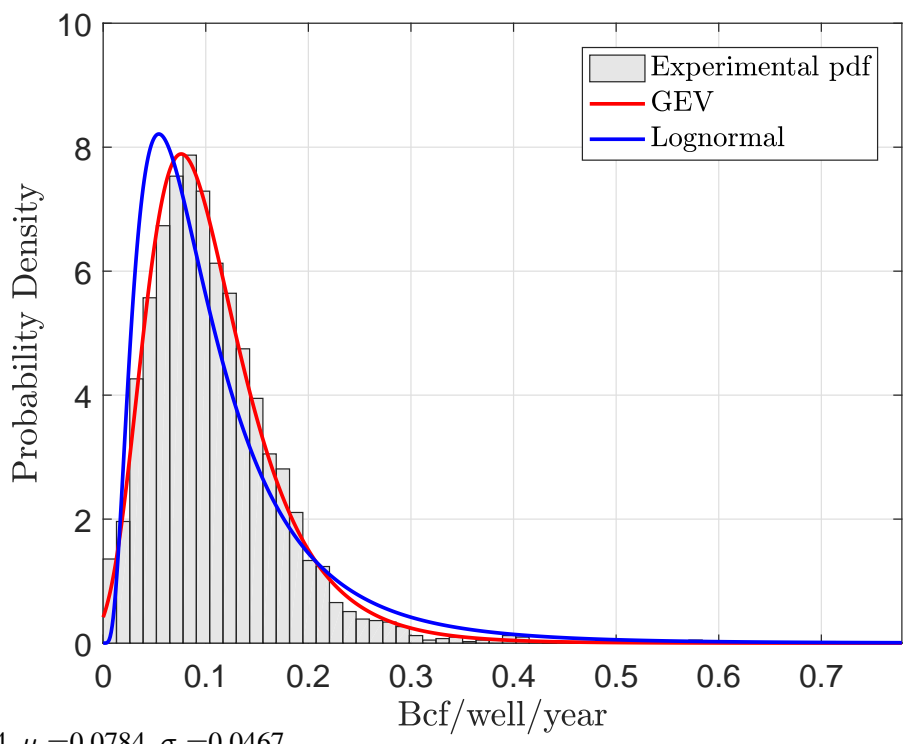

GEV pdf: $\xi=0.0504, \mu=0.0784, \sigma=0.0467$ 


\section{MLE of GEV pdf in Johnson county}

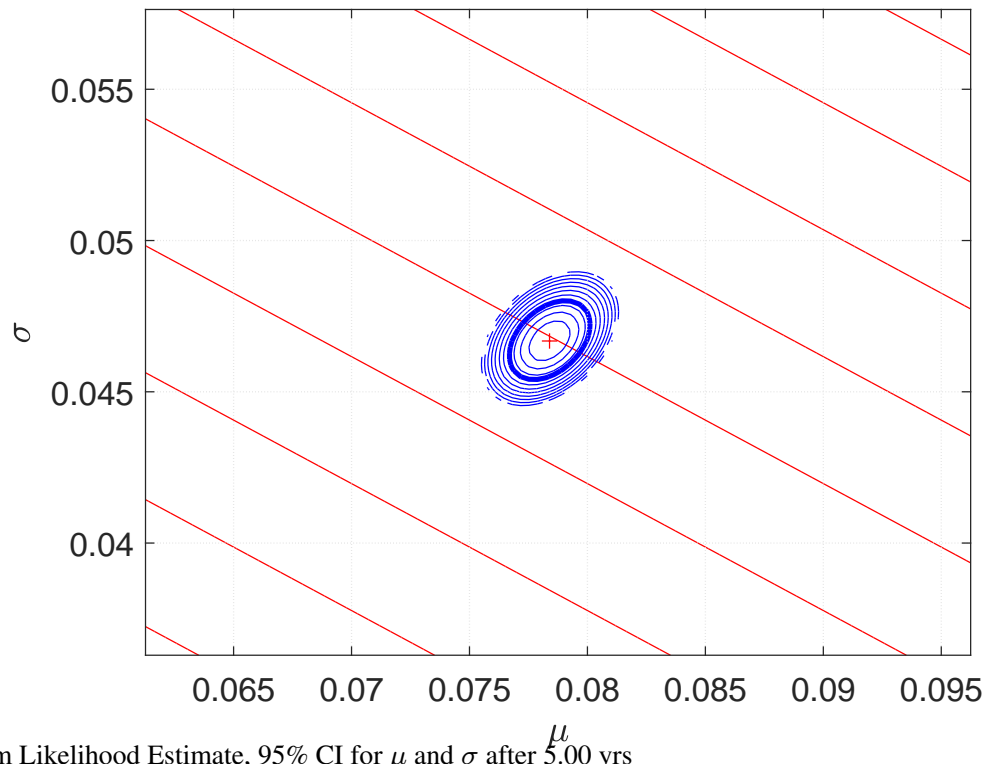

MLE $=$ Maximum Likelihood Estimate, $95 \%$ CI for $\mu$ and $\sigma$ after 5.00 yrs 


\section{Johnson county after 5.00 yrs}

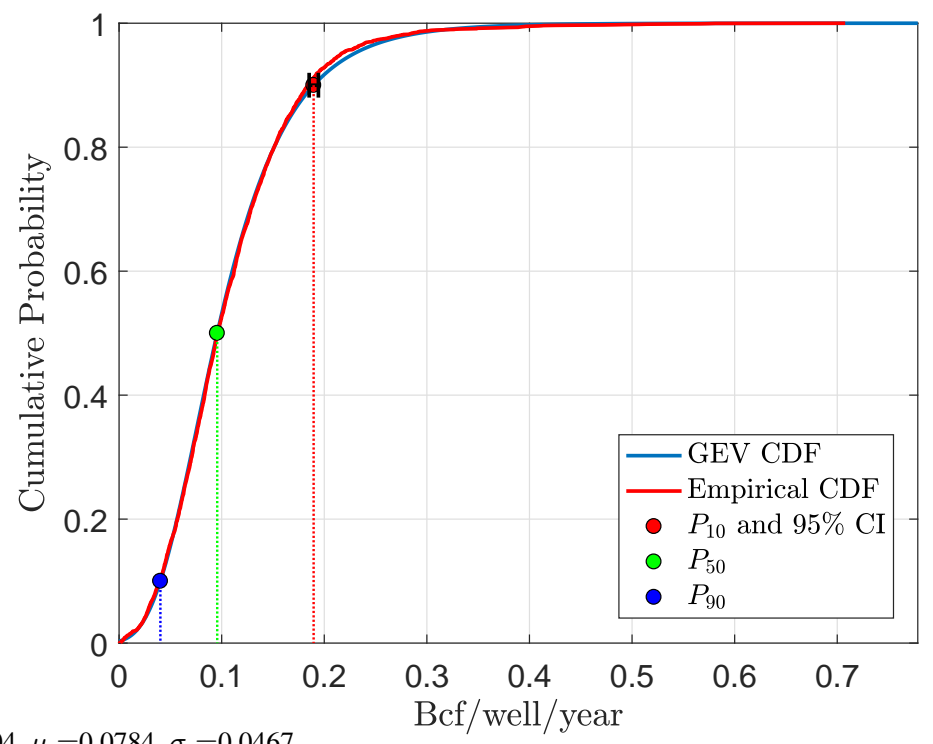

GEV cdf: $\xi=0.0504, \mu=0.0784, \sigma=0.0467$ 


\section{Johnson county after 6 yrs}

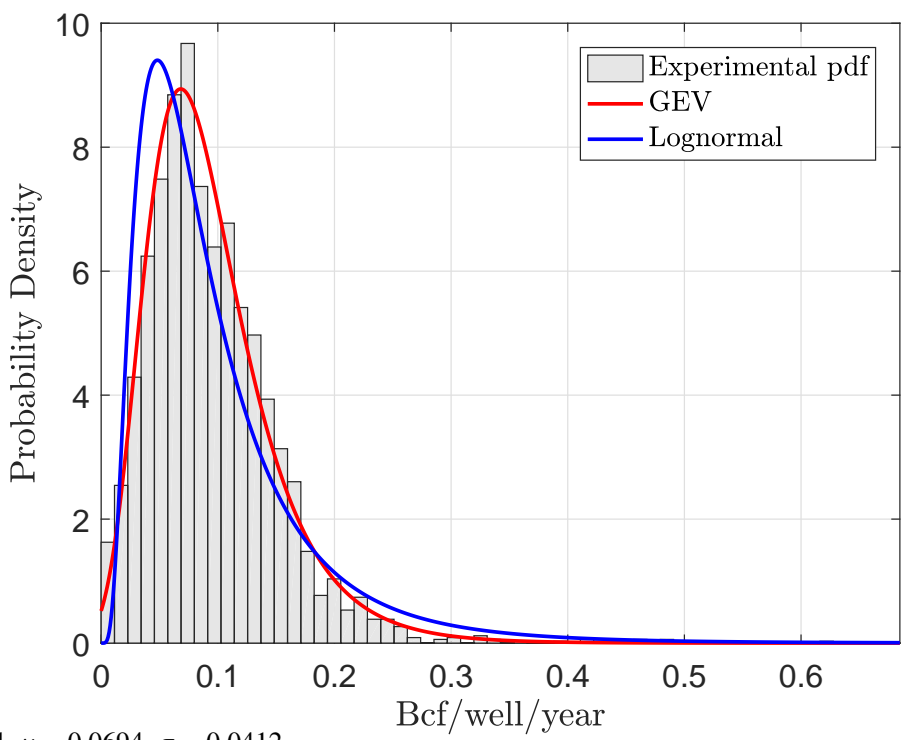

GEV pdf: $\xi=0.0284, \mu=0.0694, \sigma=0.0412$ 


\section{MLE of GEV pdf in Johnson county}

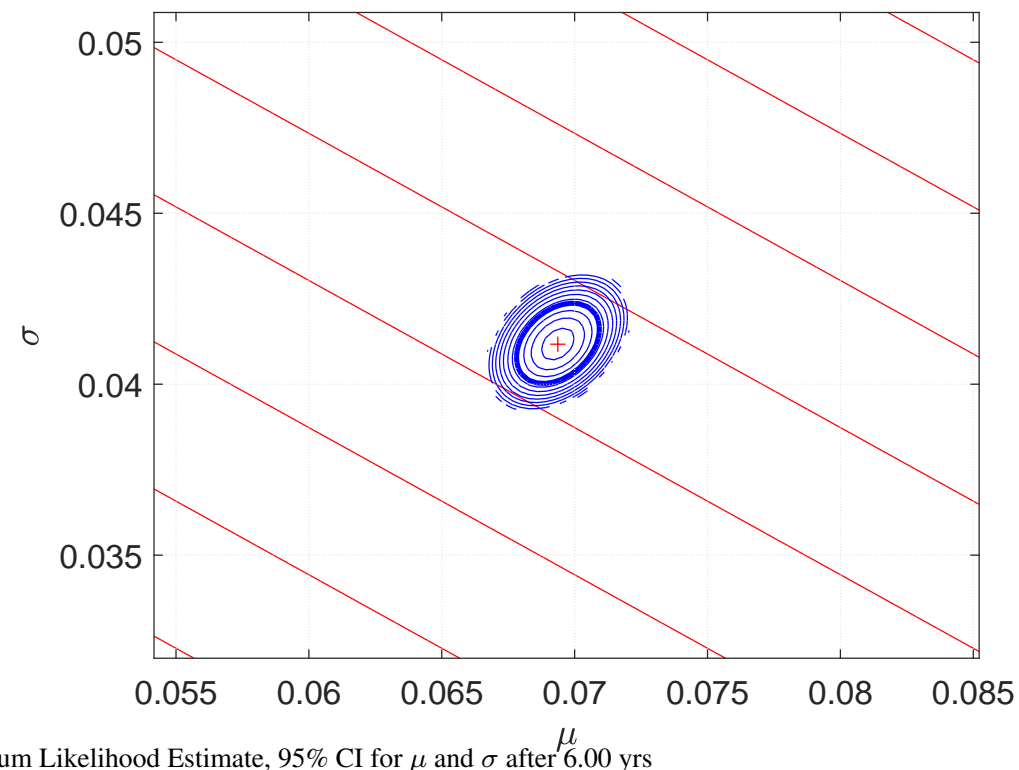

MLE $=$ Maximum Likelihood Estimate, $95 \%$ CI for $\mu$ and $\sigma$ after 6.00 yrs 


\section{Johnson county after 6.00 yrs}

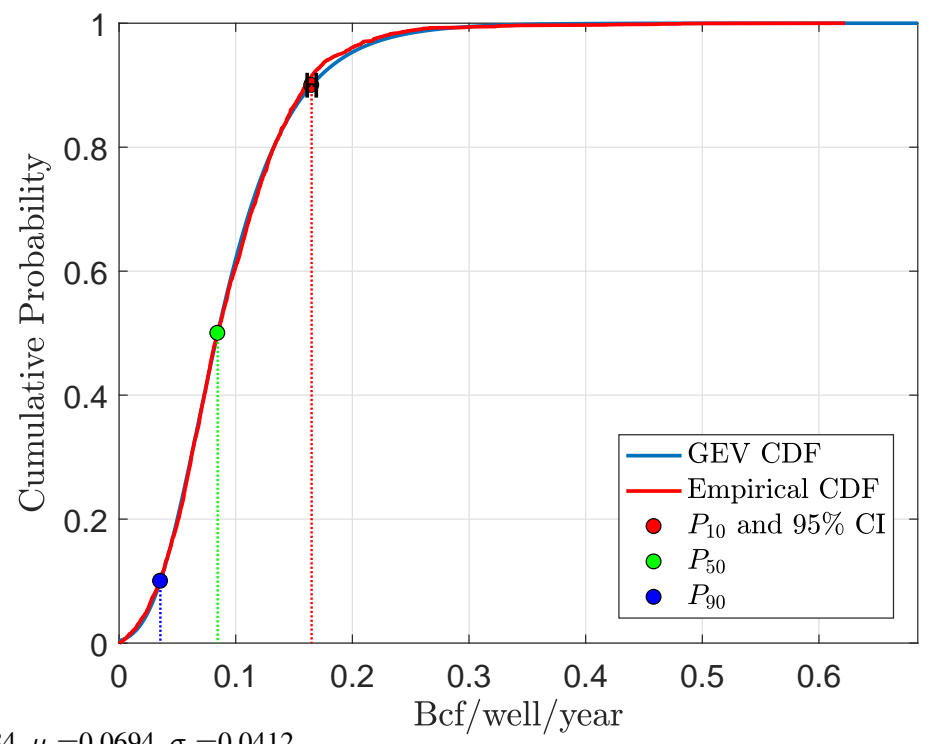

GEV cdf: $\xi=0.0284, \mu=0.0694, \sigma=0.0412$ 


\section{Johnson county after 7 yrs}

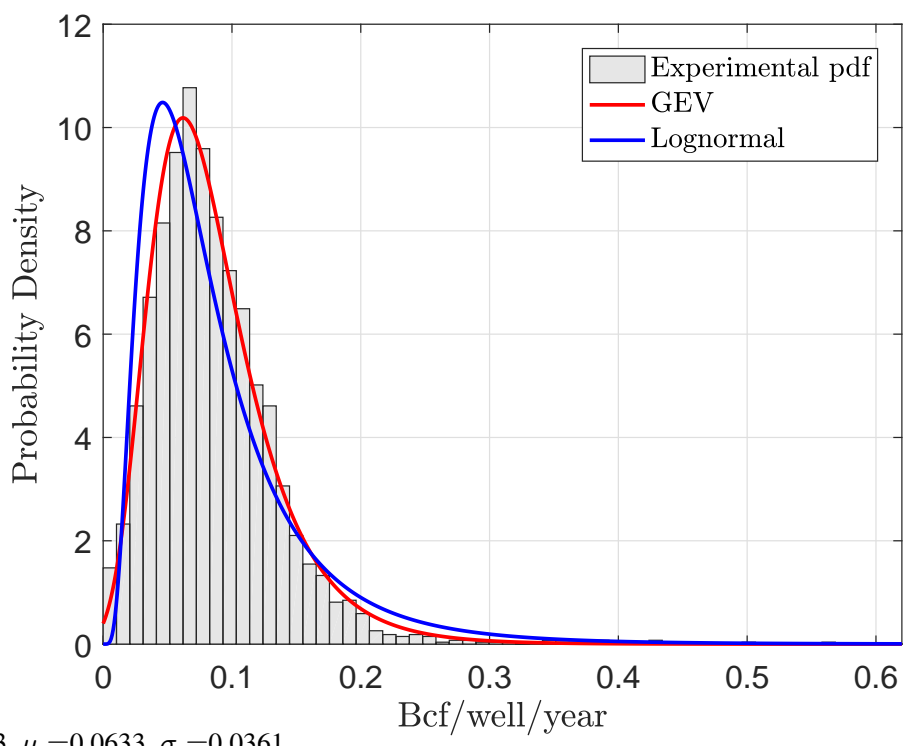

GEV pdf: $\xi=0.0373, \mu=0.0633, \sigma=0.0361$ 


\section{MLE of GEV pdf in Johnson county}

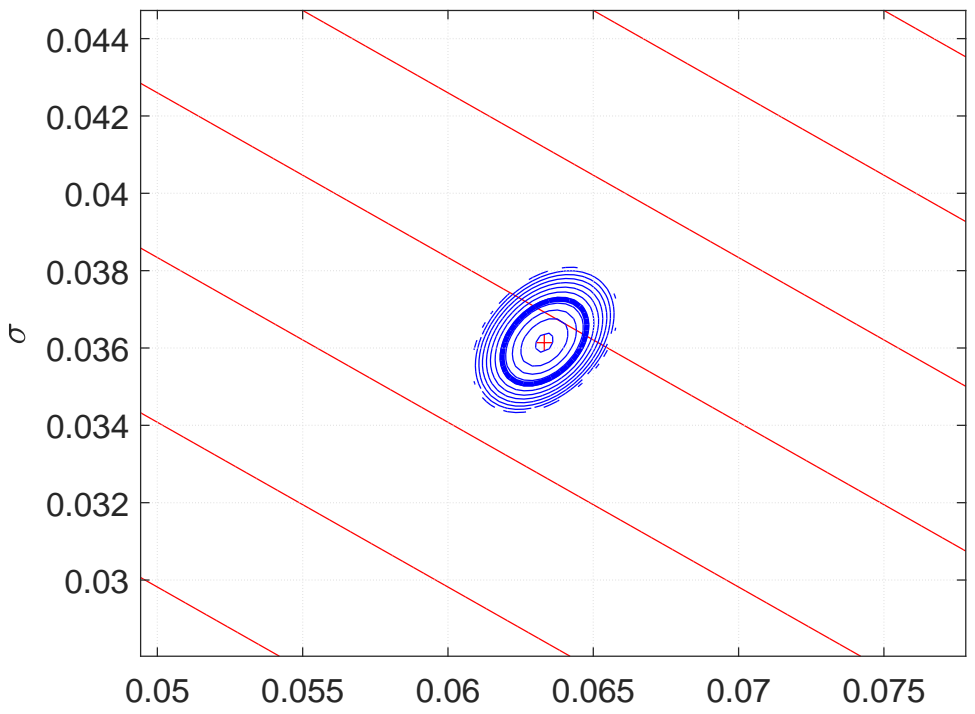

MLE $=$ Maximum Likelihood Estimate, $95 \%$ CI for $\mu$ and $\sigma$ after $\mu_{.00}$ yrs 


\section{Johnson county after 7.00 yrs}

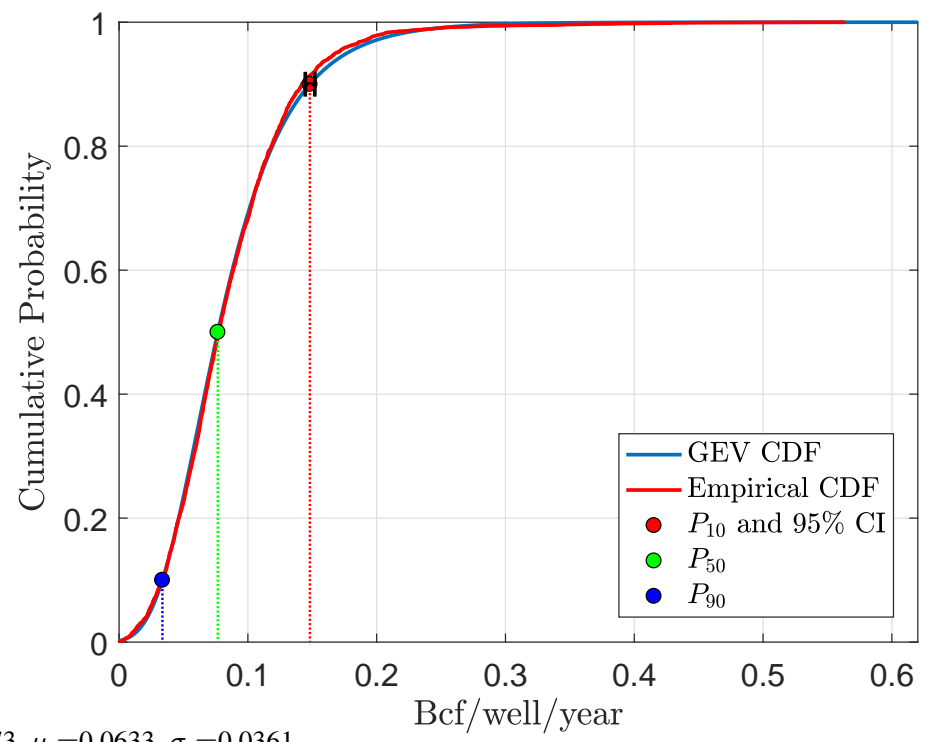

GEV cdf: $\xi=0.0373, \mu=0.0633, \sigma=0.0361$ 


\section{Johnson county after 8 yrs}

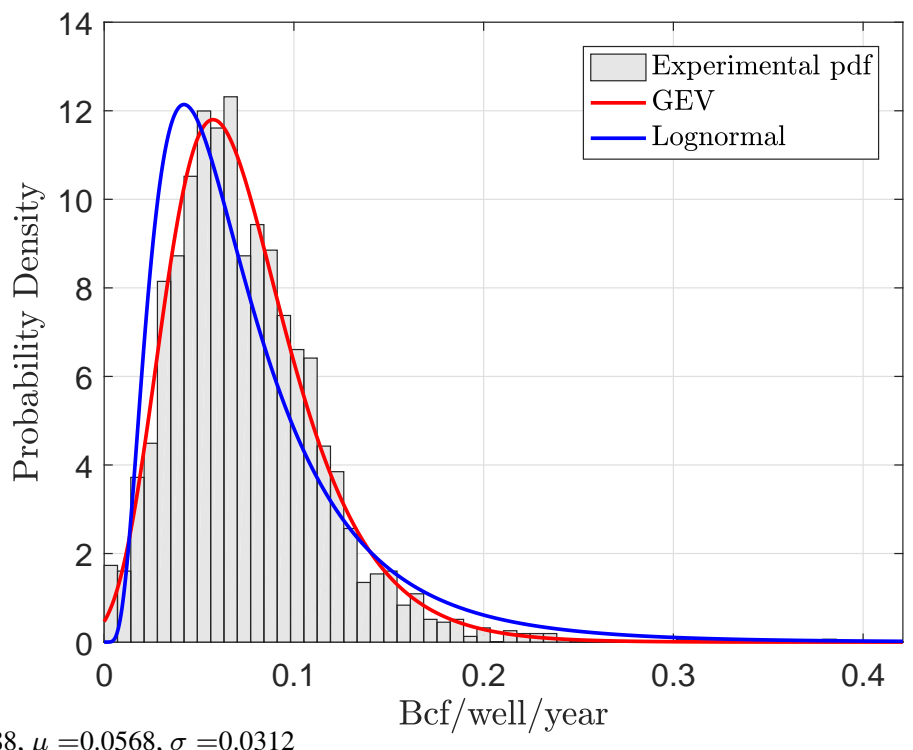

GEV pdf: $\xi=-0.0188, \mu=0.0568, \sigma=0.0312$ 


\section{MLE of GEV pdf in Johnson county}

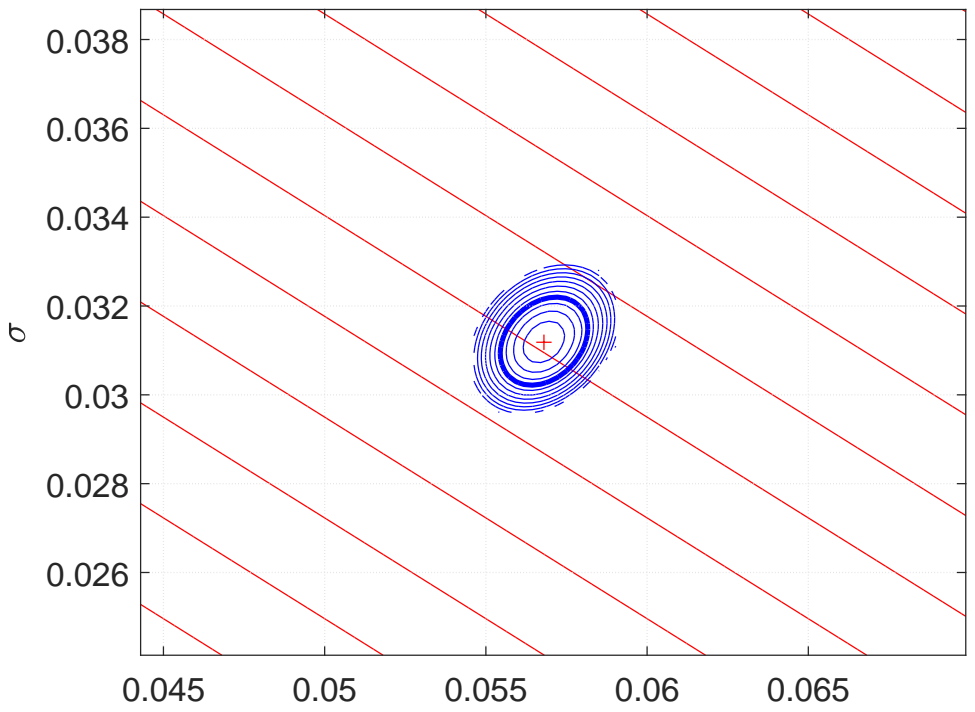

MLE $=$ Maximum Likelihood Estimate, $95 \%$ CI for $\mu$ and $\sigma$ after $\stackrel{\mu}{8.00}$ yrs 


\section{Johnson county after 8.00 yrs}

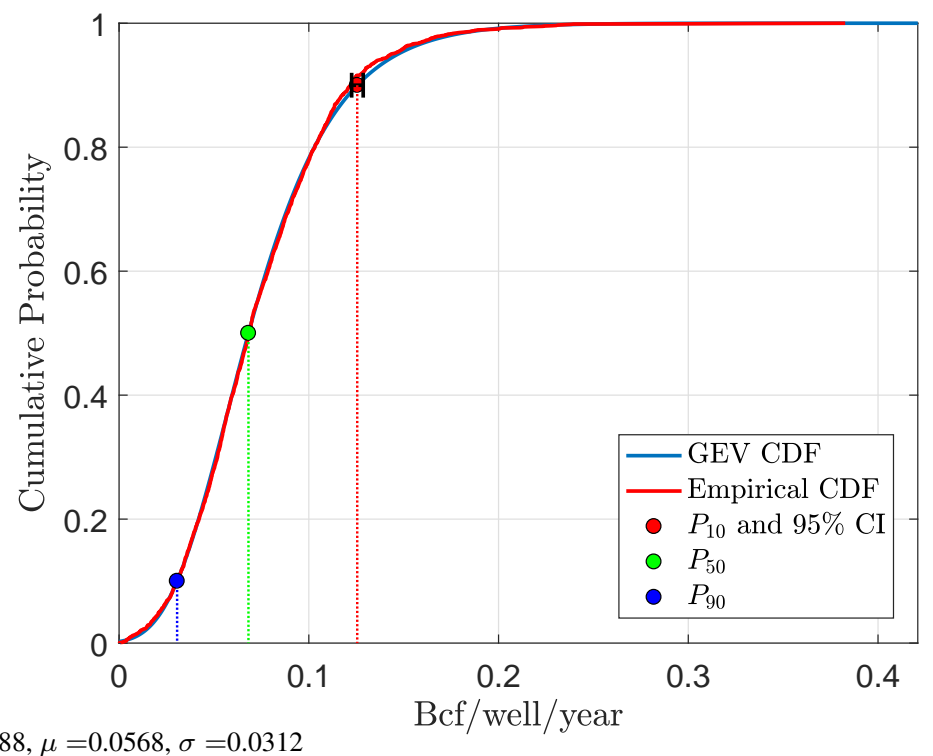

GEV cdf: $\xi=-0.0188, \mu=0.0568, \sigma=0.0312$ 


\section{Johnson county after 9 yrs}

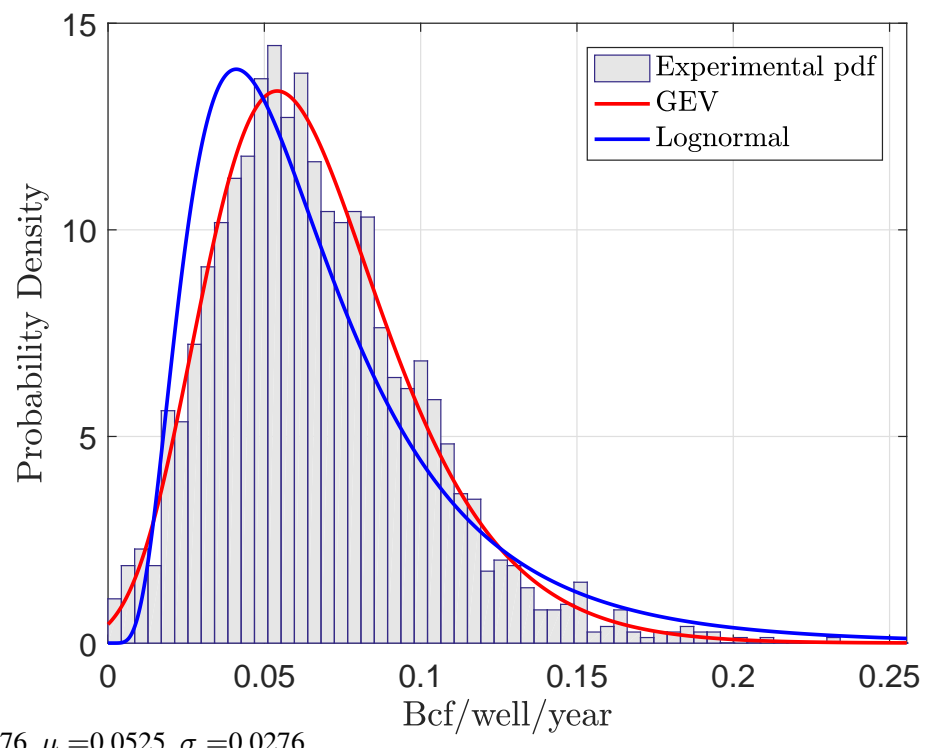

GEV pdf: $\xi=-0.0576, \mu=0.0525, \sigma=0.0276$ 


\section{MLE of GEV pdf in Johnson county}

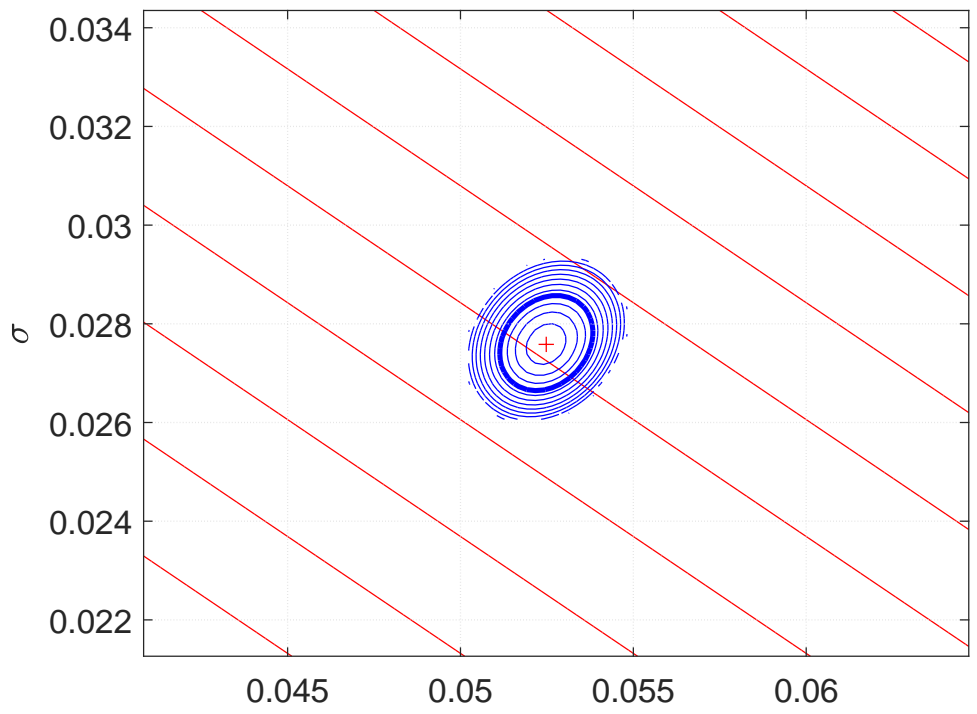

MLE $=$ Maximum Likelihood Estimate, $95 \%$ CI for $\mu$ and $\sigma$ after 9.00 yrs 


\section{Johnson county after 9.00 yrs}

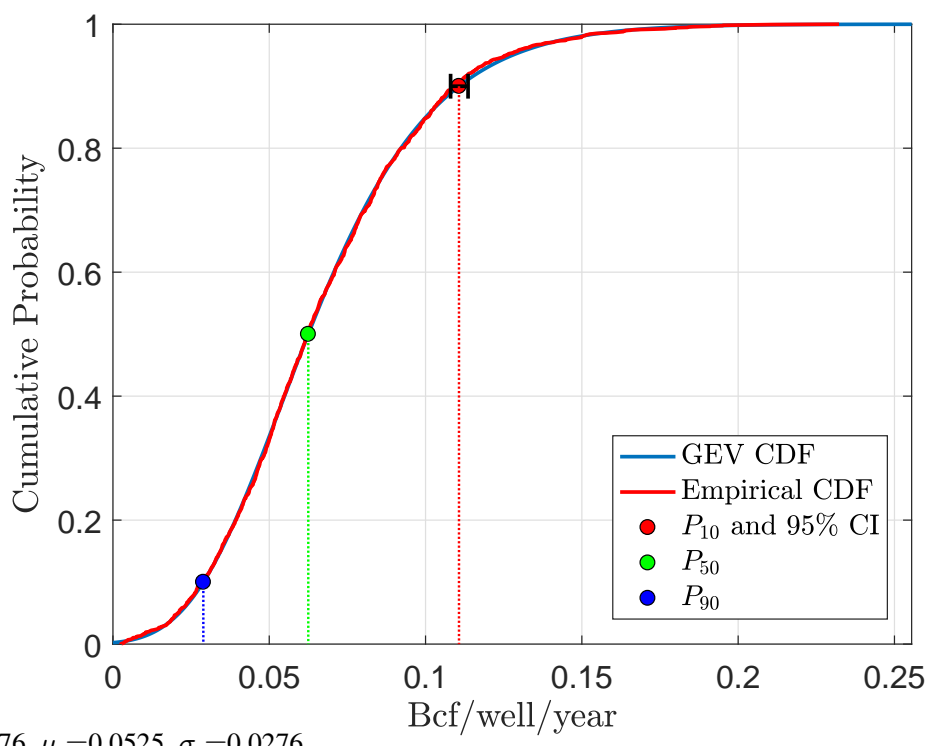

GEV cdf: $\xi=-0.0576, \mu=0.0525, \sigma=0.0276$ 


\section{Johnson county after 10 yrs}

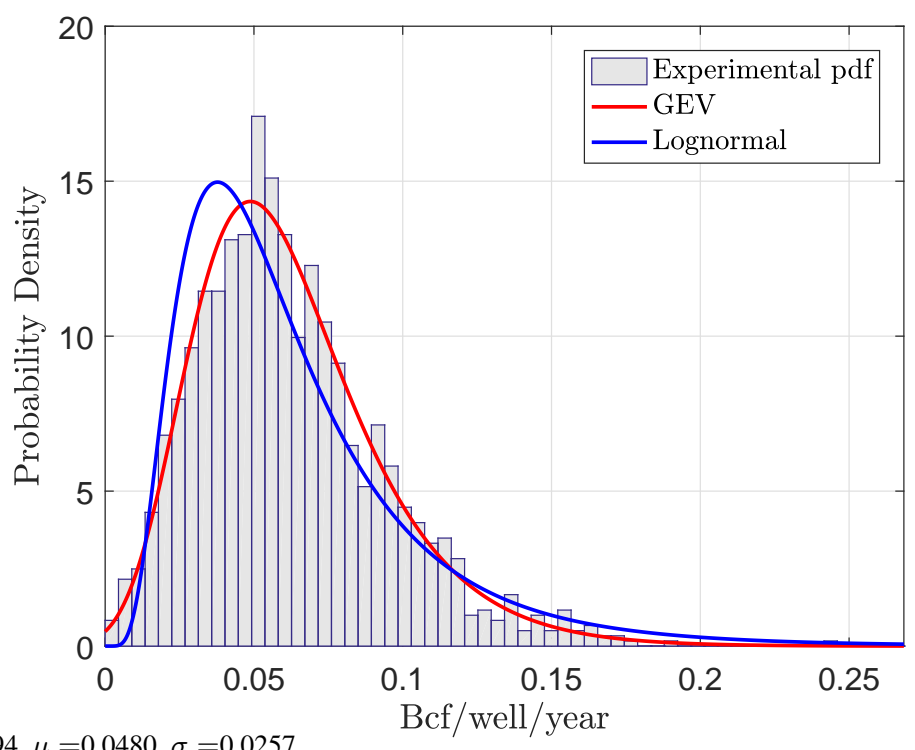

GEV pdf: $\xi=-0.0294, \mu=0.0480, \sigma=0.0257$ 


\section{MLE of GEV pdf in Johnson county}

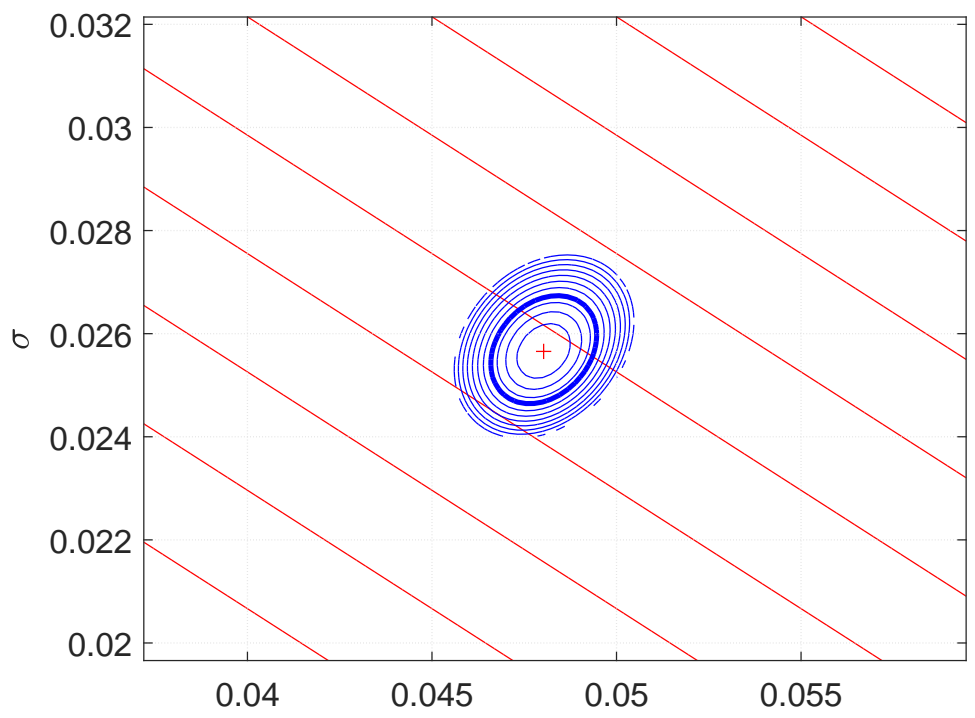

MLE = Maximum Likelihood Estimate, 95\% CI for $\mu$ and $\sigma$ after 10.00 yrs 


\section{Johnson county after 10.00 yrs}

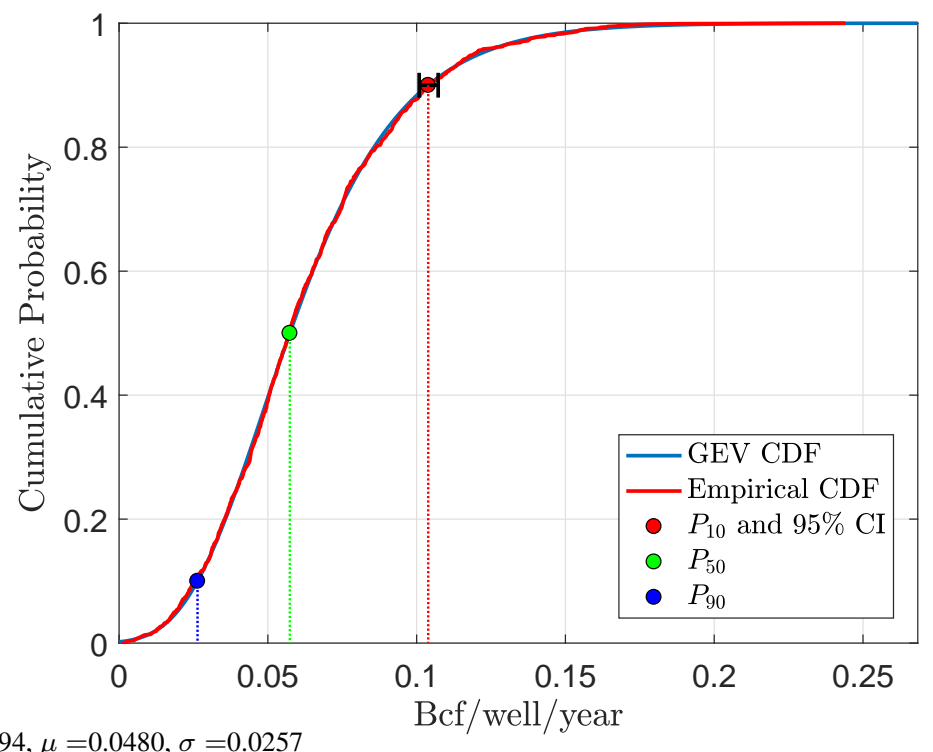

GEV cdf: $\xi=-0.0294, \mu=0.0480, \sigma=0.0257$ 


\section{Johnson county after 11 yrs}

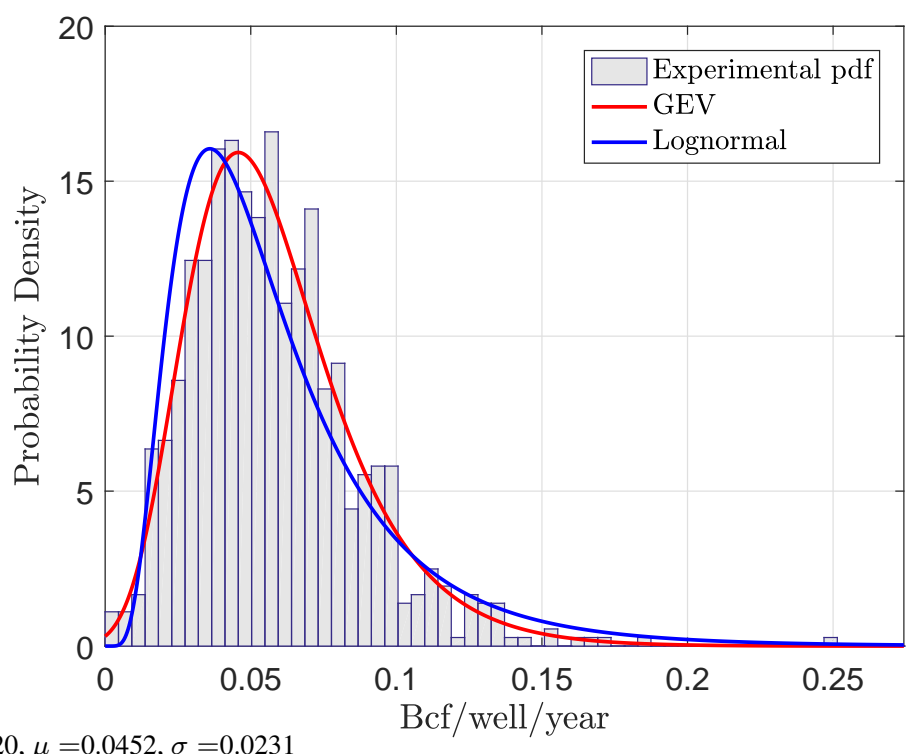

GEV pdf: $\xi=-0.0220, \mu=0.0452, \sigma=0.0231$ 


\section{MLE of GEV pdf in Johnson county}

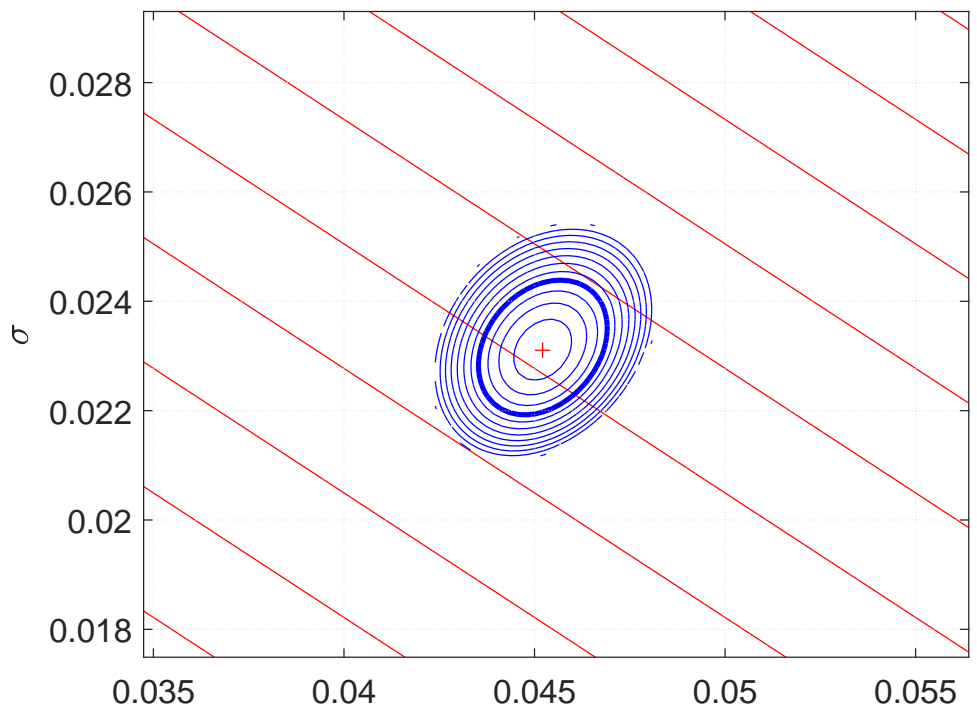

MLE = Maximum Likelihood Estimate, 95\% CI for $\mu$ and $\sigma$ after 11.00 yrs 


\section{Johnson county after 11.00 yrs}

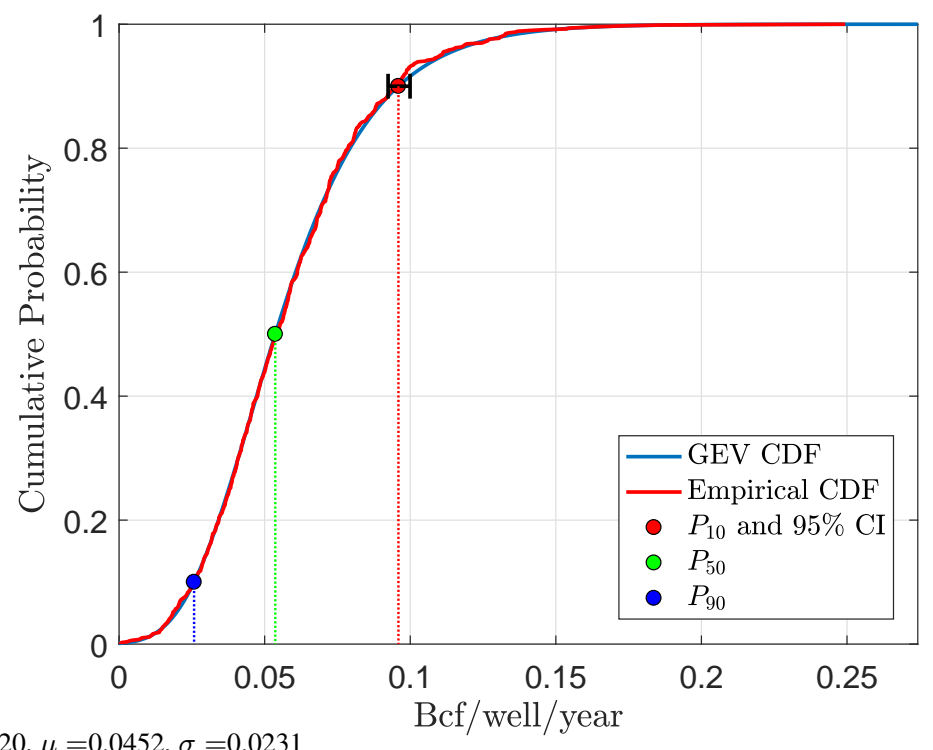

GEV cdf: $\xi=-0.0220, \mu=0.0452, \sigma=0.0231$ 


\section{Johnson county after 12 yrs}

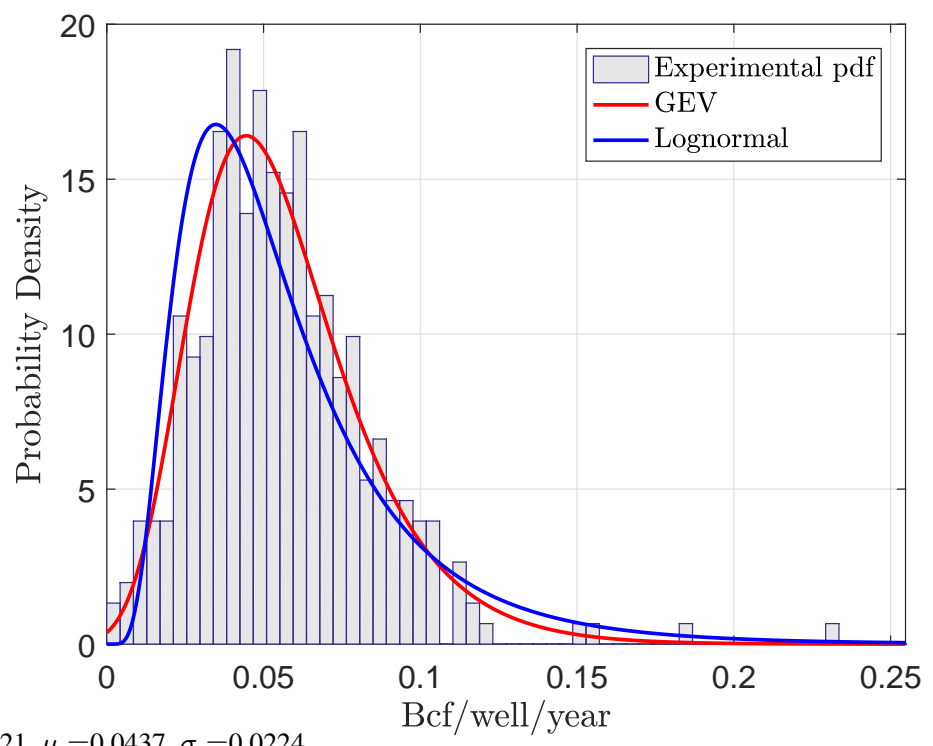

GEV pdf: $\xi=-0.0321, \mu=0.0437, \sigma=0.0224$ 


\section{MLE of GEV pdf in Johnson county}

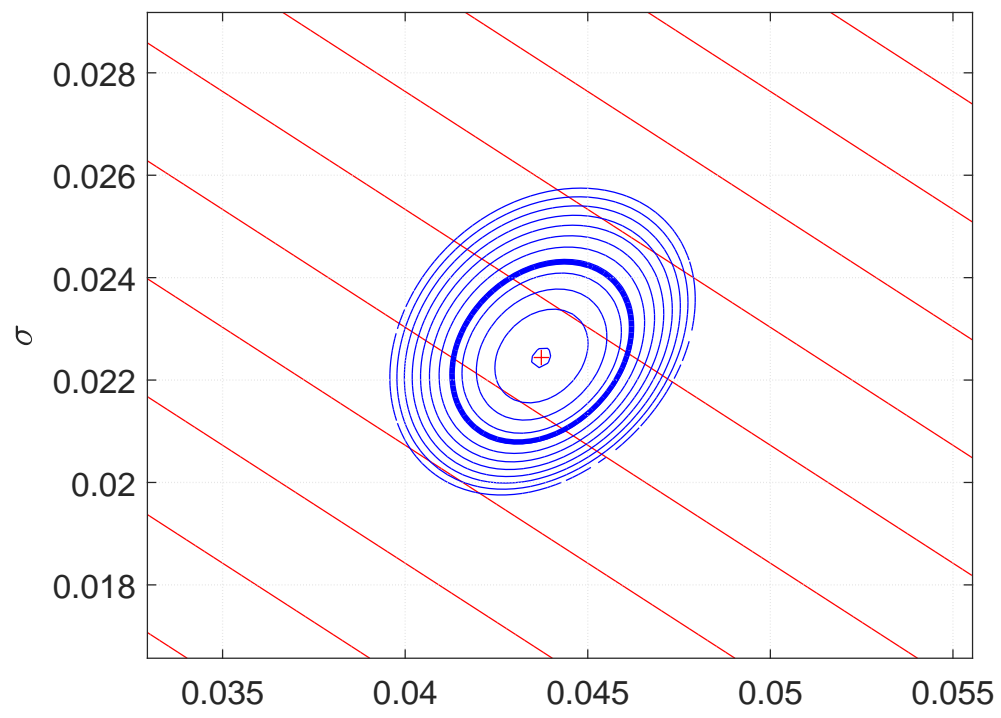

MLE $=$ Maximum Likelihood Estimate, $95 \%$ CI for $\mu$ and $\sigma$ after $12.00 \mathrm{yrs}$ 


\section{Johnson county after 12.00 yrs}

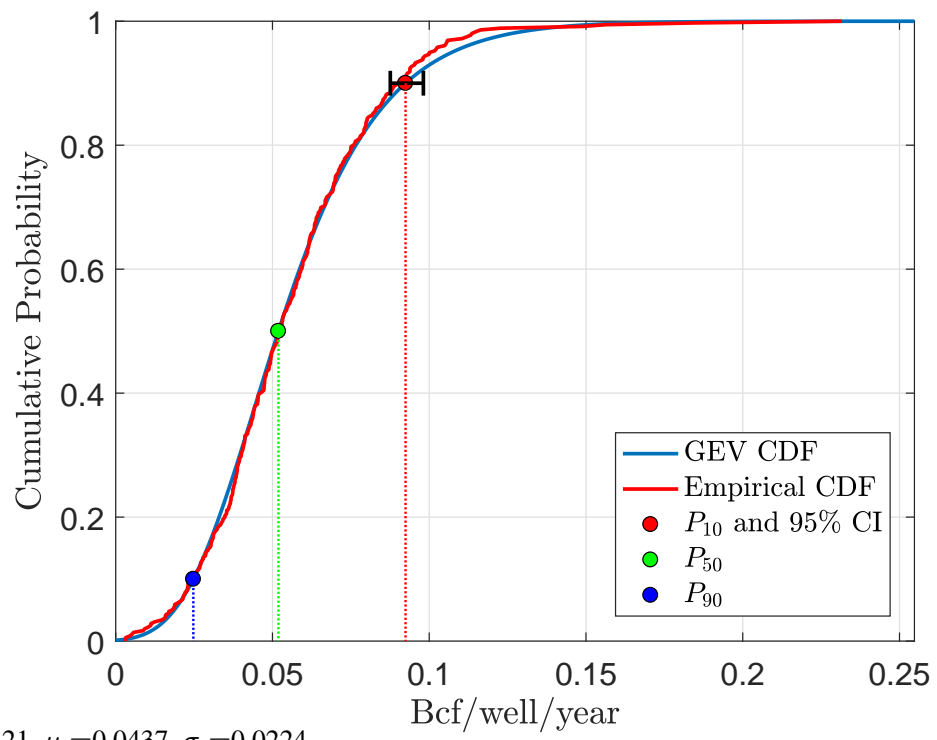

GEV cdf: $\xi=-0.0321, \mu=0.0437, \sigma=0.0224$ 


\section{Johnson county after 13 yrs}

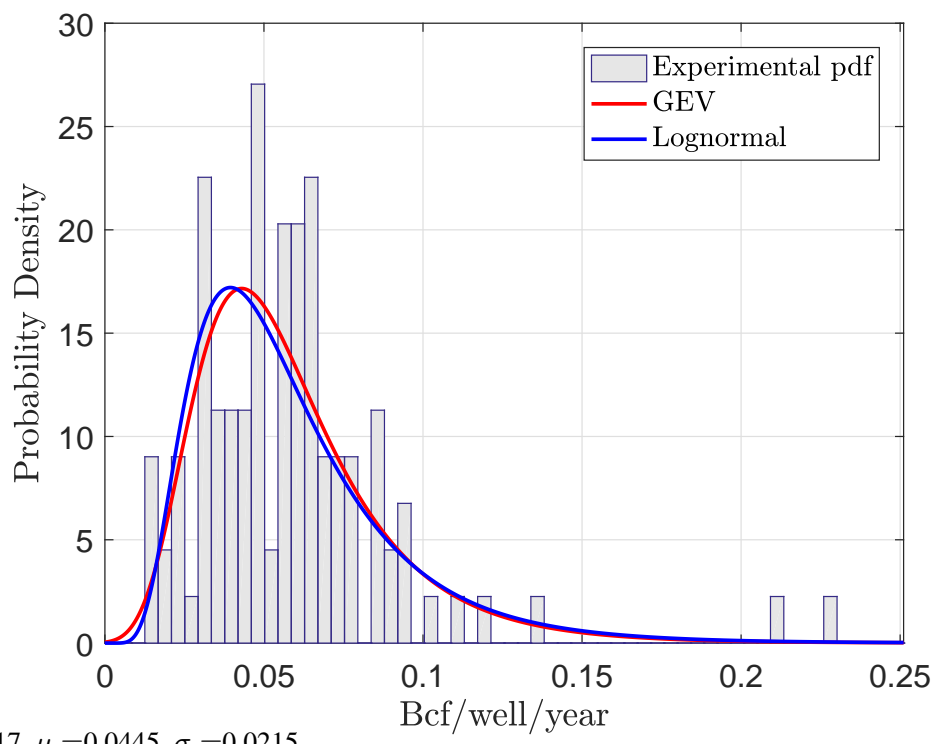

GEV pdf: $\xi=0.0717, \mu=0.0445, \sigma=0.0215$ 


\section{MLE of GEV pdf in Johnson county}

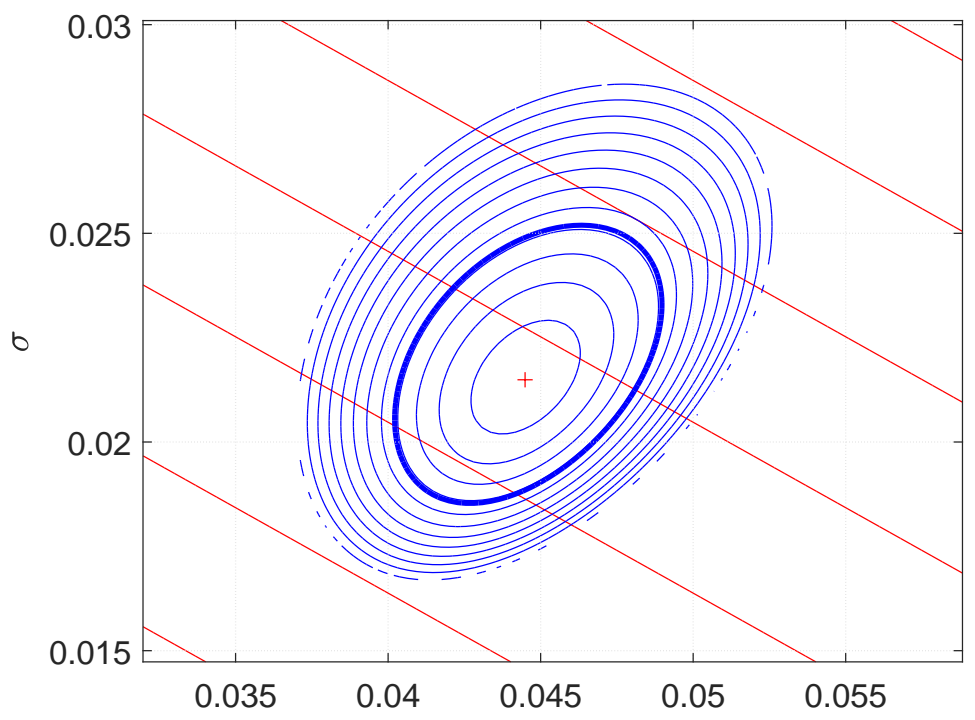

MLE $=$ Maximum Likelihood Estimate, $95 \% \mathrm{CI}$ for $\mu$ and $\sigma$ after $13.00 \mathrm{yrs}$ 


\section{Johnson county after 13.00 yrs}

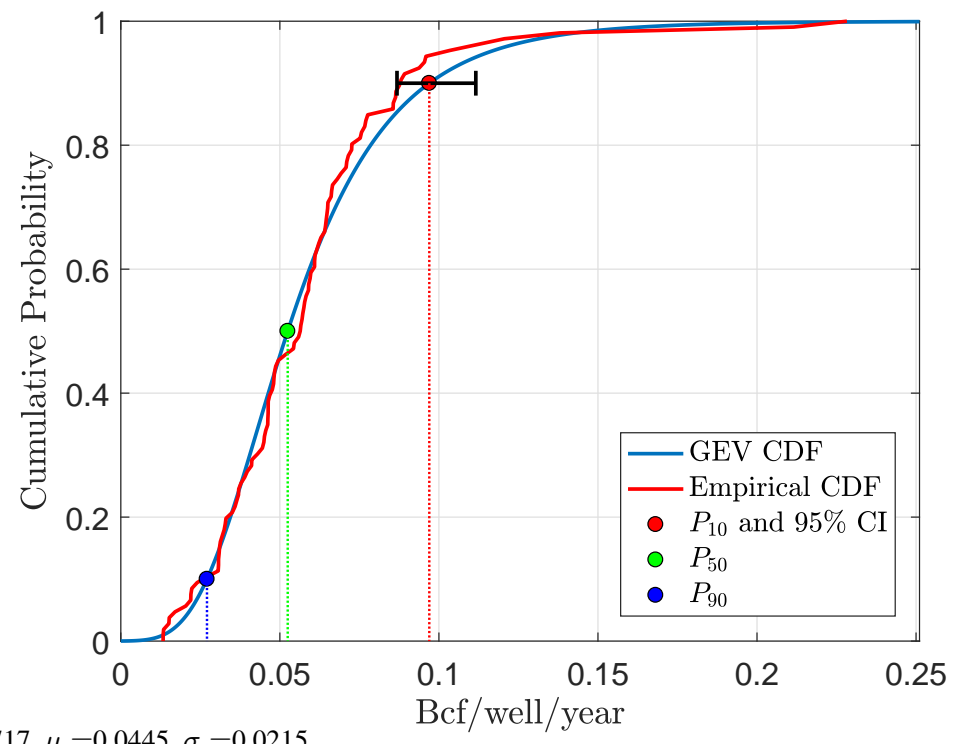

GEV cdf: $\xi=0.0717, \mu=0.0445, \sigma=0.0215$ 


\section{Johnson county after 14 yrs}

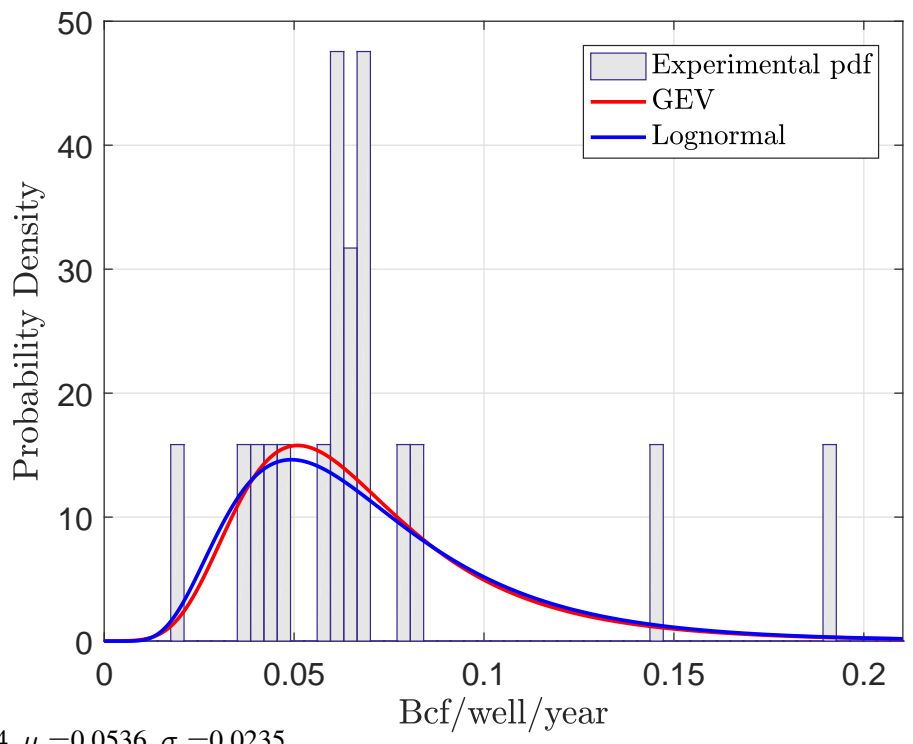

GEV pdf: $\xi=0.1214, \mu=0.0536, \sigma=0.0235$ 


\section{MLE of GEV pdf in Johnson county}

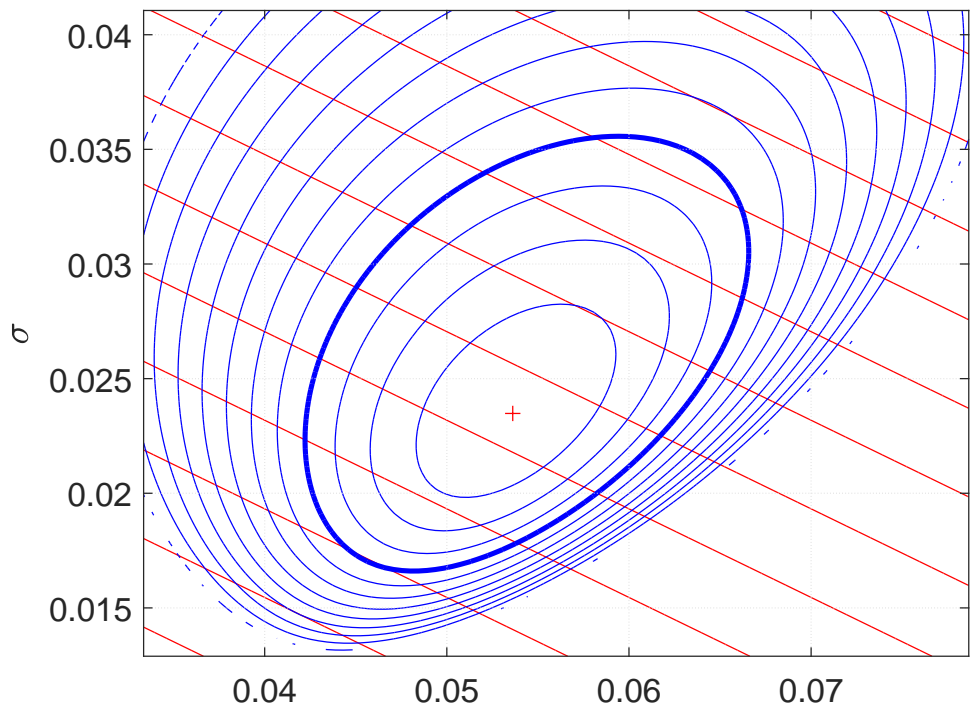

MLE $=$ Maximum Likelihood Estimate, $95 \% \mathrm{CI}$ for $\mu$ and $\sigma$ after $14.00 \mathrm{yrs}$ 


\section{Johnson county after 14.00 yrs}

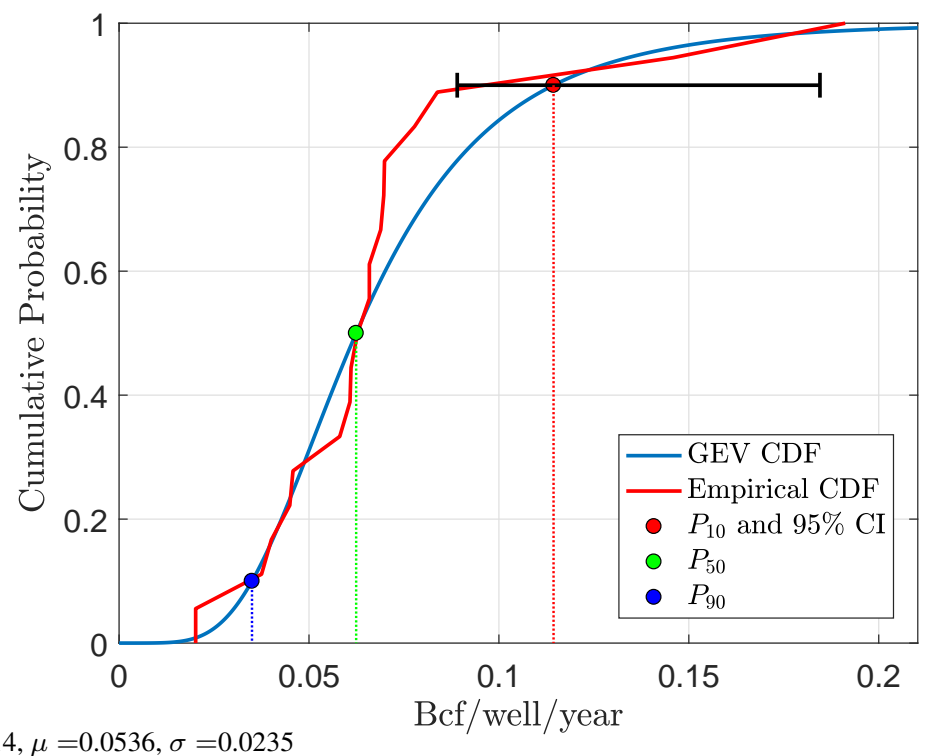

GEV cdf: $\xi=0.1214, \mu=0.0536, \sigma=0.0235$ 


\section{Wise county after 1 yrs}

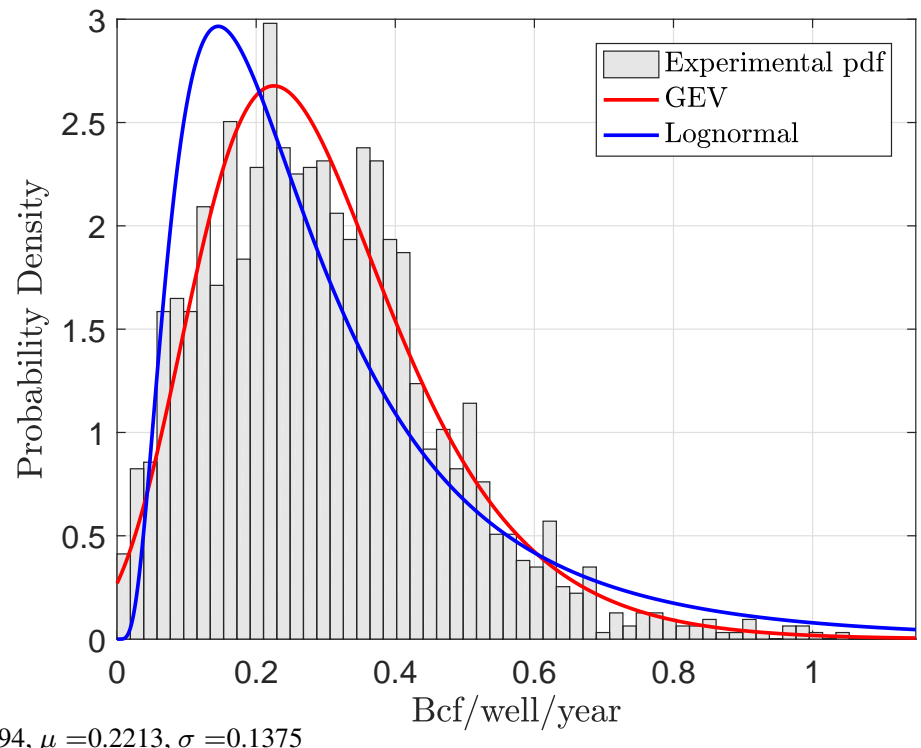

GEV pdf: $\xi=-0.0294, \mu=0.2213, \sigma=0.1375$ 


\section{MLE of GEV pdf in Wise county}

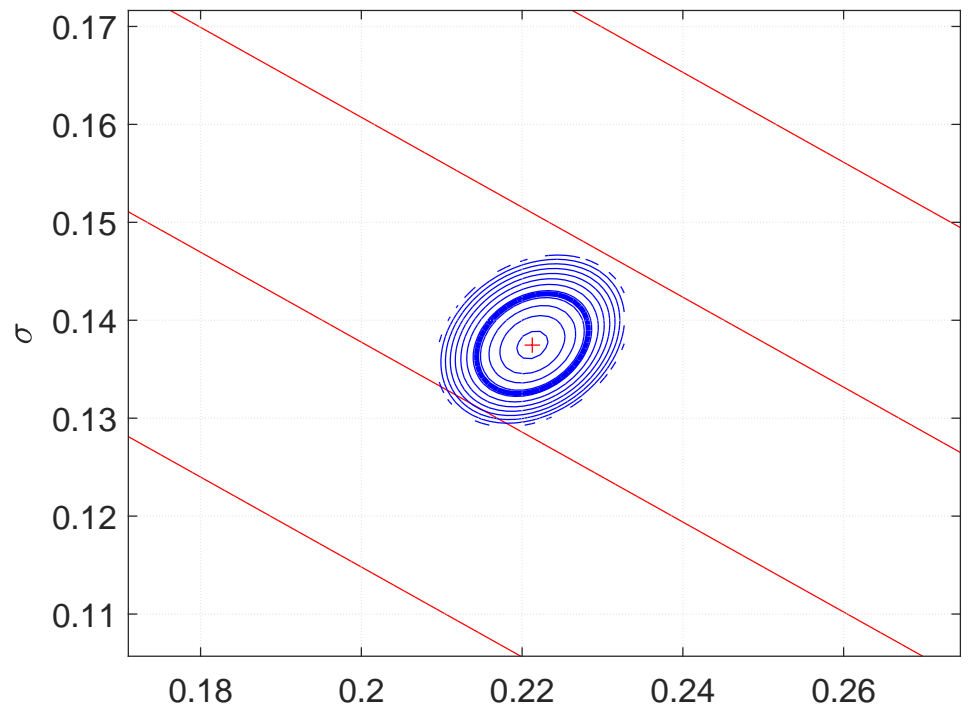

MLE $=$ Maximum Likelihood Estimate, $95 \% \mathrm{CI}$ for $\mu$ and $\sigma$ after $1.00 \mathrm{yrs}$ 


\section{Wise county after 1.00 yrs}

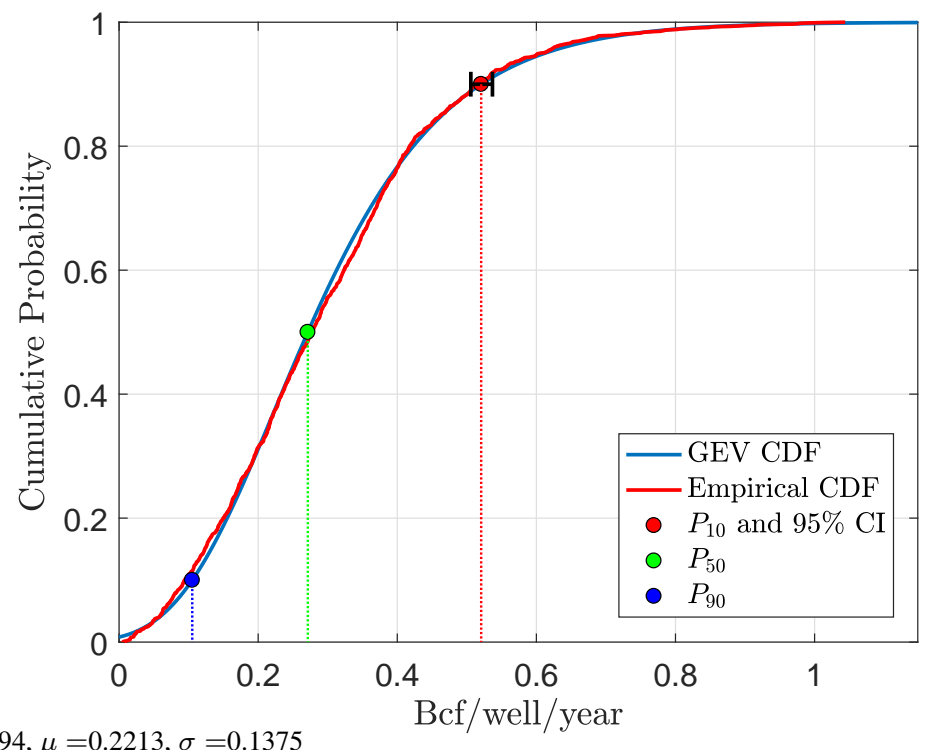

GEV cdf: $\xi=-0.0294, \mu=0.2213, \sigma=0.1375$ 


\section{Wise county after 2 yrs}

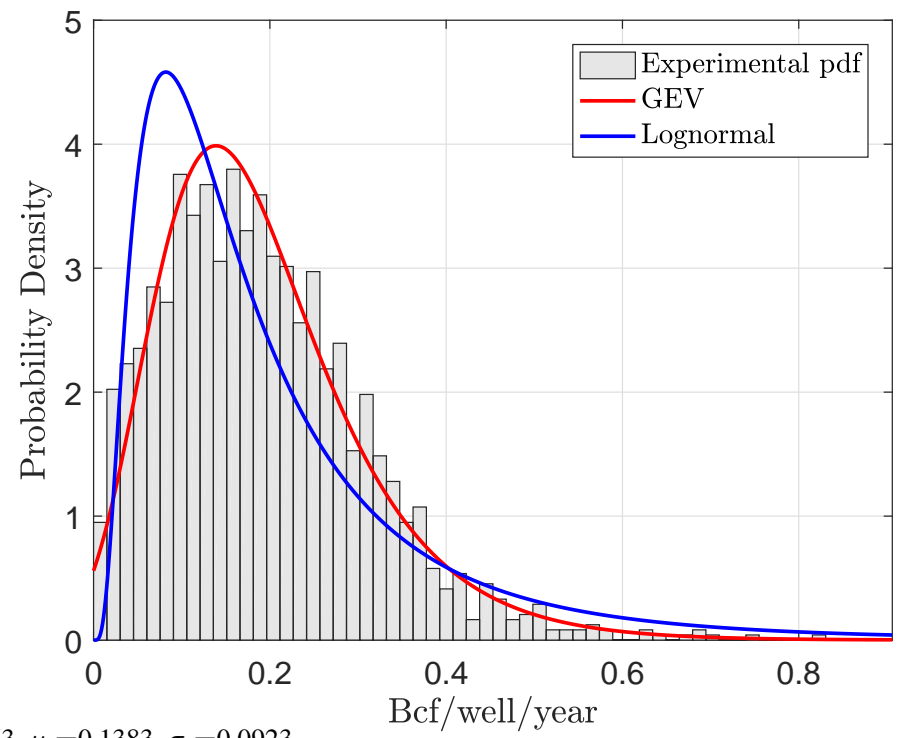

GEV pdf: $\xi=-0.0063, \mu=0.1383, \sigma=0.0923$ 


\section{MLE of GEV pdf in Wise county}

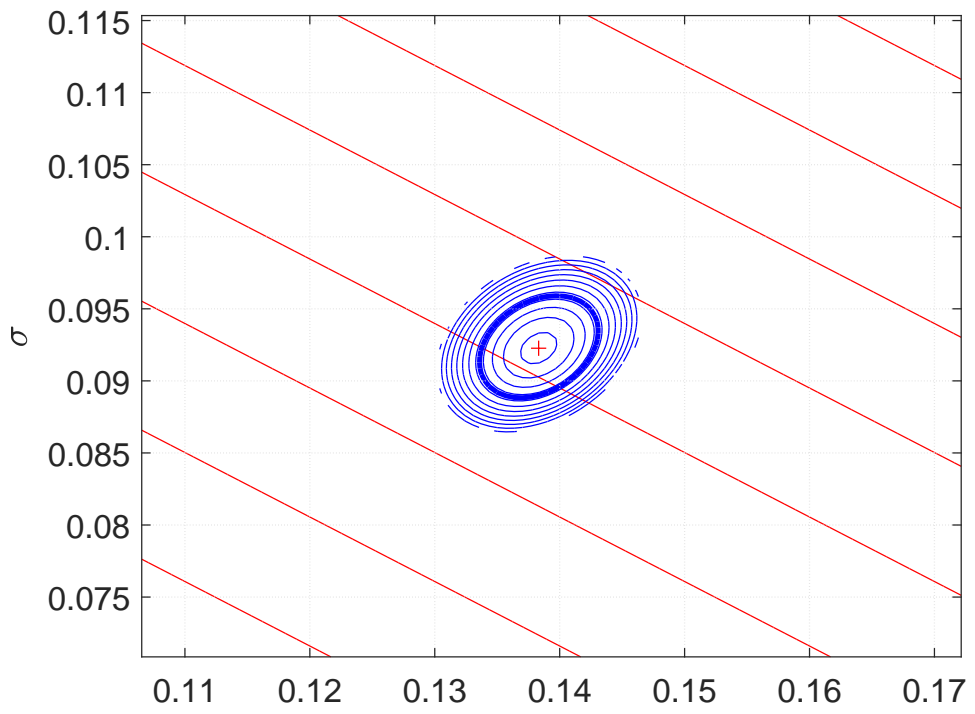

MLE $=$ Maximum Likelihood Estimate, $95 \%$ CI for $\mu$ and $\sigma$ after 2.00 yrs 


\section{Wise county after 2.00 yrs}

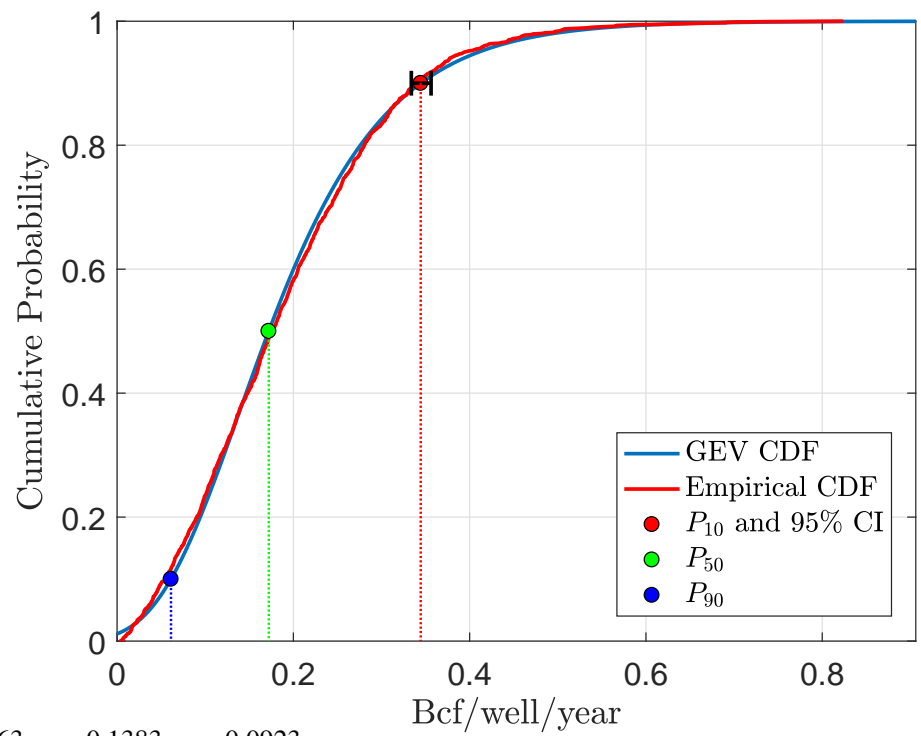

GEV cdf: $\xi=-0.0063, \mu=0.1383, \sigma=0.0923$ 


\section{Wise county after 3 yrs}

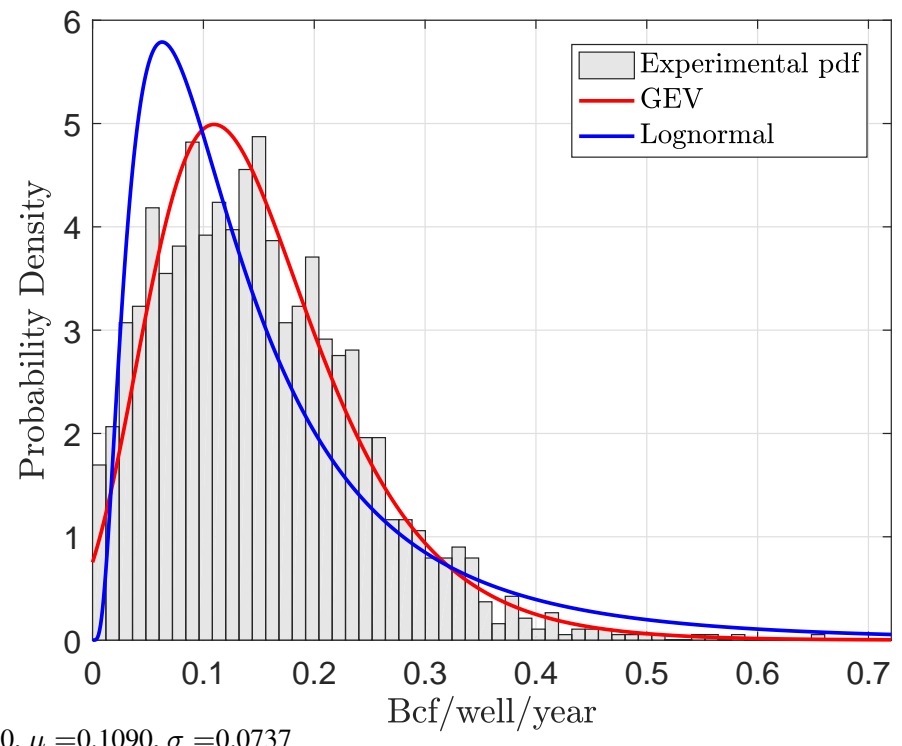

GEV pdf: $\xi=-0.0080, \mu=0.1090, \sigma=0.0737$ 


\section{MLE of GEV pdf in Wise county}

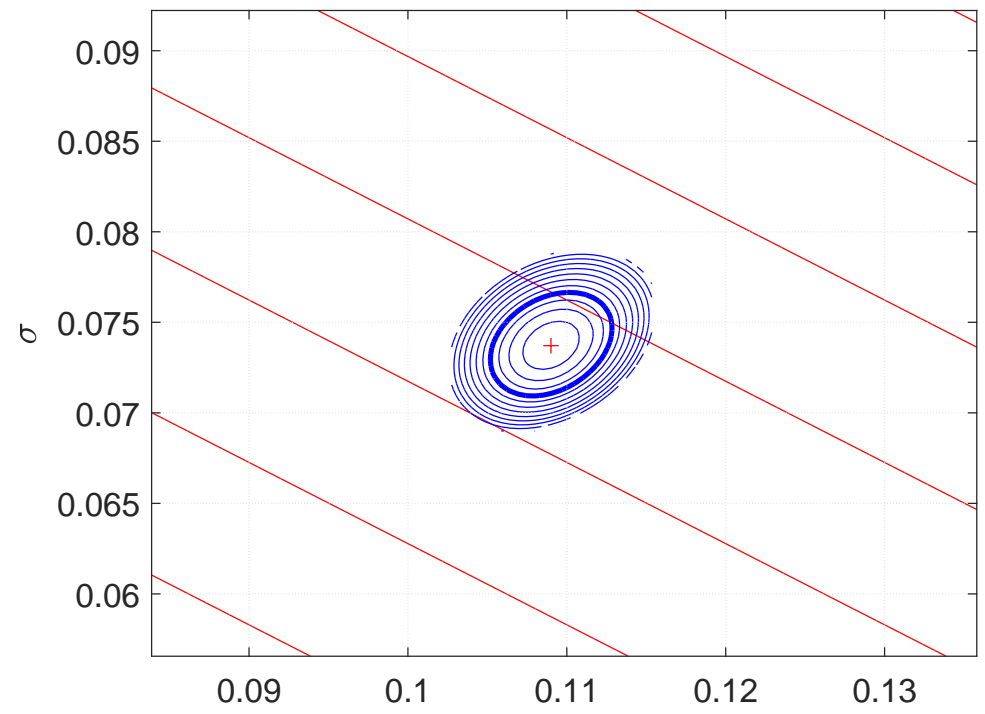

MLE $=$ Maximum Likelihood Estimate, $95 \%$ CI for $\mu$ and $\sigma$ after 3.00 yrs 


\section{Wise county after 3.00 yrs}

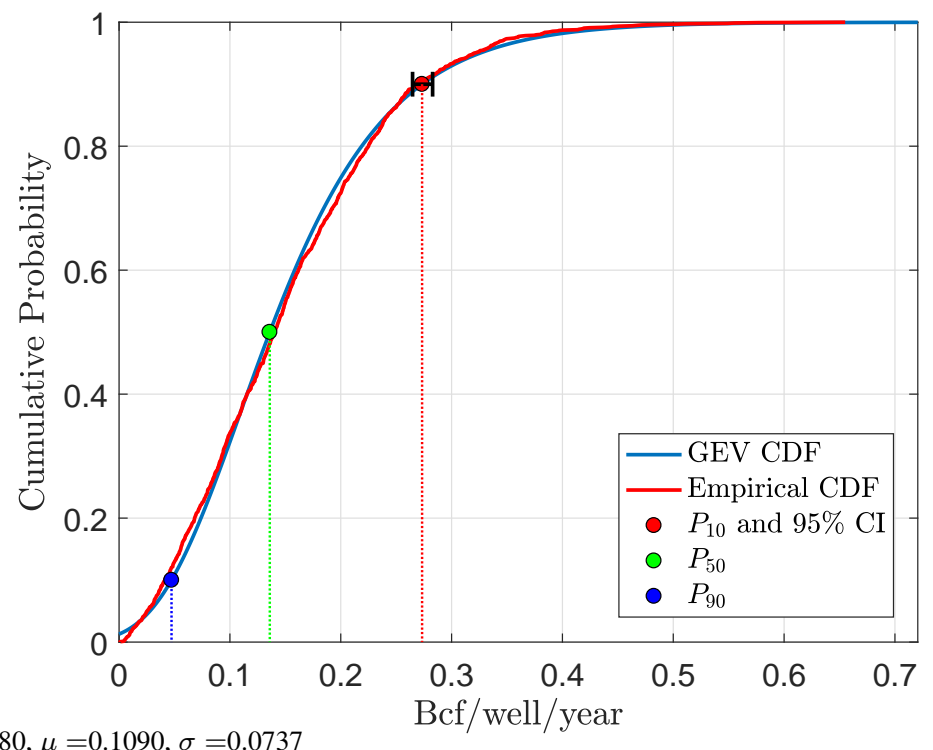

GEV cdf: $\xi=-0.0080, \mu=0.1090, \sigma=0.0737$ 


\section{Wise county after 4 yrs}

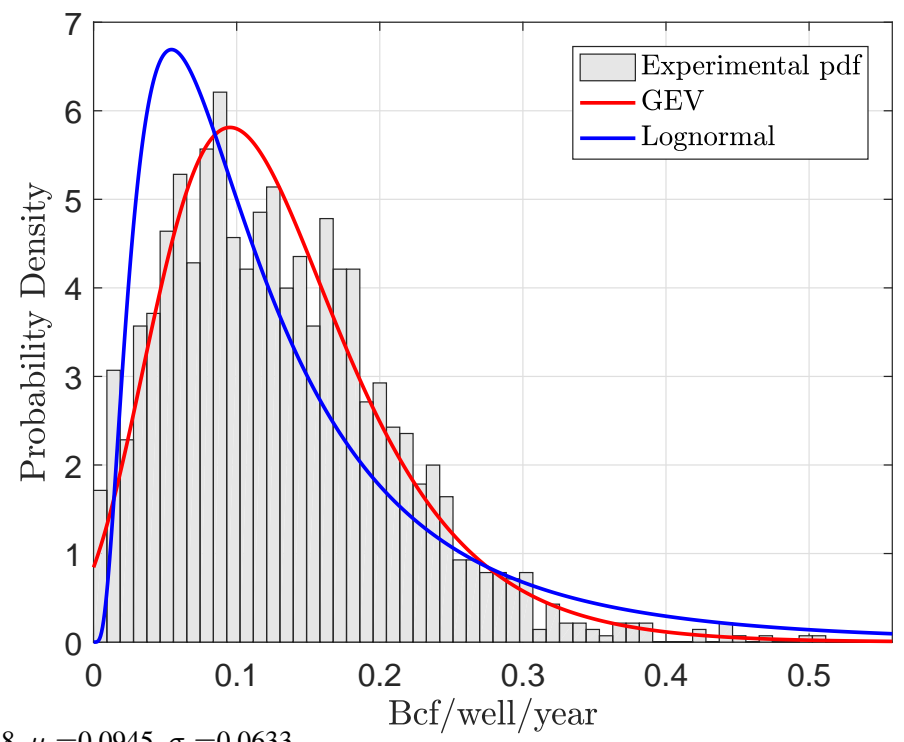

GEV pdf: $\xi=-0.0128, \mu=0.0945, \sigma=0.0633$ 


\section{MLE of GEV pdf in Wise county}

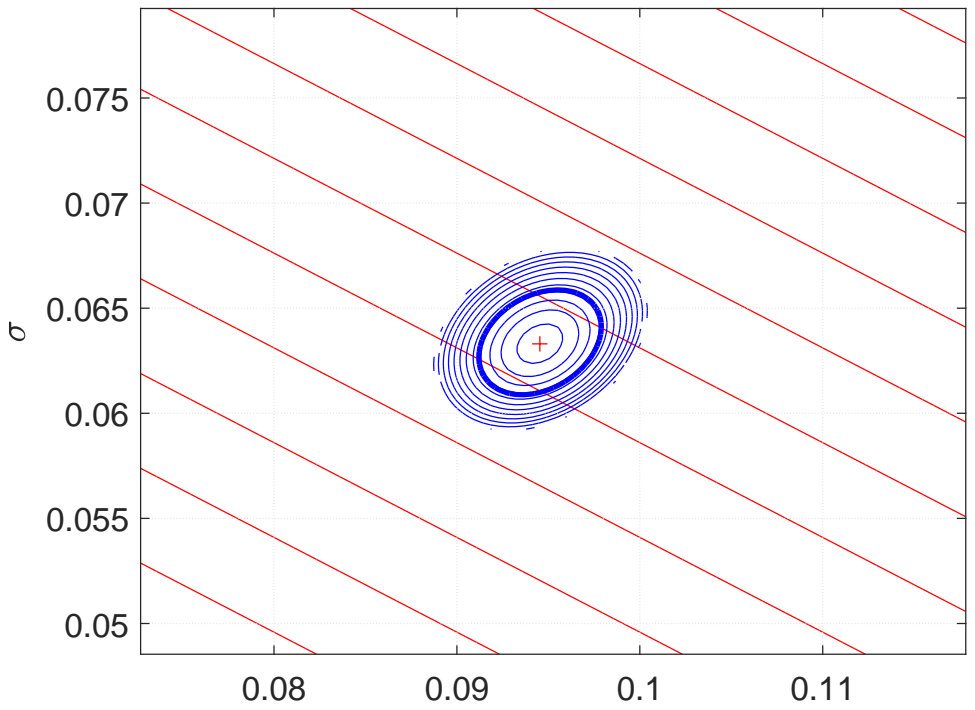

MLE = Maximum Likelihood Estimate, $95 \%$ CI for $\mu$ and $\sigma$ after $4.00 \mathrm{yrs}$ 


\section{Wise county after 4.00 yrs}

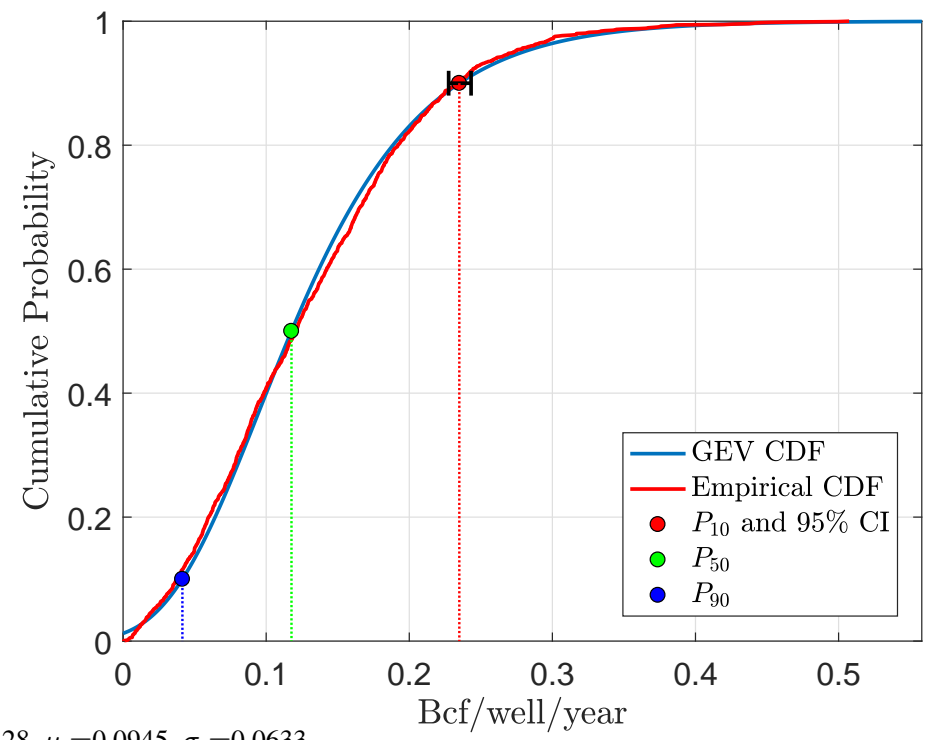

GEV cdf: $\xi=-0.0128, \mu=0.0945, \sigma=0.0633$ 


\section{Wise county after 5 yrs}

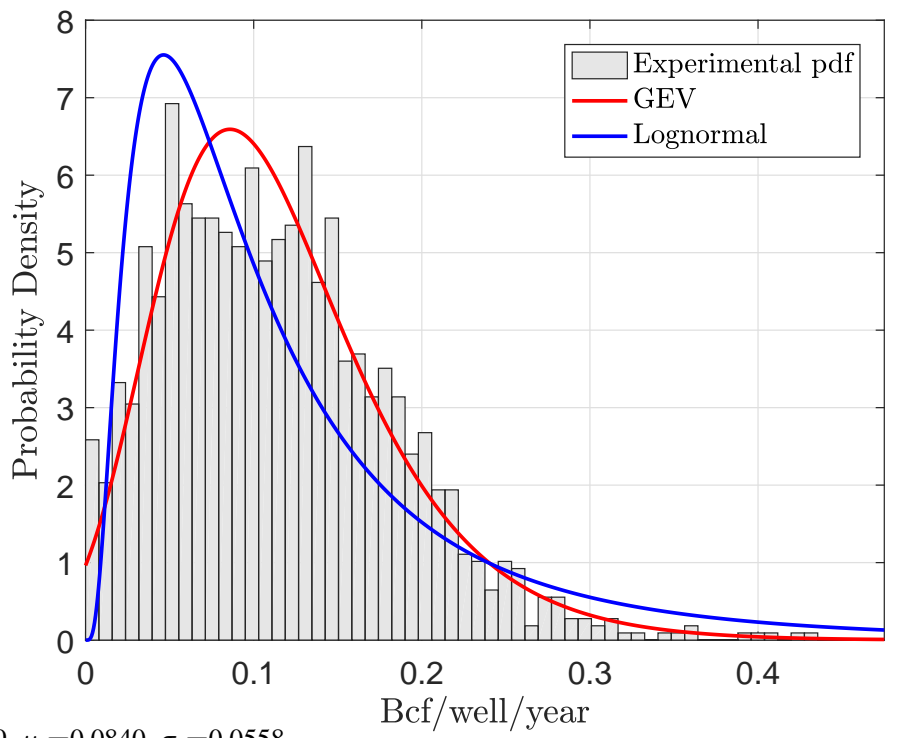

GEV pdf: $\xi=-0.0329, \mu=0.0840, \sigma=0.0558$ 


\section{MLE of GEV pdf in Wise county}

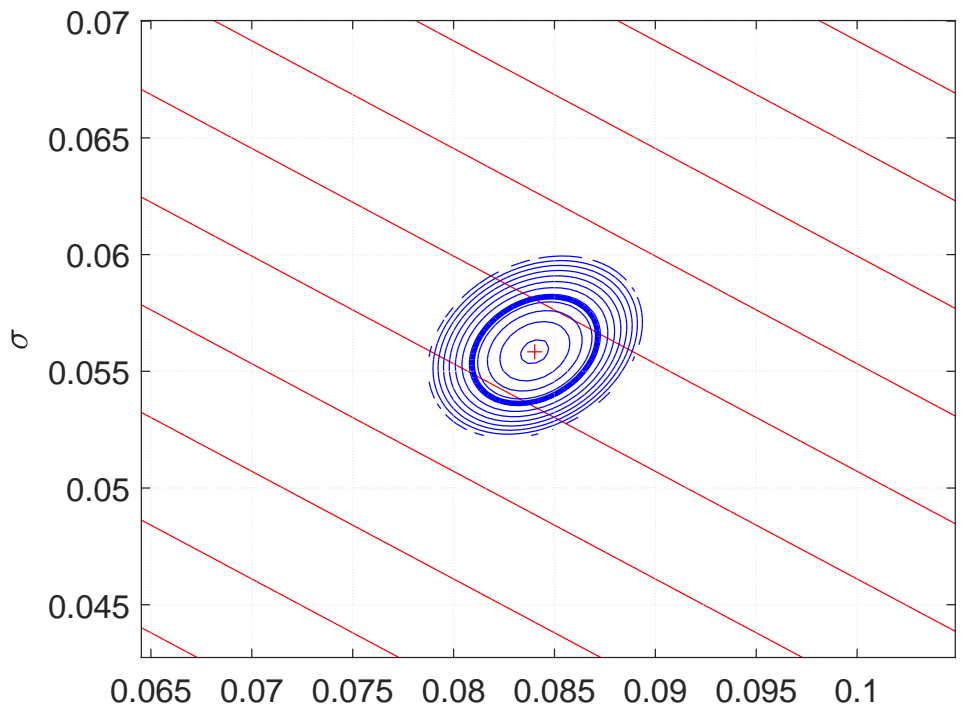

MLE = Maximum Likelihood Estimate, $95 \%$ CI for $\mu$ and $\sigma$ after 5.00 yrs 


\section{Wise county after 5.00 yrs}

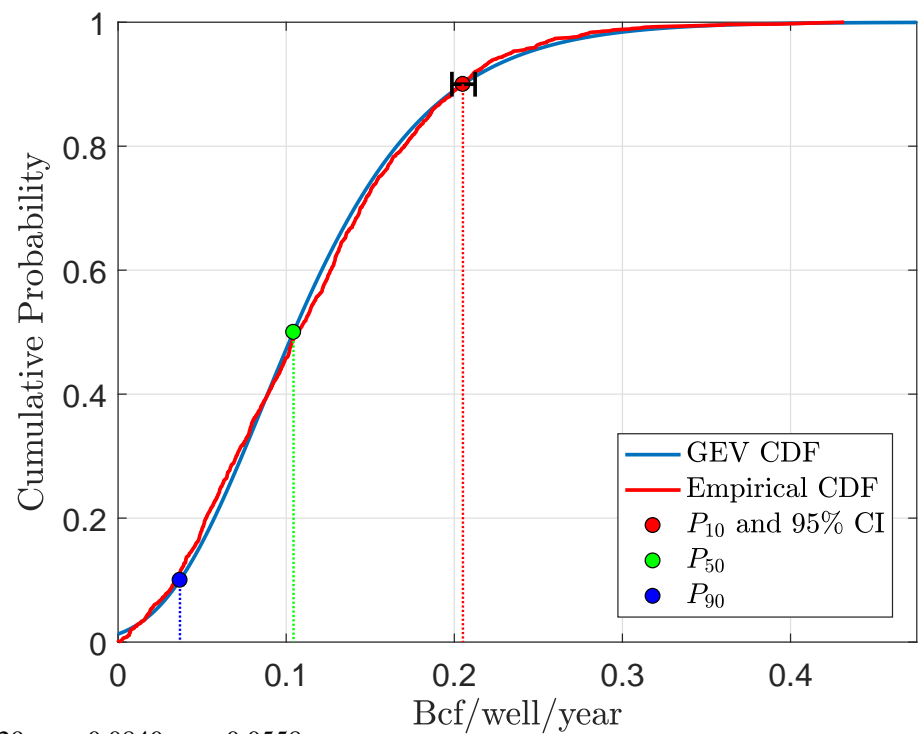

GEV cdf: $\xi=-0.0329, \mu=0.0840, \sigma=0.0558$ 


\section{Wise county after 6 yrs}

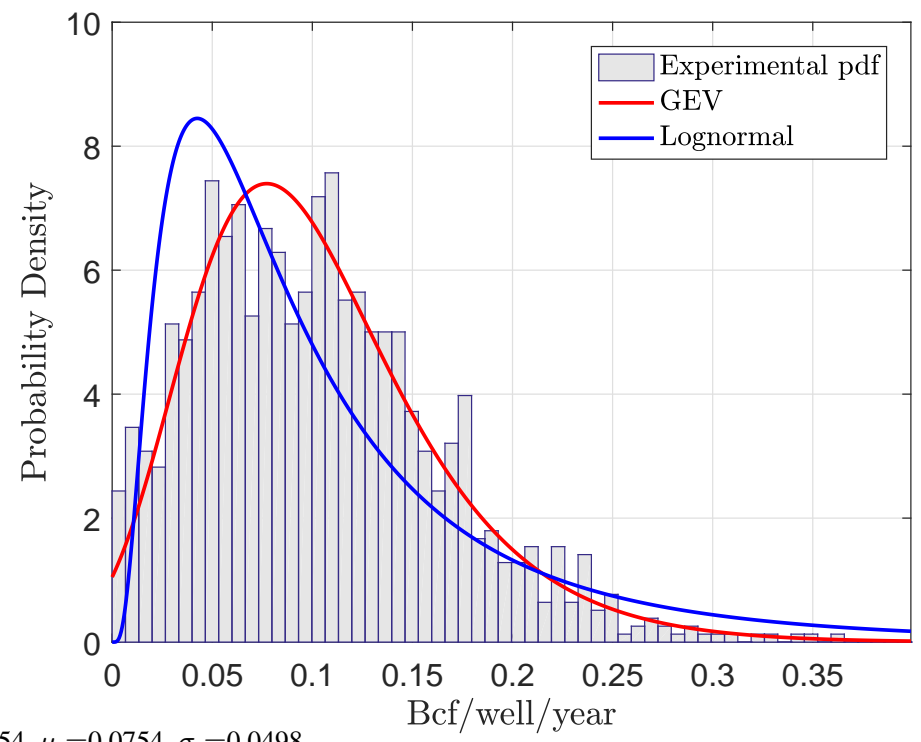

GEV pdf: $\xi=-0.0354, \mu=0.0754, \sigma=0.0498$ 


\section{MLE of GEV pdf in Wise county}

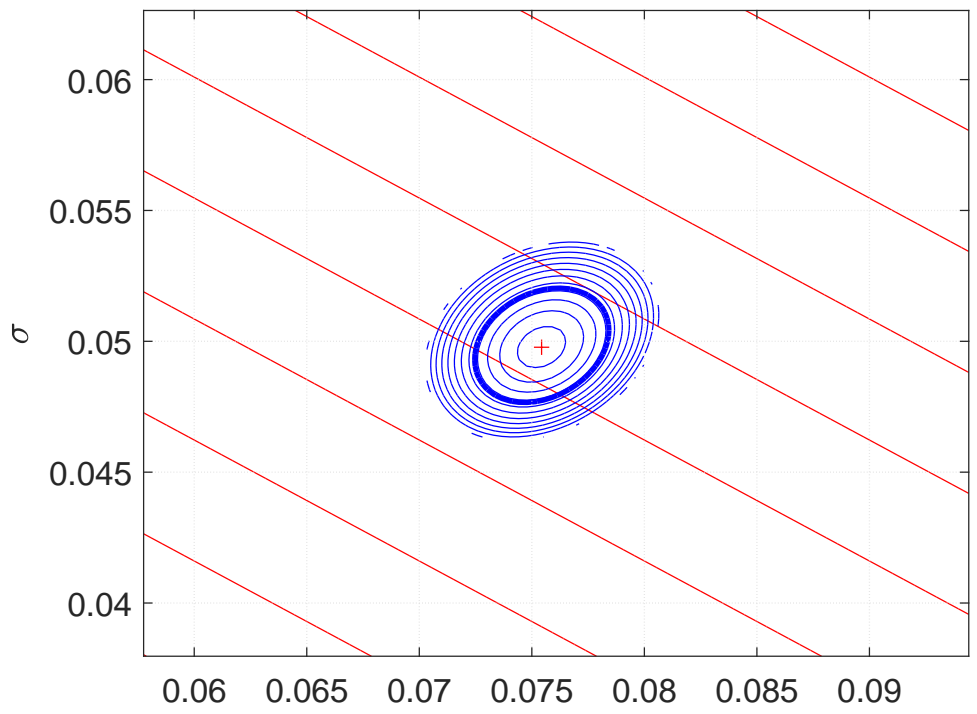

MLE = Maximum Likelihood Estimate, $95 \%$ CI for $\mu$ and $\sigma$ after 6.00 yrs 


\section{Wise county after 6.00 yrs}

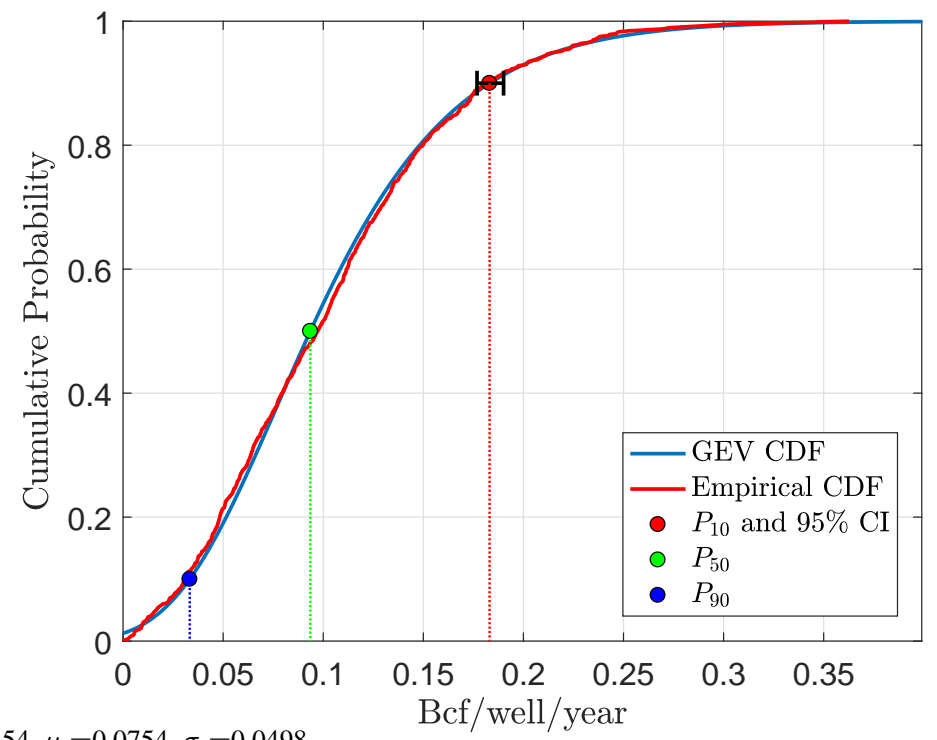

GEV cdf: $\xi=-0.0354, \mu=0.0754, \sigma=0.0498$ 


\section{Wise county after 7 yrs}

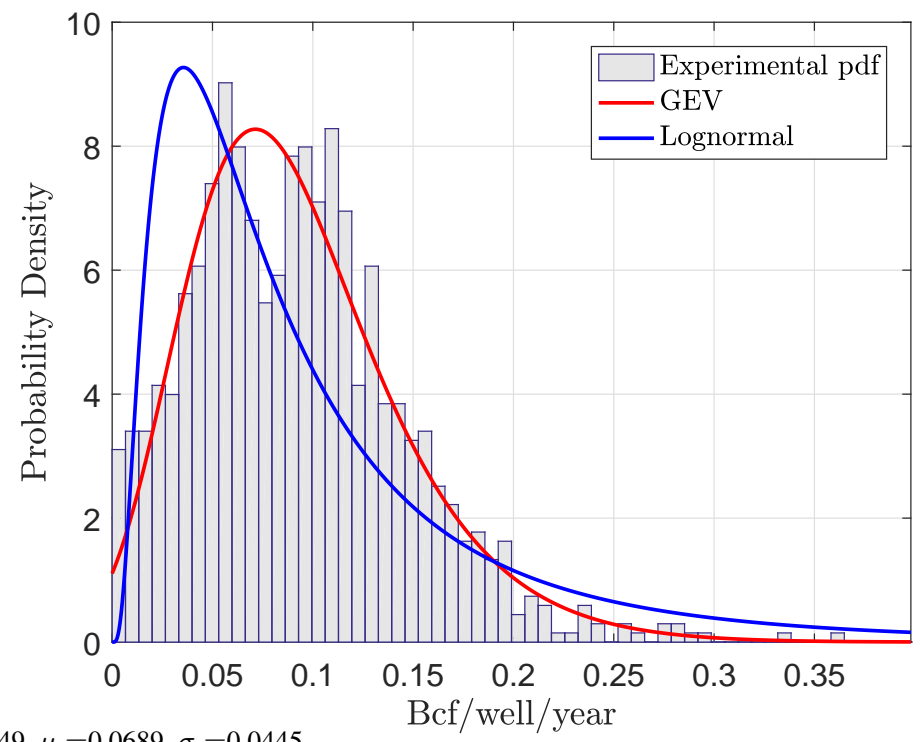

GEV pdf: $\xi=-0.0549, \mu=0.0689, \sigma=0.0445$ 


\section{MLE of GEV pdf in Wise county}

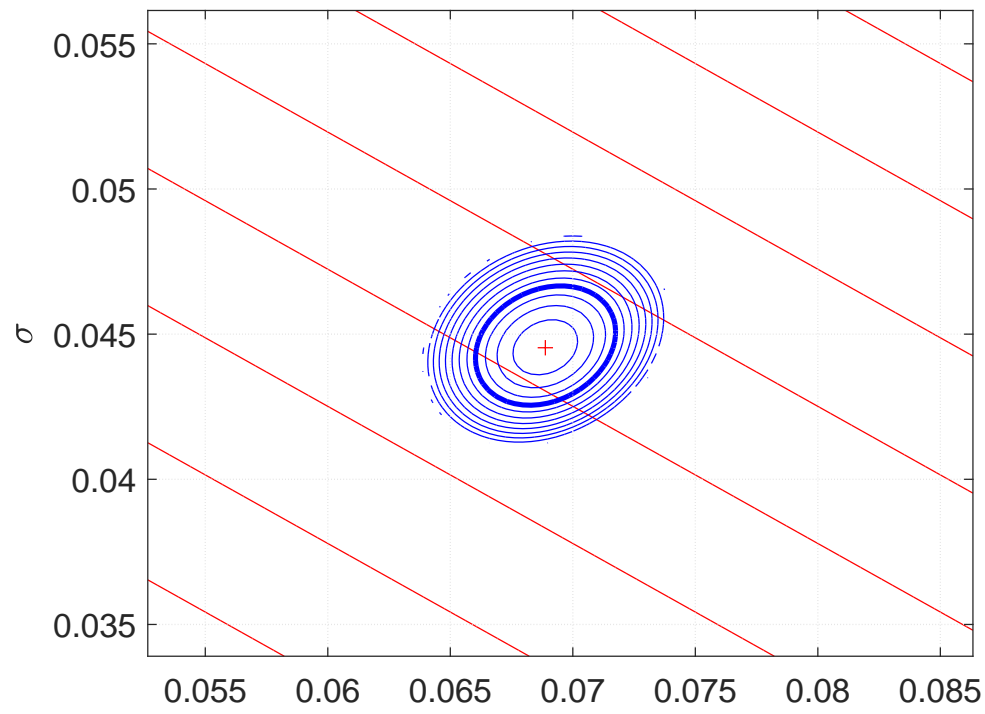

MLE = Maximum Likelihood Estimate, $95 \%$ CI for $\mu$ and $\sigma$ after $\stackrel{\mu}{7.00}$ yrs 


\section{Wise county after 7.00 yrs}

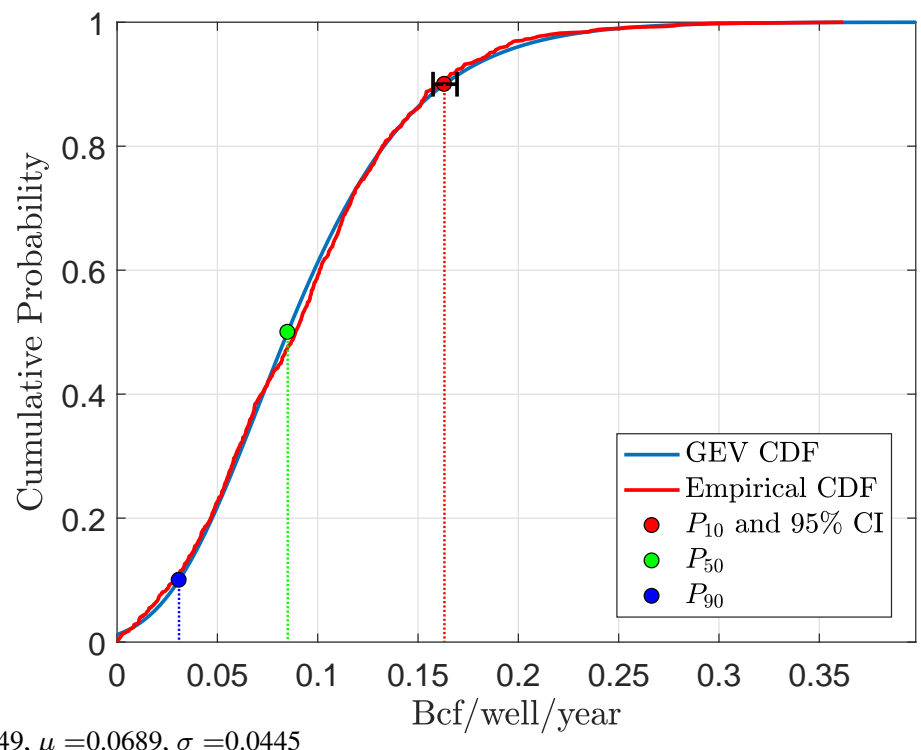

GEV cdf: $\xi=-0.0549, \mu=0.0689, \sigma=0.0445$ 


\section{Wise county after 8 yrs}

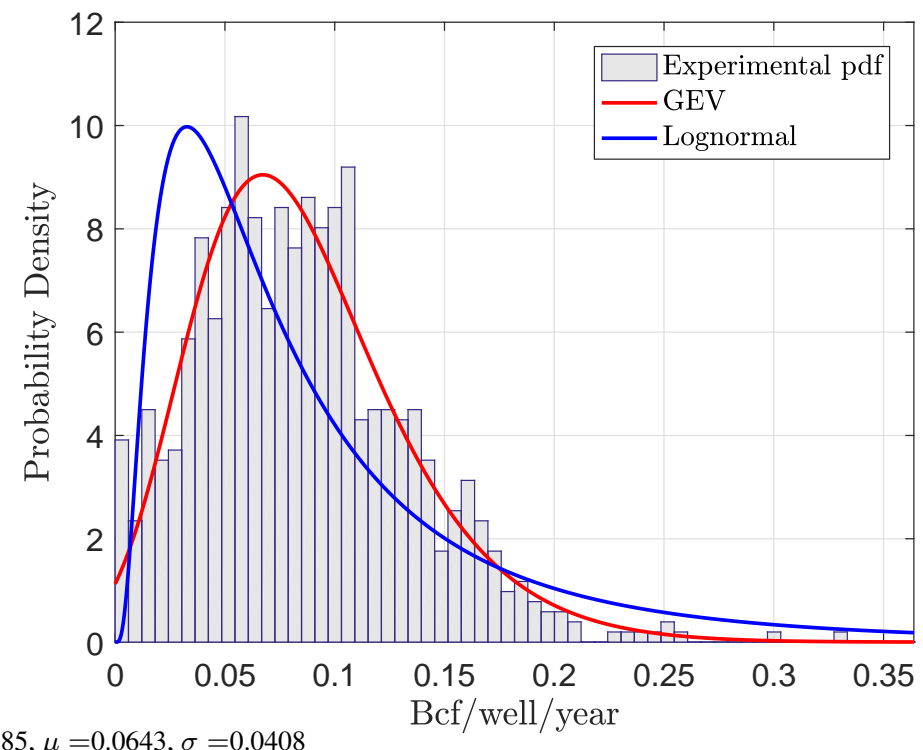

GEV pdf: $\xi=-0.0685, \mu=0.0643, \sigma=0.0408$ 


\section{MLE of GEV pdf in Wise county}

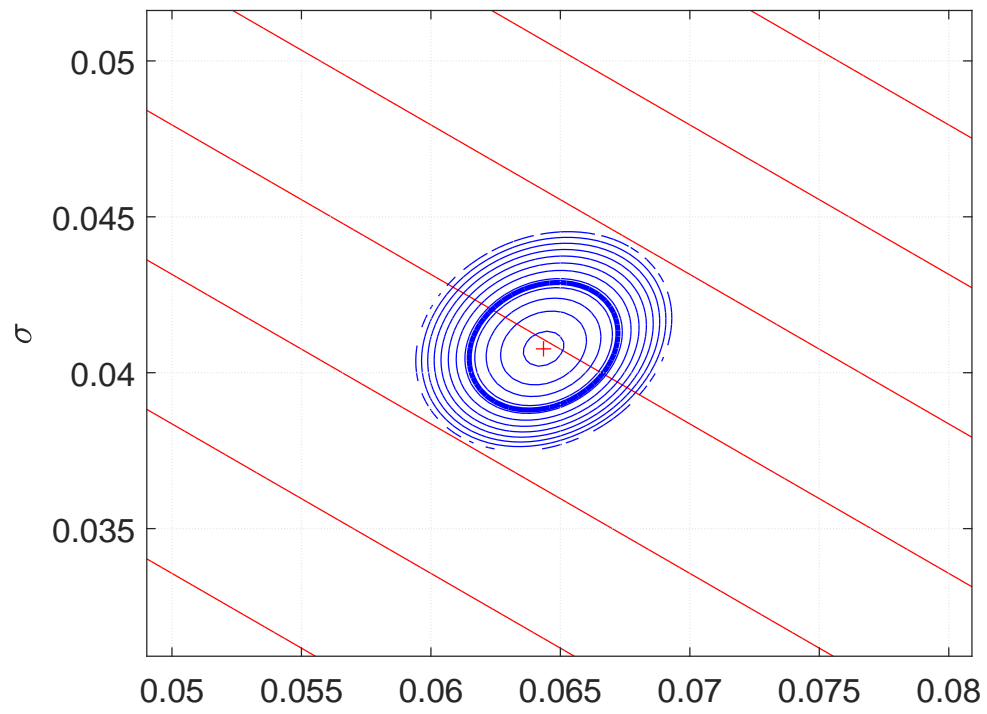

MLE $=$ Maximum Likelihood Estimate, $95 \%$ CI for $\mu$ and $\sigma$ after $\stackrel{\mu}{8.00}$ yrs 


\section{Wise county after 8.00 yrs}

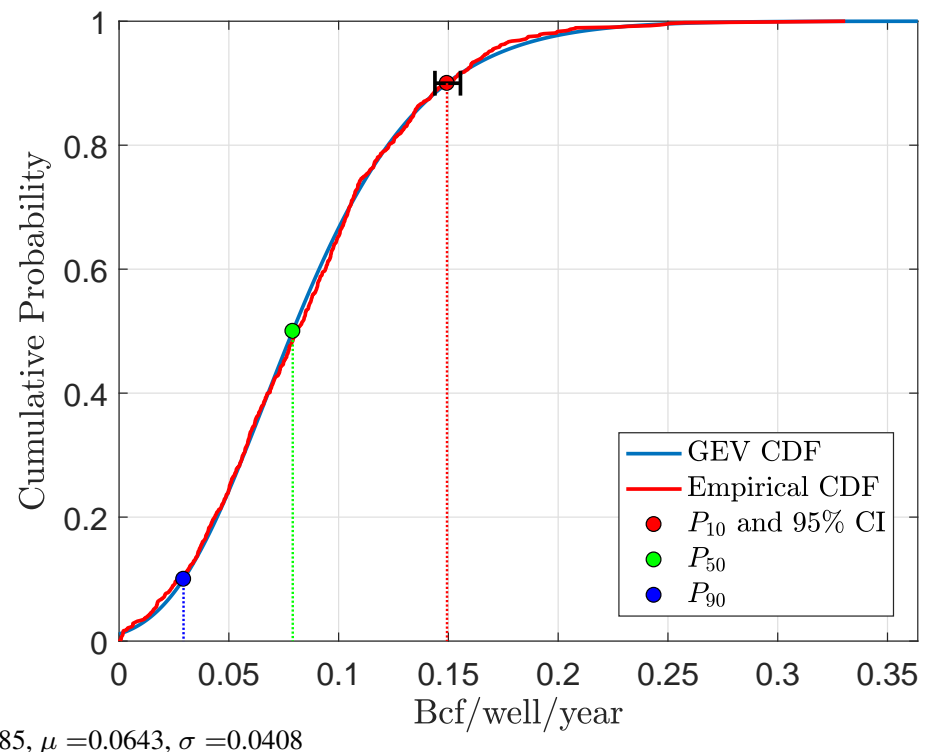

GEV cdf: $\xi=-0.0685, \mu=0.0643, \sigma=0.0408$ 


\section{Wise county after 9 yrs}

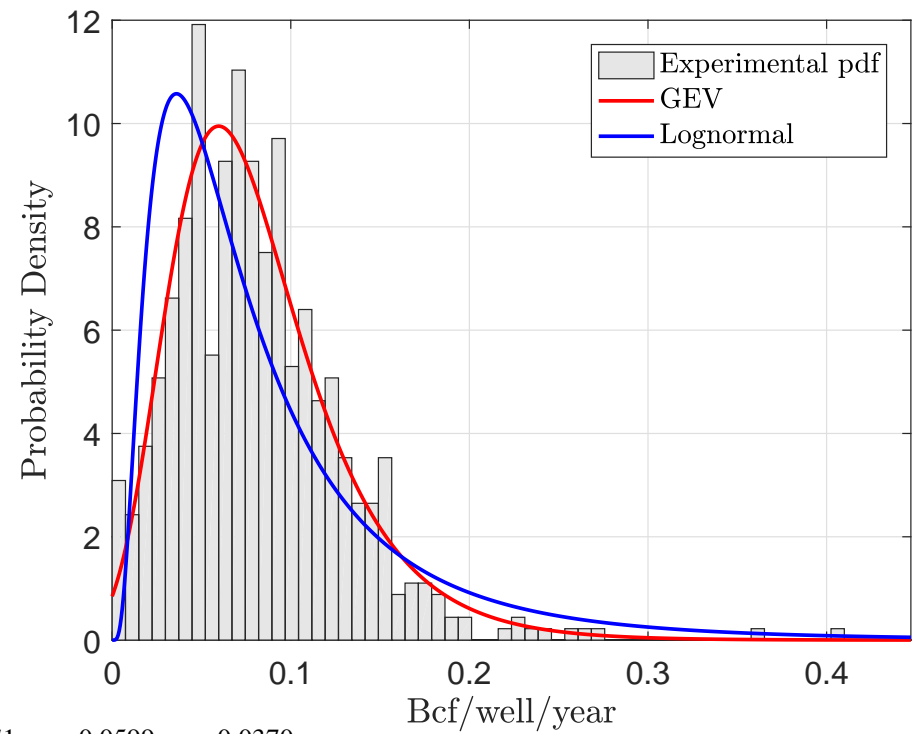

GEV pdf: $\xi=0.0071, \mu=0.0599, \sigma=0.0370$ 


\section{MLE of GEV pdf in Wise county}

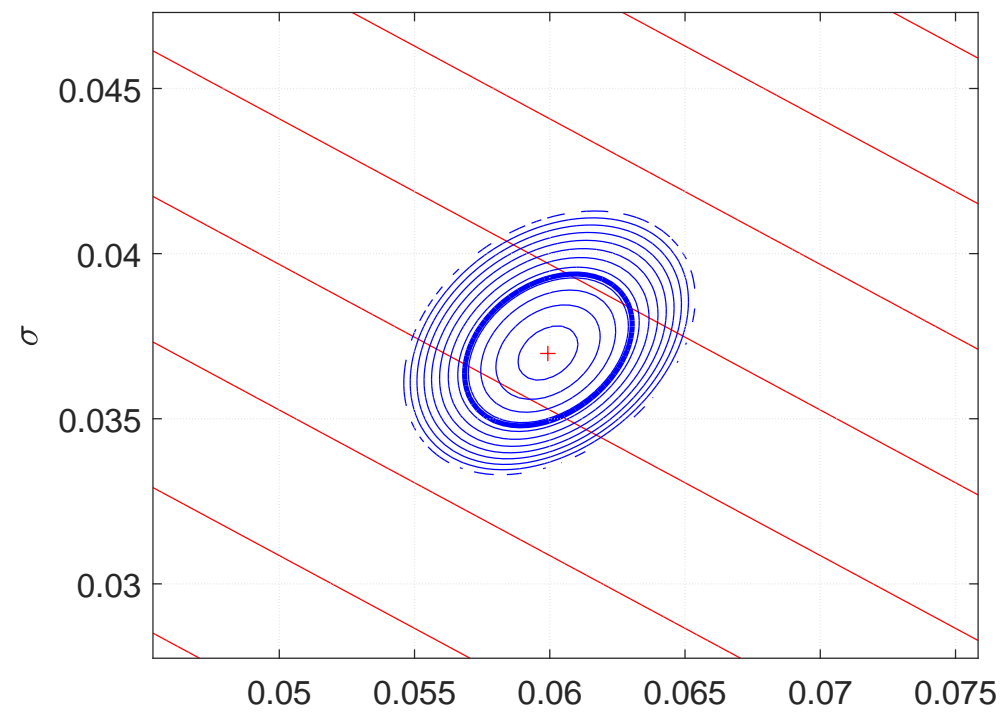

MLE $=$ Maximum Likelihood Estimate, $95 \%$ CI for $\mu$ and $\sigma$ after $\stackrel{\mu}{9.00}$ yrs 


\section{Wise county after 9.00 yrs}

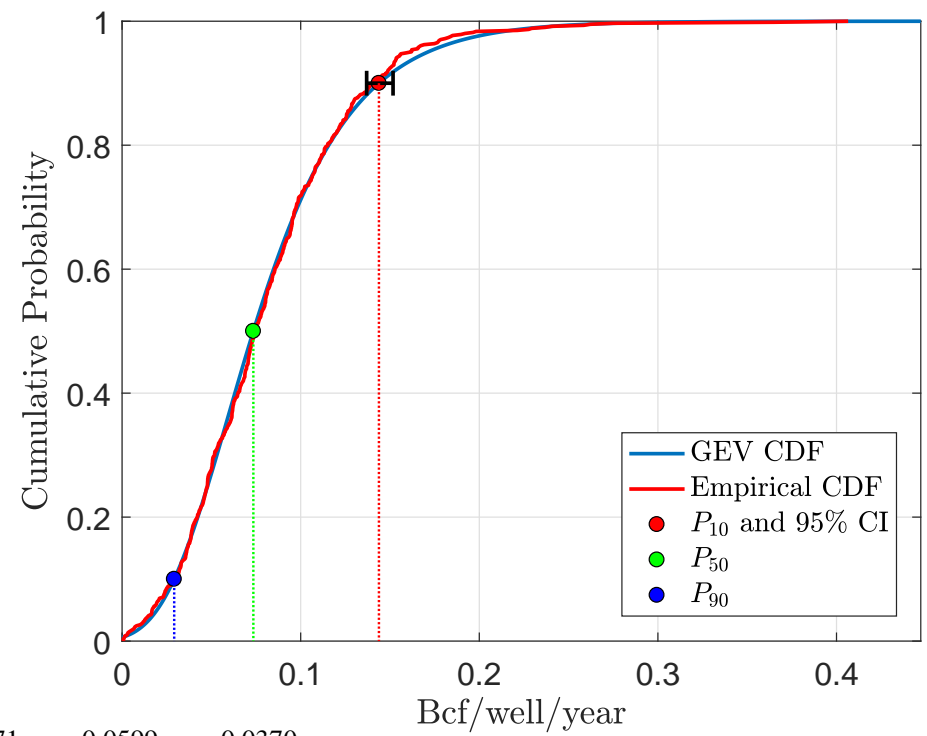

GEV cdf: $\xi=0.0071, \mu=0.0599, \sigma=0.0370$ 


\section{Wise county after 10 yrs}

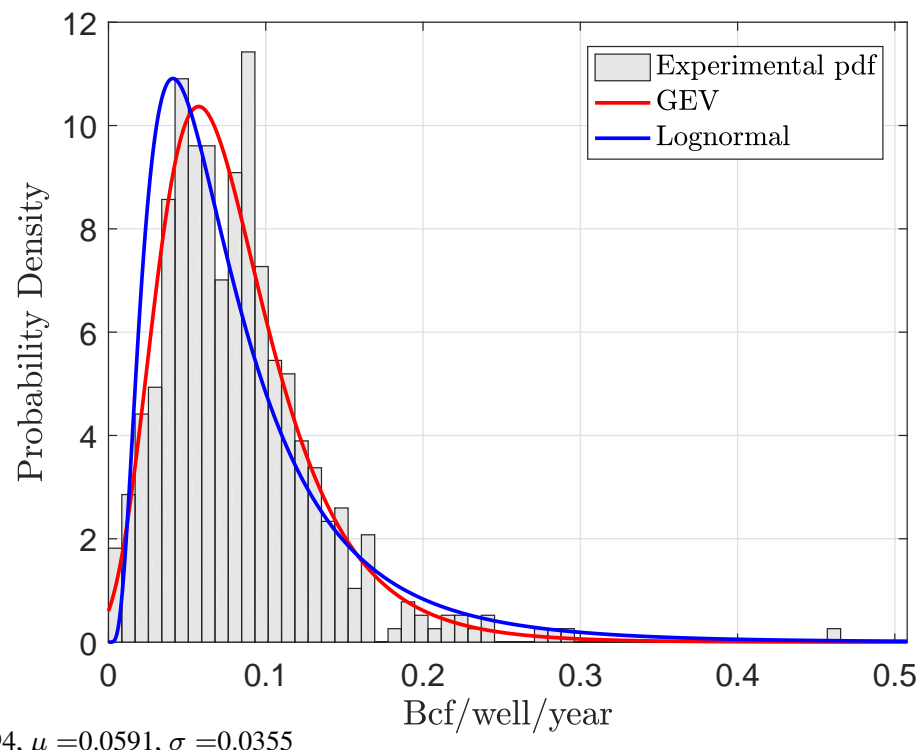

GEV pdf: $\xi=0.0494, \mu=0.0591, \sigma=0.0355$ 


\section{MLE of GEV pdf in Wise county}

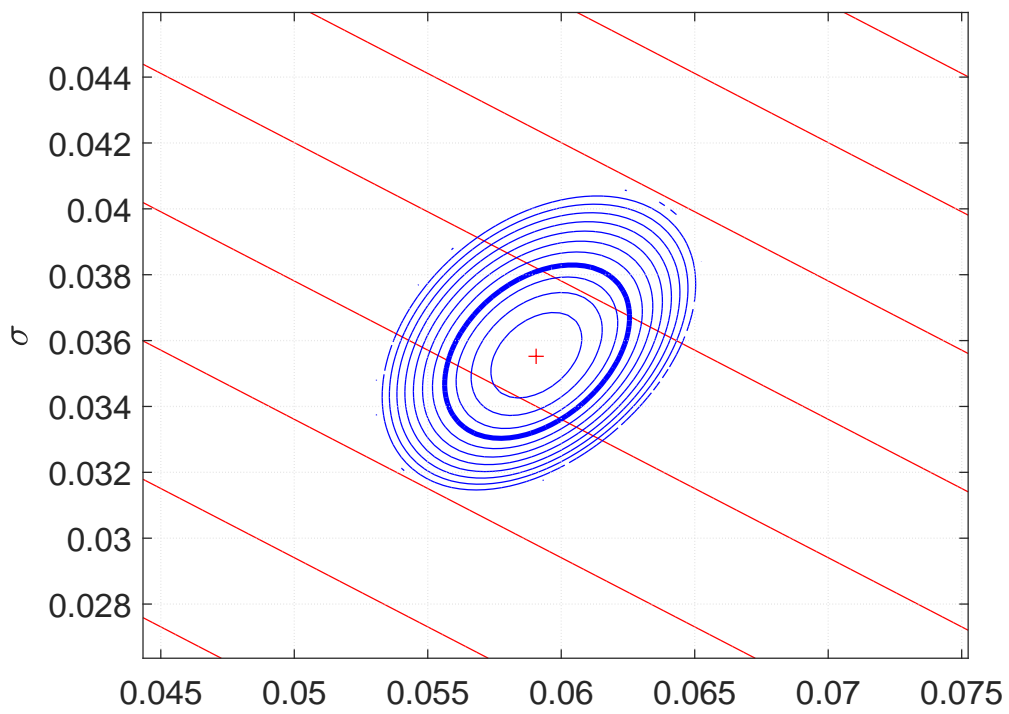

MLE = Maximum Likelihood Estimate, $95 \%$ CI for $\mu$ and $\sigma$ after $\stackrel{\mu}{10.00}$ yrs 


\section{Wise county after 10.00 yrs}

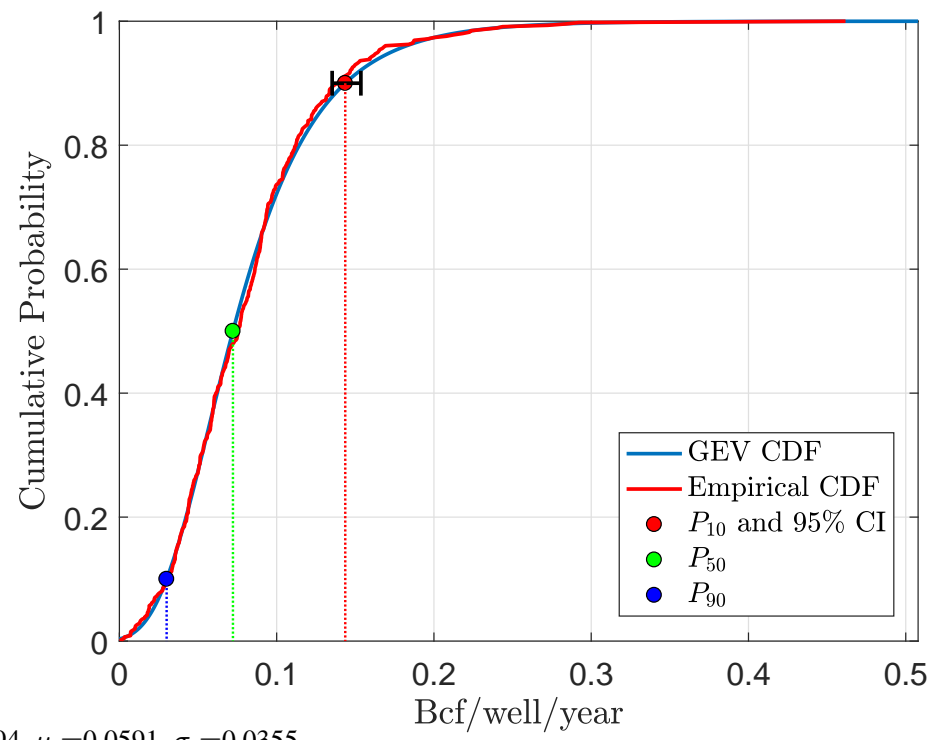

GEV cdf: $\xi=0.0494, \mu=0.0591, \sigma=0.0355$ 


\section{Wise county after 11 yrs}

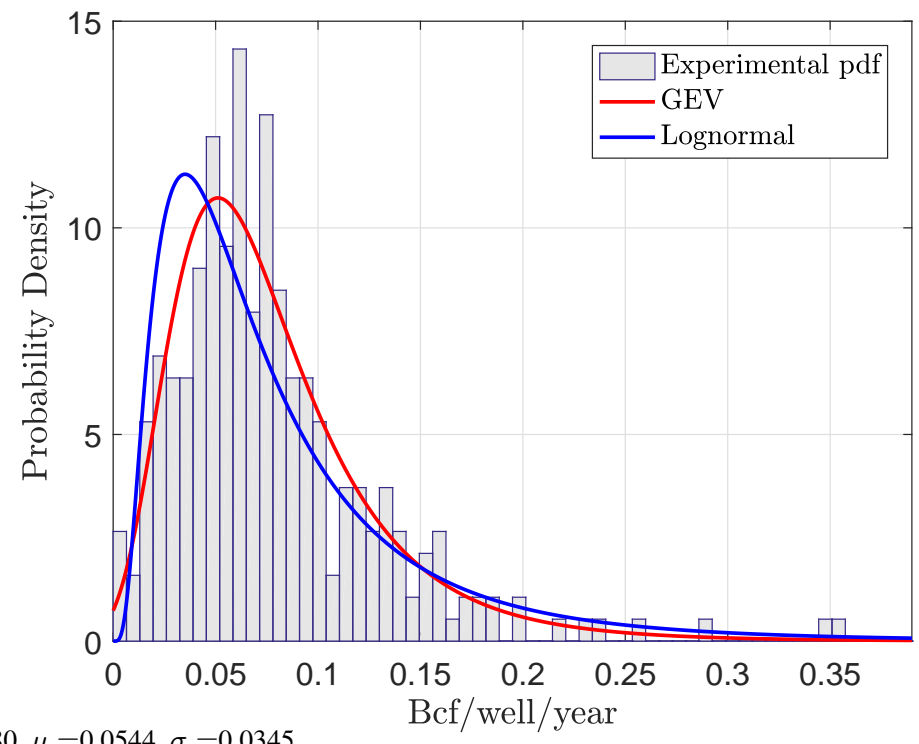

GEV pdf: $\xi=0.0980, \mu=0.0544, \sigma=0.0345$ 


\section{MLE of GEV pdf in Wise county}

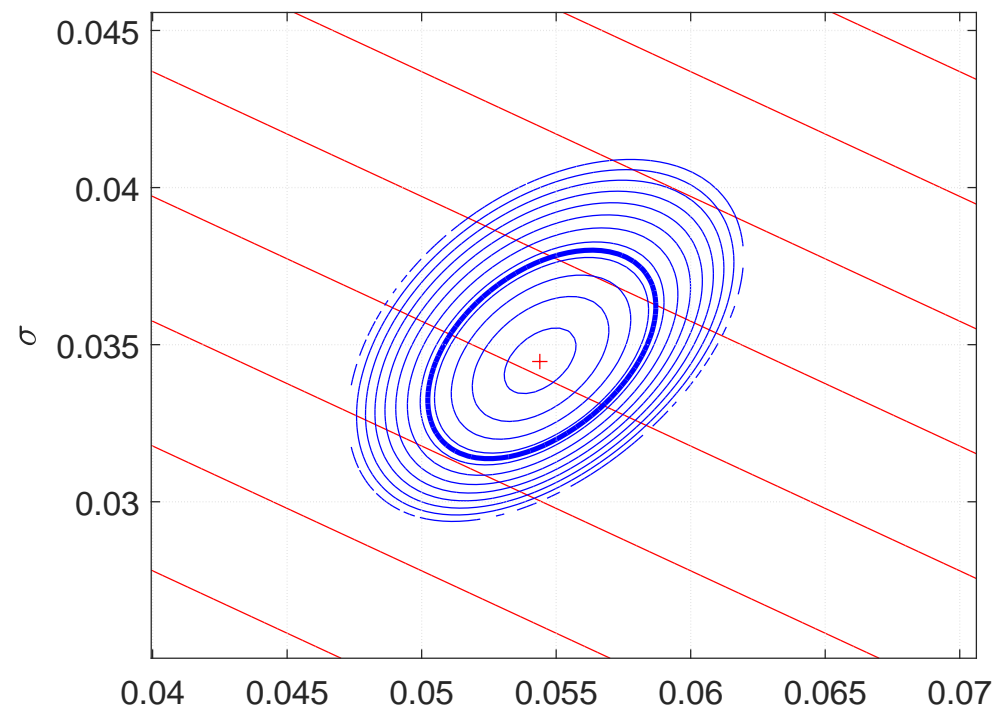

MLE $=$ Maximum Likelihood Estimate, 95\% CI for $\mu$ and $\sigma$ after $\mu 1.00$ yrs 


\section{Wise county after 11.00 yrs}

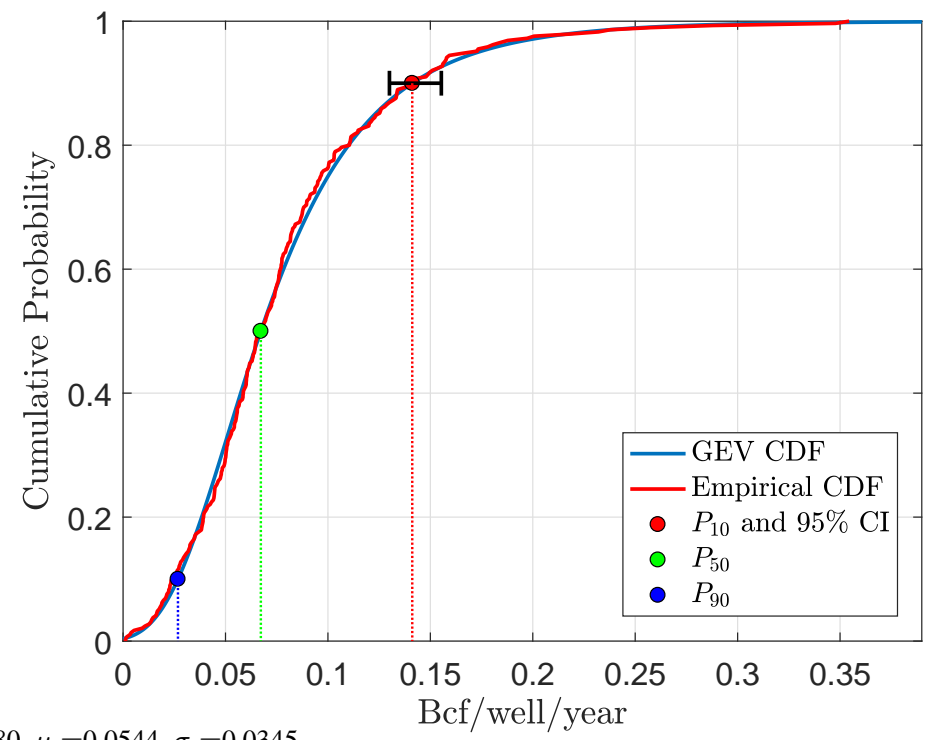

GEV cdf: $\xi=0.0980, \mu=0.0544, \sigma=0.0345$ 


\section{Wise county after 12 yrs}

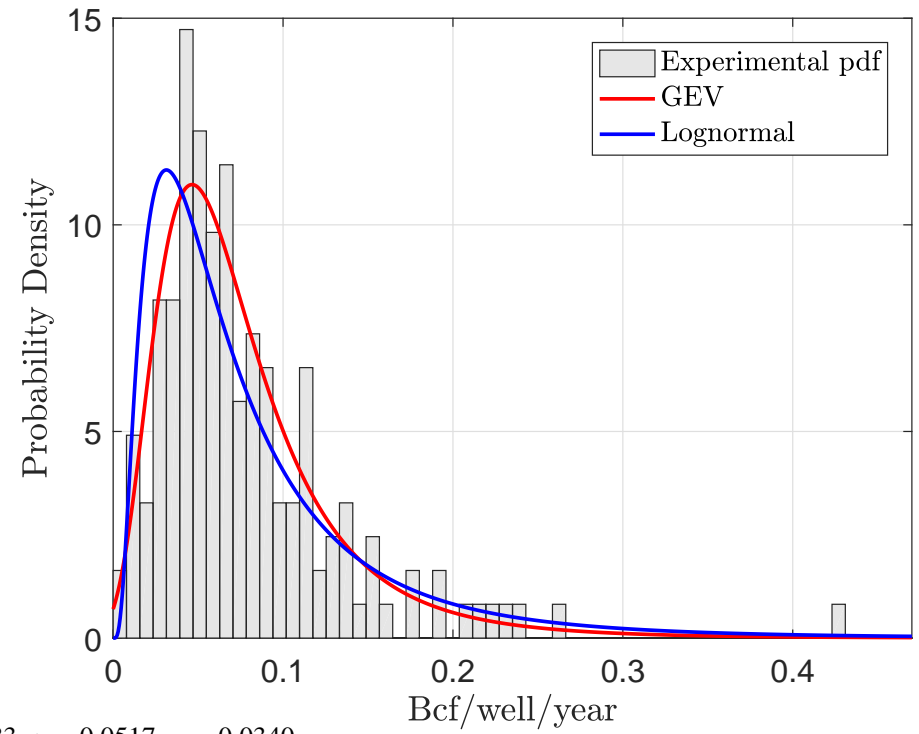

GEV pdf: $\xi=0.1683, \mu=0.0517, \sigma=0.0340$ 


\section{MLE of GEV pdf in Wise county}

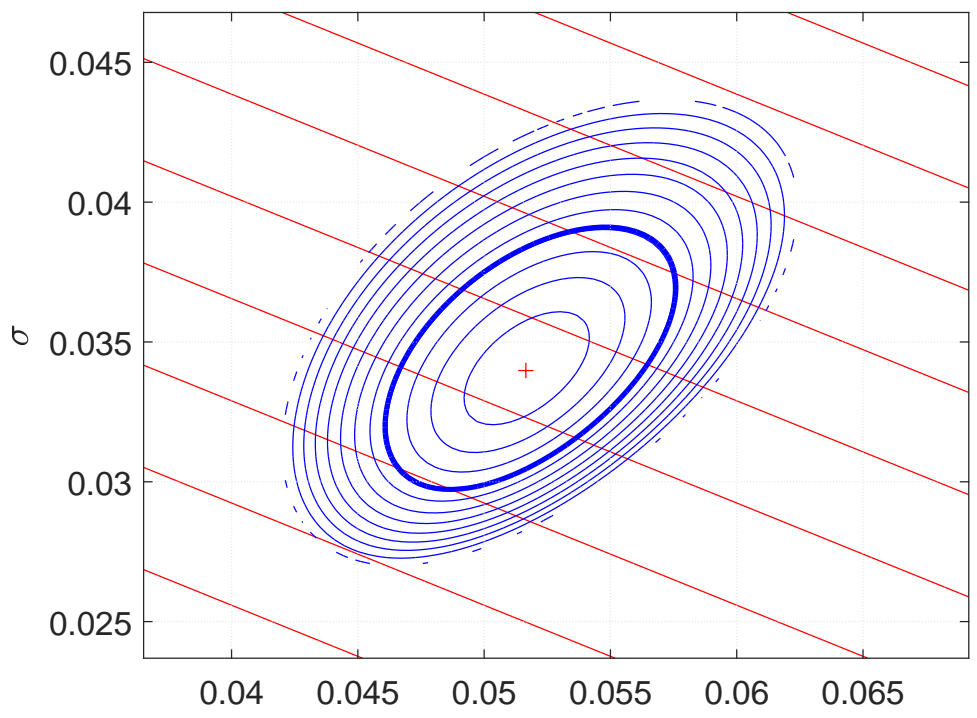

MLE = Maximum Likelihood Estimate, 95\% CI for $\mu$ and $\sigma$ after 12.00 yrs 


\section{Wise county after 12.00 yrs}

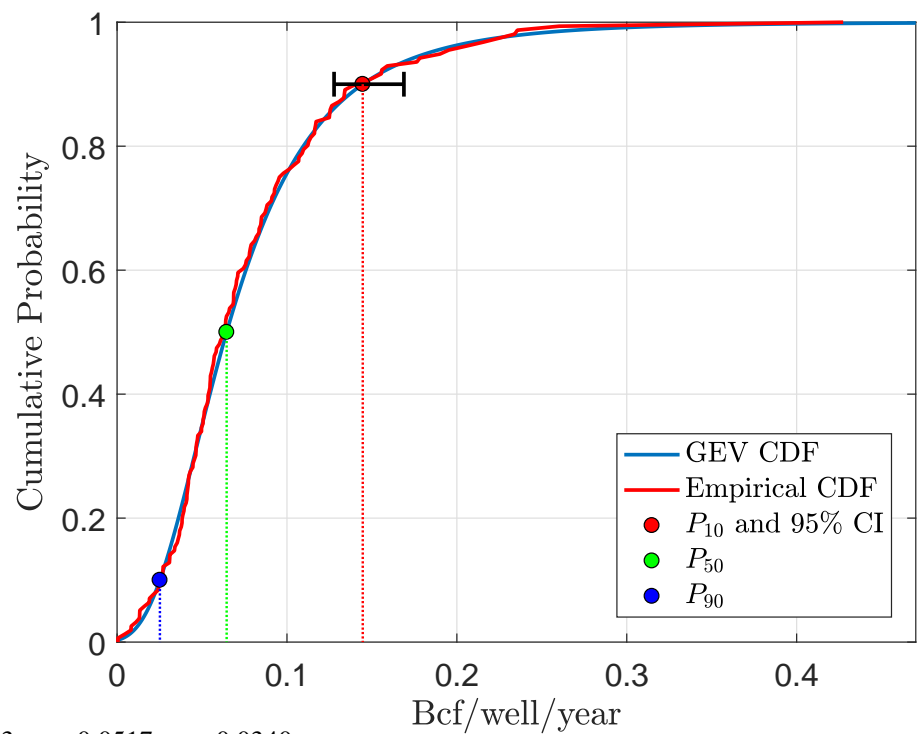

GEV cdf: $\xi=0.1683, \mu=0.0517, \sigma=0.0340$ 


\section{Wise county after 13 yrs}

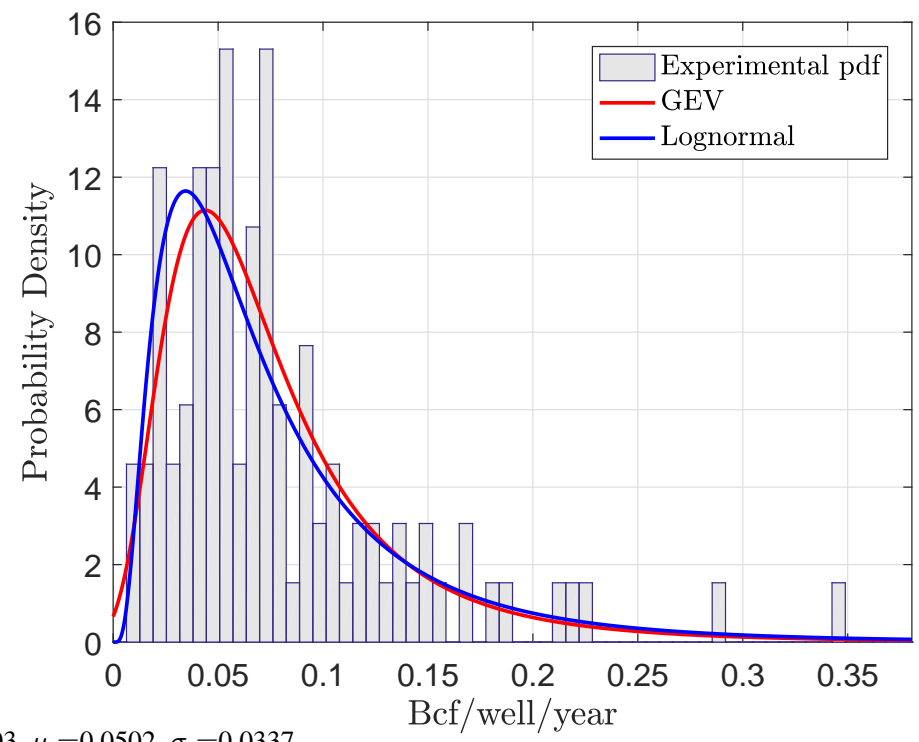

GEV pdf: $\xi=0.2103, \mu=0.0502, \sigma=0.0337$ 


\section{MLE of GEV pdf in Wise county}

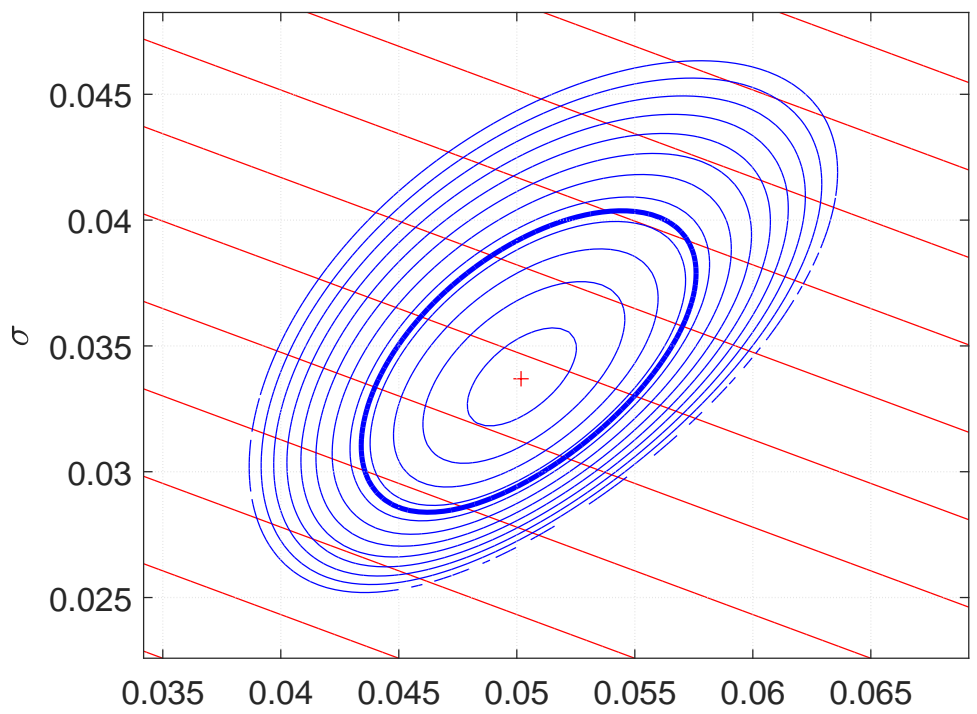

MLE $=$ Maximum Likelihood Estimate, $95 \%$ CI for $\mu$ and $\sigma$ after $13.00 \mathrm{yrs}$ 


\section{Wise county after 13.00 yrs}

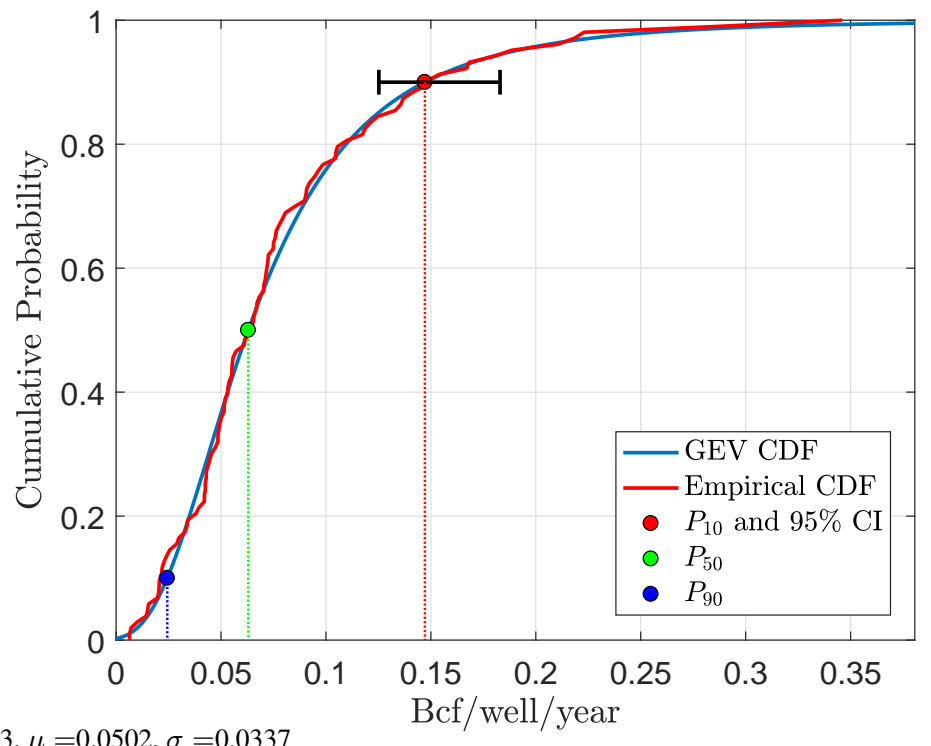

GEV cdf: $\xi=0.2103, \mu=0.0502, \sigma=0.0337$ 


\section{Wise county after 14 yrs}

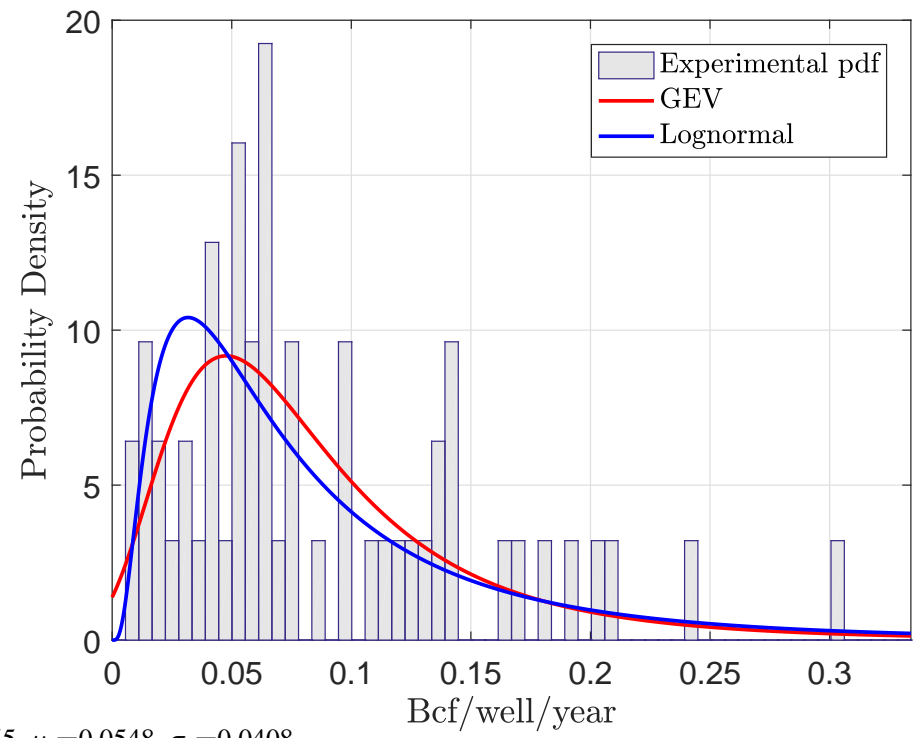

GEV pdf: $\xi=0.1955, \mu=0.0548, \sigma=0.0408$ 


\section{MLE of GEV pdf in Wise county}

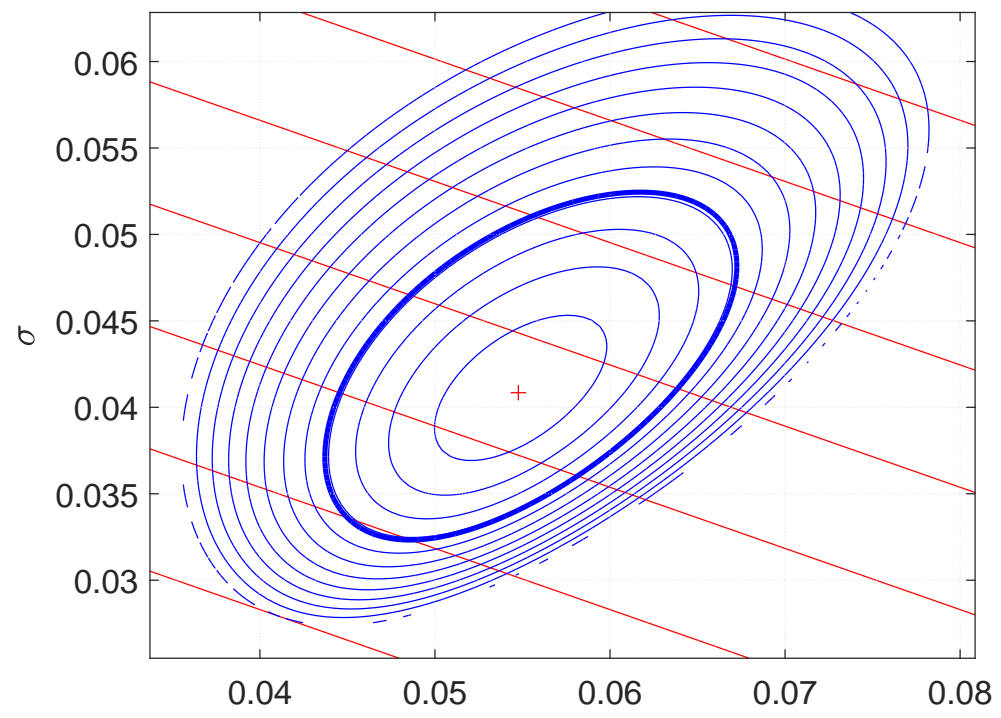

MLE = Maximum Likelihood Estimate, $95 \% \mathrm{CI}$ for $\mu$ and $\sigma$ after $\mu_{4.00}$ yrs 


\section{Wise county after 14.00 yrs}

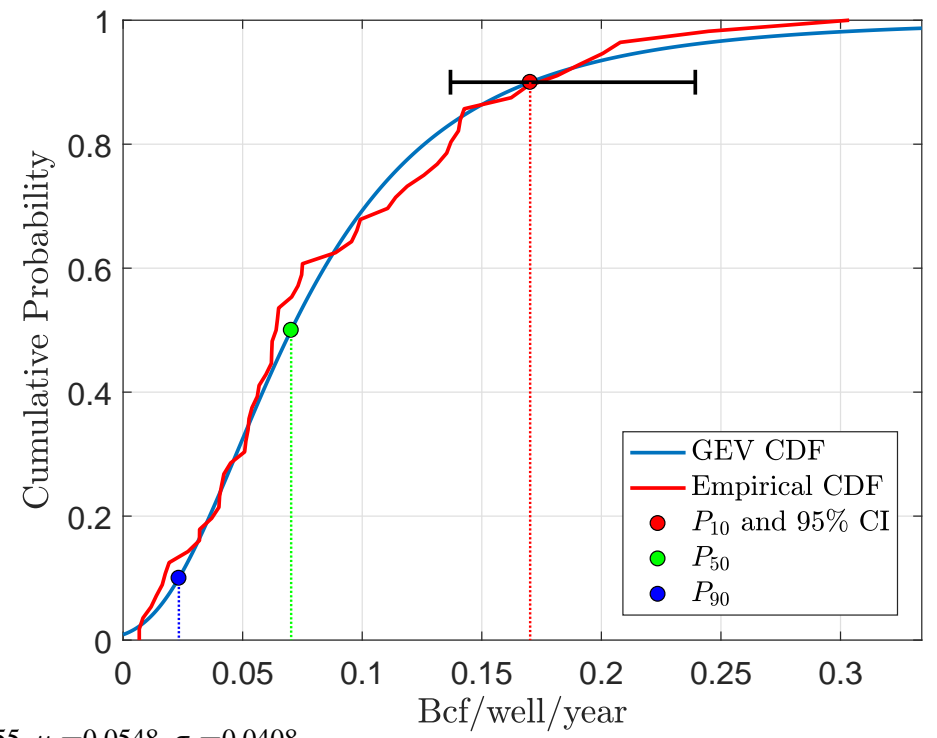

GEV cdf: $\xi=0.1955, \mu=0.0548, \sigma=0.0408$ 


\section{Wise county after 15 yrs}

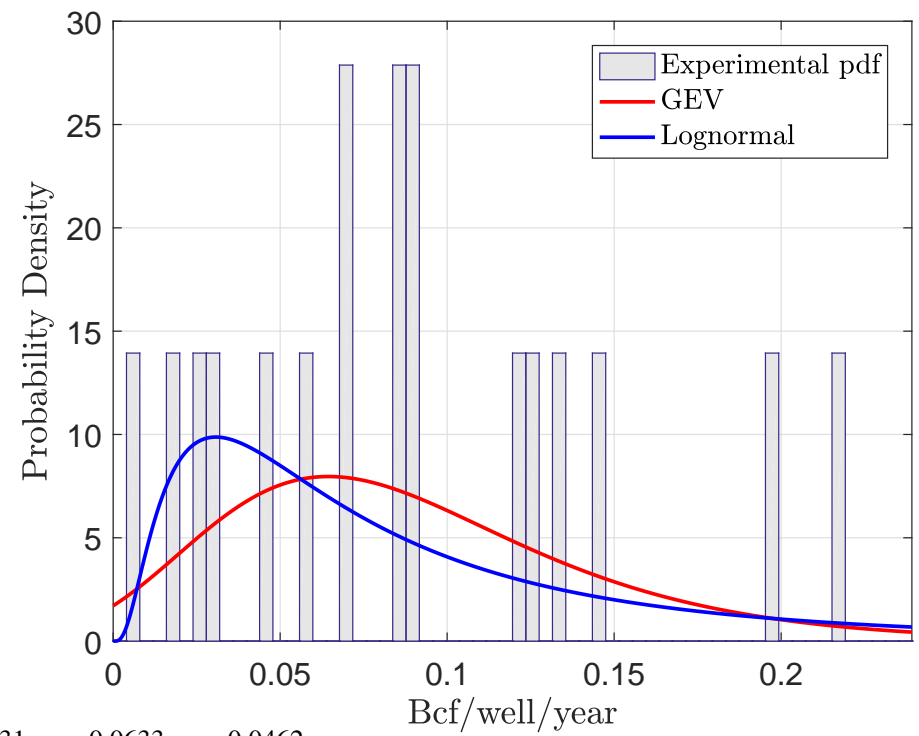

GEV pdf: $\xi=-0.0231, \mu=0.0633, \sigma=0.0462$ 


\section{MLE of GEV pdf in Wise county}

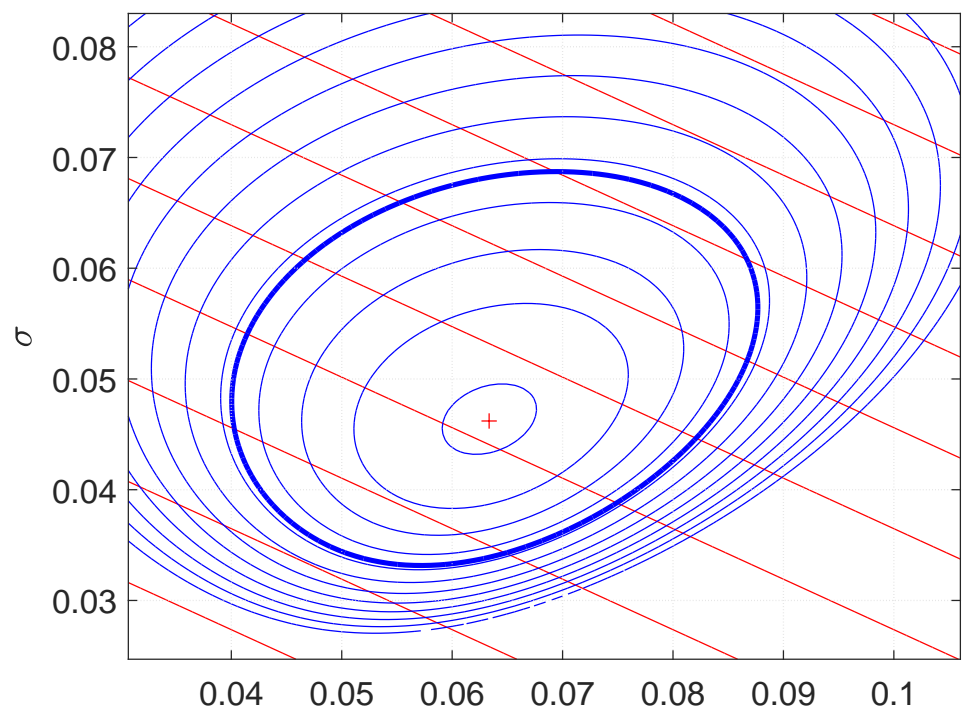

MLE $=$ Maximum Likelihood Estimate, $95 \%$ CI for $\mu$ and $\sigma$ after $15.00 \mathrm{yrs}$ 


\section{Wise county after 15.00 yrs}

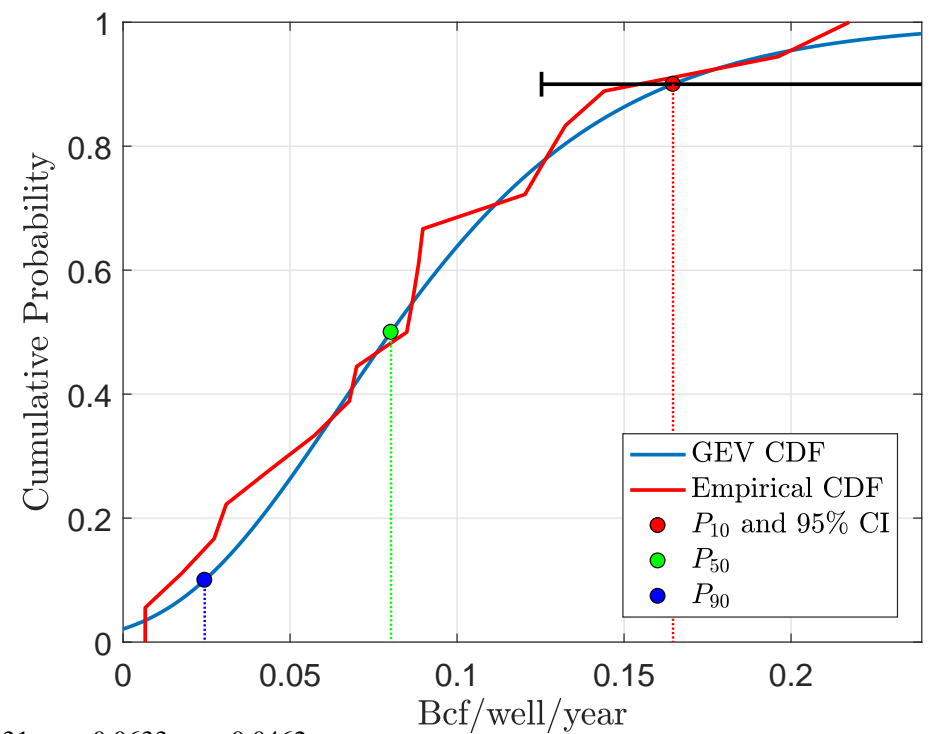

GEV cdf: $\xi=-0.0231, \mu=0.0633, \sigma=0.0462$ 


\section{Denton county after 1 yrs}

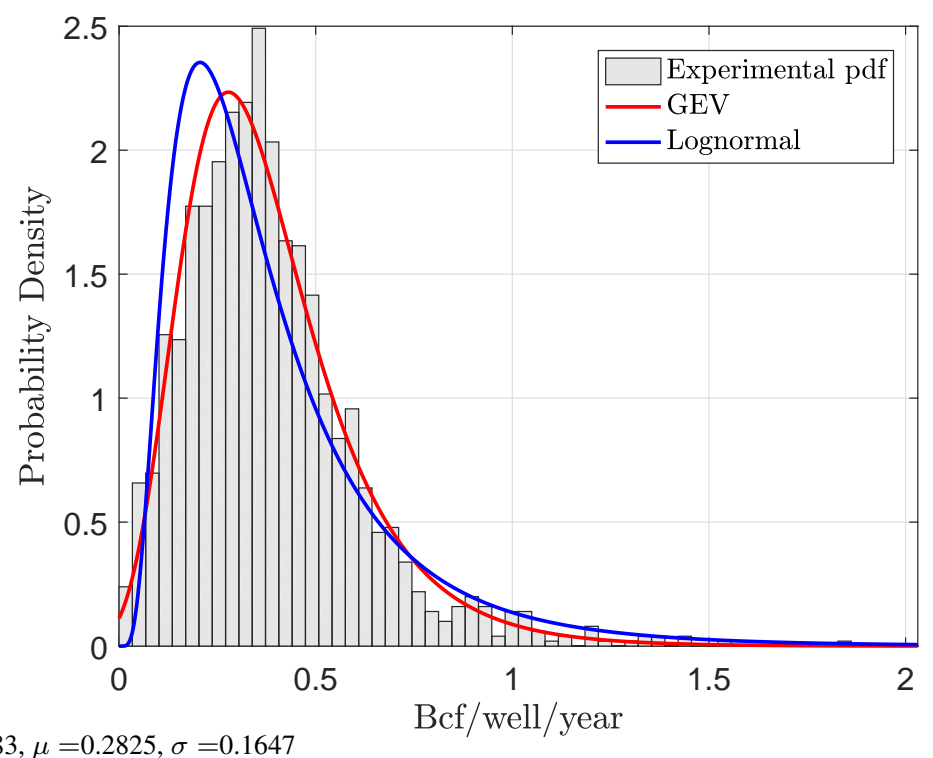

GEV pdf: $\xi=0.0283, \mu=0.2825, \sigma=0.1647$ 


\section{MLE of GEV pdf in Denton county}

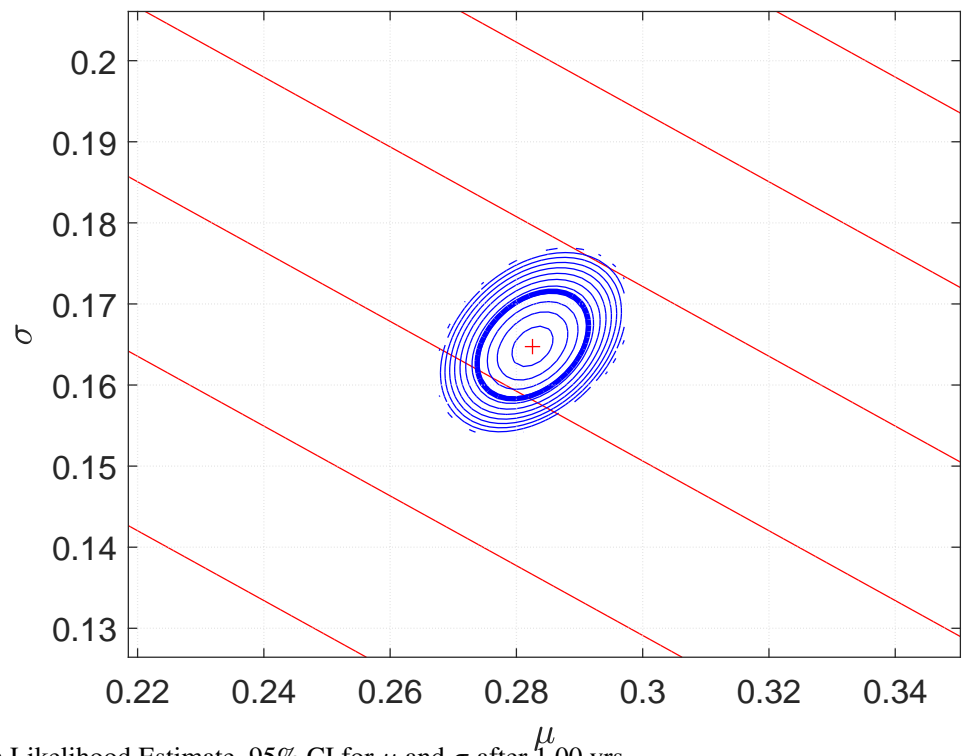

MLE $=$ Maximum Likelihood Estimate, $95 \%$ CI for $\mu$ and $\sigma$ after $1.00 \mathrm{yrs}$ 


\section{Denton county after 1.00 yrs}

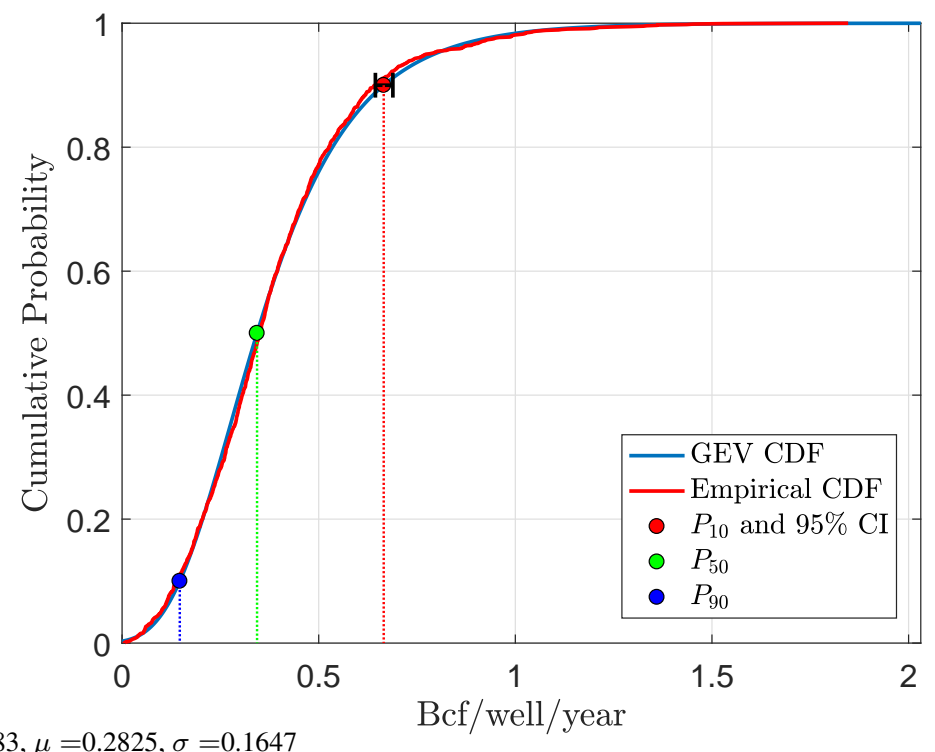

GEV cdf: $\xi=0.0283, \mu=0.2825, \sigma=0.1647$ 


\section{Denton county after 2 yrs}

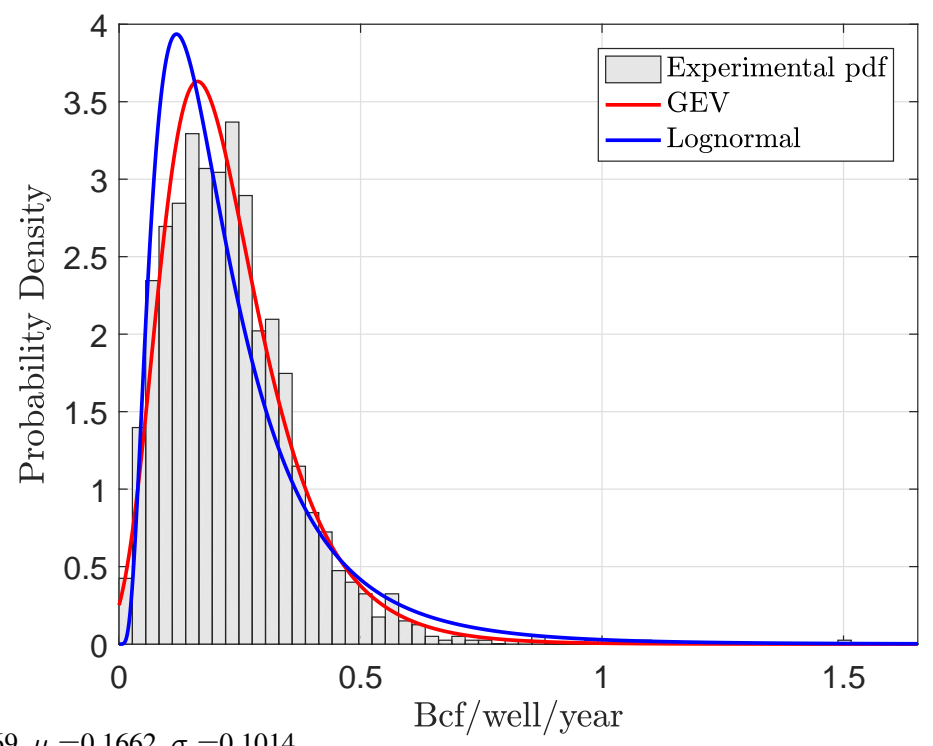

GEV pdf: $\xi=0.0369, \mu=0.1662, \sigma=0.1014$ 


\section{MLE of GEV pdf in Denton county}

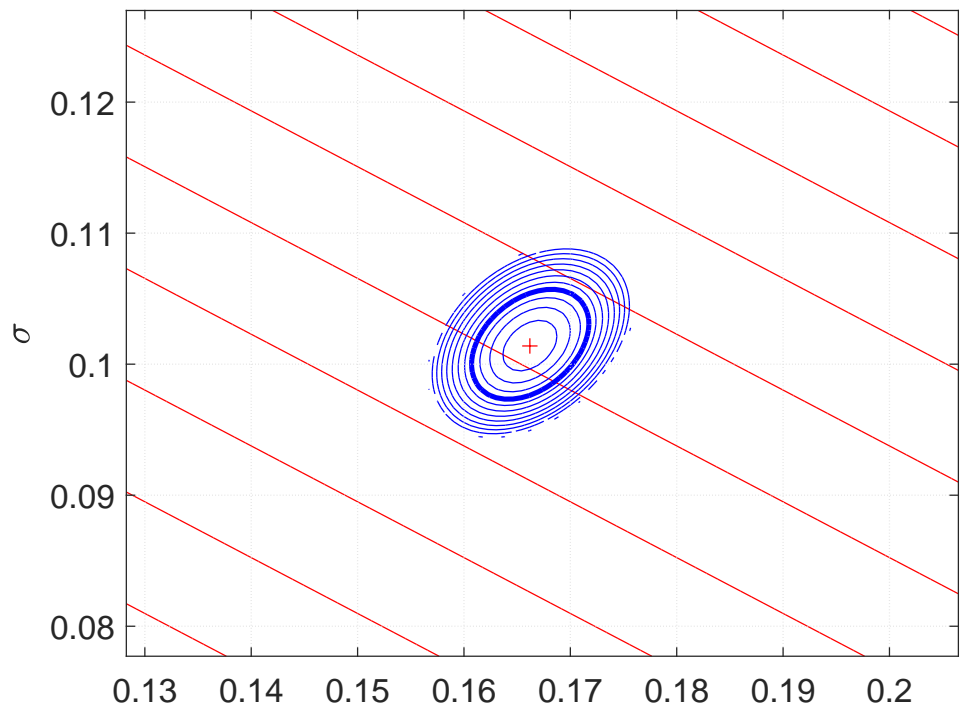

MLE $=$ Maximum Likelihood Estimate, $95 \%$ CI for $\mu$ and $\sigma$ after 2.00 yrs 


\section{Denton county after 2.00 yrs}

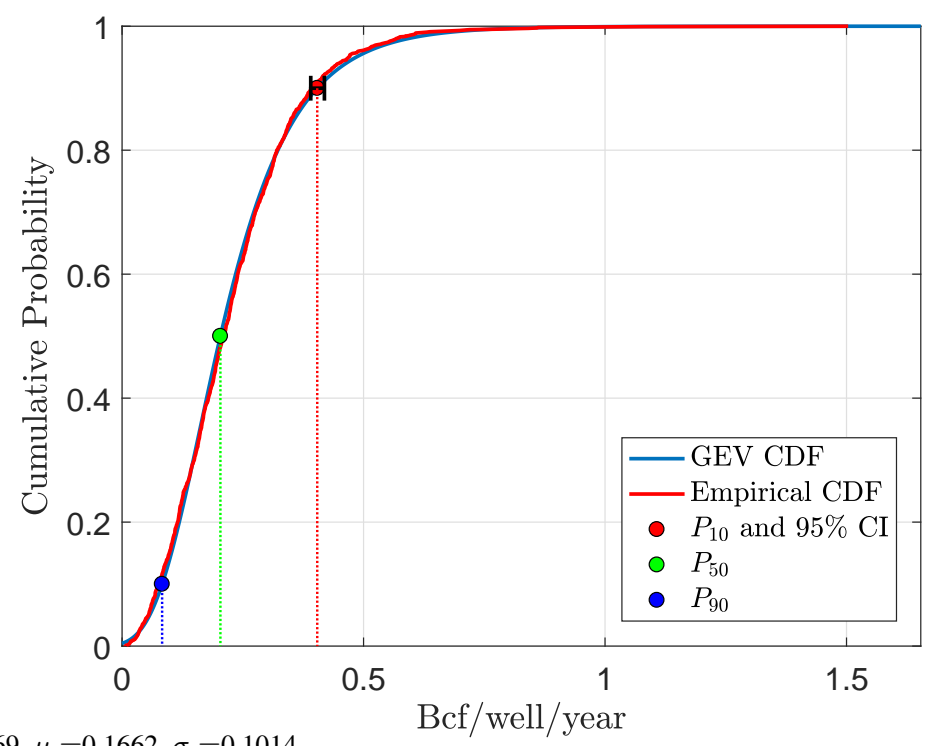

GEV cdf: $\xi=0.0369, \mu=0.1662, \sigma=0.1014$ 


\section{Denton county after 3 yrs}

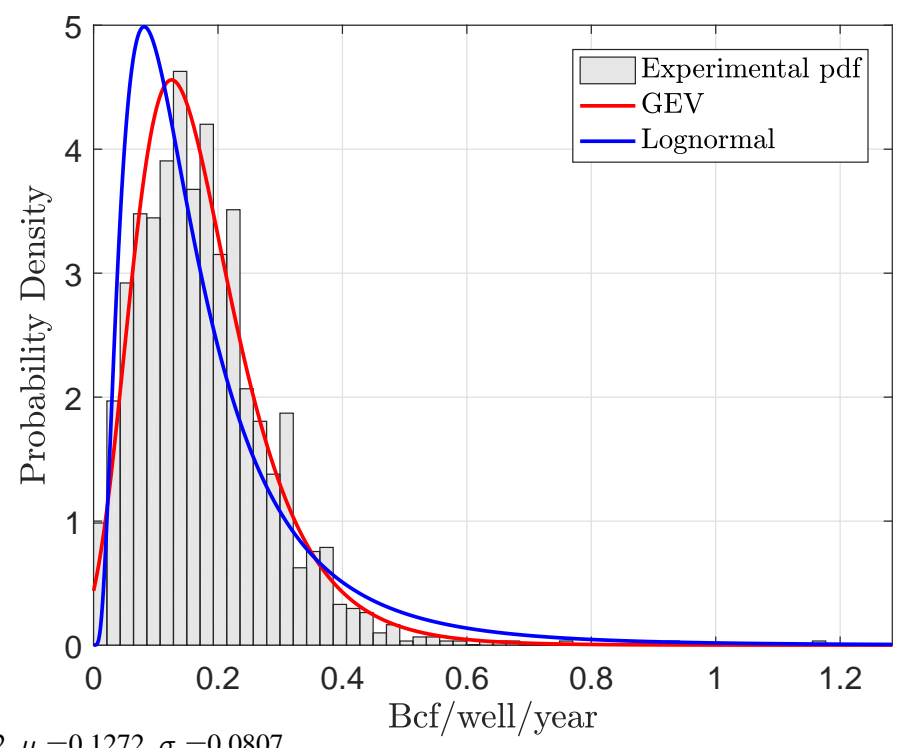

GEV pdf: $\xi=0.0242, \mu=0.1272, \sigma=0.0807$ 


\section{MLE of GEV pdf in Denton county}

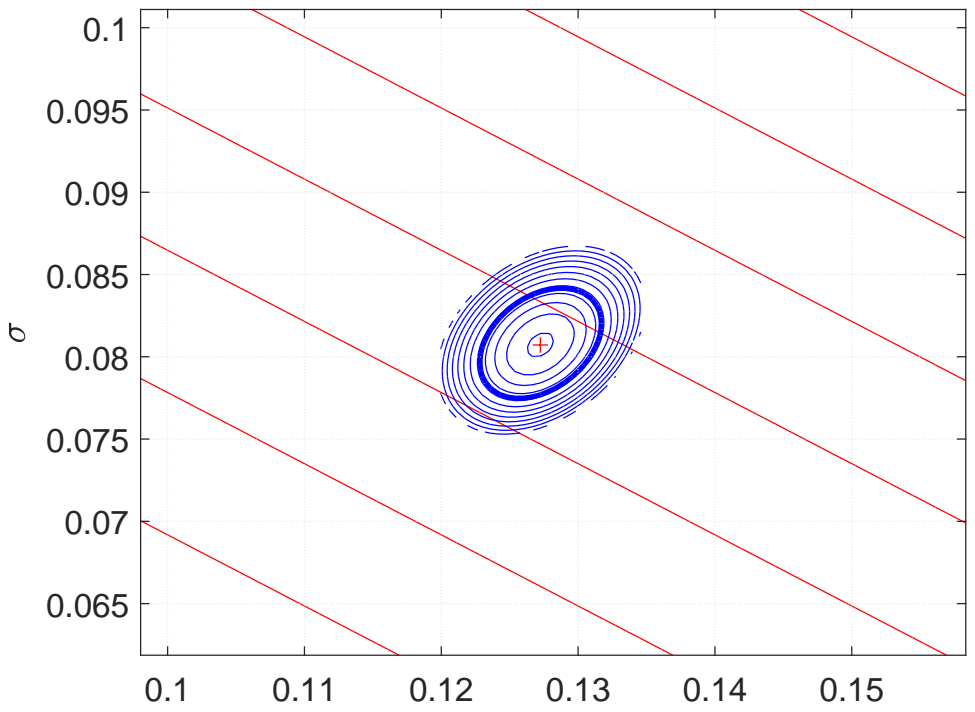

MLE $=$ Maximum Likelihood Estimate, $95 \%$ CI for $\mu$ and $\sigma$ after 3.00 yrs 


\section{Denton county after 3.00 yrs}

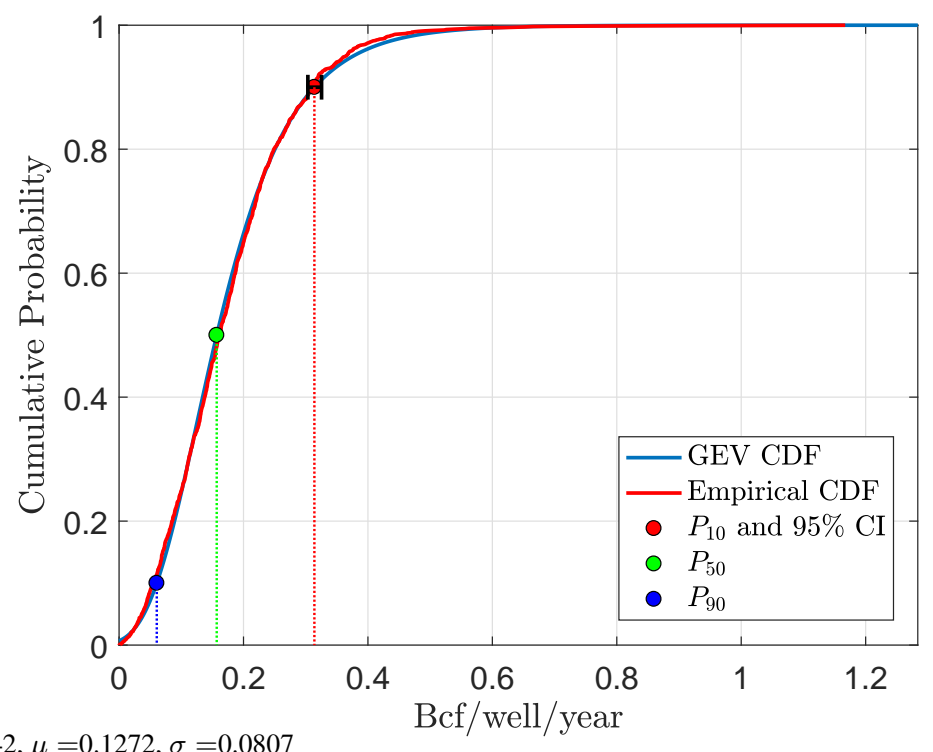

GEV cdf: $\xi=0.0242, \mu=0.1272, \sigma=0.0807$ 


\section{Denton county after 4 yrs}

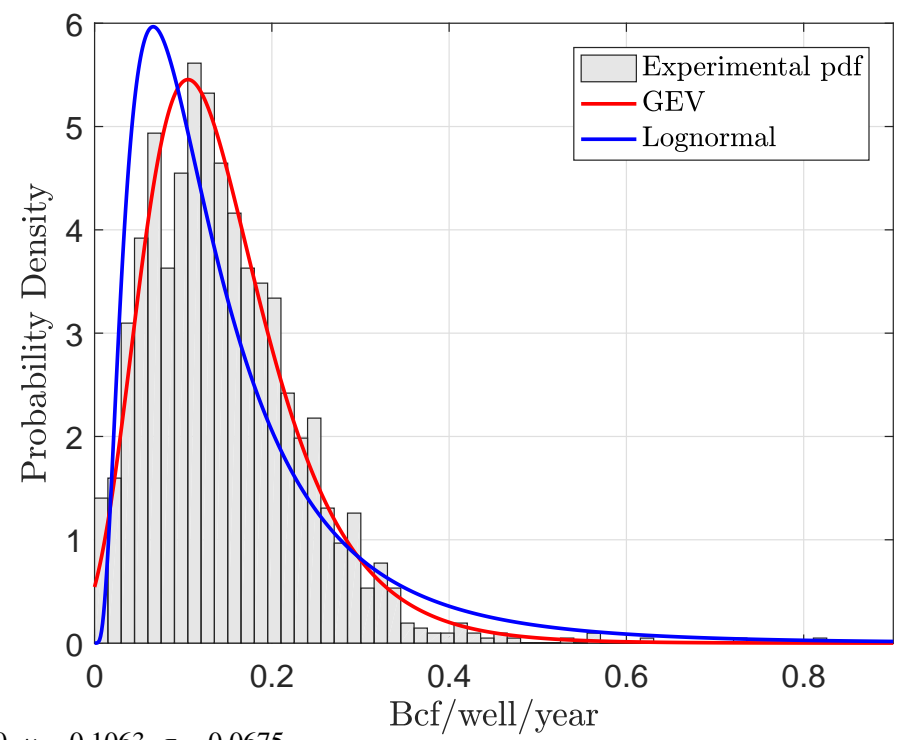

GEV pdf: $\xi=0.0140, \mu=0.1063, \sigma=0.0675$ 


\section{MLE of GEV pdf in Denton county}

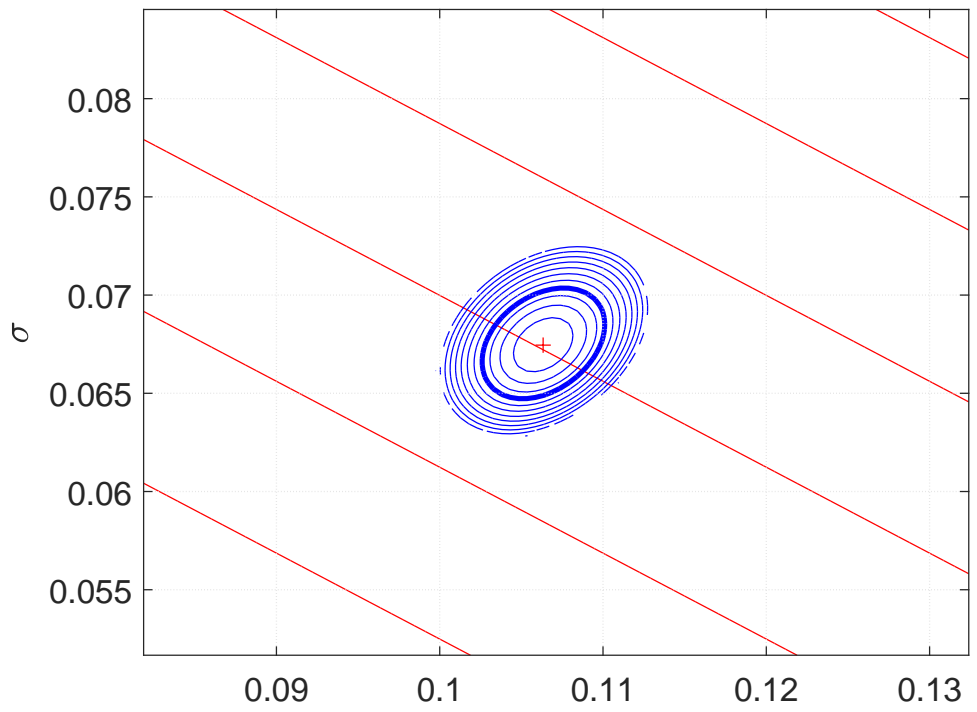

MLE = Maximum Likelihood Estimate, $95 \%$ CI for $\mu$ and $\sigma$ after 4.00 yrs 


\section{Denton county after 4.00 yrs}

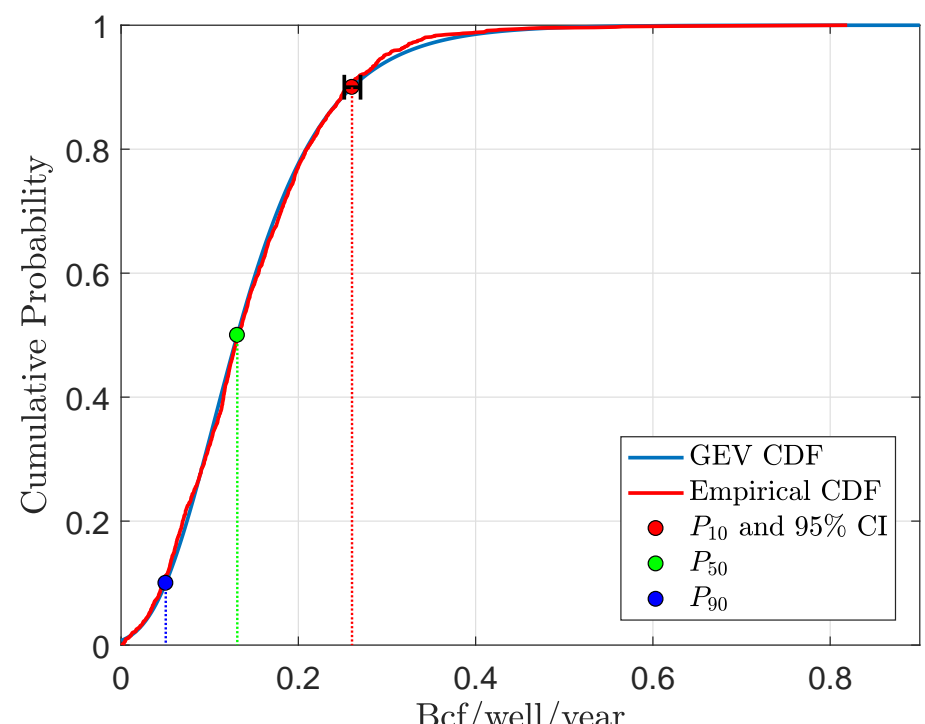

GEV cdf: $\xi=0.0140, \mu=0.1063, \sigma=0.0675$ 


\section{Denton county after 5 yrs}

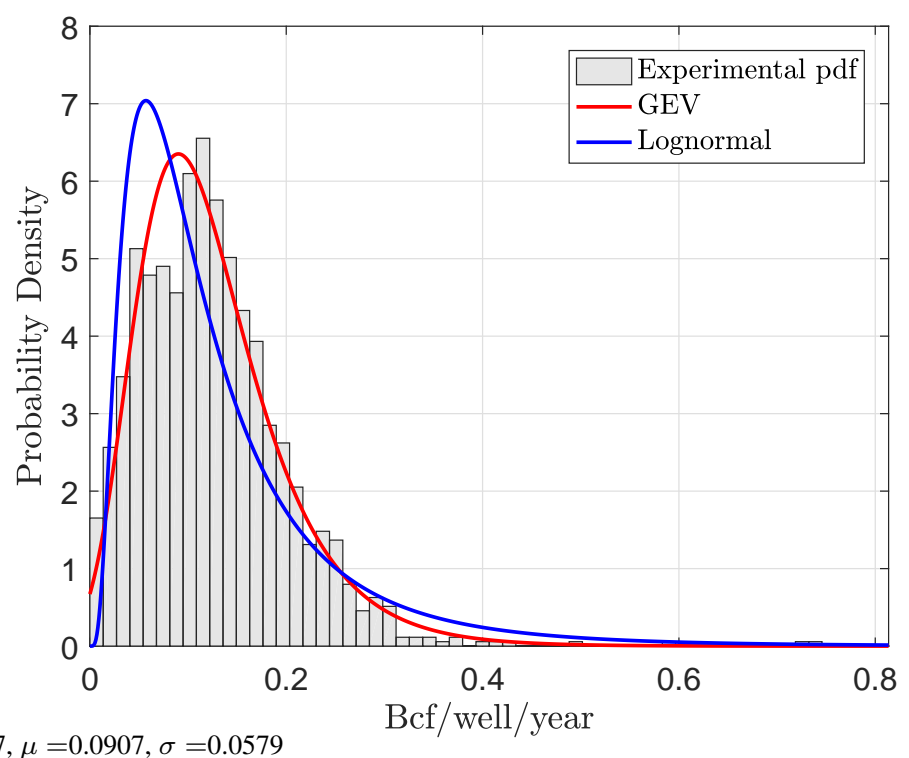

GEV pdf: $\xi=0.0087, \mu=0.0907, \sigma=0.0579$ 


\section{MLE of GEV pdf in Denton county}

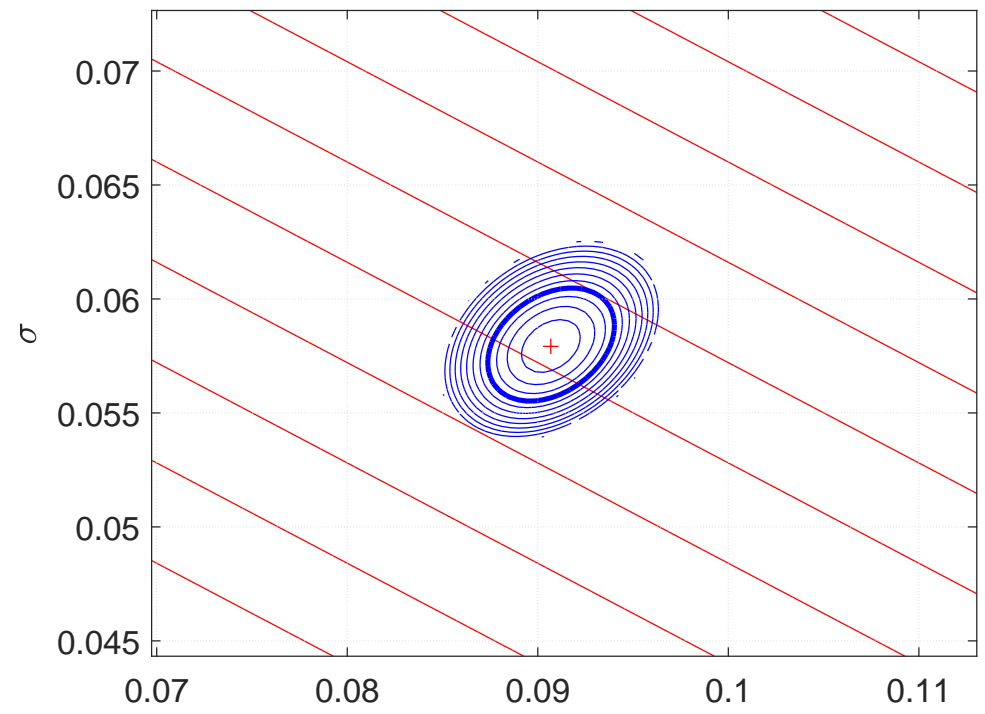

MLE $=$ Maximum Likelihood Estimate, $95 \%$ CI for $\mu$ and $\sigma$ after $5.00 \mathrm{yrs}$ 


\section{Denton county after 5.00 yrs}

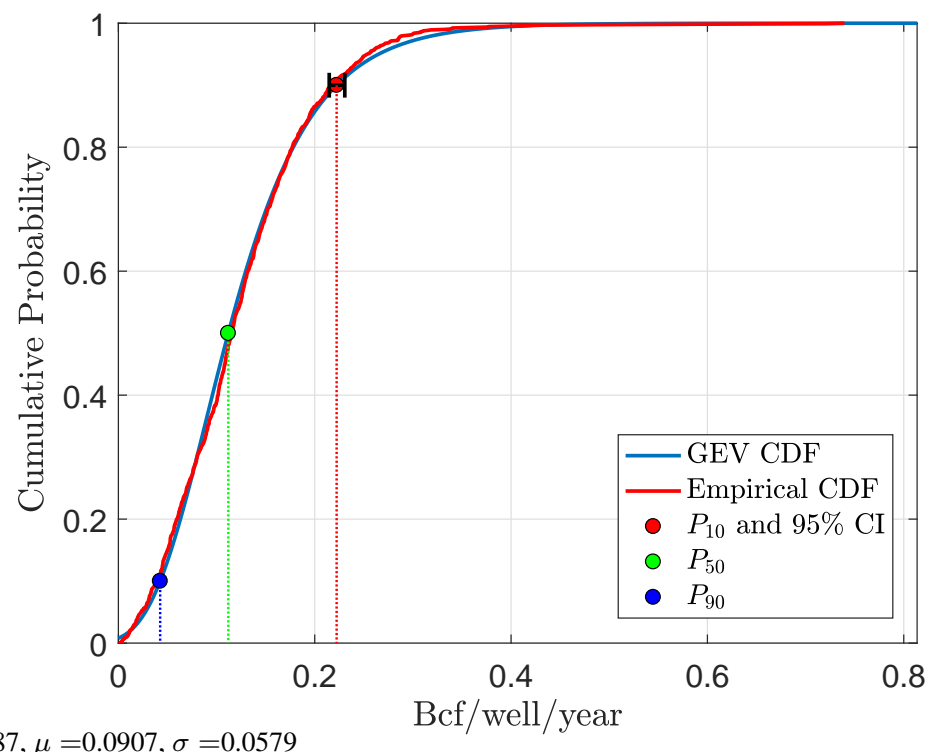

GEV cdf: $\xi=0.0087, \mu=0.0907, \sigma=0.0579$ 


\section{Denton county after 6 yrs}

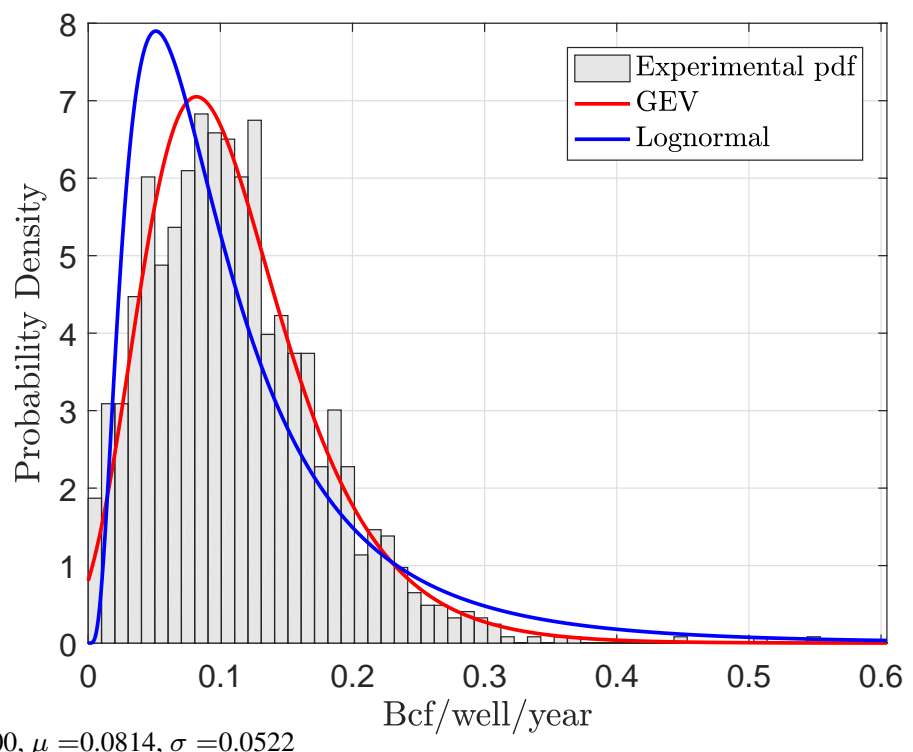

GEV pdf: $\xi=-0.0100, \mu=0.0814, \sigma=0.0522$ 


\section{MLE of GEV pdf in Denton county}

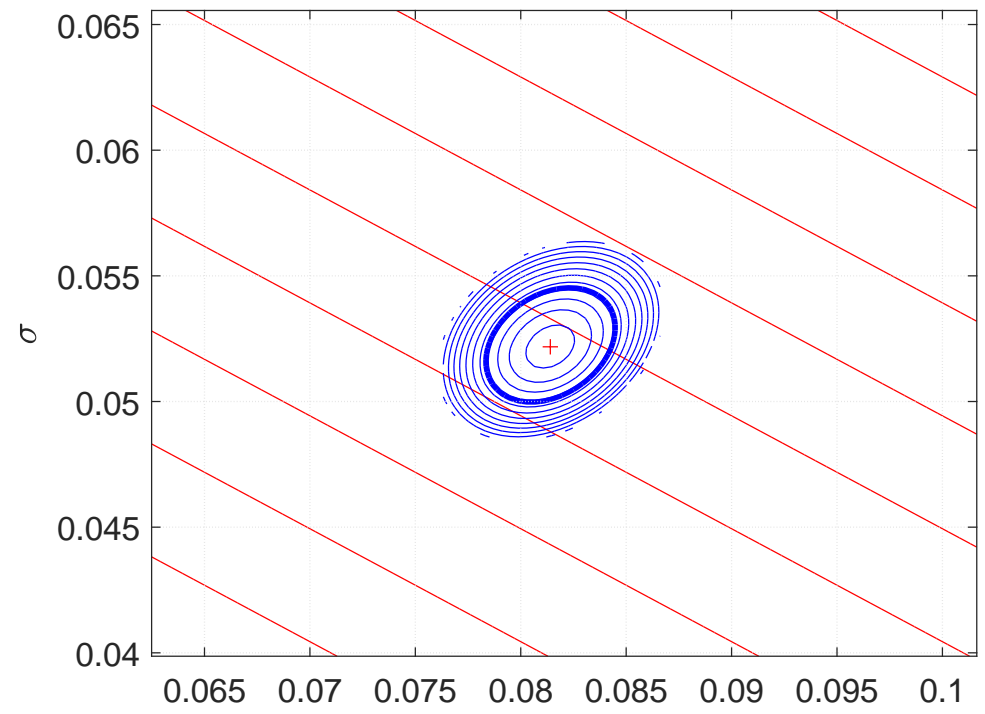

MLE = Maximum Likelihood Estimate, $95 \%$ CI for $\mu$ and $\sigma$ after 6.00 yrs 


\section{Denton county after 6.00 yrs}

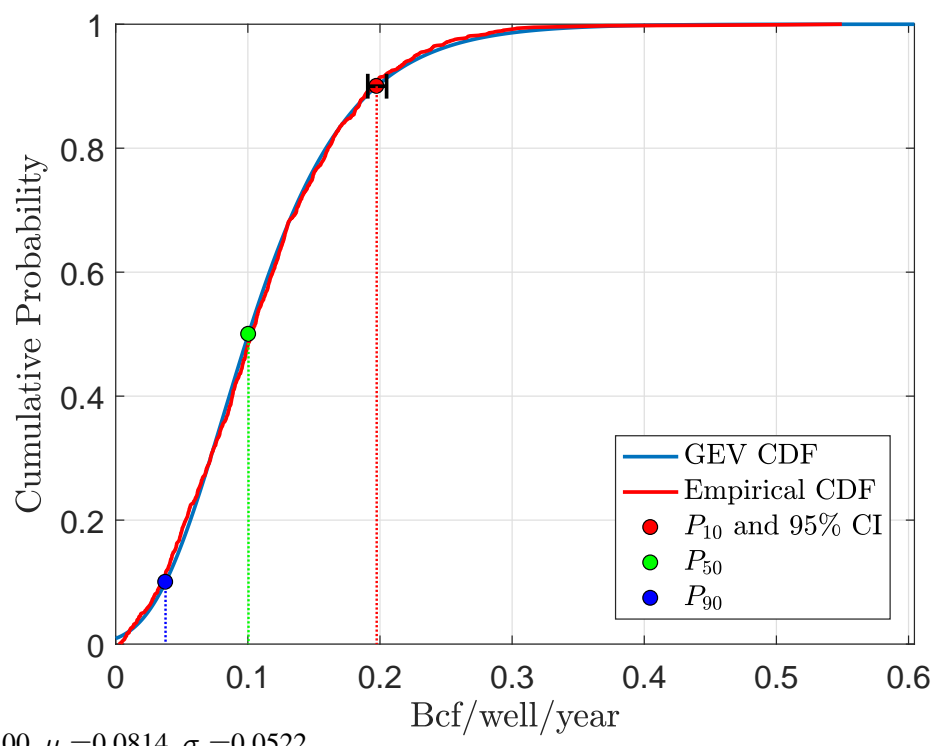

GEV cdf: $\xi=-0.0100, \mu=0.0814, \sigma=0.0522$ 


\section{Denton county after 7 yrs}

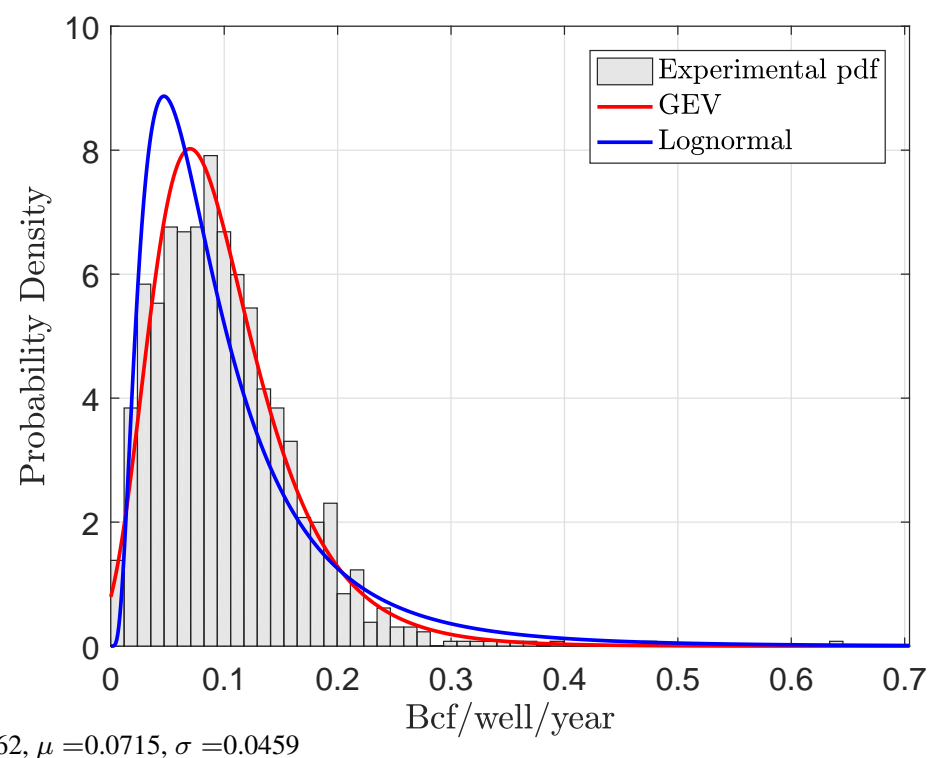

GEV pdf: $\xi=0.0362, \mu=0.0715, \sigma=0.0459$ 


\section{MLE of GEV pdf in Denton county}

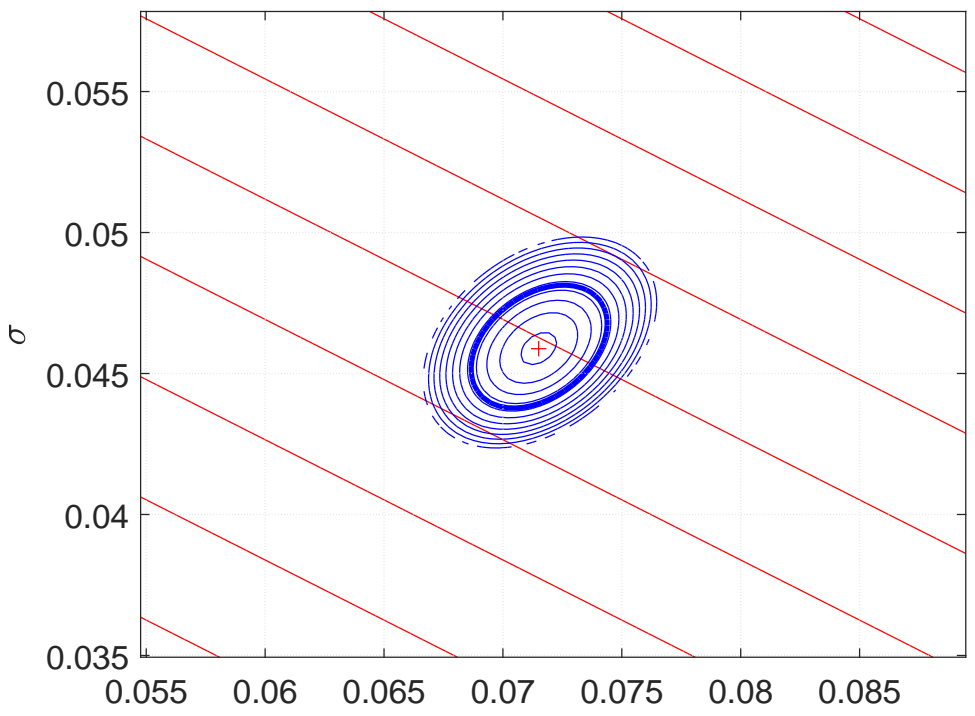

MLE $=$ Maximum Likelihood Estimate, $95 \%$ CI for $\mu$ and $\sigma$ after $\mu_{.00}$ yrs 


\section{Denton county after 7.00 yrs}

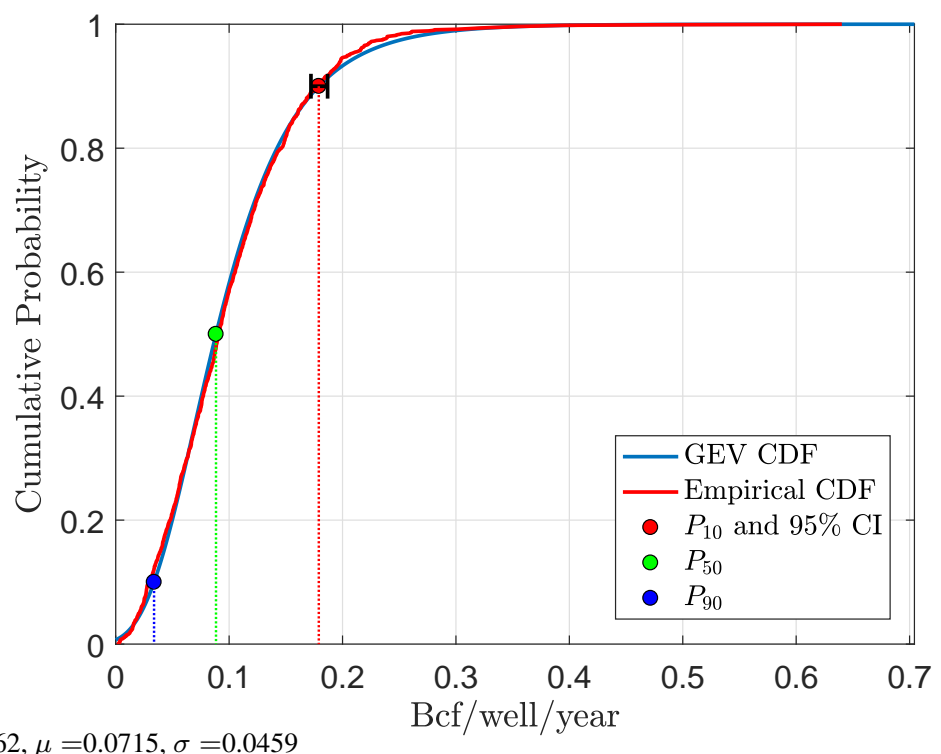

GEV cdf: $\xi=0.0362, \mu=0.0715, \sigma=0.0459$ 


\section{Denton county after 8 yrs}

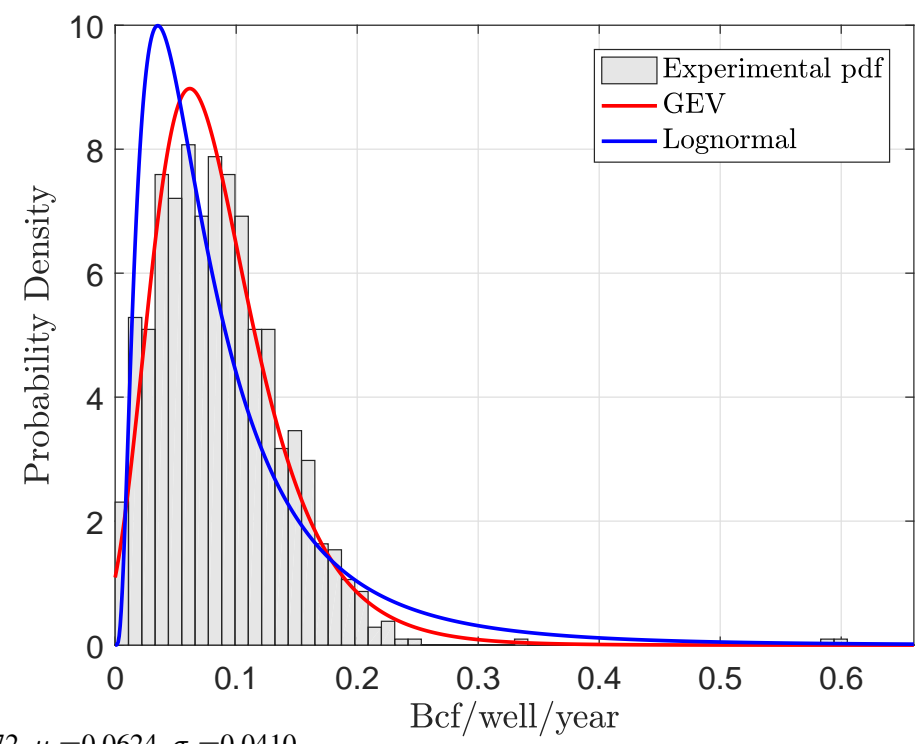

GEV pdf: $\xi=0.0172, \mu=0.0624, \sigma=0.0410$ 


\section{MLE of GEV pdf in Denton county}

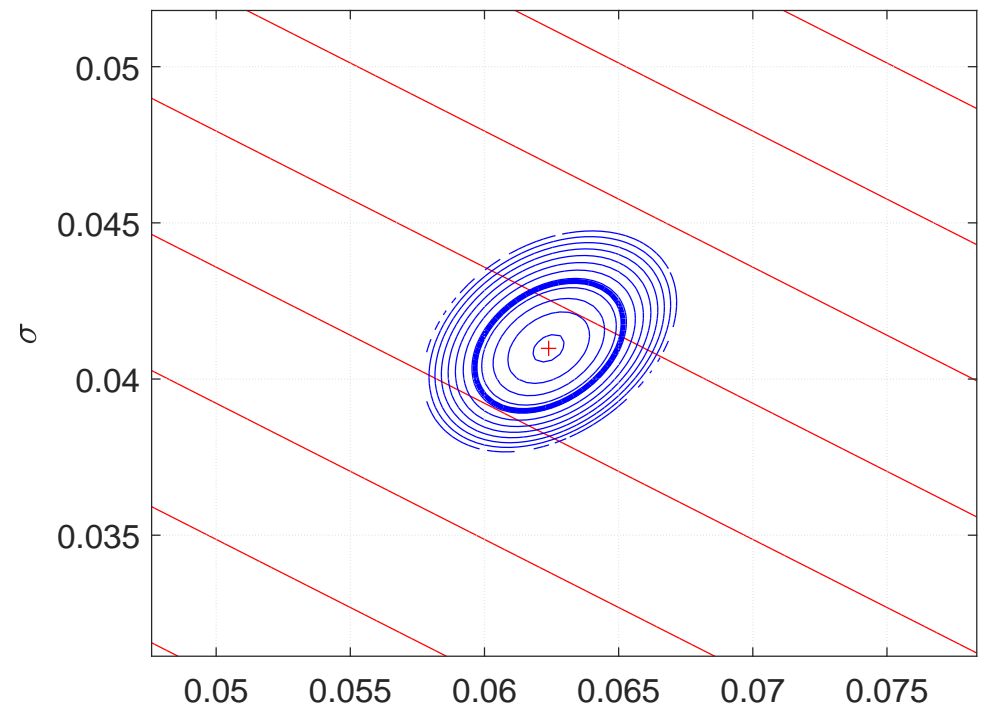

MLE $=$ Maximum Likelihood Estimate, $95 \%$ CI for $\mu$ and $\sigma$ after $\stackrel{\mu}{8.00}$ yrs 


\section{Denton county after 8.00 yrs}

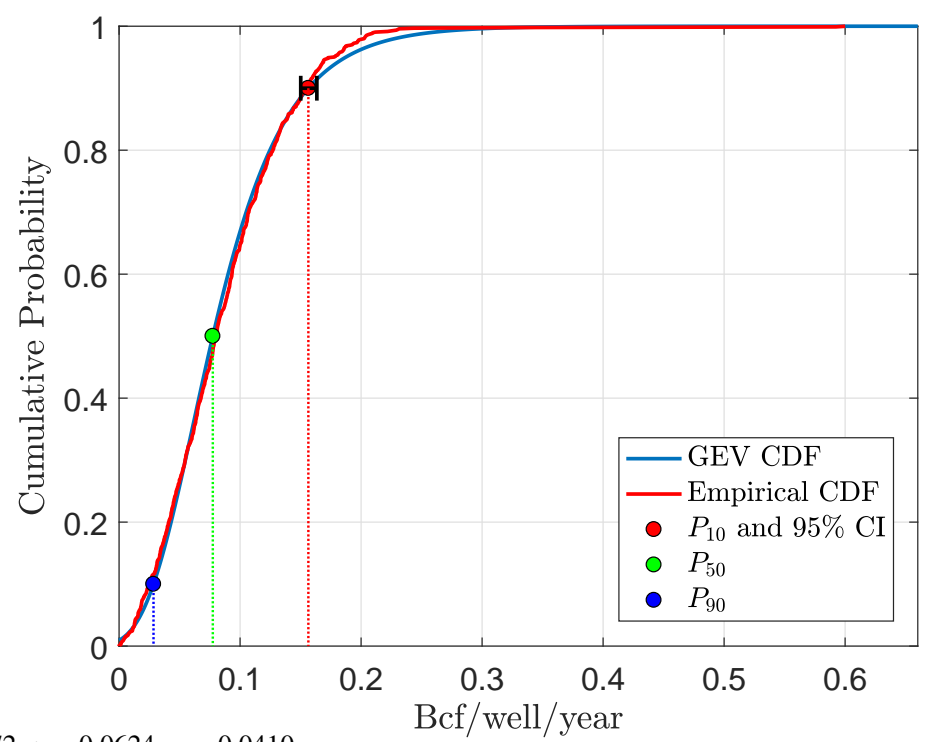

GEV cdf: $\xi=0.0172, \mu=0.0624, \sigma=0.0410$ 


\section{Denton county after 9 yrs}

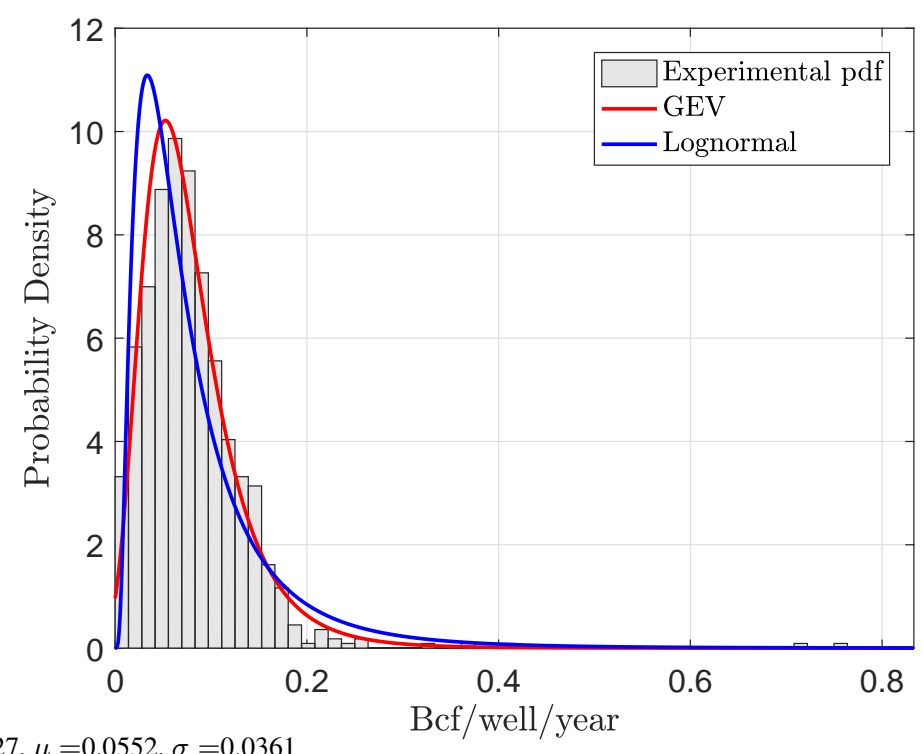

GEV pdf: $\xi=0.0827, \mu=0.0552, \sigma=0.0361$ 


\section{MLE of GEV pdf in Denton county}

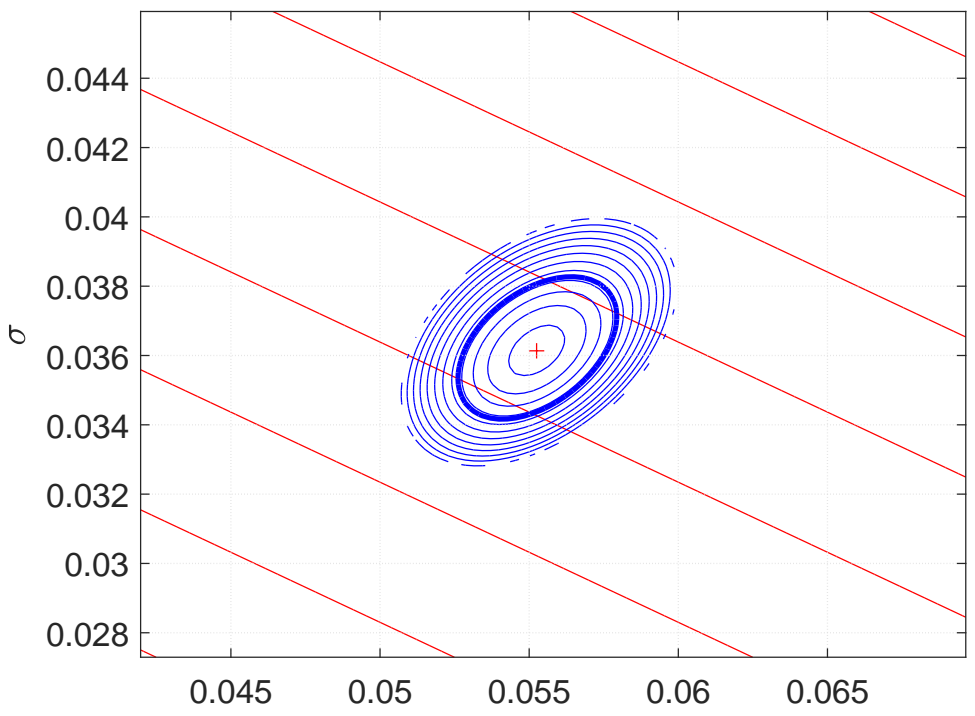

MLE $=$ Maximum Likelihood Estimate, $95 \%$ CI for $\mu$ and $\sigma$ after 9.00 yrs 


\section{Denton county after 9.00 yrs}

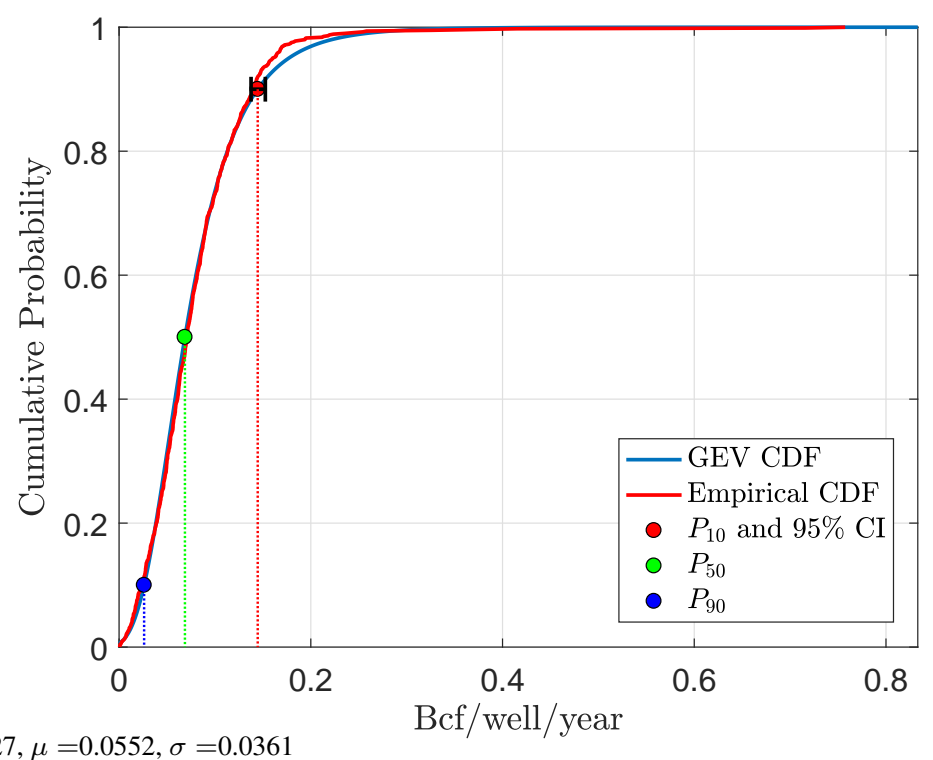

GEV cdf: $\xi=0.0827, \mu=0.0552, \sigma=0.0361$ 


\section{Denton county after 10 yrs}

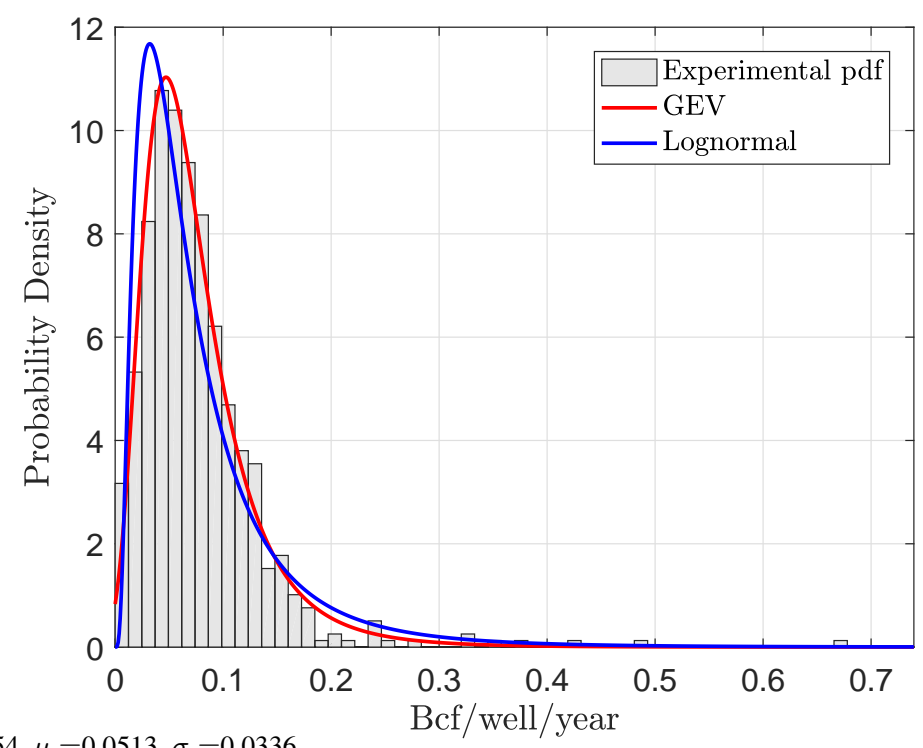

GEV pdf: $\xi=0.1354, \mu=0.0513, \sigma=0.0336$ 


\section{MLE of GEV pdf in Denton county}

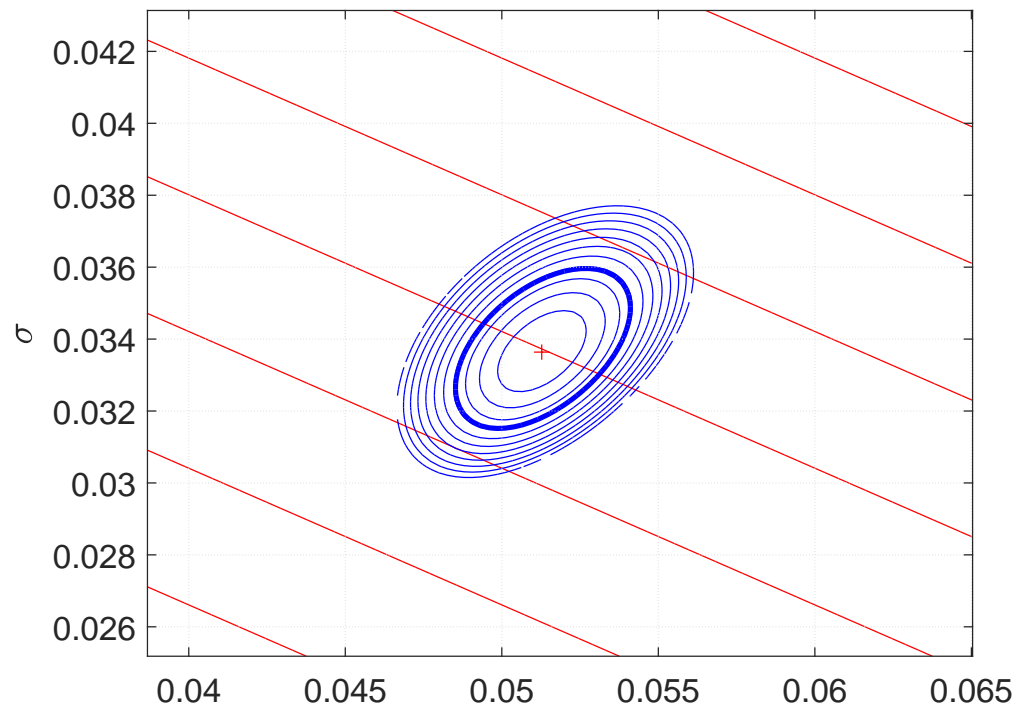

MLE = Maximum Likelihood Estimate, $95 \%$ CI for $\mu$ and $\sigma$ after 10.00 yrs 


\section{Denton county after 10.00 yrs}

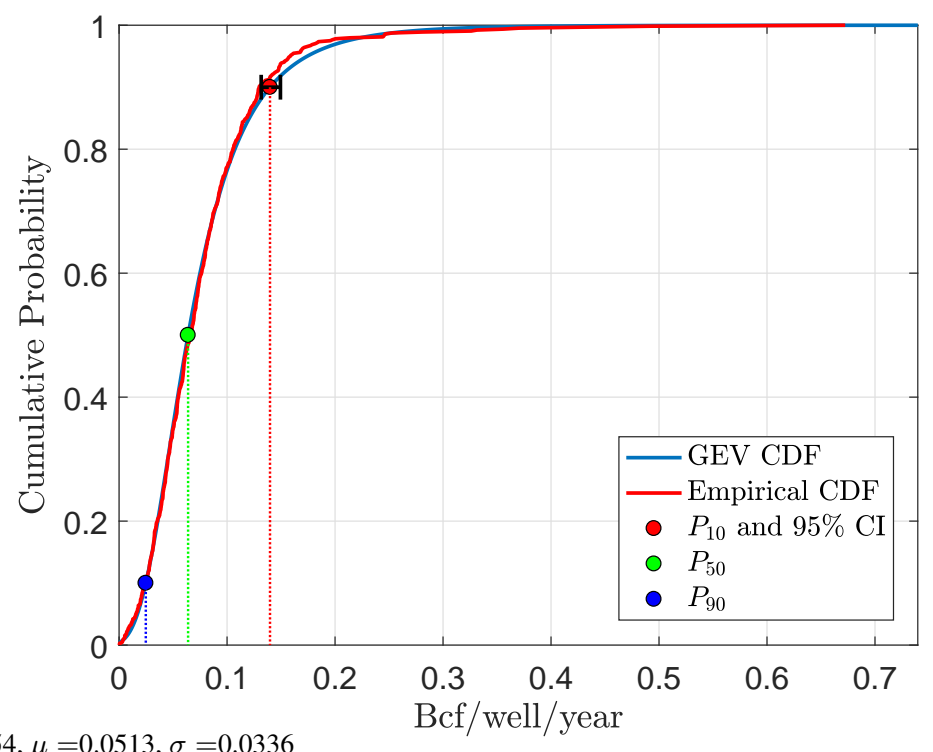

GEV cdf: $\xi=0.1354, \mu=0.0513, \sigma=0.0336$ 


\section{Denton county after 11 yrs}

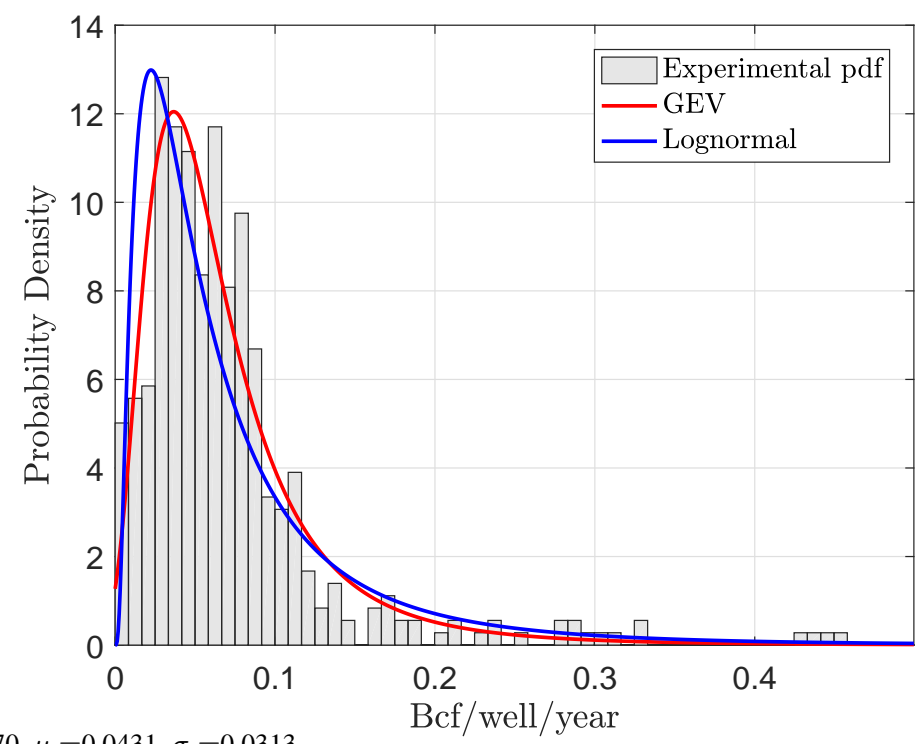

GEV pdf: $\xi=0.2370, \mu=0.0431, \sigma=0.0313$ 


\section{MLE of GEV pdf in Denton county}

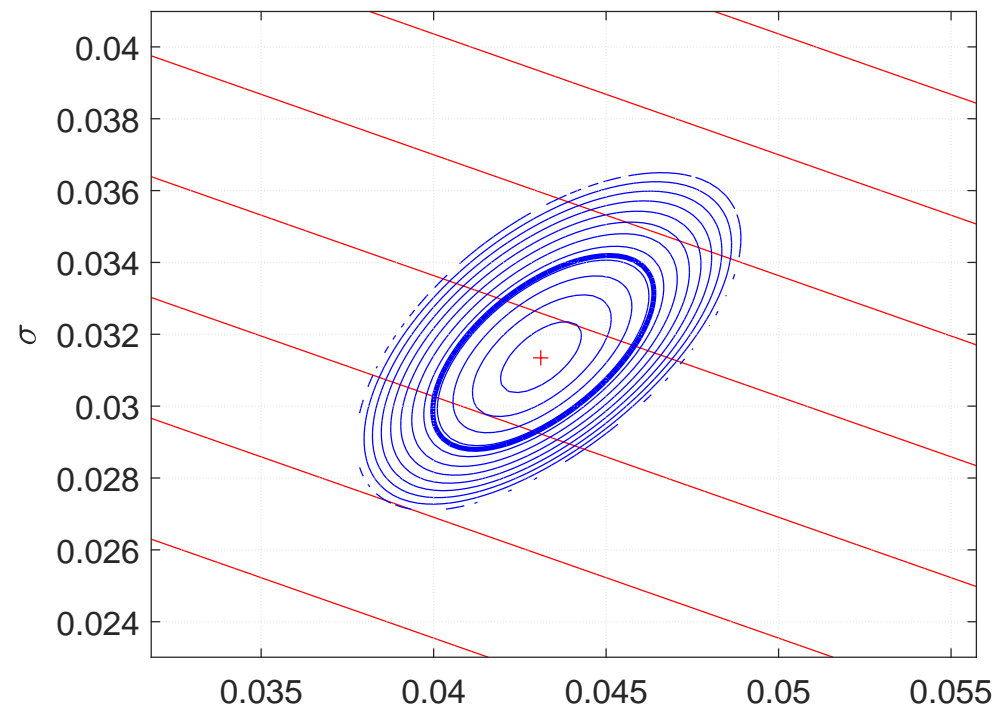

MLE $=$ Maximum Likelihood Estimate, $95 \% \mathrm{CI}$ for $\mu$ and $\sigma$ after $\mu 1.00$ yrs 


\section{Denton county after 11.00 yrs}

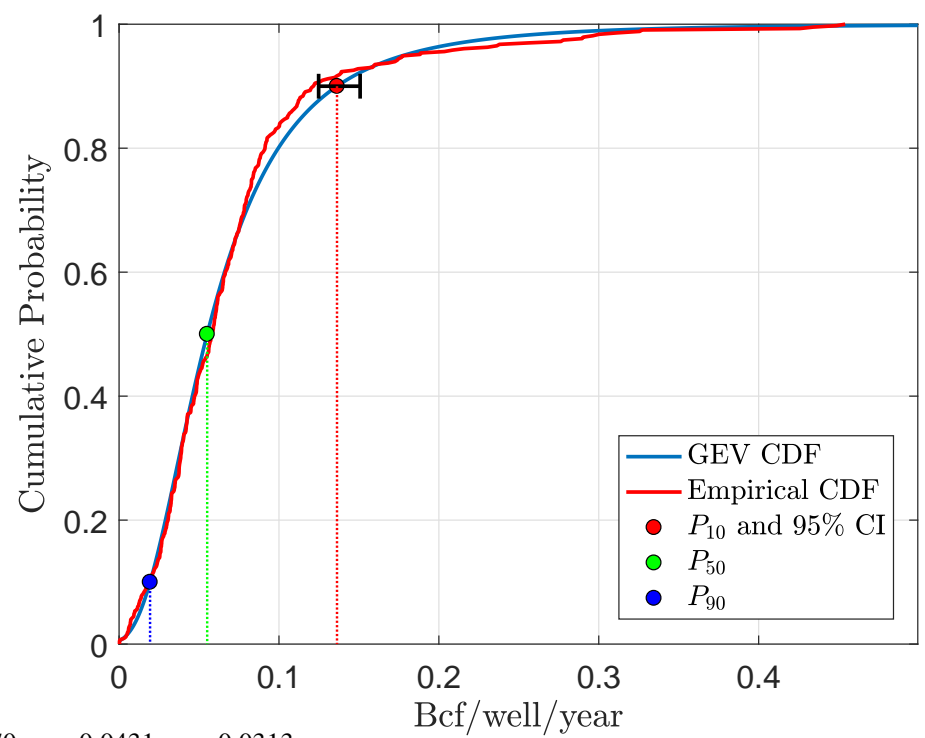

GEV cdf: $\xi=0.2370, \mu=0.0431, \sigma=0.0313$ 


\section{Denton county after 12 yrs}

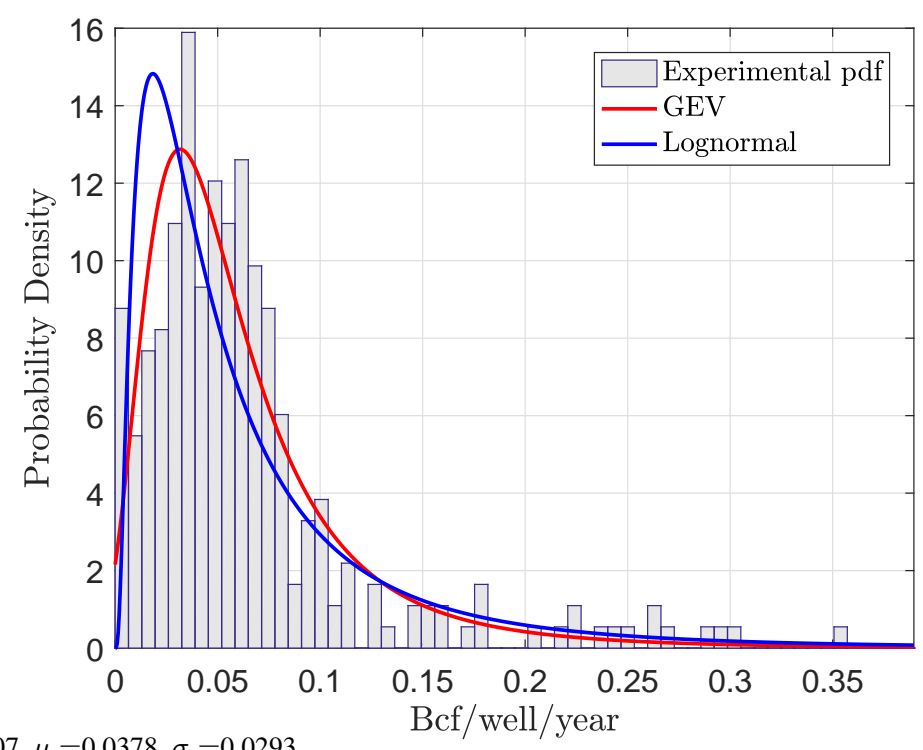

GEV pdf: $\xi=0.2407, \mu=0.0378, \sigma=0.0293$ 


\section{MLE of GEV pdf in Denton county}

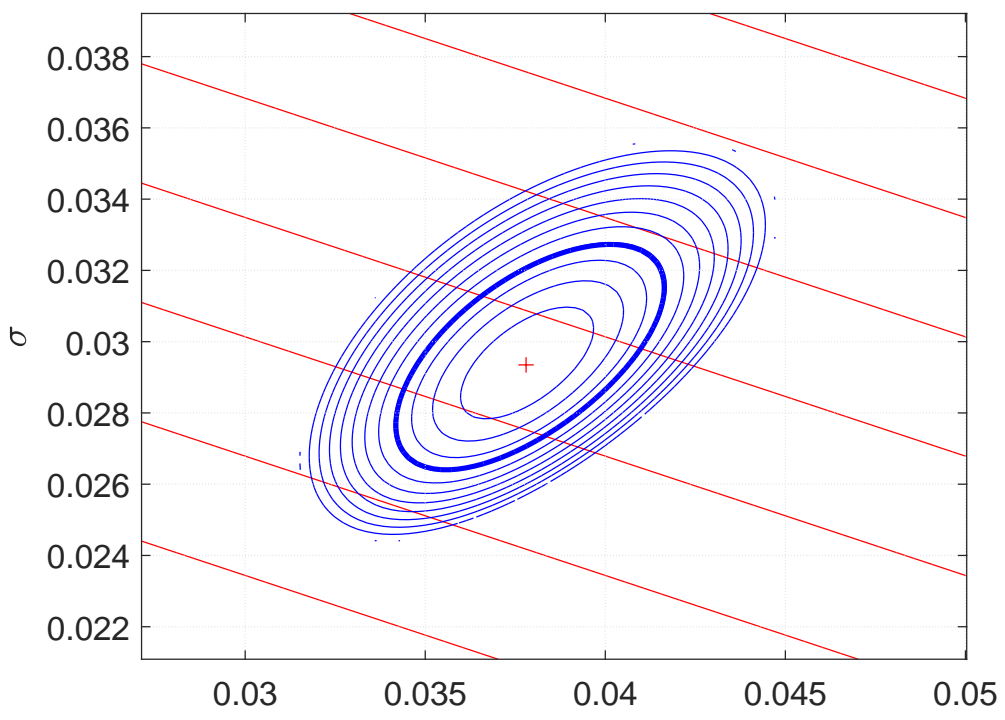

MLE $=$ Maximum Likelihood Estimate, $95 \% \mathrm{CI}$ for $\mu$ and $\sigma$ after $\stackrel{\mu}{12.00 \mathrm{yrs}}$ 


\section{Denton county after 12.00 yrs}

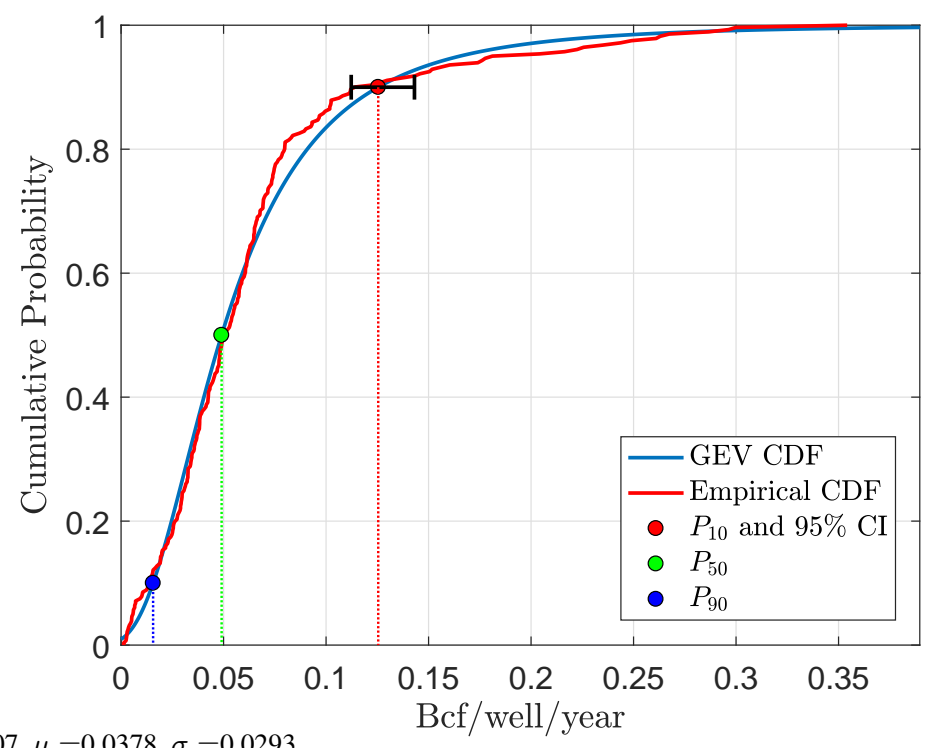

GEV cdf: $\xi=0.2407, \mu=0.0378, \sigma=0.0293$ 


\section{Denton county after 13 yrs}

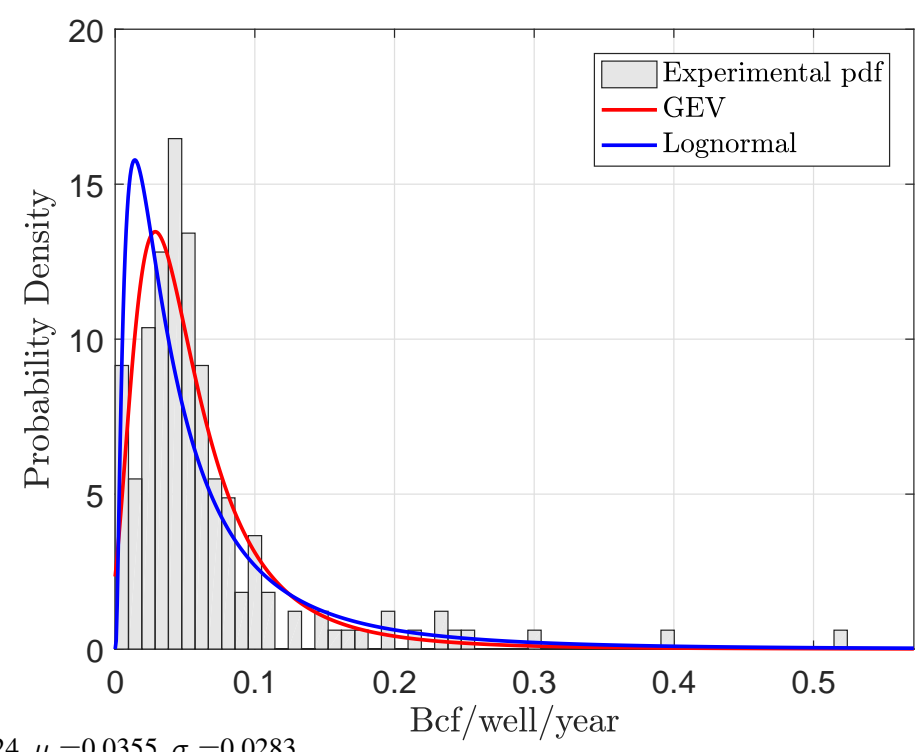

GEV pdf: $\xi=0.2824, \mu=0.0355, \sigma=0.0283$ 


\section{MLE of GEV pdf in Denton county}

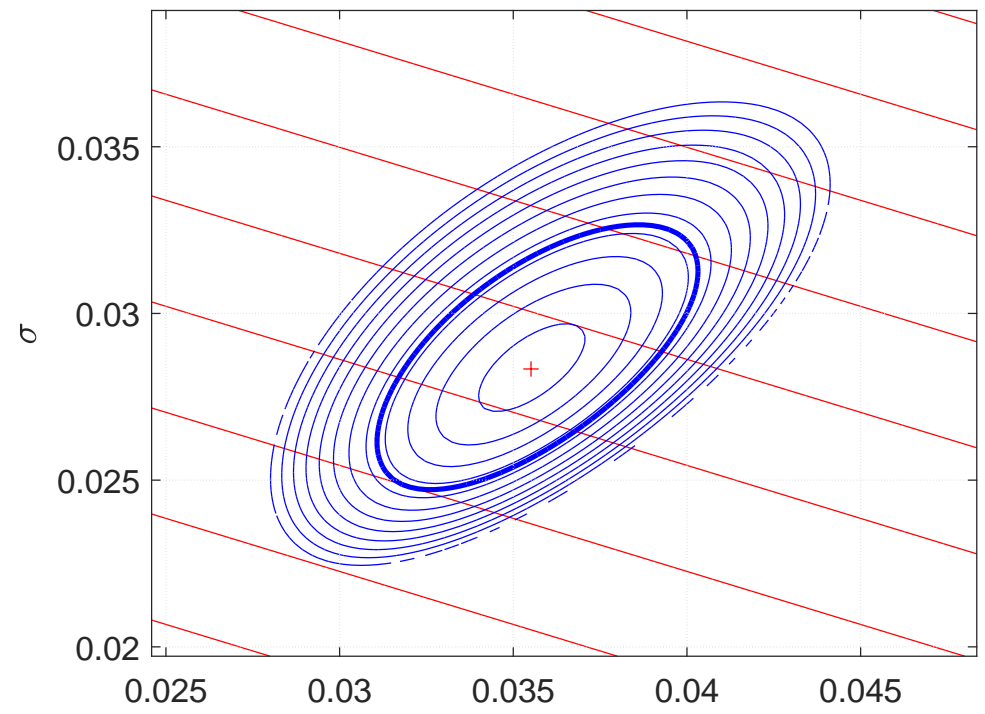

MLE = Maximum Likelihood Estimate, $95 \% \mathrm{CI}$ for $\mu$ and $\sigma$ after $13.00 \mathrm{yrs}$ 


\section{Denton county after 13.00 yrs}

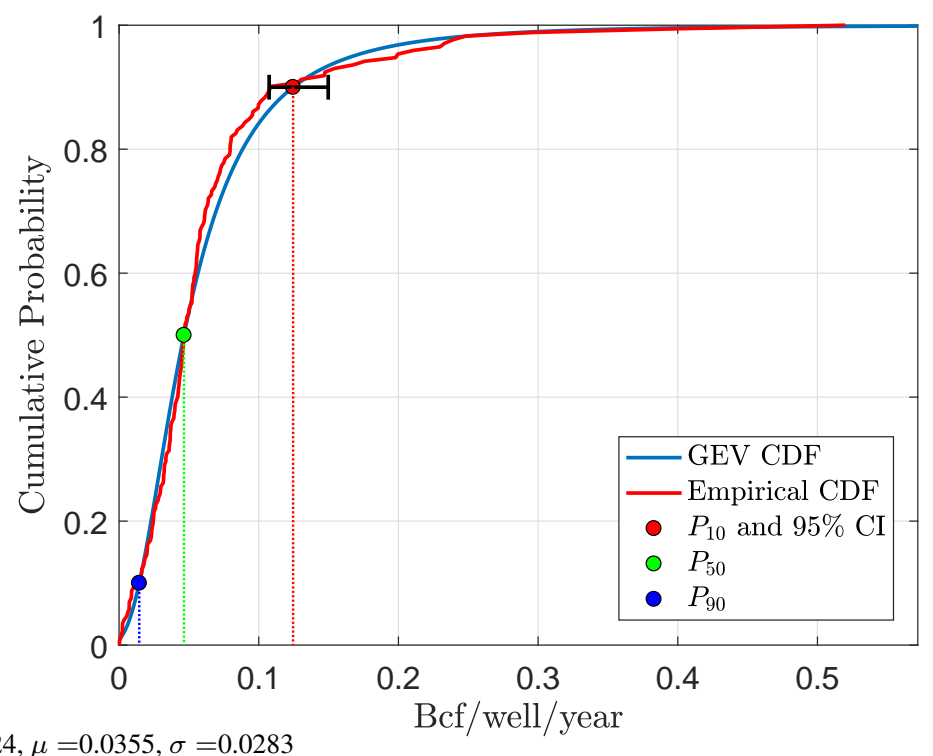

GEV cdf: $\xi=0.2824, \mu=0.0355, \sigma=0.0283$ 


\section{Denton county after 14 yrs}

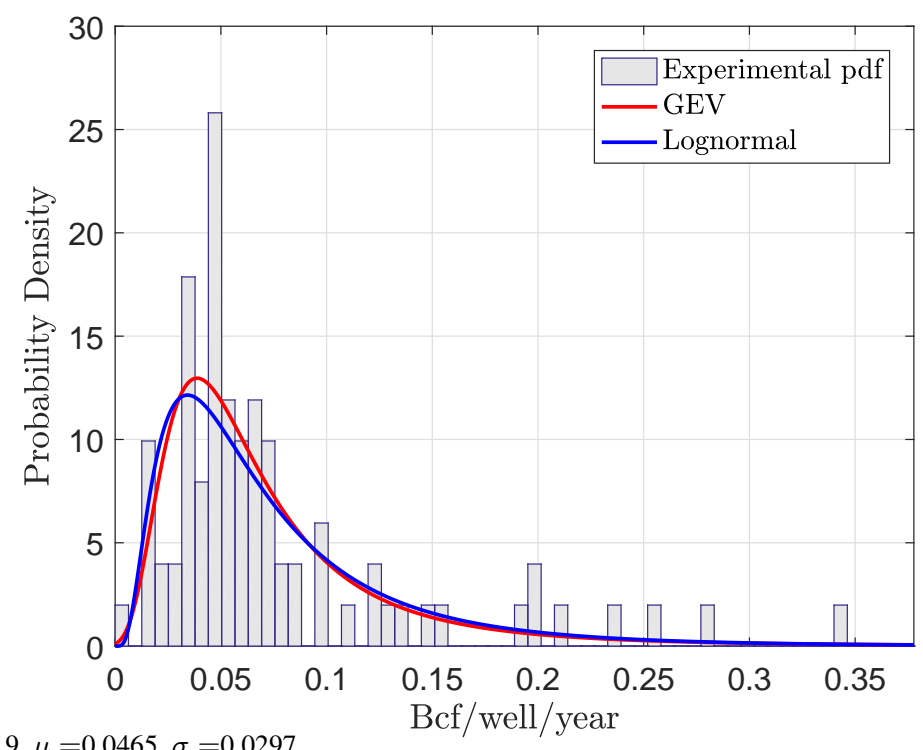

GEV pdf: $\xi=0.3119, \mu=0.0465, \sigma=0.0297$ 


\section{MLE of GEV pdf in Denton county}

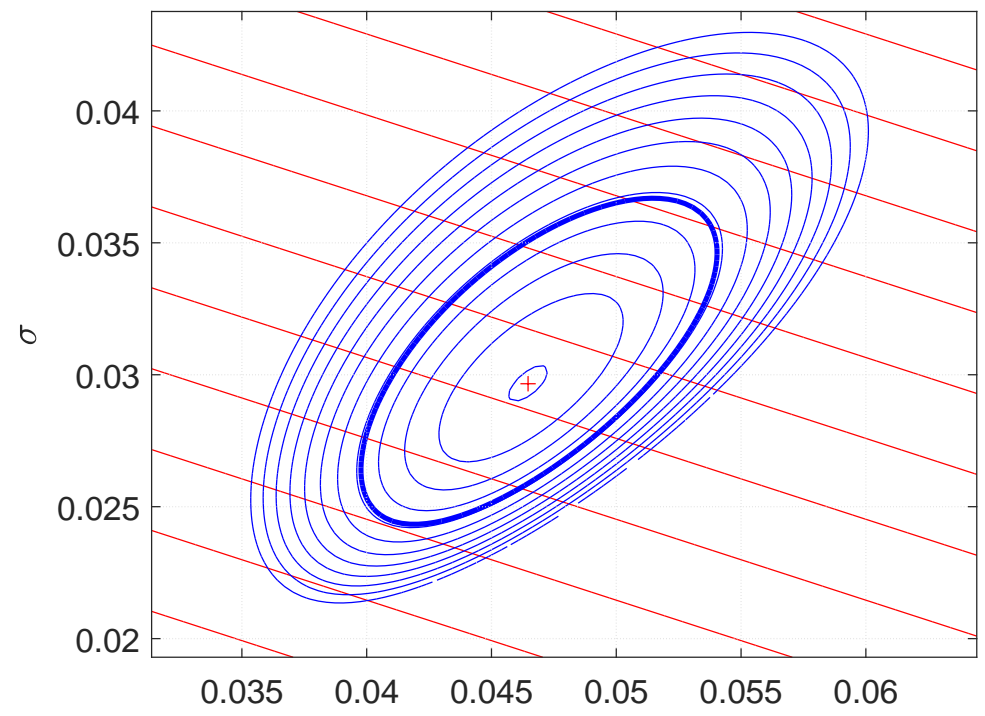

MLE = Maximum Likelihood Estimate, $95 \%$ CI for $\mu$ and $\sigma$ after 14.00 yrs 


\section{Denton county after 14.00 yrs}

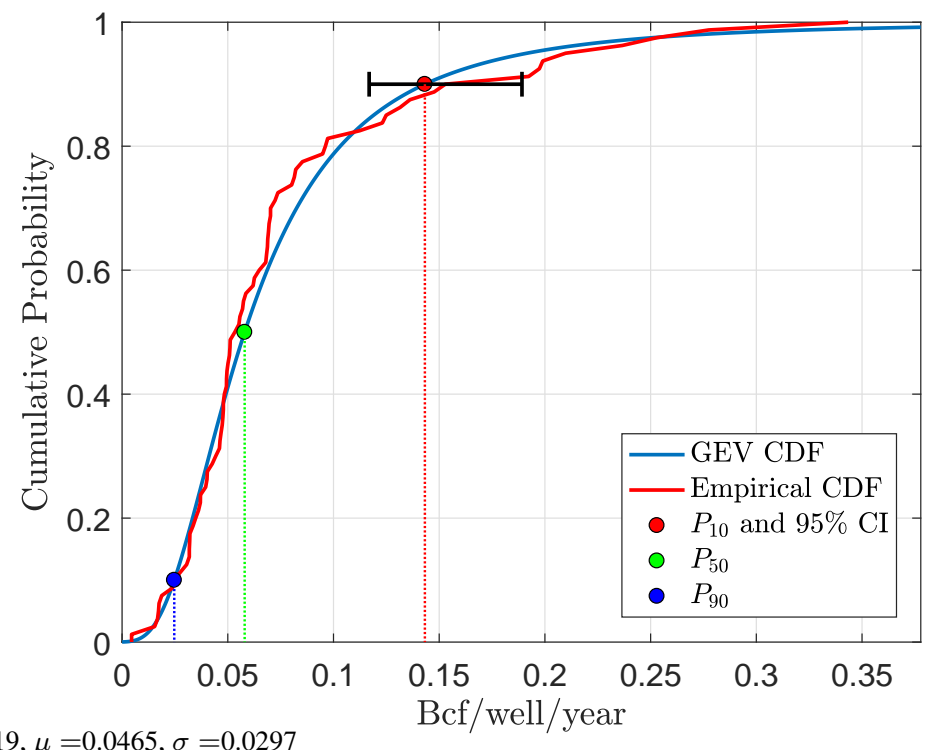

GEV cdf: $\xi=0.3119, \mu=0.0465, \sigma=0.0297$ 


\section{Denton county after 15 yrs}

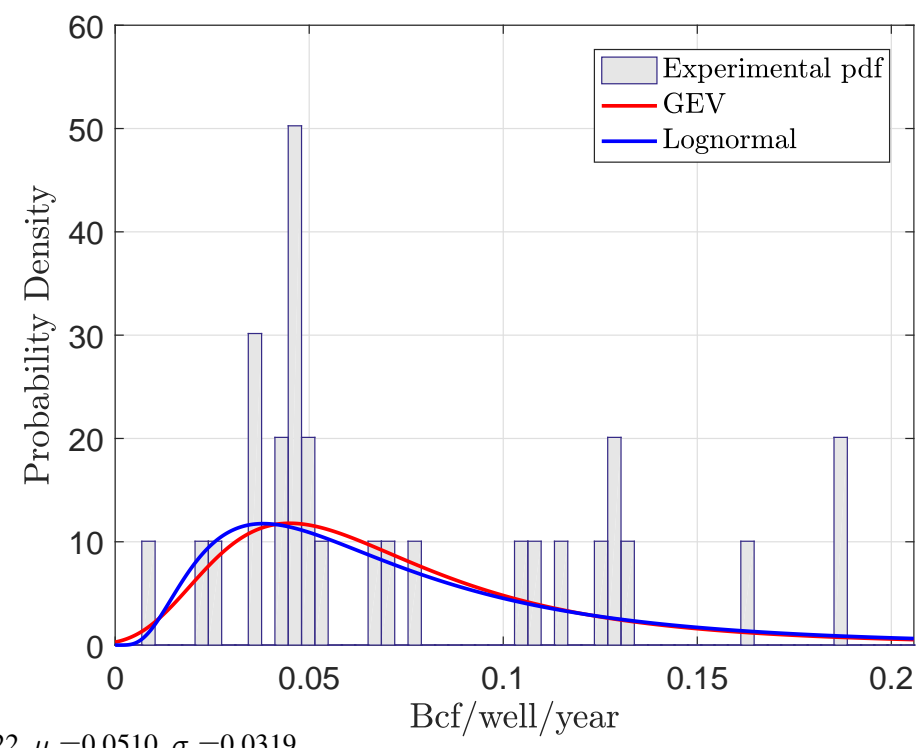

GEV pdf: $\xi=0.2122, \mu=0.0510, \sigma=0.0319$ 


\section{MLE of GEV pdf in Denton county}

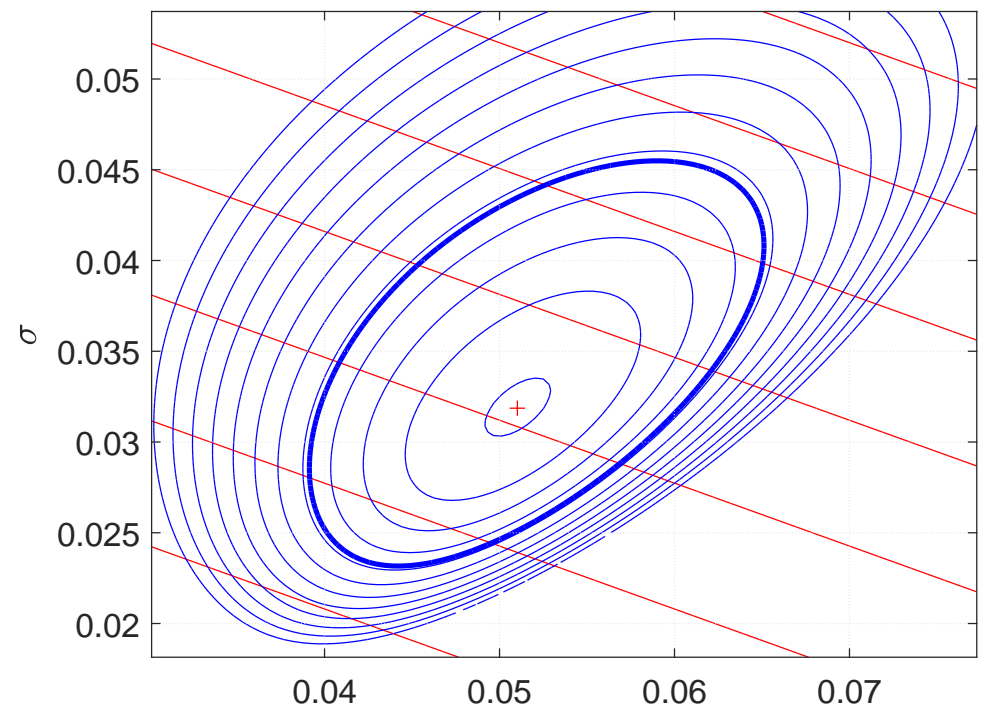

MLE = Maximum Likelihood Estimate, $95 \%$ CI for $\mu$ and $\sigma$ after ${ }_{15}^{\mu} .00$ yrs 


\section{Denton county after 15.00 yrs}

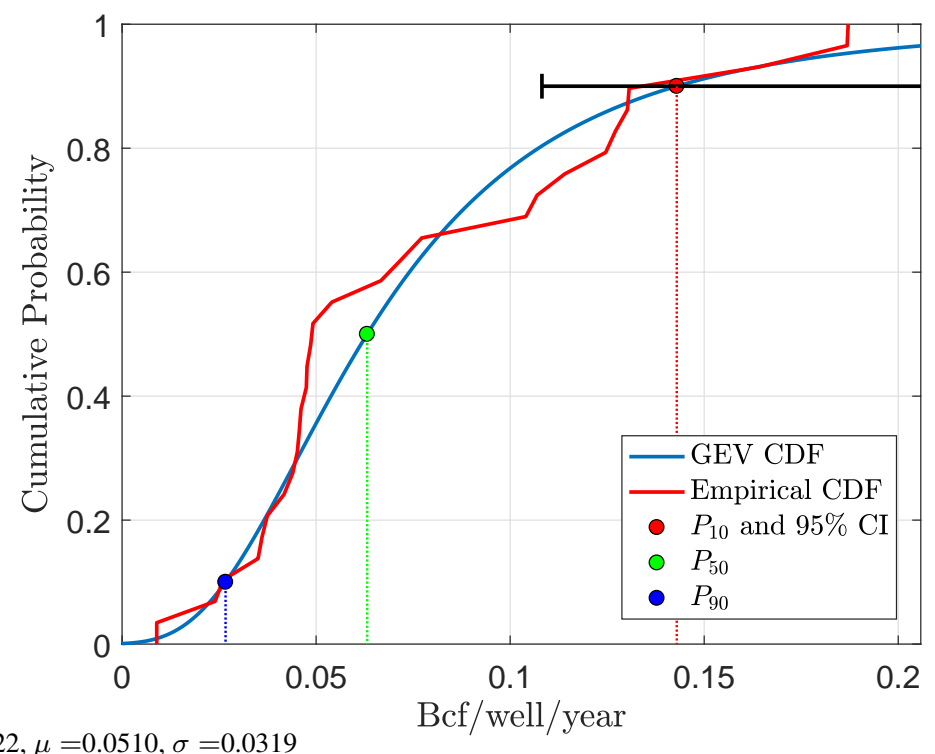

GEV cdf: $\xi=0.2122, \mu=0.0510, \sigma=0.0319$ 


\section{Parker county after 1 yrs}

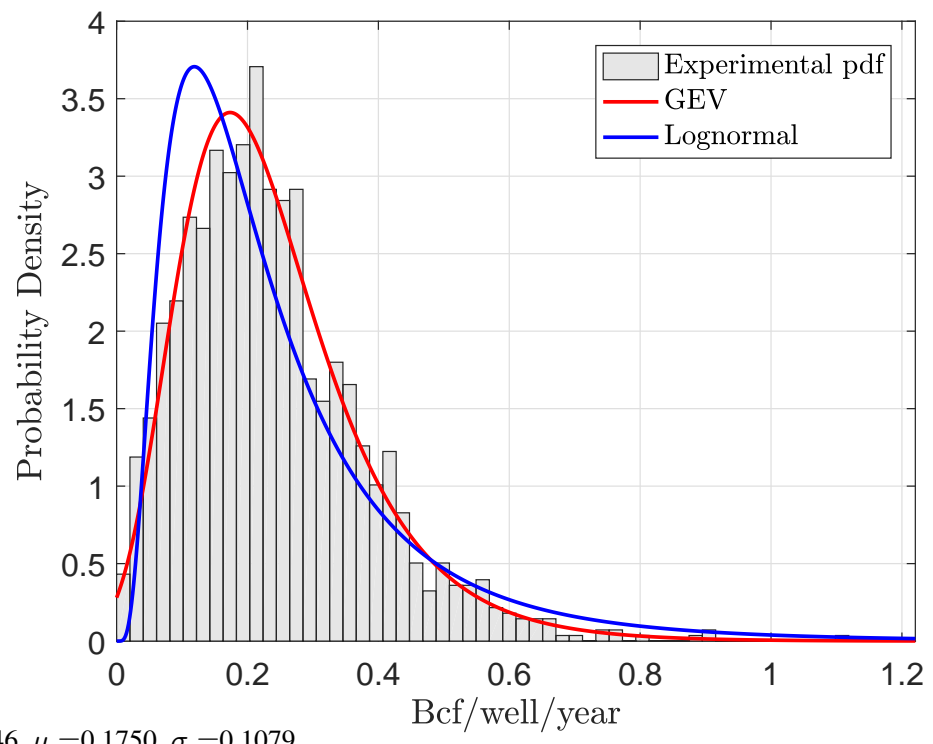

GEV pdf: $\xi=0.0146, \mu=0.1750, \sigma=0.1079$ 


\section{MLE of GEV pdf in Parker county}

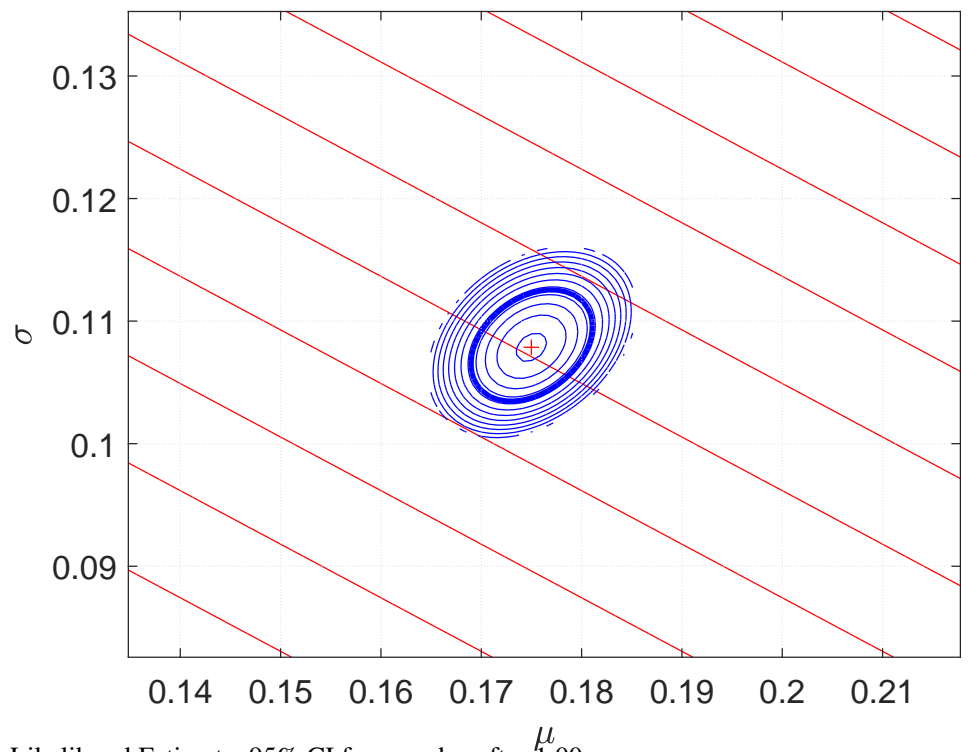

MLE $=$ Maximum Likelihood Estimate, $95 \%$ CI for $\mu$ and $\sigma$ after 1.00 yrs 


\section{Parker county after 1.00 yrs}

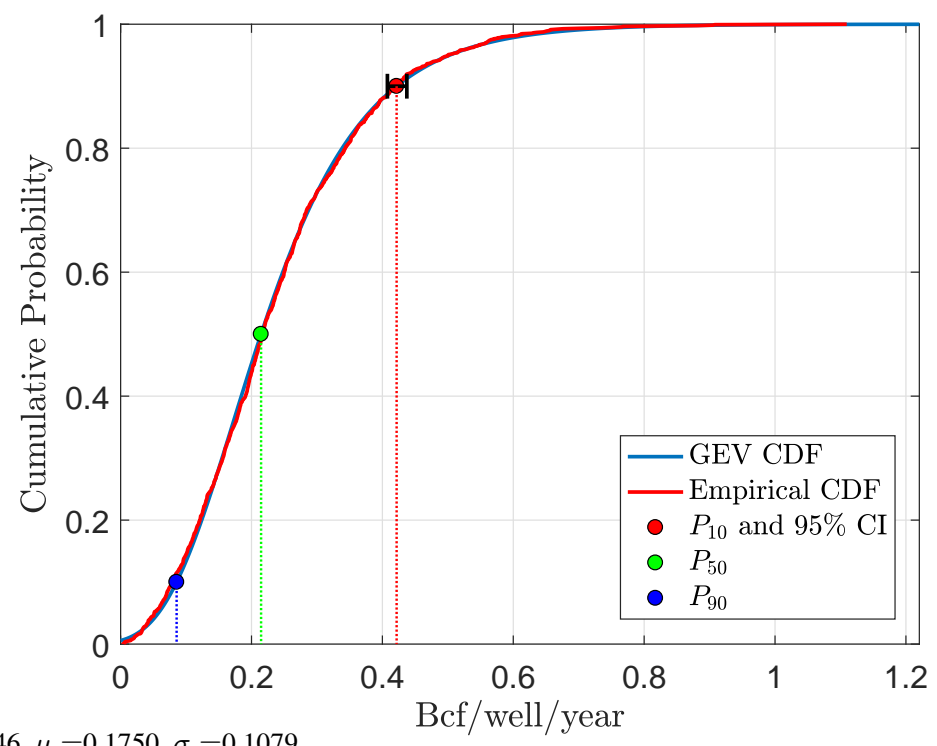

GEV cdf: $\xi=0.0146, \mu=0.1750, \sigma=0.1079$ 


\section{Parker county after 2 yrs}

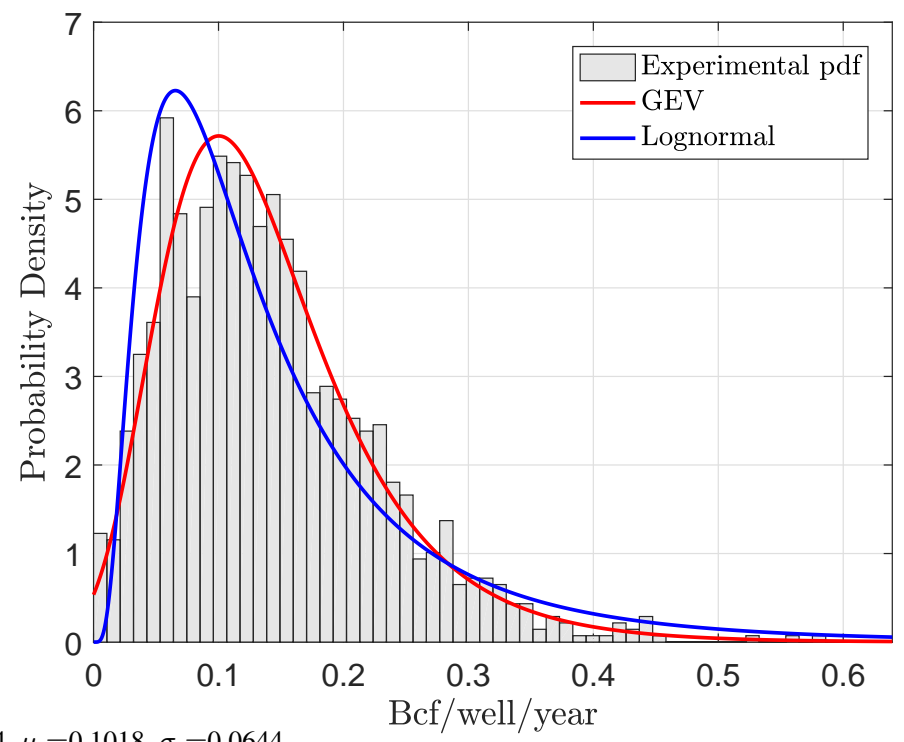

GEV pdf: $\xi=0.0254, \mu=0.1018, \sigma=0.0644$ 


\section{MLE of GEV pdf in Parker county}

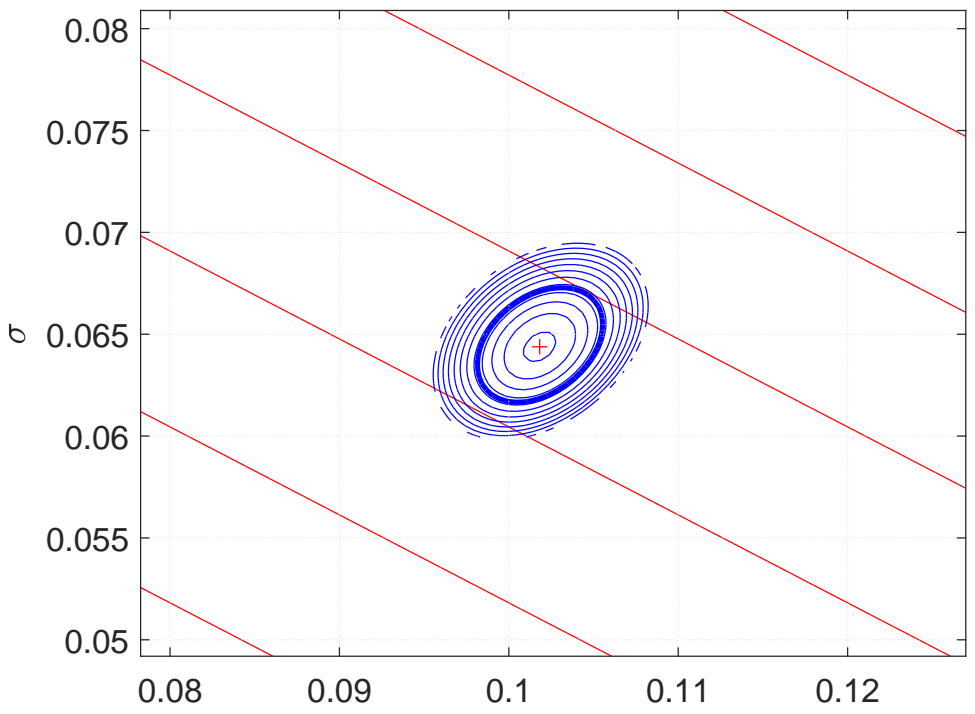

MLE $=$ Maximum Likelihood Estimate, $95 \%$ CI for $\mu$ and $\sigma$ after 2.00 yrs 


\section{Parker county after 2.00 yrs}

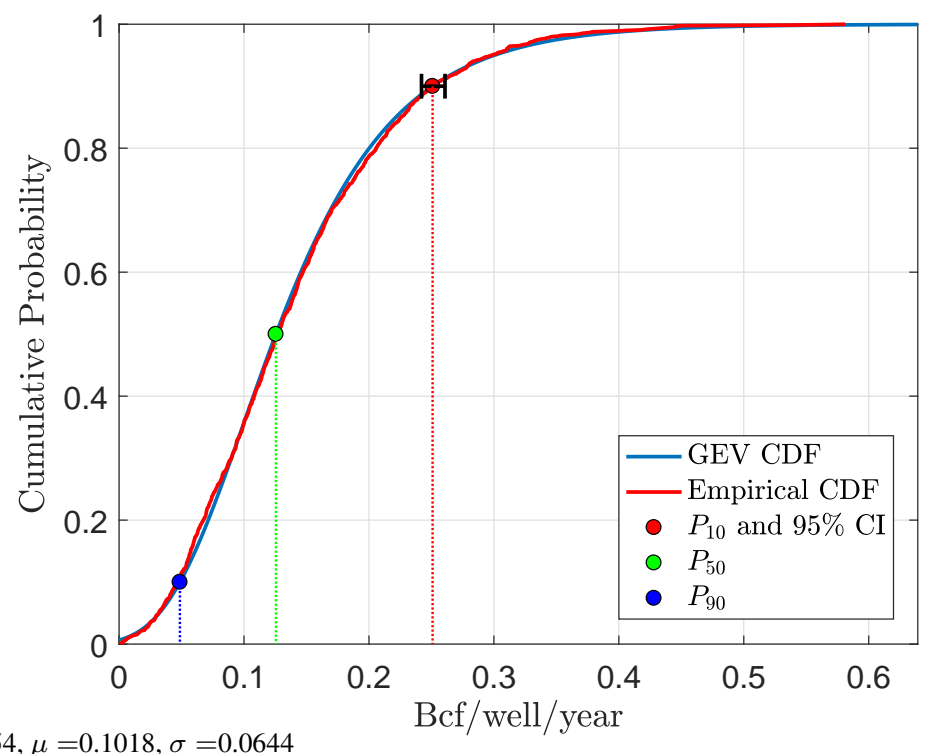

GEV cdf: $\xi=0.0254, \mu=0.1018, \sigma=0.0644$ 


\section{Parker county after 3 yrs}

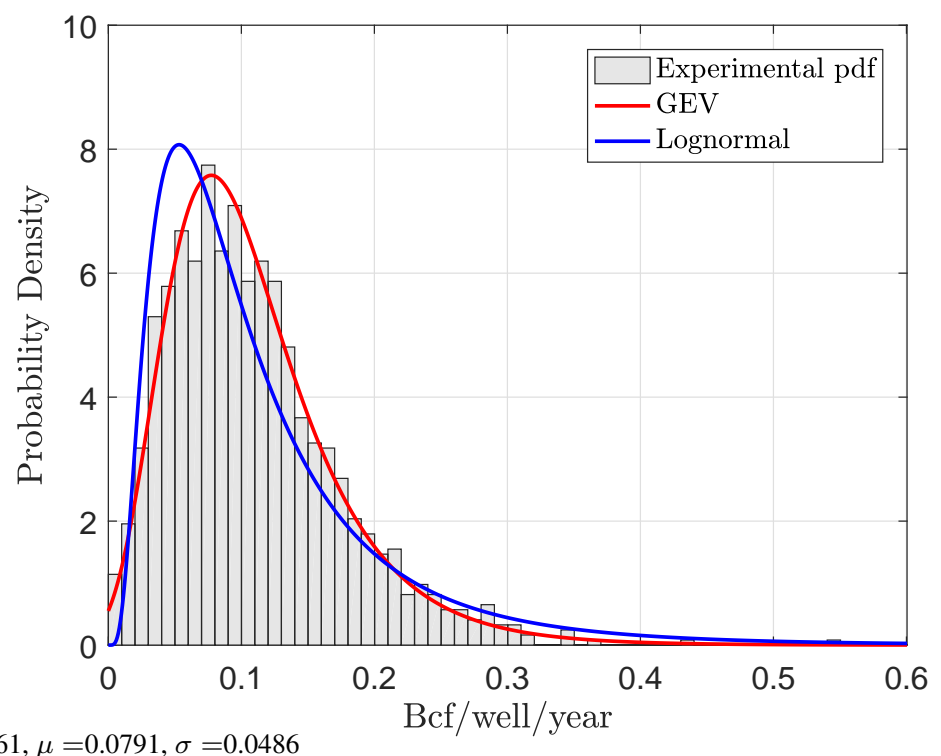

GEV pdf: $\xi=0.0361, \mu=0.0791, \sigma=0.0486$ 


\section{MLE of GEV pdf in Parker county}

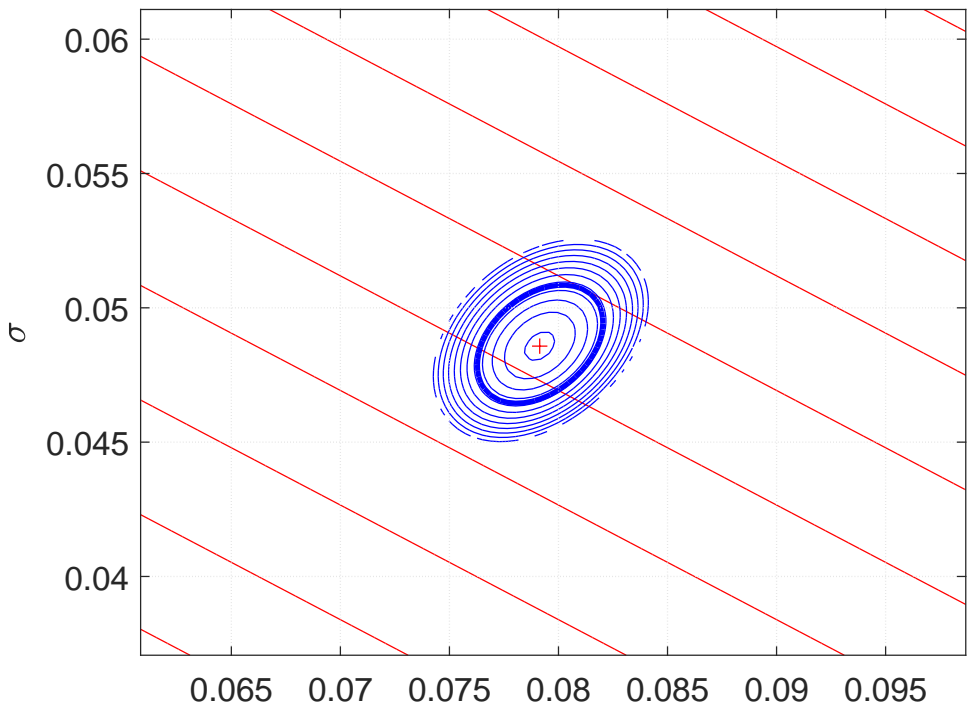

MLE $=$ Maximum Likelihood Estimate, $95 \%$ CI for $\mu$ and $\sigma$ after 3.00 yrs 


\section{Parker county after 3.00 yrs}

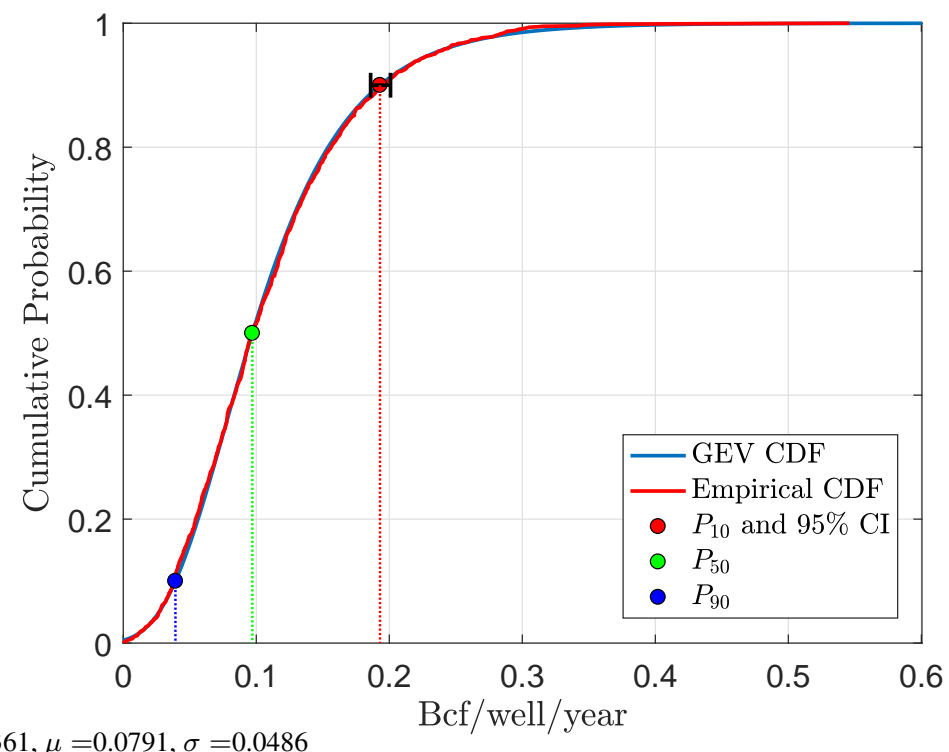

GEV cdf: $\xi=0.0361, \mu=0.0791, \sigma=0.0486$ 


\section{Parker county after 4 yrs}

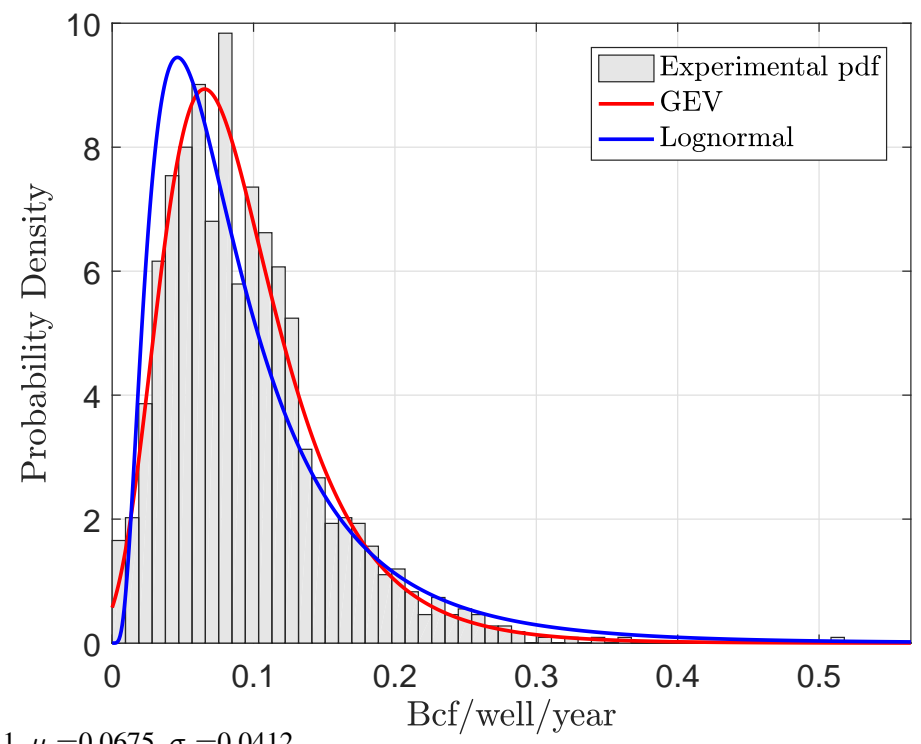

GEV pdf: $\xi=0.0541, \mu=0.0675, \sigma=0.0412$ 


\section{MLE of GEV pdf in Parker county}

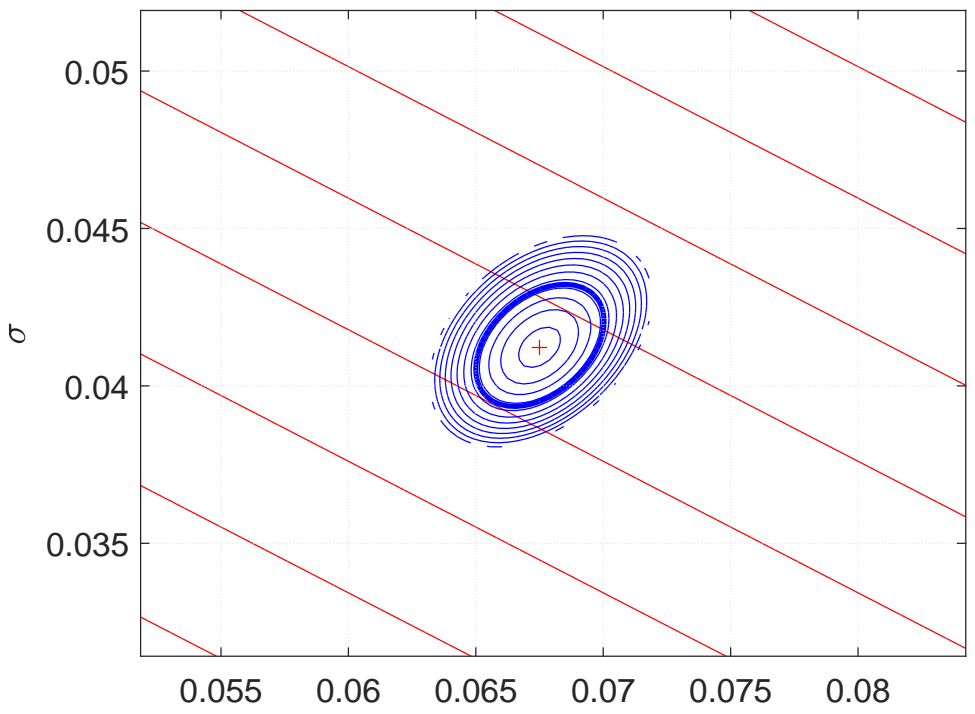

MLE $=$ Maximum Likelihood Estimate, $95 \%$ CI for $\mu$ and $\sigma$ after 4.00 yrs 


\section{Parker county after 4.00 yrs}

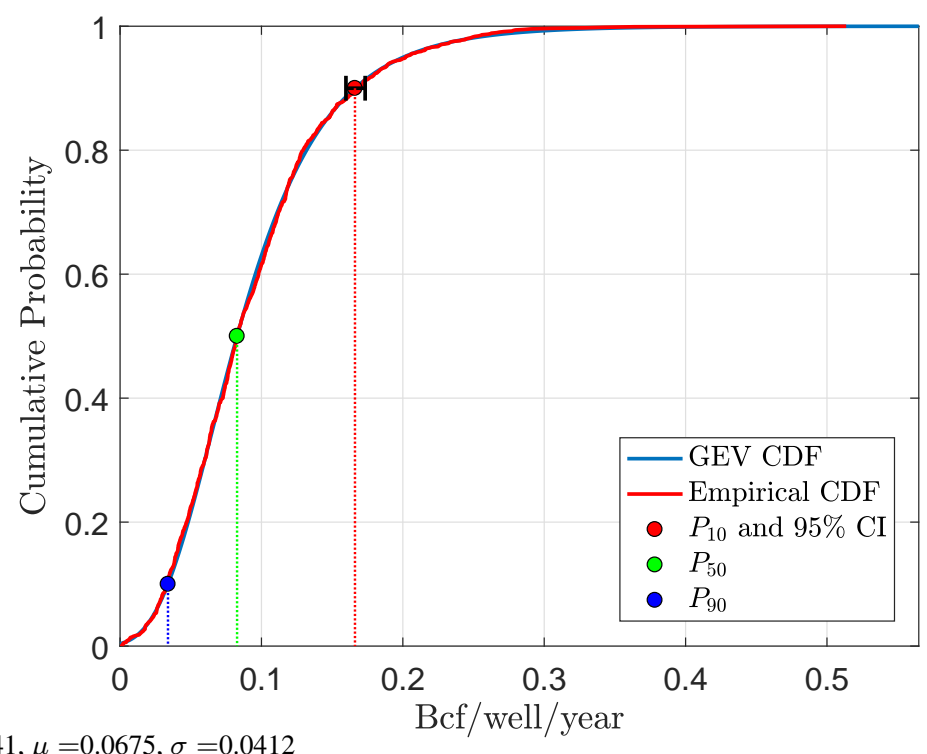

GEV cdf: $\xi=0.0541, \mu=0.0675, \sigma=0.0412$ 


\section{Parker county after 5 yrs}

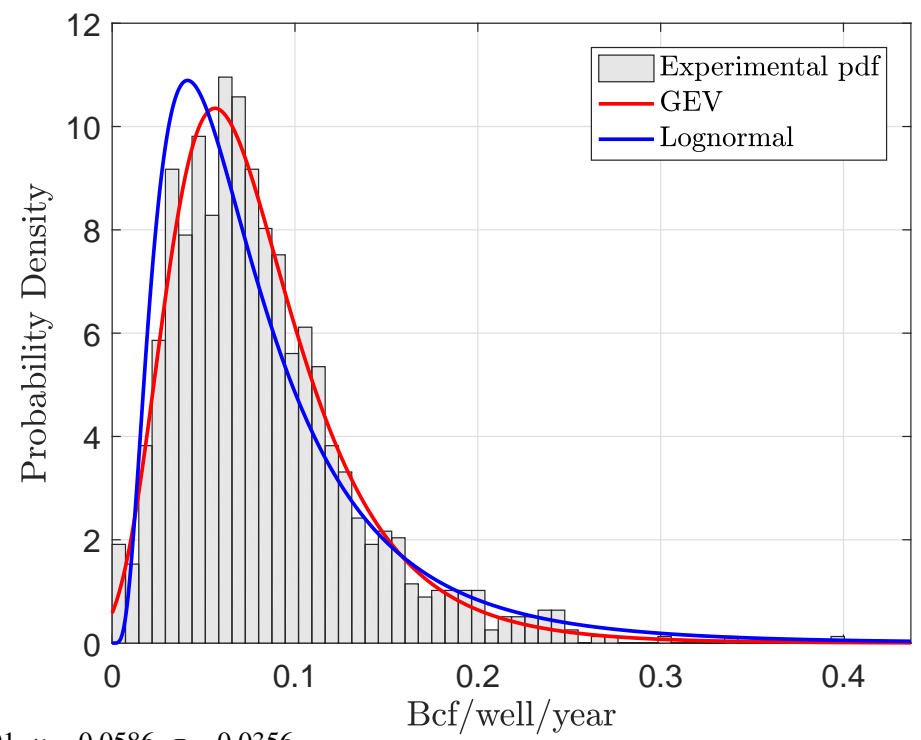

GEV pdf: $\xi=0.0701, \mu=0.0586, \sigma=0.0356$ 


\section{MLE of GEV pdf in Parker county}

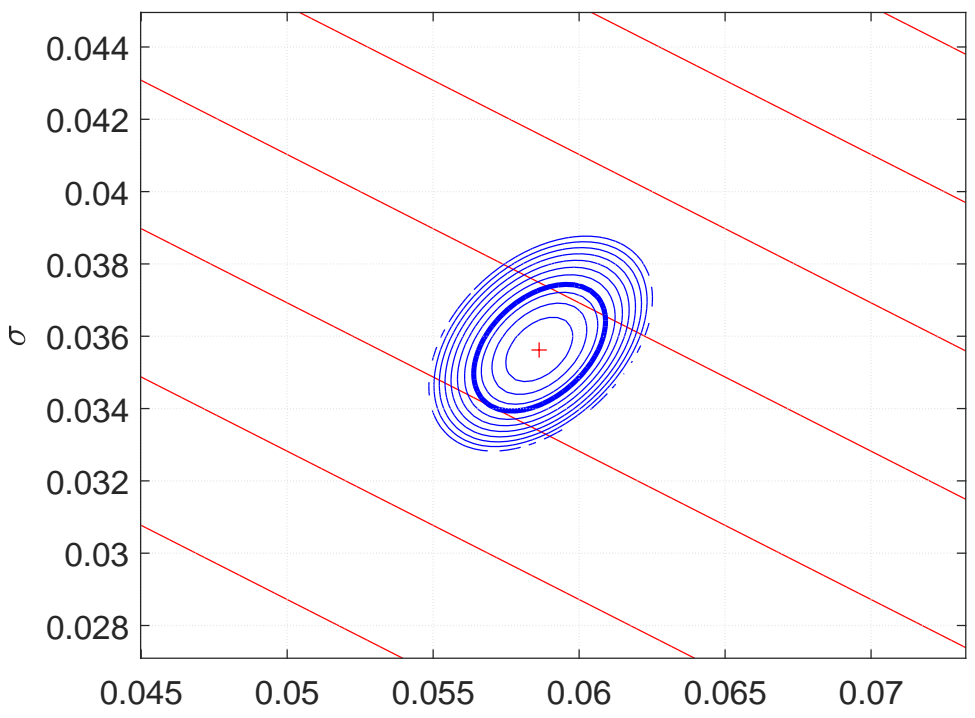

MLE $=$ Maximum Likelihood Estimate, $95 \%$ CI for $\mu$ and $\sigma$ after 5.00 yrs 


\section{Parker county after 5.00 yrs}

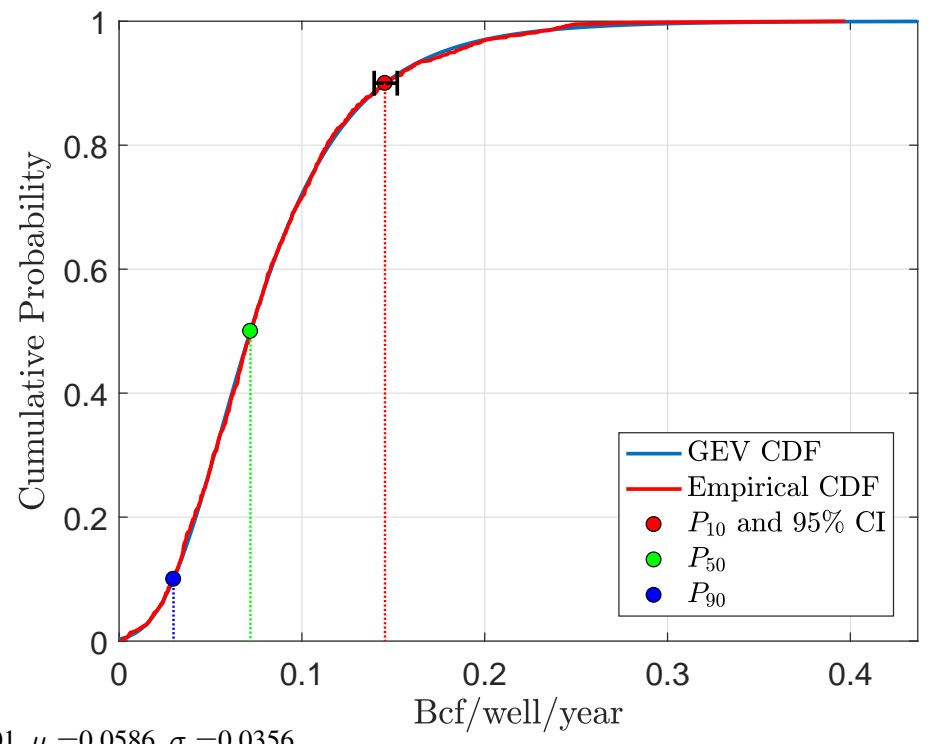

GEV cdf: $\xi=0.0701, \mu=0.0586, \sigma=0.0356$ 


\section{Parker county after 6 yrs}

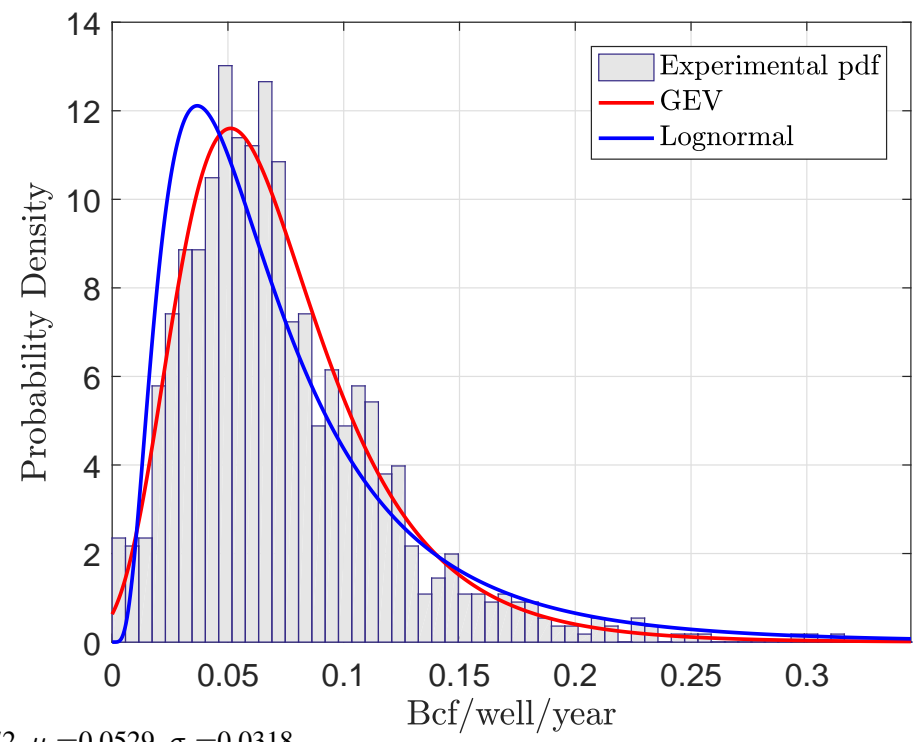

GEV pdf: $\xi=0.0572, \mu=0.0529, \sigma=0.0318$ 


\section{MLE of GEV pdf in Parker county}

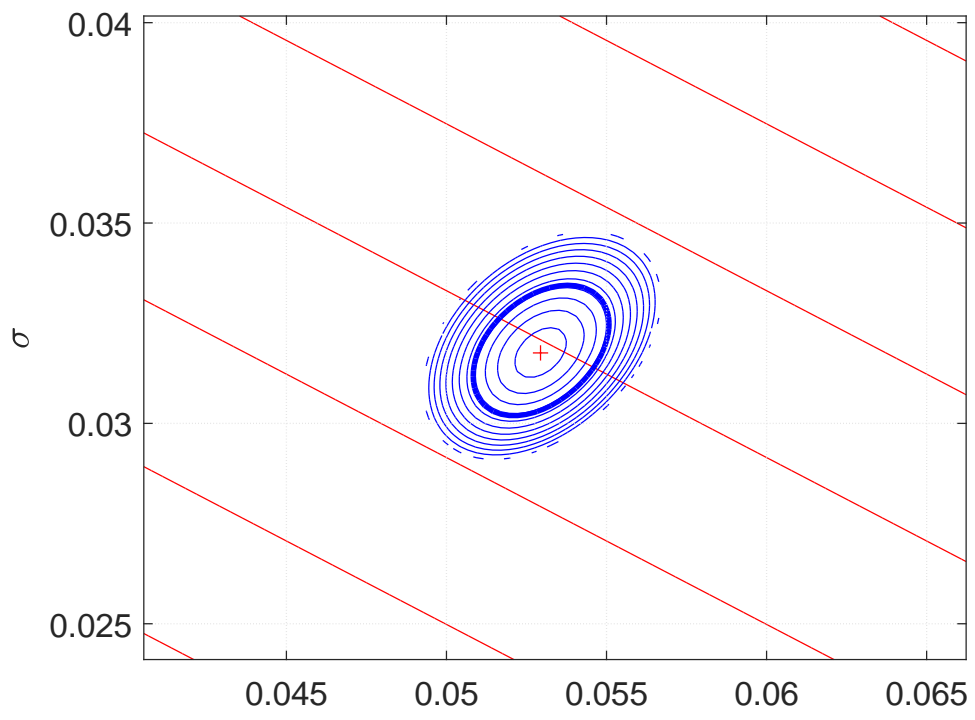

MLE = Maximum Likelihood Estimate, $95 \%$ CI for $\mu$ and $\sigma$ after 6.00 yrs 


\section{Parker county after 6.00 yrs}

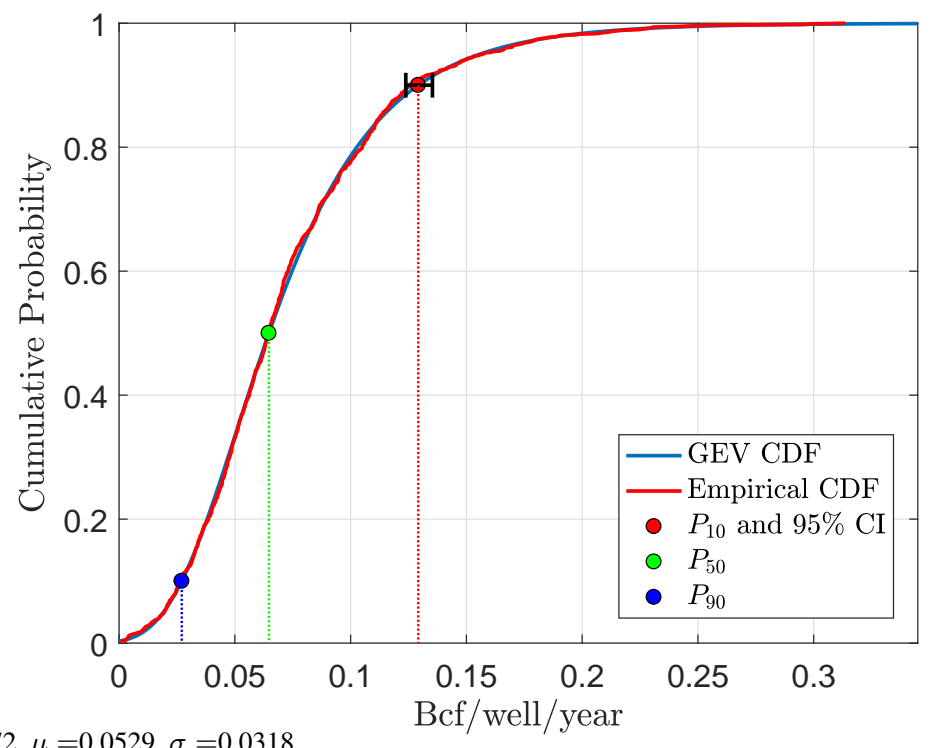

GEV cdf: $\xi=0.0572, \mu=0.0529, \sigma=0.0318$ 


\section{Parker county after 7 yrs}

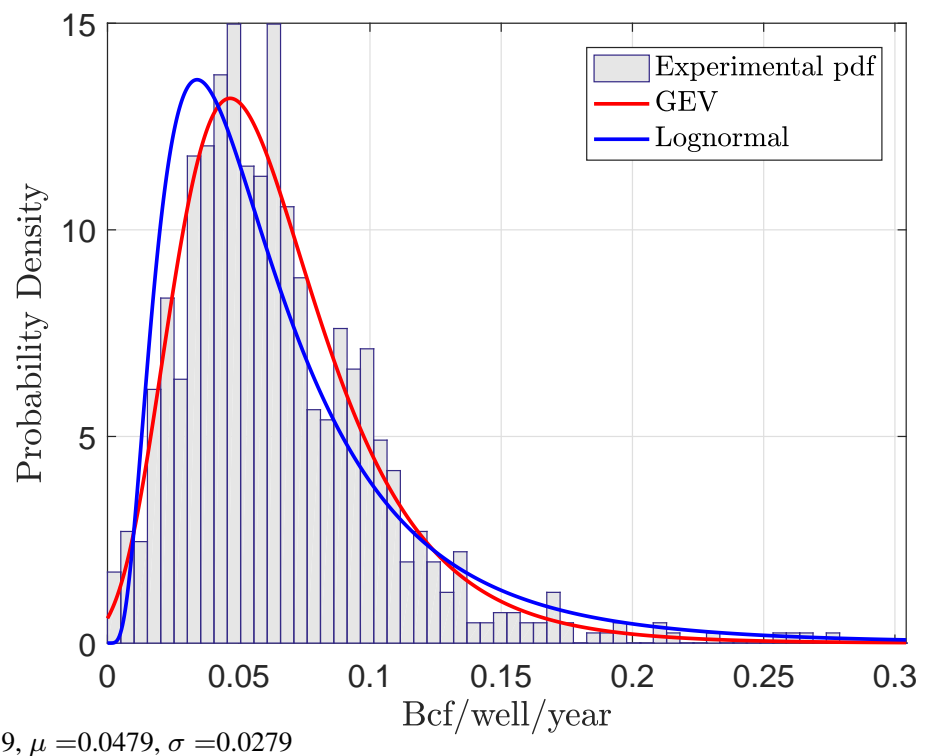

GEV pdf: $\xi=0.0439, \mu=0.0479, \sigma=0.0279$ 


\section{MLE of GEV pdf in Parker county}

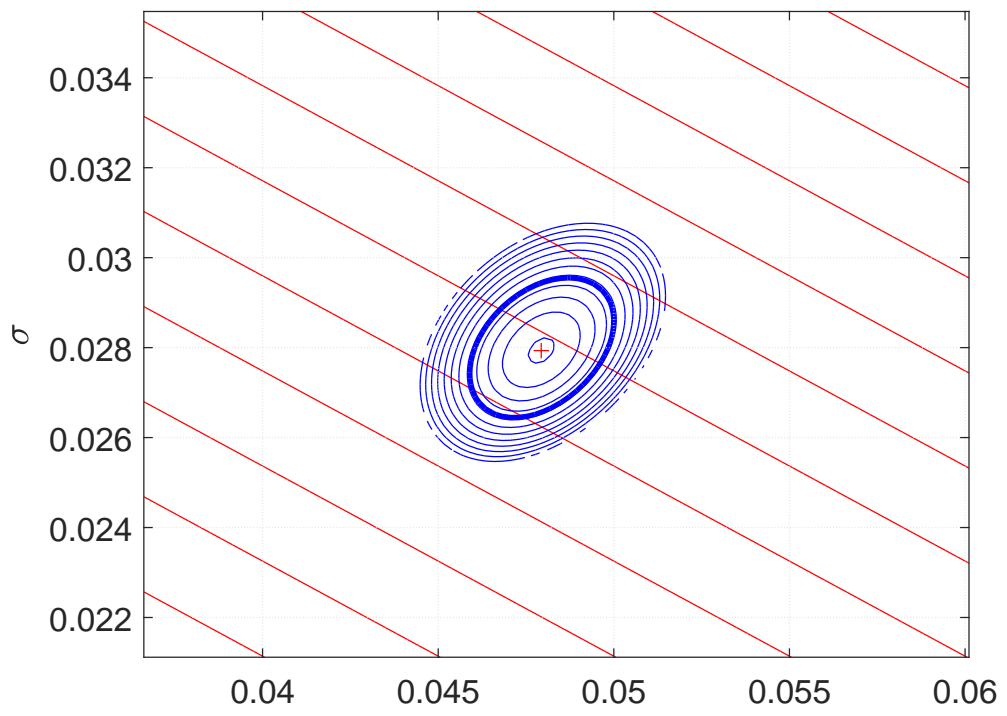

MLE $=$ Maximum Likelihood Estimate, $95 \%$ CI for $\mu$ and $\sigma$ after $\stackrel{\mu}{\mu} .00$ yrs 


\section{Parker county after 7.00 yrs}

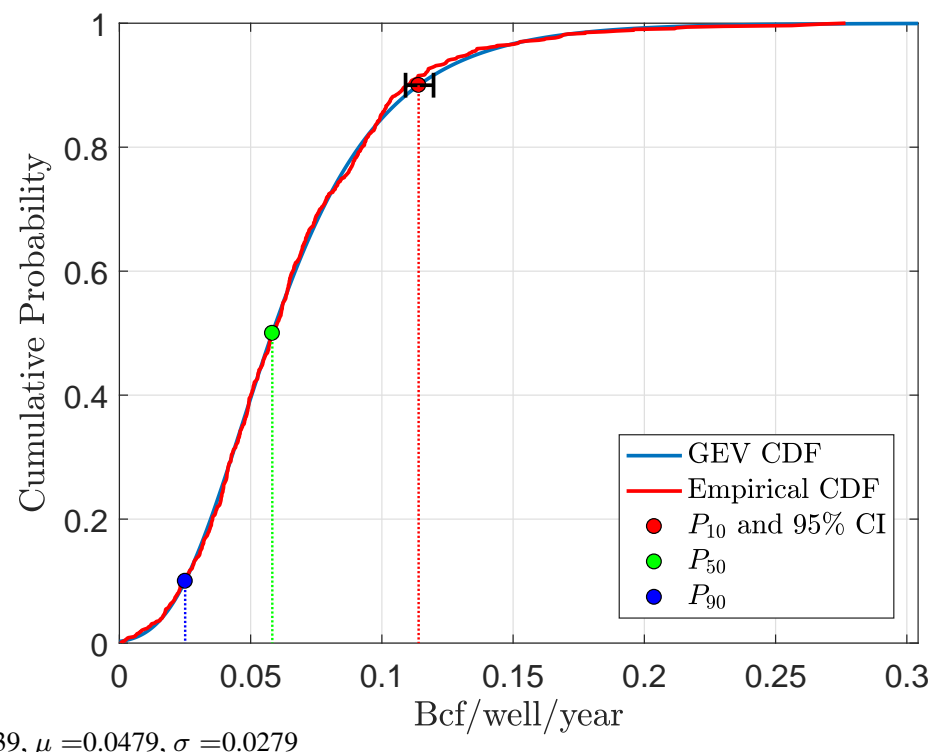

GEV cdf: $\xi=0.0439, \mu=0.0479, \sigma=0.0279$ 


\section{Parker county after 8 yrs}

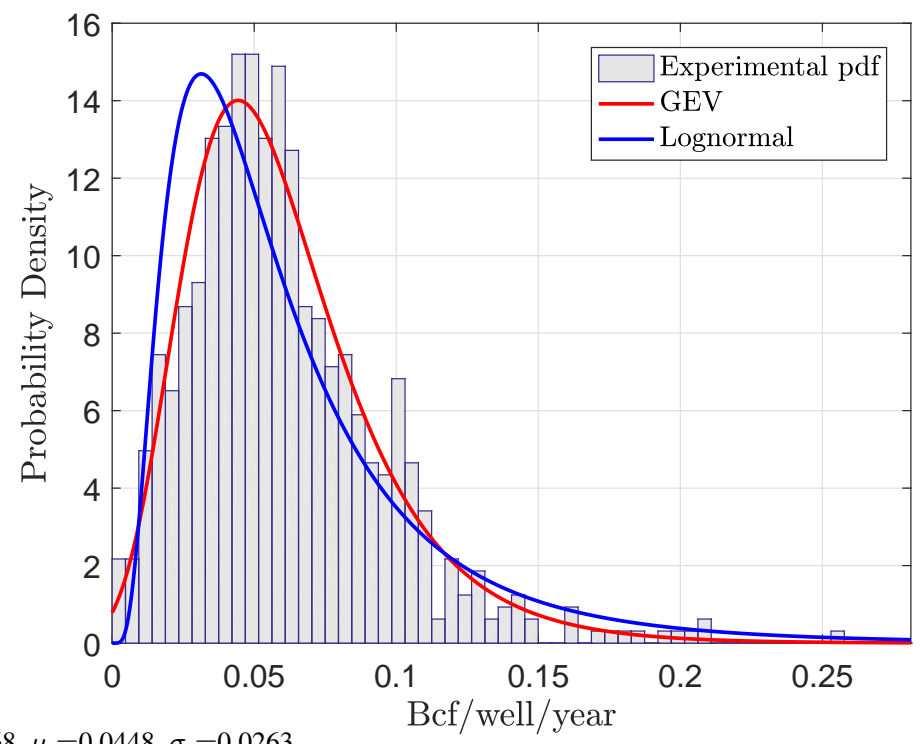

GEV pdf: $\xi=0.0168, \mu=0.0448, \sigma=0.0263$ 


\section{MLE of GEV pdf in Parker county}

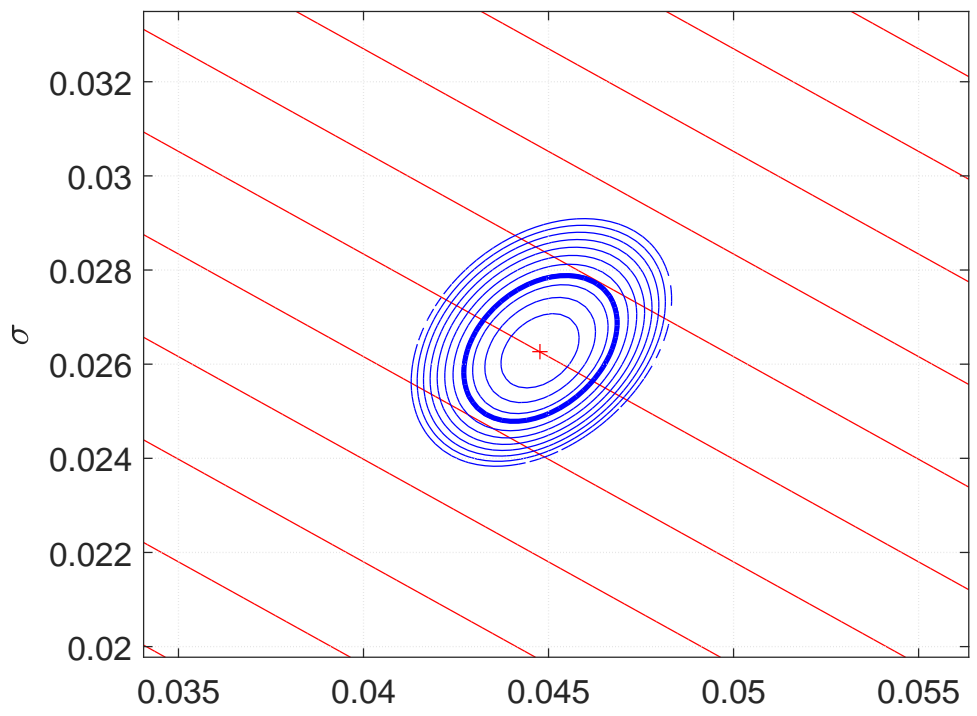

MLE $=$ Maximum Likelihood Estimate, $95 \%$ CI for $\mu$ and $\sigma$ after $\stackrel{\mu}{8.00}$ yrs 


\section{Parker county after 8.00 yrs}

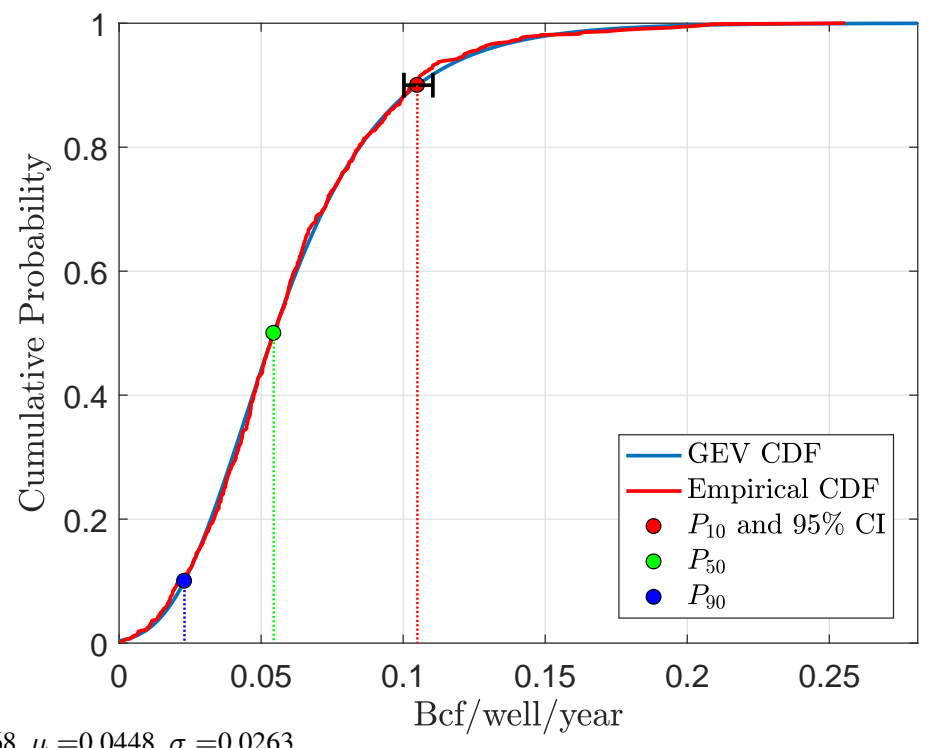

GEV cdf: $\xi=0.0168, \mu=0.0448, \sigma=0.0263$ 


\section{Parker county after 9 yrs}

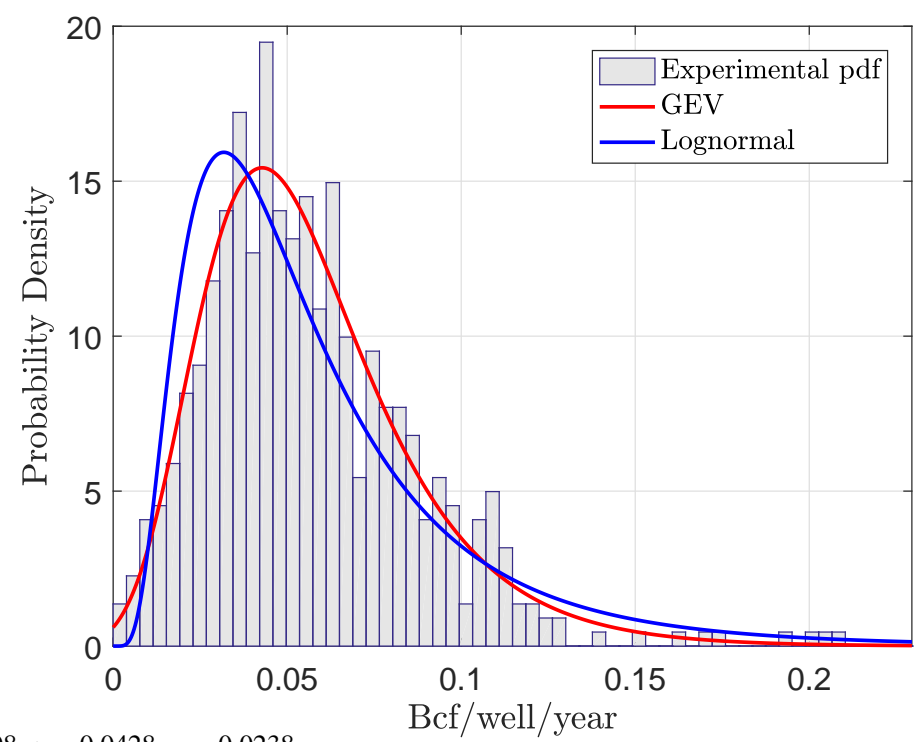

GEV pdf: $\xi=0.0008, \mu=0.0428, \sigma=0.0238$ 


\section{MLE of GEV pdf in Parker county}

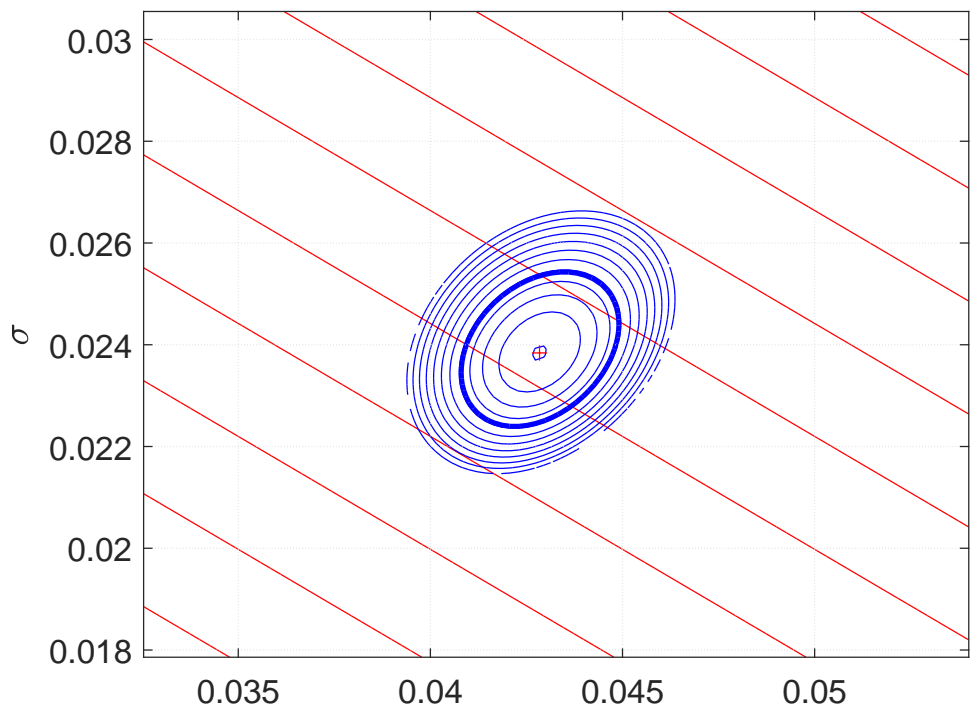

MLE $=$ Maximum Likelihood Estimate, $95 \%$ CI for $\mu$ and $\sigma$ after 9.00 yrs 


\section{Parker county after 9.00 yrs}

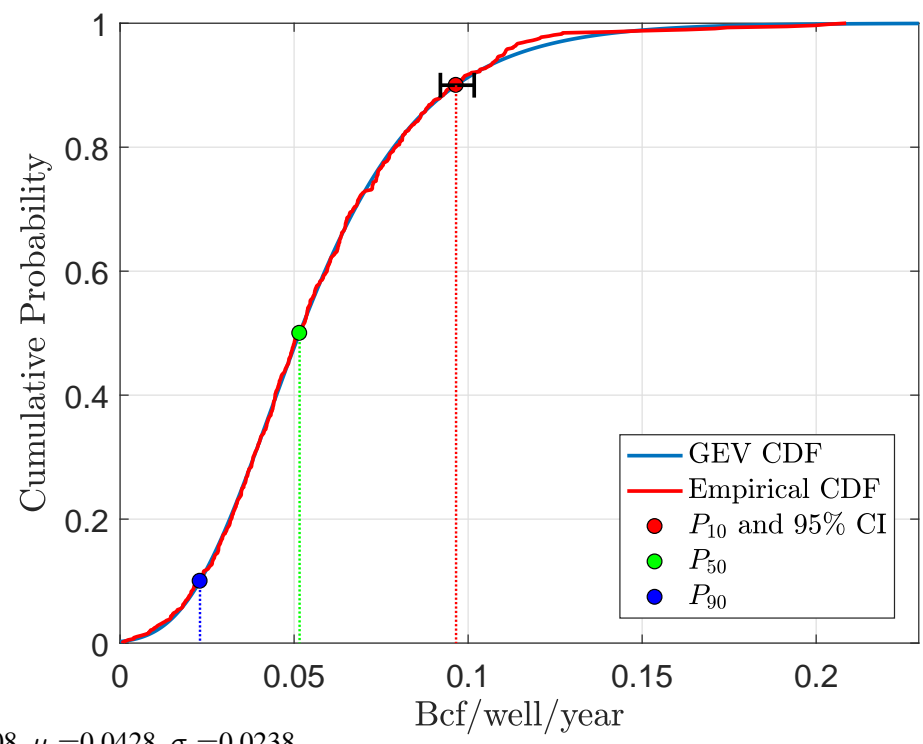

GEV cdf: $\xi=0.0008, \mu=0.0428, \sigma=0.0238$ 


\section{Parker county after 10 yrs}

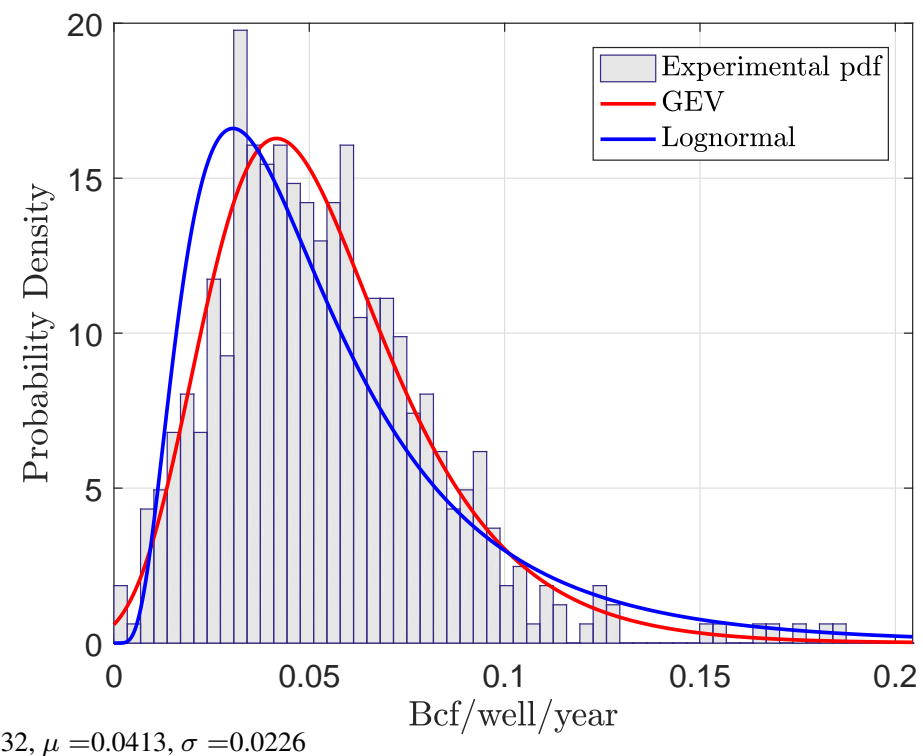

GEV pdf: $\xi=-0.0132, \mu=0.0413, \sigma=0.0226$ 


\section{MLE of GEV pdf in Parker county}

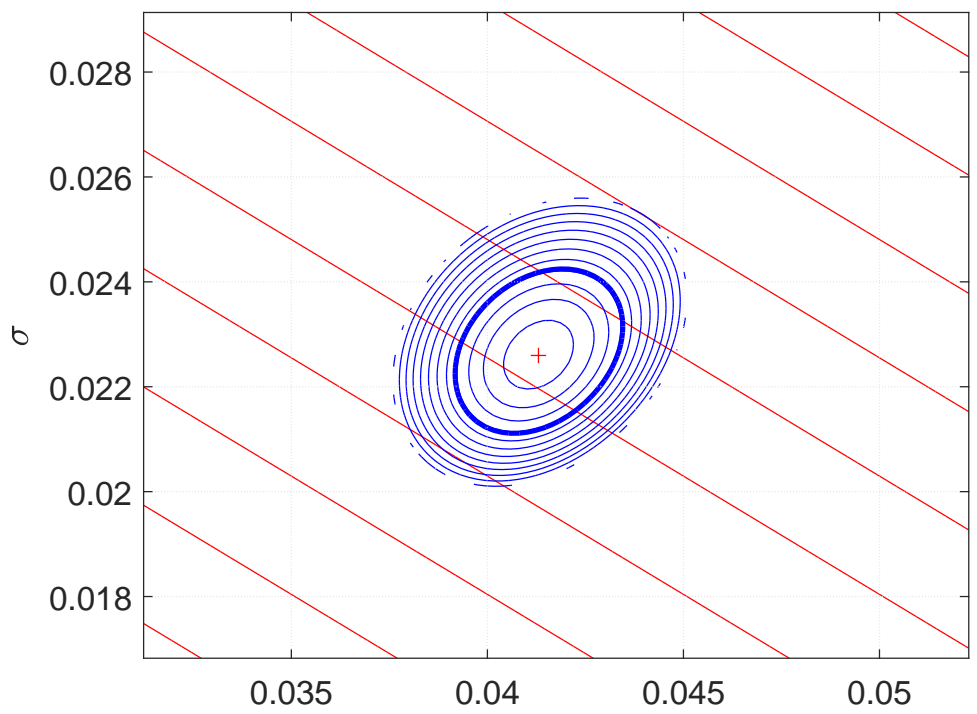

MLE = Maximum Likelihood Estimate, 95\% CI for $\mu$ and $\sigma$ after 10.00 yrs 


\section{Parker county after 10.00 yrs}

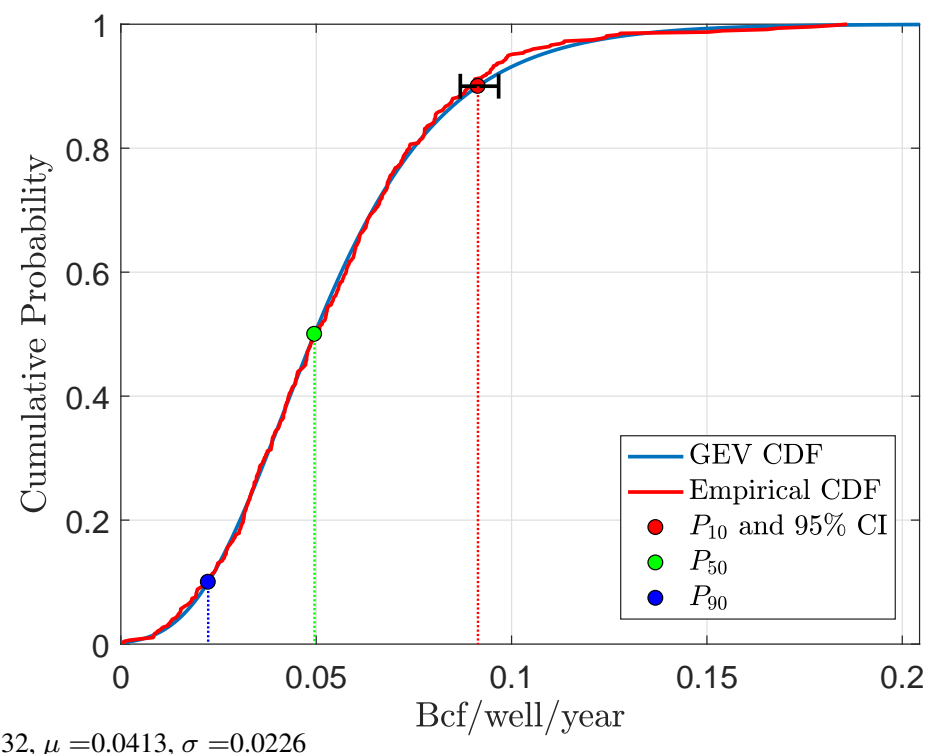

GEV cdf: $\xi=-0.0132, \mu=0.0413, \sigma=0.0226$ 


\section{Parker county after 11 yrs}

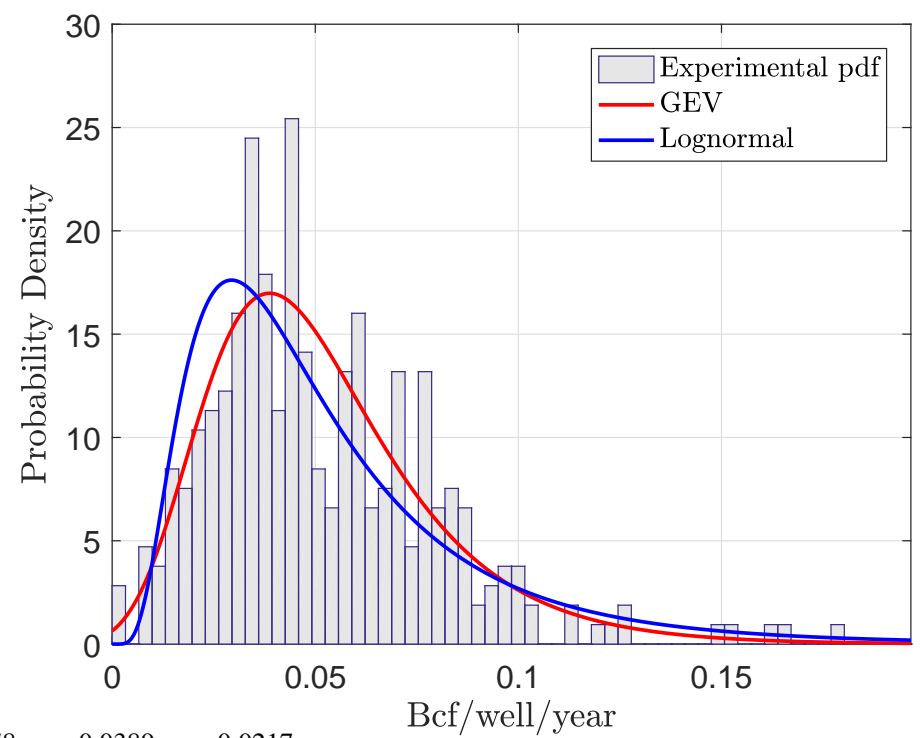

GEV pdf: $\xi=0.0078, \mu=0.0389, \sigma=0.0217$ 


\section{MLE of GEV pdf in Parker county}

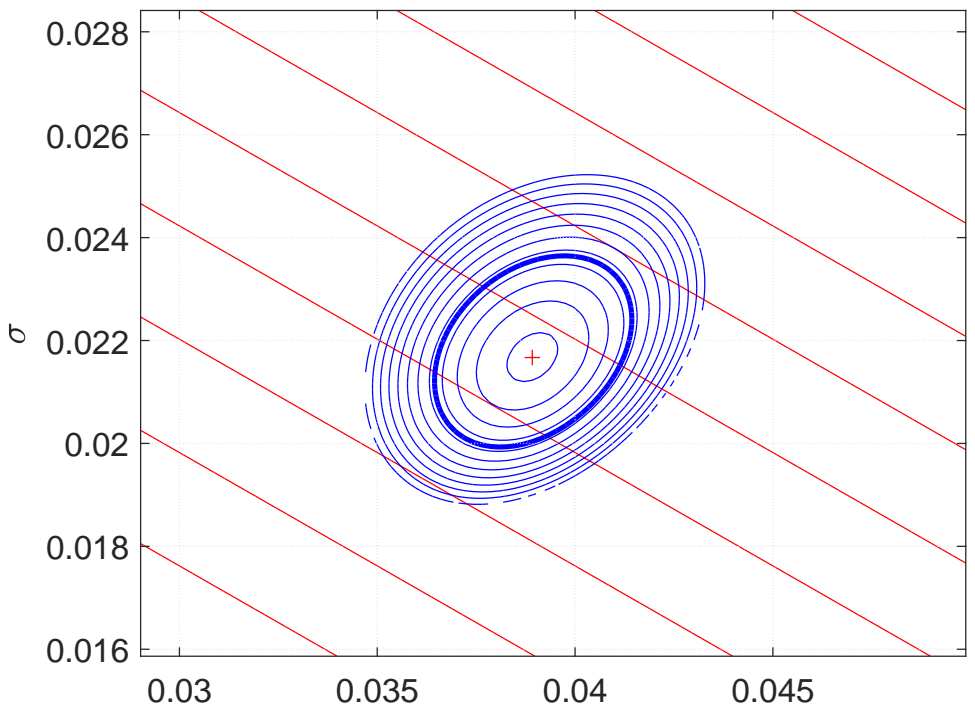

MLE = Maximum Likelihood Estimate, $95 \% \mathrm{CI}$ for $\mu$ and $\sigma$ after $11.00 \mathrm{yrs}$ 


\section{Parker county after 11.00 yrs}

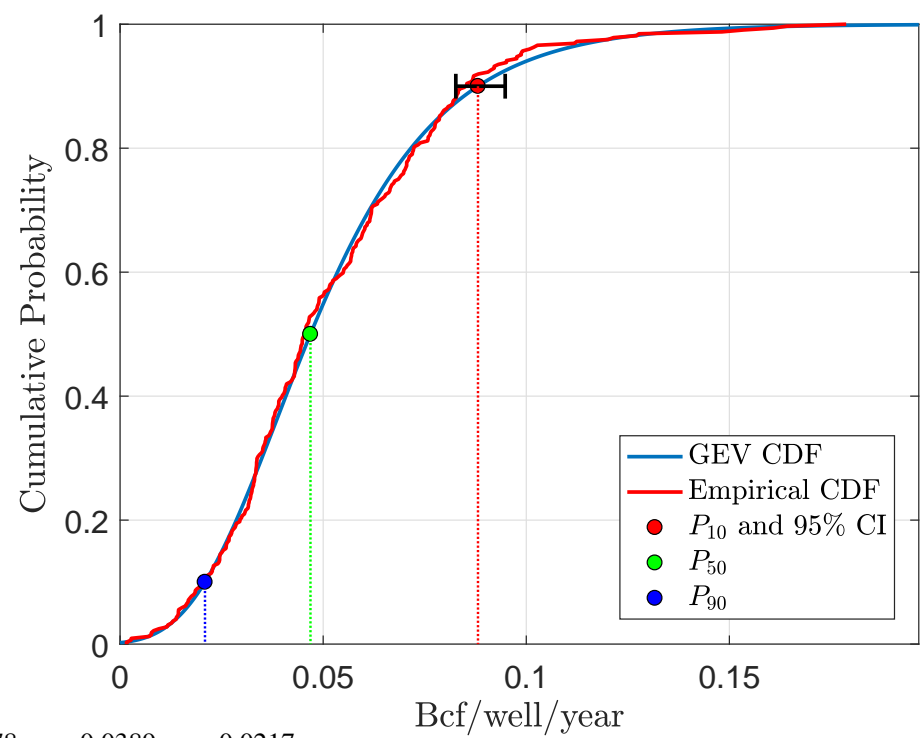

GEV cdf: $\xi=0.0078, \mu=0.0389, \sigma=0.0217$ 


\section{Parker county after 12 yrs}

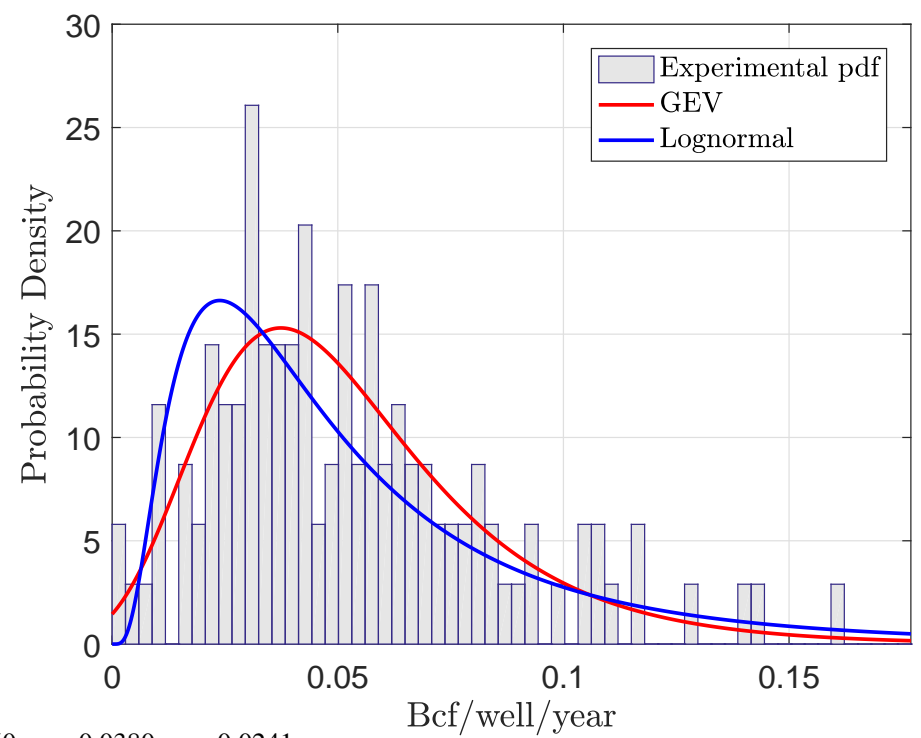

GEV pdf: $\xi=0.0250, \mu=0.0380, \sigma=0.0241$ 


\section{MLE of GEV pdf in Parker county}

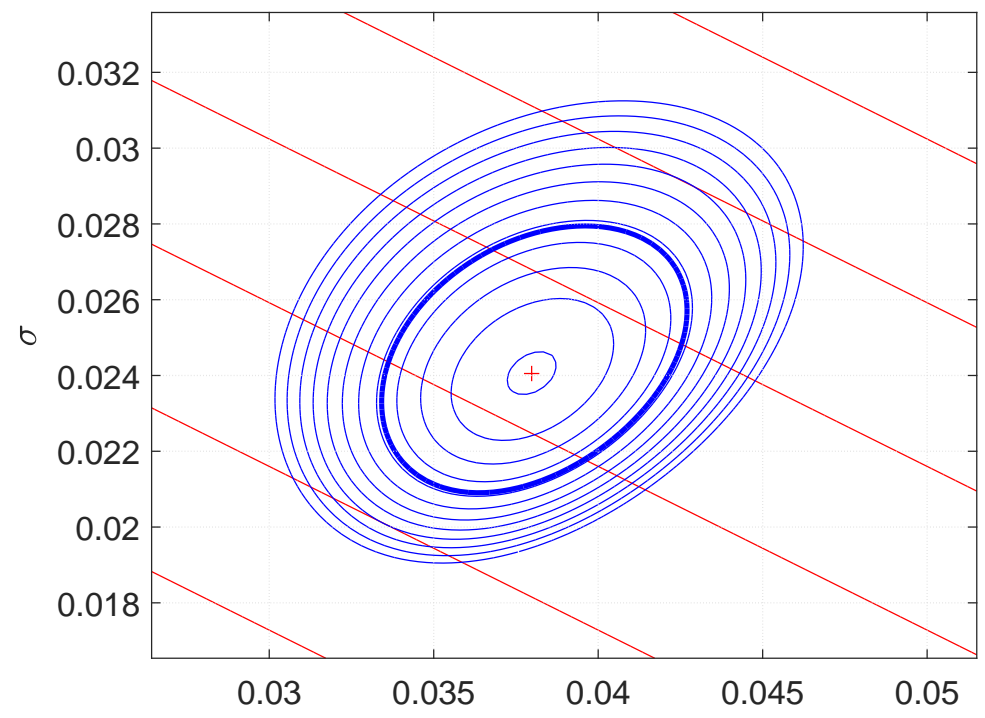

MLE = Maximum Likelihood Estimate, 95\% CI for $\mu$ and $\sigma$ after 12.00 yrs 


\section{Parker county after 12.00 yrs}

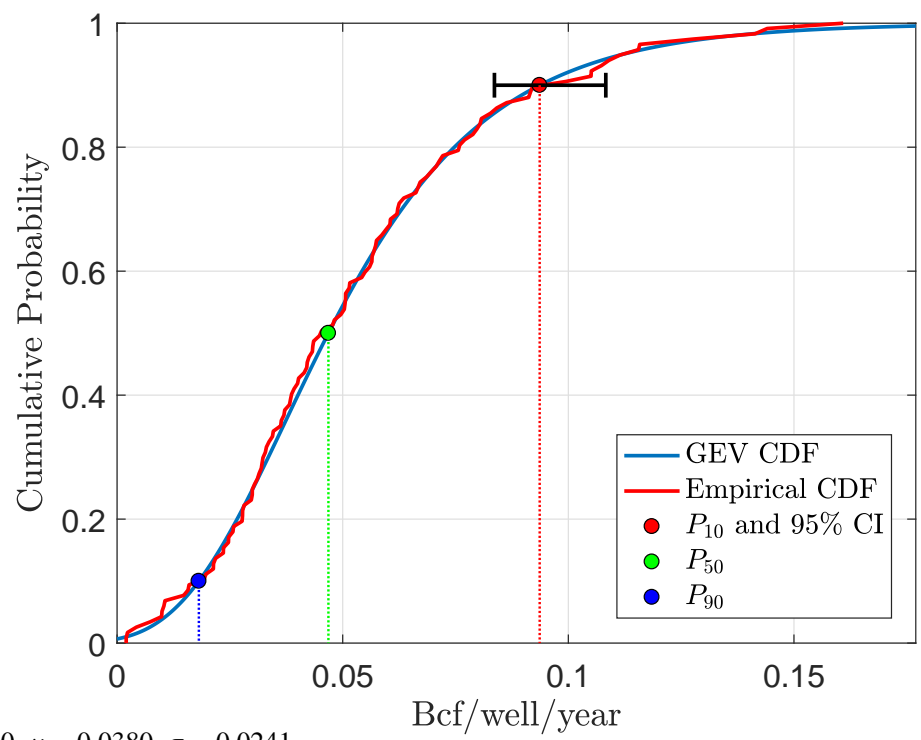

GEV cdf: $\xi=0.0250, \mu=0.0380, \sigma=0.0241$ 


\section{Parker county after 13 yrs}

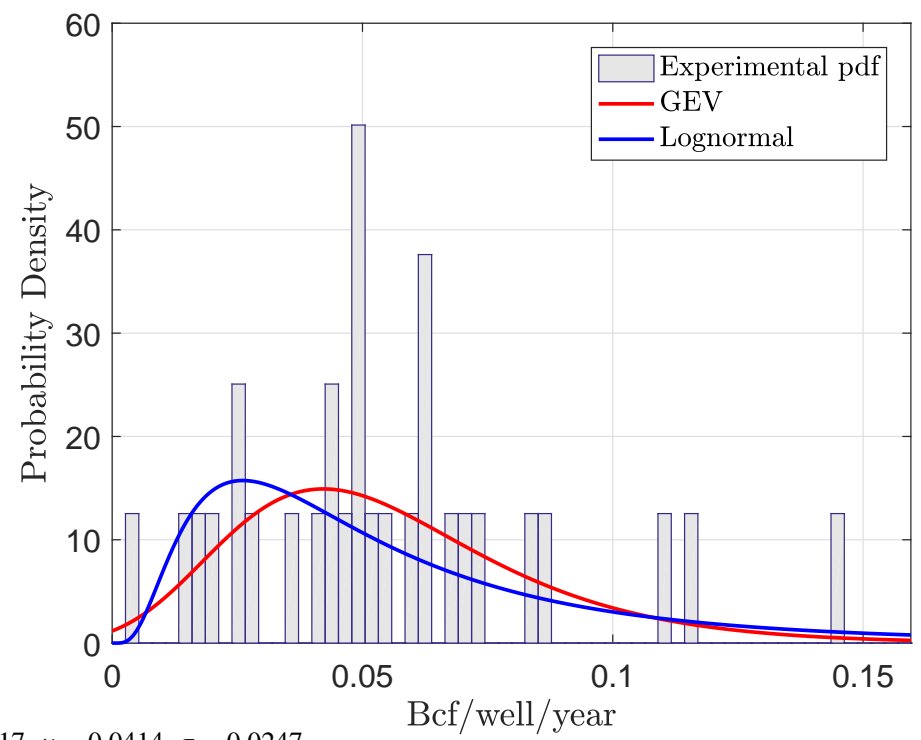

GEV pdf: $\xi=-0.0317, \mu=0.0414, \sigma=0.0247$ 


\section{MLE of GEV pdf in Parker county}

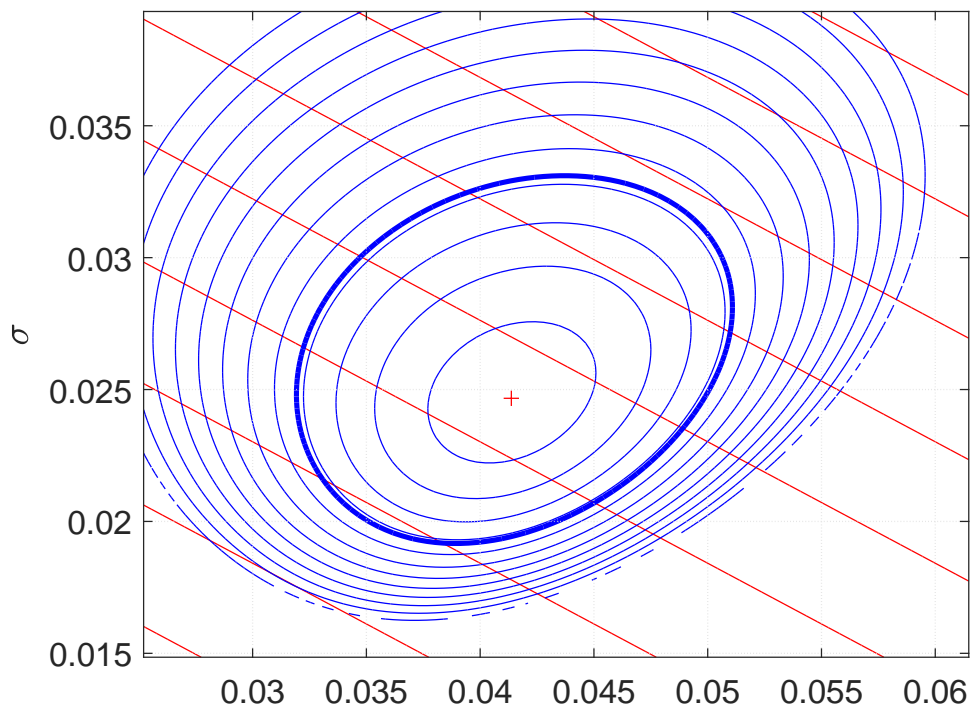

MLE = Maximum Likelihood Estimate, $95 \% \mathrm{CI}$ for $\mu$ and $\sigma$ after $13.00 \mathrm{yrs}$ 


\section{Parker county after 13.00 yrs}

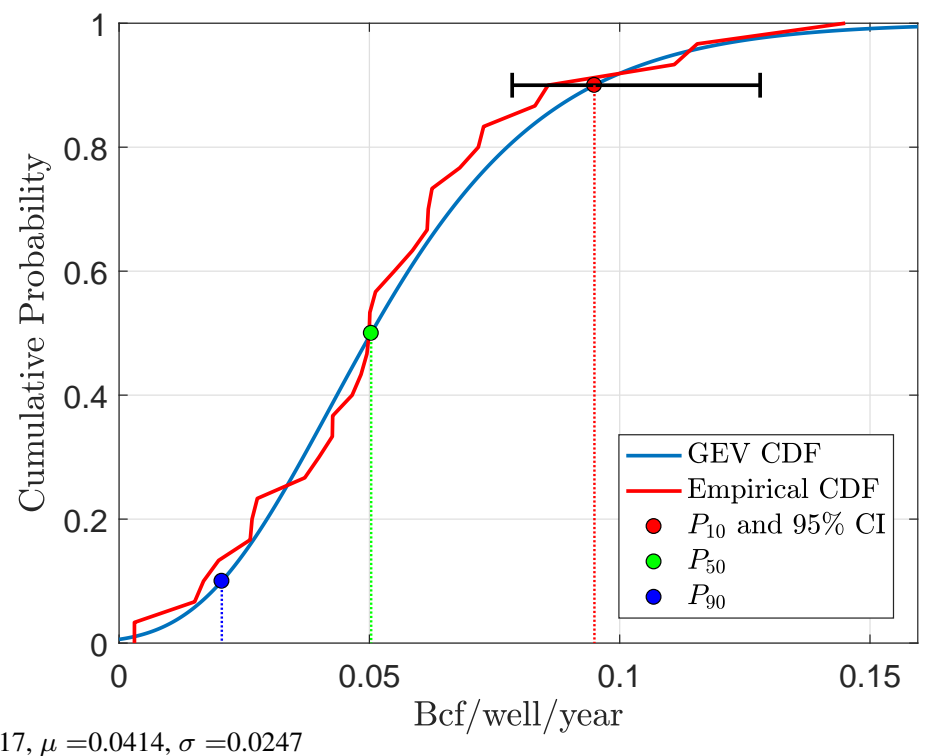

GEV cdf: $\xi=-0.0317, \mu=0.0414, \sigma=0.0247$ 


\section{Hood county after 1 yrs}

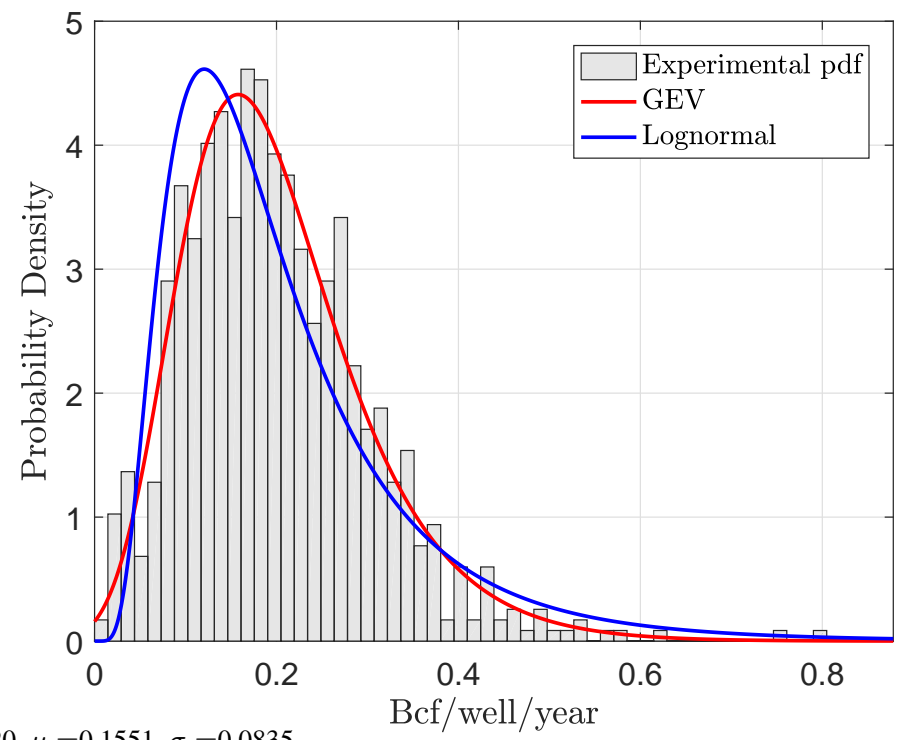

GEV pdf: $\xi=-0.0320, \mu=0.1551, \sigma=0.0835$ 


\section{MLE of GEV pdf in Hood county}

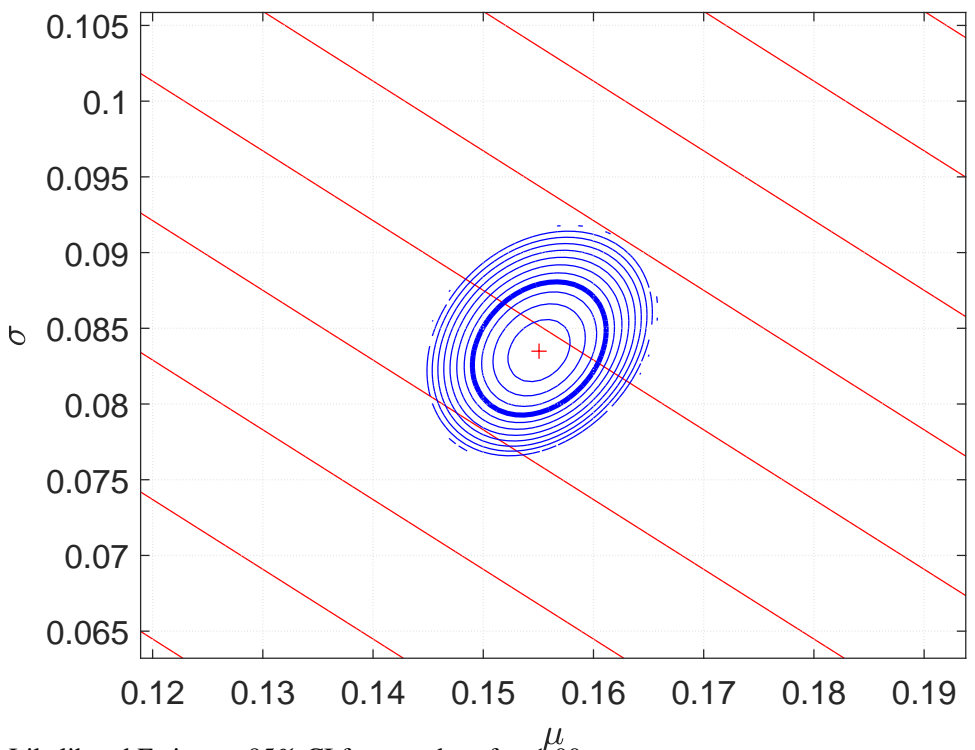

MLE $=$ Maximum Likelihood Estimate, $95 \%$ CI for $\mu$ and $\sigma$ after 1.00 yrs 


\section{Hood county after 1.00 yrs}

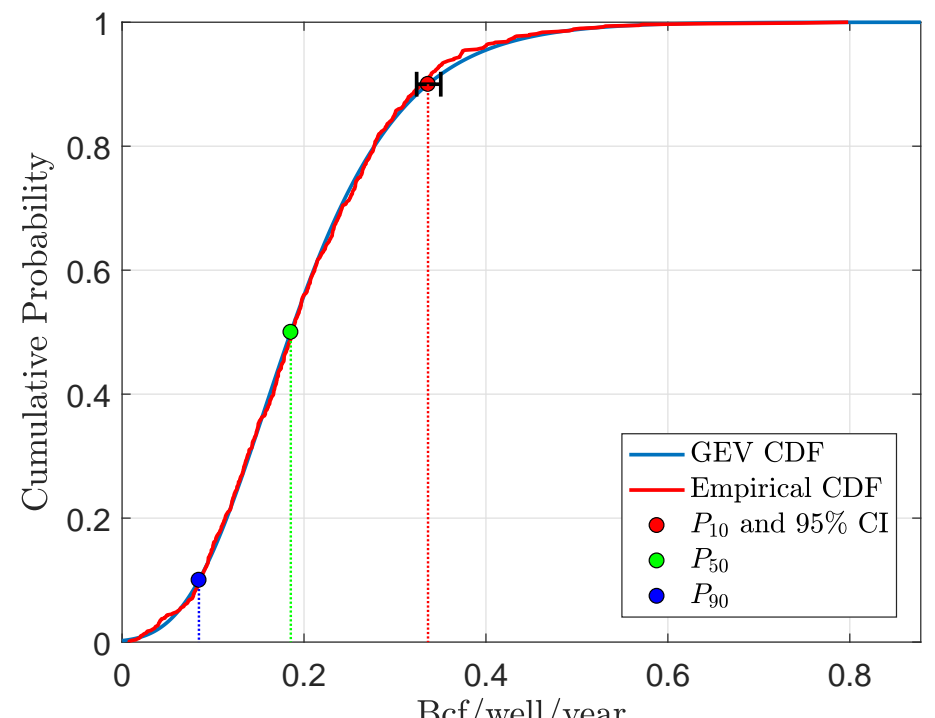

GEV cdf: $\xi=-0.0320, \mu=0.1551, \sigma=0.0835$

Bcf/well/year 


\section{Hood county after 2 yrs}

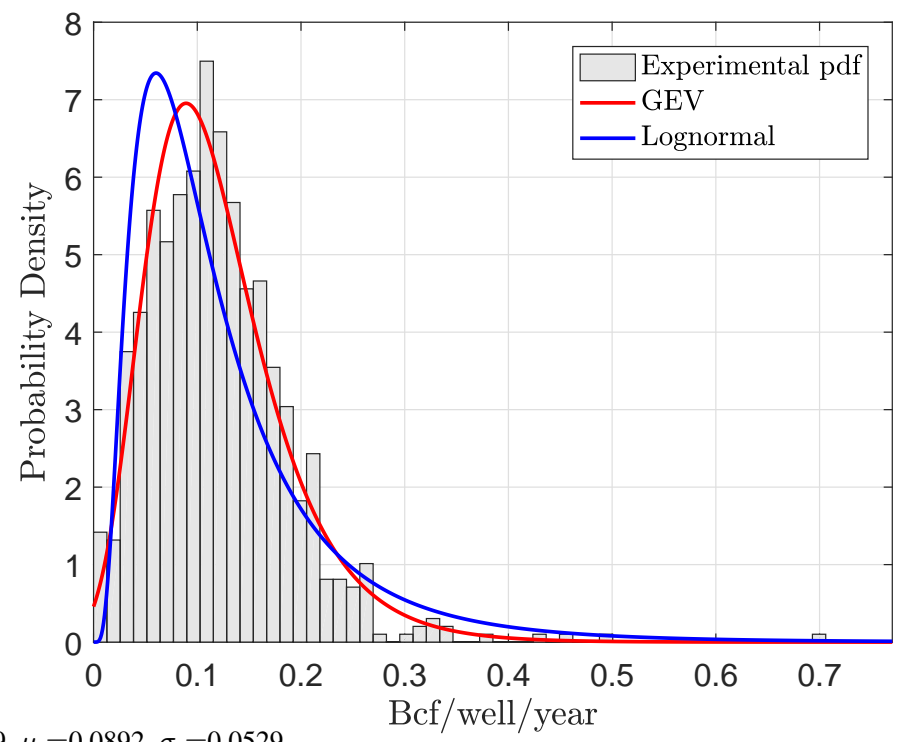

GEV pdf: $\xi=0.0009, \mu=0.0892, \sigma=0.0529$ 


\section{MLE of GEV pdf in Hood county}

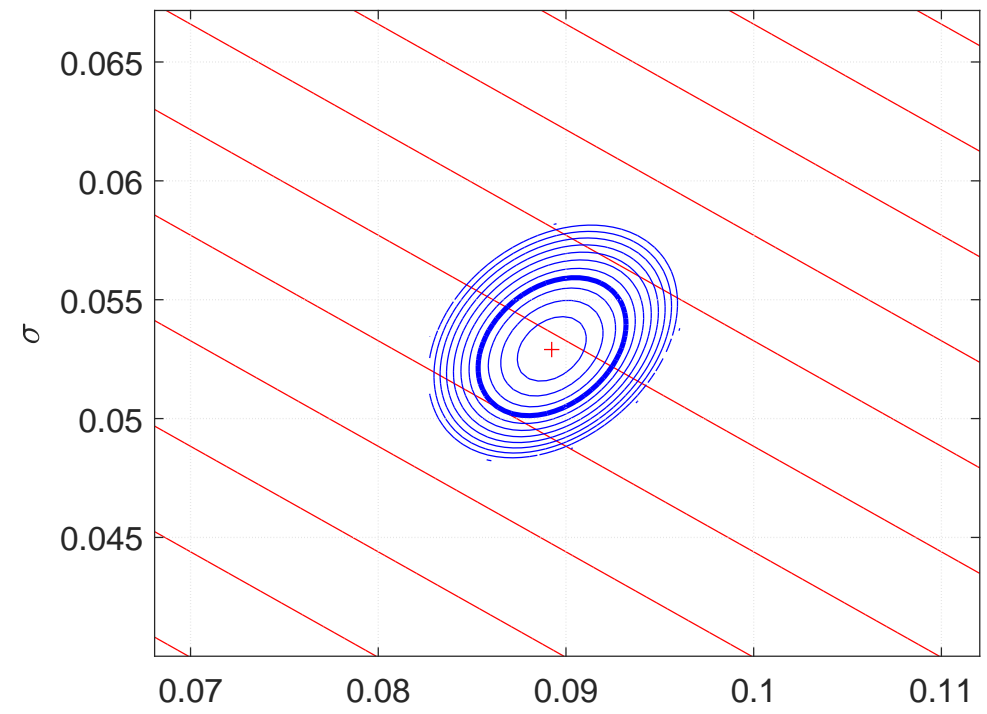

MLE $=$ Maximum Likelihood Estimate, $95 \%$ CI for $\mu$ and $\sigma$ after 2.00 yrs 


\section{Hood county after 2.00 yrs}

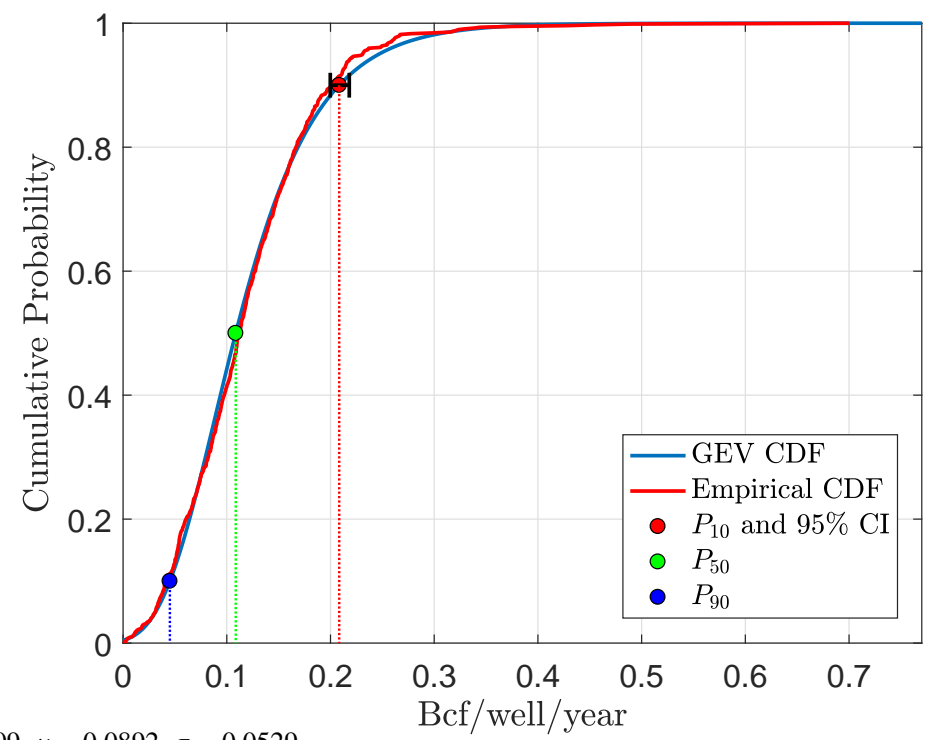

GEV cdf: $\xi=0.0009, \mu=0.0892, \sigma=0.0529$ 


\section{Hood county after 3 yrs}

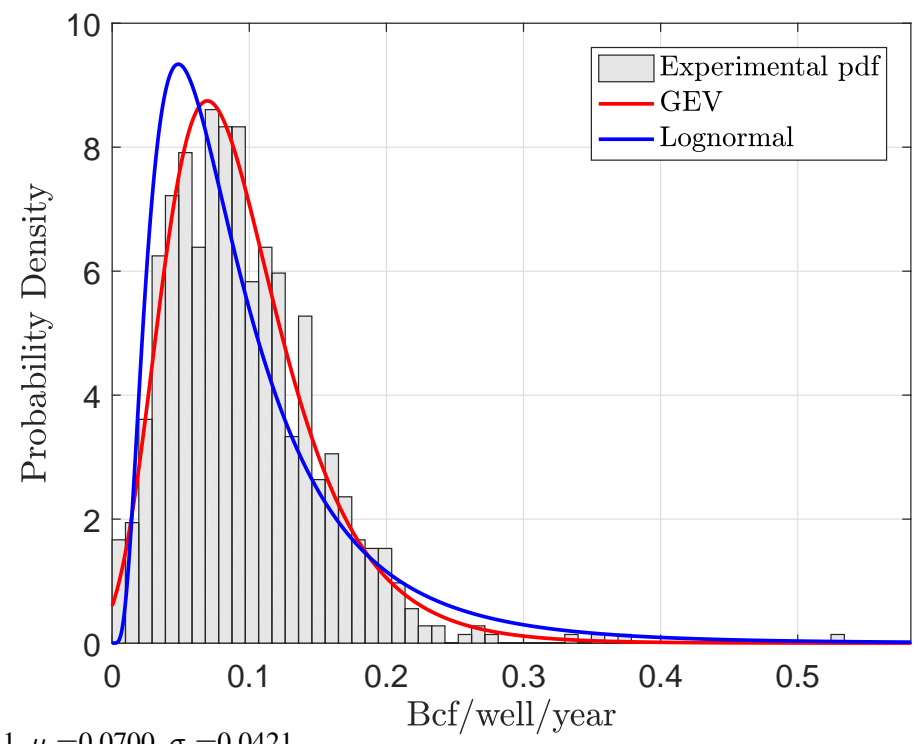

GEV pdf: $\xi=0.0141, \mu=0.0700, \sigma=0.0421$ 


\section{MLE of GEV pdf in Hood county}

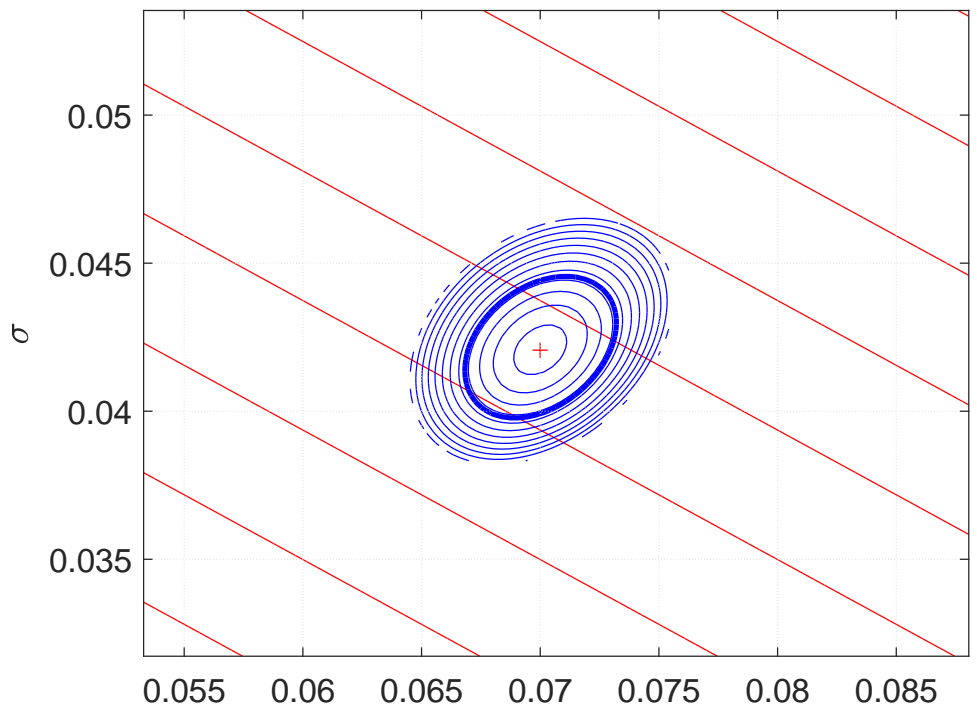

MLE $=$ Maximum Likelihood Estimate, $95 \%$ CI for $\mu$ and $\sigma$ after 3.00 yrs 


\section{Hood county after 3.00 yrs}

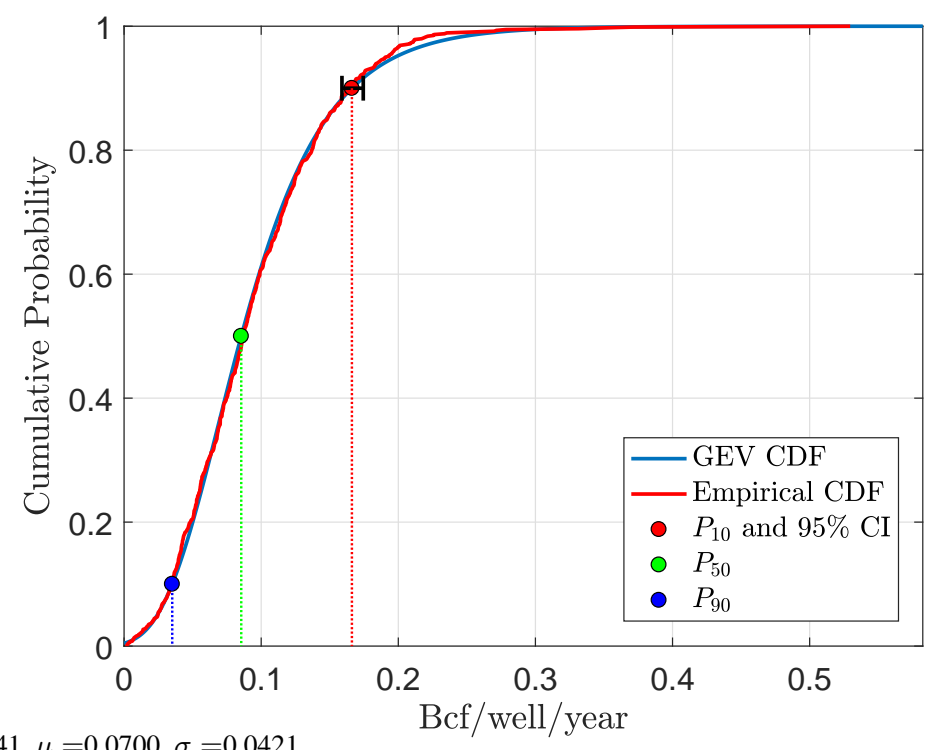

GEV cdf: $\xi=0.0141, \mu=0.0700, \sigma=0.0421$ 


\section{Hood county after 4 yrs}

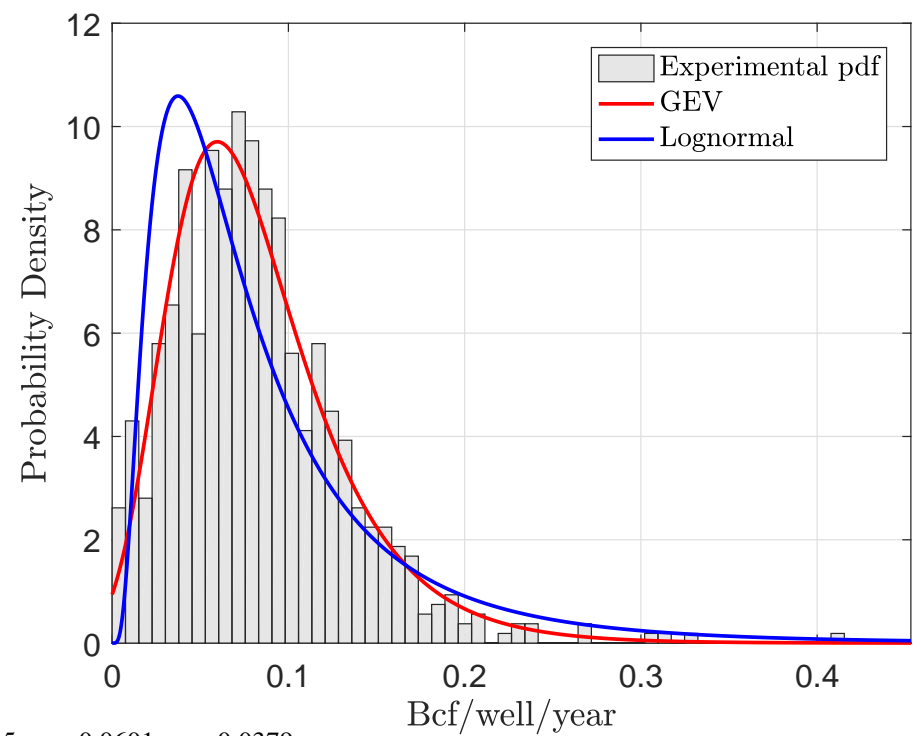

GEV pdf: $\xi=0.0115, \mu=0.0601, \sigma=0.0379$ 


\section{MLE of GEV pdf in Hood county}

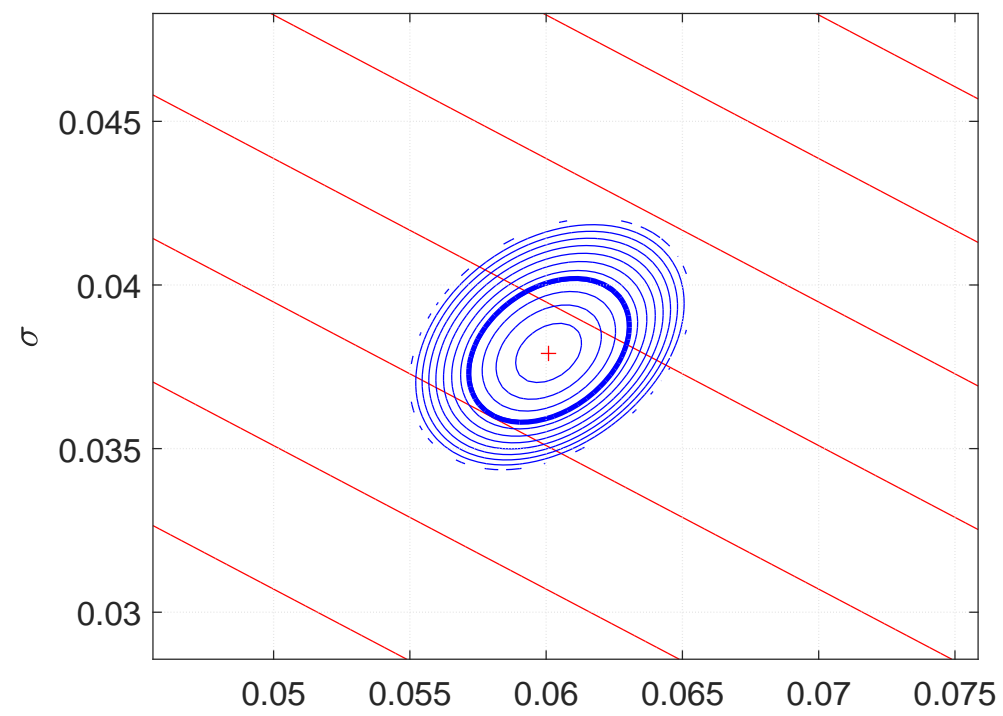

MLE $=$ Maximum Likelihood Estimate, $95 \%$ CI for $\mu$ and $\sigma$ after $4.00 \mathrm{yrs}$ 


\section{Hood county after 4.00 yrs}

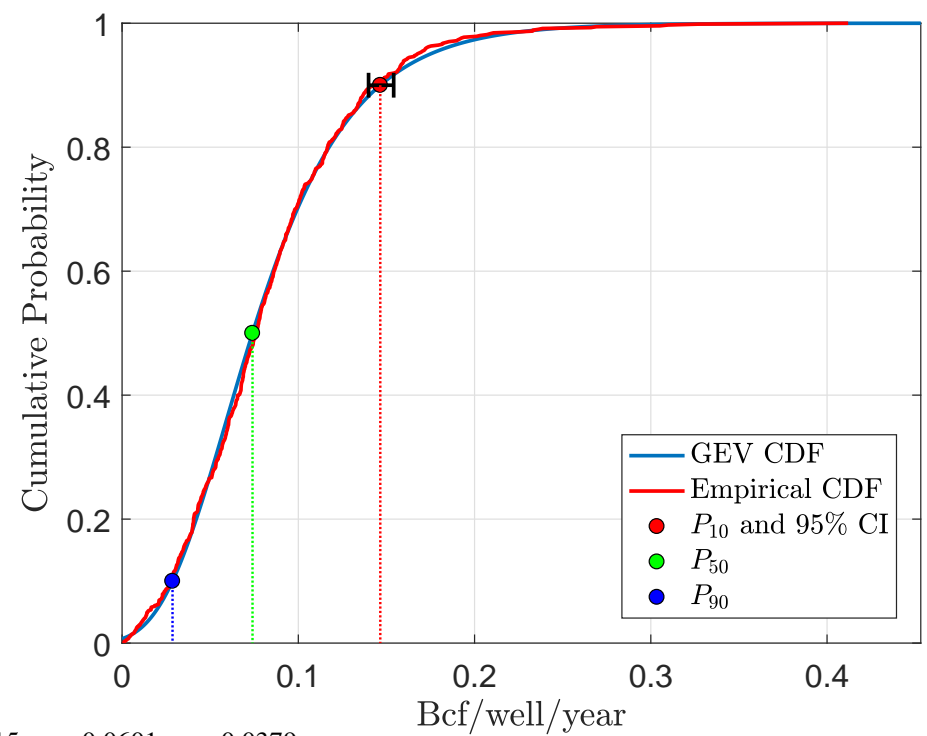

GEV cdf: $\xi=0.0115, \mu=0.0601, \sigma=0.0379$ 


\section{Hood county after 5 yrs}

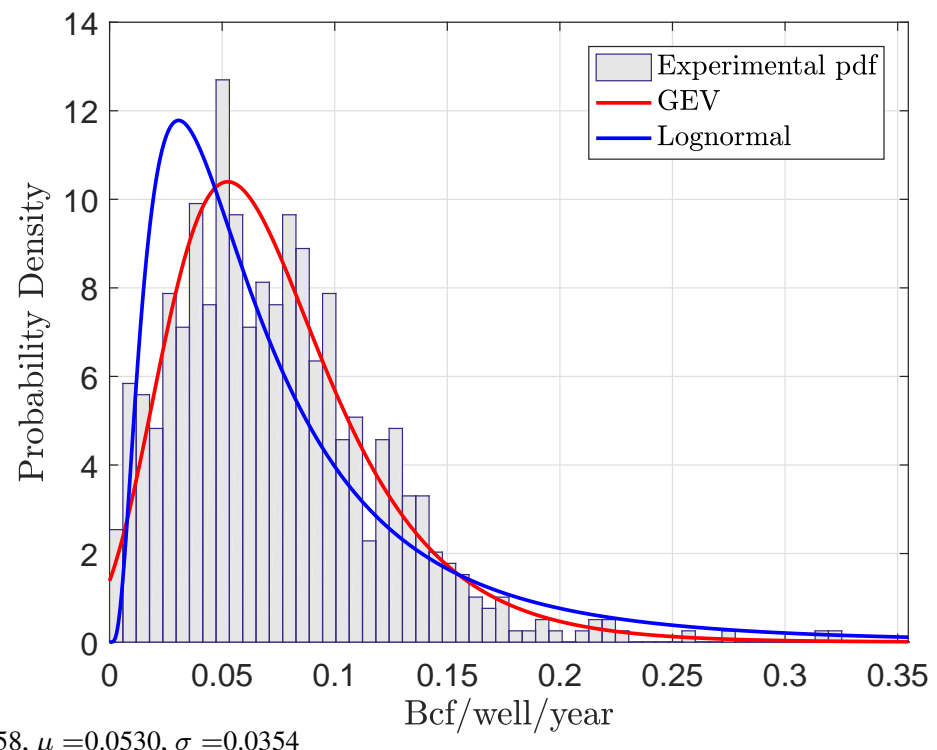

GEV pdf: $\xi=0.0158, \mu=0.0530, \sigma=0.0354$ 


\section{MLE of GEV pdf in Hood county}

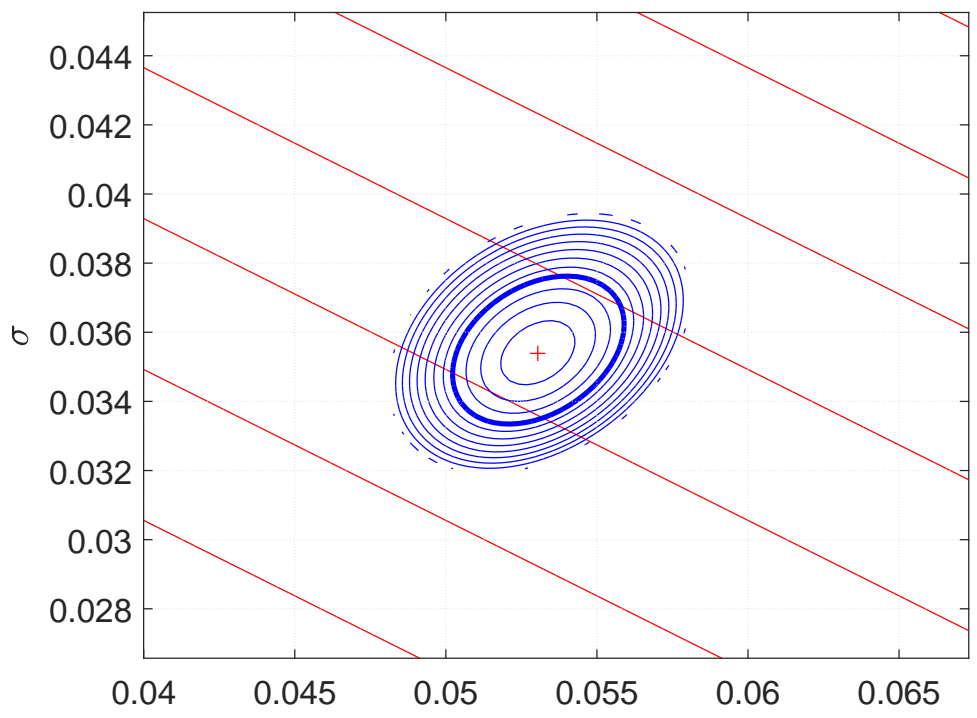

MLE $=$ Maximum Likelihood Estimate, $95 \%$ CI for $\mu$ and $\sigma$ after 5.00 yrs 


\section{Hood county after 5.00 yrs}

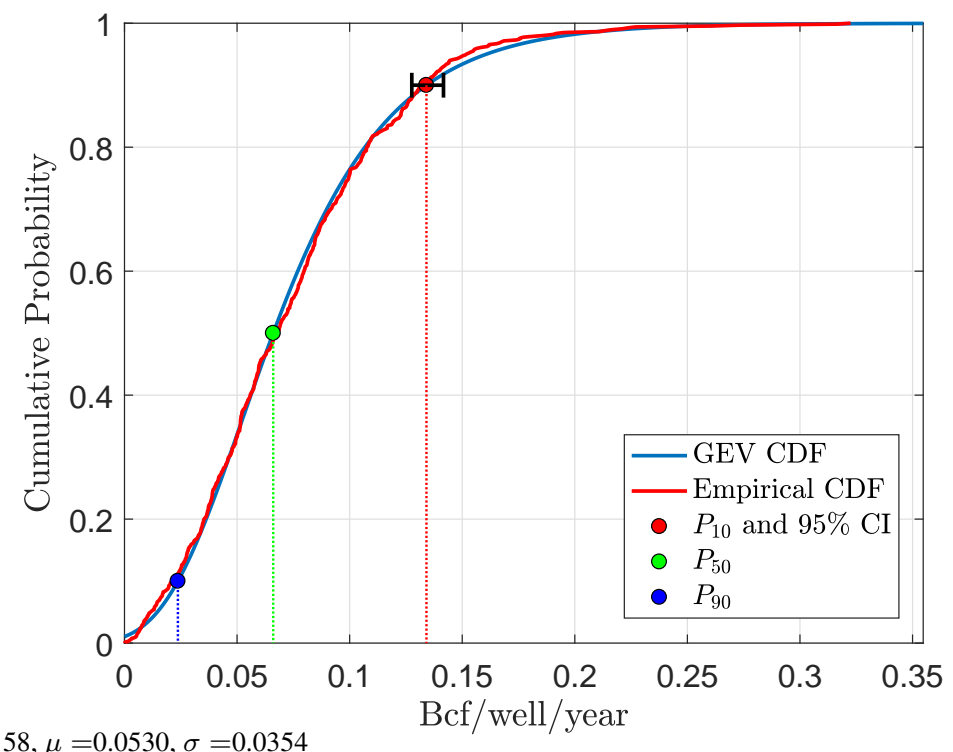

GEV cdf: $\xi=0.0158, \mu=0.0530, \sigma=0.0354$ 


\section{Hood county after 6 yrs}

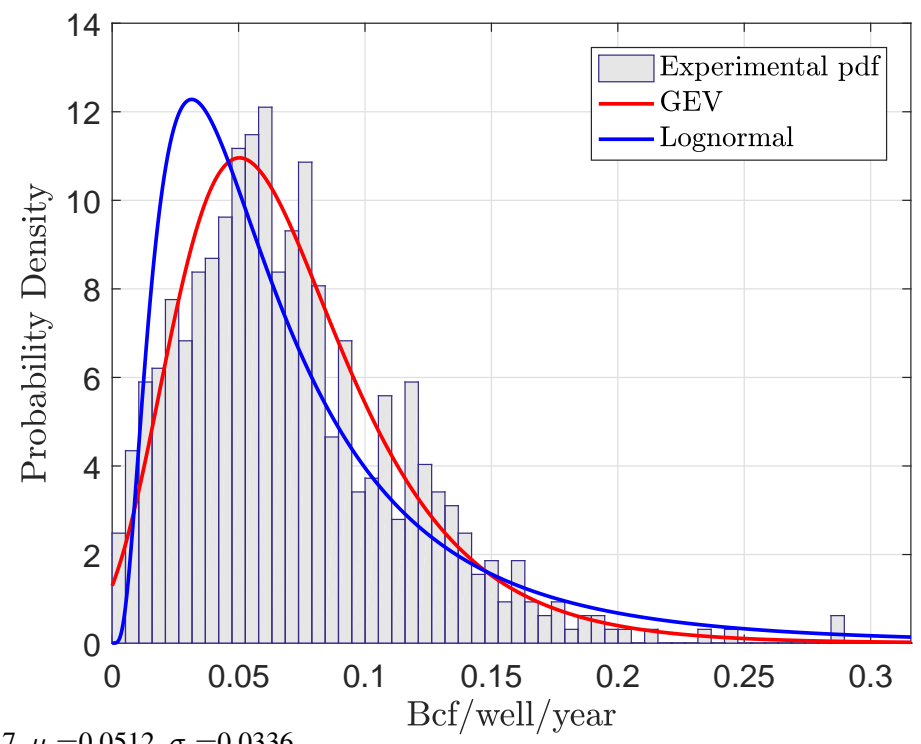

GEV pdf: $\xi=0.0247, \mu=0.0512, \sigma=0.0336$ 


\section{MLE of GEV pdf in Hood county}

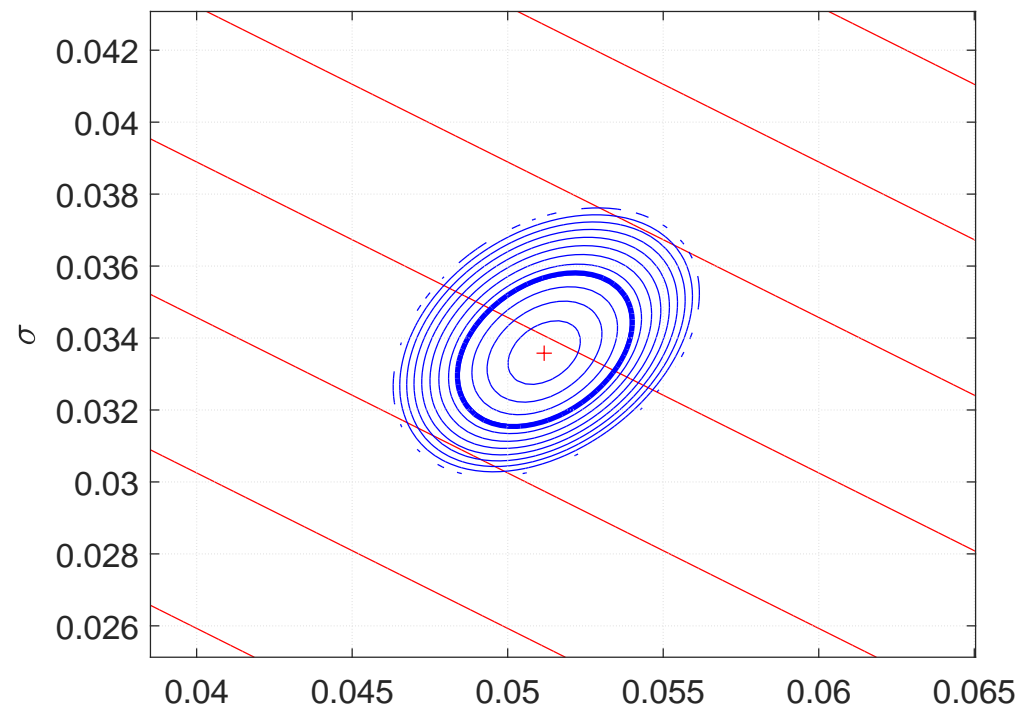

MLE $=$ Maximum Likelihood Estimate, $95 \%$ CI for $\mu$ and $\sigma$ after 6.00 yrs 


\section{Hood county after 6.00 yrs}

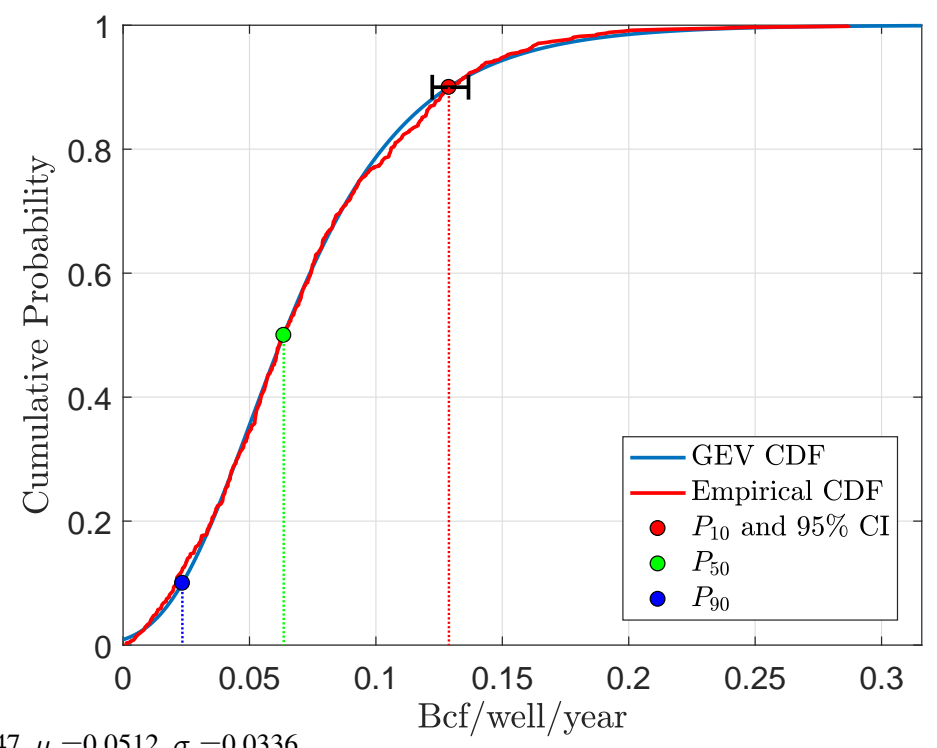

GEV cdf: $\xi=0.0247, \mu=0.0512, \sigma=0.0336$ 


\section{Hood county after 7 yrs}

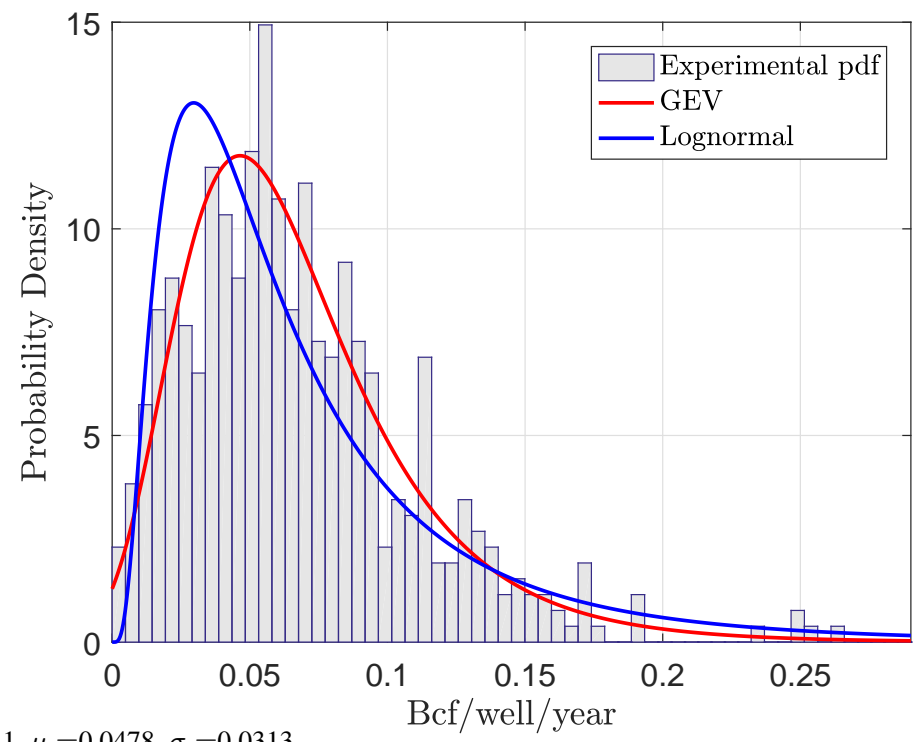

GEV pdf: $\xi=0.0441, \mu=0.0478, \sigma=0.0313$ 


\section{MLE of GEV pdf in Hood county}

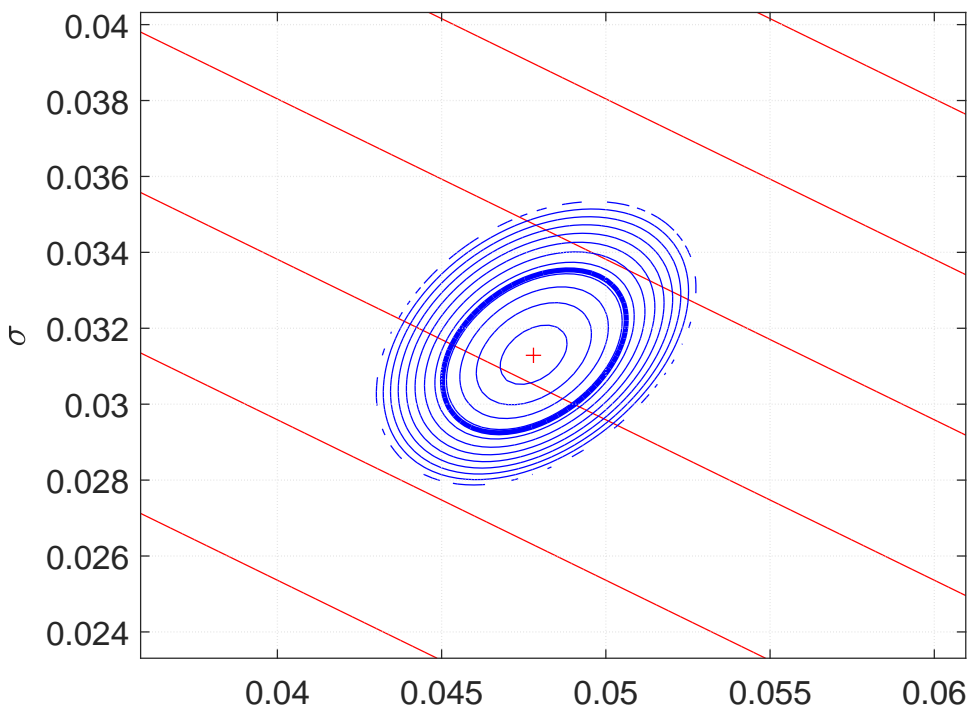

MLE $=$ Maximum Likelihood Estimate, $95 \%$ CI for $\mu$ and $\sigma$ after $\mu_{.00}$ yrs 


\section{Hood county after 7.00 yrs}

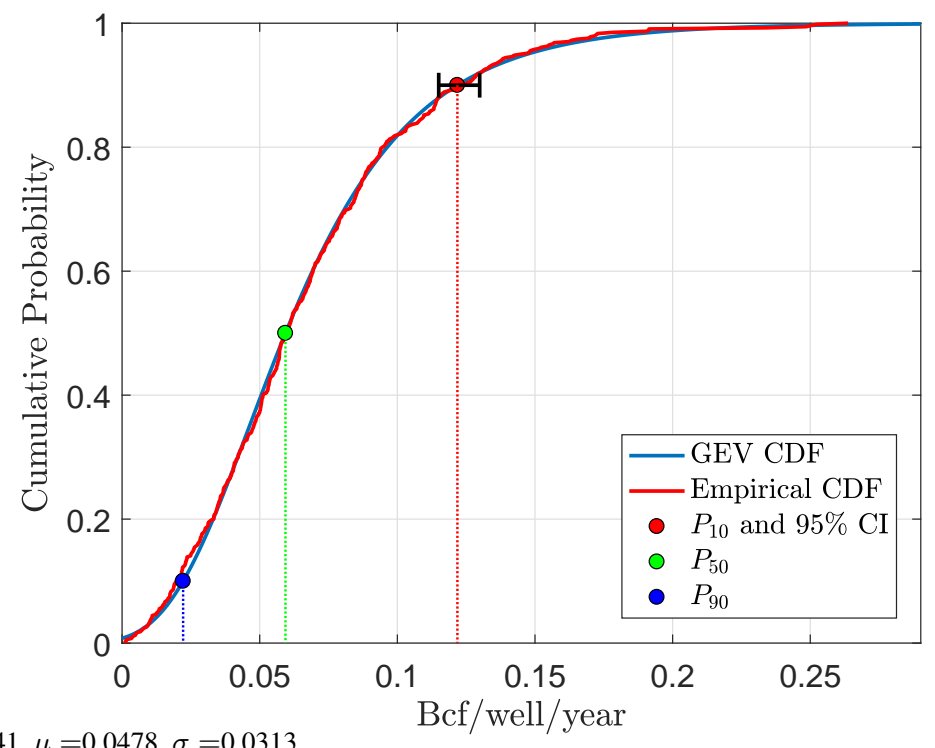

GEV cdf: $\xi=0.0441, \mu=0.0478, \sigma=0.0313$ 


\section{Hood county after 8 yrs}

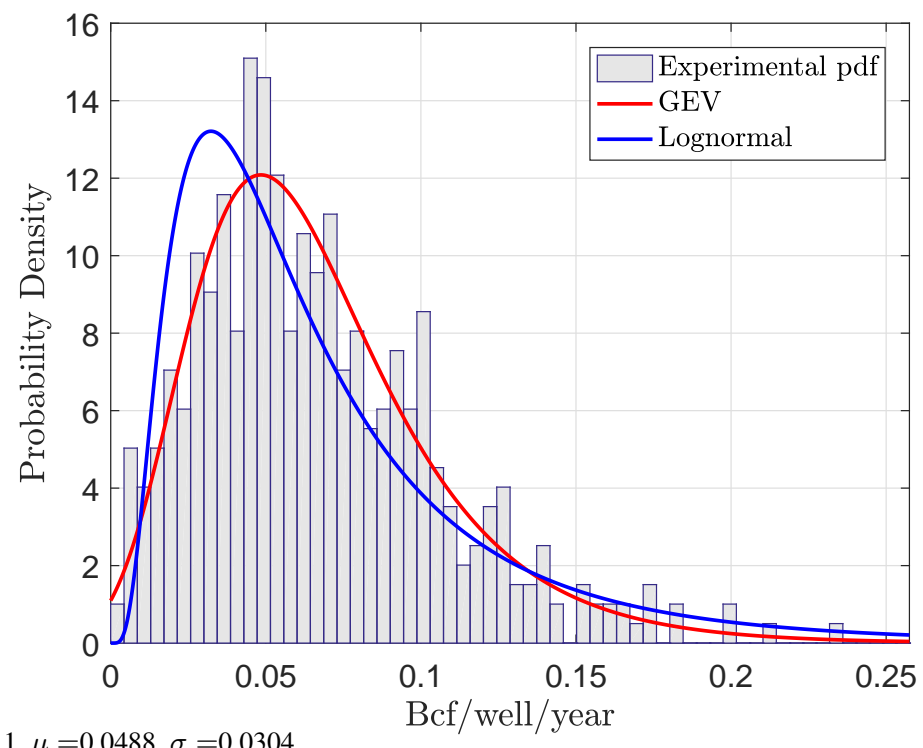

GEV pdf: $\xi=0.0111, \mu=0.0488, \sigma=0.0304$ 


\section{MLE of GEV pdf in Hood county}

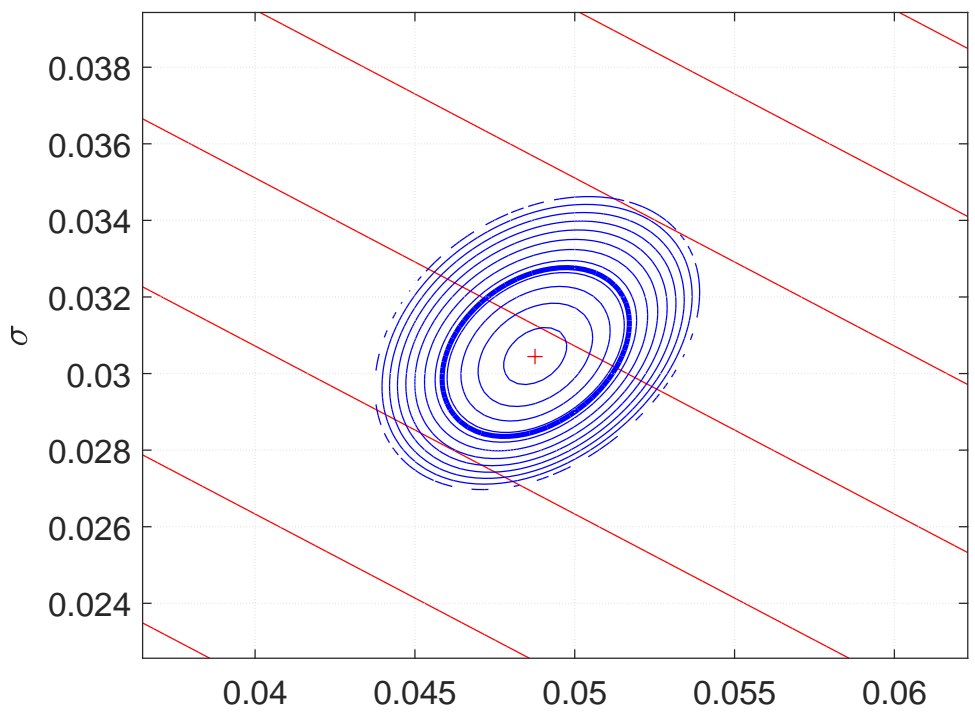

MLE $=$ Maximum Likelihood Estimate, $95 \%$ CI for $\mu$ and $\sigma$ after $\stackrel{\mu}{8.00}$ yrs 


\section{Hood county after 8.00 yrs}

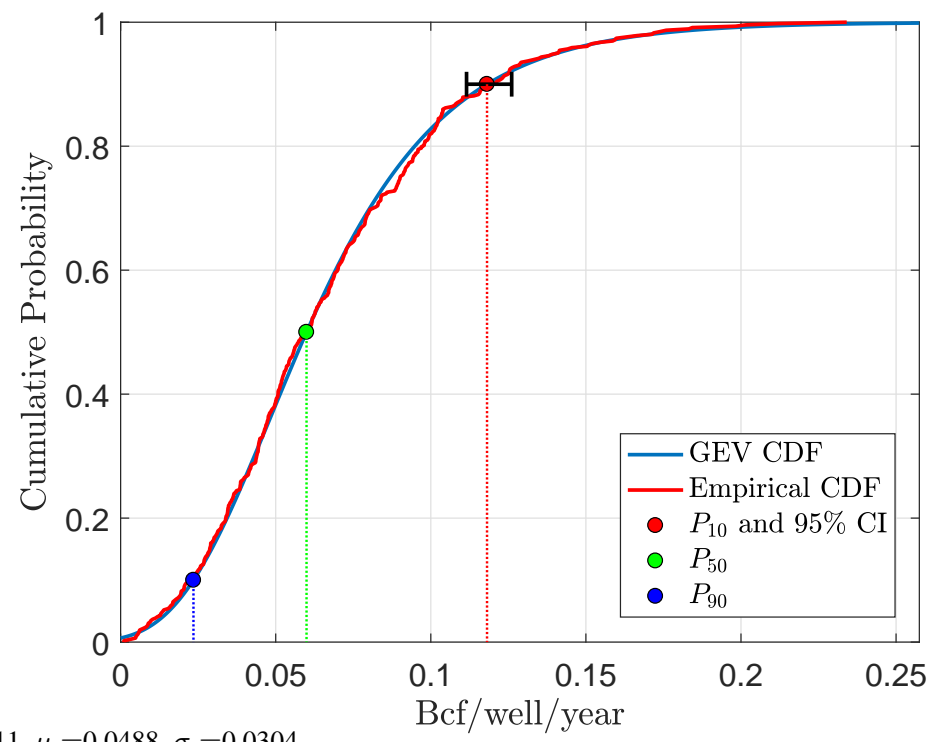

GEV cdf: $\xi=0.0111, \mu=0.0488, \sigma=0.0304$ 


\section{Hood county after 9 yrs}

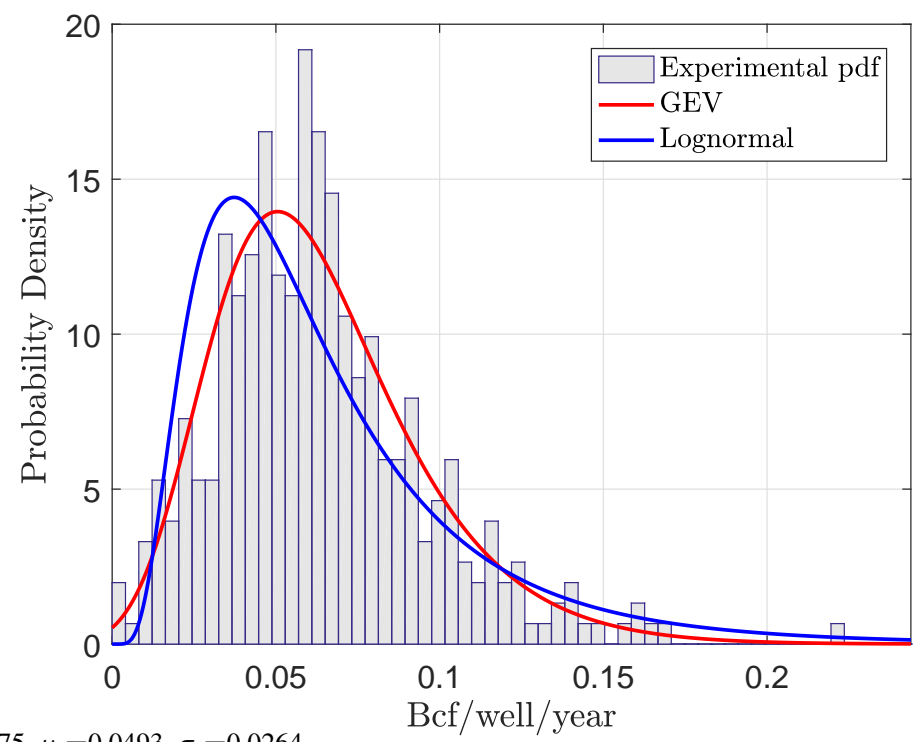

GEV pdf: $\xi=-0.0475, \mu=0.0493, \sigma=0.0264$ 


\section{MLE of GEV pdf in Hood county}

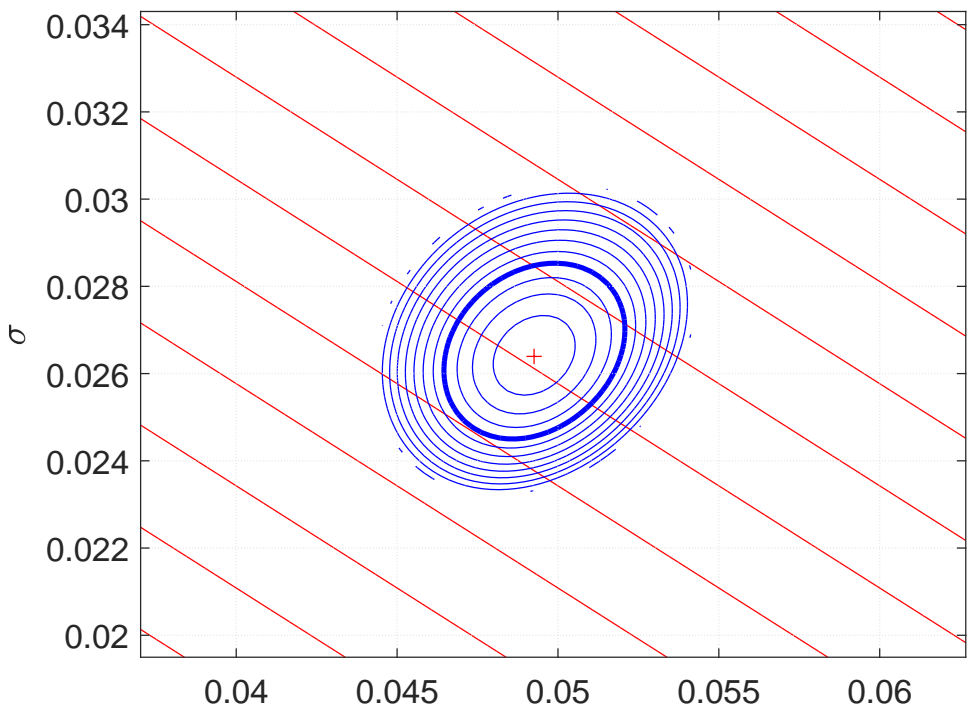

MLE $=$ Maximum Likelihood Estimate, $95 \%$ CI for $\mu$ and $\sigma$ after 9.00 yrs 


\section{Hood county after 9.00 yrs}

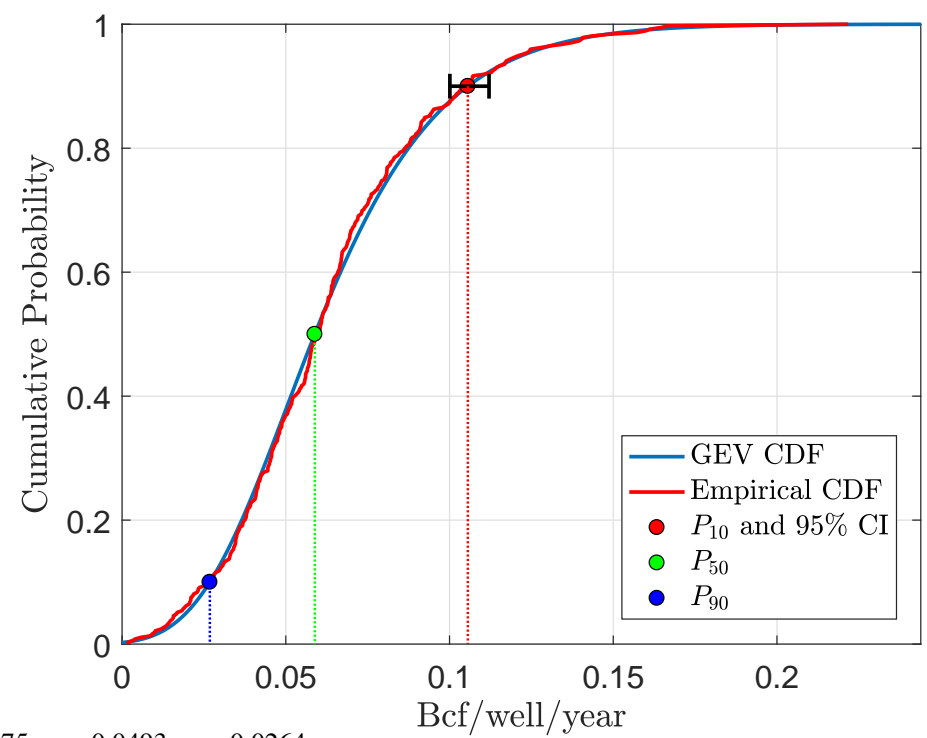

GEV cdf: $\xi=-0.0475, \mu=0.0493, \sigma=0.0264$ 


\section{Hood county after 10 yrs}

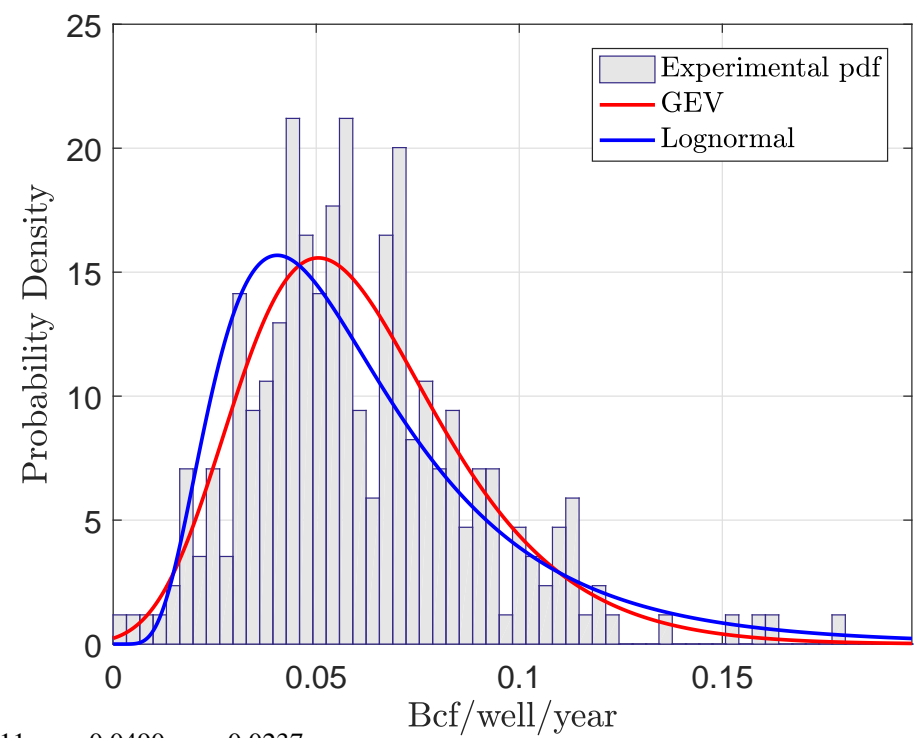

GEV pdf: $\xi=-0.0611, \mu=0.0490, \sigma=0.0237$ 


\section{MLE of GEV pdf in Hood county}

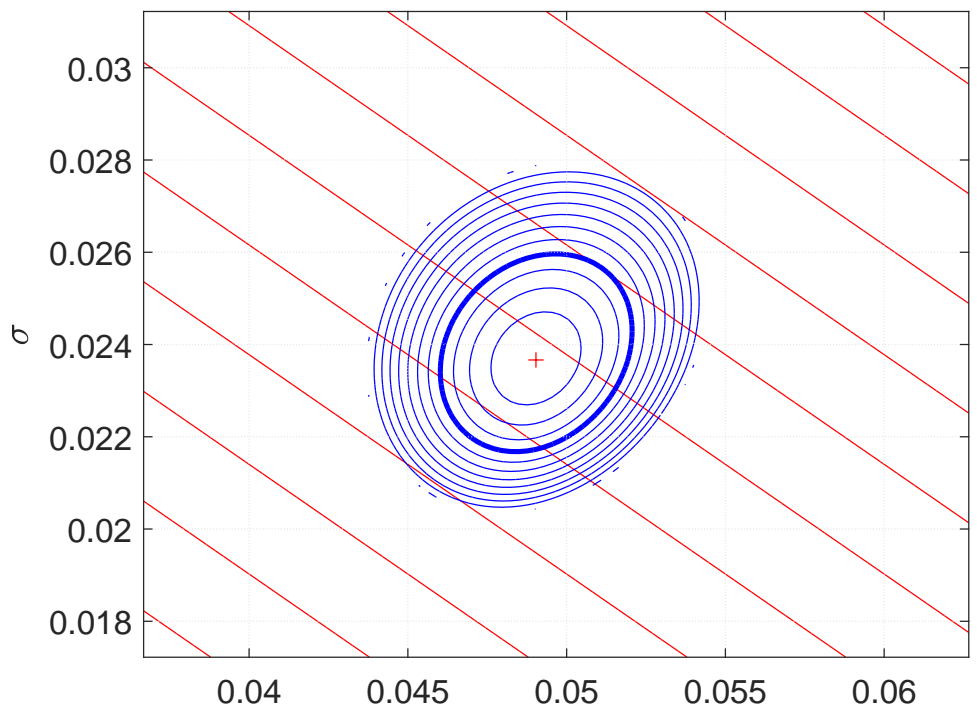

MLE $=$ Maximum Likelihood Estimate, $95 \%$ CI for $\mu$ and $\sigma$ after 10.00 yrs 


\section{Hood county after 10.00 yrs}

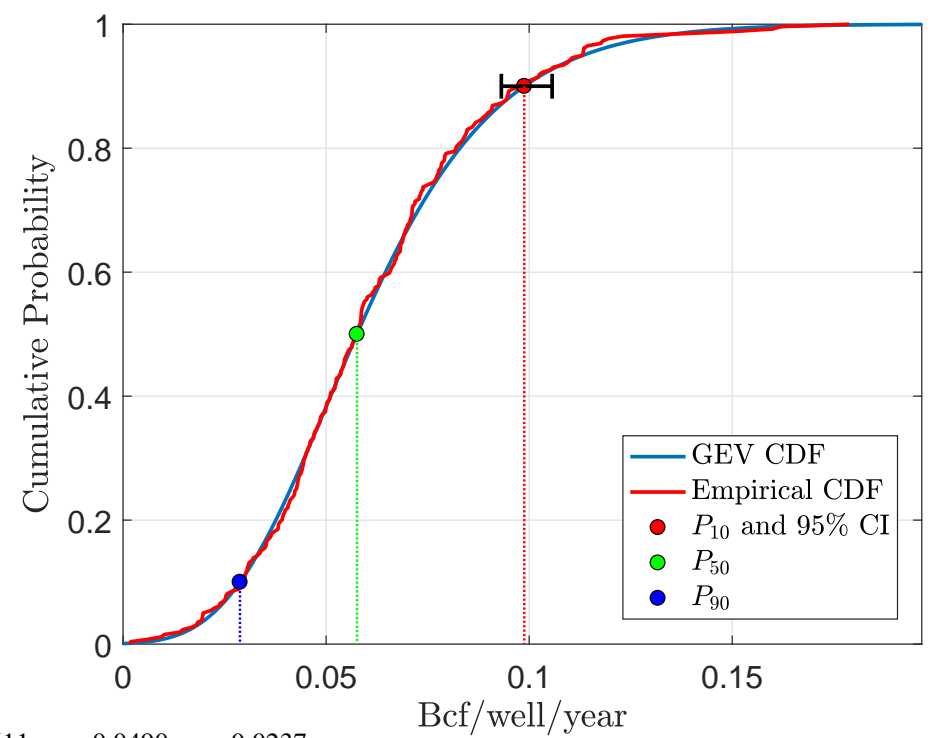

GEV cdf: $\xi=-0.0611, \mu=0.0490, \sigma=0.0237$ 


\section{Hood county after 11 yrs}

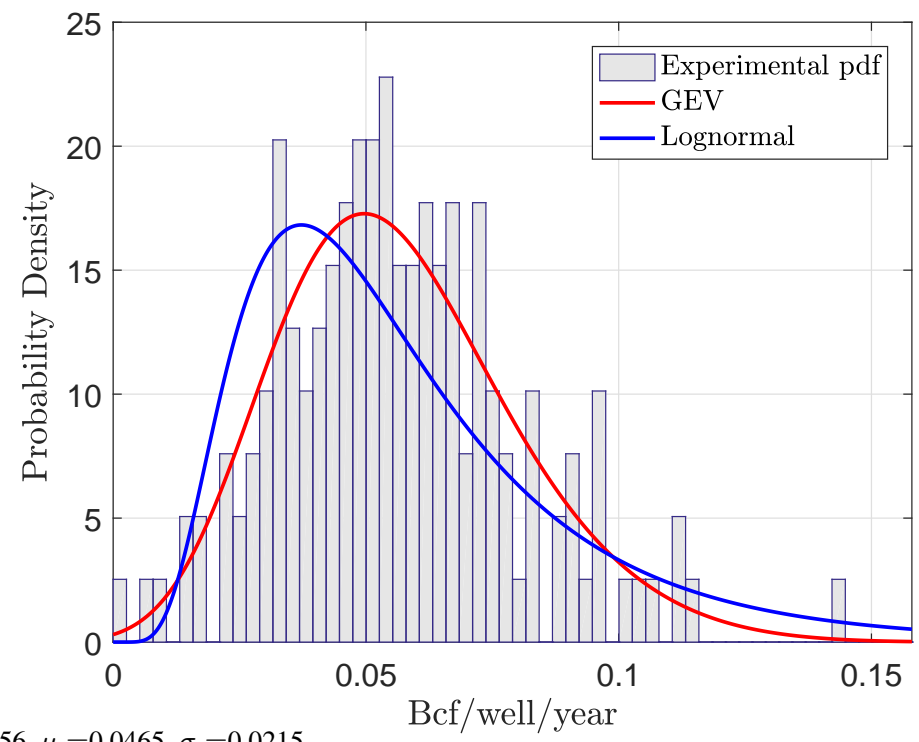

GEV pdf: $\xi=-0.1356, \mu=0.0465, \sigma=0.0215$ 


\section{MLE of GEV pdf in Hood county}

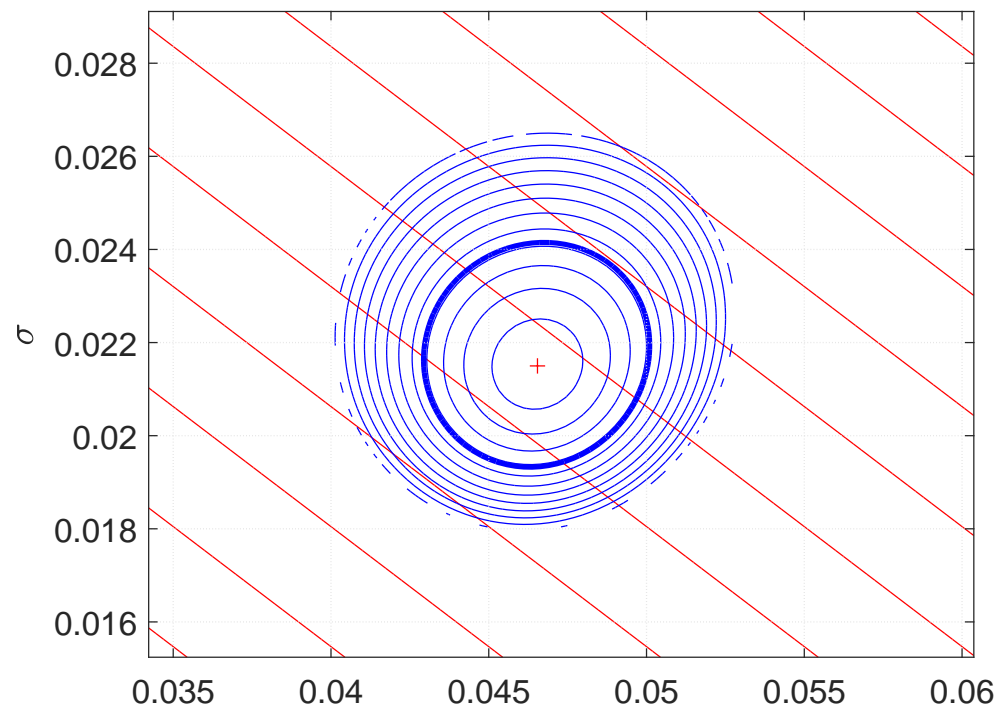

MLE $=$ Maximum Likelihood Estimate, $95 \%$ CI for $\mu$ and $\sigma$ after $\mu$ 11.00 yrs 


\section{Hood county after 11.00 yrs}

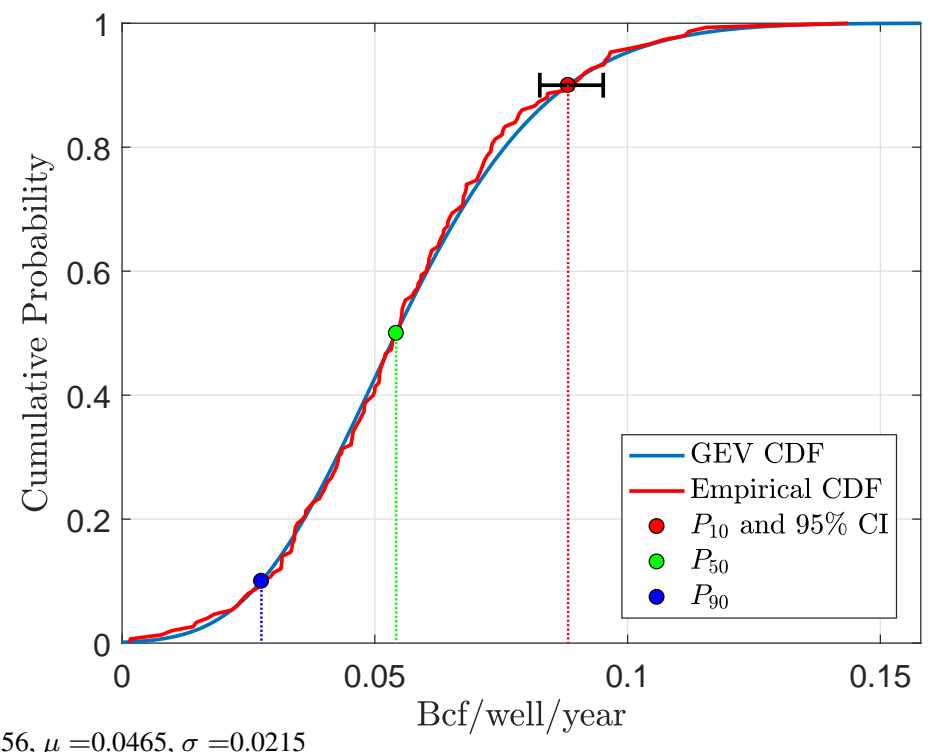

GEV cdf: $\xi=-0.1356, \mu=0.0465, \sigma=0.0215$ 


\section{Hood county after 12 yrs}

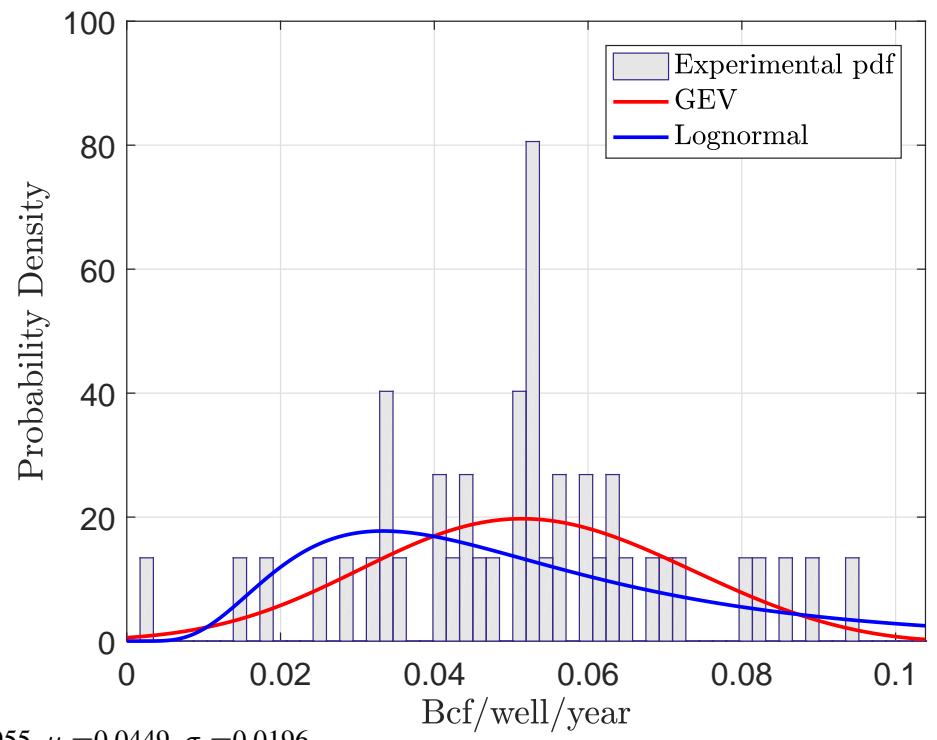

GEV pdf: $\xi=-0.2955, \mu=0.0449, \sigma=0.0196$ 


\section{MLE of GEV pdf in Hood county}

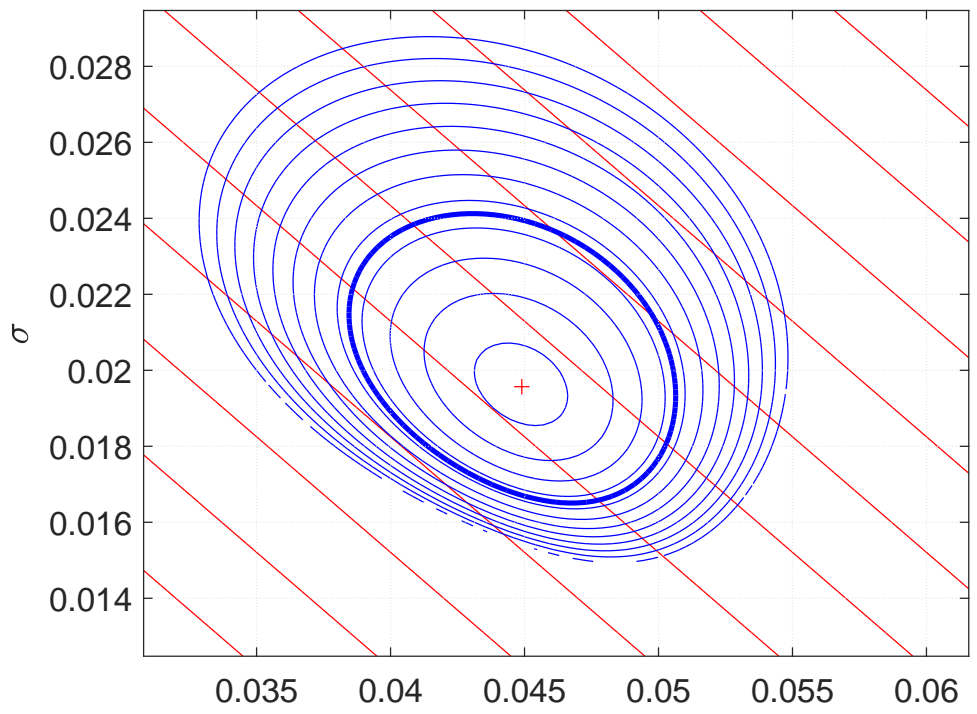

MLE $=$ Maximum Likelihood Estimate, $95 \% \mathrm{CI}$ for $\mu$ and $\sigma$ after $12.00 \mathrm{yrs}$ 


\section{Hood county after 12.00 yrs}

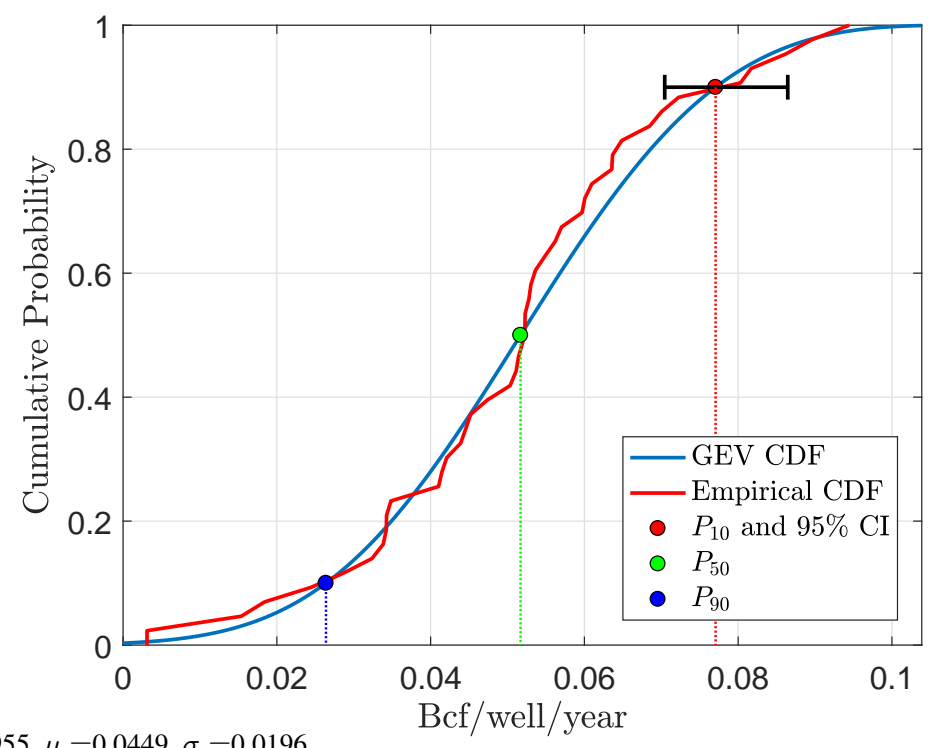

GEV cdf: $\xi=-0.2955, \mu=0.0449, \sigma=0.0196$ 


\section{Tarrant county wells with 1 yrs on production}

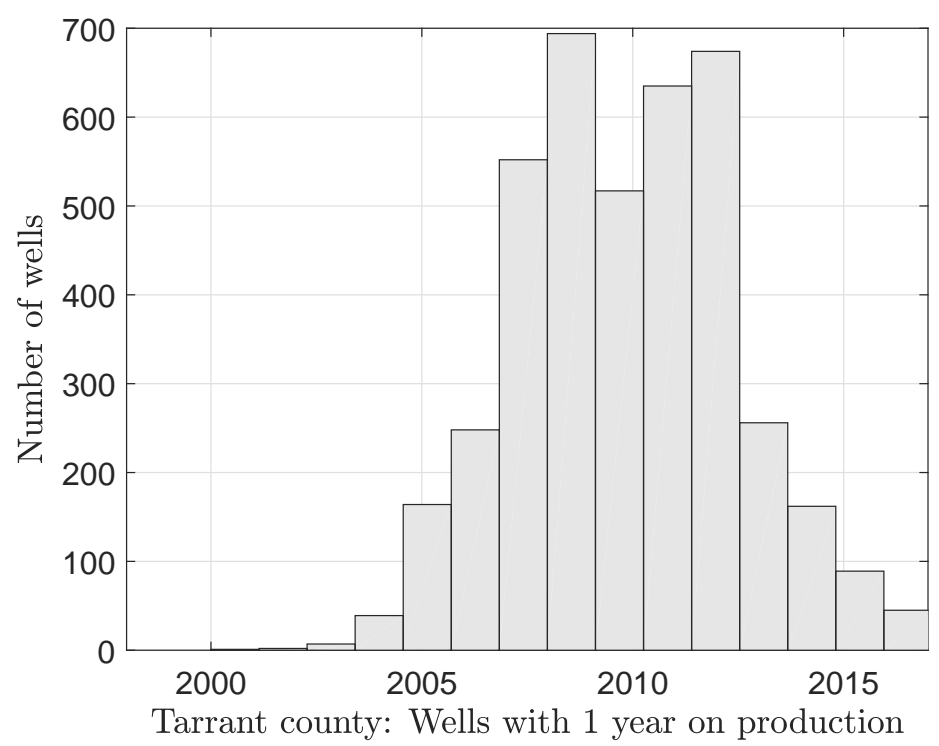




\section{Tarrant county wells with 2 yrs on production}

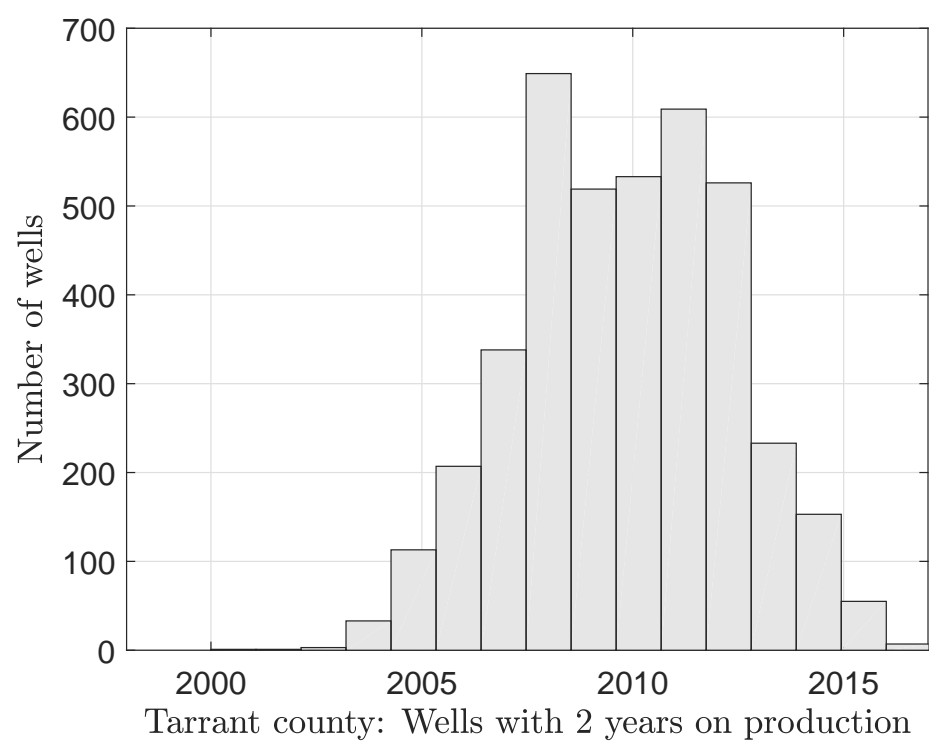




\section{Tarrant county wells with 3 yrs on production}

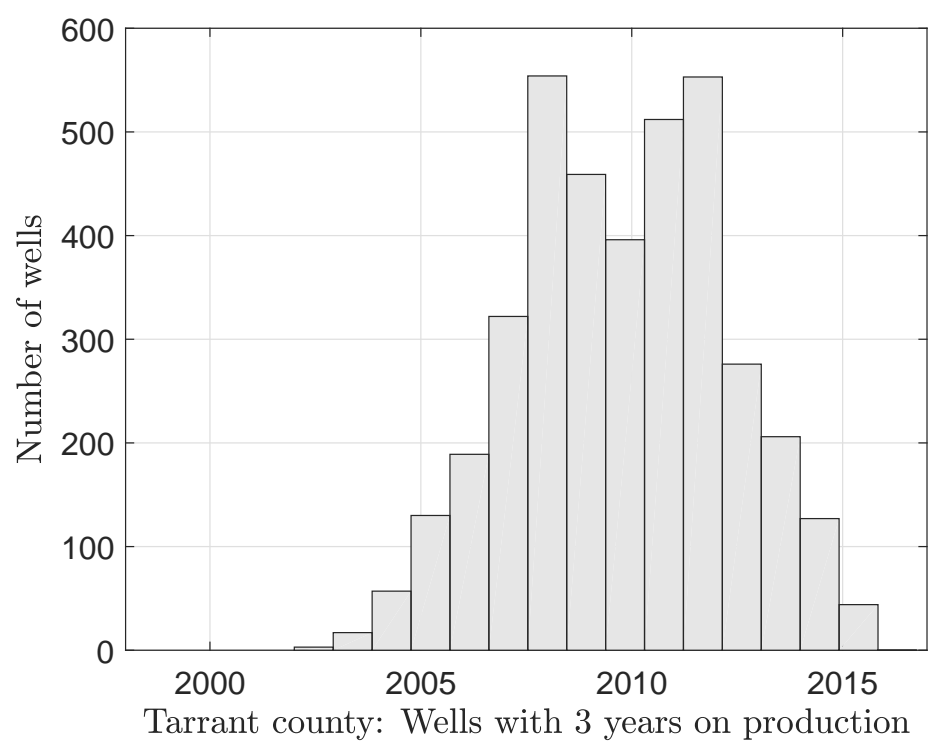




\section{Tarrant county wells with 4 yrs on production}

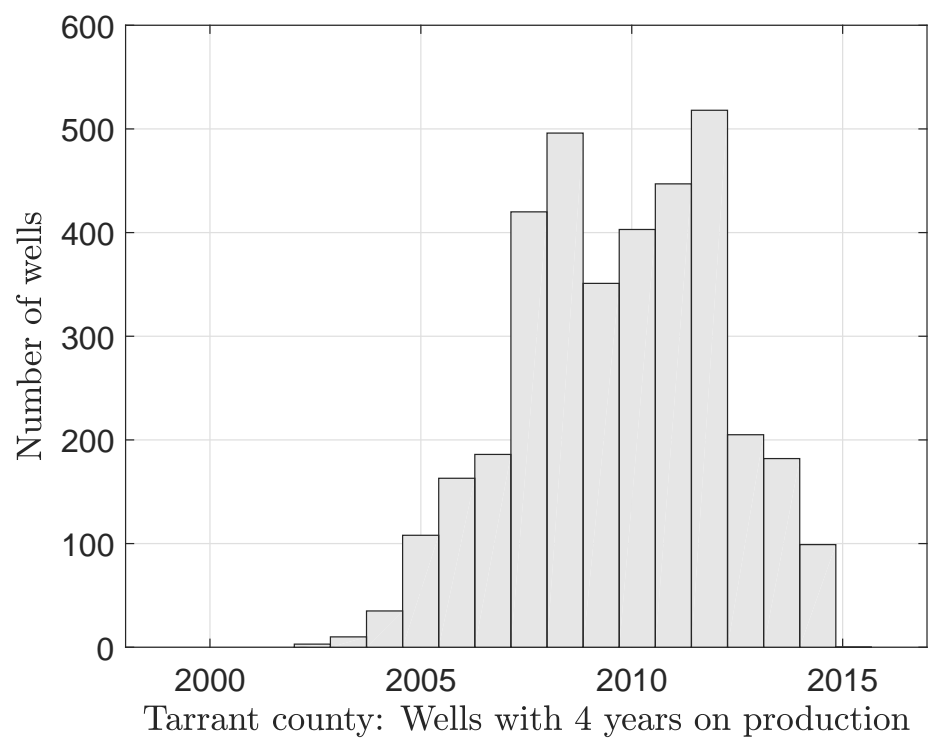




\section{Tarrant county wells with 5 yrs on production}

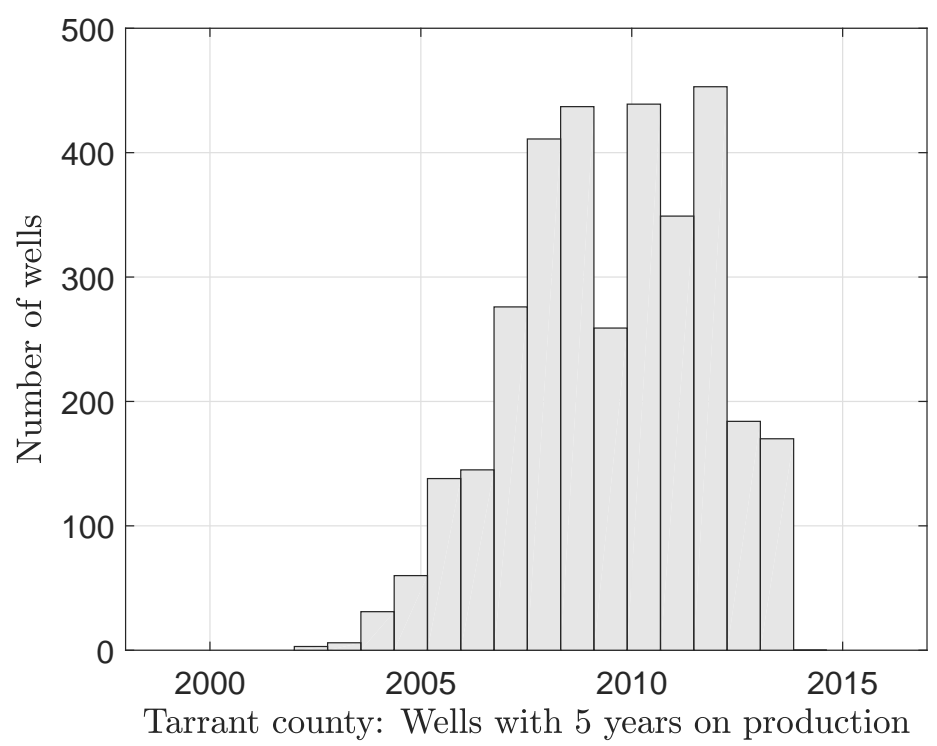




\section{Tarrant county wells with 6 yrs on production}

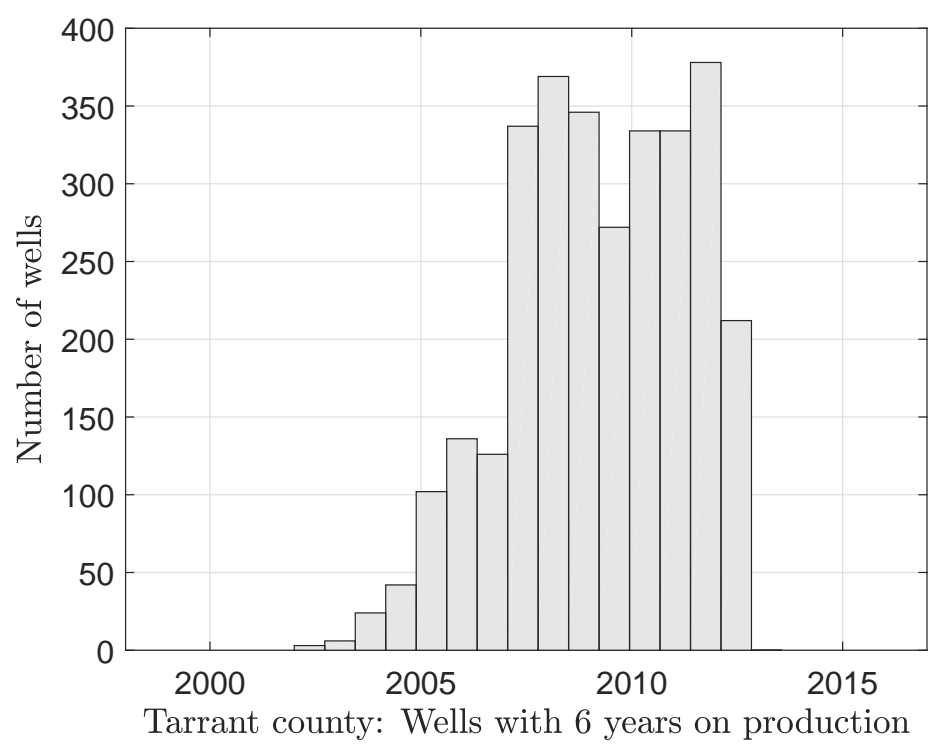




\section{Tarrant county wells with 7 yrs on production}

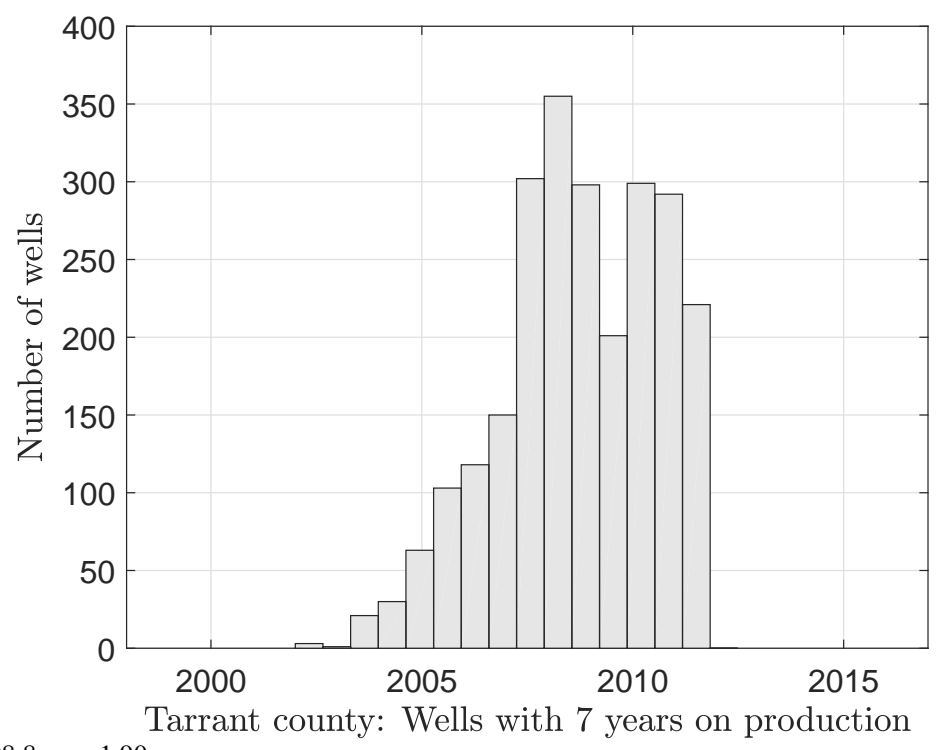




\section{Tarrant county wells with 8 yrs on production}

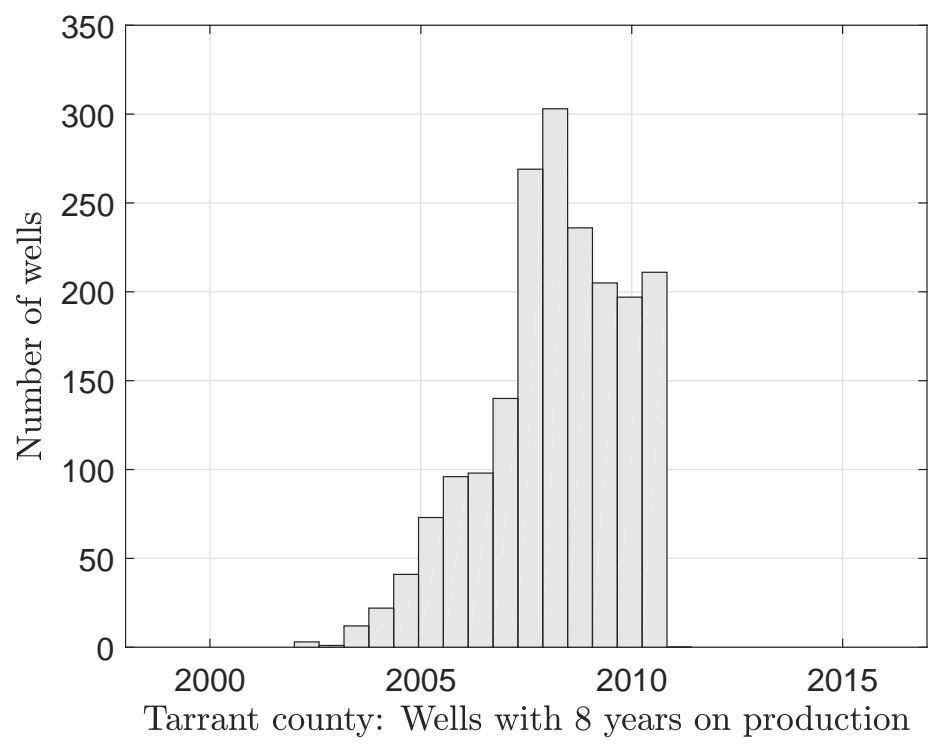




\section{Tarrant county wells with 9 yrs on production}

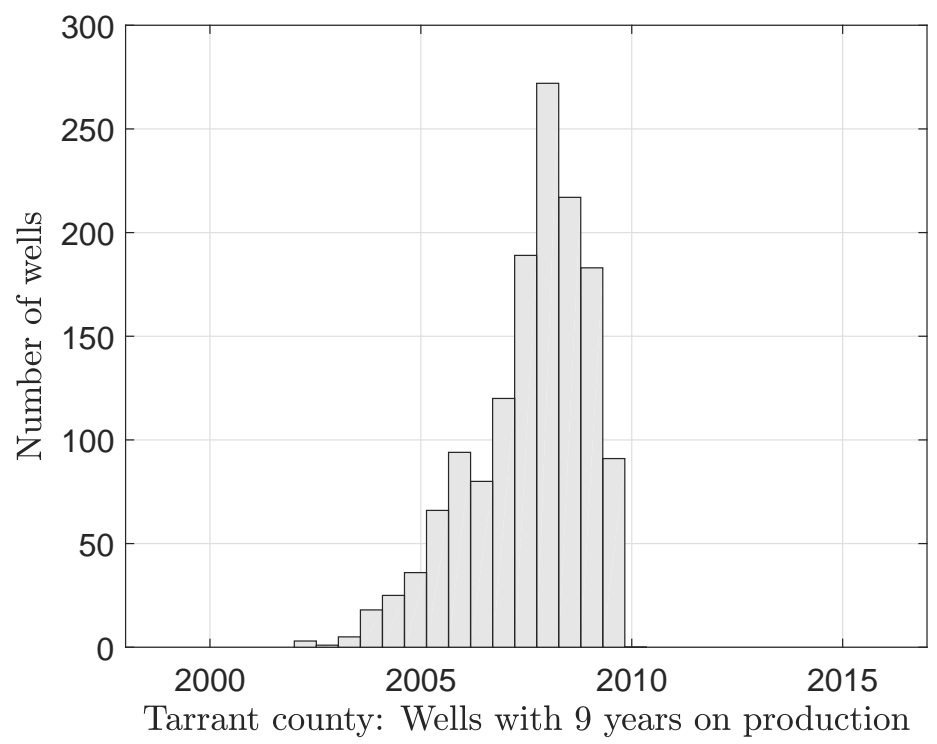




\section{Tarrant county wells with 10 yrs on production}

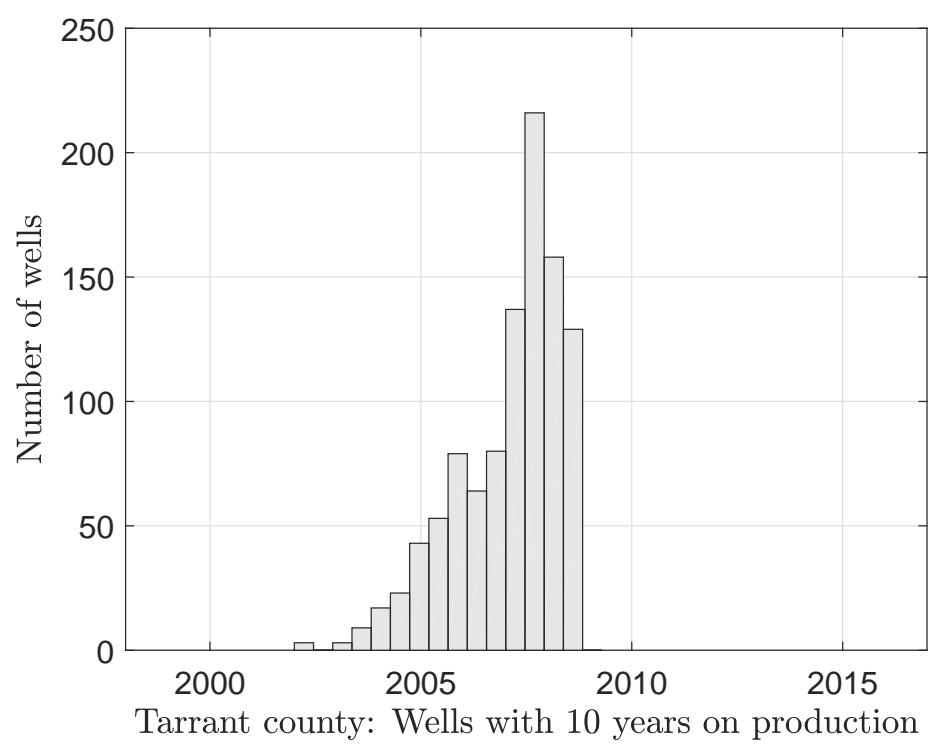




\section{Tarrant county wells with 11 yrs on production}

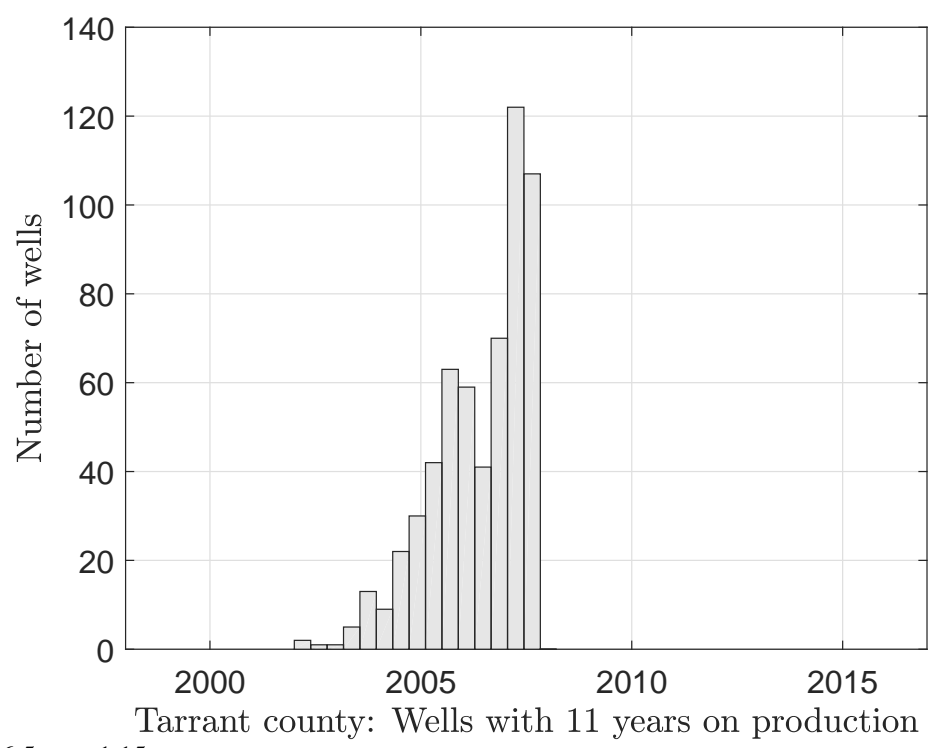




\section{Tarrant county wells with 12 yrs on production}

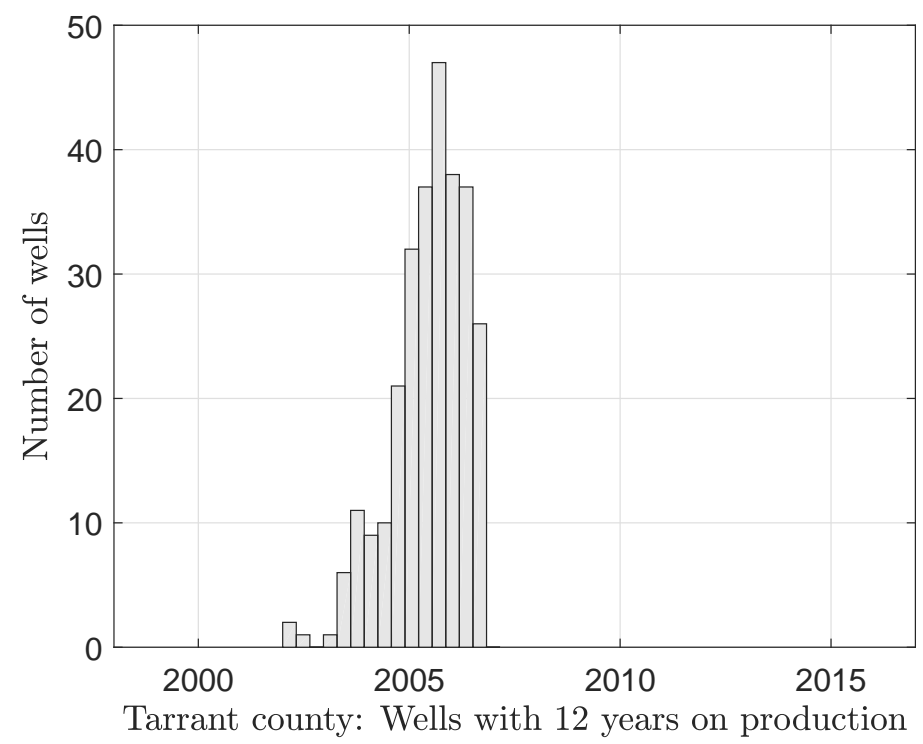




\section{Tarrant county wells with 13 yrs on production}

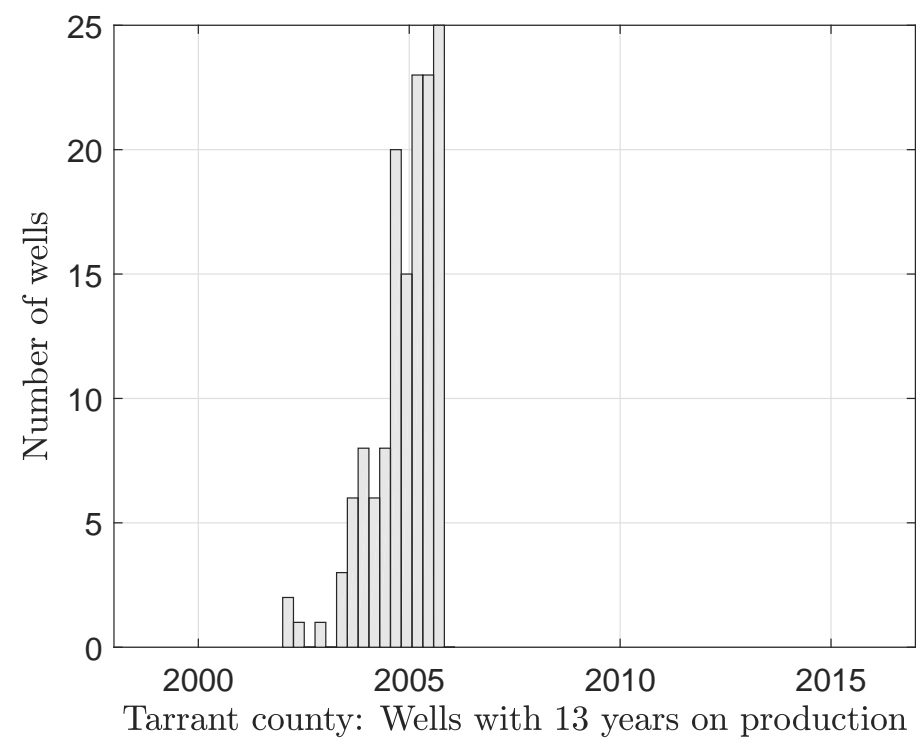




\section{Tarrant county wells with 14 yrs on production}

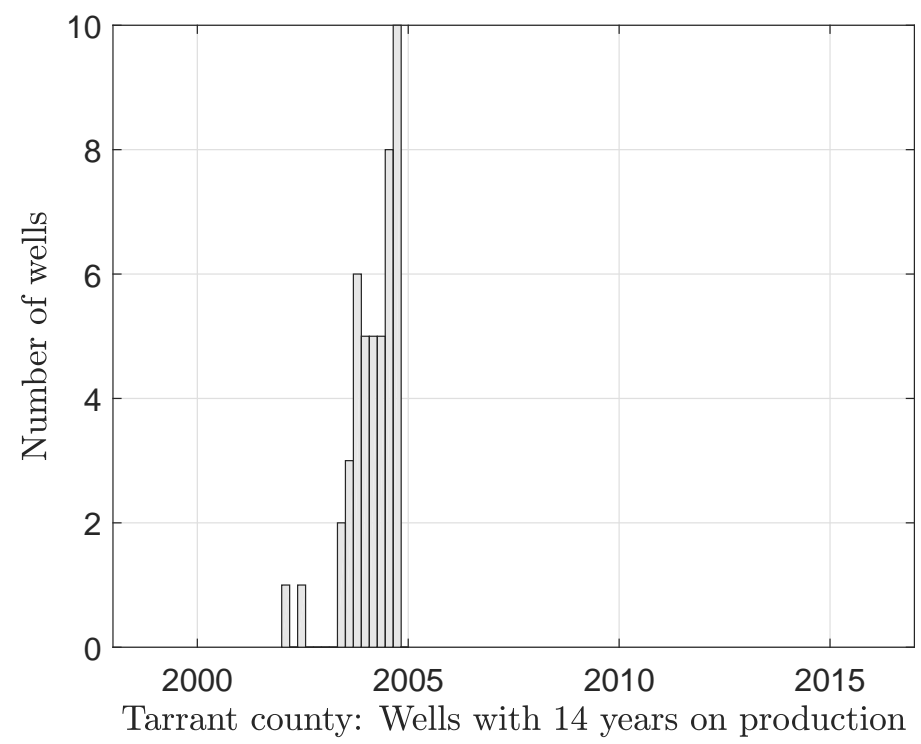




\section{Johnson county wells with 1 yrs on production}

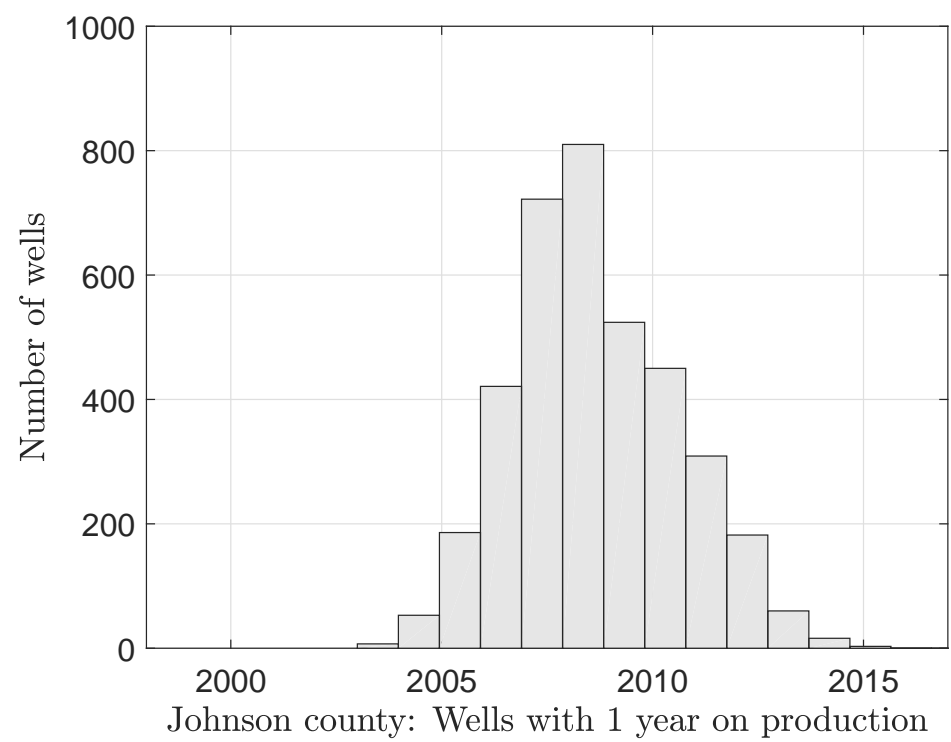




\section{Johnson county wells with 2 yrs on production}

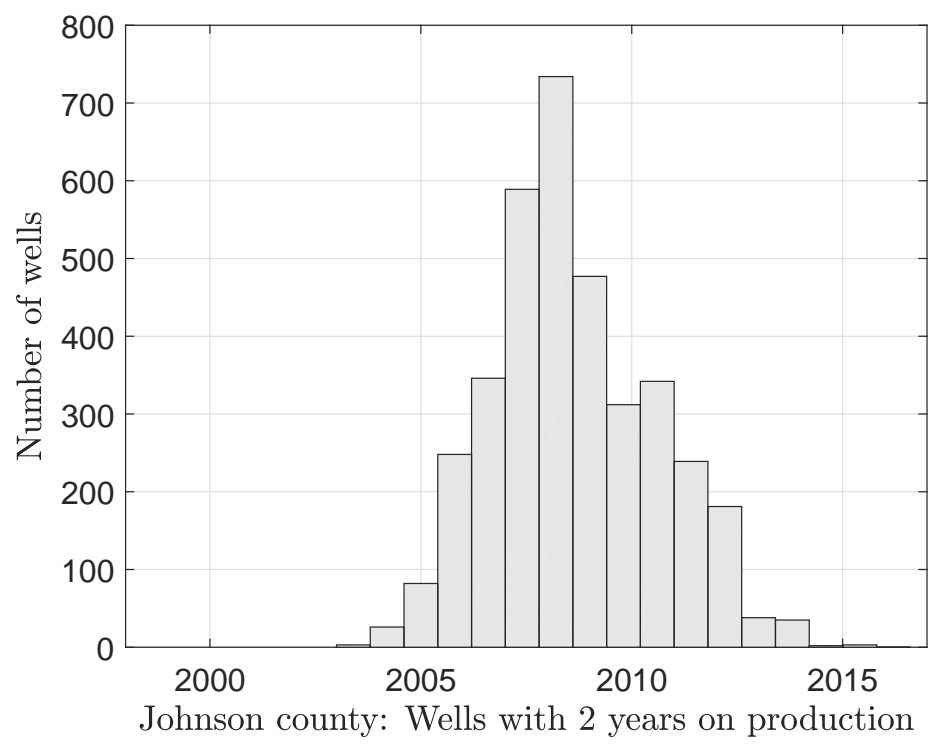




\section{Johnson county wells with 3 yrs on production}

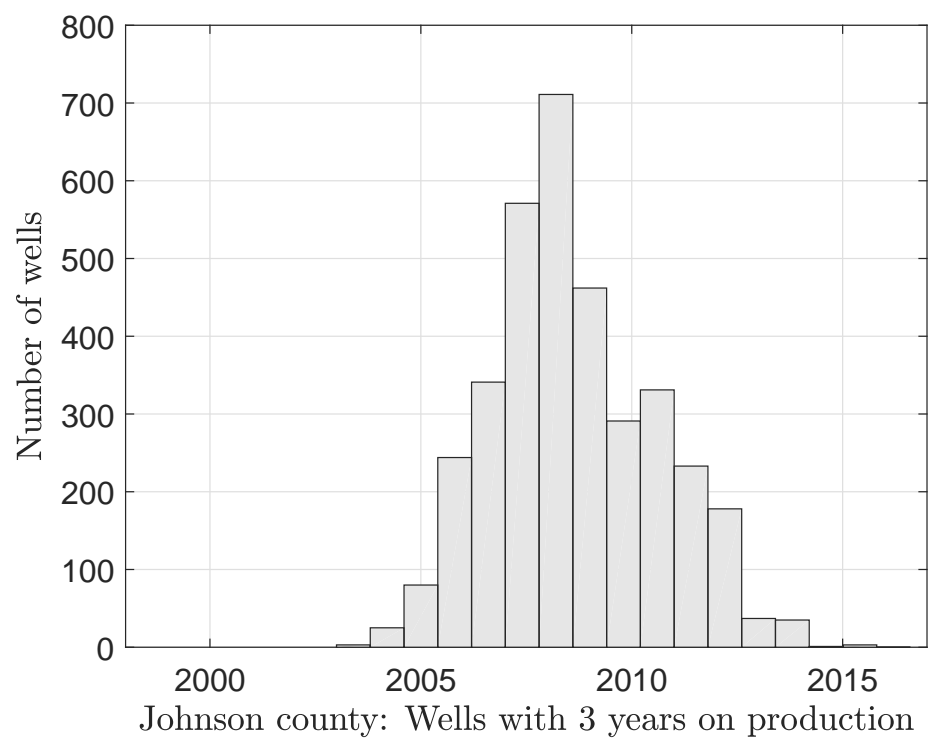




\section{Johnson county wells with 4 yrs on production}

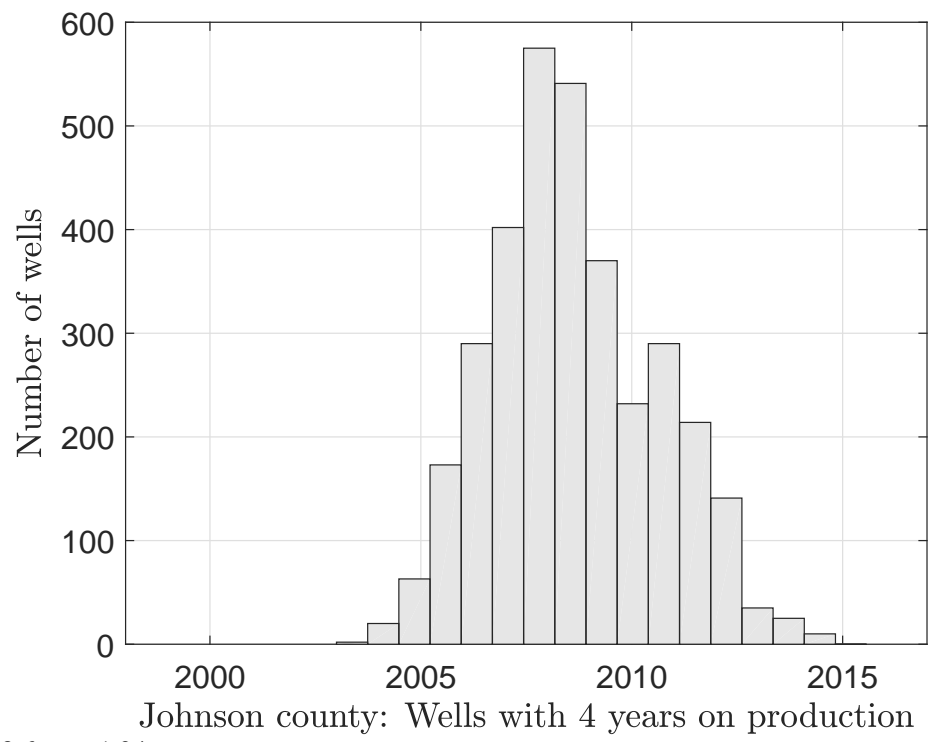




\section{Johnson county wells with 5 yrs on production}

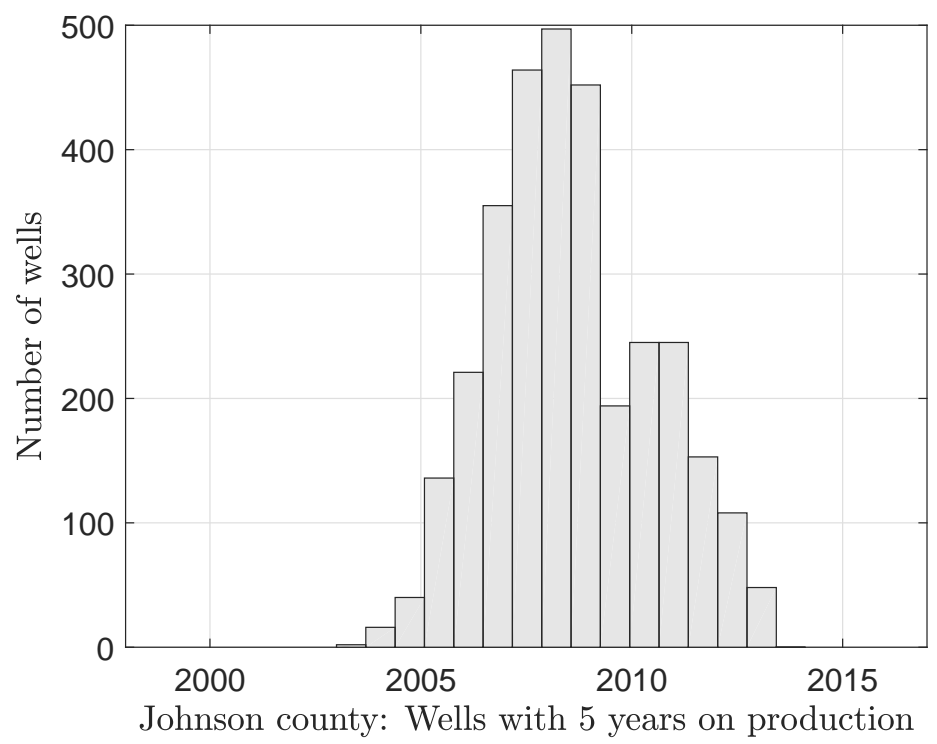




\section{Johnson county wells with 6 yrs on production}

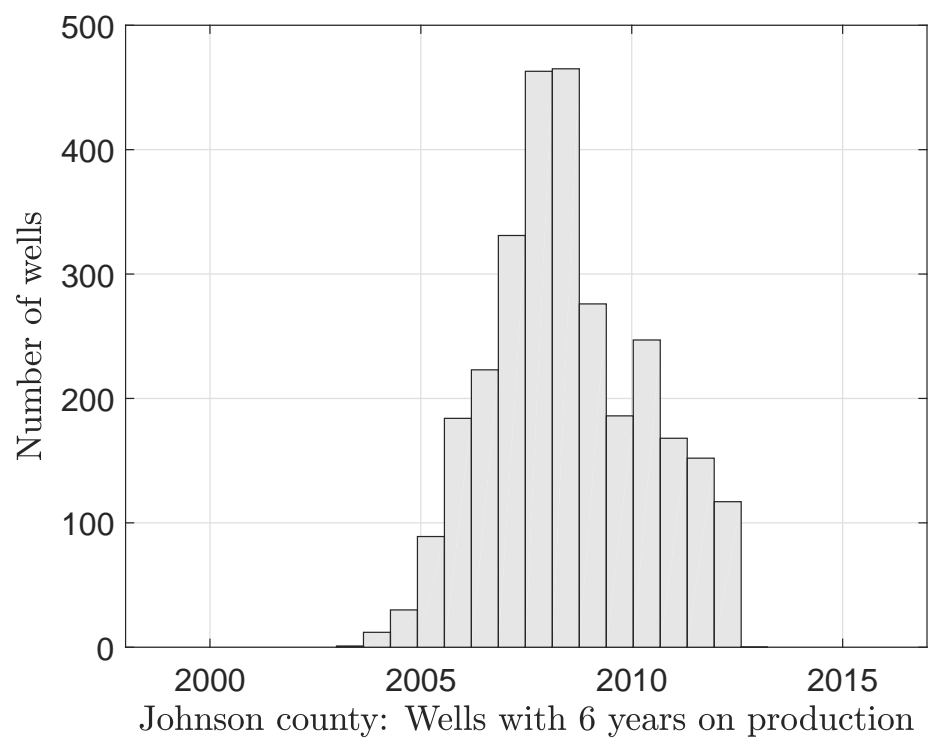




\section{Johnson county wells with 7 yrs on production}

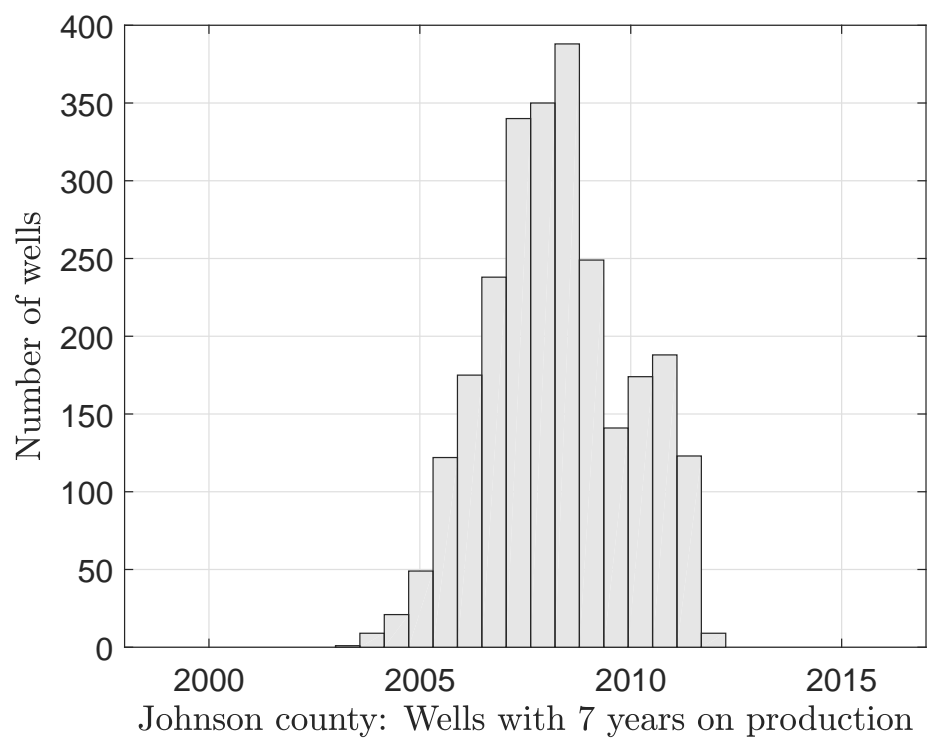




\section{Johnson county wells with 8 yrs on production}

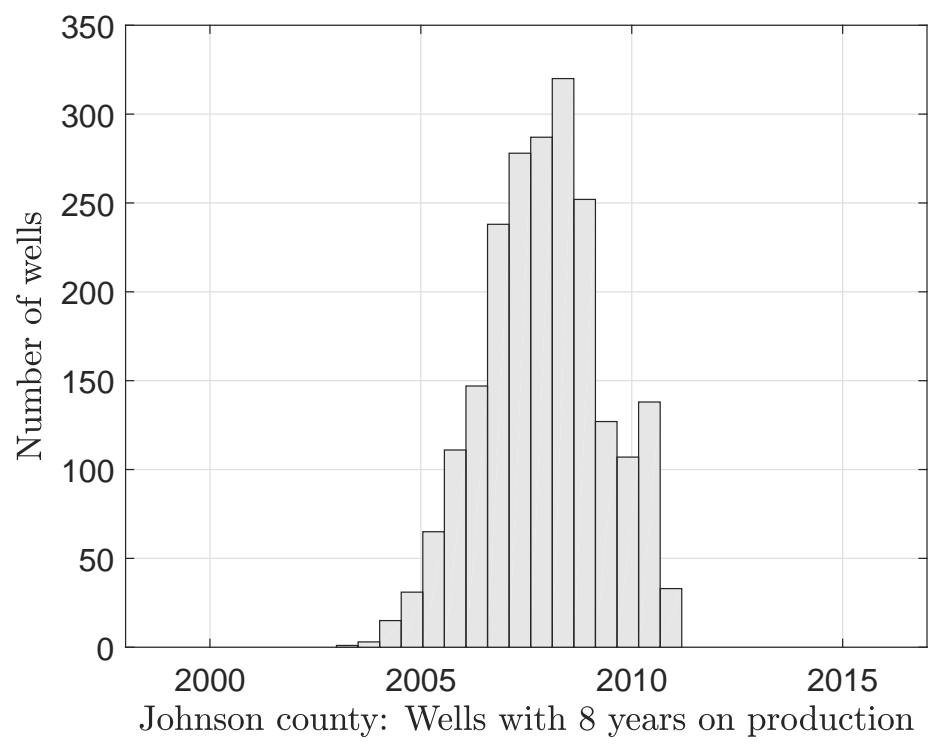




\section{Johnson county wells with 9 yrs on production}

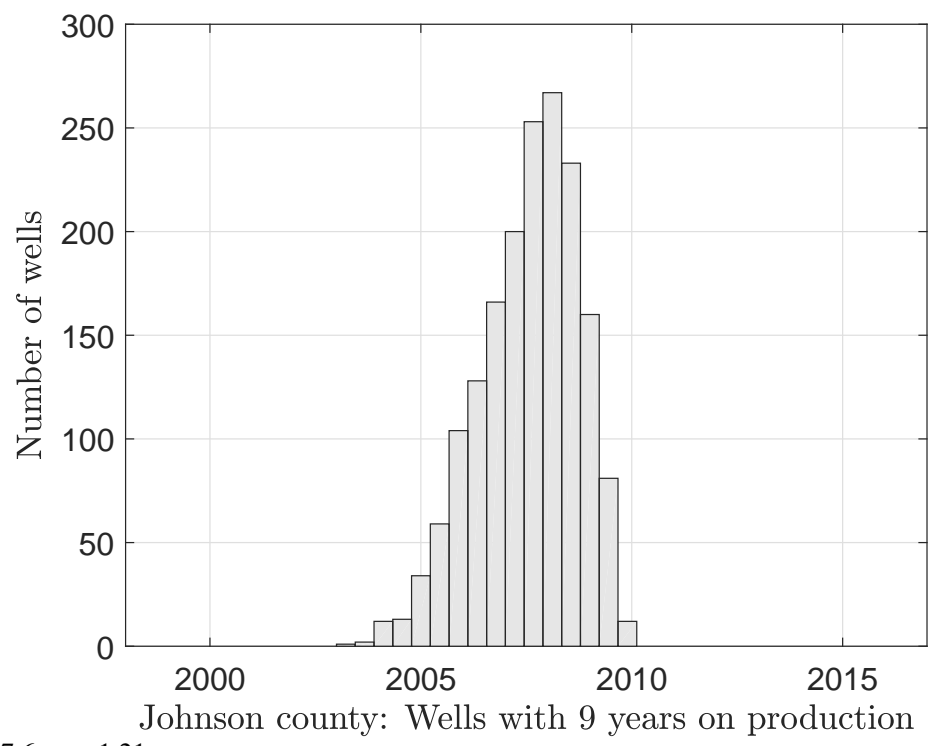




\section{Johnson county wells with 10 yrs on production}

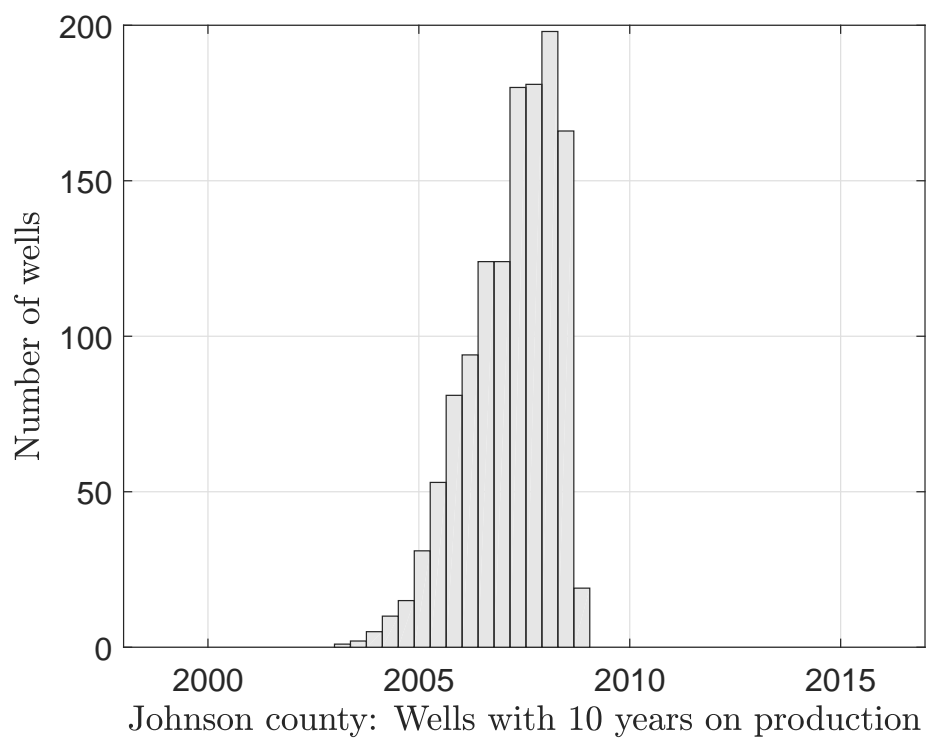




\section{Johnson county wells with 11 yrs on production}

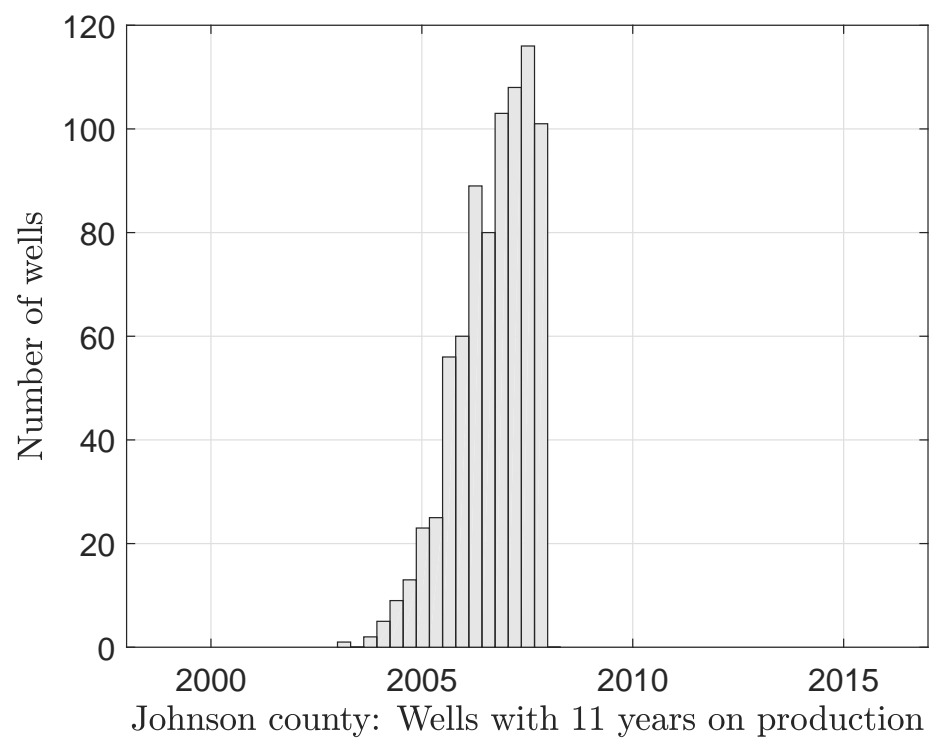




\section{Johnson county wells with 12 yrs on production}

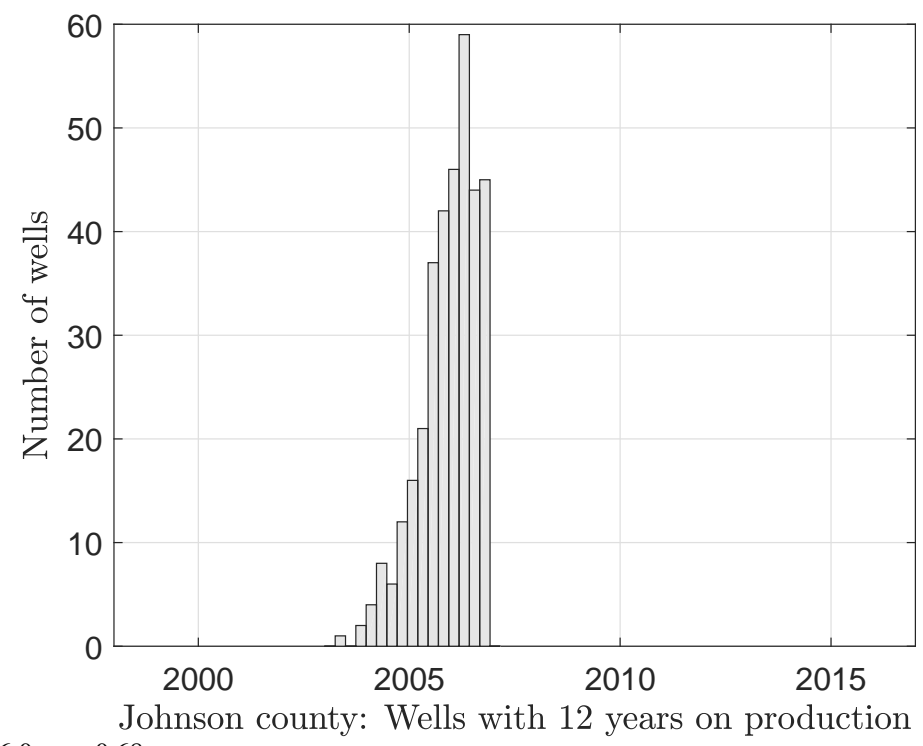




\section{Johnson county wells with 13 yrs on production}

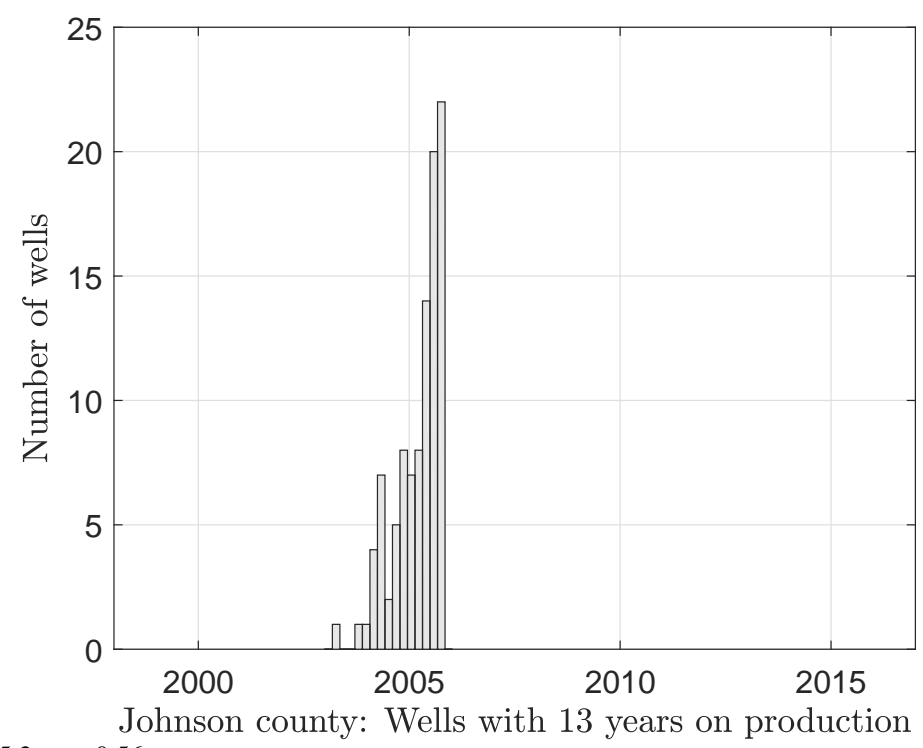




\section{Johnson county wells with 14 yrs on production}

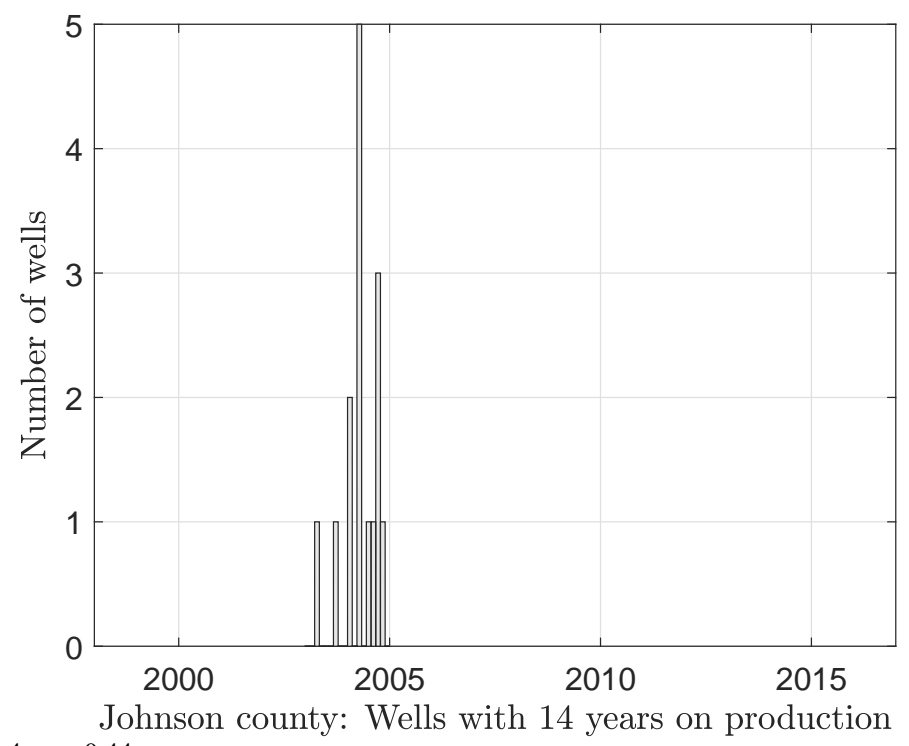




\section{Wise county wells with 1 yrs on production}

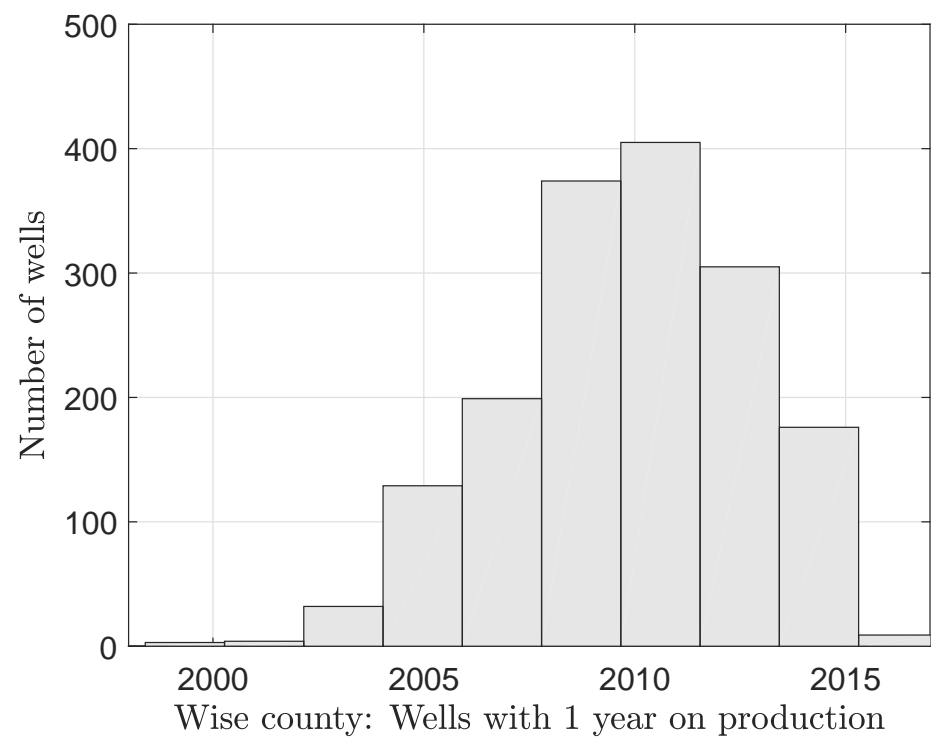




\section{Wise county wells with 2 yrs on production}

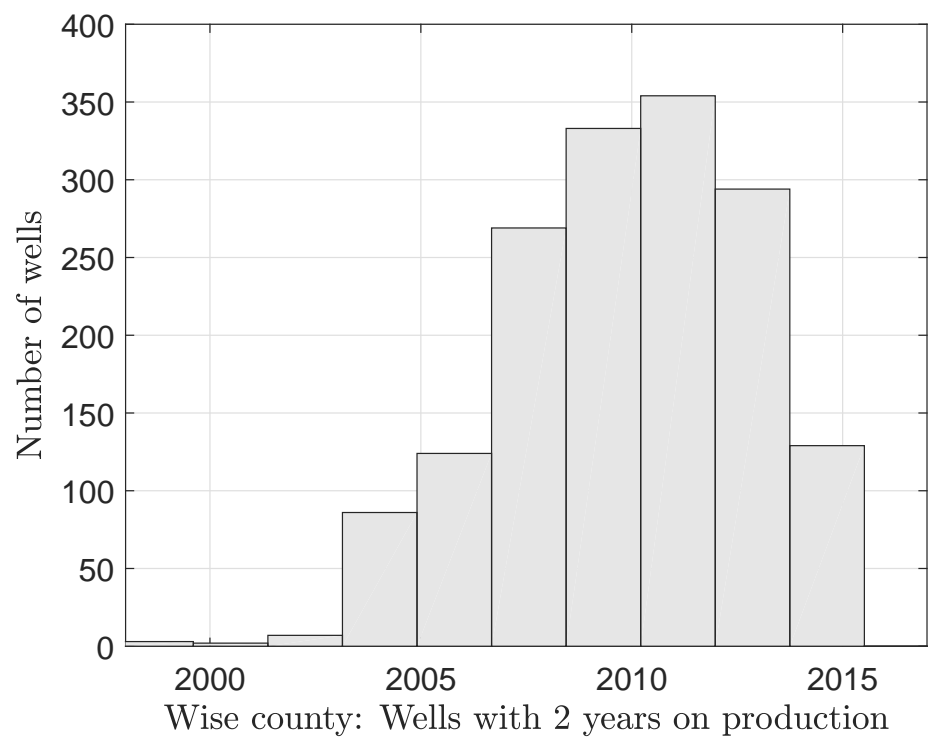




\section{Wise county wells with 3 yrs on production}

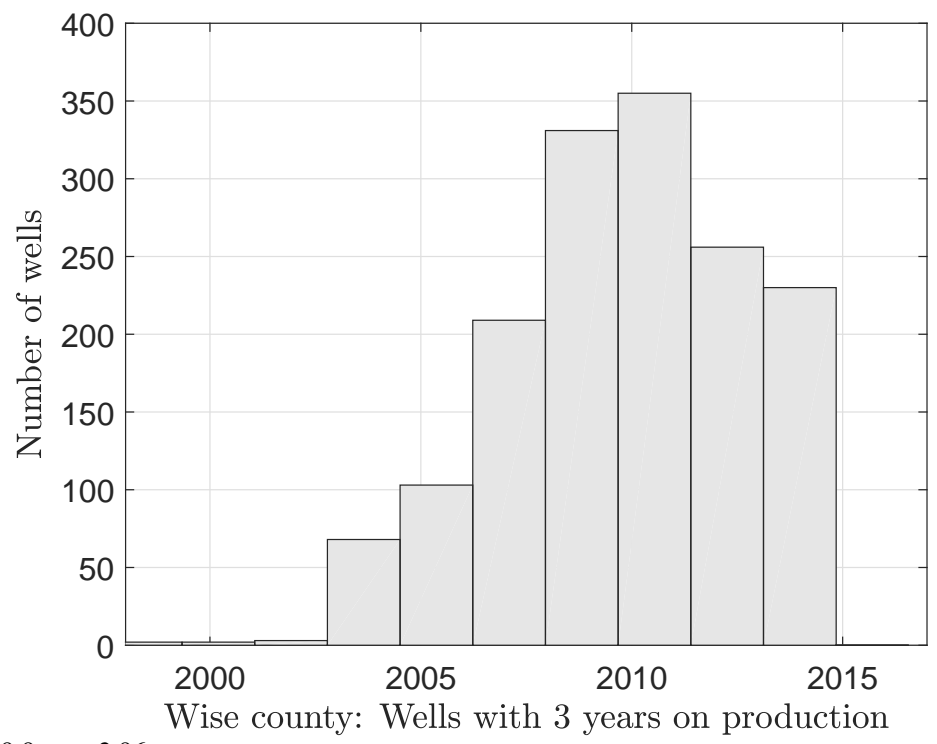




\section{Wise county wells with 4 yrs on production}

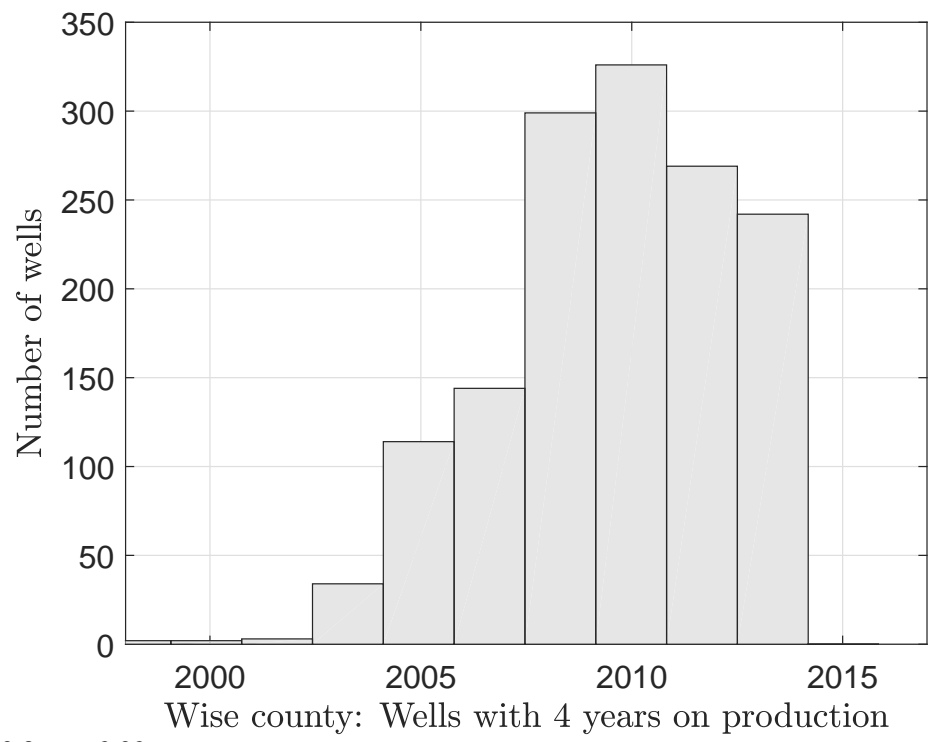




\section{Wise county wells with 5 yrs on production}

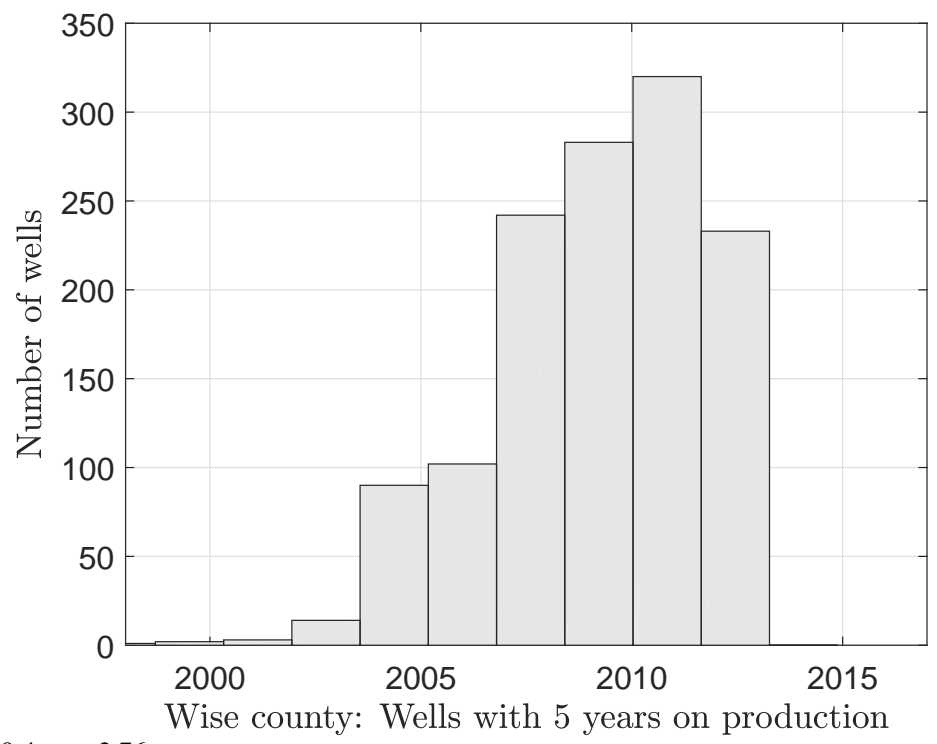




\section{Wise county wells with 6 yrs on production}

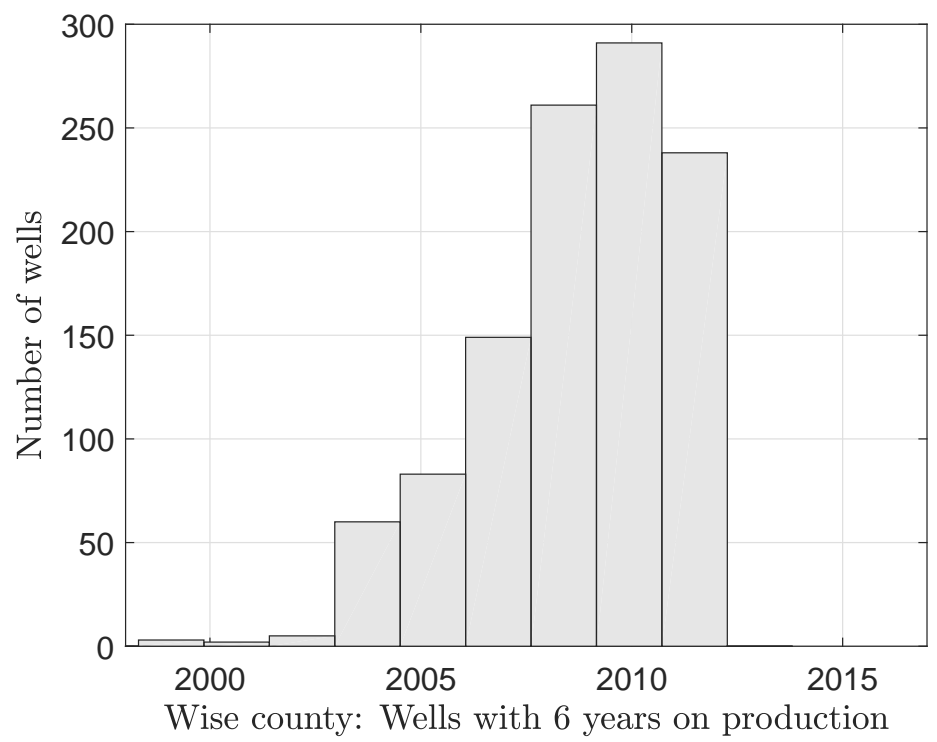




\section{Wise county wells with 7 yrs on production}

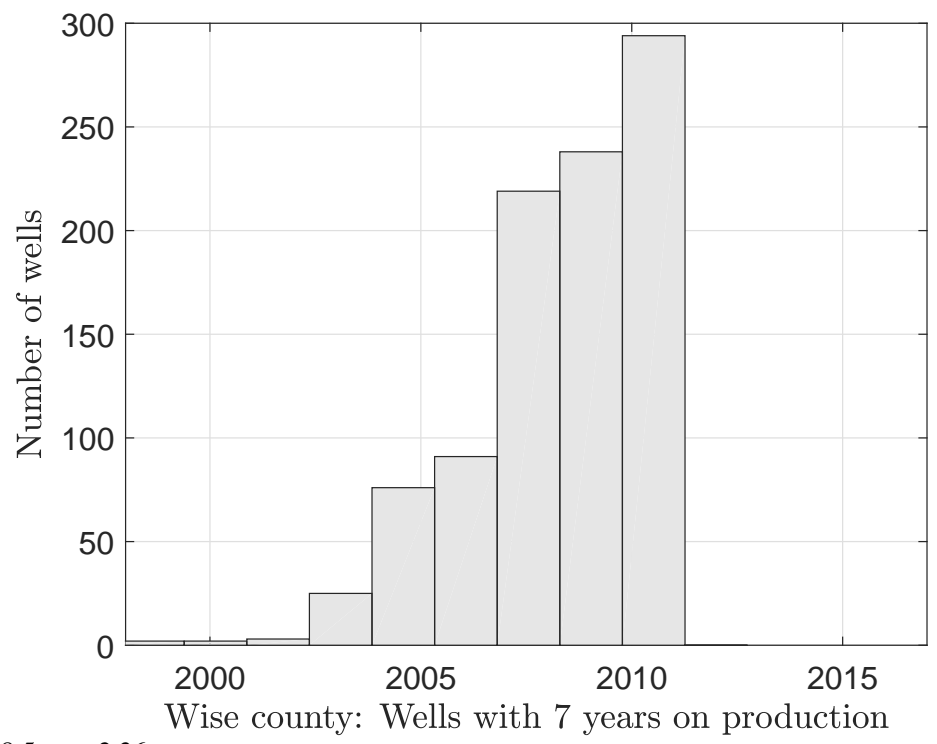




\section{Wise county wells with 8 yrs on production}

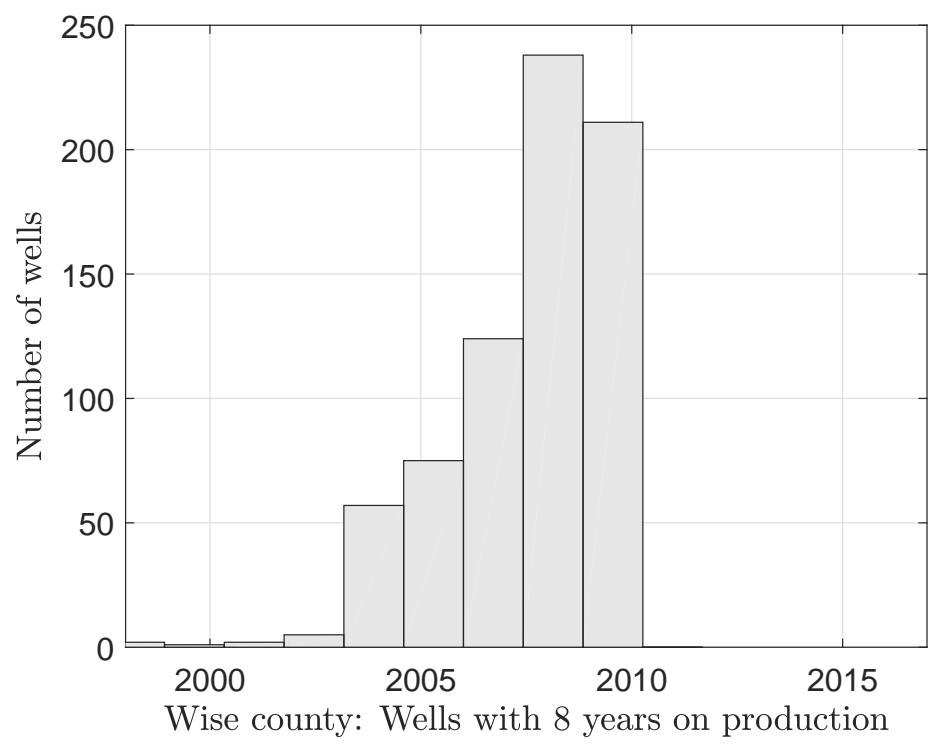




\section{Wise county wells with 9 yrs on production}

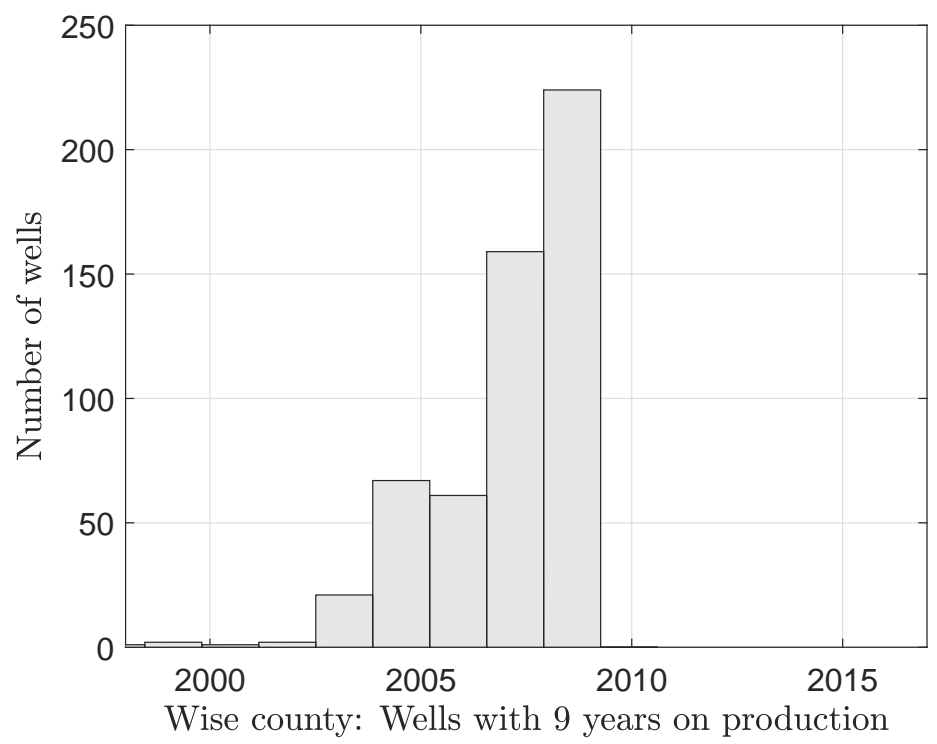




\section{Wise county wells with 10 yrs on production}

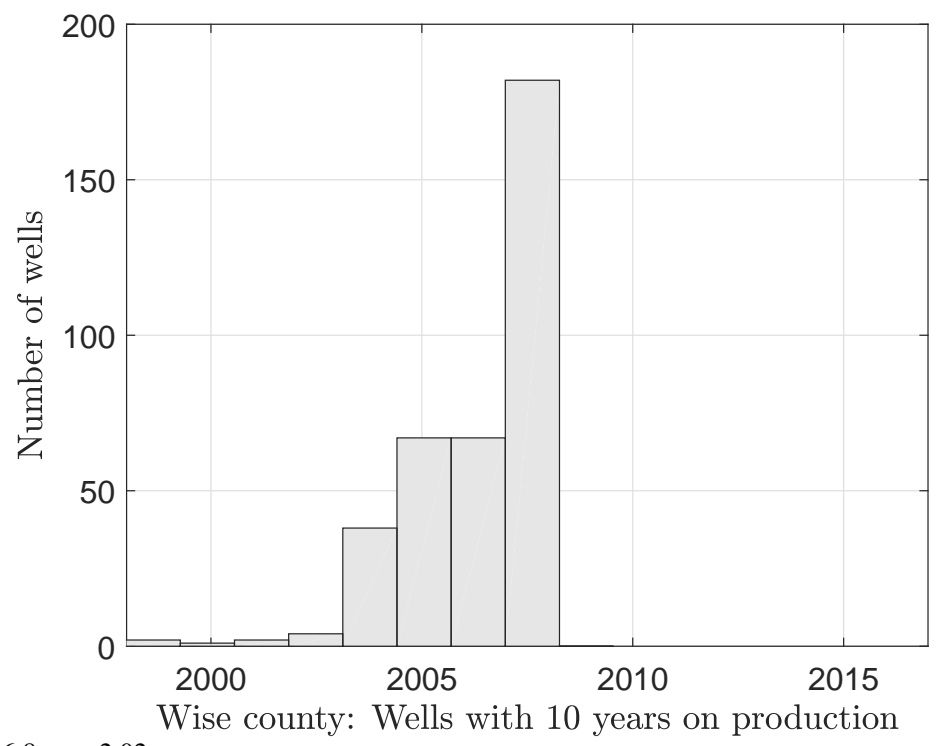




\section{Wise county wells with 11 yrs on production}

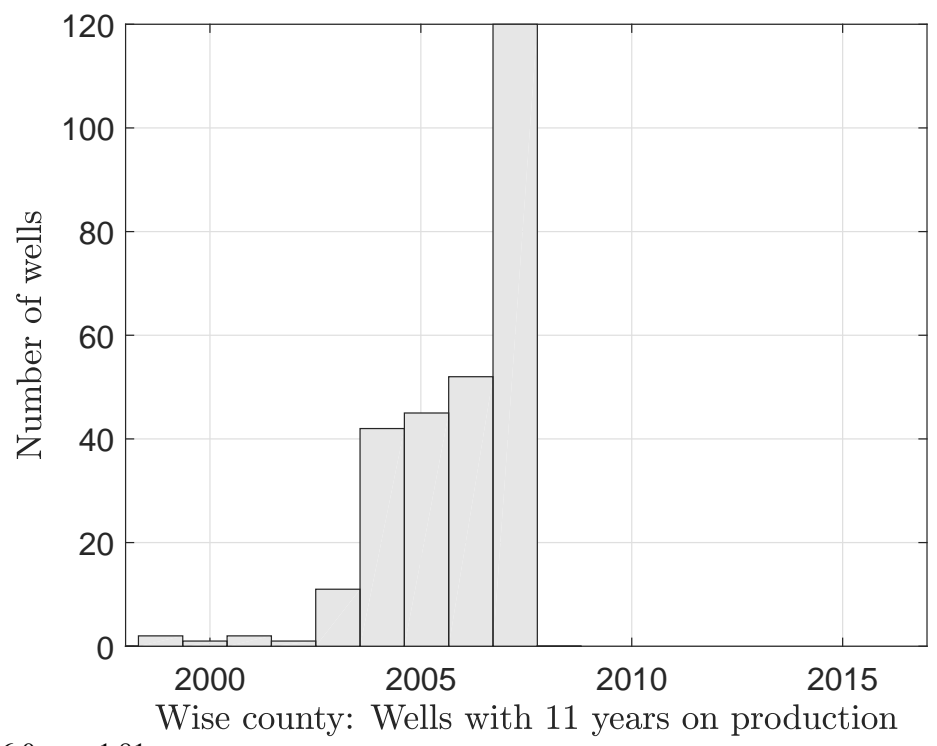




\section{Wise county wells with 12 yrs on production}

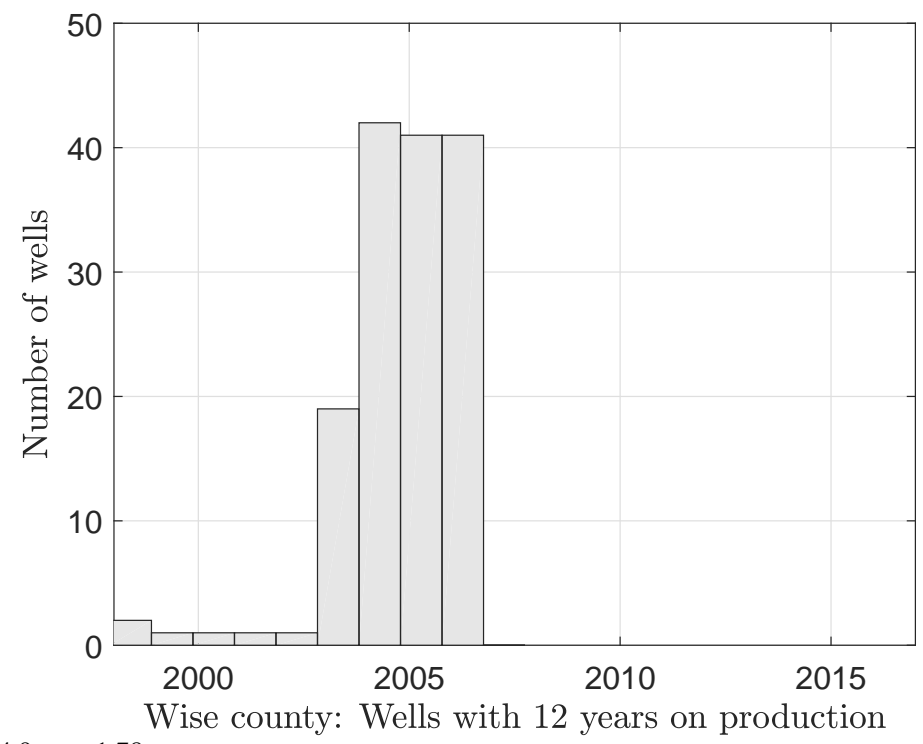




\section{Wise county wells with 13 yrs on production}

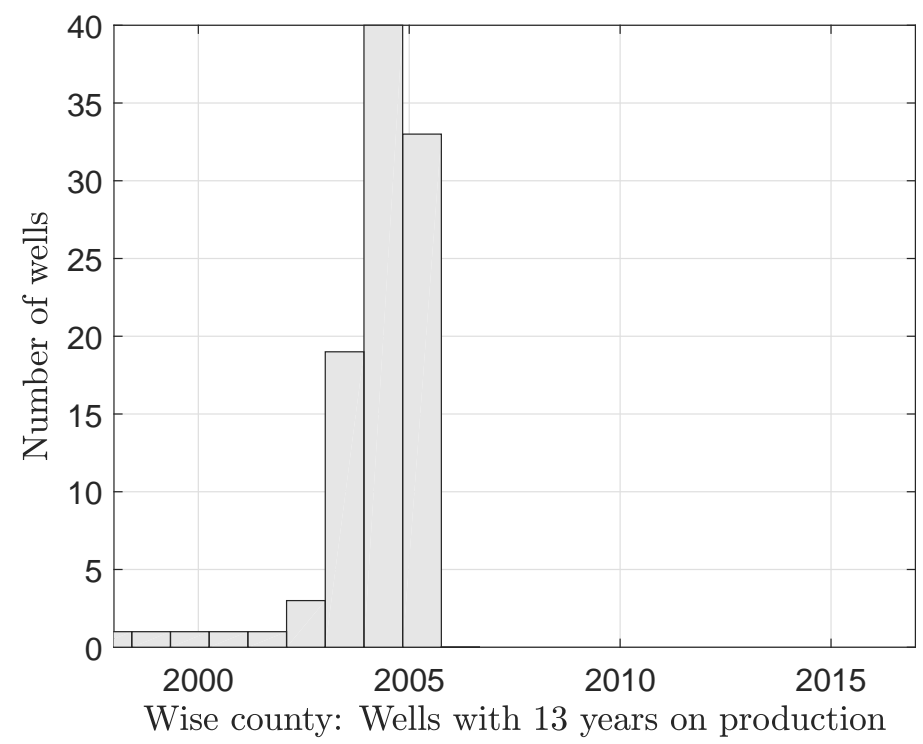




\section{Wise county wells with 14 yrs on production}

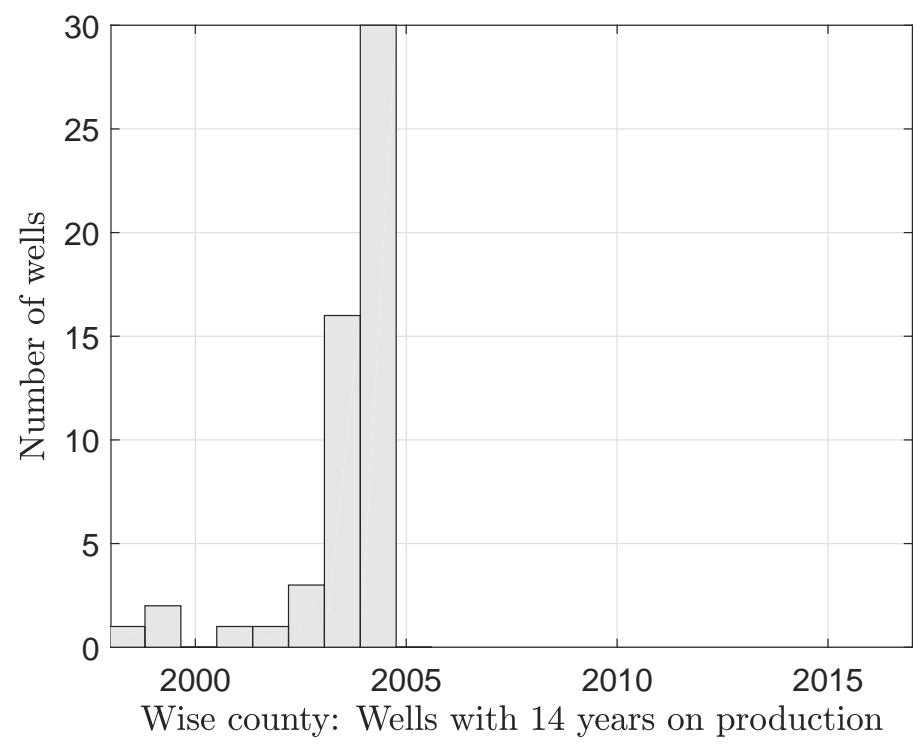




\section{Wise county wells with 15 yrs on production}

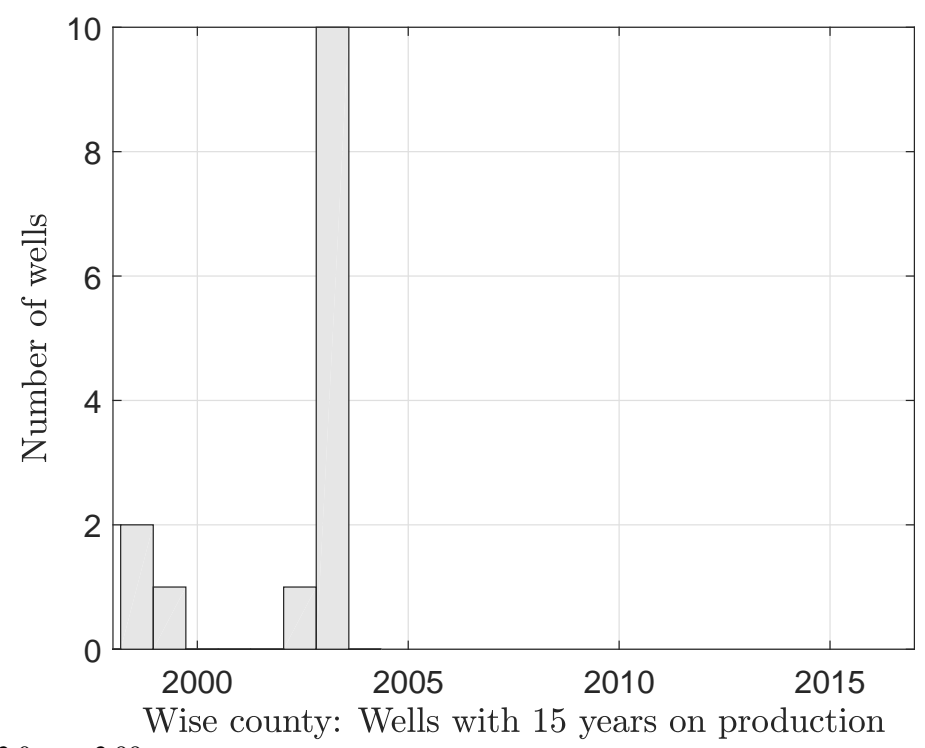




\section{Denton county wells with 1 yrs on production}

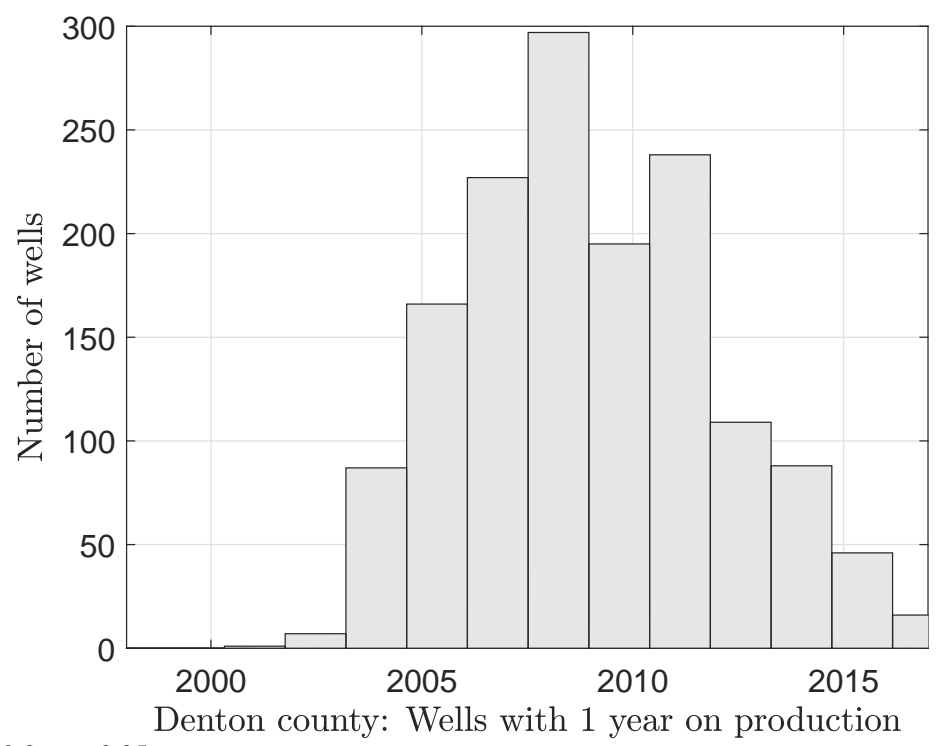




\section{Denton county wells with 2 yrs on production}

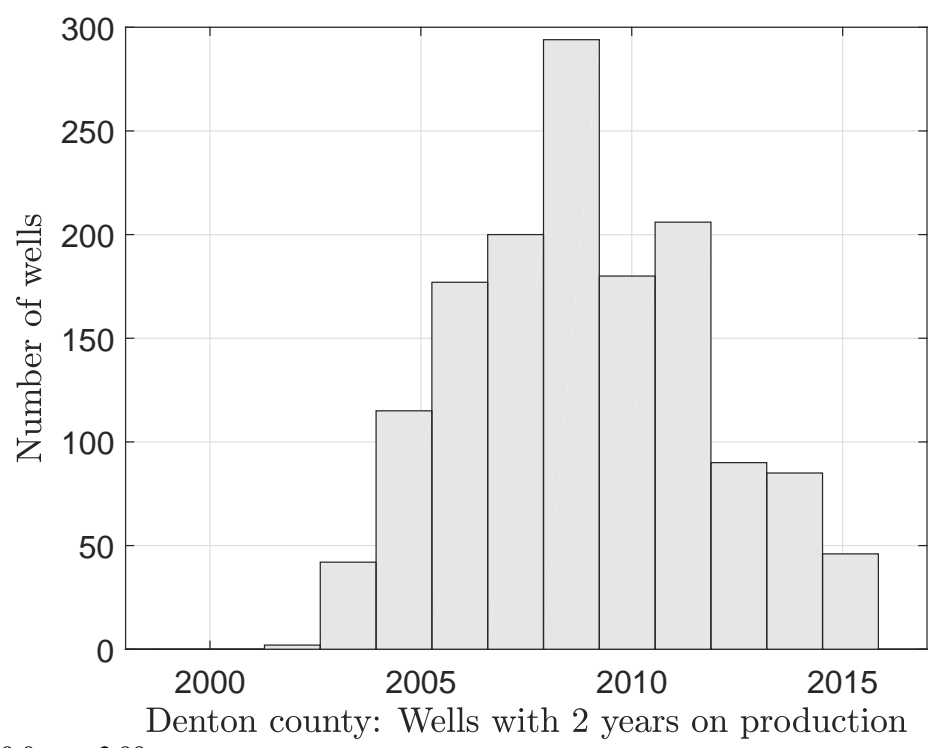




\section{Denton county wells with 3 yrs on production}

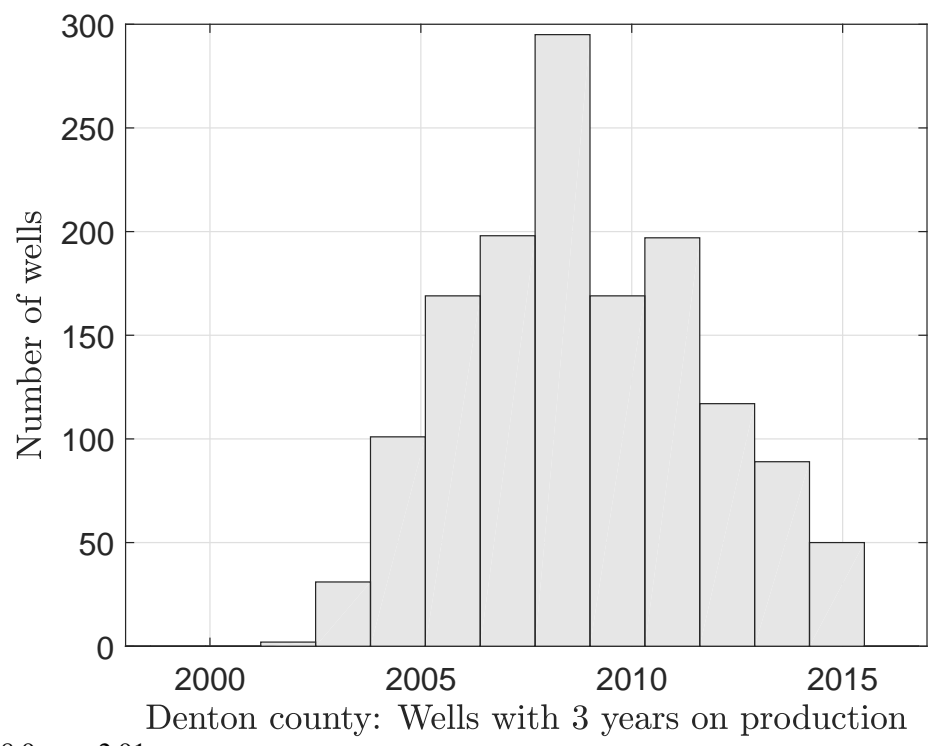




\section{Denton county wells with 4 yrs on production}

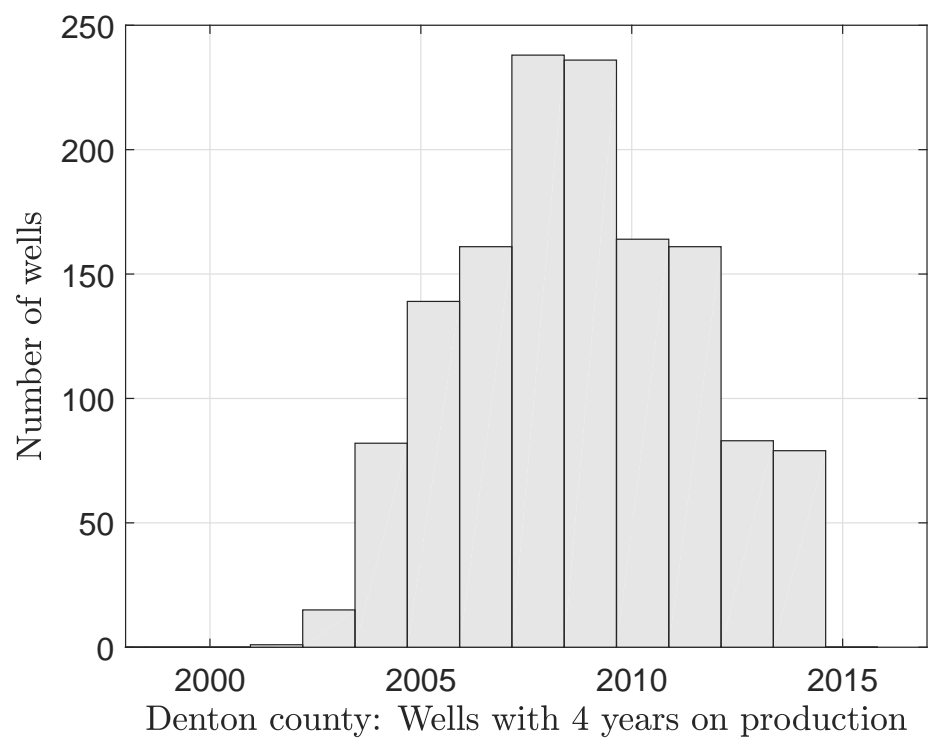




\section{Denton county wells with 5 yrs on production}

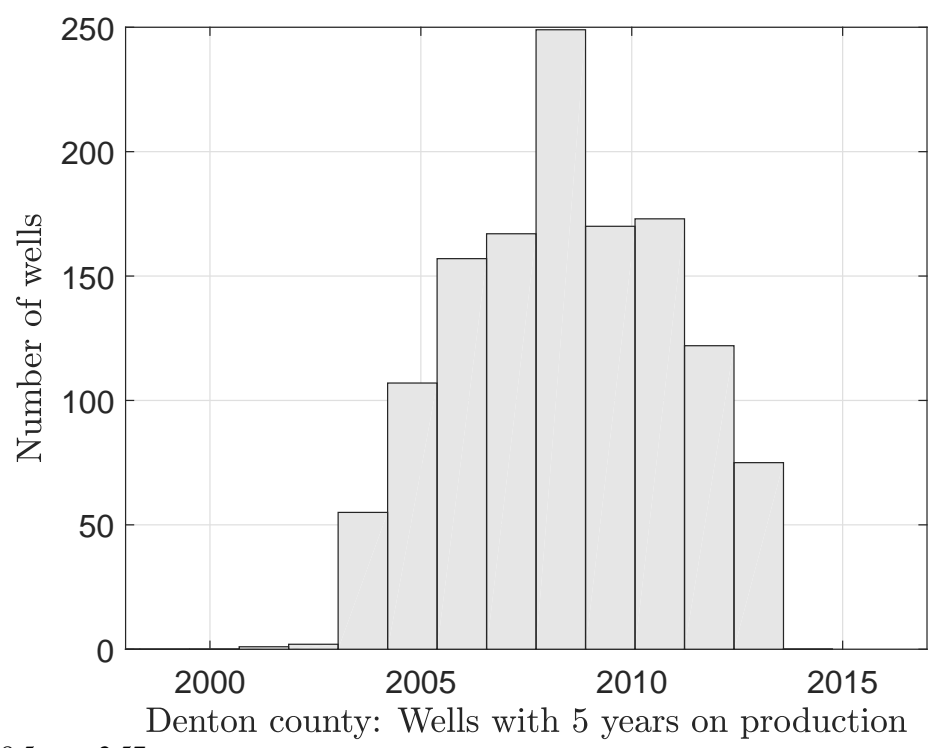




\section{Denton county wells with 6 yrs on production}

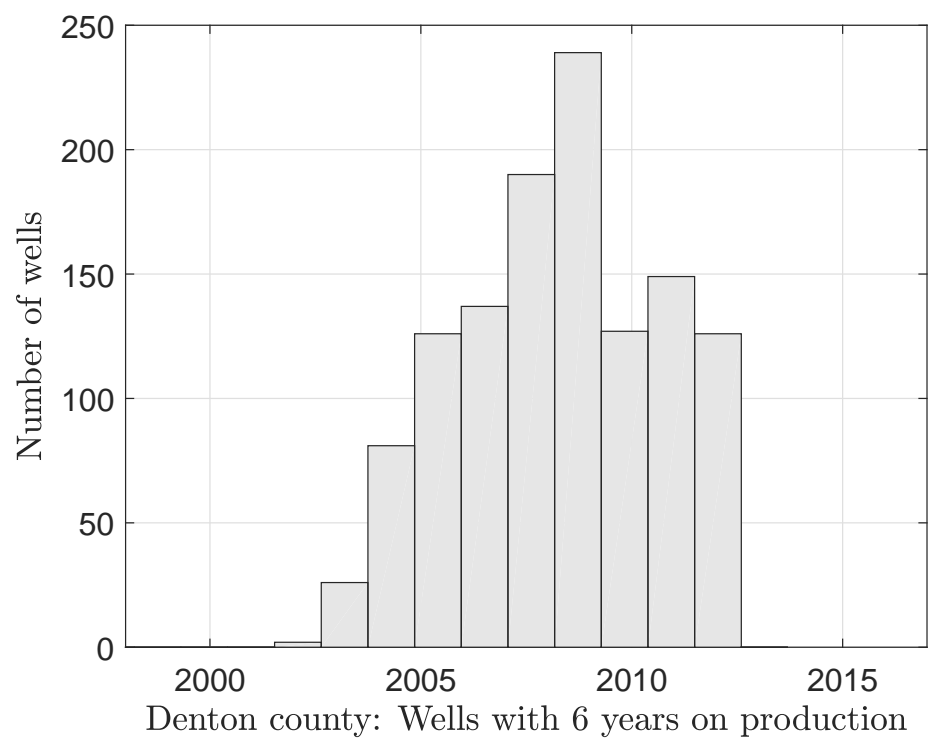




\section{Denton county wells with 7 yrs on production}

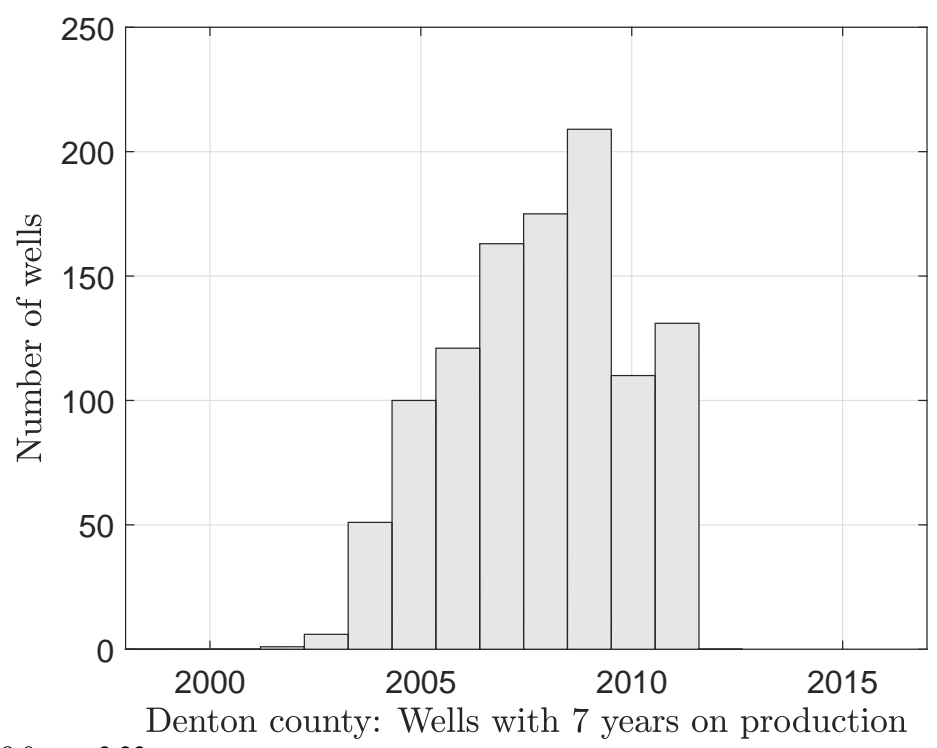




\section{Denton county wells with 8 yrs on production}

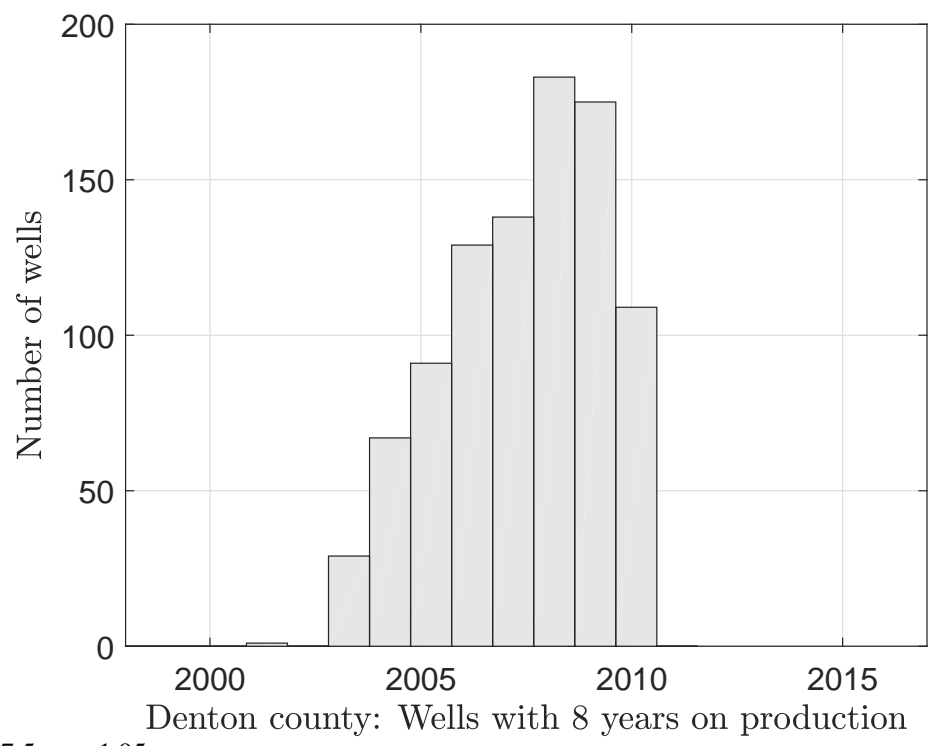




\section{Denton county wells with 9 yrs on production}

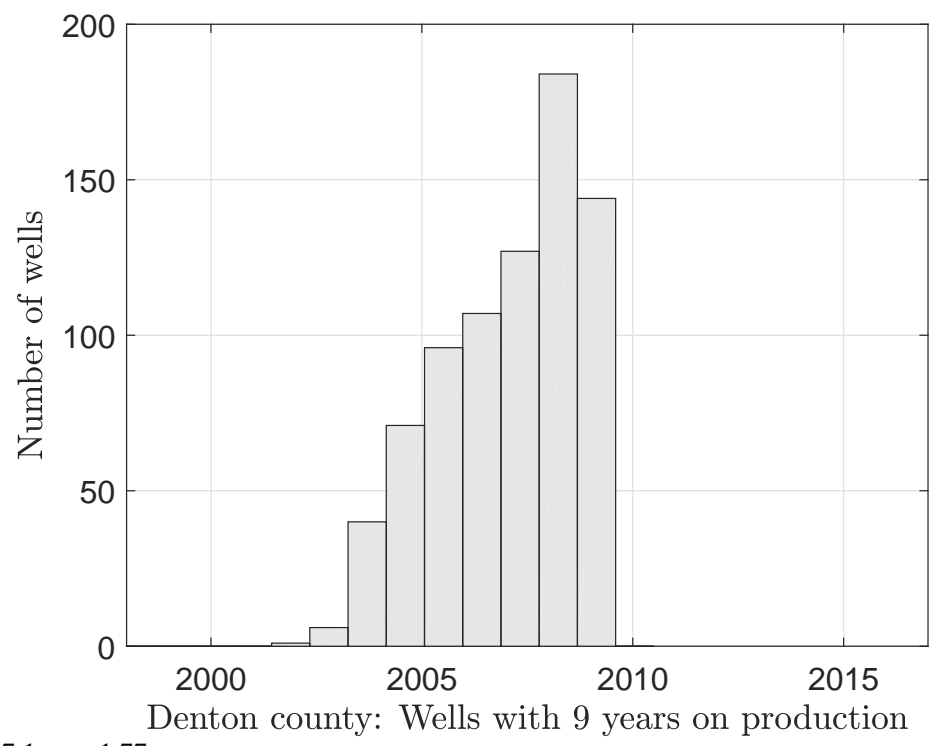




\section{Denton county wells with 10 yrs on production}

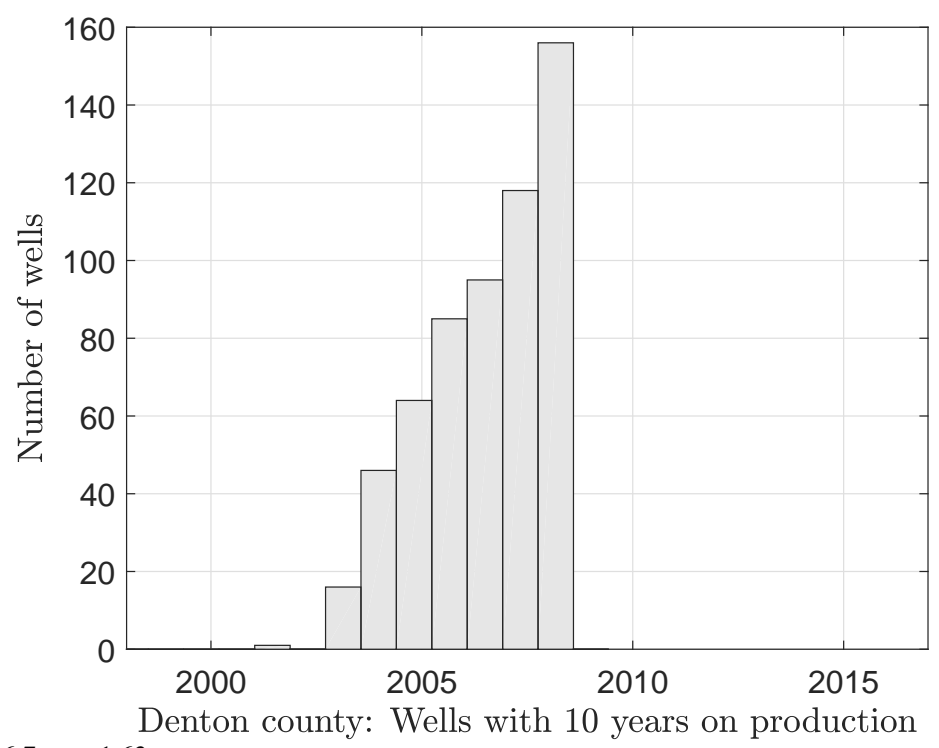




\section{Denton county wells with 11 yrs on production}

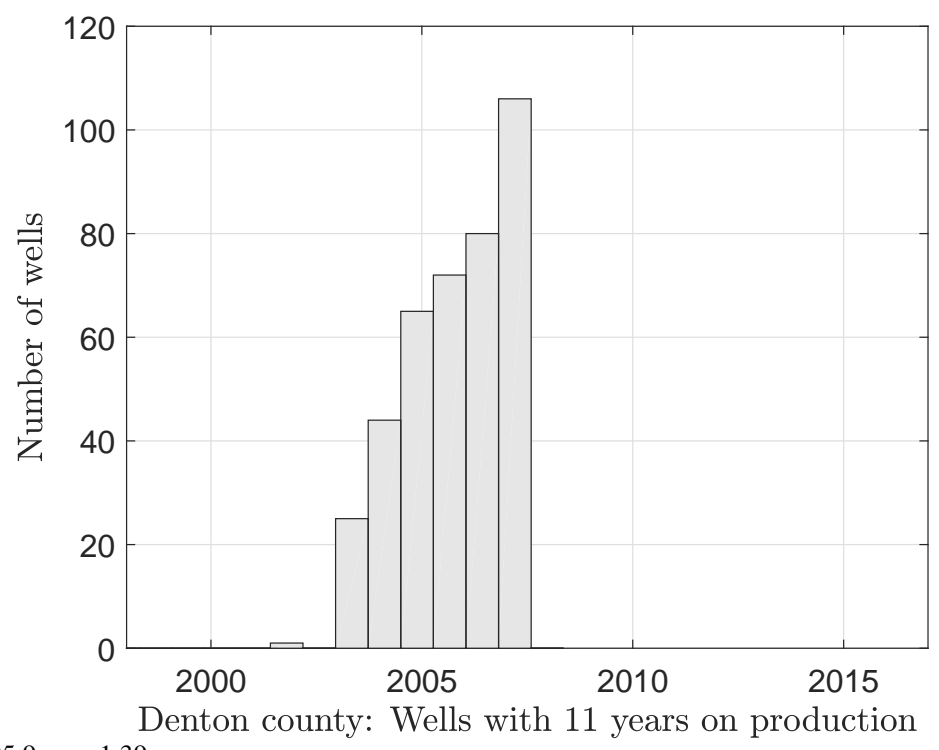




\section{Denton county wells with 12 yrs on production}

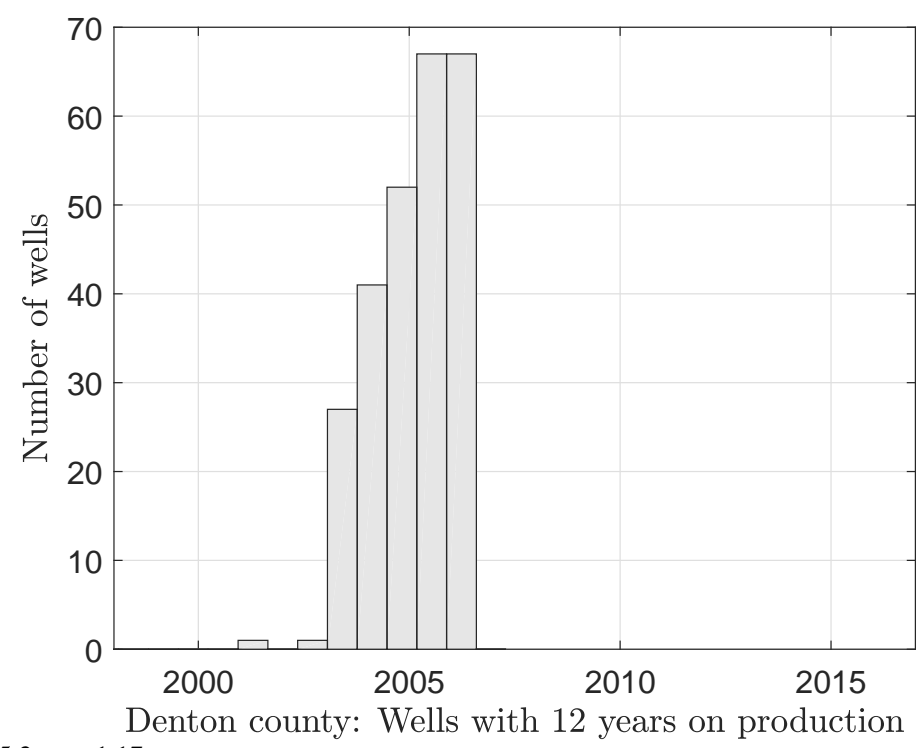




\section{Denton county wells with 13 yrs on production}

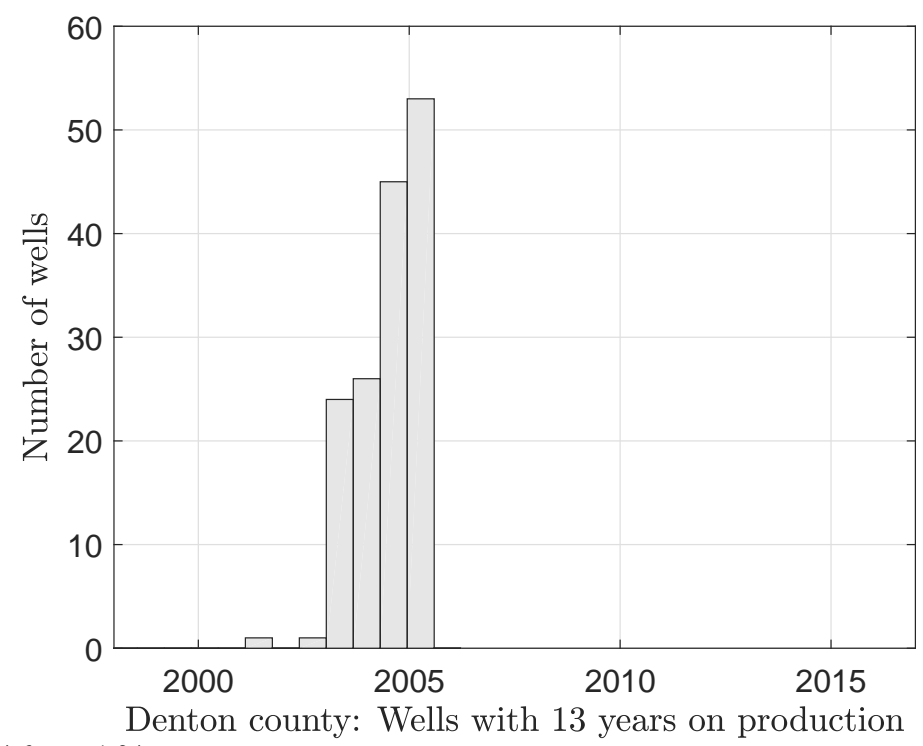




\section{Denton county wells with 14 yrs on production}

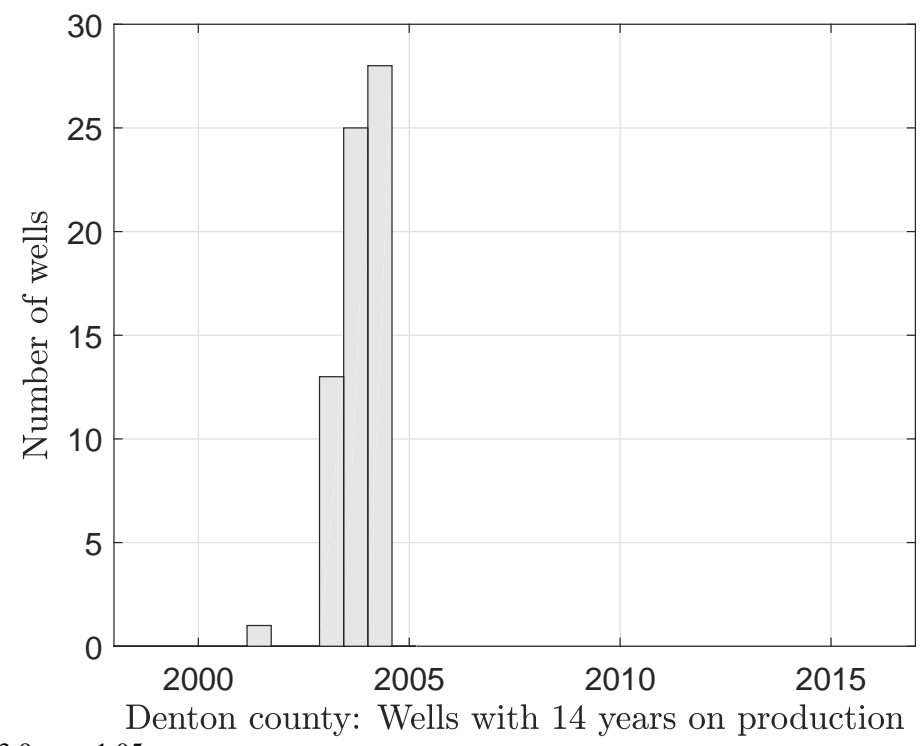




\section{Denton county wells with 15 yrs on production}

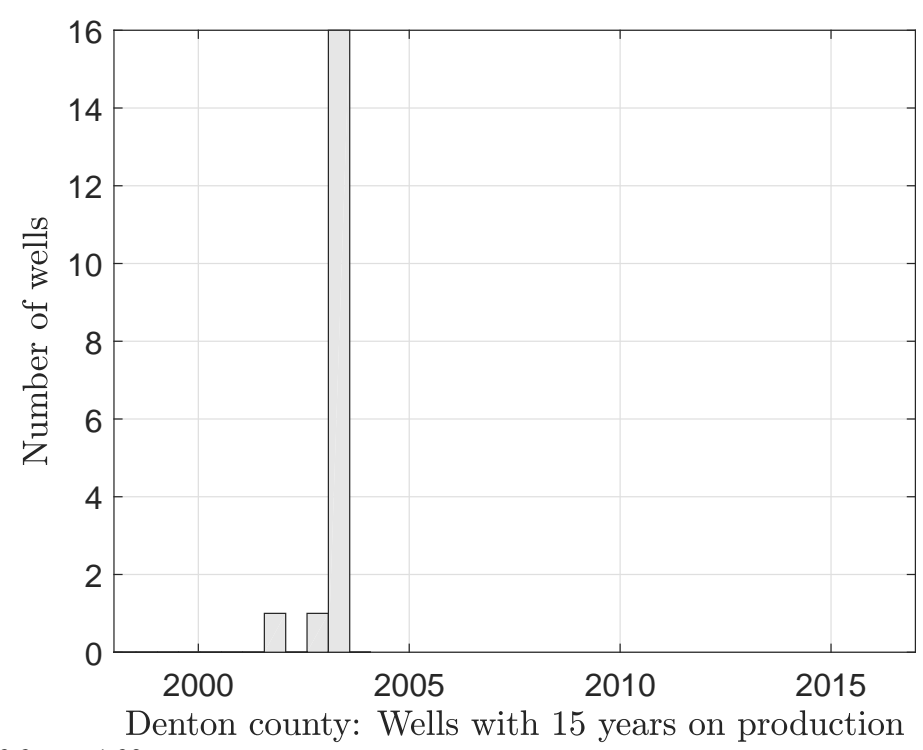




\section{Parker county wells with 1 yrs on production}

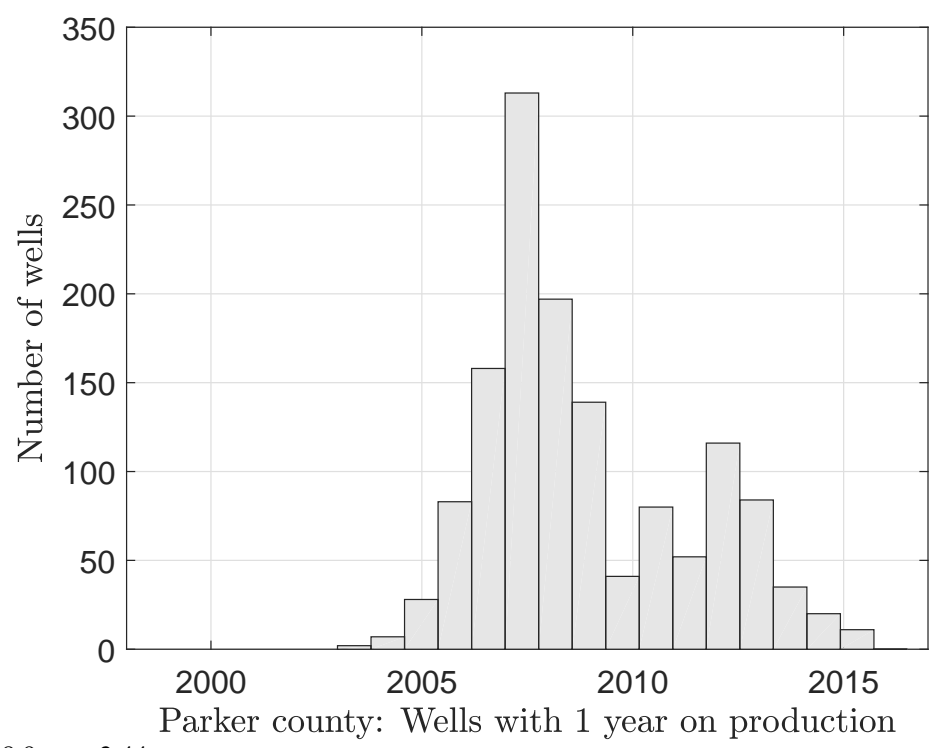




\section{Parker county wells with 2 yrs on production}

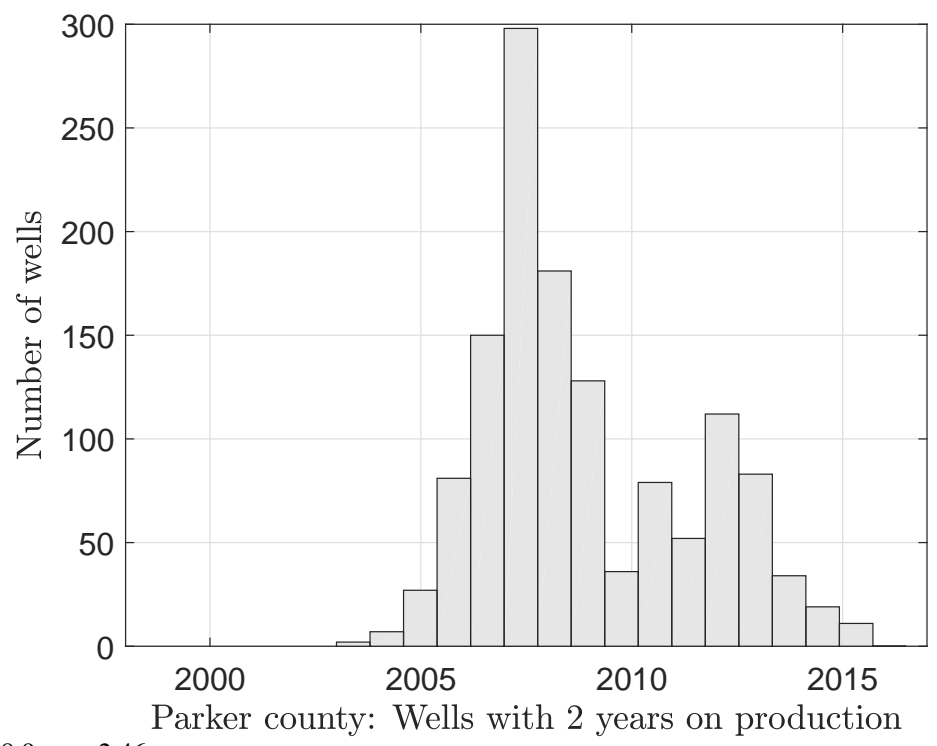




\section{Parker county wells with 3 yrs on production}

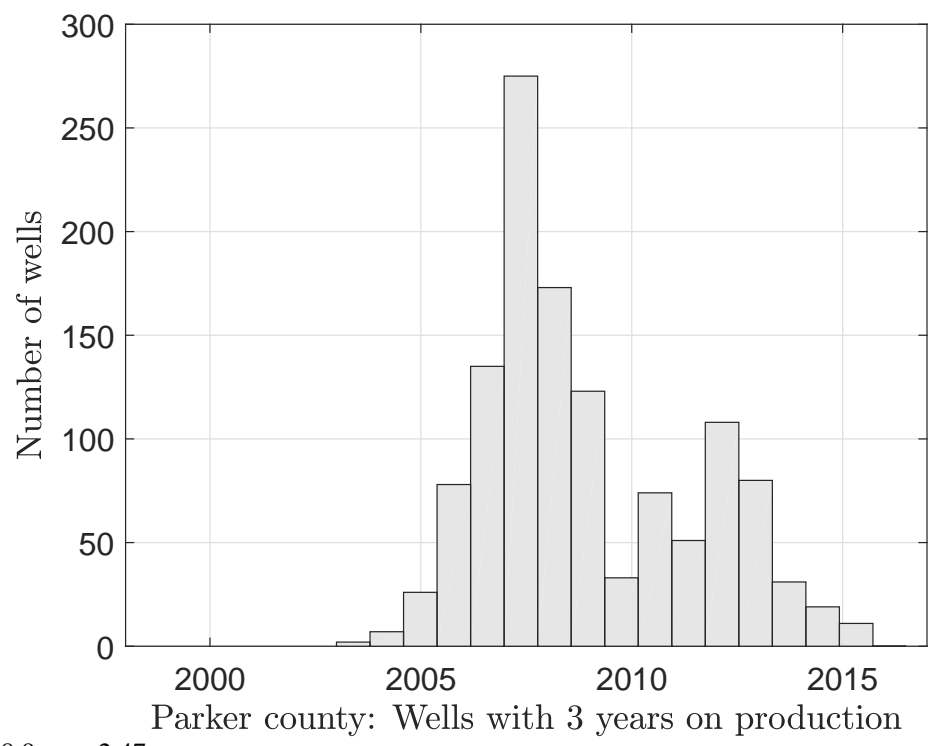




\section{Parker county wells with 4 yrs on production}

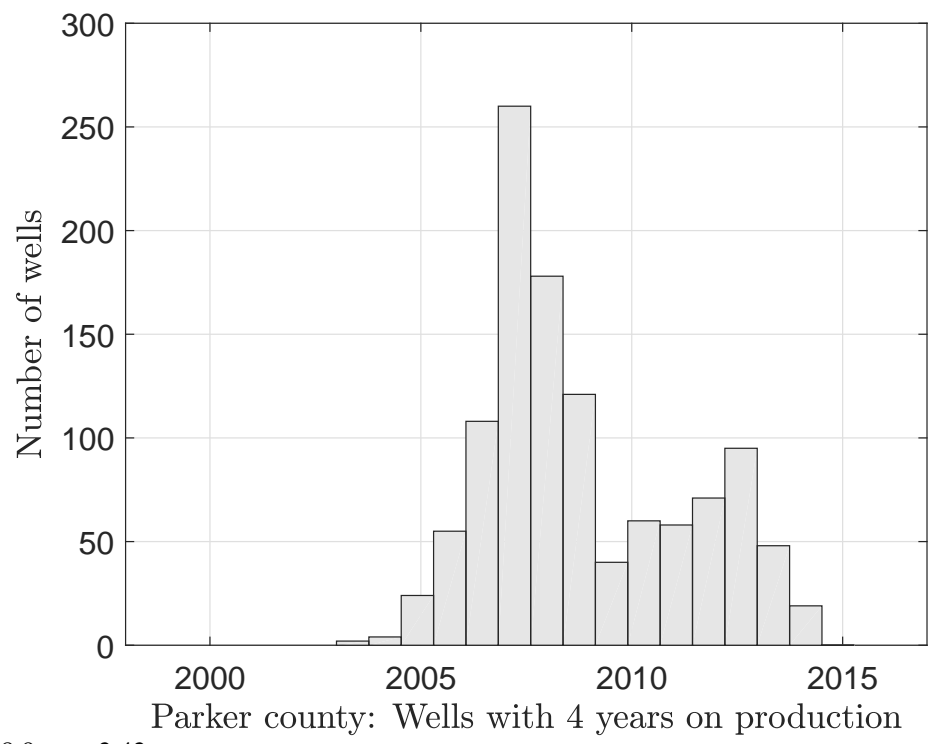




\section{Parker county wells with 5 yrs on production}

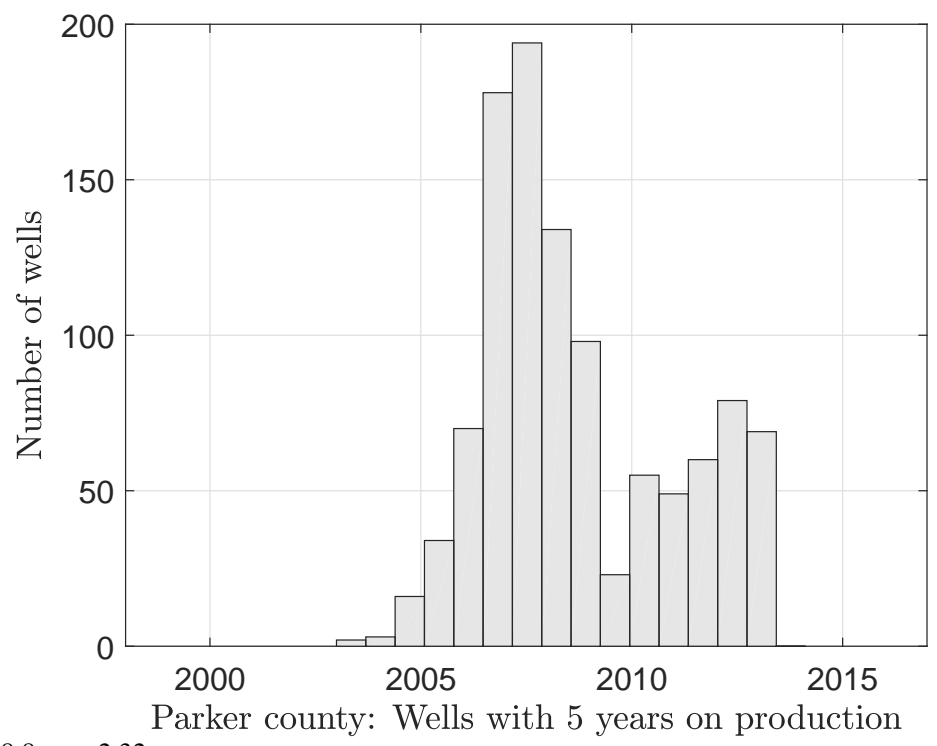




\section{Parker county wells with 6 yrs on production}

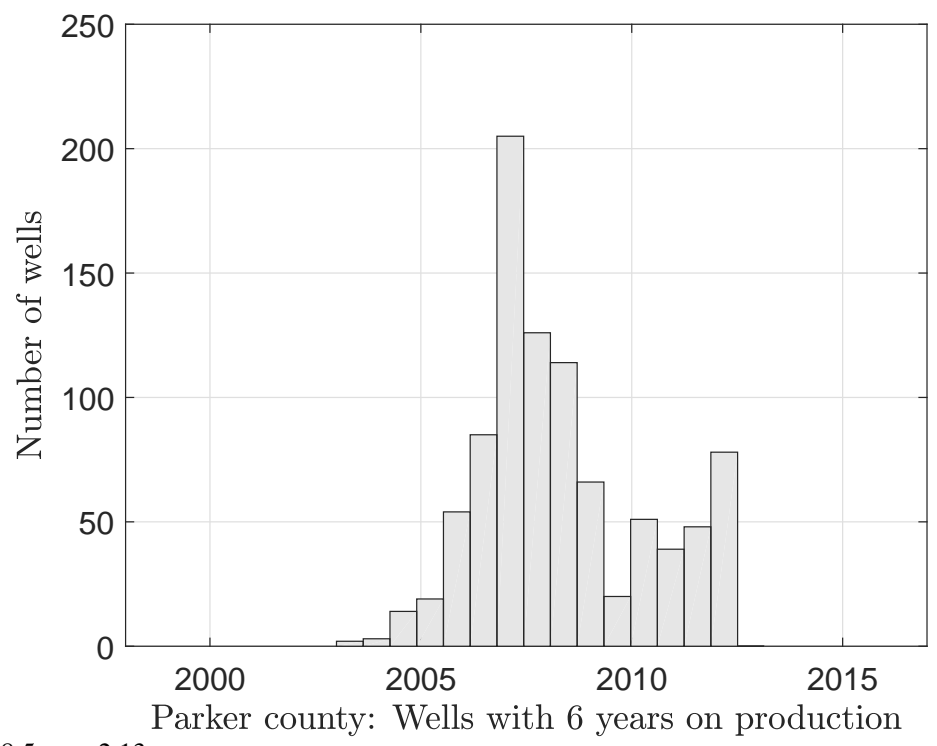




\section{Parker county wells with 7 yrs on production}

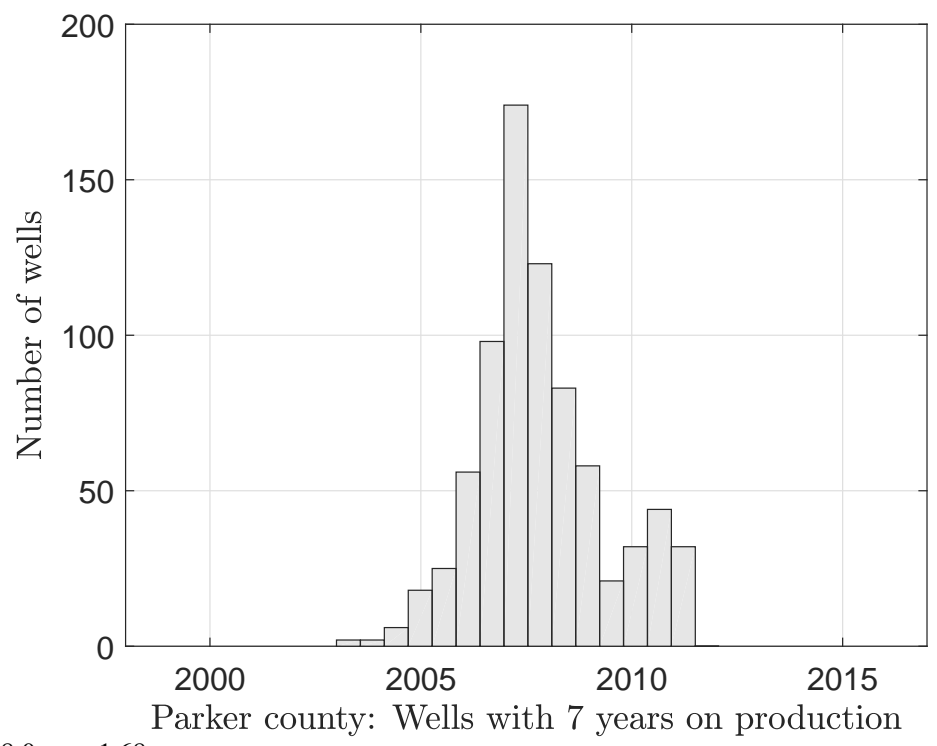




\section{Parker county wells with 8 yrs on production}

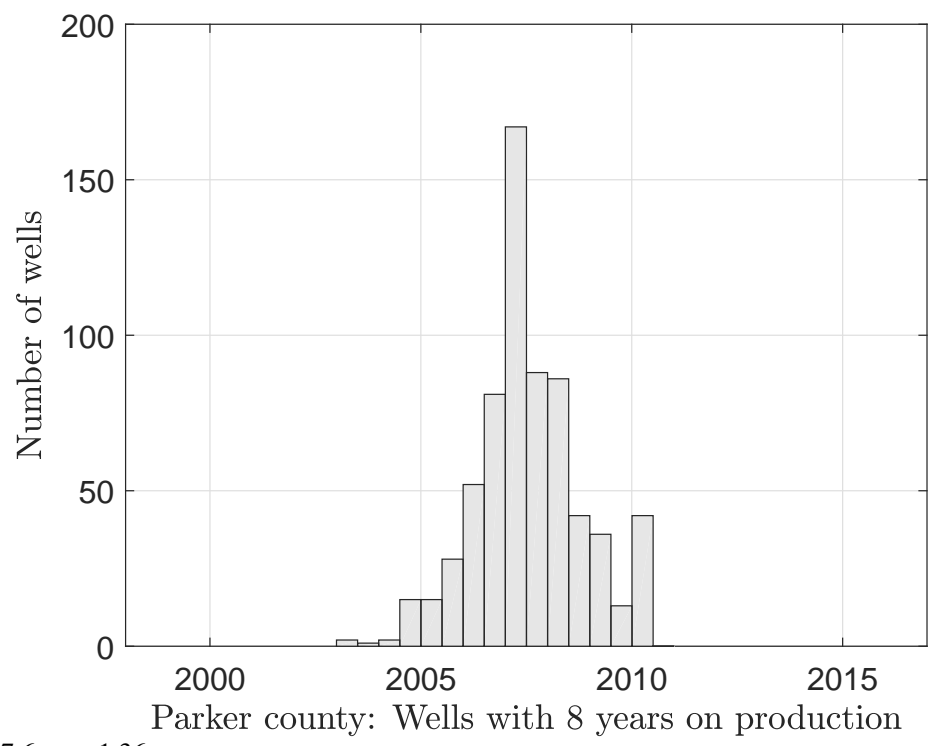




\section{Parker county wells with 9 yrs on production}

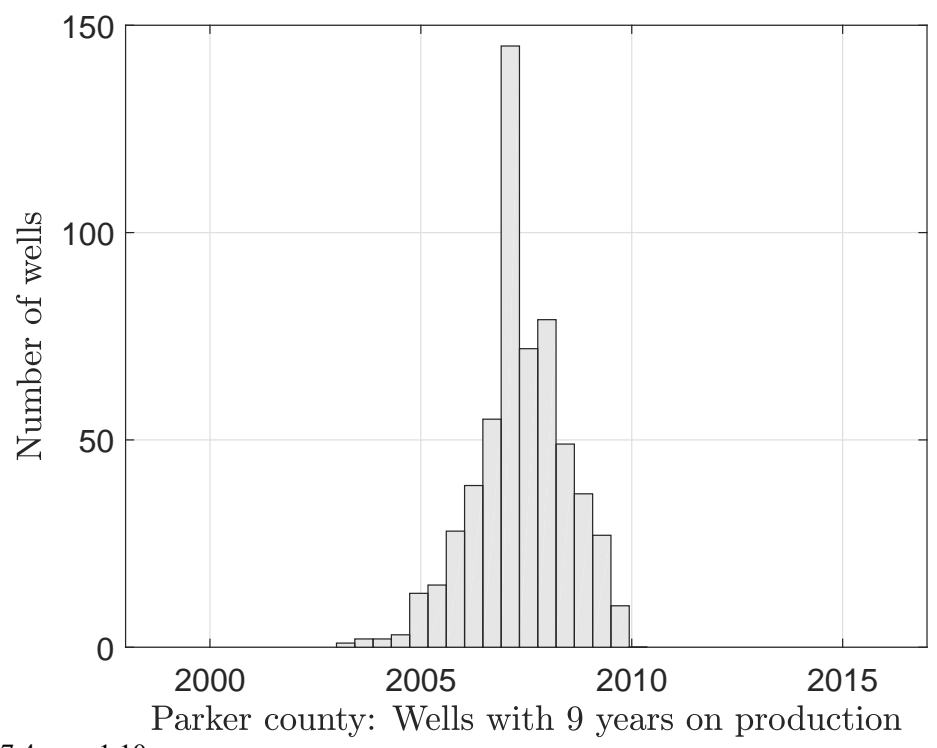




\section{Parker county wells with 10 yrs on production}

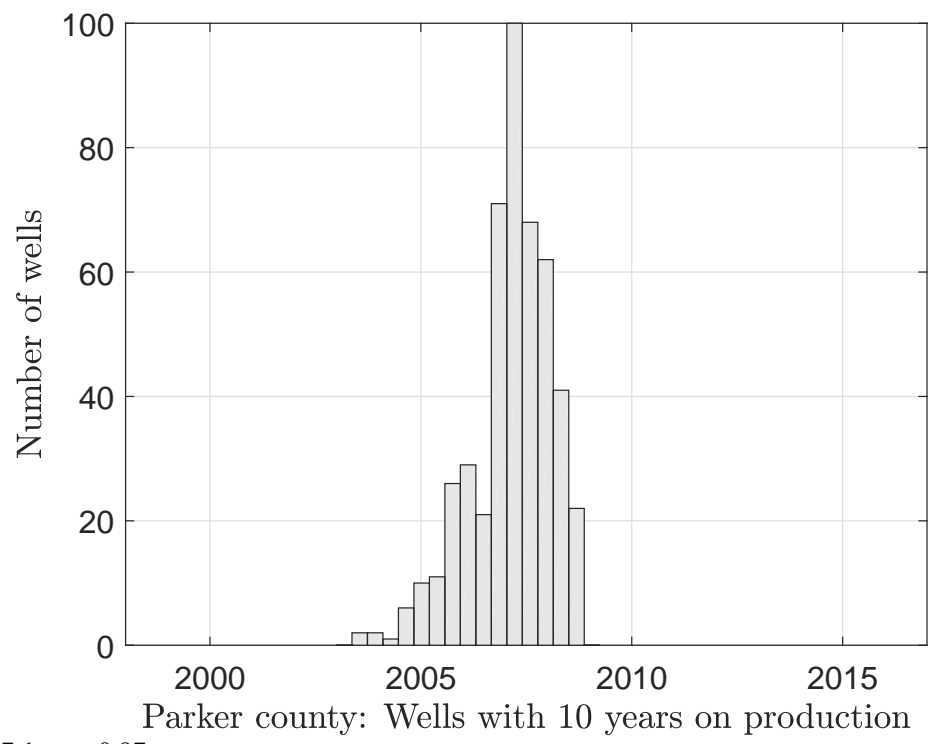




\section{Parker county wells with 11 yrs on production}

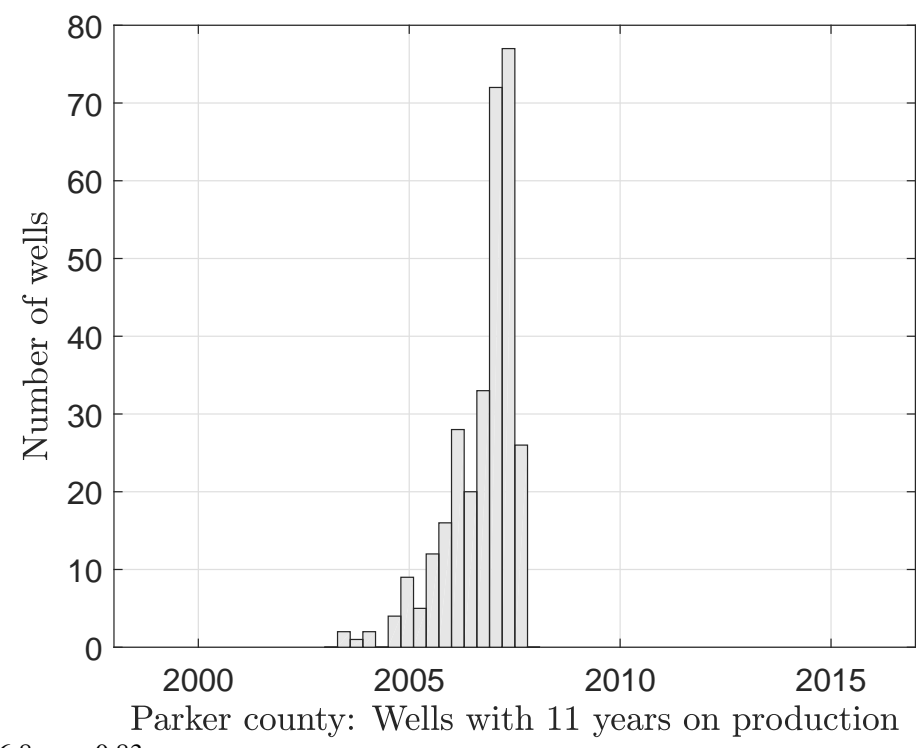




\section{Parker county wells with 12 yrs on production}

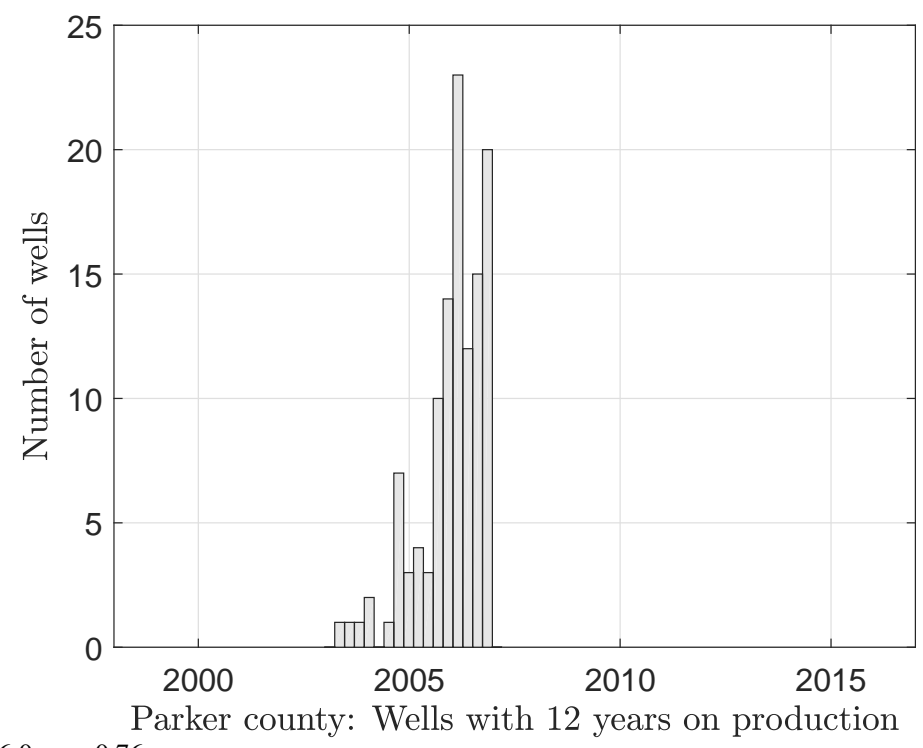




\section{Parker county wells with 13 yrs on production}

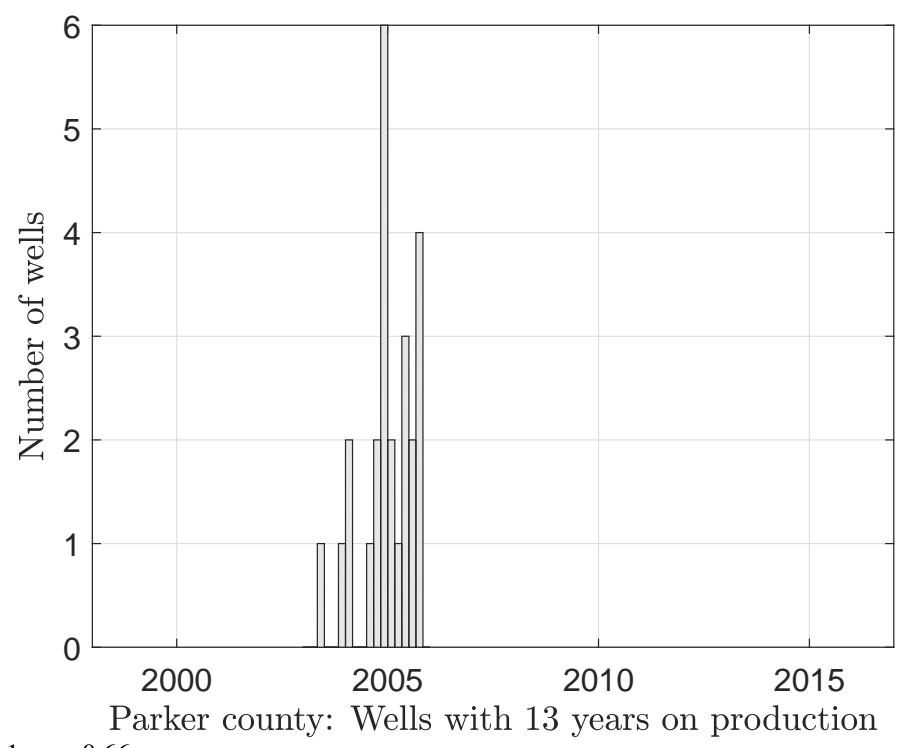




\section{Hood county wells with 1 yrs on production}

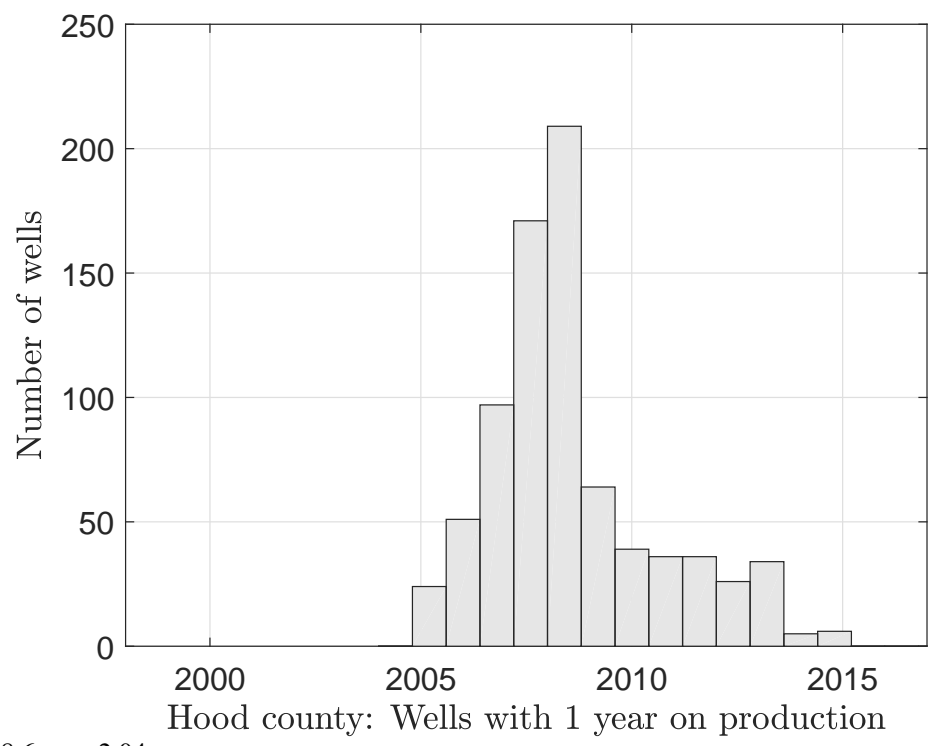




\section{Hood county wells with 2 yrs on production}

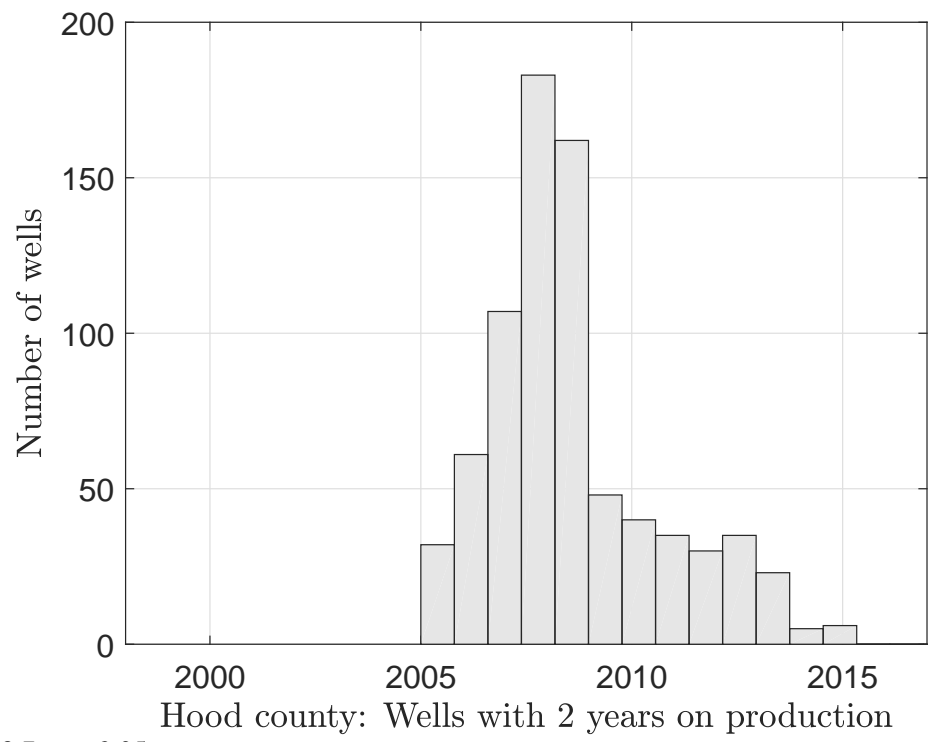




\section{Hood county wells with 3 yrs on production}

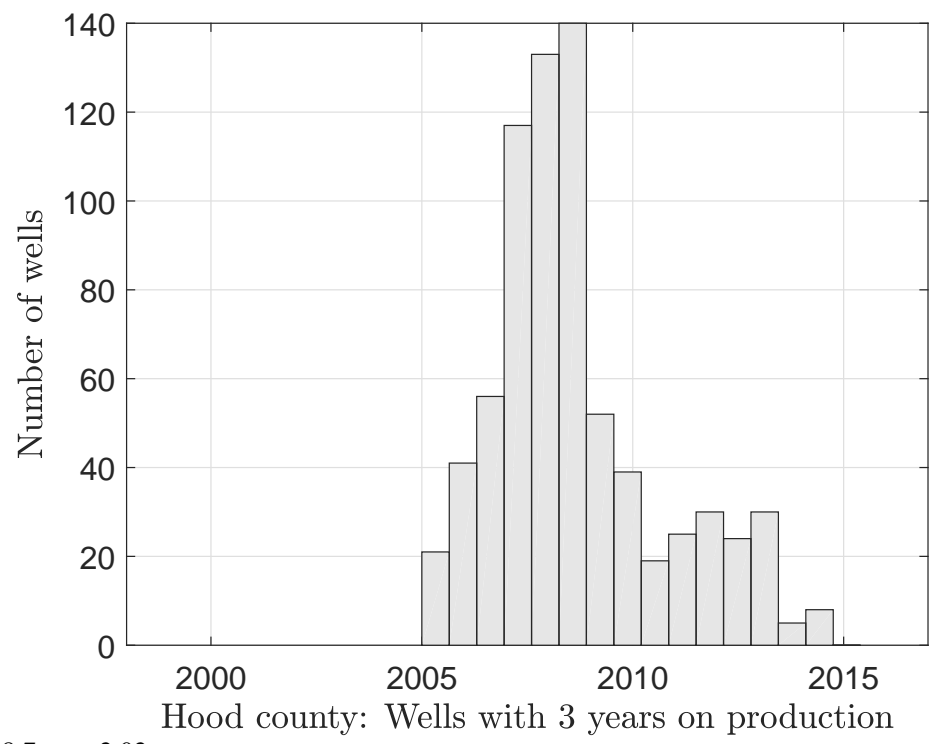




\section{Hood county wells with 4 yrs on production}

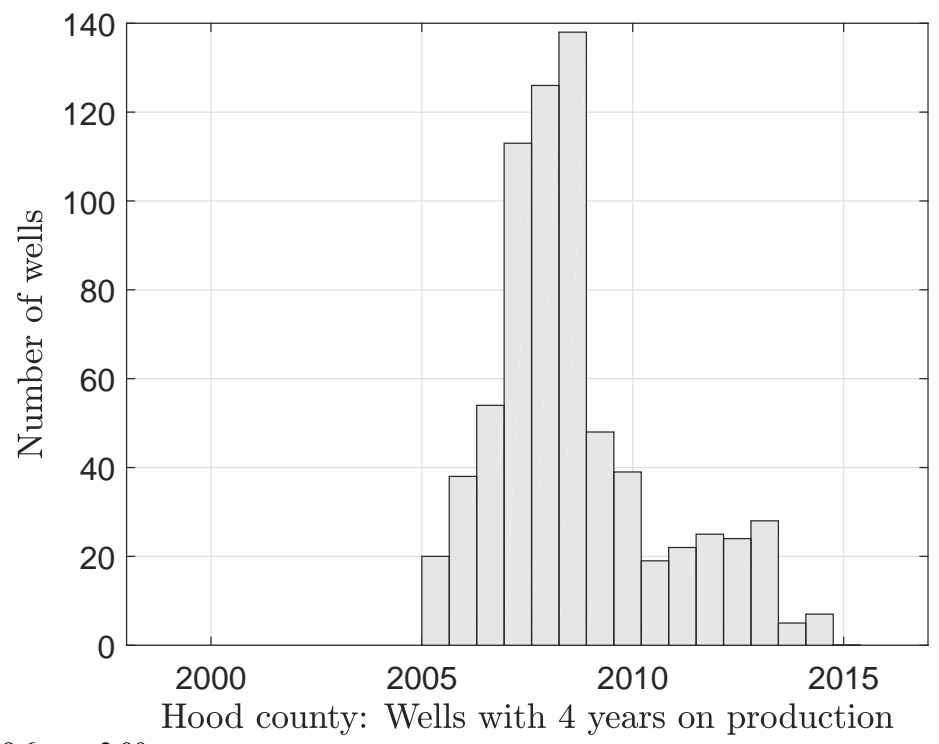




\section{Hood county wells with 5 yrs on production}

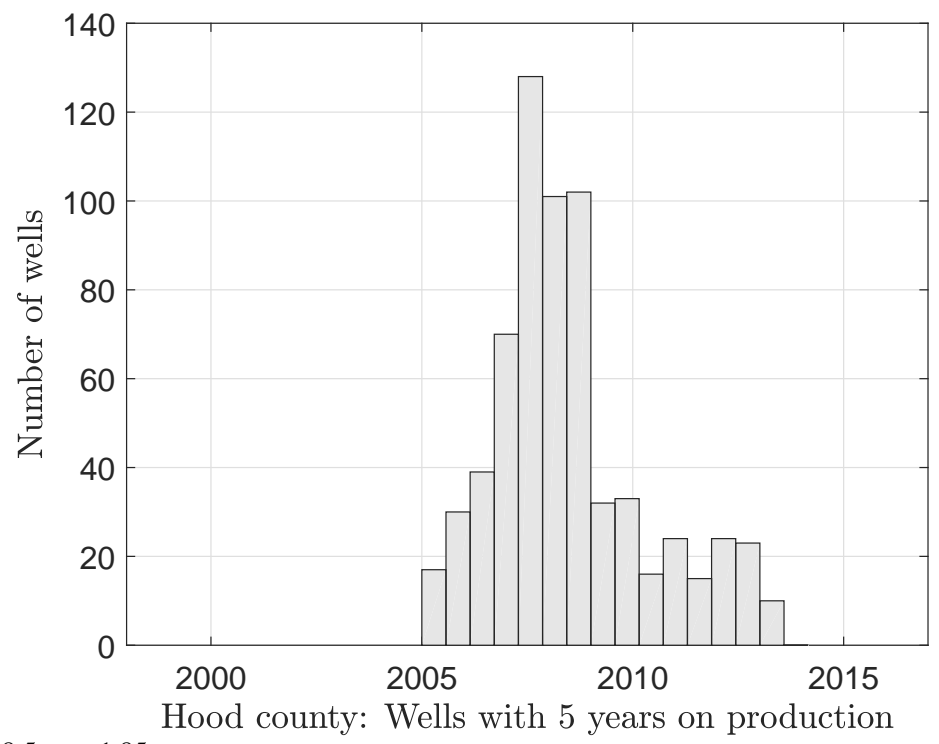




\section{Hood county wells with 6 yrs on production}

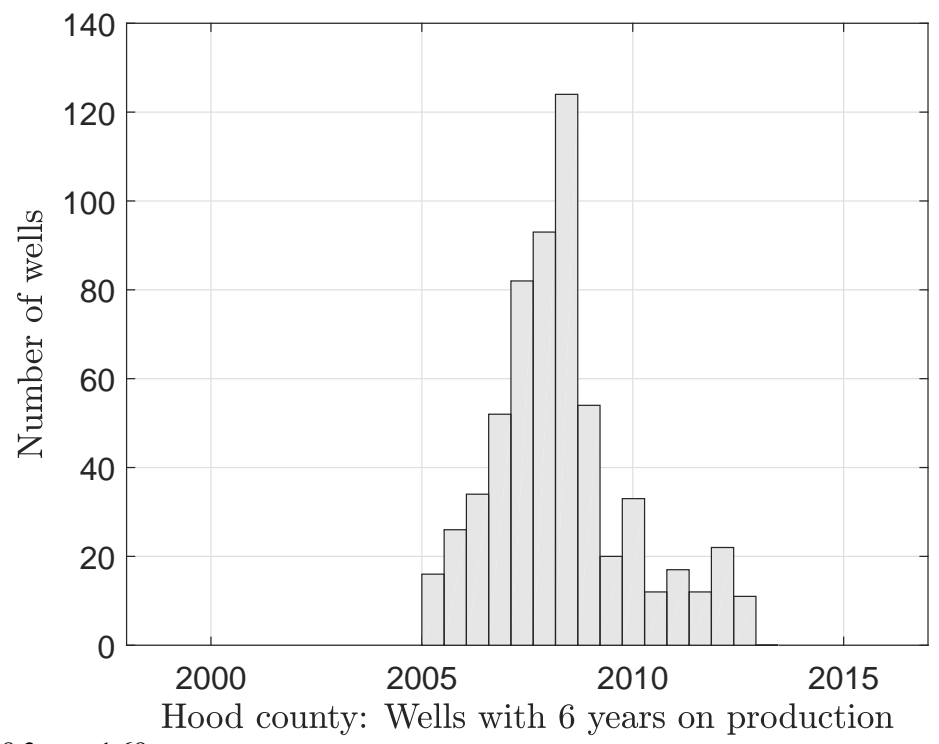




\section{Hood county wells with 7 yrs on production}

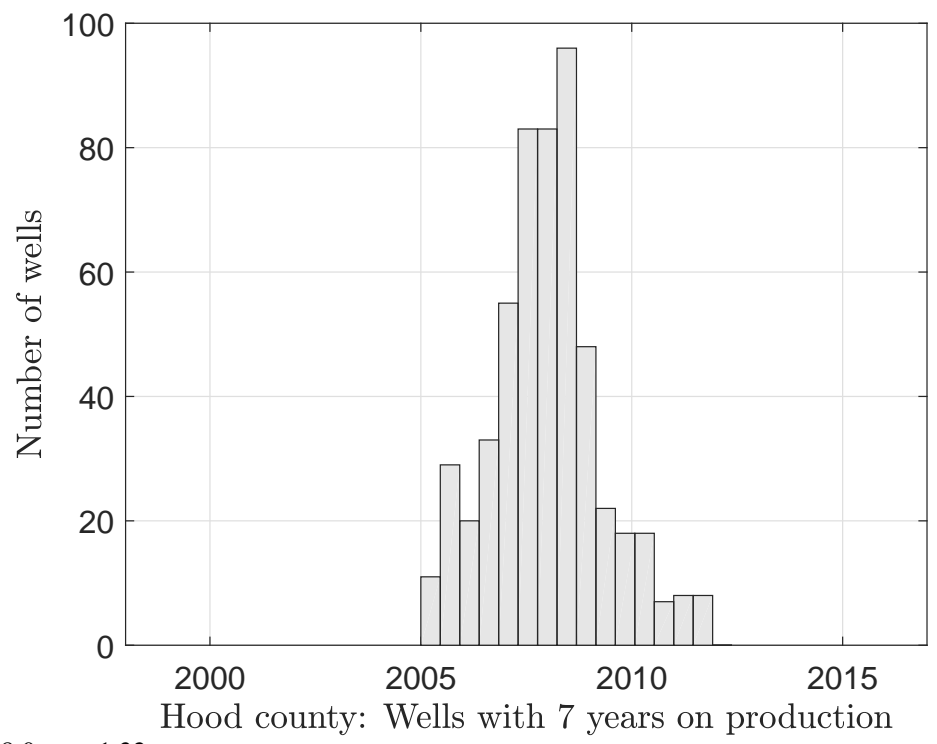




\section{Hood county wells with 8 yrs on production}

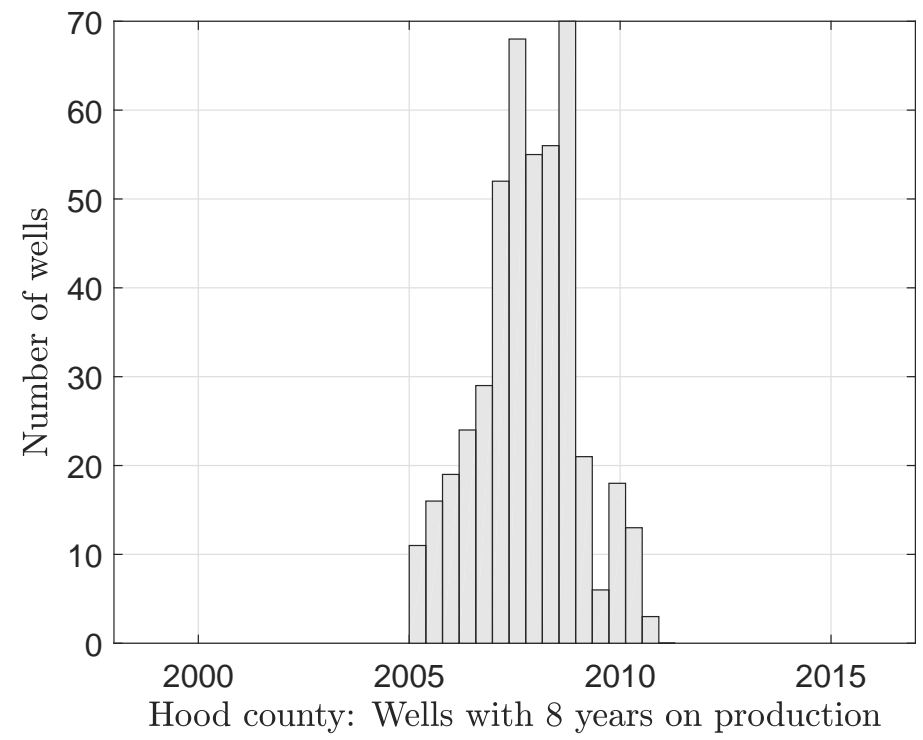




\section{Hood county wells with 9 yrs on production}

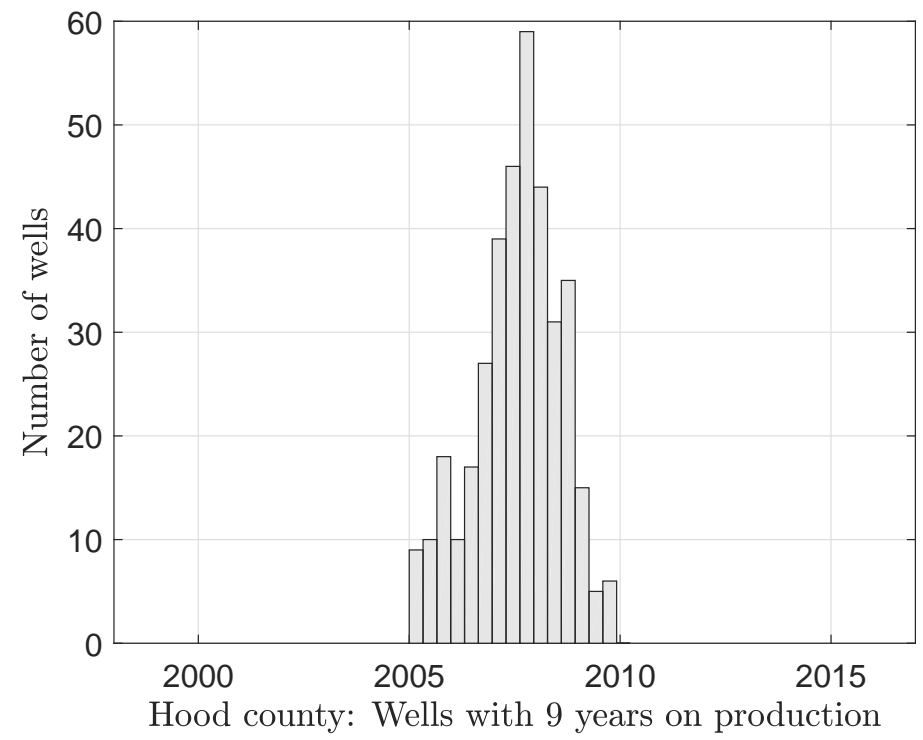




\section{Hood county wells with 10 yrs on production}

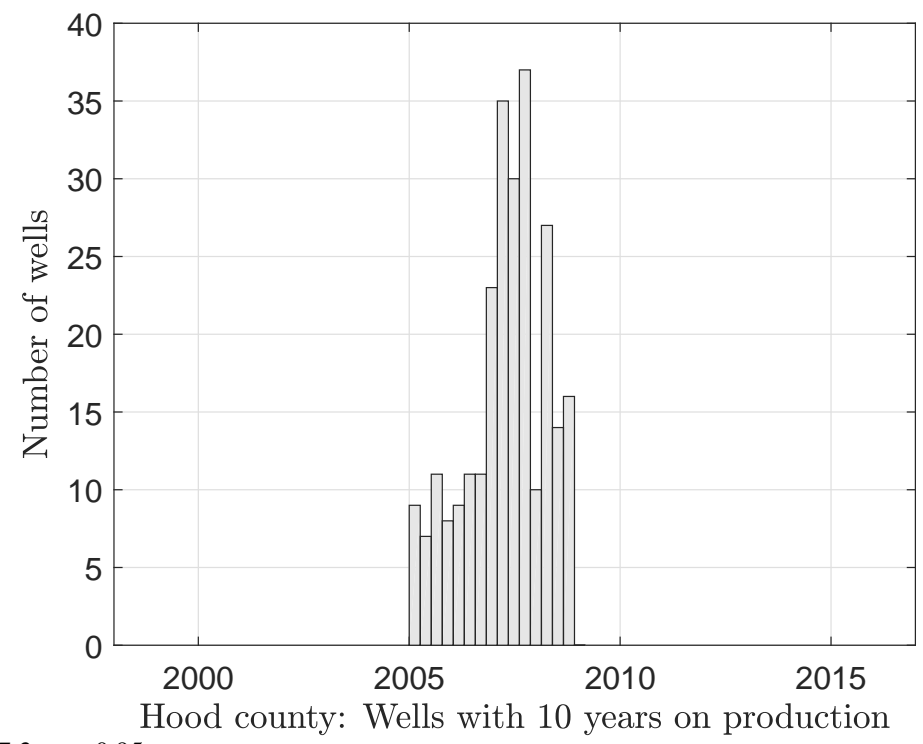




\section{Hood county wells with 11 yrs on production}

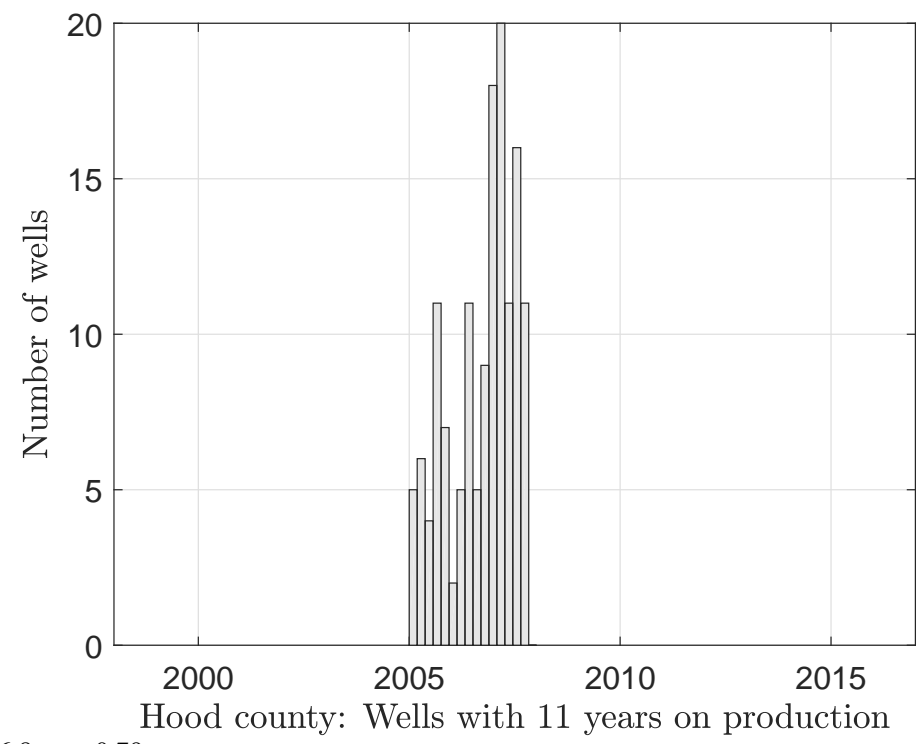




\section{Hood county wells with 12 yrs on production}

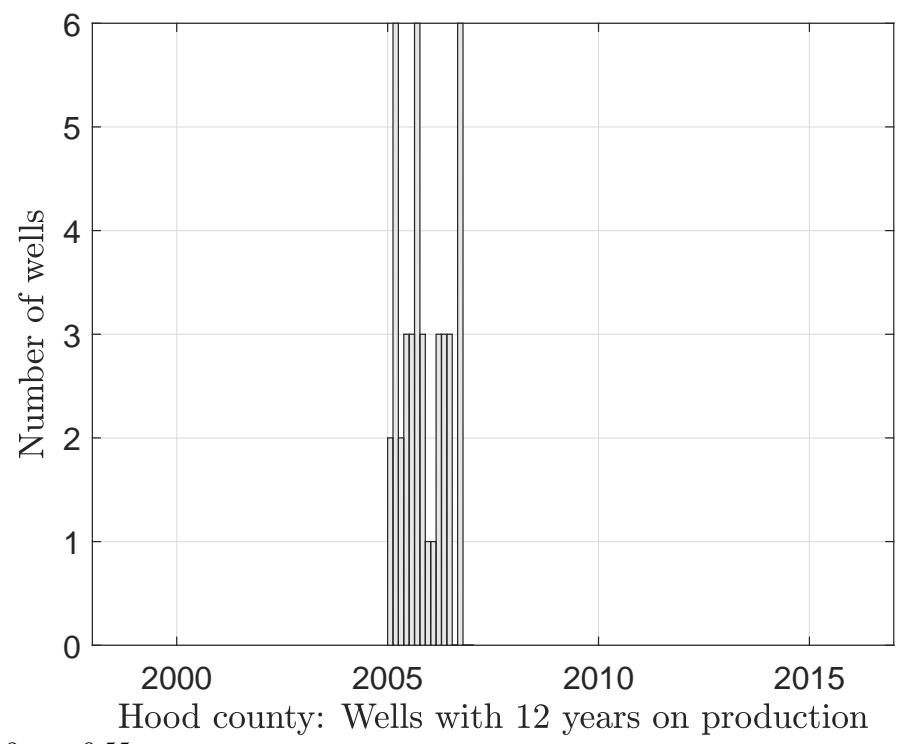




\section{Mean of well completion dates in Tarrant}

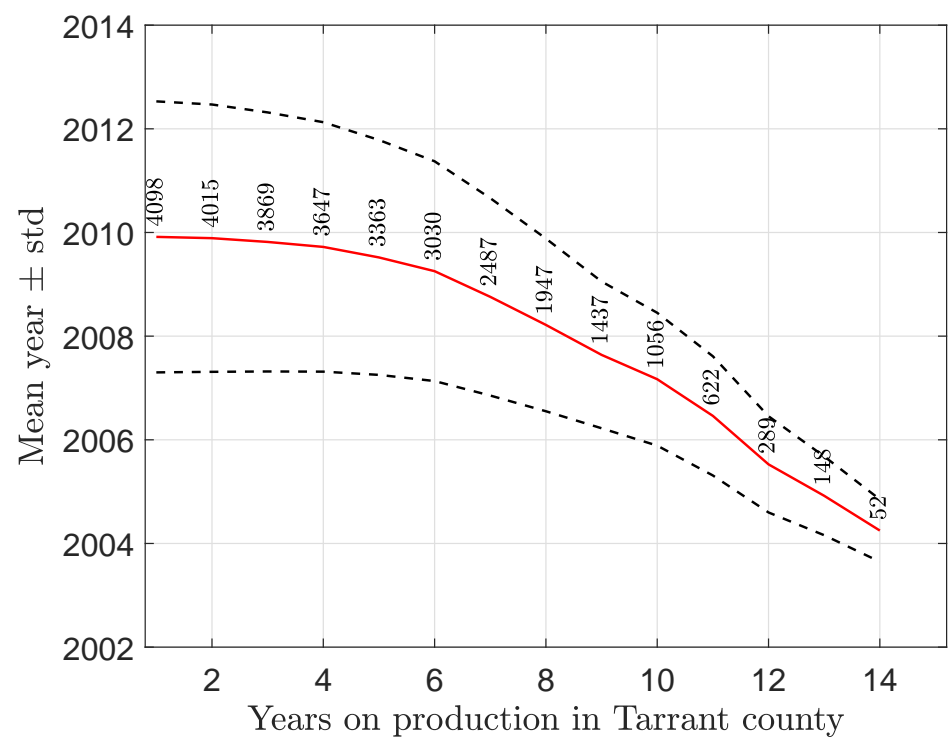




\section{Mean of well completion dates in Johnson}

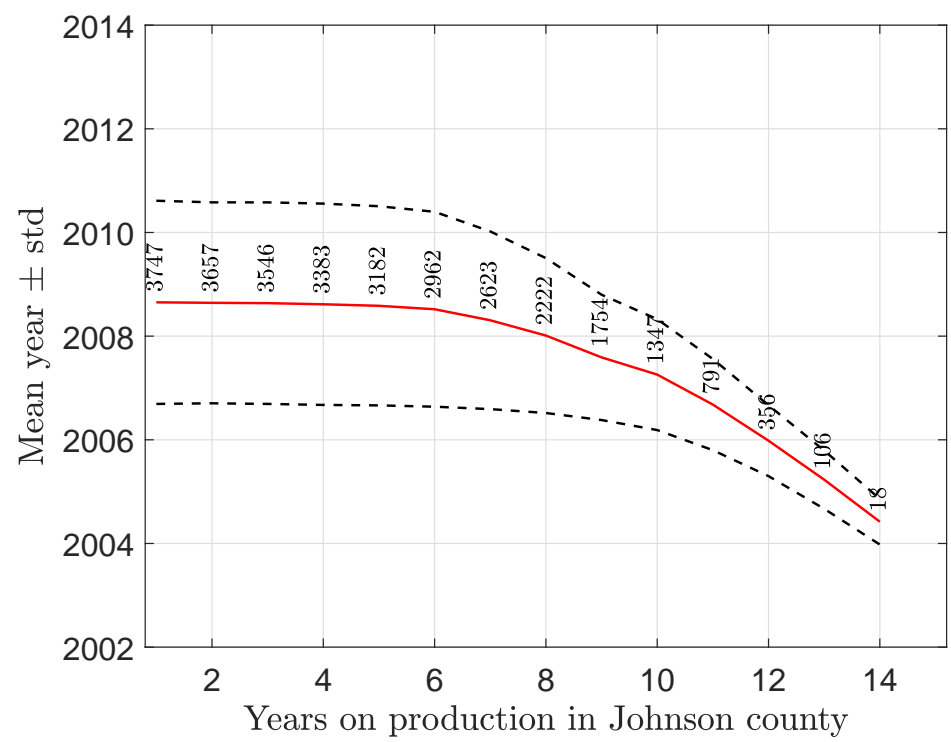




\section{Mean of well completion dates in Wise}

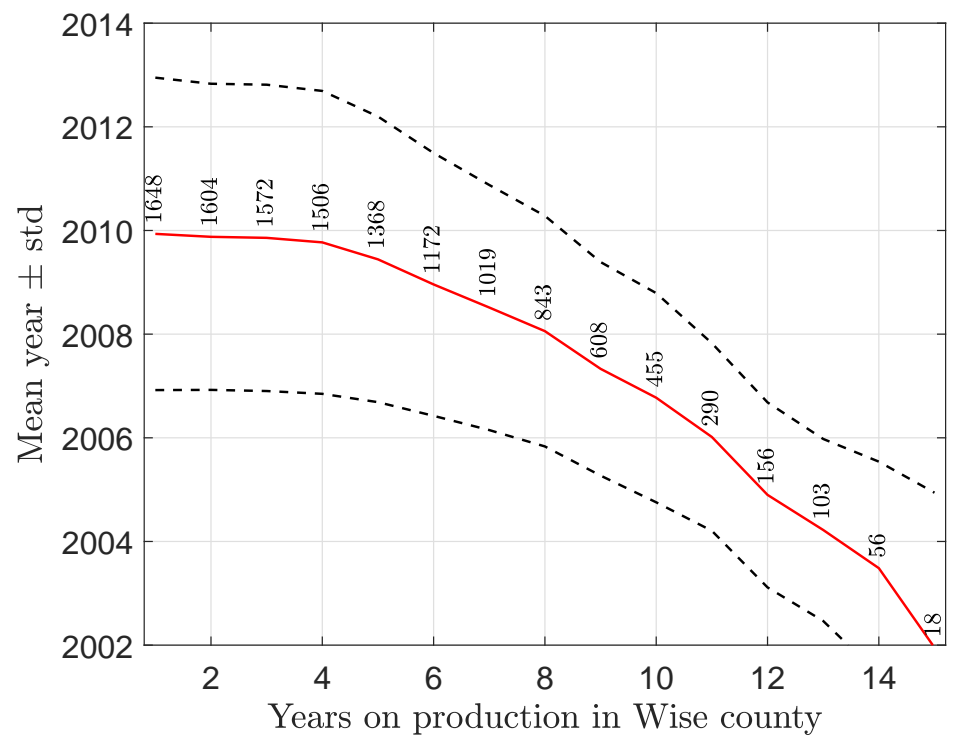




\section{Mean of well completion dates in Denton}

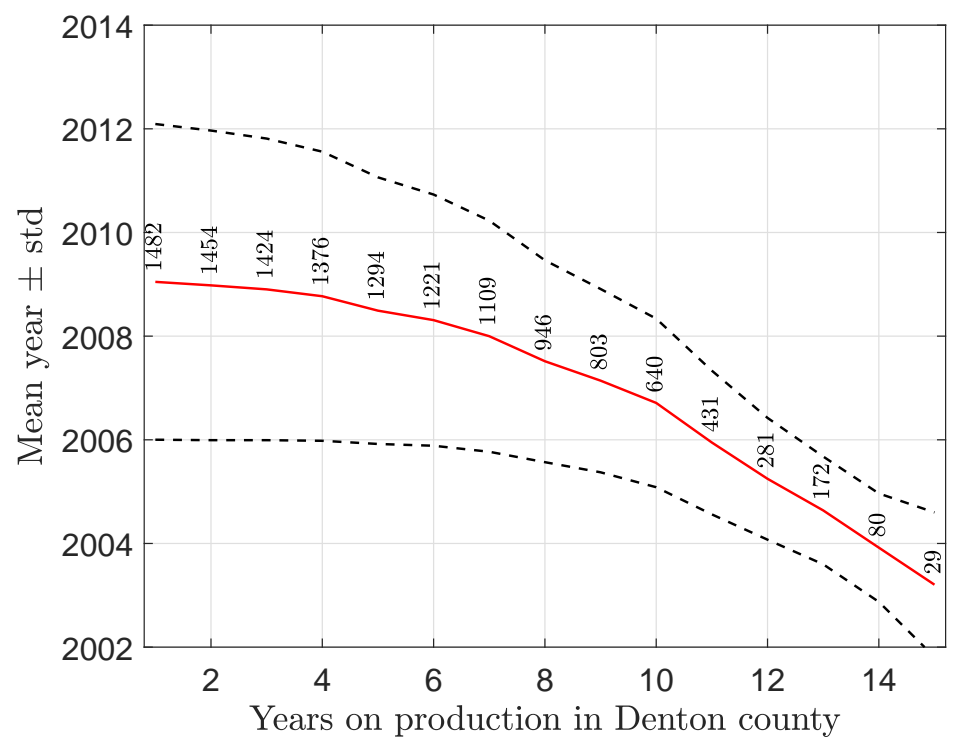




\section{Mean of well completion dates in Parker}

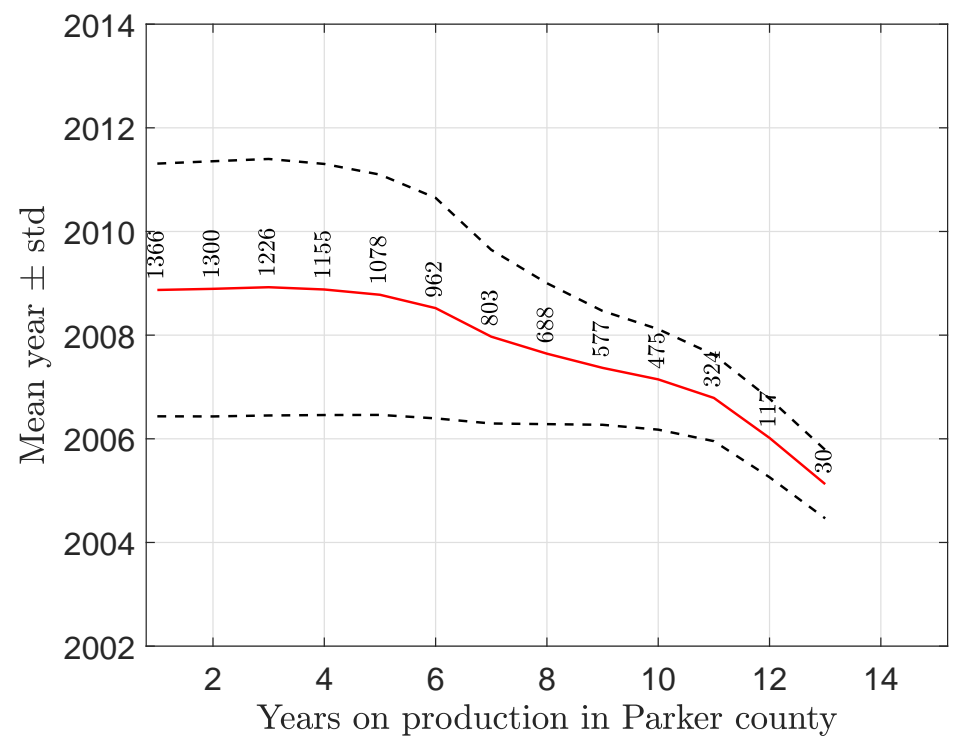




\section{Mean of well completion dates in Hood}

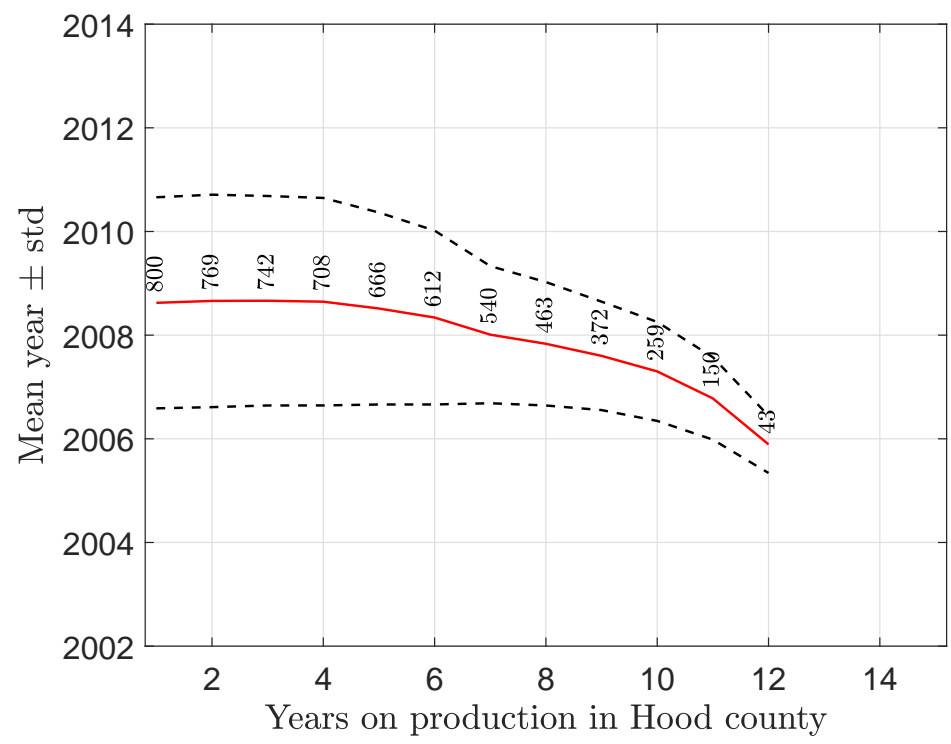




\section{Probability of survival of well cohorts}

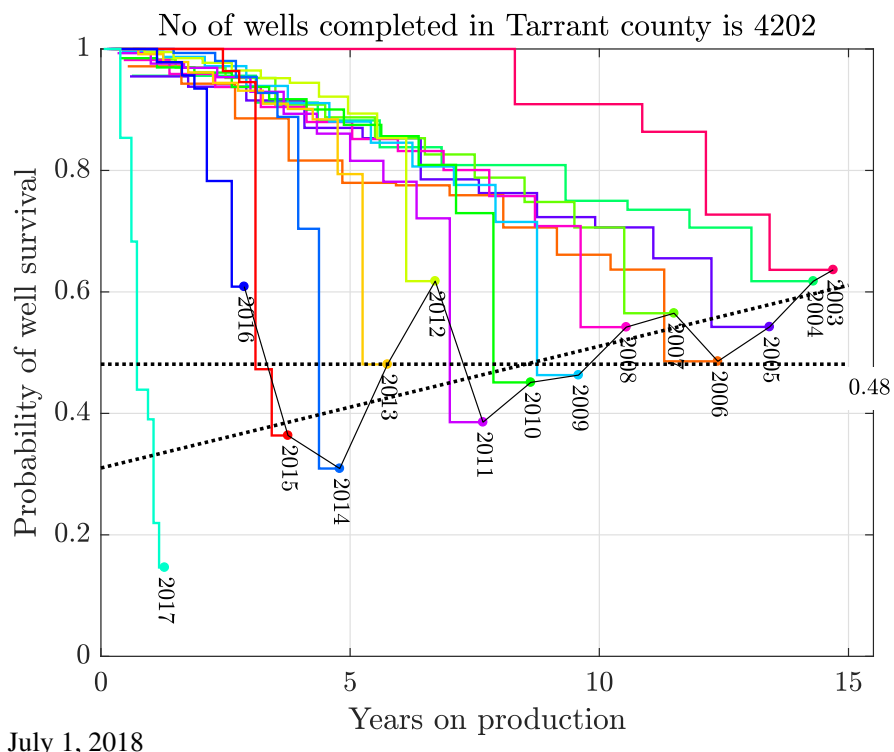




\section{Probability of survival of well cohorts}

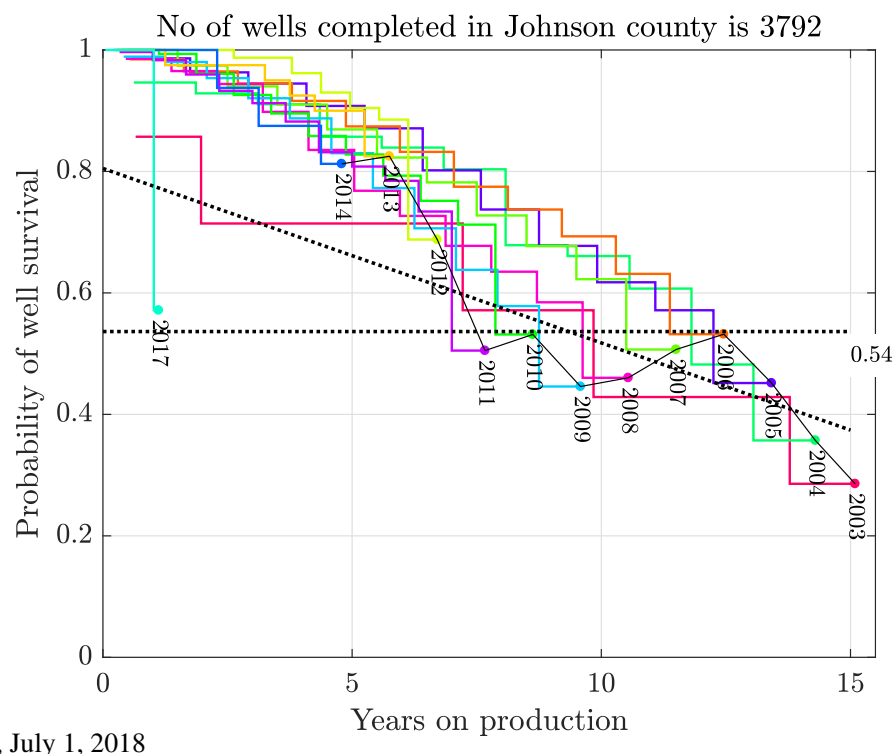

Source: DrillingInfo, July 1, 2018 


\section{Probability of survival of well cohorts}

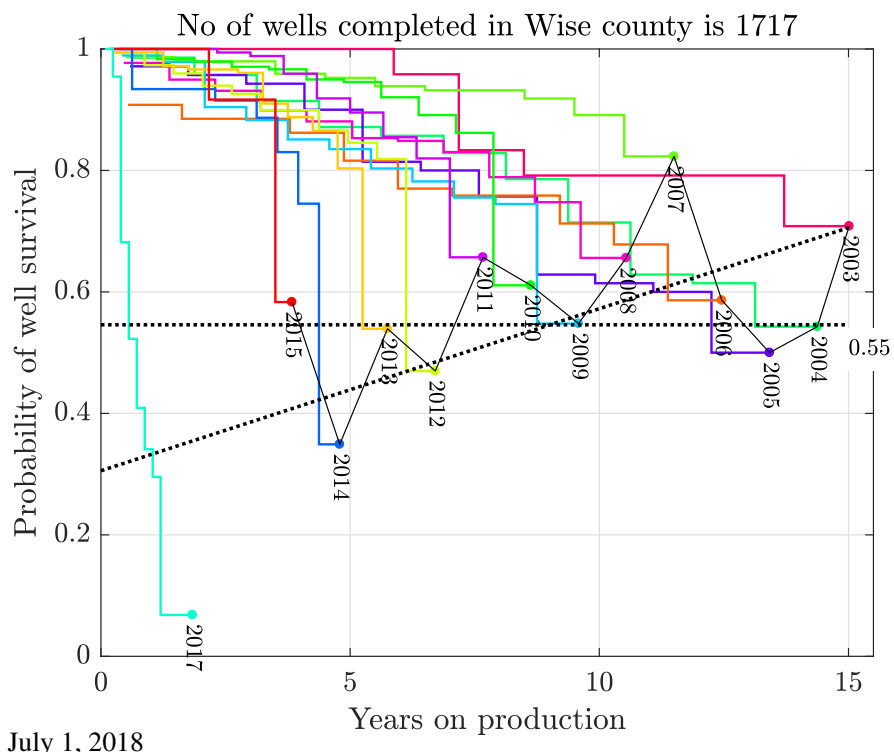

Source: DrillingInfo, July 1, 2018 


\section{Probability of survival of well cohorts}

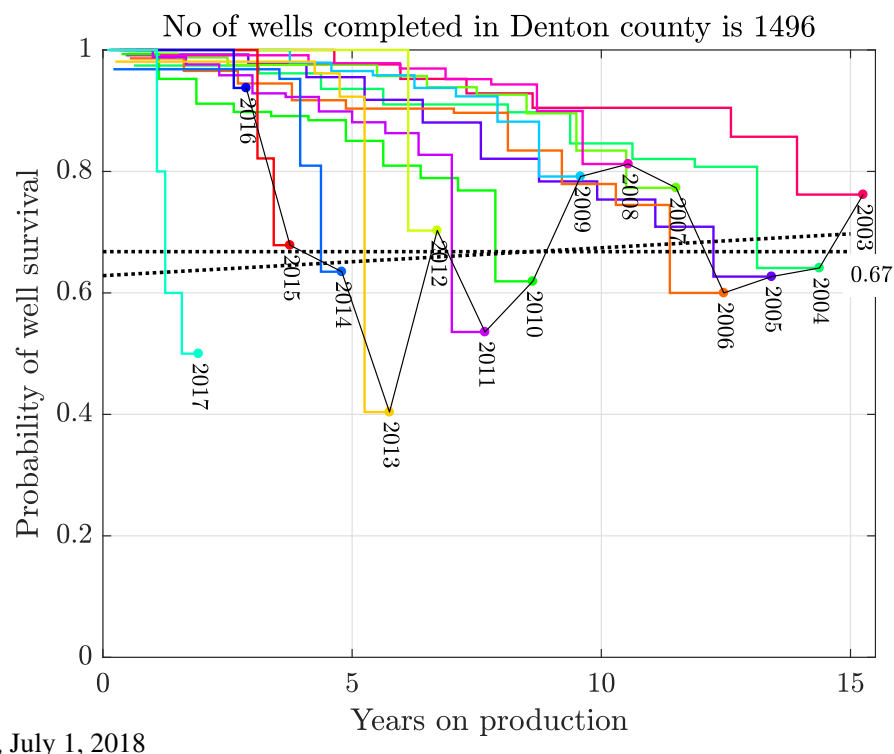

Source: DrillingInfo, July 1, 2018 


\section{Probability of survival of well cohorts}

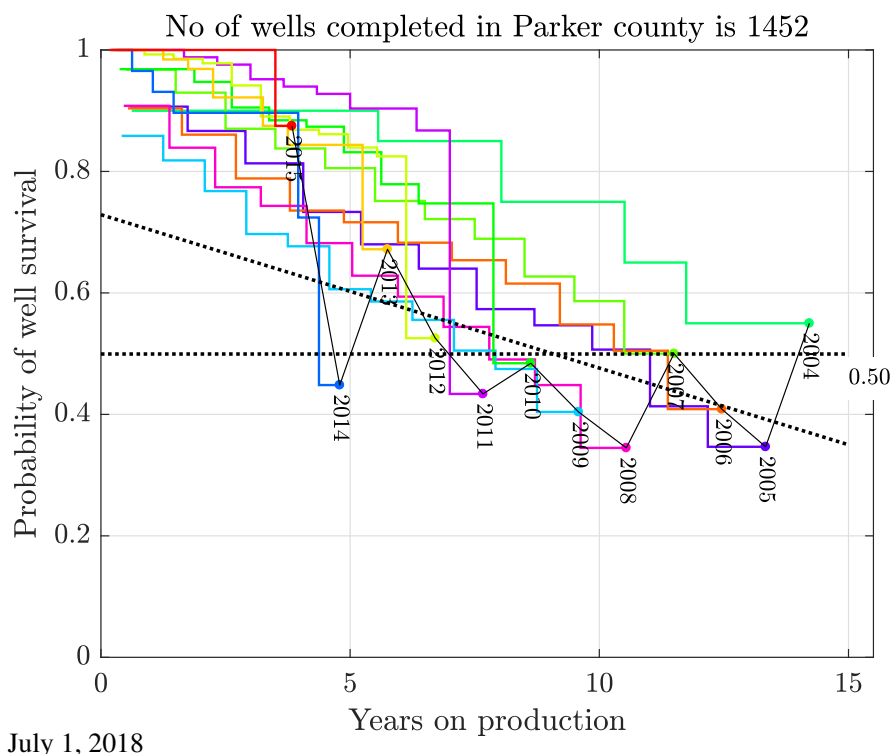

Source: DrillingInfo, July 1, 2018 


\section{Probability of survival of well cohorts}

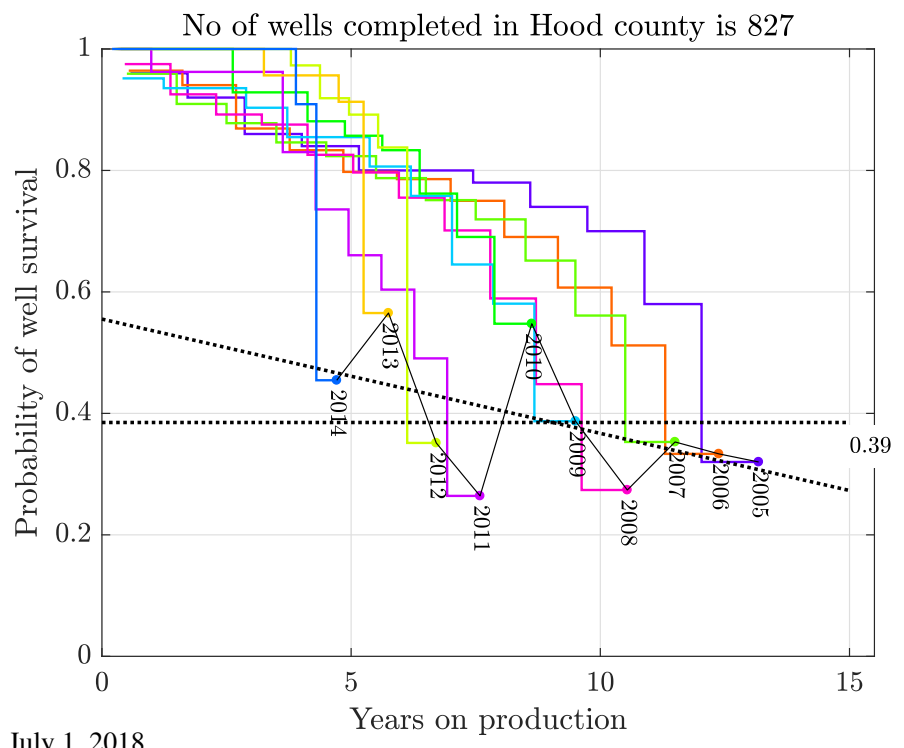

Source: DrillingInfo, July 1, 2018 


\section{Tarrant county: GEV mean well}

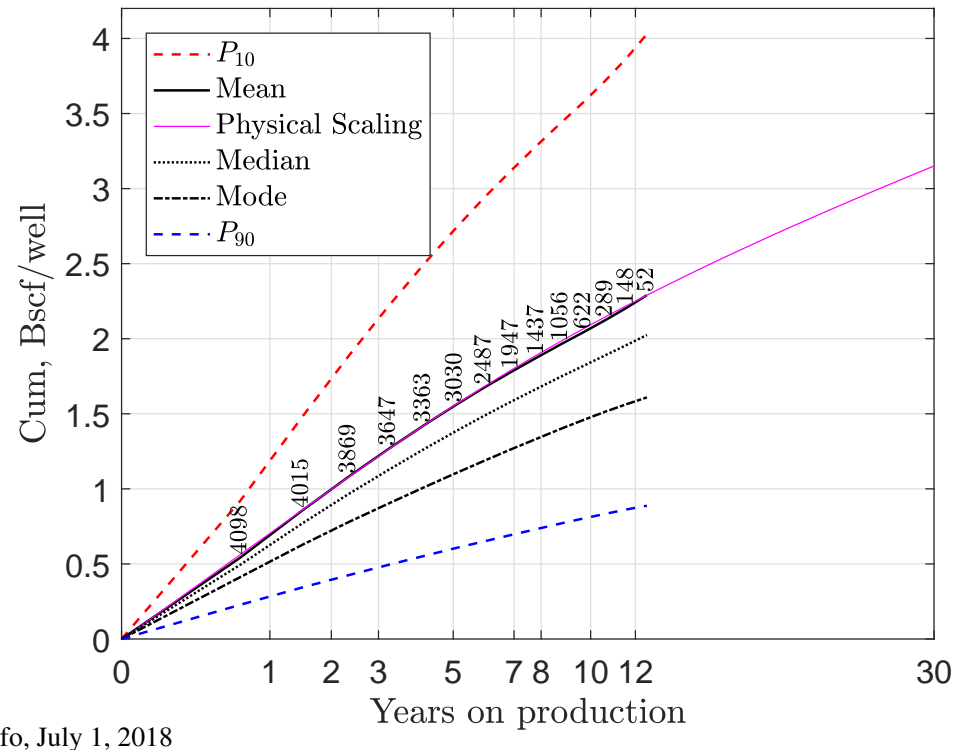

Source: DrillingInfo, July 1, 2018 


\section{Denton county: GEV mean well}

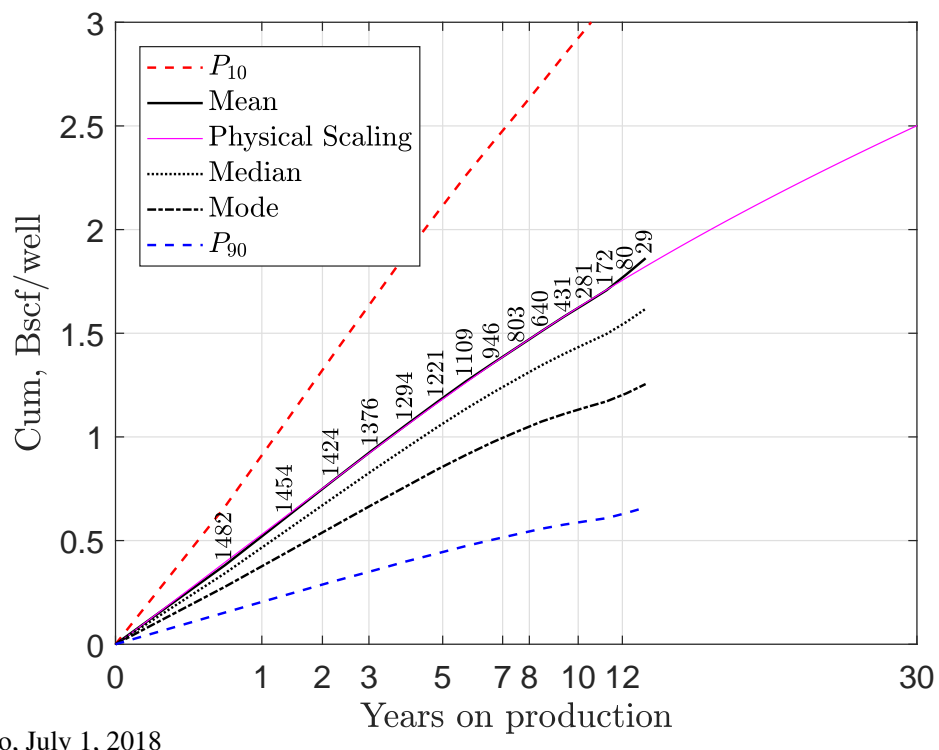




\section{Wise county: GEV mean well}

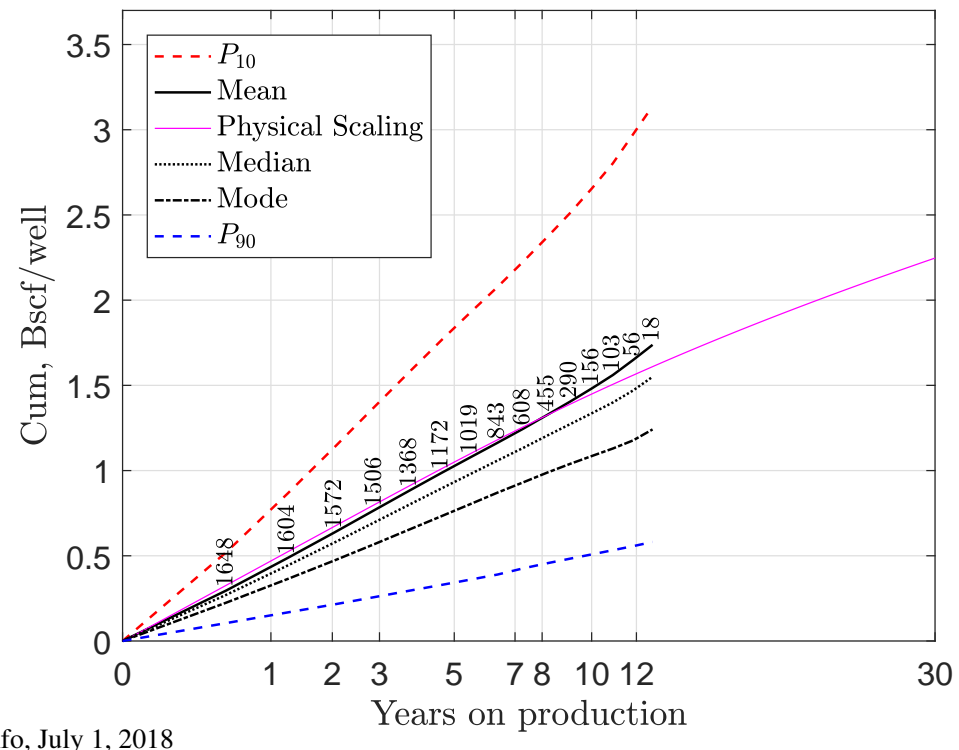

Source: DrillingInfo, July 1, 2018 


\section{Johnson county: GEV mean well}

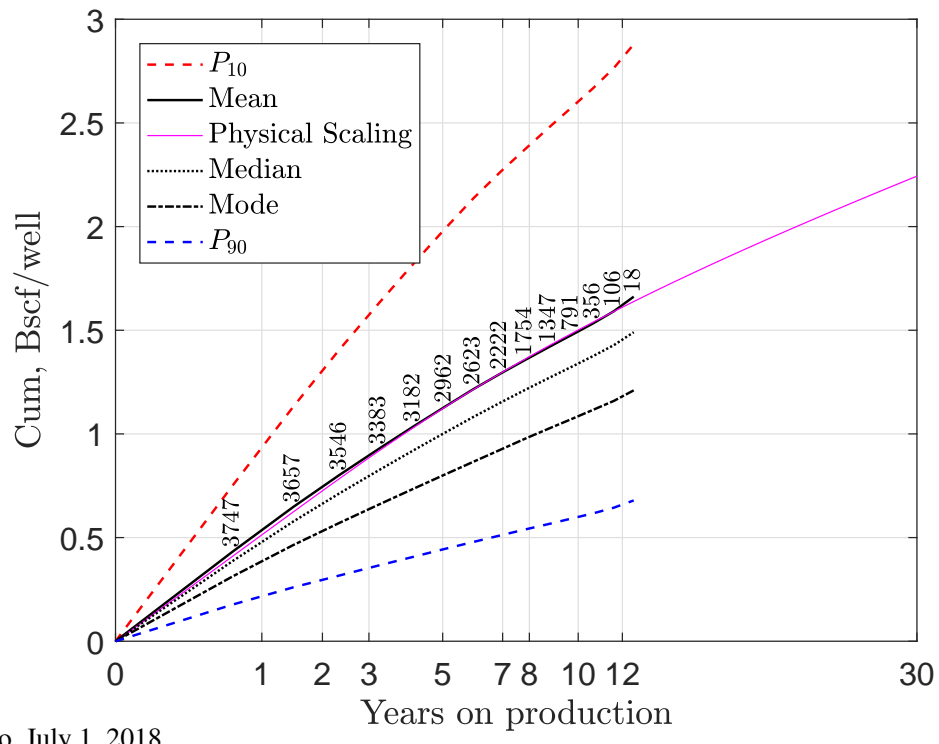




\section{Parker county: GEV mean well}

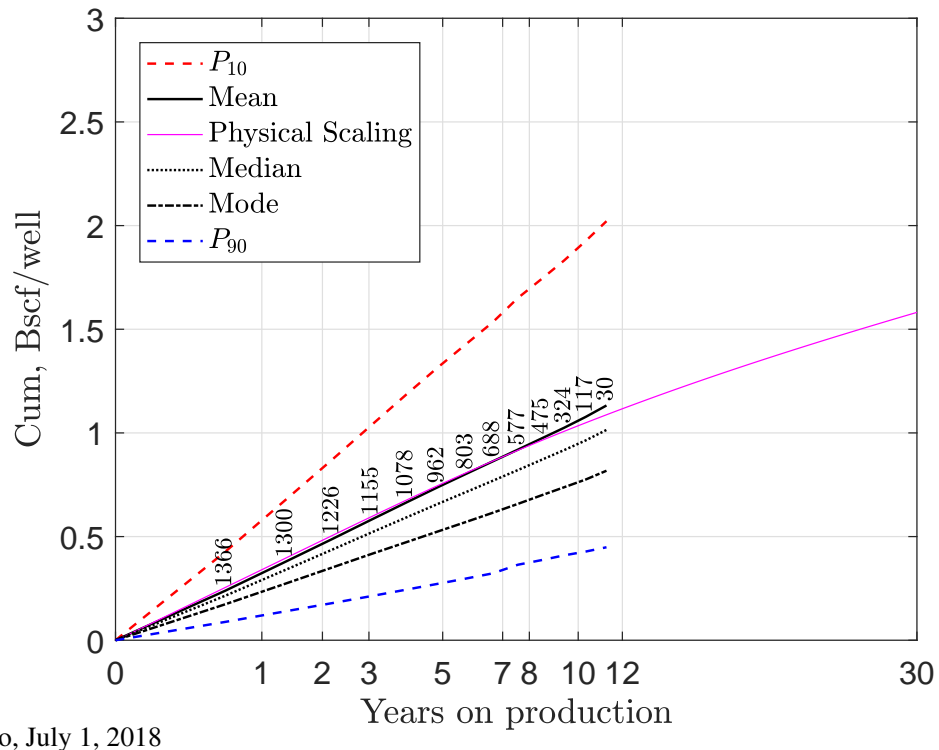

Source: DrillingInfo, July 1, 2018 


\section{Hood county: GEV mean well}

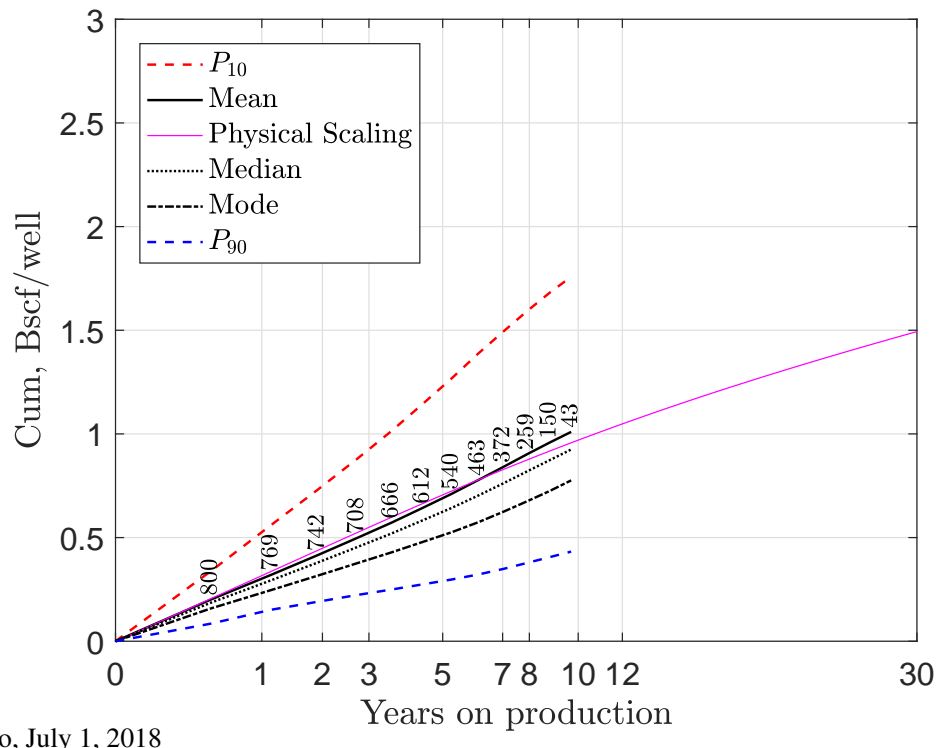




\begin{tabular}{r|cccc}
\hline County & $\begin{array}{c}\text { No. active } \\
\text { wells }^{a}\end{array}$ & $\begin{array}{c}\text { Time shift } \\
\text { months }\end{array}$ & $\begin{array}{c}\mathcal{M} \\
\text { Bscf/kt }\end{array}$ & $\begin{array}{c}\tau \\
\text { years }\end{array}$ \\
\hline Tarrant & 4098 & -2.4 & $3.2 / 74.97$ & 7 \\
\hline Denton & 3747 & -3.0 & $2.5 / 59.52$ & 10 \\
\hline Wise & 1648 & -3.6 & $2.2 / 53.51$ & 11 \\
\hline Johnson & 1482 & -2.4 & $2.2 / 53.41$ & 6 \\
\hline Parker & 1366 & -3.0 & $1.6 / 37.65$ & 9 \\
\hline Hood & 800 & -4.2 & $1.5 / 35.54$ & 10 \\
\hline
\end{tabular}

${ }^{a}$ With at least one year on production. 
